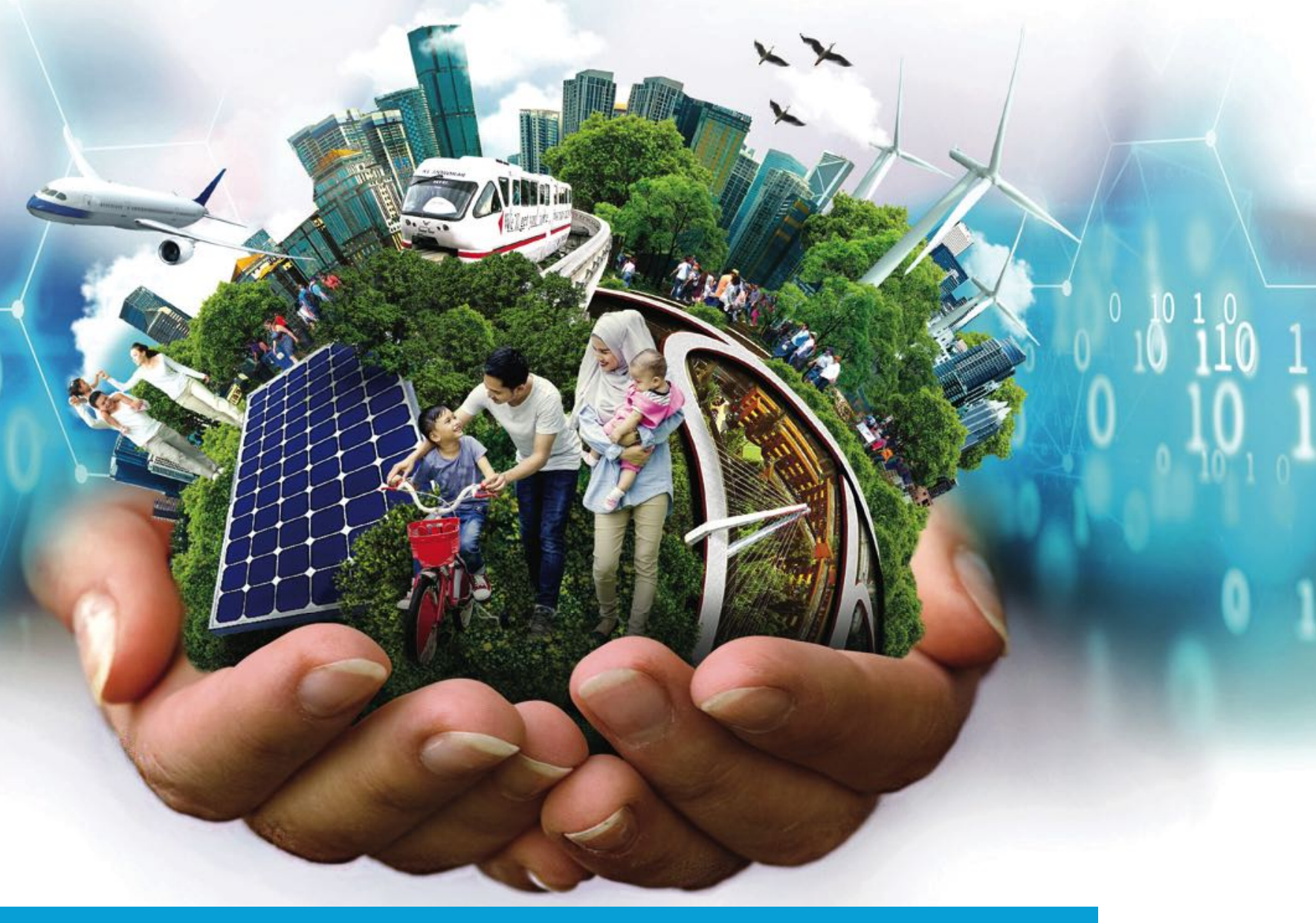

\title{
CREATING LIVABLE ASIAN CITIES
}

Edited by Bambang Susantono and Robert Guild

APRIL 2021 



\section{Book Endorsements}

\section{Seung-soo Han}

Former Prime Minister of the Republic of Korea

Creating Livable Asian Cities comes at a timely moment. The book emphasizes innovative technologies that can overcome challenges to make the region's cities better places to live and grow. Its approach encourages stronger urban institutions focused on all people in every community.

The book will inspire policy makers to consider concrete measures that can help cities 'build back better,' in other words, to be more resilient and able to withstand the next crisis. In the post-pandemic period, livable Asian cities are a public good, just as green spaces are. Following this credo, however, requires Asia to invest in creating livable cities so they can fulfil their potential as avenues of innovation, prosperity, inclusiveness, and sustainability.

In this book, Asian Development Bank experts map the challenges facing cities in the region. Its five priority themes - smart and inclusive planning, sustainable transport, sustainable energy, innovative financing, and resilience and rejuvenation-illuminate a path for urbanization in Asia over the next decade. This book will lead us to the innovative thinking needed to improve urban life across the region.

\section{Maimunah Modh Sharif}

Under-Secretary-General and Executive Director, United Nations Human Settlements Programme (UN-Habitat)

Creating Livable Asian Cities addresses various urban development challenges and offers in-depth analysis and rich insights on urban livability in Asia from an urban economics perspective. The Asian Development Bank $(A D B)$ is well-placed to review the investment needs of cities that will contribute to sustainable development. As the authors point out, innovations and technologies in planning, urban transport, sustainable energy, municipal finance, and urban resilience and rejuvenation are all vital for transformative change, and Asian cities need more opportunities to learn from good practices elsewhere.

The book recognizes the formidable challenges to finance future urban growth. This includes recovery beyond the pandemic and hence it recommends financial innovations through improved revenue collection such as land value capture. UN-Habitat looks forward to further collaboration with the ADB and other partners in domains such as this.

Urban development professionals and practitioners around the world will benefit from the perspectives and take note of the recommendations in this book. 


\section{Yumiko Noda}

Chair and Representative Director, Veolia Japan

People move to cities with hopes and dreams. They go there in pursuit of a better life and new opportunities. Cities must be able to respond to their expectations. However, rapid urbanization in Asia often entails severe environmental, economic, and social consequences that undermine peoples' quality of life.

This book offers profound insights and practical guidance that will help Asian cities address a wide range of urban challenges and transform into truly livable, sustainable, and resilient cities. It will be useful not only for policy makers, but also for business leaders in developing new ideas and solutions to make cities better places to live.

I strongly believe that this masterpiece is a result of long-standing efforts of the Asian Development Bank and its partners to accumulate and share knowledge on cities and infrastructure. I truly admire their persistent endeavors to bring prosperity to Asia.

\section{Karen Chapple}

Professor and Chair of City \& Regional Planning at the University of California, Berkeley, the United States

Finally, the definitive book to guide sustainable city-building in Asia in the 21st century! Asian Development Bank leaders Bambang Susantono and Robert Guild have skillfully assembled a set of cutting-edge essays that outline creative ideas and best practices in creating a more livable and equitable future for Asian cities. A rich set of provocative and incisive chapters push urban stakeholders to innovate smarter and more resilient planning, as well as more sustainable transport, energy, and finance systems. With the tremendous challenges ahead of us in this century, this book offers a clear path forward to livability for all. 


\section{Fumiko Hayashi}

Mayor, City of Yokohama, Japan

I believe that achieving livable cities for all residents should be the ultimate mission for everyone involved in urban development policy making. To help us move toward this goal, Creating Livable Asian Cities provides an excellent compilation of information on the latest smart and innovative planning tools and examples from Asia and beyond.

As the authors point out, each city has its own geopolitical context, and there is no single universal solution to each city's various urban issues. The book provides analytical frameworks, important insights on policy making, and practical references for those involved in urban development.

I hope that everyone involved in city management will refer to the examples in this book. The City of Yokohama looks forward to continued collaboration with the Asian Development Bank to contribute to the region's city management knowledge base.

\section{Se-hoon Oh}

Mayor of Seoul Metropolitan Government, Republic of Korea

My congratulations to the Asian Development Bank (ADB) for publishing Creating Livable Asian Cities. This book ruminates over cases of various Asian cities and will be a great guide for Asian city governments as they seek sustainable development.

As the book emphasizes, Asia's future is urban. Indeed, cities are important indicators of quality of life and global competitiveness. This is because as "small governments," cities are closely connected to the lives of citizens and act as mirrors that reflect a nation's vision.

Drawing on Seoul's development experience, the Seoul Metropolitan Government hopes to work with ADB to support and inspire other cities in the region to address rapid urbanization challenges and achieve their sustainable development goals. 



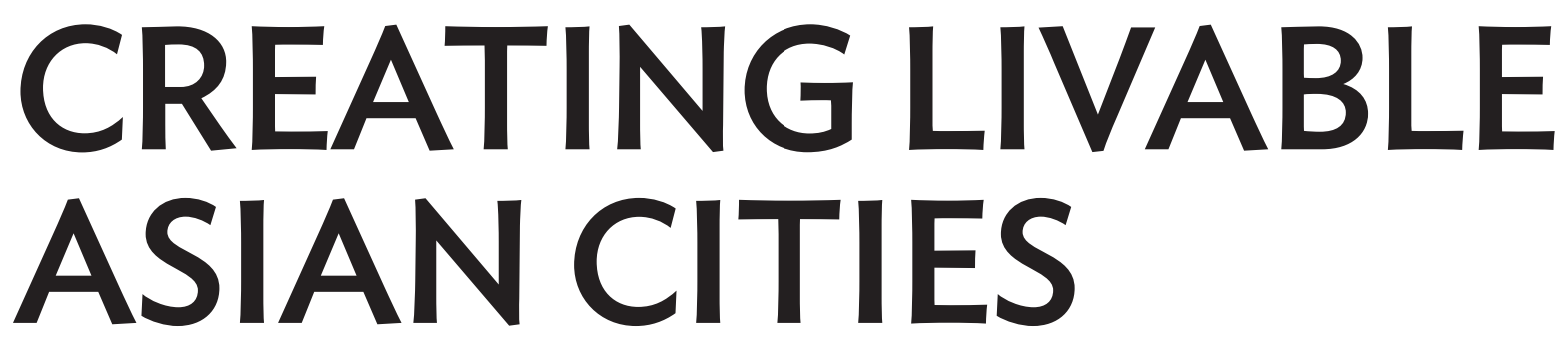
Edited by Bambang Susantono and Robert Guild APRIL 2021 
(C) 2021 Asian Development Bank

6 ADB Avenue, Mandaluyong City, 1550 Metro Manila, Philippines

Tel +632 8632 4444; Fax +63286362444

www.adb.org

Some rights reserved. Published in 2021.

ISBN 978-92-9262-782-9 (print); 978-92-9262-783-6 (electronic); 978-92-9262-784-3 (ebook)

Publication Stock No. SGP210110

DOI: http://dx.doi.org/10.22617/SGP210110

The views expressed in this publication are those of the authors and do not necessarily reflect the views and policies of the Asian Development Bank (ADB) or its Board of Governors or the governments they represent.

ADB does not guarantee the accuracy of the data included in this publication and accepts no responsibility for any consequence of their use. The mention of specific companies or products of manufacturers does not imply that they are endorsed or recommended by ADB in preference to others of a similar nature that are not mentioned.

By making any designation of or reference to a particular territory or geographic area, or by using the term "country" in this document, $A D B$ does not intend to make any judgments as to the legal or other status of any territory or area.

This work is available under the Creative Commons Attribution 3.0 IGO license (CC BY 3.0 IGO)

https://creativecommons.org/licenses/by/3.0/igo/. By using the content of this publication, you agree to be bound by the terms of this license. For attribution, translations, adaptations, and permissions, please read the provisions and terms of use at https://www.adb.org/terms-use\#openaccess.

This CC license does not apply to non-ADB copyright materials in this publication. If the material is attributed to another source, please contact the copyright owner or publisher of that source for permission to reproduce it. $\mathrm{ADB}$ cannot be held liable for any claims that arise as a result of your use of the material.

Please contact pubsmarketing@adb.org if you have questions or comments with respect to content, or if you wish to obtain copyright permission for your intended use that does not fall within these terms, or for permission to use the ADB logo.

Corrigenda to ADB publications may be found at http://www.adb.org/publications/corrigenda.

Notes:

In this publication, "\$” refers to United States dollars unless otherwise stated.

ADB recognizes "Brunei" as Brunei Darussalam; "Hong Kong" as Hong Kong, China; "China" as the People's Republic of China; "Korea" and "South Korea" as the Republic of Korea; and "Macau" as Macau, China.

Cover design by Anthony Victoria and Jan Carlo Dela Cruz. 


\section{Contents}

Tables, Figures, Boxes, and Maps

Abbreviations

Weights and Measures

xiii

About the Editors

xiv

Authors

xvi

Introduction: Opportunities for Creating Livable Asian Cities

Bambang Susantono, Marlon Boarnet, and Robert Guild

\section{Smart and Inclusive Planning}

1A An Analytical Framework and Guidance for Smart City Planning

1B Housing Affordability and Adequacy in Developing Asia

Matthias Helble and Kwan Ok Lee

1C Earth Observation for Planning and Resilience of Livable Cities

1D Gender-Responsive and Inclusive Urban Planning Gillian Brown, Prabhjot Khan, and Samantha Hung

1E Urban Synergies Through Coordinated City Cluster Governance Stefan Rau

\section{Sustainable Transport}

2A Transport and Urban Form

James Leather

2B E-mobility: Transition to Sustainable Transport Ki-Joon Kim and Ritu Mishra

2C Planning and Design of Intelligent Transport Systems toward Livable Asian Cities Susan Lim and Gloria Gerilla-Teknomo

2D Prospects for Mobility as a Service Robert Valkovic, Lidia Signor, Gayang Ho, and Clémence Morlet

2E Road Safety in Asian Cities 
3 Sustainable Energy $\quad 223$

3A Sustainable Energy Solutions for Livable Cities 224 David Elzinga and Okju Jeong

3B The Role of Microgrids in 21st Century Urban Development 251 Susumu Yoneoka and Dan Millison

3C Waste, Waste-to-Energy, and the Circular Economy Stephen Peters and Keshan Samarasinghe

4 Financial Innovation $\quad 283$

4A Advancing the Financial Sustainability of Asian Cities 284 Manoj Sharma, Sarah Hui Li, and Renard Teipelke

4B Urban Housing Bond Market Development in Asia 315 Heejoon Jeong, Bambang Susantono, Donghyun Park, and Shu Tian

4C Enhancing Infrastructure Investment through Value Capture 339 Abdul Abiad, Kathleen Farrin, Chris Hale, Matthias Helble, and Grant Stillman

5A Increasing Urban Resilience through Nature-Based Solutions and Total Asset Management 356 Lara Arjan, Stefan Rau, and Sonia Chand Sandhu

5B Building Disaster Resilience in Cities in Asia and the Pacific 375 Thomas Kessler and Arup Chatterjee

5C Post-Pandemic Response, Recovery, and Rejuvenation 


\section{Tables, Figures, Boxes, and Maps}

1 Smart and Inclusive Planning

1A An Analytical Framework and Guidance for Smart City Planning

Table

B1 Smart City Models

Figures

1 Published Smart City Strategies $\quad 19$

2 Comprehensiveness of Smart City Strategies $\quad 20$

3 Smart City Objectives $\quad 22$

4 Smart City Action Fields 23

5 Number of Action Fields by Smart City Model 23

6 Smart City Models by Region 23

$7 \quad$ Smart City Objectives $\quad 24$

8 Smart City Action Enablers $\quad 24$

9 Smart City Action Fields, Asian and Non-Asian Region 25

10 Proposed Smart City Analytical Framework 39

A1 Roland Berger City Scores $\quad 42$

\section{Boxes}

1 Affordable Satellite-Based High-Speed Broadband Internet in Asia and the Pacific 26

2 Land Registry with Blockchain Technology in Fiji 27

3 Intelligent Transport System in Guizhou, People's Republic of China 28

4 Piloting Smart Devices for Drinking Water Management in Dhaka, Bangladesh 29

5 Digital Systems to Support COVID-19 Response in the Republic of Korea 32

6 Household CCTV Subsidies to Improve Women's Security in New Delhi, India 33

1B Housing Affordability and Adequacy in Developing Asia

\section{Tables}

1 Demographia Housing Affordability Benchmarks 49

2 Price-to-Income Ratio by City Size and Location in the City 51

3 Homeownership Rates in Selected Asian Economies 52

4 Concentration Index of Housing Adequacy in 10 Economies $\quad 55$

5 Main Affordable Housing Policy Options Used in Asia 59

Figures

1 Housing Affordability of 211 Cities in 27 Economies in Asia and the Pacific 50

2 Housing Adequacy in South Asia, Central West Asia, and Southeast Asia 53

3 Housing Adequacy in Four Dimensions and by Type of Agglomeration 54

4 Diagram for Mechanisms of Housing Policy Options 61 
1C Earth Observation for Planning and Resilience of Livable Cities

Figures

1 Earth Observation-Based Products for Urban Development 70

2 ADB Spatial Data Analysis Explorer $\quad 72$

3 Shares of Urban Area and Urban Population Across 43 Countries Studied 75

Maps

1 Spatial Development $\quad 76$

2 Formation of City Cluster Centered Around Shanghai $\quad 78$

3 Flood Risk Assessment in Kampong Chhnang, Cambodia 80

$4 \quad$ Subset of the Kolkata Land Use and Landcover Mapping for the Reference Year 2017

$5 \quad 25$-Year Flood Projection in Hue City, Viet Nam 82

6 Location and Condition of Sanitation Facilities in Patuakhali, Bangladesh 84

7 Impact of COVID-19 in Asia and the Pacific 84

8 Hospitals and Informal Settlements in the Philippines' National Capital Region 85

1D Gender-Responsive and Inclusive Urban Planning

\section{Figures}

1 PALMS Framework $\quad 91$

2 Examples of Women-Focused Investments in Resilience 96

3 Example of ur-scape Visualization $\quad 101$

\section{Boxes}

1 Participatory Process in Action in Tbilisi, Georgia 91

2 Institutionalizing Gender Equality 92

3 Small Towns Water Supply and Sanitation Sector Project in the Lao People's Democratic Republic 94

4 Examples of Programs Supporting Women in Urban Climate Action 97

$1 \mathrm{E} \quad$ Urban Synergies Through Coordinated City Cluster Governance

Boxes

1 The Beijing-Tianjin-Hebei City Cluster Coordination $\quad 115$

2 Harbin-Changchun City Cluster and Songhua River Basin Water Pollution 118

and Flood Risk Management Coordination in the People's Republic of China

3 Visakhapatnam-Chennai Industrial Corridor along India's East Coast 127

Maps

$1 \quad$ Large City Clusters with Populations Above 10 Million in Developing Asia, $2016 \quad 109$

2 Central Asia Regional Economic Cooperation 124

3 New Configuration of the Greater Mekong Subregion Economic Corridors 126

\section{Sustainable Transport}

\section{A Transport and Urban Form}

\section{Figures}

1 Road Length and Built-Up Areas 139

2 Transit Length and Built-Up Areas 140

3 Private Transport Modes and Urban Form 141

4 Transport Mode Share in Selected Areas in Asia 141

5 Barter's Transport Development Paths and City Typology 142

6 Key Success Factors for Sustainable Urban Transport 144 
2B E-mobility: Transition to Sustainable Transport

Tables

1 Assessment Criteria, Parameters, and Benchmarks

152

2 Environmental Potential of Electric Vehicles in ADB Developing Member Countries

153

3 Potential Impact of Electric Vehicle Subsidy Schemes

Figures

1 Electric Vehicle Market Adoption

150

2 Key Concerns of Consumers on Electric Vehicles 151

3 Fiscal Incentives and Vehicle Market Update 158

Box

1 Electrification of Buses in Shenzhen

2C Planning and Design of Intelligent Transport Systems toward Livable Asian Cities

Figures

$1 \quad$ Relationships between Framework and Regional Architectures, Intelligent Transport Systems

Standards, and Intelligent Transport Systems Projects

2 Steps in Developing the Intelligent Transport Systems Conceptual Design

170

3 Generic Intelligent Transport Systems Elements in the Framework Architecture

172

4 Information Flow Context Diagram for Cultural Tourism Investment Transit Vehicle

174

On-Board Equipment

5 Customized Service Package for Basic Traffic Surveillance

Box

1 Gui'an New District's Smart Transport System Development-A Project Case Study

2D Prospects for Mobility as a Service

Table

1 Features of Mobility as a Service Levels

Figures

$1 \quad$ Individual Urban Modes versus Holistic Mobility as a Service Model 183

2 Urban Mobility Services 184

3 Japan's Common Data Platform-MaaS Japan 188

\section{Boxes}

1 Zipster-Asia's First Integrated Mobility as a Service App and Payment Wallet in Singapore 186

2 The Potential of Mobility as a Service-The Low-Tech Pilot of Great Manchester, United Kingdom 191

3 The Whim System in Helsinki, Finland 200

4 UMAJI+ - A Mobility as a Service Platform in Taipei,China 201

5 Grab’s Trip Planner-A Commercial Mobility as a Service Option in Southeast Asia 202

2E Road Safety in Asian Cities

Tables

1 Road Crash Fatalities in Developing Countries in Asia and the Pacific 207

2 Save LIVES Priority Components and Interventions 217

Figures

1 Maximum Default Speed Limits for Urban Roads in Asia and the Pacific 210

2 Proportion of Fatalities by Road User 211

3 Gross Domestic Product Per Capita and Road Fatality in Selected Countries 212 


\section{Boxes}

1 Harmonization of Data on Road Fatalities in Thailand 209

2 Lessons from Asia and the Pacific Experiences in Addressing Road Safety 218

\section{Sustainable Energy}

3A Sustainable Energy Solutions for Livable Cities

Table

1 Supply-Side versus Demand-Side Energy Efficiency

Figures

$1 \quad$ Key Elements of Sustainable Urban Energy Systems

2 Framework of Chapter Aligned with Interconnected Urban Energy Systems 226

3 Level of Influence of City Government in Various Urban Sectors 229

4 Changes in Floor Area, Population, Buildings Sector Energy Use, 239 and Energy-Related Emissions Globally, 2010-2018

$5 \quad$ Energy Usage for 12-Meter Bus 242

6 Benchmark Power Grid Factors That Result in Lower Electric Vehicle Carbon Dioxide Emissions 242

\section{Boxes}

$1 \quad$ Tackling Air Pollution and Climate Change-Study for Energy Master Plan of Ulaanbaatar 230

2 Rooftop Solar Photovoltaic Power Generation Systems in Sri Lanka 232

3 Grid-Connected Solar Floating Photovoltaic Power Project in Visakhapatnam, India 234

4 Waste-to-Energy Plant in Greater Malé 235

5 Cases of Smart Electricity Distribution Technologies in Differing Applications 237

6 Innovative Private Initiatives as Leverage to Energy Efficiency in the Building Sector 240

7 Ulaanbaatar Green Affordable Housing 241

8 Successful Operation of Electric Bus Fleet in Kolkata, India 244

9 Electric Vehicle Provision of Power System Ancillary Services in Delaware, United States 244

10 Challenges to Upscale Smart and Energy-Efficient Street Lighting in Viet Nam 246

3B The Role of Microgrids in 21st Century Urban Development

\section{Figures}

$1 \quad$ Urban Microgrid Conceptual Design and Key Components 252

2 Microgrids Classified by Technology Complexity and Ownership Structure 255

\section{Boxes}

1 Case Study-500-Kilowatt Microgrid at the Nagoya Landfill, Japan 257

2 Case Study-The Sendai Microgrid in the Aftermath of the Tohoku Earthquake 258

3 Case Study-Microgrid in Delhi, India 258

3C Waste, Waste-to-Energy, and the Circular Economy

Table

1 Implementation Challenges and Way Forward

Figure

1 Resource Recycling Management Policy

Boxes

1 Community Empowerment with Private Sector Participation

2 Digitization of Extended Producer Responsibility Schemes 


\section{Financial Innovation}

\section{A Advancing the Financial Sustainability of Asian Cities}

\section{Tables}

$1 \quad$ Factors Impacting Availability of Financing Modalities

289

2 Exemplary Source of Municipal Finance 290

3 City-Level Public-Private Partnership Areas 300

$4 \quad$ Illustrative Subnational Government Financing Arrangements 305

Figures

1 Local Government Revenue as Percentage of GDP, 2019 or Latest Available Year 286

2 Local Government Expenditure as Percentage of GDP, 2019 or Latest Available Year 287

3 Property Taxes Share of Total Revenues of Local Government, 2019 or Latest Available Year 291

4 Tariffs and Fees Share of Local Government Total Revenues, 2019 or Latest Available Year 297

5 Grants and Subsidies Share of Local Government Total Revenues, 2019 or Latest Available Year 298

Boxes

1 Property Tax Innovations in Jharkhand, India 294

2 The Manila Water Story 301

3 Pooled Financing in Tamil Nadu $\quad 304$

4 Advancing Local Currency Markets in Asia and the Pacific 306

5 Blended Finance Applied in the Shandong Green Development Fund 308

4B Urban Housing Bond Market Development in Asia

\section{Figures}

$1 \quad$ Housing Bonds Outstanding in the United States

2 Outstanding Covered Bonds in European Union, 2016

3 Growth of the Housing Bond Market in Japan 323

$4 \quad$ Per Capita Housing Loans in East Asia

5 Thailand's Housing Bond Market 326

6 Housing Bonds Outstanding in Singapore 327

7 Cagamas Housing Bonds Outstanding in Malaysia 328

8 Hong Kong Mortgage Corporation Housing Bonds Outstanding 329

9 Housing Bond Market in Indonesia 330

10 Residential Mortgage-Backed Securities Outstanding in the People's Republic of China 331

11 Trends in National Housing Bond Issuance and Volume in the Republic of Korea 333

12 Housing Bonds Outstanding in the Republic of Korea 333

4C Enhancing Infrastructure Investment through Value Capture

Table

1 Menu of Potential Types of Taxes That Could be Designated for Catchment as Categorized by Mobility

Figures

$1 \quad$ Project Phasing and Value Impact

2 Evolution of Commercial and Residential Land Values 344

3 Potential Ways to Transfer Back-End Tax Participation to Original Investors 350

Box

1 The Value Capture Finance Policy Framework in India 


\section{Resilience and Rejuvenation}

5A Increasing Urban Resilience through Nature-Based Solutions and Total Asset Management Figure

1 Hybrid Approach: Physical Infrastructure and Nature-Based Solution

\section{Boxes}

1 The New Clark City River Study 358

2 Jiangxi Pingxiang Integrated Rural-Urban Infrastructure Development Project 361

3 Sponge City Concept Evolution-Yanji Low-Carbon, Climate-Resilient, and Healthy City Project 362

4 Revitalization of Informal Settlements and Their Environments Using a Water-Sensitive Approach 363

5B Building Disaster Resilience in Cities in Asia and the Pacific

\section{Figures}

1 The CLIMADA Disaster Risk Modeling Tool

2 Disaster Risk Financing-A Layered Approach

3 Leveraging Innovation and Technology

\section{Boxes}

1 Building Back Better in Marawi City, Philippines 388

$2 \quad$ Building Back Better in Sulawesi, Indonesia 389

3 Disaster Risk Financing in Nepal 392

4 City Disaster Insurance Pool in the Philippines 393

5 Protecting Coral Reefs in Fiji, Indonesia, the Philippines, and Solomon Islands 395

5C Post-Pandemic Response, Recovery, and Rejuvenation

Tables

1 Energy Sector Priorities for Immediate Response $\quad 420$

2 Energy Sector Priorities for Recovery 421

Figure

1 Possible Post-COVID-19 Trends in the Asia and Pacific Region's Transport Sector 


\section{Abbreviations}

\begin{tabular}{|c|c|}
\hline$A D B$ & Asian Development Bank \\
\hline API & application programming interface \\
\hline APRSO & Asia Pacific Road Safety Observatory \\
\hline $\mathrm{BEB}$ & battery electric bus \\
\hline BESS & battery energy storage system \\
\hline BMP & bike-sharing/micromobility provider \\
\hline BTH & Beijing-Tianjin-Hebei region \\
\hline CAPEX & capital expenditure \\
\hline CAREC & Central Asia Regional Economic Cooperation \\
\hline C-ITS & cooperative intelligent transport system \\
\hline $\mathrm{CO}_{2}$ & carbon dioxide \\
\hline COVID-19 & coronavirus disease \\
\hline CSP & car-sharing provider \\
\hline CSP & customized service package \\
\hline CYR & Central Yangtze River City Cluster \\
\hline CTI & Cultural Tourism Investment \\
\hline DIAS & Data and Information Access Services \\
\hline DMC & developing member country \\
\hline $\mathrm{EE} \& \mathrm{C}$ & Energy Efficiency and Conservation \\
\hline EO4SD & Earth Observation for Sustainable Development \\
\hline EPR & extended producer responsibility \\
\hline ESA & European Space Agency \\
\hline FSR & feasibility study report \\
\hline FYP & Five-Year Plan \\
\hline GBA & Greater Bay Area \\
\hline GDP & gross domestic product \\
\hline GFDRR & Global Facility for Disaster Reduction and Recovery \\
\hline GHG & greenhouse gas \\
\hline GHLC & Government Housing Loan Corporation (Japan) \\
\hline GIS & geographical information system \\
\hline GMS & Greater Mekong Subregion \\
\hline GMSUDF & Greater Mekong Subregion Strategic Urban Development Framework \\
\hline GPS & global positioning system \\
\hline GRUMP & Global Rural-Urban Mapping Project \\
\hline FHLB & Federal Home Loan Bank \\
\hline HDB & Housing and Development Board (Singapore) \\
\hline HEV & hybrid electric vehicle \\
\hline HKMC & Hong Kong Mortgage Corporation \\
\hline
\end{tabular}




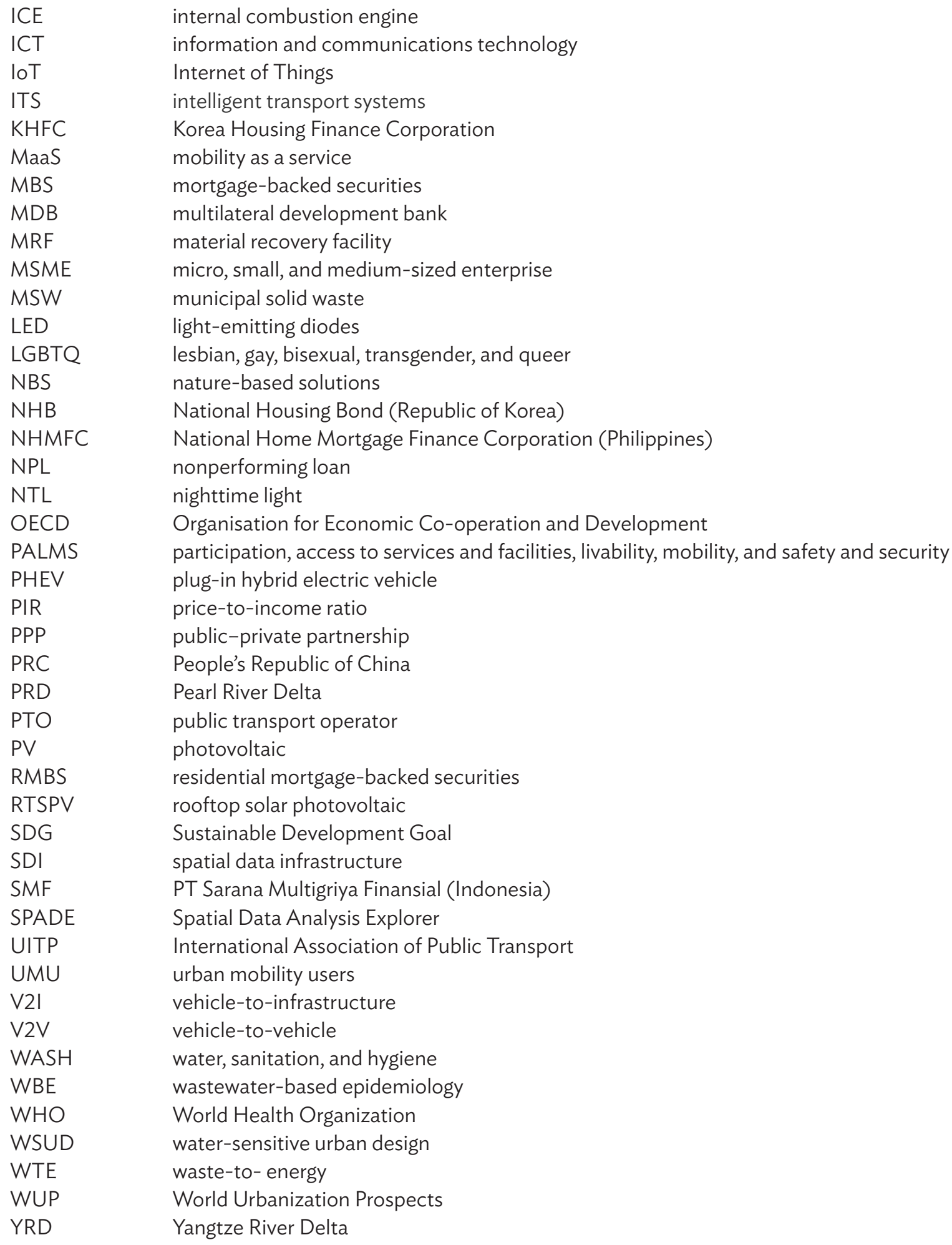




\section{Weights and Measures}

$\begin{array}{ll}\mathrm{km} & \text { kilometer } \\ \mathrm{kWh} & \text { kilowatt-hour } \\ \mathrm{kgCO}_{2} \mathrm{e} / \mathrm{kWh} & \text { kilogram of carbon dioxide equivalent emission per kilowatt-hour } \\ \mathrm{km}^{2} & \text { square kilometer } \\ \mathrm{MW} & \text { megawatt } \\ \text { Mtoe } & \text { million tonnes of oil equivalent }\end{array}$




\section{About the Editors}

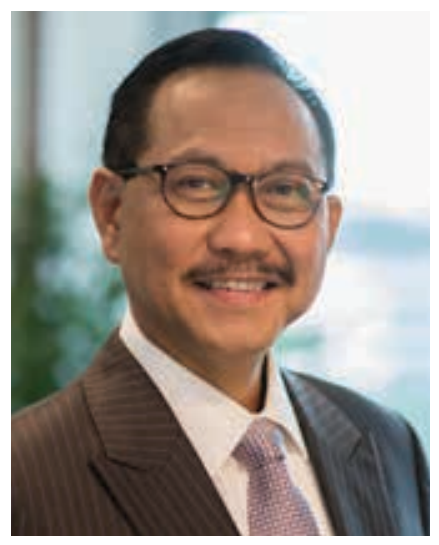

Bambang Susantono is Vice-President for Knowledge Management and Sustainable Development of the Asian Development Bank (ADB).

$\mathrm{He}$ is the first Indonesian in this position.

He holds a doctor of philosophy (PhD) degree in infrastructure planning and master's degrees in transportation engineering and in city and regional planning from the University of California, Berkeley. He graduated with a bachelor's degree in engineering from the Civil Engineering Department, Bandung Institute of Technology.

Susantono is responsible for managing knowledge in ADB. He supervises research and studies on various topics such as energy, transport, education, health, finance, and urban development; and crosscutting nexus themes such as climate change, governance, gender, social development, environment, rural development and food security, and regional cooperation. He coordinates ADB's annual flagship publications such as the Asian Development Outlook, Key Indicators for Asia and the Pacific, and Asian Economic Integration Report.

Prior to his ADB work, Susantono was the Acting Minister and Vice-Minister of Transportation of Indonesia, and Deputy Minister for Infrastructure and Regional Development at the Coordinating Ministry for Economic Affairs. He was also a member of the board for airline, port, telecommunications, and media companies.

He has chaired several research institutes and taught in universities. He is actively doing research; has published several books; and has written articles on infrastructure, transportation, urban and regional planning, sustainable development, and climate change.

Susantono has received several accolades, including Bintang Mahaputra Utama, Satya Lencana Pembangunan, Satya Lencana Wira Karya, Rekor MURI 2015, Sustainable Leadership Award 2018, Ganesha Widya Jasa Adiutama (ITB) 2019, and Top 100 Fintech for SDG Influencer 2019. 


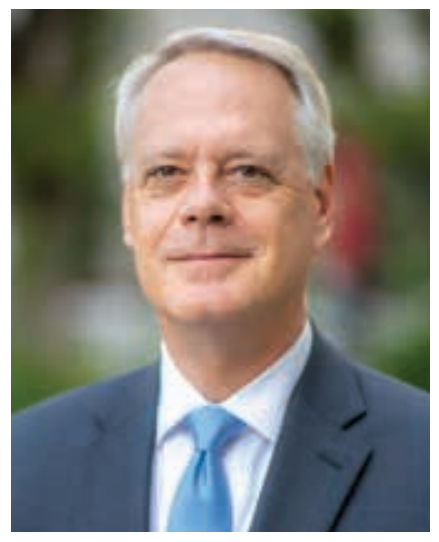

Robert Guild is Chief Sector Officer of the Asian Development Bank (ADB). $\mathrm{He}$ is responsible for $\mathrm{ADB}$-wide technical collaboration, innovation, and knowledge management for sector groups in transport, energy, urban, water, education, health, and finance. His previous roles at ADB were Director for Transport in the East Asia Department and Director for Transport, Energy, and Environment in the Pacific Department. He has been with ADB since 2003.

Guild is an expert on infrastructure investment for social and economic development. He has advised governments, the private sector, and multilateral institutions in more than 24 countries in Asia, the Pacific, and Latin America on public investments, public-private partnerships, and national and regional development plans.

Guild began his career as a professional engineer in the United States and worked extensively with bilateral and multilateral agencies in international development. He held faculty appointments at universities in the United States, the Pacific region, and New Zealand. He holds a doctor of philosophy (PhD) degree in planning and master's degrees in public administration and in urban and regional planning from the University of Southern California. He graduated with a civil engineering degree from California State University. 


\title{
Authors
}

\begin{abstract}
Abdul Abiad
Director, Macroeconomics Research Division, Economic Research and Regional Cooperation Department, Asian Development Bank
\end{abstract}

\section{Elliot Aguirre}

Consultant, Sustainability and Resilience, AECOM

\section{Michael Anyala}

Senior Road Asset Management Specialist, Transport Sector Group, Sustainable Development and Climate Change Department, Asian Development Bank

\section{Lara Arjan}

Urban Development Specialist, Urban Sector Group, Sustainable Development and Climate Change Department, Asian Development Bank

\section{Marlon Boarnet}

Professor and Chair, Department of Urban Planning and Spatial Analysis, Sol Price School of Public Policy, University of Southern California

\section{Gillian Brown}

Independent consultant with 30 years of experience working on gender and social development issues

\section{Arup Chatterjee}

Principal Financial Sector Specialist, Finance Sector Group, Sustainable Development and Climate Change Department, Asian Development Bank

\section{Alexandra Pamela Chiang}

Senior Transport Specialist, Transport Sector Group, Sustainable Development and Climate Change Department, Asian Development Bank

\section{David Elzinga}

Senior Energy Specialist, Energy Sector Group, Sustainable Development and Climate Change Department, Asian Development Bank

\section{Kathleen Farrin}

Economist, Policy and Evaluation Department, Millennium Challenge Corporation 


\section{Chris Hale}

Founder and Chief Executive Officer, Hale Infra Strategy, Melbourne, Australia

\section{Matthias Helble}

Senior Economist, Regional Cooperation and Integration Division, Economic Research and Regional Cooperation Department, Asian Development Bank

\section{Gayang Ho}

Leader of Research and Policy Development, Union Internationale des Transports Publics

\section{Samantha Hung}

Chief of the Gender Equity Thematic Group, Sustainable Development and Climate Change Department, Asian Development Bank

\section{Heejoon Jeong}

Professor of Finance, Jeonju University, Republic of Korea

\section{Okju Jeong}

Regional Planner and Urban Climate Change Resilience Consultant, Urban Climate Change Resilience Trust Fund (administered by the Asian Development Bank)

\section{Yi Jiang}

Principal Economist, Economic Analysis and Operational Support Division, Economic Research and Regional Cooperation Department, Asian Development Bank

\section{Thomas Kessler}

Principal Finance Specialist (Disaster Insurance), Finance Sector Group, Sustainable Development and Climate Change Department, Asian Development Bank

\section{Prabhjot Khan}

Social Development Specialist (Gender and Development), Gender Equity Thematic Group, Sustainable Development and Climate Change Department, Asian Development Bank

\section{Ki-Joon Kim}

Principal Transport Specialist, Transport Sector Group, Sustainable Development and Climate Change Department, Asian Development Bank

\section{James Leather}

Chief of the Transport Sector Group, Sustainable Development and Climate Change Department, Asian Development Bank

\section{Kwan Ok Lee}

Associate Professor of Urban Planning and Dean's Chair in the Department of Real Estate, National University of Singapore

\section{Hong Soo Lee}

Senior Urban Specialist (Smart Cities), Urban Sector Group, Sustainable Development and Climate Change Department, Asian Development Bank 
Sarah Hui Li

Urban Development Consultant, Urban Sector Group, Sustainable Development

and Climate Change Department, Asian Development Bank

\section{Susan Lim}

Senior Transport Specialist, Transport and Communications Division, Southeast Asia Department, Asian Development Bank

\section{Paolo Manunta}

Senior Infrastructure Specialist (Earth Observation), Digital Technology for Development Unit, Sustainable Development and Climate Change Department, Asian Development Bank

\section{Charles Melhuish}

Independent consultant with more than 45 years of experience in the transport sector; former Lead Transport Sector Specialist, Asian Development Bank

\section{Dan Millison}

Independent consultant with more than 30 years of professional experience in sustainable infrastructure development; former Senior Energy Specialist, Asian Development Bank

\section{Ritu Mishra}

Young Professional, Transport and Communications Division, Central and West Asia Department, Asian Development Bank

\section{Clémence Morlet}

Researcher, Union Internationale des Transports Publics

\section{Ulf Narloch}

Specialist on Smart City and Project Manager, Roland Berger

\section{Donghyun Park}

Principal Economist, Macroeconomics Research Division, East Asia Department, Asian Development Bank

\section{Stephen Peters}

Senior Energy Specialist (Waste-to-Energy), Energy Sector Group, Sustainable Development and Climate Change Department, Asian Development Bank

\section{Stefan Rau}

Senior Urban Development Specialist, Urban and Social Sectors Division, East Asia Department, Asian Development Bank

\section{Sonia Chand Sandhu}

Principal Evaluation Specialist, Knowledge and Evaluation Capacity Development Division, Independent Evaluation Department, Asian Development Bank

\section{Manoj Sharma}

Chief of the Urban Sector Group, Sustainable Development and Climate Change Department, Asian Development Bank 
Virinder Sharma

Senior Urban Development Specialist, Urban Sector Group, Sustainable Development and Climate Change Department, Asian Development Bank

\section{Lidia Signor}

Combined Mobility Manager, Union Internationale des Transports Publics

\section{Grant Stillman}

Legal Adviser and Senior Administrative Officer, Asian Development Bank Institute, Tokyo;

Adjunct Professor of International Law, Temple University, Japan

\section{Renard Teipelke}

Associate Director, Climate Change, Sustainability, Resilience Practice, AECOM

\section{Gloria Gerilla-Teknomo}

Senior Transport Officer, Sustainable Infrastructure Division, East Asia Department, Asian Development Bank

\section{Shu Tian}

Economist, Macroeconomics Research Division, East Asia Department, Asian Development Bank

\section{Robert Valkovic}

Principal Transport Specialist, Transport Sector Group, Sustainable Development and Climate Change Department, Asian Development Bank

\section{Geoffrey Wilson}

Senior Water Resources Specialist, Water Sector Group, Sustainable Development and Climate Change Department, Asian Development Bank

\section{Susumu Yoneoka}

Senior Manager of Technology Planning, Nippon Telegraph and Telephone Corporation; former Energy Specialist (Smart Grids), Energy Sector Group, Sustainable Development and Climate Change Department, Asian Development Bank

\section{Seok Yong Yoon}

Principal Public Management Specialist (e-Governance), Digital Technology for Development Unit, Sustainable Development and Climate Change Department, Asian Development Bank

\section{Thilo Zelt}

Partner, Roland Berger 



\section{Introduction: Opportunities for Creating Livable Asian Cities}

Bambang Susantono, Marlon Boarnet, and Robert Guild

Asia's future is urban. More than half of the 4 billion residents of developing Asia lived in urban areas in 2019. About 1 billion may join them in the next 30 years, pushing the regional urbanization rate above $64 \%$ by 2050 . The region has some of the largest and densest cities in the world. Seventeen of the 33 global megacities with more than 10 million population are in Asia. Developing Asia has outpaced the rest of the world not only in absolute growth in urban population, but also by growth rate. Urban populations in the region increased at an average of $3.4 \%$ per annum from 1970 to 2017 , well above the rates of $2.6 \%$ in the rest of the developing world and $1.0 \%$ in developed economies (UN DESA 2018).

Cities are booming in Asia because they are hubs of economic and social opportunities. By concentrating labor and capital, they enable gains in productivity. The economies of scale they create have allowed the effective and efficient provision of infrastructure.

While urbanization has driven regional productivity growth, it has also created major challenges (ADB 2019a). Increasing urbanization does not necessarily translate to increasing opportunities for all city residents. Asia's cities will continue to grow, but may not fulfill their potential as engines of growth and job creation due to unsynchronized spatial and economic planning, lack of affordable housing, marginalization of the poor and vulnerable, significant air and water pollution, failure to mitigate the effects of climate change, and deficits in urban infrastructure (ADB 2018).

This book makes the case for five priorities to create livable cities and realize a sustainable urban future in Asia. Pursuing smart and inclusive planning, sustainable transport, sustainable energy, sustainable finance, and resilience and rejuvenation will create more livable cities in the future. Getting these essentials right in cities today is vital to adapt to the demands of tomorrow.

\section{Smart and Inclusive Planning}

Planning for cities that are smart and inclusive can make them more people-centered and improve the access to and quality of urban services for citizens, businesses, and governments in Asian cities. As pointed out in a recent survey of smart city initiatives across Asia:

Policy makers are already developing smart cities planning models to leverage the innovation of technological entrepreneurs, bridge the digital divide, support smart mobility and include the perspectives of local stakeholders, while ensuring their safety. Dozens of smart solutions are available today, focused on virtually every domain of city life: mobility, social infrastructure, built environment, utilities, security, community and economic development. Not only have these smart systems proven essential to the 
efficient delivery of municipal services, rich data sets gathered from networked devices that are now ubiquitous in highly developed cities have also offered unprecedented opportunities to understand, analyze and even predict how the various aspects of these types of cities function (UN 2019).

\section{Smart City Pathways}

In article 1A, Yoon, Lee, Zelt, Narloch, and Aguirre present an analytical framework to assess, design, and implement smart city concepts in specific contexts to support the implementation of smart city initiatives by developing countries. The framework can help professionals make sense of the abundance of information, define priorities, identify opportunities and implementation barriers, link strategy and actions, and monitor progress. The strategic use of digital technologies and data analysis are even more important given the unprecedented speed and scale of urbanization and its consequent challenges.

Learning from the critical discussions on smart cities over the past 2 decades, there can be no one-size-fits-all approach for smart city development. It is not possible to prescribe a universal set of smart city solutions and actions. Throughout Asia, developing countries possess different urban settings, distinct challenges, and varied capacities. National and subnational settings vary in terms of development status, digital maturity, and government capacityfrom highly developed to least developed information and communication technology (ICT) infrastructure. A tailored approach is necessary to reflect specific urban challenges as well as a city's capacity to address those challenges, and sustainably implement and manage smart city solutions. The article recognizes the diversity of smart city initiatives, models, and implementation modes, then draws out the potential opportunities and challenges to facilitate the advancement of tailored smart city pathways and support the development of livable cities in Asia.

Key enablers of smart and sustainable cities include strong policies and institutions, access to technology and innovation, innovative finance, digital skills and capacity, and a high level of collaboration in planning and coordination. The article aims to guide the work of smart city practitioners, facilitate effective technical advice, inform decision-making, and support discussions with stakeholders in developing countries on how to initiate actions that help realize the opportunities of smart city solution.

\section{Housing Affordability}

In article 1B, Helble and Lee explain why housing affordability is crucial to the success of cities in developing Asia. Rapid urbanization is putting enormous pressure on many cities in developing Asia to provide affordable and adequate housing at large scale and in a short amount of time. Decent living conditions at an affordable price are a fundamental need for every human being. Several countries in the region have enshrined access to affordable housing in their constitutions. Adequate housing means that people are not only able to live in healthy conditions, but that they also have access to public services and opportunities. From an economic perspective, affordable housing is important for various reasons. Most importantly, high housing costs translate into high costs of labor and thus undermine agglomeration economies and the competitiveness of cities.

The article assesses housing affordability across cities in developing Asia by calculating the price-to-income ratio for 211 cities in 27 developing countries. Results indicate that most cities in developing Asia suffer from an acute unaffordability crisis, and only about one-third of urban residents live in adequate housing conditions. The article then explores the causes and consequences of housing unaffordability and finds that supply has been very slow in reacting to the rapidly increasing demand. Strict land use regulation and high construction costs are two important factors that have constrained a rapid supply response. 
Finally, the article compares various housing policies that have been tried in the region. It concludes with four main lessons from the comparative assessment. These are the importance of (i) holistic policy approaches that are embedded in urban planning to expand housing supply, (ii) strategies to promote private sector participation, (iii) not overlooking challenges in distributing policy benefits and losses, and (iv) taking advantage of the opportunities presented by combining multiple policy options to achieve equity across households in different income segments.

\section{Earth Observation}

In article 1C, Manunta, Sharma, and Yi provide a basic background on Earth observation, describe current trends in the technology, and share practical examples of how it is being utilized in developing countries in Asia. Earth observation involves collecting and analyzing information on the natural and human-made environment using satellite constellations and new software and methodologies. It plays a significant role in shaping how cities in developing countries plan for resilience. There has been a significant increase in its use to address development challenges such as unplanned settlement growth, population growth, food and water security, and disaster risk.

The collection and analysis of satellite images have advanced significantly in the last decade, developing a broad range of mature solutions for environmental management and situation awareness. Freely available data are suitable for getting information in areas that are difficult to access in cities. Their timeliness and high frequency are particularly useful for monitoring aspects of urban development. Furthermore, analysis-ready data that are available for use within days or even hours after they are acquired can be crucial for rapid assessment and disaster risk amelioration. These trends in Earth observation are supporting governments to quantify better and prepare for the unprecedented impacts of both climate change and human-induced activities on the global environment.

The article discusses analytical tools that utilize Earth observation technology to inform project design and development. It also presents practical applications of Earth observation technology, and cases of how the technology is used in climate resilience and disaster risk management, urban services improvement, flood risk assessment, and pandemic response mapping. Because the availability of satellite data or calibrated models vary across Asia, three different approaches to calculate flood risk assessment are given in the case studies. The article concludes with future directions for Earth observation technology involving the use of artificial intelligence and open-source data.

\section{Gender-Responsive and Inclusive Urban Planning}

In article 1D, Brown, Khan, and Hung discuss improving gender equality through inclusive urban planning to bring important economic and social benefits to developing Asian cities. Women are becoming the majority in urban areas, and many people live in female-headed households as urban populations in Asia continue to grow rapidly.

Urban living may bring many advantages for women and girls, such as better access to health and education, and more opportunities for paid work. On the other hand, gender inequalities persist and limit the extent to which women can contribute to the social and economic life of cities. Urban women shoulder the burden of unpaid care work. Since many of them have migrated to cities away from their rural families, they may lack the family support mechanisms that rural women turn to. Hence, they are disproportionately impacted by inadequate provision of childcare and other facilities and services that would help reduce their time poverty. Many urban women also experience gender bias in various economic and social aspects such as lack of access to assets and finance due to their lack of security or tenure (not owning land or housing), long commutes, and poor water and sanitation. 
Women's participation in governance, politics, and decision-making helps improve the equitable and inclusive allocation and targeting of resources to address these inequalities and build urban resilience. The article therefore sets out how to promote gender equality as an important goal for urban planners. It presents a framework for mainstreaming gender in urban planning covering participation, access to services and facilities, livability, mobility, and safety and security. One application of the framework is presented in a detailed case study of spatial planning technology. The article demonstrates how to make the participation and leadership of women a priority at all levels of urban planning, implementation, and service delivery.

\section{Coordinated City Cluster Governance}

In article 1E, Rau discusses opportunities for enhancing urban synergies through improved governance of city clusters. These are regions in which natural cities have become spatially connected with one another through urban expansion and the development of intercity transport infrastructure. Some of these urban regions are as large as some nations by population, economic output, and territory. With continued urbanization, megaregions are increasingly expanding and strengthening connectivity between each other and can form even larger-scale economic corridors. They generate much of their respective countries' gross domestic product (GDP), but they also contribute to most ecosystem loss, environmental pollution, and greenhouse gas emissions.

Despite their massive economic output, many large city clusters are far from efficient as they are fragmented by administrative boundaries and typically have weak or non-existing cluster-wide physical and institutional systems. The article therefore discusses examples of coordination from Asia and also from more developed countries. Although cities have their respective administrative and governance systems, more cross-sector integration is usually needed to address contemporary challenges like livability, climate change, environmental protection, natural resource management, and inclusive and sustainable urban development. On the metropolitan scale, examples of coordinated governance, planning, and management across local administrative boundaries are presented to offer lessons that may be applied at the city cluster scale.

The growing importance of city clusters in developing Asia means that spatial and economic planning must be better coordinated across multiple local government units. The article concludes that developing countries in Asia can learn from international cases that horizontally arranged governance can achieve good results. Principles, institutions, and cooperation mechanisms developed in other contexts can be successfully transferred to larger city clusters. Such arrangements can have authority over land use, transport, and open space planning, and can assign sustainable budgets from the participating local governments and provincial and national governments to invest in the plans and operate and maintain infrastructure.

\section{Sustainable Transport}

Urbanization and transport in Asia are interrelated and codetermined by land use planning, transport planning, and business and labor markets. Urban transport planning and different transport modes have different spatial and functional implications on urban land use. And yet, less-than-optimum transport planning and investment have led to overburdened infrastructure, congestion, and inefficient location decisions by businesses and households. Improved mobility will help realize urban economic potential and increase inclusion. 
Important aspects of the sustainable transport agenda include increased investment in public transport to improve mobility, improved sector governance to increase efficiency and crowd in private capital and partnerships, managing demand to tackle congestion, taking advantage of new technologies to provide sustainable alternatives, and improving road safety to reduce the currently unacceptable toll on lives and livelihoods.

\section{Transport and Urban Form}

In article 2A, Leather describes the interactions between transport and infrastructure services and the evolution of urban form. While investments in all forms of infrastructure are important, transport has the greatest influence on the evolution of a city. Technological advances have allowed different transport modes to play an increasingly significant role. As new modes of transport develop, people are able to travel further and businesses face new location opportunities, opening up new economic and social activities and stretching urban boundaries, design, and form.

Asian cities tend to be larger and denser than their counterparts in Europe or North America. The most efficient way to move such large numbers of people in limited space is via mass transit or public transport. The majority of people in Asian cities travel by public transport and nonmotorized transport. Rapid increase in private vehicle ownership and use, especially of two-wheeled vehicles, has had a big impact on urban transport and urban form. The freedom of movement that private transport provides means urban areas can grow in all directions via the entire road network as opposed to being limited to main transport corridors as with rail or bus systems. The resultant increase the use of private vehicles has transformed many cities and given rise to urban sprawl -worsening congestion, pollution, environmental degradation, and road crashes, and causing a decline in the quality of urban life.

While most Asian cities have a central business district connected to areas that have various land uses as they radiate away from the center, there are some cities where the transport link and access have themselves become a more dispersed central business district. It is also important to recognize that cities across Asia also have large informal settlements where the transport system and space allocated to movement is very small. As such areas become more permanent, the ability to retrofit or allocate sufficient space for transport systems becomes increasingly difficult. These areas continue to be deprived of access to transport and other basic services, further marginalizing the poorest in society.

Until recently, urban land use and transport planning that actively manage mobility and promote sustainable and balanced mode shares have not been realized in many developing countries. Most Asian cities suffer from inadequate funding for investment and operations of those modes, while directing more investments to roads to ease traffic congestion. Consensus is now building on successful strategies that would help Asian countries develop sustainable urban transport systems and build livable cities. These include consistency in policy, legislation, institutions, incentives, and planning procedures; sound analysis of trip patterns, delivery needs, and accessibility, assisted by the use of big data; and integration of all transport policies and modes.

\section{E-mobility and Electric Vehicles}

In article 2B, Kim and Mishra provide a comprehensive survey of the rapid evolution of electric mobility (e-mobility) and electric vehicles in Asia, primarily those for public and commercial transport. A main motivation of this growth is the recognition that transport affects the worldwide climate through its emissions. Pollutants reduce air quality and have adverse effects on human health and ecosystems. The majority of national climate 
change plans in Asia identify transport as an immediate mitigation priority, and multiple countries have made e-mobility pledges. The electrification of transport is one of the megatrends in mobility and is a vital pillar to attain decarbonization.

Electric vehicles are present in all transport modes and vehicle categories. However, the penetration of electric vehicles in Asia and Pacific countries is still quite variable. Most of the electric vehicles are concentrated in the People's Republic of China (PRC), home to $99 \%$ of electric buses in the world and the majority of global manufacturing capacity. Publicly accessible infrastructure, especially fast chargers, is also growing rapidly. The power generation required to meet the demand from electric vehicles is unlikely to be a major constraint. The additional capacity needed to meet electric vehicle demand represents only $1.5 \%$ of total electricity demand by 2030 and can be accommodated fairly easily as long as the vehicles are charged off-peak.

Promoting further uptake of electric vehicles will depend on their economic and financial viability. This could be influenced by fossil fuel prices, electricity prices, public financial incentives, and nonfinancial incentives such as zero-emission mandates, special access permits, and exemptions from certain charges. Specific support for public charging infrastructure for passenger cars is currently essential in Asian cities. It would be difficult to convince private companies to invest if electric vehicles account for only a small share of the total number of vehicles. Municipal policies affecting these factors can have an important role in driving greater adoption of electric vehicles and crowding in private sector investments.

\section{Intelligent Transport Systems}

In article 2C, Lim and Gerilla-Teknomo describe the steps involved in planning and designing intelligent transport systems (ITS) to improve safety, efficiency, and convenience for all users of transport networks. The article explains how a comprehensive ITS framework can boost economic growth by enabling citizens and governments to better manage their resources. ITS can be used to connect multiple modes of transport, facilitate travel demand management, mitigate traffic congestion, and reduce accident risks. Developing such systems will facilitate economic growth and sustainable urbanization as ITS improves efficiency, traffic safety, productivity, and network operational resilience.

ITS projects tend to be extremely challenging due to many modern and complex technologies involved. There are also many stakeholder entities each with their own ITS elements that need to be interoperable. In addition, agencies need to share information across institutional boundaries. There are thus many integration risks inherent to designing and deploying transportation systems involving new and complex technologies. Planning, design, and implementation of ITS requires a systematic approach that follows a globally accepted ITS framework architecture that meets the specific transportation needs of stakeholders. The article details the technical requirements for planning the architecture, analysis, and design through an extended case study from the PRC.

Considering the varying stages of ITS development across Asia, it is important to promote sharing of experiences, best practices, and innovation. Development partners can proactively seek ways to promote the use of advanced technologies across operations and to provide capacity-building support to developing member countries. Advanced technologies should be mainstreamed in infrastructure operations to reduce life cycle costs, improve efficiency, and maintain the quality of services, while minimizing the negative environmental and social impacts of the transport sector. 


\section{Mobility as a Service}

In article 2D, Valkovic, Signor, Ho, and Morlet explore the rapidly evolving area of mobility as a service (MaaS). MaaS refers to the advancement of mobility technologies that create variations of traditional mobility choices such as car sharing, bike sharing, on-demand transport, and ride hailing. MaaS also involves new innovations in shared micromobility like conventional and electric scooters, bicycles, and mopeds. These modes are currently meeting only a very small percentage of transport demand in Asia but are growing rapidly.

Urban mobility has traditionally been developed from the perspective of individual modes such as private vehicles and public transport. Integration between services has historically been poor, although encouraged through urban planning and sometimes augmented through government regulations. Strategic objectives like increasing the mode share for public transport may exist in city master plans, but these are rarely effectively implemented. There is often a mismatch between mode share targets and the investments needed to achieve them. The end result is usually a less effective public transport system that discourages its use and creates more favorable conditions for private vehicle usage.

To deliver on its promise, MaaS must integrate a real-time on-demand platform that can include any combination of transport modes and provide everything for the traveler from trip planning to payments. The article maps out the different business models and regulatory environments to achieve the objectives of integration and usability. Shifting travel behavior toward different modes, offering better service, and reducing costs, while offering similar flexibility and convenience, can lead to a more sustainable transport system.

\section{Road Safety}

In article 2E, Anyala and Melhuis explain that road safety is a serious issue in Asian cities. While increasing urbanization and motorization are underpinning the rapid economic growth in the region, the surge in vehicle fleets, especially motorcycles, has escalated road safety risks. Asia has the highest per capita crash rates in the world. Approximately half of global road crash fatalities-estimated by the World Health Organization to be as high as 750,000 a year - are in Asia. Asian countries may lose about 3\% to $6 \%$ of their GDP to road crashes each year.

Most governments in the region have adopted policies and legislation to promote safe mobility, including through greater use of public transport and nonmotorized transport as part of their policies to promote sustainable transport. However, relatively few countries have adopted or enforced adequate design standards for transport infrastructure across all modes. Consistently applying such policies is required in all urban areas to achieve safer mobility. City planners, managers, and policy makers should ensure that urban streets are safe for all.

The article sets out a range of solutions to improve urban road safety. These include adopting the safe systems approach wherein all components of the transport system are strengthened to reinforce safety, improve vehicle and infrastructure design and operations standards, invest in the required safety components, and more strictly enforce actions against infringement. 


\section{Sustainable Energy}

Fast-growing cities in Asia and the Pacific region need to be decisive in securing the region's energy future and minimizing its carbon footprint. Cities consume approximately $70 \%$ of global energy production, and its use is the largest contributor to global greenhouse gas emissions. Developing sustainable energy systems in the urban context has far-reaching benefits for societies, such as significantly lowering pollution while delivering essential services like potable water and transportation and providing comfort in both residential and commercial spaces. Sustainable urban energy systems, therefore, are key enablers for making cities more livable.

\section{Sustainable Urban Energy}

In article 3A, Elzinga and Jeong provide an overview of the opportunities for sustainability in urban energy systems in Asia. The article explores six areas where city, national, and regional governments can focus to reduce emissions: urban energy systems, buildings, transport and urban planning, green infrastructure, sustainable land use, and water management. Case studies on key energy solutions are presented, including distributed renewable technologies, energy-efficient building and housing, e-mobility, and smart street lighting systems.

The case studies demonstrate that a wide range of technological options are already available for the transition to clean and low-carbon urban energy systems. These options are continuously decreasing in cost and improving in capability. Hence, there is a compelling case for cities to make progress now and adjust their strategies as new approaches and technologies become viable. The potential of a single energy solution can be optimized when it is implemented as a part of an integrated systems approach. Such integrated urban energy systems may also require improved sector governance and institutions.

Action in these areas, each of which interacts with the others, will bring considerable co-benefits including improved public health and reduced air pollution. It is essential to balance the opportunities of specific individual interventions, while at the same time looking for synergies across energy supply and demand and across sectors such as waste management, building construction, and transport. The combination of technological and institutional approaches, decentralized energy governance, and effective collaboration between public and private stakeholders will be key to modernize urban energy governance.

\section{Microgrids for Urban Development}

In article 3B, Yoneoka and Millison introduce the use of urban microgrids in Asia for greater urban energy flexibility, efficiency, and resilience. Microgrids are localized groups of interconnected loads and distributed energy resources within clearly defined electrical boundaries such as cities, communities, and campuses that act as a single controllable entity within a regional or a national electric grid. Recent innovations in distributed renewable generation, energy storage, energy-efficient controllable loads, and ICT can now help decentralize systems to achieve those objectives.

The article describes various types of microgrids and their typical design and operating modes. The normal operating mode is enabled when a microgrid is connected to the main grid; but when a power interruption or disturbance on the main grid takes place, the microgrid will be disconnected and shift to isolated mode. Whether planned or unplanned, the disconnection will not affect the microgrid's operation. These transitions, along with 
maintenance of system stability and fault detection, are the three critical aspects of proper microgrid operations. The concepts are illustrated with two case studies.

There are a few challenges to scaling up the implementation of microgrids, including their typically customized nature, limited financing models, regulatory barriers, nonstandard interconnection protocols, and operational mismatches. These can be mitigated with appropriate governance approaches, such as specific urban energy policies, harmonized technical standards, net metering, open network access, and financial incentives. Microgrids can then play a substantial role in the electricity ecosystem of the future with decarbonization, digitalization, and decentralization as key attributes.

\section{Waste Management, Waste-to-Energy, and the Circular Economy}

In article 3C, Peters and Samarasinghe make the case for greater efforts to develop the circular economy in which waste-to-energy initiatives are but one component in a cycle leading to improved urban sustainability. Asian cities often struggle to plan and manage waste, and do not invest enough to develop sufficient waste infrastructure. As a result, Asian cities are only able collect and properly dispose less than half of urban solid waste, making higher-value end-of-life uses such as recycling and energy generation even more challenging.

The article explains solutions and actions that can be considered to improve waste management outcomes, including sustainable consumption and production and development, and implementation of necessary policies, laws, and regulations. Seven approaches are described in detail: (i) improving waste collection efficiency, (ii) digitizing recyclable waste collection to create income and business opportunities, (iii) providing smaller-scale intermediate collection facilities, (iv) building waste-to-energy facilities and operating more sanitary landfills, (v) creating "zero waste community centers" to encourage more recycling, (vi) developing eco-industrial parks that combine treatment and energy generation, and (vii) enacting extended producer responsibility schemes.

While there are many challenges to developing a circular economy, they can be overcome through awareness creation, capacity building, investment in infrastructure, technology availability, law enforcement and policy implementation, international collaboration, public-private partnership, fiscal policy support, and industry formalization. As an alternative to traditional economy, a circular economy can be a more sustainable solution in the longer term, with the goals of optimizing the use of resources, minimizing waste generation, and keeping resources in use for as long as possible.

\section{Financial Innovation}

Improved municipal finance is an important factor in sustainable development of Asian cities. Developing countries in Asia and the Pacific need to invest \$1.7 trillion annually to meet the Sustainable Development Goals, maintain their current growth, and respond to climate change. Around $70 \%$ of these investments will need to be made in cities. Governments will meet about half of these needs, thus private sector finance should also be mobilized. With current annual investment at about $\$ 881$ billion, the gap is approximately $\$ 460$ billion, or just under half of the total financing need (ADB 2017). 
The benefits of increased investment are clear, but the sources of such a dramatic increase must be found. Governments have traditionally provided most of the financing for infrastructure in cities, but cannot easily scale up to the level needed. More recently, the private sector has assumed an increasingly important role that is likely to continue. Another much more recent trend, not yet common in Asia, has been the use of "crowdfunding" to raise capital from local residents through small-scale share offerings to finance urban infrastructure such as parks, stadiums, and other public facilities.

While improving traditional revenue sources is the first step in financing the infrastructure gap, it is also necessary to pursue more innovative models. These include new forms of partnerships with the private sector, leveraging capital markets and bonds for housing finance, and value capture mechanisms including those that take advantage of the spillover effects of infrastructure investment on property values (Susantono et al., eds. 2019).

\section{Financial Sustainability of Cities}

In article 4A, Sharma, Li, and Teipelke underscore the importance of financial sustainability of Asian cities in light of the region's growing urbanization and the considerable infrastructure investment that they need to make. The article notes that municipalities and subnational governments often struggle to maximize the potential of all sources of revenues. They also need to improve their expenditure management, resource allocation mechanisms, and spending prioritization. Asian cities should enhance their capacities, systems, and processes to effectively and efficiently manage their revenues and expenditures, and to attract investments to meet the growing demands for recurrent expenditures and capital investments.

The article discusses options for municipalities to improve and maximize common revenue sources. Taxes, particularly property taxes, are still underutilized, although they have the most potential to generate revenue if well designed and executed. Land value capture can be an effective mechanism to derive revenues from one of the most important assets in urban development-land. As a means of cost recovery, tariff and user charges highlight the importance of sufficient funding allocation for infrastructure operations and maintenance. Intergovernmental transfers from higher-level governments to municipalities, while being useful, come with shortcomings and limited discretion for local needs.

There are mechanisms to catalyze additional revenue sources at the local level. These include public-private partnerships for city infrastructure, municipal bonds and municipal development funds particularly for revenuegenerating projects, and increased creditworthiness to attract additional investments. These instruments can also create benefits, such as enhanced financial transparency, enforced spending discipline, and improved fiscal management and governance. The article concludes with recommendations to improve management of local expenditures and revenues in the areas of budget formulation, expenditure management, financing, and revenue generation. The options and practices discussed in this article will help create the resources needed to realize more livable cities.

\section{Housing Bond Market Development}

In article 4B, Jeong, Susantono, Park, and Tian examine the development of housing bond markets in Asia. In many cities in the region, housing prices are often so expensive that households cannot afford them with only their income earned and saved over a short period. Increasing home ownership is in the interest of national and urban development as it contributes to the well-being of people through residential stability. Home ownership also enables households to acquire properties that can generate long-term rental income. Housing construction 
is known to affect household employment, savings, investment, and productivity. Housing development generates demand in the real economy, including the construction sector, thereby becoming an important driver of economic growth.

Development of a mortgage system can greatly contribute to housing stability in urban areas and ultimately benefit the country as a whole. However, because traditional financial intermediaries acting as mortgage lenders used to rely on savings to finance mortgage loans, only limited loan amounts and maturities were available to home buyers in the earliest forms of mortgage systems. In developed economies with active housing bond markets, housing finance sources include not only financial intermediaries but also investors, both institutional and individual, in capital markets.

The article details the experiences of Asian countries in a wide range of housing finance markets-from less to more developed. It shows how more-developed housing finance markets, especially housing bond markets, can generate high efficiency in large-scale housing finance in urban areas. These markets are not only a means to increase the amount and diversity of housing finance, but also are pillars of bond markets that play a role in financial deepening and economic growth. Although the policy direction for developing the housing bond market may be different depending on economy-specific conditions and constraints, the experiences described in the article provide important policy implications for economies that want to develop their housing bond markets and housing finance.

\section{Enhancing Infrastructure Investment through Value Capture}

In article 4C, Abiad, Farrin, Hale, Helble, and Stillman describe the opportunities available to Asian cities for financing infrastructure through value capture. Rapid urbanization has led to very large investment needs to address inadequate utilities, traffic congestion, air pollution, climate change, and unequal access to vital services. However, revenues and expenditures are not keeping up, creating a typical financing gap of about $3 \%$ to $6 \%$ of national GDP. Value capture mechanisms, based on the positive spillover effects on property values derived from public investment, can help close this gap.

The article describes five value capture mechanisms illustrated by case studies. These include the regular taxation system, special fees and levies, auction of development rights, urban renewal agencies, and direct property development. Cities need to build the appropriate environment to successfully implement the value capture mechanisms. This can be done by strengthening the legal, regulatory, tax-raising, and institutional frameworks and developing sufficient institutional capacity to apply context-specific value capture techniques across complex projects.

A combination of short- and long-term actions can pave a practical pathway toward better investment by actively mobilizing key value capture and beneficiary funding mechanisms. Recycling value capture revenues back into infrastructure investment allows cities to sustainably expand their infrastructure over decades, rather than worrying how each new addition will be funded and whether the ratepayers or potential users are sufficient and will comply. When undertaken in a context of enlightened and integrated urban planning, value capture also can promote and support a broader set of sustainable urban planning and development outcomes. 


\section{Resilience and Rejuvenation}

The need to improve urban resilience has long been apparent from the natural disasters that cities have always faced, and more recently from the effects of climate change. This has been made even clearer by the wide ranging social and economic costs of the coronavirus disease (COVID-19) pandemic that began in early 2020. There is an urgent need to make cities healthier and more accessible (ADB 2020). As a recent UN report puts it, "To ensure sustainable growth and development, it is critical that cities adopt resilience strategies to improve policy efficacy, scale up nature-based infrastructure solutions, adopt new risk mitigation and finance tools, and guard against potential shocks and stresses including climate change, pandemics, and natural disasters. Resilience has become an essential tool in urban governance (UN 2019)." Some of the important tools that can help build resilience include nature-based solutions, financial tools drawn from the insurance industry, and a range of operational approaches drawn from the lessons being learned while cities are responding to the pandemic.

\section{Nature-Based Solutions for Resilience}

In article 5A, Arjan, Arjan, Rau, and Chand Sandhu discuss how nature-based solutions (NBS) use ecosystem services to resolve diverse economic, social, environmental, and climate challenges. NBS can provide sustainable and cost-effective options with multiple benefits, such as restoring ecosystems, promoting health and wellbeing, improving institutional capacity for risk management, and mitigating and adapting to climate change. NBS complement and provide alternatives to conventional gray infrastructure, or ideally function together with these through systemic integration in planning and design.

The article covers four concepts of NBS that are interrelated and are often used interchangeably. Case studies for each of the concepts are also presented. They include, among others, green infrastructure, sponge city water-sensitive urban design, low-impact design, and total asset management. Green infrastructure uses natural processes and elements such as combination of vegetation, soils, gravel, and rocks to manage water, temperature, and air quality to create healthier, resilient, and aesthetical urban environments for the well-being of populations. Sponge city concepts include managing flooding caused by increased runoff from paved areas by using green space to retain water, and retaining stormwater in a cascading system of green infrastructure. Total asset management integrates physical and social infrastructure with the natural environment and cultural heritage.

Given the current development patterns and without adequate planning, continuing urbanization in Asia will cause further pollution and loss of green environment, ecosystem degradation and fragmentation, and unsustainable urban patterns. NBS can inform and enhance policy and regulation frameworks, which in turn can mainstream NBS into national urban planning, plans, policies, building standards, and regulatory frameworks. A comprehensive approach to integrate NBS in planning for new urban areas and for retrofitting existing urban areas is more important than ever.

\section{Building Disaster Resilience}

In article 5B, Kessler and Chatterjee discuss how an integrated disaster risk management approach combined with risk reduction techniques and innovative financing solutions can help Asian cities better prepare for and respond to natural hazards and other human-made disasters. Disaster risk resilience is particularly relevant in Asia and the Pacific, which is highly exposed and vulnerable to natural hazards. Asia suffers more disasters and associated deaths and economic losses than any other continent, with the risks compounded by the effects 
of climate change. Millions of people in the region face the risk of falling into, or back into, extreme poverty by 2030 if the most vulnerable countries do not implement measures to increase their resilience to climate hazards (UNESCAP 2016).

Cities have started undertaking efforts to better manage disaster risks and improve urban environments to build resilience to climate change. Risk assessment and financial optimization tools are being used, including those developed in the insurance industry over decades of experience. Building greater resilience in physical, eco-based, social and institutional, and financial aspects can reduce death, damage, and losses, and help provide immediate financing to manage residual risk when disaster strikes. The article illustrates innovative techniques through case studies on building back better during disaster recovery, a new city disaster risk insurance pool, insuring critical public assets at the municipal level, and insuring coral reefs through large-scale financing to increase the climate resilience of coastal cities and their businesses, communities, and livelihoods.

The article makes the case that city governments should improve planning, budgeting, prioritization, and implementation of public and public-private projects, including structural and nonstructural measures, and work with private insurance and capital markets. Disaster and climate risk assessments should be part of project feasibility studies, and governments need to prioritize resiliency investments based on cost-effectiveness in risk reduction. City governments also need to adopt a full range of disaster risk financing instruments using a risk-layered approach. Using such an integrated approach, cities can become more resilient.

\section{Post-Pandemic Response, Recovery, and Rejuvenation}

In article 5C, Chiang, Elzinga, Lee, and Wilson set out a response, recovery, and rejuvenation framework for developing countries in Asia. The framework aims to help cities effectively respond to the current pandemic crisis in the immediate term, and plan for a green and resilient recovery in the short- and medium-term, while continuously adapting to a new normal with respect to human behaviors, social interactions, and business practices. The framework is applied to four sectors-urban development, transport, water, and energy.

The key principles of the framework include continued safe operation of essential services, particular attention to vulnerable populations, building back in more sustainable ways, supporting the financial recovery of service providers, and mainstreaming "new normal" measures into standard operating procedures. Cities in Asia may be expected to put greater focus on strengthening financial sustainability and supporting financial inclusion, using digital solutions to improve urban services, and building capacities of urban institutions and other stakeholders including the communities.

The article addresses the challenges and opportunities of sector rejuvenation in the medium term. Short- and medium-term actions can synergize with ongoing or planned investments and with broader agendas such as national development strategies, public investment plans, the UN Sustainable Development Goals and Agenda 2030, and Nationally Determined Contributions in line with the Paris Climate Agreement. Investment programs in all sectors can be designed to help cities become more healthy, inclusive, and resilient, and to support local economic development and create jobs. 


\section{A Livable Urban Future for Asia}

Cities drive development in Asia, but they face challenges that must be addressed for them to become sustainable, competitive, resilient, and productive. This book was written during the COVID-19 pandemic. While it might be tempting to think that COVID-19 has changed everything, a more useful lens is to focus on how the pandemic has accelerated pre-pandemic trends and exacerbated pre-pandemic inequalities.

Several themes were clear before the pandemic. The fiscal health of cities and urban megaregions will be essential. Asia's rapid urbanization makes land value capture an attractive public finance instrument, but many Asian cities have sparingly used land value capture tools, such as property taxes, auctions of development rights, and urban renewal. In cities with large inequities, housing and transport are essential social safety net functions while also being central to economic development and environmental sustainability. Effective institutions are fundamental. New technologies provide opportunities to enhance the efficiency of urban services. Obsolete technology can be skipped by moving directly to metered utility provision, real-time energy conservation and pricing, and traffic management methods and micromobility sectors that leverage smartphone and wireless technology.

Applying these methods, from technology to institutions to financing, requires attention to context. Asian cities have a broad range of examples and best practices, and this book provides an avenue for learning. The themes outlined here illustrate common challenges and opportunities.

Equity and livability are central to Asia's future. Climate change poses a huge challenge for the most vulnerable. Housing in many Asian cities has rapidly become unaffordable to large segments of the population. Transport systems, which are a lifeline to work, school, health care, shopping, and recreation, are the source of traffic safety and pollution hazards that are more common in lower-income neighborhoods. Urban planners, policy makers, and leaders should give attention to policy tools that increase opportunities while building the foundation for economic growth. The concept of livability is an excellent rubric for that work.

The concept of "livable cities" puts people and community well-being at the center of urban development and decision-making. Although definitions vary, livability has five crosscutting themes, coined as the " $5 \mathrm{Es}$ " by ADB. These are (i) economic competitiveness, (ii) environmental sustainability and resilience, (iii) equity and inclusiveness, (iv) enablers, and (v) engagement (ADB 2019b).

A competitive city creates vibrant markets. It acts like a magnet to attract talent, skills, and investments, and generates new ideas, economic opportunities, well-paying jobs, and a productive economy and tax base. The region's urban economies have grown tremendously over the past decades, but their competitiveness is still lagging.

An environmentally sustainable and resilient city helps individuals, communities, institutions, businesses, and industries survive, adapt, and grow when shocks and stresses from natural disasters, infrastructure failures, and disruptive socioeconomic events occur (ADB 2019b). Cities, particularly those in low-lying areas along the coastlines, are increasingly becoming vulnerable to climate change risks and disasters. Environmental sustainability and resilience require reducing pollution and environmental hazards, while proactively preparing for adaptation in the face of a warming climate. Resilience to disasters, including disease events and pandemics, will require effective governance; sophisticated information systems; and strong collaboration across the private, public, and nonprofit sectors. 
An equitable and inclusive city is built on a strategic vision shared by well-informed and engaged stakeholders through participatory planning and decision-making. An inclusive city aims to create a safe, livable environment with affordable and equitable access to infrastructure, services, technology, finance, and livelihood opportunities for all people, especially the most disadvantaged and vulnerable.

An enabling environment can be created through effective institutions, policies, and governance systems including integrated planning, sound financial management, and appropriate technologies. Cities can create the enabling environment through leadership and partnerships that forge synergies among the different sectors and across various stakeholders. This enabling environment is not about doing different things, but it is about doing things differently. The aim is to enable transformative change in urban development and maximize the impact and sustainability of infrastructure investments.

The "5Es" provide a framework for a way forward into more livable urban development. Urban development and urban governance must be sensitive to the context. There is not a single policy program, or one algorithmic solution, that will work everywhere. Rather, Asian cities should learn from each other, focusing on their commonalities while building a body of best practice. By bringing together the best practitioners and scholars on Asian cities, this book aims to be a resource for that project. Asian cities are among the largest, most vibrant, and most technologically advanced metropolises in the world. While challenges are evident, the opportunities are even more striking. This book will guide and help Asian cities learn from each other while charting a better future for urban livability.

\section{References}

Asian Development Bank (ADB). 2017. Meeting Asia's Infrastructure Needs. Manila. https://www.adb.org/ publications/asia-infrastructure-needs.

-- - 2018. Asian Development Outlook 2018 Update: Maintaining Stability Amid Heightened Uncertainty. Manila. https://www.adb.org/publications/asian-development-outlook-2018-update.

-_- 2019a. Asian Development Outlook 2019 Update: Fostering Growth and Inclusion in Asia's Cities. Manila. https://www.adb.org/publications/asian-development-outlook-2019-update.

- - - 2019b. Creating Livable Cities: Regional Perspectives. Manila. https://www.adb.org/publications/creatinglivable-cities.

Roth, S., S. Rau, N. Habib, F. Silva, and J. Shandro. 2020. Healthy and Age-friendly Cities in the People's Republic of China: Proposal for Health Impact Assessment and Healthy and Age-friendly City Action and Management Planning. Manila: ADB. https://www.adb.org/publications/healthy-age-friendly-cities-prc.

Susantono, B., D. Park, and S. Tian, eds. 2019. Infrastructure Financing in Asia. Manila: ADB. https://www.adb.org/ publications/infrastructure-financing-asia.

United Nations. 2018. World Urbanization Prospects: The 2018 Revision. New York. https://population.un.org/wup/ Publications/Files/WUP2018-KeyFacts.pdf. 
United Nations Economic and Social Commission for Asia and the Pacific (UNESCAP). 2016. The Economics of Climate Change in the Asia-Pacific Region. Bangkok. https://www.unescap.org/resources/economics-climatechange-asia-pacific-region.

UNESCAP. 2019. The Future of Asian and Pacific Cities 2019: Transformative Pathways Towards Sustainable Development. Bangkok. https://www.unescap.org/resources/economics-climatechange-asia-pacific-region. 


\section{CHAPTER 1 \\ Smart and Inclusive Planning}

An Analytical Framework and Guidance for Smart City Planning Seok Yong Yoon, Hong Soo Lee, Thilo Zelt, Ulf Narloch, and Elliot Aguirre

ARTICLE 1B

Housing Affordability and Adequacy in Developing Asia

Matthias Helble and Kwan Ok Lee

ARTICLE 1C

Earth Observation for Planning and Resilience of Livable Cities

Paolo Manunta, Virinder Sharma, and Jiang Yi

ARTICLE 1D

Gender-Responsive and Inclusive Urban Planning

Gillian Brown, Prabhjot Khan, and Samantha Hung

ARTICLE 1E

Urban Synergies Through Coordinated City Cluster Governance 


\section{An Analytical Framework and Guidance for Smart City Planning}

Seok Yong Yoon, Hong Soo Lee, Thilo Zelt, Ulf Narloch, and Elliot Aguirre

\section{Introduction}

Smart cities can improve the access to and quality of urban services for citizens, businesses, and governments through the strategic use of digital technologies. Given the variety and complexity of smart city initiatives, this article presents an analytical framework to assess, design, and implement a smart city concept in specific contexts in Asia and the Pacific. The framework aims to support the implementation of smart city initiatives by developing member countries (DMCs) of the Asian Development Bank (ADB).

The proposed analytical framework can help professionals make sense of the abundance of information, define priorities, identify opportunities and implementation barriers, link strategy and actions, and monitor progress. The analytical framework for smart city pathways in developing Asia has been developed based on an extensive review of 150 smart city initiatives worldwide and an analysis of 29 international smart city models.

This article has been informed by ADB's ongoing discussions on smart city opportunities and project activities across sectors and regions, including the March 2018 brainstorming session. The session brought together representatives from ADB's Digital for Technology Development Unit; Governance Thematic Group; Environment Thematic Group; Climate Change and Disaster Risk Management Thematic Group; Urban Sector Group; Transport Sector Group; South Asia Department's Urban Development and Water Division; and Pacific Department's Urban, Social Development, and Public Management Division.

This article is designed to guide the work of smart city practitioners, facilitate effective technical advice, and inform decision-making. It will also support discussions with stakeholders in DMCs on how to initiate the implementation of smart city solutions presented in this article.

Learning from the critical discussions on smart cities over the past 2 decades, there is no one-size-fits-all approach for smart city development. It is not possible to prescribe a universal set of smart city solutions and actions. Further, not all devices are smart devices. Smartness arises when data can be used to improve decisionmaking. Throughout Asia and the Pacific, countries possess different urban settings, and distinct challenges and capacities. Within the region, the national and subnational setting varies in terms of development status, digital maturity, and government capacity. Such variation ranges from highly developed to least developed information and communication technology (ICT) infrastructure, and from a wide to a very limited accessibility.

\section{Acknowledgments}

The Digital Technology for Development Unit and the Urban Sector Group of the Asian Development Bank (ADB) collaborated in preparing this article. Robert Guild, ADB chief sector officer; Manoj Sharma, ADB chief of the Urban Sector Group; and Thomas Abell, ADB advisor and chief of the Digital Technology for Development Unit provided guidance. Elliot Aguirre of AECOM gave technical inputs. 
A tailored approach is necessary to reflect the specific urban challenges as well as a city's capacity to address those challenges, and to sustainably implement and manage smart city solutions. The analytical framework presented in this article acknowledges the diversity of smart city initiatives, models, and implementation modes. Taking into account such diversity, it draws out the potential opportunities and challenges to facilitate the advancement of tailored smart city pathways across Asia and the Pacific, and to support the development of livable cities.

\section{Smart City Initiatives}

\section{Smart City Initiatives by Region and Income Group}

Smart cities have become a global trend, evolving from the improvement of infrastructure and service delivery by use of sensors and technology, to the improvement of city-wide decision-making by use of data analytics. Yet, most cities have had difficulties making their smart vision a reality. Cities set ambitious objectives, and the private sector often tries to promote the vision for marketing its solutions. Today, most cities attempting a transformation to become smarter in their planning and management are still at the initial stages of the process.

In a desk review, 153 cities with official documents on smart city strategies by city authorities were analyzed (Roland Berger 2019). There was a sharp increase in the number of such publications between 2014 and 2015. Today, about 40 new official smart city publications are produced every year. This rise indicates a strong momentum toward applying smart city solutions to urban development challenges. Although smart city approaches can be found all around the world, they originated in Europe. The number of smart city strategies there almost equals the number of strategies in Asia and the Pacific and North America combined (Figure 1).

In Asia and the Pacific, most strategies come from the People's Republic of China (PRC) and India. Hardly any smart city publications by governments can be found in Africa or South America, and no strategies were identified in low-income countries. This finding suggests that cities in low-income countries lack the means and resources to develop and implement smart city strategies, or that it may not be their core priority in light of more pressing basic infrastructure and services demands.

Figure 1: Published Smart City Strategies

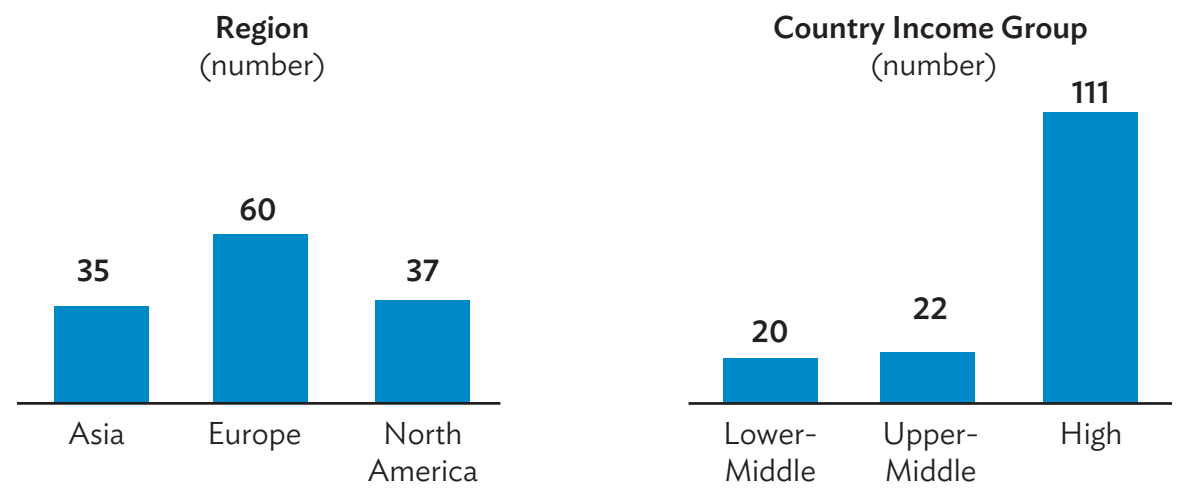

Source: R. Berger. 2019. The Smart City Breakaway: How a Small Group of Leading Digital Cities Is Outpacing the Rest. Munich. 


\section{Smart City Initiatives by Sector Focus}

The development of smart city strategies takes place in different contexts driven by various policies. In Europe, the concept has arisen mostly in the context of energy efficiency and sustainability, promoted by various funding and support programs of the European Union's Directorate General of Energy (Ferrara 2015). In the United States, many smart city approaches have a strong mobility focus, bolstered by a funding challenge of the United States Department of Transportation. ' In the PRC, the formal announcement of a national smart cities pilot in 2013 and several related policy and guidance papers have led to a combined focus on transport, water, energy, and healthcare. ${ }^{2}$

\section{Smart City Initiatives by Comprehensiveness}

Effective smart city initiatives are all based on a comprehensive strategy that considers relevant action fields within a city and assigns priorities to specific projects that channel scarce municipal resources to core action areas. As such, a comprehensive smart city strategy needs to support financing plans, engagement strategies, stakeholders' roles and responsibilities, and road maps and implementation plans of various associated projects.

A comparison of the comprehensiveness of different smart city strategies (Figure 2) based on the Smart City Strategy Index (Appendix A) shows that cities in Asia have higher scores than cities in other regions (footnote 1). A small difference in comprehensiveness by income groups was observed, although high-income countries in Europe tend to have more smart city strategies when compared to Asian countries. While many cities are moving ahead with the implementation, not all cities are acting upon their defined strategies.

Figure 2: Comprehensiveness of Smart City Strategies
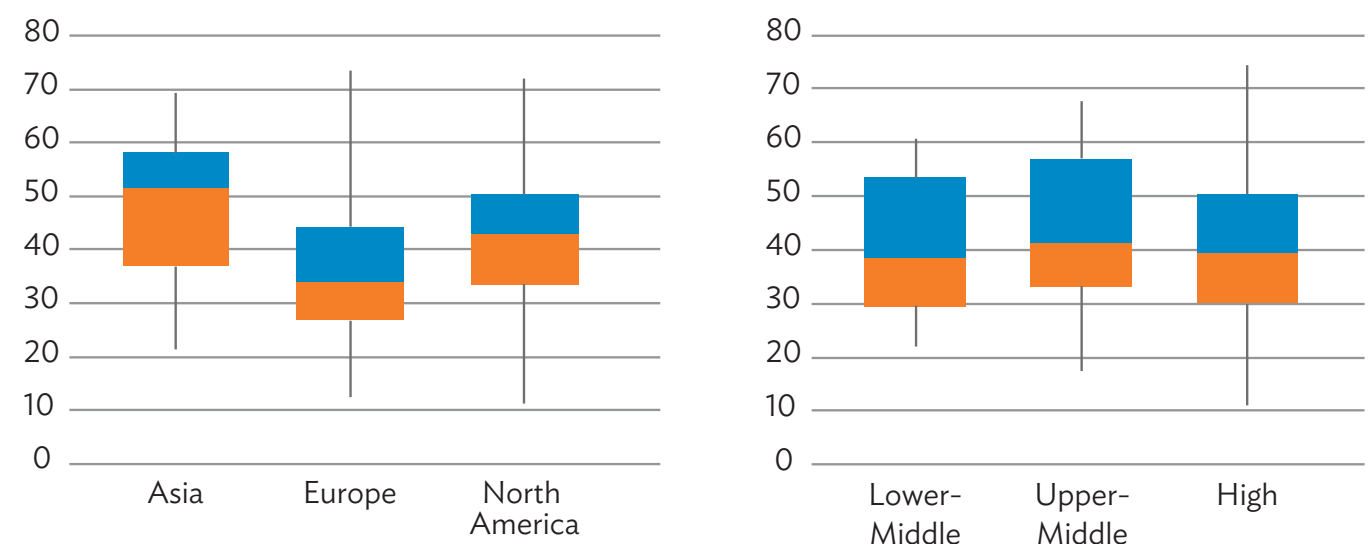

Note: Vertical lines illustrate the range of scores reached within the region, the box illustrate the range between the first and third quartile, and the line within the box represents the median.

Source: R. Berger. 2019. The Smart City Breakaway: How a Small Group of Leading Digital Cities Is Outpacing the Rest. Munich.

Government of the United States, Department of Transportation. 2015. Smart City Challenge. Washington, DC.

2 The PRC's Ministry of Housing and Urban-Rural Development led the 2013 national smart cities pilot. See EU SME Centre. 2015. Sector Report: Smart Cities in China. http://ccilc.pt/wp-content/uploads/2017/07/eu_sme_centre_report_-_smart_cities_in_china_i_ edit_-_jan_2016_1_1.pdf. 


\section{Smart City Initiatives by Action Field}

Smart city action fields are chosen depending on the cities' challenges and priorities. The scores for the different indicators within the action fields of the Smart City Strategy Index are used as a proxy for the ambition or level of willingness to achieve set targets for each action field. Comparing these scores among cities grouped by region, income, and population size shows different priority settings within smart city action fields. In Asia and the Pacific, cities are defining more ambitious approaches for almost all action fields.

Further, larger cities have better-developed strategies regarding the smart city action fields. Corresponding to the findings for Asian cities, large cities have higher scores for almost all indicators within the action fields. Aiming to provide solutions for larger populations and to manage limited space and resources, larger cities often seek more ambitious targets for buildings, environmental management, transport, education, health, and e-government than smaller cities. For the income category, however, differences between the actions of poorer and wealthier cities are less pronounced. Higher-income cities have higher scores for multimodal transport, while lower-income cities score significantly higher on civil security.

\section{Smart City Models}

\section{Smart City Model Components}

This section presents the results from a review of 29 international smart city models, their common elements, and their applicability to cities in developing Asia. Conceptual guideposts for smart city plans, processes, and action checklists have been identified (Appendix B).

The smart city models have been recently developed and offer a varied regional focus. Official bodies (e.g., European Union and multilateral development banks), think tanks, research institutions, foundations, technology providers, and consultancy firms have developed these models. The smart city models serve as a practical guideline for cities preparing smart city plans, outline key actions for the development of these plans, or assess and compare the status of different cities. While these models serve different purposes, their structural elements are often similar, consisting of high-level objectives, action fields, and enabling factors, in which digital maturity is implicitly reflected.

The models identified are composed of various elements, categorized into three building blocks:

(i) high-level objectives, which define the desired outcome to be achieved, such as quality of life, economic growth, sustainability, resilience, and inclusiveness;

(ii) enabling factors, which represent crosscutting entry points for digital transformation, such as technology, policy, skills, business, and planning; and

(iii) action fields in which smart city solutions can be applied.

All existing models differ in the coverage of these building blocks and their sub-elements.

Most models define high-level objectives to guide smart city programs. Following the eight high-level objectives is common among the reviewed smart city models. Innovation, sustainability, and efficiency are covered by more than $50 \%$ of the reviewed models, followed by quality of life, competitiveness, economic growth, and 
Figure 3: Smart City Objectives

$(\%)$

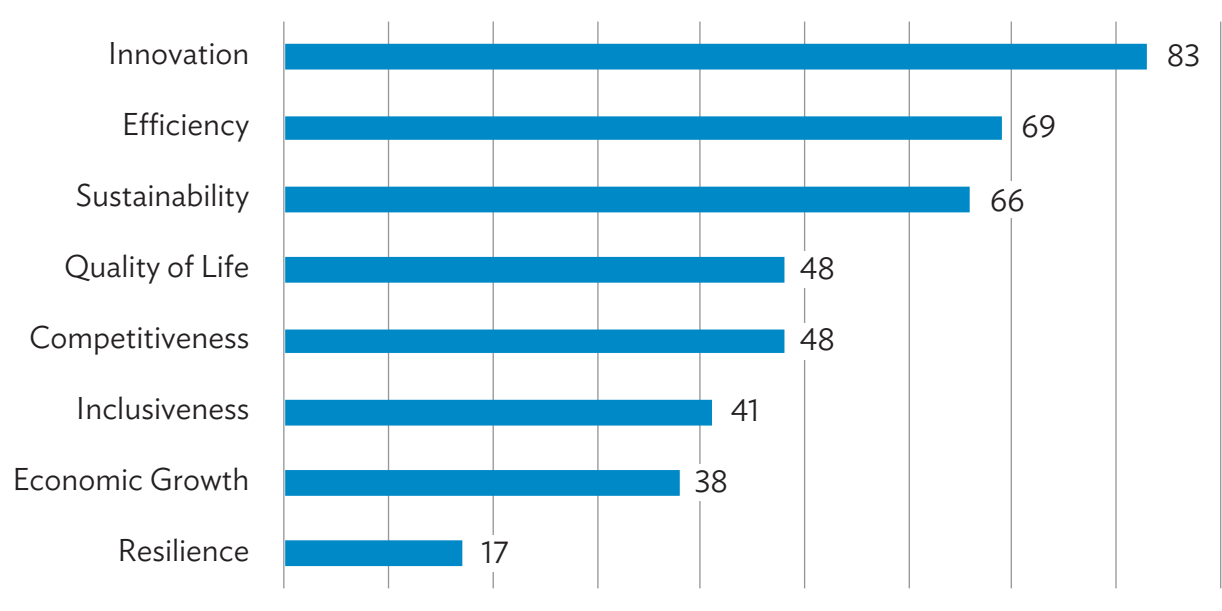

Source: Asian Development Bank.

inclusiveness. The latter four objectives appear in about one-third of the models. Resilience is the leastmentioned objective and mostly limited to models that focus on high-risk contexts (Figure 3).

Key enabling factors of a smart city can be found in most of the models. Not surprisingly, most of the models recognize the crucial role of technology and innovation. The crucial role of planning and coordinating the implementation of a smart city approach, however, is recognized by only one-third of the models. To a large extent, digital maturity is covered by the enabling factors that determine the city's readiness for digital transformation.

Almost all models include action fields, but the number and segmentation of these areas vary. Across all models, 14 action fields were identified, although the degree to which these are covered in the models differ (Figure 4). E-government and ICT infrastructure are the most defined action fields as they reflect obvious action fields in any smart city utilizing digital solutions. Urban agriculture comes last and seems not to be perceived as a primary concern for many city governments. Nevertheless, new farming methods are gaining attention due to the challenge of feeding the growing urban populations. Most of the models take a variety of action fields into account, but only a few consider the full range of actions to be addressed (Figure 5). More than one-third of the models cover fewer than 10 action fields limiting their focus on the digital transformation of their cities.

\section{Smart City Model Comparison by Regions}

Many of the reviewed smart city models either have a specific European or global (not region-specific) focus (Figure 6). Only three models have been specifically devised for Asia and the Pacific. ${ }^{3}$ In total, 16 of the 29 models have already been used in Asian cities.

3 See Association of Southeast Asian Nations (ASEAN). 2018. ASEAN Smart Cities Framework. Jakarta; IESE. 2018. Cities in Motion Index 2018. Barcelona; IESE Business School https://www.iese.edu; Indian School of Business and The Shakti Foundation. 2017. Smart Cities Index: A Tool for Evaluating Cities. Delhi; and KPMG. 2019. Connected Cities. Citizen Insights across Asia Pacific. https://assets.kpmg/content/ dam/kpmg/cn/pdf/ en/2019/01/connected-cities-citizen-insights-across-asia-pacific.pdf. 
Figure 4: Smart City Action Fields

(\%)

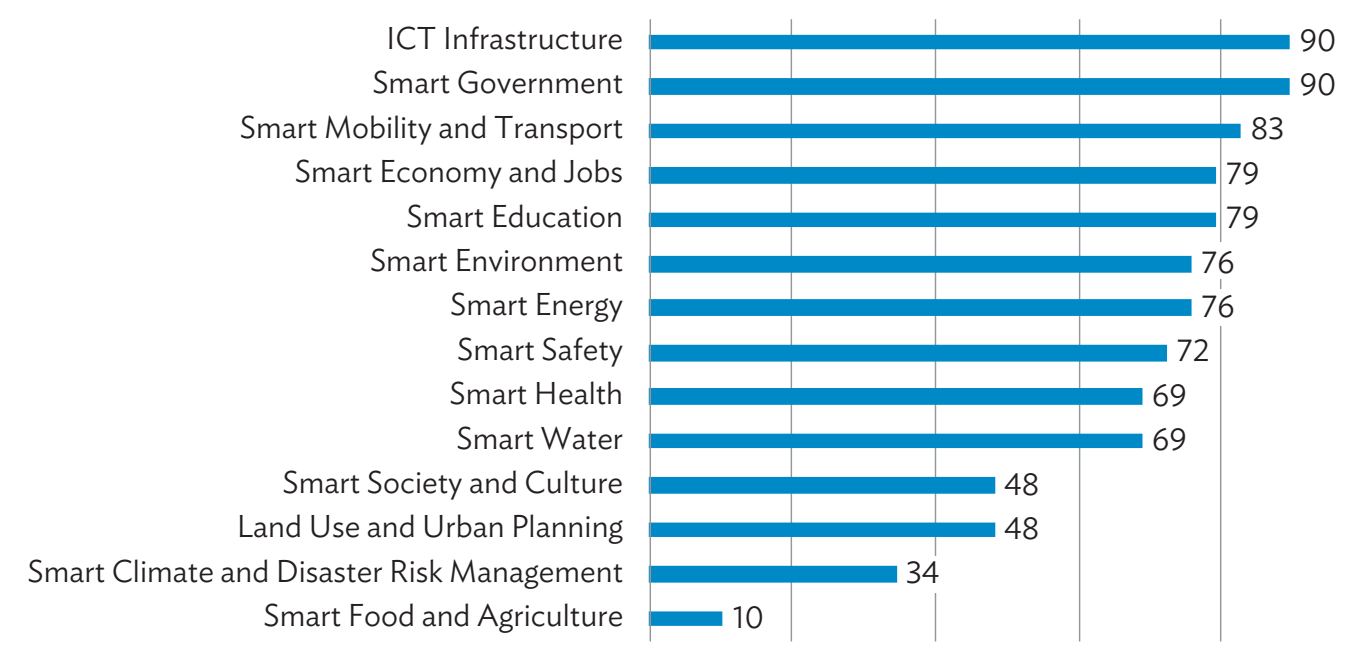

ICT = information and communication technology.

Source: Asian Development Bank.

Figure 5: Number of Action Fields by Smart City Model

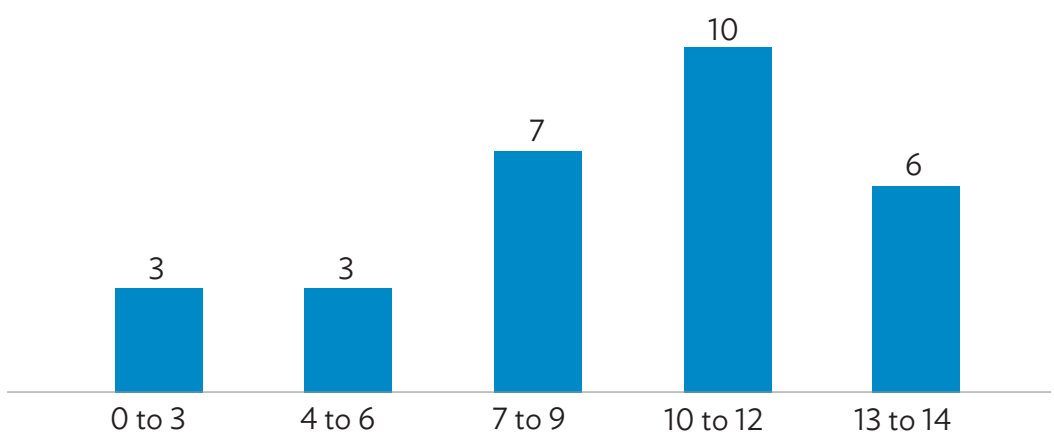

Source: Asian Development Bank.

Figure 6: Smart City Models by Region

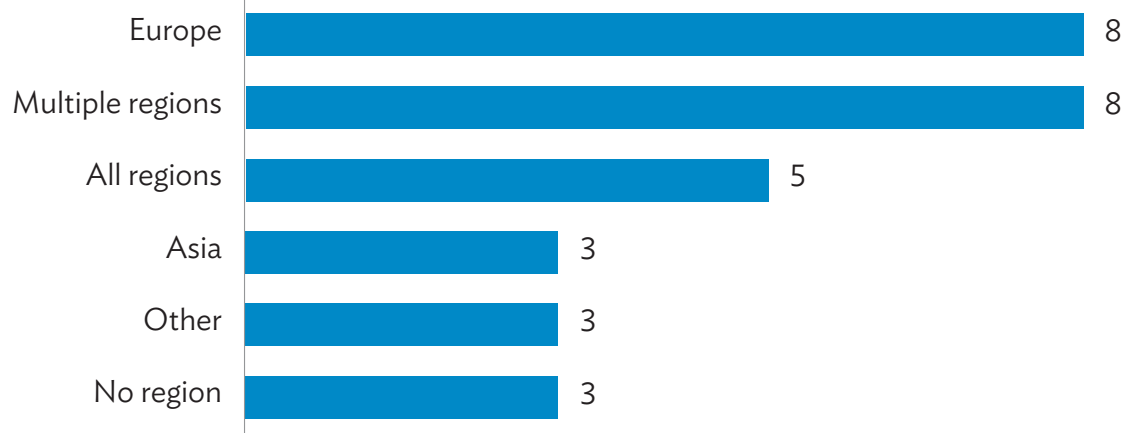

Source: Asian Development Bank. 
Smart city objectives. Models for Asian cities have a broader coverage of economic and social objectives than other models. Innovation, efficiency, and sustainability come first in both Asian and non-Asian groups, while competitiveness, economic growth, and inclusiveness are considered more in models for Asia (Figure 7). Despite the importance of increasing climate and disaster risks, particularly in Asia and the Pacific, only three models have mentioned resilience.

Smart city enablers. Fewer differences between Asian and non-Asian models are observed in terms of smart city enablers. Yet, Asian models put more emphasis on digital skills and capacities, which rank first with technology and innovation (Figure 8). This finding implies that training and capacity building on the application of new technologies are key in the region.

Figure 7: Smart City Objectives

(\%)
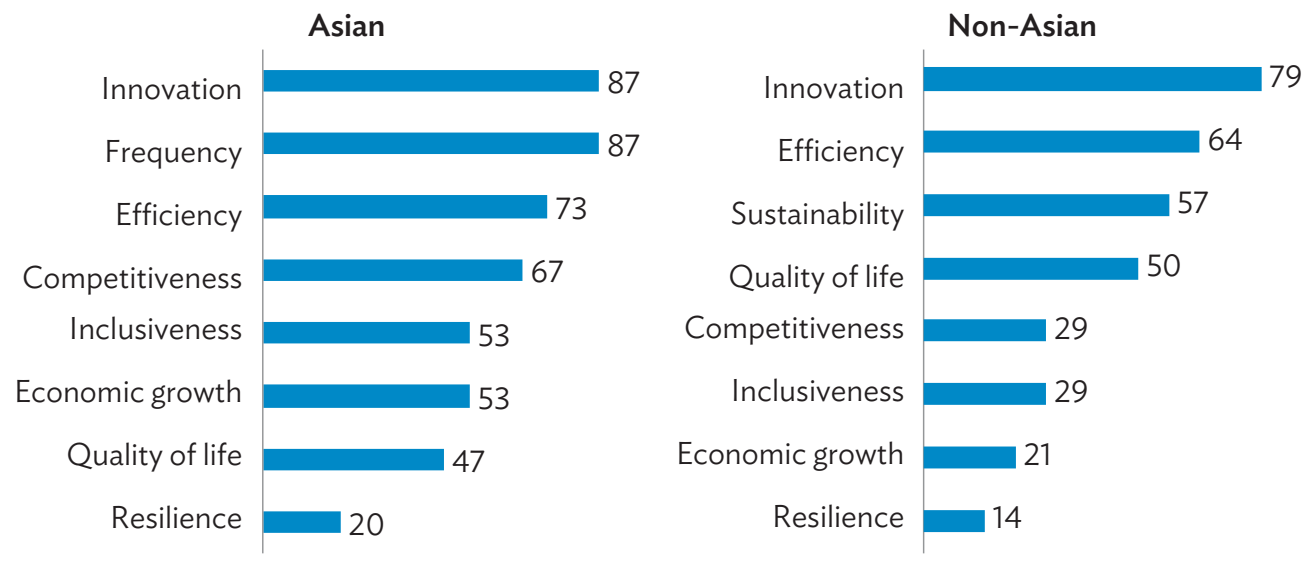

Source: Asian Development Bank.

Figure 8: Smart City Action Enablers

(\%)
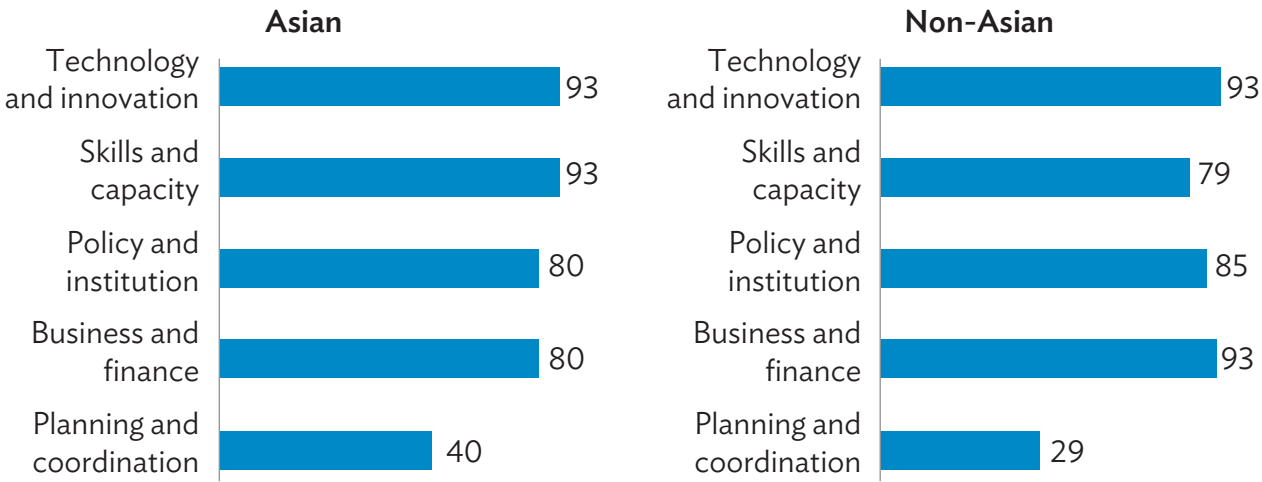

Source: Asian Development Bank. 
Smart city action fields. Only minor differences in smart city action fields appear. ICT infrastructure and education rank higher among the Asian models, confirming a focus on skills development and technical capacity building in most of the cases (Figure 9). Land use and urban planning are covered, more often reflecting the mounting challenge of limited land availability and urban sprawl in many Asian cities (African Development Bank et al. 2019).

Figure 9: Smart City Action Fields, Asian and Non-Asian Region

(\%)

Asian

ICT Infrastructure Smart Government

Smart Education Smart Mobility and Transport Smart Economy and Jobs Smart Energy

Smart Environment Smart Health Smart Water Land Use and Urban Planning Smart Safety

Smart Society and Culture Smart Climate and Disaster Risk Management Smart Food and Agriculture

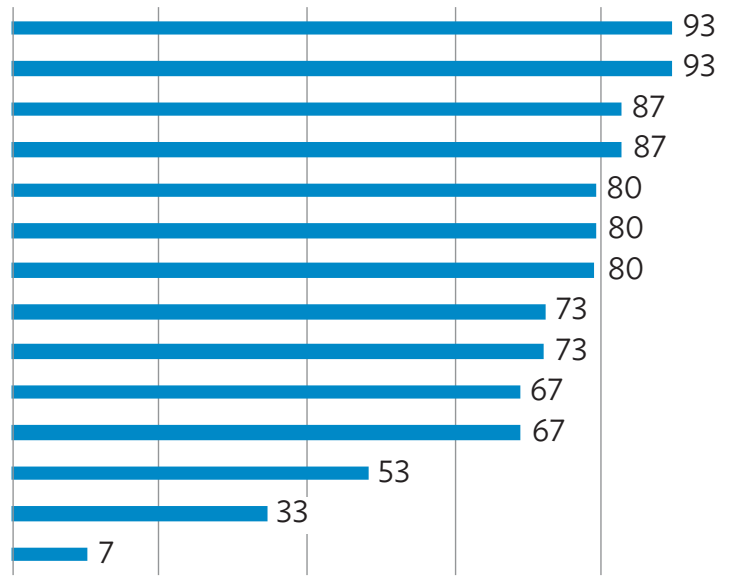

Non-Asian

ICT Infrastructure Smart Government Smart Economy and Jobs Smart Mobility and Transport Smart Safety Smart Education Smart Energy Smart Environment Smart Health Smart Water

Smart Society and Culture Smart Climate and Disaster Risk Management Land Use and Urban Planning Smart Food and Agriculture

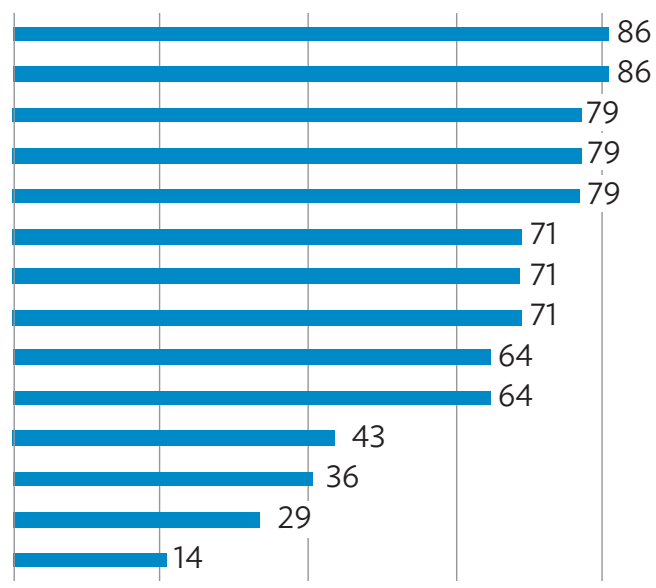

ICT = information and communication technology.

Source: Asian Development Bank.

\section{Smart City Action Fields}

In the two previous sections, the common elements of smart city initiatives and models as high-level objectives, enabling factors, and action fields have been defined. This section then presents and discusses each of the action fields and their role in smart city solutions. Each action field is illustrated by an ADB case that utilizes smart city solutions. 


\section{Information and Communication Technology Infrastructure}

Smart city operations are built upon resilient and accessible ICT infrastructure, in which a city-wide network of connectivity systems exchange and update information in real-time (ITU-T 2020). This information can then be provided to the public. ICT connectivity is strengthened through infrastructure network equipment components such as fixed-line and mobile network infrastructure, satellites, data centers, and corresponding transmission lines (Box 1).

Box 1: Affordable Satellite-Based High-Speed Broadband Internet in Asia and the Pacific

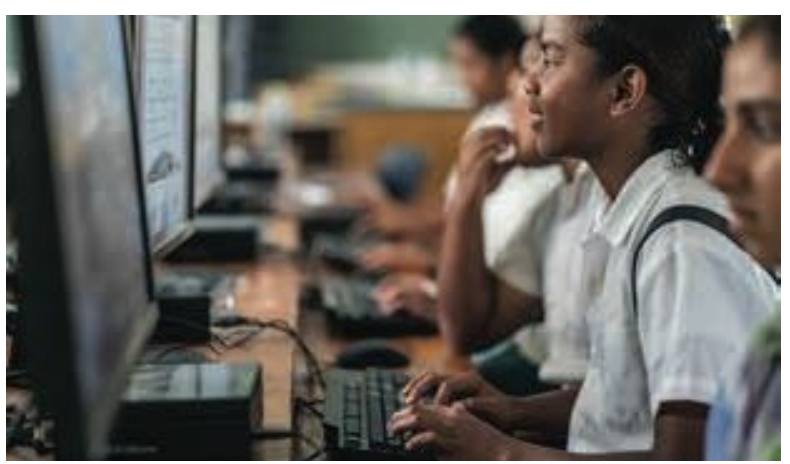

The Asian Development Bank (ADB) approved a $\$ 50$ million project with Kacific Broadband Satellites International Limited (Kacific) -its first satellite financing. The project will provide affordable high-speed broadband internet connections to countries in Asia and the Pacific. It will connect the remote areas of small island nations in the Pacific and larger island nations like Indonesia and the Philippines through satellitebased internet.

Online connectivity. Internet connection facilitates access to education, especially in remote areas (photo by ADB).

Source: Asian Development Bank. 2019. ADB's First Satellite Financing to Expand Internet Access in Asia and Pacific. Manila. https://www.adb.org/news/adbs-first-satellite-financing-expand-internet-access-asia-and-pacific.

Mobile phone applications also extend ICT connectivity to the end user, increasing accessibility. This infrastructure is supplemented by emerging intelligent systems, including Internet of Things (loT) and artificial intelligence. ${ }^{4}$ ICT systems are dependent on broadband internet; public Wi-Fi; and/or long-range, low-power, and wide-area networks. The loT networks transfer data from sensors, while the city control centers monitor data flows in real time. Data platforms provide access to these data sets for multiple users; data centers and cloud computing enhance the real-time exchange of data. Meanwhile, the ICT security and resilience protocols protect the systems and the underlying data.

\section{Urban and Land Use Planning}

Rapid growth in many regions of Asia often generates urban sprawl and unregulated development in risk-prone areas such as flood zones (African Development Bank et al. 2019). To address these challenges, smart cities can harness a myriad of digital technologies to improve land use planning and decision-making through more effective monitoring, mapping, and analysis of urban environments (Box 2). These technologies include new data from remote sensing Earth observation, geographic information systems (GIS), and big data analytics.

4 Intelligent systems are advanced, internet-connected computers that combine artificial intelligence and machine learning to gather and analyze data and can communicate with other systems. 


\section{Box 2: Land Registry with Blockchain Technology in Fiji}

The Asian Development Bank and the iTaukei Land Trust Board have developed a modernized land management system for Fiji. The system features a proof-of-concept for a blockchain-based system that seeks to secure customary land records, streamline land leave transaction steps, and ensure transparency of the auditing process. The simple process, fully adopted in 2019, is fast and secure, and has significantly improved the user experience. Due to its accuracy and low cost, other countries, including India and Japan, are also rolling out the blockchain for land value registration.

Source: Asian Development Bank. 2019. Distributed Ledger Technology and Digital Assets: Policy and Regulatory Challenges in Asia. Manila. https://www.adb.org/sites/default/files/publication/509941/distributed-ledger-technology-digital-assetsasia.pdf.

Remote sensing data from satellites provide real-time Earth observation. The GIS stores, integrates, and displays this data alongside other geocoded information to spatialize key patterns that inform land use planning. Big data analytics enables further integrated analysis of this data with other ground data, including user-generated mobile phone data. Parametric modeling software and computational design programs also help visualize different urban planning scenarios. Collating this information on open data platforms further widens the potential of new urban planning solutions and other smart city applications.

\section{Mobility and Transport}

Urban environments face a multitude of challenges related to mobility and transport, including traffic congestion and associated air quality impacts, diffused urban pollution, and accidents, among others. Smart cities can address these challenges using technologies that link to four transformational trends: the rise of shared mobility, the emergence of autonomous technology and self-driving vehicles, the digital transformation of automotive production processes, and the growth of e-mobility (Arup 2014). The following are examples of how these technologies are used:

- Intelligent traffic management systems control traffic flows in real time.

- Smart traffic lights regulate traffic flows to decrease congestion.

- $\quad$ Shared mobility services reduce the number of vehicles on the street.

- Multimodal platforms enable the combination of different transport modes.

- Autonomous vehicles provide safe and convenient transport.

- $\quad$ Electric vehicles double as battery storages or energy generators increase.

- Smart-parking apps decrease congestion and pollution in city centers.

Collectively, these systems allow cities to balance the demand for accessible mobility and transport with the objective of low-carbon and livable cities (Box 3). ${ }^{5}$

5 See ADB Operational Priority 7-Fostering Regional Cooperation and Integration. https://www.adb.org/documents/strategy-2030-op7regional-cooperation-integration. 


\section{Box 3: Intelligent Transport System in Guizhou, People's Republic of China}

In August 2019, the Asian Development Bank signed a \$200 million loan to develop an innovative intelligent transport system aimed to boost transport safety, lessen air pollution, and lighten traffic congestion in Gui'an, a new city in Guizhou Province, People's Republic of China (PRC). This project will finance real-time traffic and road-weather monitoring, multimodal transportation systems management and operations center, integrated traffic operations, and safety and emergency management system. The intelligent transport system will also include some sustainable transport infrastructure, such as clean energy buses, bus stations, and electric vehicle charging stations. It will be a pilot for other cities demonstrating integrated smart transport development.

Source: Asian Development Bank. 2019. ADB-Supported Sustainable Transport Project to Reduce Pollution, Improve Mobility in Guizhou, PRC. https://www.adb.org/news/adb-supported-sustainable-transport-project-reduce-pollutionimprove-mobility-guizhou-prc.

\section{Energy}

The growth of urban populations, combined with rising income levels, places a corresponding increase in per capita energy demand. Moreover, the proliferation of renewables and decentralization of energy networks introduces opportunities and challenges around energy supply and variance. Digital technologies can improve and stabilize energy supply from renewable sources across decentralized grids. This will enhance energy efficiency and optimize supply and demand (Word Bank 2017). While urban energy networks have historically relied on ICT infrastructure, several technologies are driving transformation in the energy sector, including smart meters and grids, sensors, virtual powerplants, and distributed energy generators.

Smart metering systems and sensors provide utility companies and their customers with information on realtime energy consumption. This information allows for more individual energy management and tailored energy supply. Smart grid systems work to stabilize energy supply and demand while incorporating renewable energy. Virtual powerplants connect energy storage systems and power consumption units and play a crucial role in decentralized energy generation, grid stability, and flexibility.

\section{Environment}

Rapid urbanization in developing Asia has contributed to environmental problems, such as deteriorating air quality from transport and industrial emissions and challenges associated with increased waste generation and solid waste disposal practices. To reduce air pollution, improve emissions control, and establish sustainable waste management systems, harnessing digital opportunities has been a priority in smart city operations (Vinod Kumar 2020). Sensors provide a novel method to monitor and manage not only the levels of waste generation but also the quality of air, water, and soil.

While remote sensing provides satellite data on the quality of environmental resources, sensors on vehicles and other devices, such as streetlights, provide real-time data on air pollution and emissions levels. Such data provide useful insights around patterns of pollutants that can better inform decision-making. Similar solutions are applied to monitor the quality of land and water resources. For example, the health of vegetation-a key component of functioning ecosystem services in urban and peri-urban environments - can be assessed using remote sensing techniques. Finally, smart waste management systems and devices, such as smart bins, smart trucks, and robotic sorting, can sustain enhanced waste management practices. 


\section{Water}

Supply of reliable and potable water to urban residents, alongside wastewater and drainage networks, are a basic service that cities need to provide (Box 4). Developing Asia experiences climate change impacts, aging infrastructure, and growing water demand due to urbanization and increasing household incomes. These are some of the challenges that smart technologies can help address (ADB 2011). Smart technologies enable smart cities manage their water resources more efficiently by controlling water quality and consumption in real-time and enabling improved detection of water leaks, overflows, and damage to water and wastewater infrastructure.

Smart meters manage water distribution by controlling valves in targeted areas respondent to water demand. Water-point mapping and monitoring through drones or mobile phones also help control and measure water use. Smart technologies can also aid the operation and maintenance of water treatment utilities and sewerage systems. Moreover, technologies such as remote sensing enable more precise forecasting of water flows over the broader water catchment, thereby supporting integrated water resource management.

\section{Box 4: Piloting Smart Devices for Drinking Water Management in Dhaka, Bangladesh}

As part of the Asian Development Bank (ADB) technical assistance on Smart Drinking Water Management in South Asian Cities, smart water devices were piloted in key cities of Bangladesh, such as Dhaka. The program aims to enhance the capacity of water utilities and increase their operational efficiency and financial sustainability. Twelve smart meters, one base station, and one monitoring station were set up during the pilot phase. In Dhaka, this program supplemented a major initiative to upgrade the city's water network and increase its accessibility to all residents. Dhaka achieved this by delineating the city into smaller and more manageable "district metered areas." The district metering areas use smart meters to monitor the network for leaks and to ensure that clean, pressurized water is delivered 24 hours a day to all residents.

Sources: Asian Development Bank. 2018. ADB Perspectives on Smart City. ADB Knowledge Events. Manila. https://events. development.asia/system/files/materials/2018/03/201803-adb-perspectives-smart-city.pdf; ADB. Regional: Promoting Smart Drinking Water Management in South Asian Cities. https://www.adb.org/projects/49289-001/main\#project-overview; ADB. 2017. The Dhaka Water Services Turnaround. Manila. https://www.adb.org/sites/default/files/publication/384631/dhakawater-services.pdf.

\section{Climate Resilience and Disaster Risk Management}

Cities concentrate people and assets. Combined with their specific locations (often along coasts), cities face a variety of climate and disaster risks, such as flooding, drought, sea-level rise, severe storms, and earthquakes. To help mitigate those risks, it is key to build urban resilience or strengthen a city's capacity to absorb, anticipate, adapt to, recover from, and transform in the face of acute shocks or chronic stresses (UNDRRR 2019). Developing Asia needs to integrate digital technologies into climate and disaster risk management protocols to both minimize risk and increase response capacity.

Big data analytics combines Earth observation and land-based sensors. It is a powerful tool to monitor and predict weather conditions, extreme events, and possible natural disasters. Satellites provide spatial data on floods, storms surges, and sea-level rise, which can then be combined with on-the-ground observations derived from sensors or mobile phones to establish a rich pool of data. 
Algorithms and other artificial intelligence-based solutions help detect patterns from historical data to identify risks and to forecast future events that may divert from those patterns. Concurrently, platforms and mobile phone apps help make these data accessible to a wider audience, including those with early warning messages. As such, a smart city constitutes a safer, more resilient space in which impacts from climate change and natural disasters are mitigated and better managed.

\section{Food and Agriculture}

Producing and providing food for urban centers in developing Asia, given their population growth, is a critical challenge. Similarly, increasing wealth is shifting demand to high-input products, such as meat, which in most cases have a higher ecological footprint than plant-based diets (World Bank 2018). Supply chains often require travel from rural to urban centers and, more recently, long-distance imports, to supply the growing demand for exotic food products in Asia. Such transportation demand bears high costs and leads to increased emissions. At the same time, local and small-scale food producers in rural Asia often lack the tools to more efficiently manage their production. Food production is also highly sensitive to climatic changes. Food waste is a pressing challenge as well.

In urban settings, vertical farms use hydraulic systems to produce food with limited space. Further, mobile phone applications can provide up-to-date information and connect different end users to optimize food supply chains. Similarly, zero-waste platforms, whether online or as part of a mobile phone application, can help minimize food waste, for example, by adjusting food prices based on expiration dates and alerting customers on available products.

\section{Public Management and Services}

Government and public authorities can increase the accessibility, accountability, and transparency of their services to growing urban populations using digital tools (Mahmood 2013). Cloud computing and storage expands the quality, reliability, and affordability of services provided and offers new ways to manage and record information and internal processes. It allows for large amounts of data to be shared between different departments in different locations. Additionally, it provides data storage and management capabilities, and facilitates digital identification and digital payment schemes. Both provide the public easier access to government and nongovernment services. Web portals, mobile phone apps, and digital reality solutions can also present data and information in novel, transparent, and accessible ways. ${ }^{6}$

\section{Economy and Jobs}

Cities in developing Asia are home to a large share of the region's population. They provide economic opportunities and are often the base of many industries and service sectors, acting as a key component of the regional economy (African Development Bank et al. 2019). Digital technologies provide an opportunity for new products and services that can transform existing business models and processes, and create new economic activities and employment. This occurs both through the direct development of digital technologies, which can attract investment into cities and thereby drive further economic development, and through improving the range and accessibility of opportunities to the public.

6 Including augmented and virtual reality. 
For example, innovation laboratories bring together individuals and start-ups to develop new products and services that can be prototyped and tested before being introduced to markets and scaled up. These products and services also transform traditional sectors through the digitization of existing processes, as realized in e-commerce or Industry 4.0 (African Development Bank 2018). ${ }^{7}$ Job-matching platforms can also bring together employers and prospective employees with the requisite skills. Finally, digital skills can be consistently developed through smart education.

\section{Education}

Education is key to an inclusive city in which all residents can participate in and benefit from available and emerging opportunities. While significant progress has been made in recent years, cities in developing Asia can continue to expand education services and vocational training across all ages. As digitization accelerates, education services should work to promote digital skills to ensure that citizens are well-equipped to participate in the digital economy (ADB 2015a). Digital technologies enable broader access to a variety of personalized and international education services, while changing the ways in which education is provided.

In schools, digital equipment like tablets, smartboards, and interactive whiteboards enhance the learning experience because they support a variety of learning styles. E-learning apps also provide free or lower-cost education at distance, increasing the accessibility to a wider audience. However, it should be noted that the upfront costs of digital equipment can present a huge challenge for lower-income groups to access e-learning opportunities.

\section{Health}

Affordable health care is a basic service to which cities must work to ensure all residents have access to it. Smart cities, including those cities with aging populations, can support the health of its residents, lower the incidence of chronic health issues, and decrease the risks posed by acute health crises. This can be done through using digital means in administering comprehensive health information (ADB 2018a). Specific technologies include cloud computing, mobile phone apps, robotics, and big data analytics.

Cloud computing infrastructure enables new health information systems that create an interconnected information base for patients, doctors, and other actors in the health care system. This infrastructure can be diversely applied, from individual and specific health measures to a nationwide health insurance program. Mobile phone applications can disseminate medical information and, when connected to wearable gadgets like smart watches, can improve user knowledge through up-to-date provision and sharing of health-related data (Box 5). Telemedicine connects patients and doctors remotely, increasing the accessibility of health care services.

Robotics are especially useful in cities with aging populations to supplement nursing staff or enable the elderly to live independently for longer through ambient assisted living. Finally, the application of big data analytics helps identify personal health risks and early prediction of potential epidemics.

7 Industry 4.0 refers to the new industrial practice accelerating automation using smart technologies. 
Box 5: Digital Systems to Support COVID-19 Response in the Republic of Korea

The Government of the Republic of Korea, under the National Strategic Smart City Research and Development Program, has powered the urban big data integrative COVID-19 Data Platform. It is a cloud-based open data hub used to collect, store, process, analyze, and publish cross-function data in a holistic way.

The COVID-19 Data Platform is designed to support epidemiological surveyors to quickly identify the transmission routes that infected patients have visited. The platform uses real-time data analysis including global positioning system, mobile information, and credit card transaction history. It supports health officials by comparing the data with the interview results of patient transmission routes. Big data analysis allows officials to use real-time data on coronavirus disease (COVID-19) patients, including their whereabouts and the time spent at each location.

From these multiple data points, the system can detect incidents of cluster infection and identify the source of transmission. Other mobile applications have been developed including a Self-Diagnostic App and a Self-Quarantine Safety Protection App. The applications allow users to monitor their health conditions and conduct regular self-diagnosis. They further ensure that self-quarantine measures are respected by setting off an alarm when a user ventures out of their designated quarantine area.

Source: Government of the Republic of Korea. 2020. Flattening the Curve on COVID-19: How Korea Responded to a Pandemic Using ICT. http://www.undp.org/content/seoul_policy_center/en/home/presscenter/articles/2019/flatteningthe-curve-on-covid-19.html.

\section{Society and Culture}

Digital technologies are broadly transforming the ways in which people engage with each other and with their environments. In the Asia and Pacific region, the number of mobile phone users and apps has increased from 2.34 billion users in 2014 to 2.8 billion in 2018, with an anticipated growth of another 370 million by 2025 (GSMA Association 2019). These technologies create new opportunities to bring people together with similar needs and interests.

Cities can strive to harness these tools to promote social cohesion and cultural belonging, while simultaneously working to mediate potential negative impacts. Digital platforms and new communication tools support publicsocial partnerships, providing new opportunities for civic engagement and access to cultural activities. Citizens can take part in local problem-solving and public participation, providing them with an improved sense of belonging.

App-based social services help people connect, collaborate, and stay safe in daily life. This is particularly useful for new migrants and visitors to the city, wherein these services can help with cultural integration. They can be useful as well for new residents to orient themselves in their new context. Similarly, these apps can support gender equality by providing specific tools that allow everyone to move safely in the city or by increasing access to opportunities online. Digital reality tools increase access to cultural programs such as concerts, museums, and sports matches. Social and cultural engagement opportunities will become more accessible as well to those with disabilities. 


\section{Safety and Security}

The safety and security of citizens is a key priority for governing authorities and urban service providers. With rising urban populations and the complexities of rapidly growing informal settlements, the demand on effective safety measures of central city authorities is increasing.

Evolving digital solutions may provide support for urban monitoring, crime prevention, terrorist attacks, first aid and emergency response, and integrating crime prediction and prevention into a wider concept of smart public safety (The Economist 2019). Real-time data can facilitate decision-making around the control and forecasting of crime and emergency situations. The application of smart surveillance and alarm systems, including surveillance cameras, drones, and sensors, may help identify threats in real time and trigger necessary measures, such as deploying nearby police officers (Box 6).

\section{Box 6: Household CCTV Subsidies to Improve Women's Security in New Delhi, India}

The Delhi city government has offered subsidies to households wanting to install closed-ciruit television (CCTV) cameras outside their homes. The project is set to install 140,000 cameras across the city to improve women's safety. Powered by an artificial intelligence technology, the cameras can observe, predict, and react to people who display unusual behavior.

The government subsidy will extend to the electricity consumption of the devices, upon submission of details by the users. Along with Delhi, other cities have been increasing the numbers of CCTV cameras as part of the "safe city" plan focusing on women's security. These include Ahmedabad, Bengaluru, Chennai, Hyderabad, Lucknow, and Mumbai.

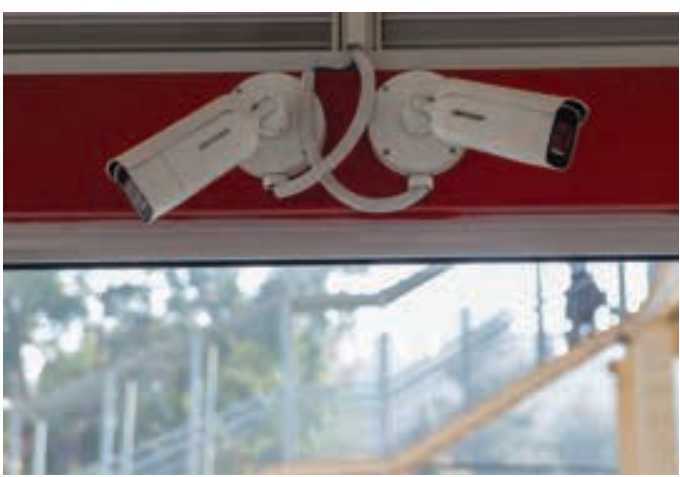

Tool for safety and security. CCTV cameras enable remote monitoring and surveillance for personal, business, and security purposes (photo by ADB).

Source: OnManorama News. 2019. Women's Safety: Free CCTV Outside Your House but with a Rider. 11 June.

Other digital tools such as facial recognition or electronic fingerprint may facilitate the identification of offenders. Mobile phone apps provide an additional means to report and monitor crime, inform on emergency procedures (first aid) or guidance (evacuation), and provide a channel to communicate with security forces for direct assistance. These systems are crucially important when requiring rapid response like for terrorist attacks. Econometric forecasting models may predict crime so that necessary prevention measures can be taken to keep high-risk areas safe such as public transport and energy distribution systems. 


\section{Smart City Enablers}

Building upon the discussion on smart city action fields and cases in the previous section, this section introduces the smart city enablers and their role, challenges, and opportunities. Smart city enablers are key components that provide the necessary foundation and tools to accelerate the effective transition toward a smart city. In this section, enablers are generally grouped into themes, but will differ from city to city depending on the context and the desired smart solutions.

\section{Policy and Institutions}

Strong policies and institutions are essential to promote the uptake of smart city initiatives. They are crucial in supporting the implementation of modern technologies and infrastructure to improve the use of data and mitigate the potential disruptive impact of technology on society.

Due to restrictions of their national frameworks, local governments may lack the necessary policy competencies to manage and coordinate local infrastructure. Some municipalities are restricted, for instance, from efficiently managing overall traffic flows and mobility, when major roads or other parts of the transport system (e.g., metro or ferry systems) are managed by regional authorities. Municipalities may also face challenges with the incompatibility of smart city initiatives with their public procurement policies.

City governments and local stakeholders should be empowered to drive their city's smart agenda and ensure that the technology is used appropriately. Aligning clear governance structures, regulatory frameworks, and urban policies behind a coherent vision or strategy for the city can provide better buy-in and oversight of the use and direction of smart technology and initiatives.

ICT availability and the provision of stable high-quality communications network are essential to supporting the functioning of digital technologies necessary for smart cities. Smart city applications run on ICT infrastructure and are generally built to manage the flows of urban data. ICT in the context of a smart city can improve quality, effectiveness, and efficiencies of urban services. It may reduce costs and other resource consumption; improve collaboration between services; and improve communication between citizens, businesses, and government.

Management, operation, and maintenance of ICT and digital technologies are therefore required to support smart city initiatives. The associated costs should be considered from the planning stage onward as a factor on city finances. Clear oversight of existing capacities and available resources is also essential in ensuring the sustainable management and maintenance of ICT for future smart city tools.

Besides the technical considerations, security and data privacy have emerged as intertwined challenges within the smart city context. Smart city initiatives may pose personal privacy threats to citizens' personal, financial, and global positioning system (GPS) data (World Bank 2017b). Citizens are often given little clarification about the implication of the consent they give on the processing of personal data, the collection of private data from public interactions, the privatization or ownership of data (as well as the infrastructure), the safety of stored data (cloud or other systems), and the repurposing of big data for profit (Edwards 2015). Strong security and privacy measures should be embedded in policy and regulations. Related smart city infrastructure and processes are also paramount to ensuring trust and engagement of various stakeholders in the planning, implementation, and management of smart city strategies and actions. 
There are more diverse people living in cities that are growing. While smart cities can help improve living conditions, social and economic disparity exists, particularly in terms of access to benefits. The disadvantaged population, such as the disabled and the elderly, face more barriers in smart cities. As digital services become more pervasive in smart cities, there is a high possibility that inequality will deepen for the disadvantaged people. Also, the poor might be excluded from the smart city services as most of them could not afford broadband internet services with smartphones. Closing the digital divide, therefore, is a critical first step. Policy makers need to design smart cities in more inclusive ways, especially for the vulnerable groups.

Another area of concern is gender. Smart city initiatives have been criticized for techno-centric visions of innovation and using gender-blind policies. Gender inequality and discrimination against women may increase with the rise of technological systems as smart cities are being developed. Gender-responsive policies are needed to ensure urban policies work for all citizens, as gender differences are apparent in socioeconomic conditions such as education, employment, and income.

As urban innovation increasingly relies on urban open data analytics, it is crucial that sex disaggregation is built into data collection and analysis processes. This is crucial in terms of identifying gender-specific needs, as well as gendered outcomes and consequences of smart city initiatives. Forgoing such disaggregation may lead to gender-blind smart city policies and initiatives, aggravating existing inequalities and increasing safety risks to women (Sangiuliano 2017). Smart city initiatives must consider the implications on gender equality and inclusivity more broadly throughout design, implementation, and monitoring stages. ${ }^{8}$ Smart city solutions should benefit all members of society, ranging from informal citizens, businesses, visitors, residents, and civil society groups, and should be as inclusive as possible.

\section{Technology and Innovation}

Access to technology and innovation can support a city toward developing smart technologies, infrastructure systems, utilities, and intelligent approaches. It also facilitates the provision of urban infrastructure and social services by tailoring and increasing the reach of smart city solutions.

Hackathons are a comparatively simple, creative way to harness public, private, and academic expertise in designing innovative and tailored solutions. These can be led by city governments, civil society organizations, or multilateral development banks (MDBs). For instance, ADB and the Asian Institute of Management initiated the 2019 hackathons which focused on solutions for the digital skills gap for today's workforce and improving digital payments (ADB 2019a). Fab Labs (fabrication laboratory) -small-scale workshops that offer personalized digital fabrication using technology-enabled products-may also support skills development and local entrepreneurship. Many of these operate in Asia under the Fablab Asia Network, combining information technology skills and manufacturing in an open setting. ${ }^{9}$

8 ADB's ASEAN Australia Smart Cities Trust Fund puts gender equality and women's empowerment at the core of the fund's digital solutions alongside social inclusiveness and climate change. ADB. ASEAN Australia Smart Cities Trust Fund. https://www.adb.org/site/ funds/funds/asean-australia-smart-cities-fund.

$9 \quad$ Fablab Asia Network. https://www.fablabs.io/organizations/fablab-asia-network-15b88e56-0c55-4329-b68a-bdc0b14a06b0. 


\section{Business and Finance}

With urban development needs becoming more complex, financing is one of the top challenges for cities across Asia and the Pacific. Very few cities are able to self-fund infrastructure and urban development projects (ADB, forthcoming), and public and private capital is often scarce or difficult to mobilize (European Commission 2017).

Multilayered and integrated public-private partnerships (PPPs) are becoming essential avenues to explore. The private sector can provide funding, technical expertise, and innovation that complements and strengthens public sector efforts. However, several countries and local authorities remain poorly equipped to address the needs of such arrangements; hence they would benefit from transaction advisory services on PPPs. Although public grants are limited, MDB financial instruments and national development banks both offer services that can be harnessed (ADB 2008). Successful cases can be found in ADB's support to New Clark City with PPP negotiations for water and energy distribution systems and ICT infrastructure, both geared toward the development of a smart, green, and inclusive city (ADB 2019b).

Partnerships with universities and nonprofit organizations can equally be explored..$^{10}$ Making urban data open and accessible to researchers and the private sector to facilitate innovation and solutions may also be explored. Telecommunications and transit companies may make their data available to support better management. ${ }^{11}$ A clear policy framework is essential to attract investors and make the partnerships more sustainable.

\section{Digital Skills and Capacity}

Local governments are usually not well-equipped in terms of ICT capacities. Digital skills and capacities at the local government level are needed to collect, process, and analyze large amounts of data about the urban environment and the services within it. Without these, the flow of information needed for effective planning and decision-making may be restricted, which can cascade down to inefficient use of resource services to citizens.

For many city administrations, attracting the right skills and talent can be difficult, particularly in cities that cannot offer the employment conditions of the private sector. Furthermore, the digital divide within and between local governments fosters an unequal playing field for data capturing, management, and application. Capacities among the local governments to effectively capitalize on the benefits of various smart tools and systems are also uneven. Compared to capital cities and economic hubs, secondary cities and smaller towns are not able to fully take advantage of smart city opportunities given their fewer resources, smaller city governments, and constraints to attracting talented personnel (ADB 2015b).

Several solutions can be explored to address this shortfall, such as upskilling of staff, twinning arrangements with more experienced or capacitated cities, or partnerships with technology providers and academic centers of excellence. From a policy perspective, cities should make use of managerial training programs and exchange of good practices with more advanced cities. The investment into smart city initiatives would benefit from being coupled with investment into digital skills training.

10 Asian Institute of Technology. 2018. Regional Training on Drones, Satellite Imagery and GIS in Agriculture. https://www.ait.ac.th/event/ regional-training-drones-satellite-imagery-gis-agriculture/.

1 Grab. 2017. Grab and MDEC together with the World Bank Group Launch OpenTraffic Platform in Malaysia to Combat Local Traffic Woes. grab.com/my/press/business/grab-mdec-together-world-bank-group-launch-opentraffic-platform-malaysia-combat-localtraffic-woes/. 
Closing the digital divide does not concern government staff alone, but more importantly the citizens (World Bank 2016). Extending access to networks and devices is a critical first step in setting the foundations for a smart city and a digitally smarter society. Technologies must serve everyone, even those on the margins of connectivity, regardless of income or status. There is a growing risk that inequality will deepen unless local governments recognize that technology-driven solutions are just as important for the poor as the affluent.

\section{Planning and Coordination}

A high level of collaboration is essential in implementing complex smart city projects between interdependent stakeholders with varying backgrounds, roles, and interests. Strong planning and coordination and thorough management and operation are required. Coordination, planning, management, and operation can be between ministries (e.g., when planning budgets). They can also be done between ministries and implementing partners while the project is ongoing. Well-structured management along with open information flows are crucial to ensure transparency and accountability.

At a political level, implementing smart city initiatives can have inadequate political will as such initiatives are perceived as risky or complex. As planning remains inherently political, challenges may arise when implementing a smart city initiative, especially if additional municipal support or staff, resources, or policy change are required. Thus, strategies are not always implemented. Accurate and abundant information can feed into evidence-based decision-making and increase transparency and accountability. However, political buy-in is also required to support, implement, and deliver smart city solutions. Further reforms are needed to capitalize on the various opportunities smart city solutions may offer.

As local governments generally work in their respective focus sectors, the coordination of smart initiatives between government departments can be delicate. Even without the addition of smart city systems, local governments are tested when encouraging their sector experts to work across departmental boundaries to increase operating efficiency. The required planning for holistic smart city solutions is often constrained with the divided institutional features of a city government wherein the sharing of information between departments can be restricted (IGLUS 2018). Smart city projects by nature involve multiple disciplines and stakeholders collaborating in an interdisciplinary approach. Such integrated projects need a variety of representatives from different disciplines with the right level of political support to plan, coordinate, and implement an initiative and its projects.

At the citizen level, stakeholder engagement is central to planning and coordinating smart city projects. However, it has been difficult to create a meaningful collaboration among stakeholders. The active participation of stakeholders in city governance can be facilitated by using online communication tools such as web pages, mobile apps, and social network platforms, among others. Issues of the digital divide and uneven access to such platforms and tools must be considered.

Smart city projects are characterized by a high level of experimentation, resulting in rounds of trial and error. Having planning and coordination processes that allow for such flexibility is essential (Borsboom-van Beurden et al. 2017). Cities can ensure that the requirements across city departments are aligned with modern technical options, and delays for bureaucratic procedures are avoided or streamlined. 


\section{Smart City Analytical Framework}

The previous section has discussed the international smart city initiatives and models, identified their common elements, presented cases to illustrate each action field, and laid out the smart city enablers needed to support smart city solutions. This section, in turn, proposes an analytical framework for smart cities in developing Asia. This analytical framework, which is tied into a wider project management lens, can guide practitioners and decision makers in assessing and devising strategies and actions to implement smart city initiatives and to understand, structure, and assess smart city programs. It is a high-level analytical framework that provides the necessary flexibility for the specific contexts of targeted countries and cities.

Smart cities are places where digital technology solutions are applied to address urban challenges to benefit citizens, businesses, and the government (ADB 2019c). Digital technology solutions are not an end goal but a means for higher-level development objectives. The application of digital technology solutions is underpinned by enablers that strengthen a city's ability to plan and to implement smart city projects, as discussed in the previous section. The proposed smart city analytical framework can serve as a general framework that is applicable to a city, but can be scaled up to provincial or national level.

Smart city enablers include the use of smart city analytical framework, policy and institutions, technology and innovation, skills and capacity, business and finance, and planning and coordination. Policy and institutions need to provide clear laws and rules for the digital transformation of a city. Technology and innovation measures must develop new digital solutions within the context of a city. Skills and capacity determine a city's digital ability to implement these solutions. Business and finance refer to a city's ability to mobilize the private sector and to generate financial resources for the rollout of digital solutions. Finally, planning and coordination can increase the organizational capacity to manage and implement the digital transformation of a city.

Based on the common building blocks from existing smart city models, three key dimensions are proposed (Figure 10):

(i) high-level objectives, such as being green, competitive, resilient, and inclusive, which together contribute to making cities more livable;

(ii) action fields where digital solutions can be applied; and

(iii) enabling factors that determine the city's readiness to apply digital solutions and set the foundations for these to take place.

The global examples of smart city strategies show the need for high-level objectives to operationalize smart city efforts. Vienna, as a leading smart city, has set three main principles: quality of life (i.e., social inclusion, participation, and health); resource efficiency (i.e., energy, mobility, and infrastructure); and innovation (i.e., education, economy, and technology). ${ }^{12}$

On the other hand, the Republic of Korea's 2018 Act on the Promotion of Smart City Development and Industry, also known as the Smart City Act, defines smart city more broadly as consisting of "interconnected services and facilities that improve competitiveness and quality of life to provide significant power to individual cities and projects (Intralink 2019, 7)." In developing Asia, while strategic objectives will naturally differ based on their context, the high-level objectives are universal enough to provide a meaningful common ground for potential collaboration.

12 For examples of smart traffic lights, see Smart City Wien. https://smartcity.wien.gv.at/site/smarte-ampeln/. 
Figure 10: Proposed Smart City Analytical Framework

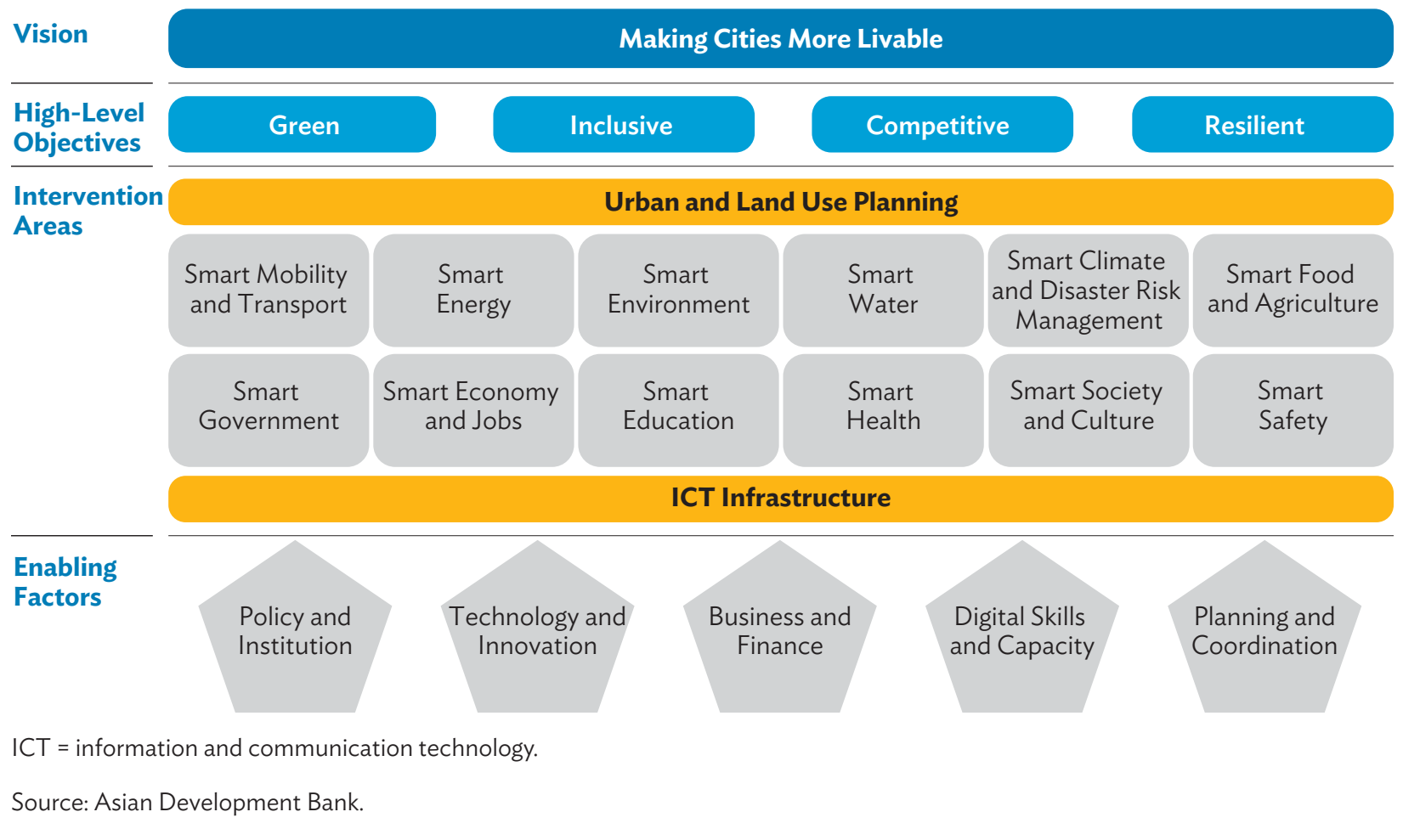

Extracted from the existing smart city models across the globe, the smart city action fields in developing Asia can be proposed along three areas:

(i) crosscutting smart city solutions, such as urban and land use planning and ICT infrastructure that constitute the foundation for different sector solutions;

(ii) smart city solutions for infrastructure and environment, such as mobility and transport, energy, environment, water, climate and disaster risk management, and food and agriculture; and

(iii) smart city solutions for social and governance sectors, such as government, economy and jobs, education, health, society and culture, and safety.

Cities should prioritize these action fields according to their challenges and needs. Individual projects can be defined within these action fields. For example, smart society encompasses projects such as Smart School, Smart Clinic, and the Smart Astana Chatbot that are all employed with the goal of improving citizens' quality of life and advancing society. Notably, the 14 action fields offer guidance for identifying smart city solutions without being exhaustive.

\section{Financing Smart City Initiatives}

As smart city initiatives gain traction and governments look to replace and upgrade infrastructure networks and services across Asia and the Pacific, a need for innovative funding solutions arises to bridge common funding gaps found in urban infrastructure provision (ADB 2017). 
Challenges to financing smart city solutions arise due to

- the perceived risk and complexity of smart city solutions,

- uncertain return on investment,

- complexity of multisector interventions versus single-sector focus,

- $\quad$ preference for long-term projects, and

- $\quad$ benefits not directly linked to financial value (ADB 2018b).

To overcome these challenges, clarity on the revenue model for smart city solutions is needed. This can include savings from improved efficiency in infrastructure and services, tapping new revenue sources, or greater effectiveness in existing revenue streams (ADB, forthcoming). Several sources of financing and funding may be applied to bridge the infrastructure gap with new and innovative approaches to enable smart infrastructure projects (ADB Urban Sector Group 2018). Among them is the involvement of the private sector, which brings in additional technical skills and avenues for joint financing and risk sharing.

Besides private sector service providers, MDBs are well placed to support financing and advice on smart city solutions. Furthermore, they are positioned to provide additional knowledge and capacity support using digital solutions to improve the livelihoods of all people, and source seed financing to pilot solutions.

ADB's Finance++ aims to offer a combination of ADB's own finance, plus leveraging resources through partnership. It also seeks to provide knowledge to DMCs to maximize and accelerate development effectiveness (ADB 2013).

Financing smart solutions depends on the level of preparation and quality of project design to access downstream funding. Support from MDBs through technical assistance and grant funding, may help in planning and piloting a smart city initiative to facilitate government implementation.

Key questions around how to make these financing streams sustainable remain, and it is crucial that governments have the capacity to cover any additional financing needs from new smart city solutions. Special consideration is needed to avoid the purchase of costly technology applications that require extensive maintenance and operation, and which cannot be used or maintained without external support.

\section{Recommendations}

This article serves two specific purposes. First, practitioners and decision makers in developing Asia can use the analytical framework and guidance based on an international review of smart city initiatives and models to assess and structure approaches to smart city initiatives. Second, the discussion of enablers, action fields, and the role of MDBs in financing smartness, supported by pragmatic cases, can inform dialogue on smart city pathways between development organizations and DMCs.

Application of the smart city analytical framework should depend on the specific context of the target country and city. Available financial, time, and human resources determine smart city programs and actions along the five phases of the framework. The output from the pre-assessment can be used to design more focused technical assistance in high-priority areas. 
Building from the five enablers, and with the support of the analytical framework, the following key recommendations for policy makers to advance smart city pathways are proposed:

(i) Review, assess, and develop a comprehensive policy and regulatory framework on data governance including data acquisition, processing, sharing, and ownership. As data is key for smart cities, a clear regulatory framework is needed to help implement smart city initiatives, support the control and coordination around data security and privacy issues, and foster innovation and investments in smart city solutions.

(ii) Identify and support innovation. Many examples of smart city initiatives are appearing internationally. These may present innovative ideas relevant to cities in Asia and the Pacific. Innovation laboratories and hackathons can be used for citizens and businesses to participate and experiment with new smart city solutions and increase their digital skills. Assessing existing cases and conducting feasibility studies can provide the first step toward developing a comprehensive smart city solution.

(iii) Consider multiple financing mechanisms. Policy makers may consider tapping into government budgets and financial support from external donors, and/or use private sector financing as a leverage for smart city initiatives. PPPs may equally build on private sector for funding, technical expertise, and innovation that complements and strengthens public sector efforts.

(iv) Attract and upskill digital capacities by mobilizing external players. Knowledge sharing within and between cities; twinning arrangements with more capacitated cities; or partnerships with technology providers, academia, or nongovernment organizations can be explored. These efforts will increase digital skills and capacities needed to develop inclusive smart solutions for the benefit of all members of society.

(v) Implement a program management unit with sufficient capacity for planning, coordination, and implementation of a smart city initiative. Bringing together multiple actors and departments into such unit can facilitate well-coordinated and effective delivery, results monitoring, and learning.

Moving beyond the many debates around smart cities (e.g., marketed strategies, risk to personal data), there are clear applications of digital solutions that allow urban development opportunities to flourish. These entail better resource use, wider access, and improved management of urban services.

Given the right context and supported by enablers, smart city solutions can improve access, quality, and reliability of urban services; strengthen urban planning and financial sustainability of cities; and reinforce environmental, climate change, and disaster management-overall making cities more livable. Smart city solutions can help achieve a city's visions, its country's development strategies, and eventually the Sustainable Development Goals.

\section{Appendix A: Smart City Strategy Index}

Roland Berger's Smart City Strategy Index measures the comprehensiveness and ambition of cities worldwide against the key criteria of a smart city. This index allows for systematic comparison of smart city strategies with different structures and formats and to measure progress over time. As such, it identified and assessed 153 smart city strategies worldwide in 2019. It also provides a clear structure and criteria for the development of a smart city strategy. The assessment framework is based on three smart city dimensions: planning criteria, policy, and 
infrastructure as enablers.' Six action fields establish areas in which solutions are implemented in smart cities worldwide: buildings, energy and environment, mobility, education, health, and government.

Planning capacity assesses practical considerations for the implementation of the strategy, such as budget, coordination, and timeline. Policy and infrastructure focus on the regulative and infrastructure requirements for the implementation of smart city projects. Within each of these dimensions, a set of 12 criteria is defined, including 31 sub-criteria that cities should take into account in their smart city plans.

The 12 criteria were developed to measure the comprehensiveness of the Smart City Strategy. Six are related to action fields and the other six criteria are on the enablers. The 12 criteria are split into a total of 31 sub-criteria, each with a separate weight depending on its overall importance. Based on this methodology, the comprehensiveness of the 153 smart city strategies were measured. Strategic approaches earning a score of 60 points or more out of a maximum of 100 are considered comprehensive, meaning a city has detailed activities and targets of at least moderate ambition for key aspects of a smart city across the 12 criteria.

Figure A1: Roland Berger City Scores

Average of all cities' scores for each of the criteria [max. 100]

\section{Number of cities:}

153
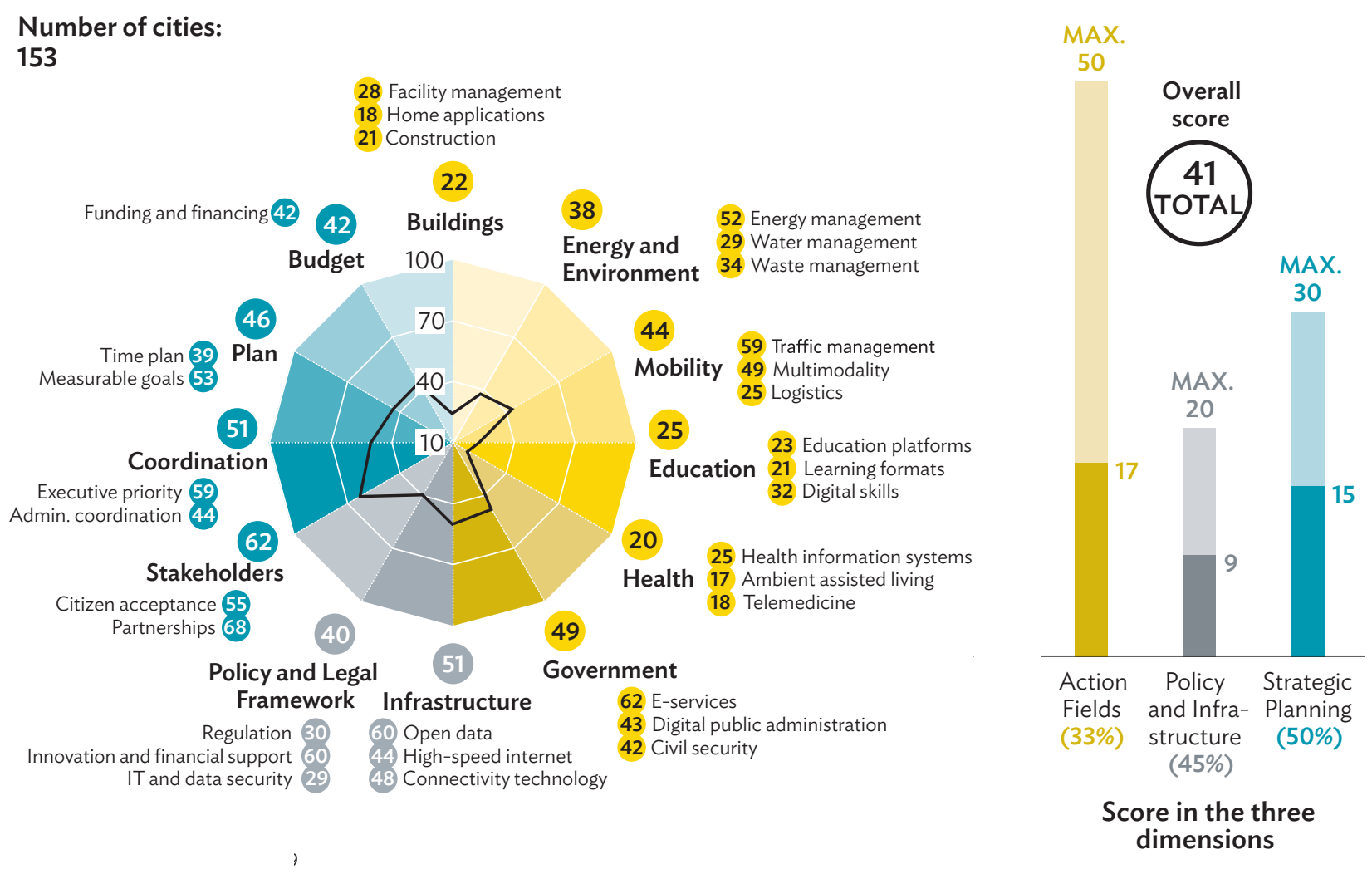

Source: Roland Berger. 2019. The Smart City Breakaway: How a Small Group of Leading Digital Cities Is Outpacing the Rest. Munich.

\footnotetext{
A maximum of 100 points can be reached based on an assessment measuring implementation progress as implementation capacity (20\%), scope (40\%), status (20\%), and results (20\%).
} 


\section{Appendix B: Smart City Models}

A total of 29 different smart city models were identified as concepts, planning frameworks, and indexes. These models were divided into four categories according to publishing institutions:

(i) Ten models from official bodies, such as the Association of Southeast Asian Nations (ASEAN), European Union, and multilateral development banks.

(ii) Seven models from research institutions, foundations, and think tanks.

(iii) Nine models from consulting firms, such as KPMG, McKinsey, and Roland Berger.

(iv) Four models from technology providers, such as ATIS and Huawei.

Three steps were used to identify and select these models. First, for official bodies, their online publications for smart city models and frameworks were reviewed. Second, a keyword online search was conducted to identify any smart city relevant reports from other organizations. Third, the identified publications from all publisher categories were analyzed in detail to derive any conceptual frameworks that were used to assess, design, and prioritize smart city approaches.

Table B1: Smart City Models

\begin{tabular}{|c|c|c|c|c|c|c|c|c|}
\hline \multirow[b]{2}{*}{ No. } & \multirow[b]{2}{*}{ Model Name } & \multirow[b]{2}{*}{ Publisher } & \multirow[b]{2}{*}{ Year } & \multicolumn{5}{|c|}{ Regions Covered } \\
\hline & & & & $\frac{.0}{4}$ & $\frac{\searrow}{\frac{0}{0}}$ & 동 월 & 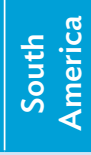 & $\frac{8}{\frac{0}{2}}$ \\
\hline \multicolumn{9}{|c|}{ Official Bodies } \\
\hline 1 & $\begin{array}{l}\text { Smart City Framework: Real-Time loT Stream } \\
\text { Processing and Large-Scale Data Analytics } \\
\text { for Smart City Applications }\end{array}$ & European Union & 2015 & & $\checkmark$ & & & \\
\hline 2 & Mapping Smart Cities in the European Union & $\begin{array}{l}\text { European Union, } \\
\text { European Parliament } \\
\text { Committee on Industry, } \\
\text { Research and Energy }\end{array}$ & 2014 & & $\checkmark$ & & & \\
\hline 3 & ASEAN Smart Cities Framework & ASEAN & 2018 & $\checkmark$ & & & & \\
\hline 4 & $\begin{array}{l}\text { ASCIMER (Assessing Smart City Initiatives } \\
\text { for the Mediterranean Region) }\end{array}$ & EIB & 2018 & $\checkmark$ & & & & \\
\hline 5 & $\begin{array}{l}\text { Smart Cities, Smart Investment in Central, } \\
\text { Eastern and Southeastern Europe }\end{array}$ & EBRD & 2018 & $\checkmark$ & & & & \\
\hline 6 & The Road toward Smart Cities & IDB & 2016 & & & $\checkmark$ & & \\
\hline 7 & $\begin{array}{l}\text { The E-Government Survey 2018: Gearing } \\
\text { E-Government to Support Transformation } \\
\text { towards Sustainable and Resilient Societies }\end{array}$ & $\begin{array}{l}\text { United Nations, } \\
\text { Department of } \\
\text { Economics and } \\
\text { Social Affairs }\end{array}$ & 2018 & $\checkmark$ & $\checkmark$ & $\checkmark$ & $\checkmark$ & $\checkmark$ \\
\hline 8 & Smart City Concept & UN Habitat & 2018 & & & & $\checkmark$ & \\
\hline 9 & $\begin{array}{l}\text { Smart Cities Study: International Study on the } \\
\text { Situation of ICT, Innovation and Knowledge in Cities }\end{array}$ & $\begin{array}{l}\text { United Cities and Local } \\
\text { Governments }\end{array}$ & 2017 & $\checkmark$ & $\checkmark$ & & $\checkmark$ & $\checkmark$ \\
\hline
\end{tabular}


Table continued

\begin{tabular}{|c|c|c|c|c|c|c|c|}
\hline \multirow[b]{2}{*}{ No. } & \multirow[b]{2}{*}{ Publisher } & \multirow[b]{2}{*}{ Year } & \multicolumn{5}{|c|}{ Regions Covered } \\
\hline & & & $\frac{\pi}{4}$ & \begin{tabular}{l|}
$\frac{\searrow}{\circ}$ \\
$\frac{0}{5}$ \\
ய
\end{tabular} & 돈 & 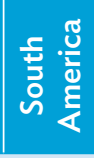 & $\stackrel{8}{\frac{8}{4}}$ \\
\hline \multicolumn{8}{|l|}{ Research Institutions, Think Tanks, Foundations } \\
\hline 10 Morgenstadt City Index & City of Morgenstadt & 2016 & & $\checkmark$ & & & \\
\hline 11 Cities in Motion Index 2018 & $\begin{array}{l}\text { Cities in Motion, IESE } \\
\text { Business School }\end{array}$ & 2018 & $\checkmark$ & $\checkmark$ & $\checkmark$ & $\checkmark$ & $\checkmark$ \\
\hline 12 European Smart Cities 4.0 & $\begin{array}{l}\text { Vienna University } \\
\text { of Technology }\end{array}$ & 2015 & $\checkmark$ & & & & \\
\hline 13 Smart Cities Index: A Tool for Evaluating Cities & $\begin{array}{l}\text { Indian School of Business } \\
\text { and the Shakti Foundation }\end{array}$ & 2017 & $\checkmark$ & & & & \\
\hline $\begin{array}{l}14 \text { Smart City: Six Steps to Successfully Transform } \\
\text { Your City }\end{array}$ & IRENA & 2017 & & & & & \\
\hline 15 Smarter Cities in 2025 & ESI Thought Lab & 2018 & $\checkmark$ & $\checkmark$ & $\checkmark$ & $\checkmark$ & $\checkmark$ \\
\hline 16 EDCI European Digital Index 2016 & Nesta & 2016 & & $\checkmark$ & & & \\
\hline \multicolumn{8}{|l|}{ Consultancies } \\
\hline 17 Smart City Governments & Eden Strategy Institute & 2018 & $\checkmark$ & $\checkmark$ & $\checkmark$ & $\checkmark$ & \\
\hline $\begin{array}{l}18 \text { The Smart City Breakaway: How a Small Group of } \\
\text { Leading Digital Cities Is Outpacing the Rest }\end{array}$ & Roland Berger & 2019 & $\checkmark$ & $\checkmark$ & $\checkmark$ & $\checkmark$ & $\checkmark$ \\
\hline 19 Smart Cities-What's in It for Citizens? & Juniper Research & 2017 & $\checkmark$ & $\checkmark$ & $\checkmark$ & $\checkmark$ & \\
\hline 20 Smart Cities: Digital Solutions for a More Livable Future & McKinsey Global Institute & 2018 & $\checkmark$ & $\checkmark$ & $\checkmark$ & $\checkmark$ & $\checkmark$ \\
\hline 21 Connected Cities. Citizen Insights across Asia Pacific & KPMG & 2019 & $\checkmark$ & & & & \\
\hline 22 WSP Global Cities Index: A Tale of Our Cities & WSP Global & 2018 & $\checkmark$ & $\checkmark$ & $\checkmark$ & $\checkmark$ & \\
\hline 23 Citizen-Centric Cities & Arcadis & 2018 & $\checkmark$ & $\checkmark$ & $\checkmark$ & & $\checkmark$ \\
\hline $\begin{array}{l}24 \text { Smart Cities: How Rapid Advances in Technology } \\
\text { Are Reshaping Our Economy and Society }\end{array}$ & Deloitte & 2015 & & & & & \\
\hline $\begin{array}{l}25 \text { PAS 181: Smart City Framework-Guide } \\
\text { to Establishing Strategies for Smart Cities } \\
\text { and Communities }\end{array}$ & bsi & 2014 & & & & & \\
\hline \multicolumn{8}{|l|}{ Technology Providers } \\
\hline 26 Smart City Index 2019 & Easy park & 2019 & $\checkmark$ & $\checkmark$ & $\checkmark$ & $\checkmark$ & \\
\hline 27 United Kingdom Smart Cities Index & Huawei & 2017 & & $\checkmark$ & & & \\
\hline $\begin{array}{l}28 \text { Gulf States Smart Cities Index: Assessment of Strategy } \\
\text { and Execution for } 10 \text { Cities }\end{array}$ & Navigant Consulting & 2016 & $\checkmark$ & & & $\checkmark$ & $\checkmark$ \\
\hline 29 The Smart Cities Data Exchange & ATIS & 2018 & & & & & \\
\hline
\end{tabular}

ASEAN = Association of Southeast Asian Nations, ATIS = Alliance for Telecommunications Industry Solutions, bsi = British Standards Institution, EBRD = European Bank for Reconstruction and Development; EDCI = European Digital City Index, $\mathrm{EIB}=$ European Investment Bank, ESI = Econsult Solutions Inc., ICT = information and communication technology, IDB = Inter-American Development Bank, IESE = Instituto de Estudios Superiores de la Empresa, IRENA = International Renewable Energy Agency, KPMG = Klynveld Peat Marwick Goerdeler, PAS = Publicly Available Specification, UN = United Nations, WSP = Williams Sale Partnership.

Source: Roland Berger. 2019. The Smart City Breakaway: How a Small Group of Leading Digital Cities is Outpacing the Rest. Munich. 


\section{References}

Asian Development Bank (ADB). 2008. Public-Private Partnership Handbook: Business Guide. Manila. https://www.adb.org/documents/public-private-partnership-ppp-handbook.

- - . 2011. Smart Water Solutions in Small Packages: Stories from Pilot and Demonstration Activities. Manila. https://www.adb.org/publications/smart-water-solutions-small-packages-stories-pilot-and-demonstrationactivities.

--_. 2013. Knowledge Management Directions and Action Plan (2013-2015): Supporting "Finance ++" at the Asian Development Bank. Manila. https://www.adb.org/documents/knowledge-management-directions-and-actionplan-2013-2015.

- - . 2015a. Innovative Strategies in Technical and Vocational Education and Training for Accelerated Human Resource Development in South Asia. Manila. https://www.adb.org/sites/default/files/publication/176571/tvet-hrdsouth-asia-sri-lanka.pdf.

- - - 2015b. Regional Balanced Urbanization for Inclusive Cities Development: Urban-Rural Poverty Linkages in Secondary Cities Development in Southeast Asia. ADB Southeast Asia Working Paper Series. Manila. https://www.adb.org/sites/default/files/publication/161353/sewp-11.pdf.

-_- 2017. Meeting Asia's Infrastructure Needs. Manila. https:/www.adb.org/sites/default/files/ publication/227496/special-report-infrastructure.pdf.

- - - 2018a. Transforming Health Systems Through Good Digital Health Governance. ADB Sustainable Development Working Paper Series. Manila. https://www.adb.org/publications/transforming-health-systems-gooddigital-health-governance.

- - - 2018b. Financing Smart City Solutions. Urban Sector Group Meeting Notes. https://www.unescap.org/sites/ default/files/ADB\%20-\%20Financing\%20Smart\%20City\%20Solutions.pdf.

-—-. 2019a. ADB-AIM Hackathon 2019. https://digital.adb.org/challenges.

- - 2019b. How Public-Private Partnership is Building a New Smart City in the Philippines. Manila.

https://www.adb.org/news/videos/how-public-private-partnership-building-new-smart-city-philippines.

- - . 2019c. Procurement Plans: India, Tamil Nadu Urban Flagship Investment Program, Tranche 1. Manila. https://www.adb.org/projects/documents/ind-49107-004-pp.

-_- . 2019d. Asian Development Outlook 2019: Strengthening Disaster Resilience. Manila. https://www.adb.org/ publications/asian-development-outlook-2019-strengthening-disaster-resilience.

- - Forthcoming. Contemporary Issues for Livable Asian Cities. Manila.

ADB Urban Sector Group. 2018. Financing Smart City Solutions. Manila. https:/www.unescap.org/sites/default/ files/ADB\%20-\%20Financing\%20Smart\%20City\%20Solutions.pdf. 
African Development Bank, Asian Development Bank, European Bank for Reconstruction and Development, Inter-American Development Bank. 2019. Creating Livable Cities: Regional Perspectives. Manila. https://www.adb. org/publications/creating-livable-cities.

African Development Bank, Asian Development Bank, European Bank for Reconstruction and Development, Inter-American Development Bank. 2018. The Future of Work - Regional Perspectives. https://www.adb.org/ publications/future-work-regional-perspectives.

Arup. 2014. Delivering the Smart City - Governing Cities in the Digital Age. London.

Borsboom-van Beurden, J. et al. 2017. Smart City Guidance Package for Integrated Planning and Management. https://eu-smartcities.eu/sites/default/files/2017-09/SCGP\%20Intermediate\%20version\%20June\%202017.pdf.

Edwards, L. 2015. Privacy, Security and Data Protection in Smart Cities: A Critical EU Law Perspective. Create Working Papers. https://www.create.ac.uk/publications/privacy-security-and-data-protection-in-smart-cities-acritical-eu-law-perspective/.

European Commission. 2017. The Making of a Smart City: Policy Recommendations. https://smartcities-infosystem. eu/sites/default/files/document/the_making_of_a_smart_city_-_policy_recommendations.pdf.

Ferrara, R. 2015. The Smart City and the Green Economy in Europe: A Critical Approach. Energies. 8 (6). pp. 4724-4734.

GSM Association. 2019. The Mobile Economy: Asia Pacific 2019. https://www.gsma.com/mobileeconomy/wpcontent/uploads/2020/03/GSMA_MobileEconomy2020_APAC.pdf.

Innovative Governance of Large Urban Systems (IGLUS). 2018. Smart City Concepts. https://fsr.eui.eu/iglusquarterly-vol-4-no-1-critical-and-practical-views-of-the-smart-city-concept/.

Intralink. 2019. Smart Cities South Korea Market Intelligence Report. Glasgow. p. 7. https://www.intralinkgroup.com/ getmedia/9e2bf792-458f-41f8-9a79-d11d284f4116/Korea_Smart-Cities-full-report_v2.

International Telecommunication Union (ITU). 2020. Internet of Thing and Smart Cities and Communities. Study Group 20. https://www.itu.int/en/ITU-T/ssc/Pages/default.aspx.

Mahmood, Z. 2013. E-Government Implementation and Practice in Developing Countries. Derby: University of Derby.

Roland Berger. 2019. The Smart City Breakaway: How a Small Group of Leading Digital Cities Is Outpacing the Rest. Munich.

Sangiuliano, M. 2017. Smart Cities and Gender: Main Arguments and Dimensions for a Promising Research and Policy Development Area. Geneva.

The Economist. 2019. Safe Cities Index: Urban Security and Resilience in an Interconnected World. London.

United Nations Office for Disaster Risk Reduction (UNDRR). 2019. Global Assessment Report on Disaster Risk Reduction. Geneva.

United Nations. 2015. Transforming our World: The 2030 Agenda for Sustainable Development. New York. 
Vinod, Kumar T.M. 2020. Smart Environment for Smart Cities. Springer, Singapore.

https://www.springerprofessional.de/en/smart-environment-for-smart-cities/16892646?fulltextView=true.

World Bank. 2016. World Development Report: Digital Dividends. Washington DC.

-_- 2017a. Practical Guidance for Defining a Smart Grid Modernization Strategy: The Case of Distribution. Washington DC.

- - - 2017b. Internet of Things-The New Government to Business Platform: A Review of Opportunities, Practices, and Challenges. http://documents.worldbank.org/curated/en/610081509689089303/pdf/120876-REVISED-WPPUBLIC-Internet-of-Things-Report.pdf.

_- - 2018. The Changing Wealth of Nations-Building A Sustainable Future. Washington DC.

- - . 2019. Future of Food: Harnessing Digital Technologies to Improve Food System Outcomes. Washington DC. 


\title{
Housing Affordability \\ and Adequacy in Developing Asia
}

\author{
Matthias Helble and Kwan Ok Lee
}

\section{Introduction}

The population of cities in developing Asia increases by around 130,000 every day (Yoshino and Helble 2016). Rapid urbanization is putting enormous pressure on many cities in developing Asia to provide affordable and adequate housing at large scale and in a short amount of time. Several economies in the region have enshrined the access to affordable housing in their constitutions, as decent living conditions at an affordable price are a fundamental need for every human being. This study examines whether and how cities are able to fulfill this task. At the macroeconomic level, high housing costs translate into high costs of labor, undermining agglomeration economies and the competitiveness of cities.

The definition of affordable housing encompasses housing costs, household financial resources available for housing goods, and physical adequacy of housing. The definition of adequate housing is broad as adequate housing should ensure healthy living conditions as well as access to public services and opportunities. Based on such multidimensional attributes, the analysis of affordable housing in this study focuses mainly on formal, owner-occupied housing, which is considered to meet the minimally acceptable standard.

This study takes into account the potentially important role of informal settlements and rental sectors to housing affordability in many cities in developing Asia. The analysis of adequate housing in this study therefore covers a wide range of households. It also analyzes those in informal housing and provides a more complete picture of housing adequacy in different subregions and economies.

First, the study assesses housing affordability across cities in developing Asia. Despite the fact that cities in Asia host the largest number of urban dwellers worldwide, there is surprisingly scant empirical evidence across economies on how expensive and how adequate housing is. Using comprehensive data on housing prices and household income, this study calculates the price-to-income ratio for 211 cities in 27 developing economies. Results indicate that most cities in developing Asia suffer from an acute unaffordability crisis. Closely related to that finding is that only about one-third of urban residents are living in adequate housing conditions.

Second, the study explores the causes and consequences of unaffordable and inadequate housing. It reveals that supply has been very slow in reacting to the rapidly increasing demand mainly due to strict land use regulation and high construction costs. It then explains how housing unaffordability could hinder the success of cities and threaten household well-being.

Third, the study compares and assesses the various housing policies that have been tried in the region. The study concludes that developing Asia needs to expand its rental market. Too much weight has been put on homeownership. An important lesson is that more developable land at low cost and with access to public amenities needs to be made available quicker. 


\section{Assessing Affordable and Adequate Housing in Developing Asia}

\section{Housing Affordability}

There is ample anecdotal evidence that housing prices in cities in the Asia and Pacific region have been increasing rapidly in the past years (ADB 2018). Rapid urbanization has helped to transform the cities into major centers of economic activity. At the same time, in many cities the demand for new housing has outstripped the supply. Combined with increasing household income, the supply-demand imbalance has led to a spike in housing prices. Yet, systematic evidence of housing affordability across cities in the region is lacking.

Housing affordability is typically defined in terms of a certain threshold of total household expenditure spent on housing. The housing costs can either refer to a narrow definition, such as only the rent or mortgage payments, or a wider definition comprising all costs of mandatory services and charges (OECD 2018). The most common threshold used for housing expenditure is $30 \%$, as it is assumed that this would leave the household with enough resources for nonhousing expenditures.

A variety of indicators are used to measure housing affordability, such as the price-to-income ratio (PIR), rent to income ratio, and housing-related expenditure as a percentage of income. The most commonly used indicator is the PIR, computed as the median house price divided by the annual median household income. Following the commonly used definition of Demographia (2019), housing is defined as affordable if the PIR is equal or below 3 , and unaffordable otherwise (Table 1).

Table 1: Demographia Housing Affordability Benchmarks

\begin{tabular}{lc} 
Housing Affordability Rating & PIR \\
Affordable & $\leq 3$ \\
\hline Moderately Unaffordable & $3.1-4$ \\
\hline Seriously Unaffordable & $4.1-5$ \\
\hline Severely Unaffordable & $\geq 5.1$ \\
\hline
\end{tabular}

$\mathrm{PIR}=$ price-to-income ratio

Source: Demographia. 2019. 15th Annual Demographia International Housing Affordability Survey: 2019 Rating-Middle-Income Housing Affordability. January.

To calculate the PIR at the city level, two variables are needed: housing prices and household income. Both are challenging to obtain at the city level. Housing prices are difficult to collect, as they typically vary substantially within a city, a neighborhood, and even within a building.

Comprehensive, consistent, and comparable data on housing prices are rarely available in developing economies. In this study, housing price data at the city level were collected from a variety of sources, including from official and private data providers. In total, estimates of housing prices for 211 cities in 27 ADB members were obtained. Cities 
in the following economies were included: Armenia, Azerbaijan, Bangladesh, Bhutan, Fiji, Georgia, India, Indonesia, Kazakhstan, the Kyrgyz Republic, Malaysia, Maldives, Mongolia, Myanmar, Nepal, Pakistan, Papua New Guinea, the People's Republic of China (PRC), the Philippines, Solomon Islands, Sri Lanka, Tajikistan, Thailand, Timor-Leste, Vanuatu, and Viet Nam. A detailed description of the data sources is available in Helble et al. (2020).

To calculate the median household income, the study used data from Family Income and Expenditure Surveys (FIES) and the World Bank's Povcal data on national average monthly household income as a baseline. For four economies (India, Indonesia, Pakistan, and the Philippines), FIES data is available at a disaggregate administrative level, which allowed the study to determine the household income at the city level. For the other economies, the study predicted the median household income at the city level using a simple regression model.

Study results show that, in $93 \%$ of the cities in the Asia and Pacific region, housing is unaffordable for its residents (Figure 1). In more than $80 \%$ of the cities, housing is even severely unaffordable. On average, the PIR is 16.2, which confirms an earlier study by UN Habitat (2001) revealing that the average PIR of the Asia and Pacific region was around 11.3. The PIR of developing Asian economies in the sample is thus substantially higher than in developed economies where the average PIR ranges between 3 to 6. For example, in 2018, the PIR across cities in the United States (US) was 3.8, whereas in the United Kingdom it was 4.8 (Demographia 2019). The results thus indicate that housing is highly expensive in cities in the Asia and Pacific region, leaving hundreds of millions without access to affordable housing.

One might suspect that large cities are particularly affected by high PIR, as they have attracted the largest absolute number of new inhabitants. To test this hypothesis, the 211 cities are divided into large cities (above 1 million population) and medium-sized cities, and results are compared (Table 2). The results show that the PIR is similarly high in both groups: 16.02 in large cities and 16.40 in medium-size cities. Comparing the PIR within and outside the city center, the study finds that housing unaffordability reaches particularly high levels in city centers. However, even outside the center, housing still remains unaffordable for most urban dwellers. Overall, housing affordability thus seems to be a major challenge irrespective of the city size or location within the cities in the Asia and Pacific region.

Figure 1: Housing Affordability of 211 Cities in 27 Economies in Asia and the Pacific

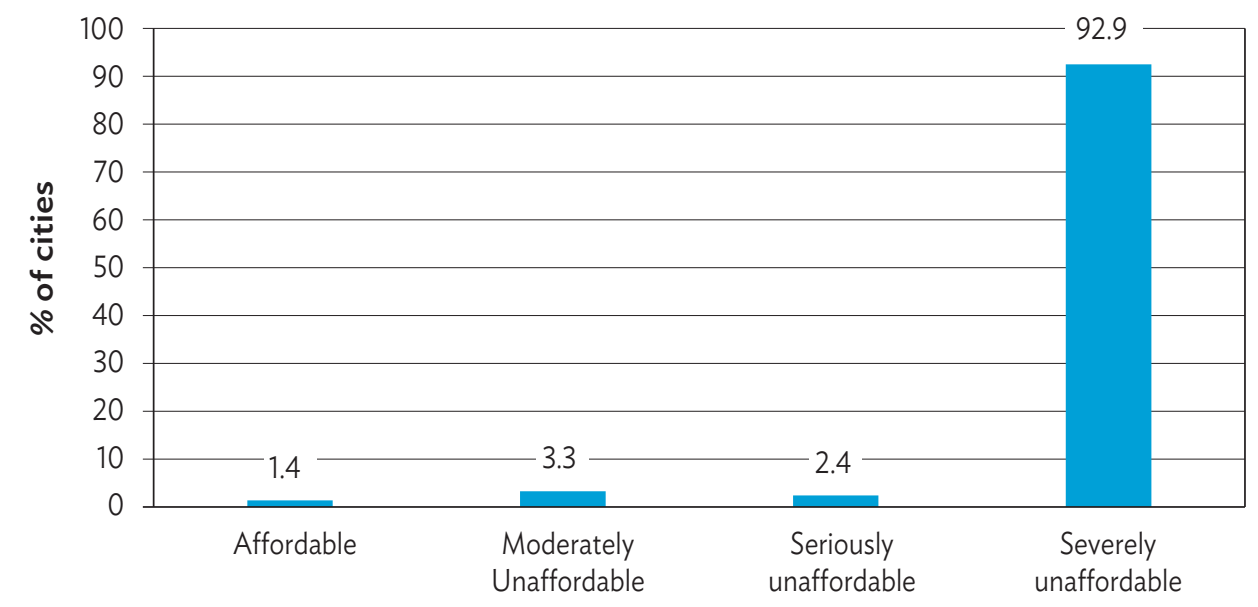

Source: Asian Development Bank. 
Table 2: Price-to-Income Ratio by City Size and Location in the City

\begin{tabular}{lll}
\multicolumn{1}{l}{ Number of Cities } & PIR \\
\hline PIR (average housing price) & & \\
\hline PIR (city center) & 85 & 16.40 \\
\hline PIR (outside city center) & 85 & 23.02 \\
\hline Cities $\geq 1$ million population & 85 & 13.23 \\
\hline PIR (average housing price) & & \\
\hline PIR (city center) & 126 & 16.02 \\
\hline PIR (outside city center) & 126 & 22.00 \\
\hline Total & 126 & 11.48 \\
\hline PIR (average housing price) & & 16.17 \\
\hline PIR (city center) & 211 & 22.41 \\
\hline PIR (outside city center) & 211 & 12.18 \\
\hline
\end{tabular}

$\mathrm{PIR}=$ price-to-income ratio.

Source: Asian Development Bank.

The high PIR clearly suggests that the rapid urban expansion in the Asia and Pacific region has not gone hand in hand with expansion of developable land with access to basic services, including transportation. Demand for housing clearly outstrips the supply. Large and medium-size cities alike struggle to find an appropriate answer.

In many Asian economies, there is a strong preference for homeownership. Table 3 shows the homeownership rates for 11 selected Asian economies. Except for Georgia and Indonesia, all homeownership rates are above 70\%, which are significantly higher than in developed economies, such as in Germany (51.4\%), the United Kingdom (63.4\%), or the US (64.8\%). There are various reasons for the high preference of homeownership in Asia. In many economies, buying a property is perceived as a relatively safe investment and a good tool to incentivize savings. In addition, rental markets are often not well developed. Given the strong preference of homeownership in Asia, high PIRs reported above pose even more serious challenges to housing affordability.

One may question how homeownership rates can be high, as shown in Table 3, when housing affordability is low. One reason is that many cities have witnessed a rapid housing price appreciation. Existing homeowners purchased their home well before the recent appreciation. The high housing prices are thus a serious burden for in-migrants and young families. Another potential reason is that the study's affordability results are mainly from the formal housing sector.

If there are many households residing in informal settlements in the sample of cities, and if informal housing is much cheaper than formal housing in these cities, then the study results may overstate the problem of housing unaffordability. In fact, the next subsection on housing adequacy shows that many urban dwellers in developing Asia are living in substandard housing. Inadequate and unaffordable housing are actually two sides of the same coin. Finally, if the share of renters is poorly documented especially for slum areas, and if the slums constitute a large residential proportion, this may lead to the discrepancy between housing affordability and homeownership.

Using an econometric approach, Helble, Lee, and Arbo (forthcoming) find a positive relationship between population growth and high PIR. 
Table 3: Homeownership Rates in Selected Asian Economies

\begin{tabular}{lrrr} 
& No. of Cities & Urban Population & $\begin{array}{c}\text { Homeownership Rate } \\
\text { Economy }\end{array}$ \\
Armenia & 1 & $1,422,816$ & 96.0 \\
\hline Georgia & 1 & $1,250,560$ & 63.8 \\
\hline India & 100 & $261,300,000$ & 87.0 \\
\hline Indonesia & 17 & $60,337,220$ & 67.0 \\
\hline Kazakhstan & 4 & $3,172,513$ & 95.0 \\
\hline Malaysia & 9 & $14,984,089$ & 72.5 \\
\hline Myanmar & 1 & $5,763,363$ & 85.5 \\
\hline Nepal & 1 & $2,271,725$ & 85.3 \\
\hline PRC & 26 & $201,500,000$ & 89.7 \\
\hline Thailand & 8 & $20,273,705$ & 81.0 \\
\hline Viet Nam & 4 & $23,197,338$ & 90.8 \\
\hline
\end{tabular}

PRC = People's Republic of China.

Source: M. Helble, K. O. Lee, and M. A. G. Arbo. How (Un)affordable is Housing in Developing Asia? International Journal of Urban Sciences. 25 (1). 80-110.

\section{Housing Adequacy}

Housing affordability and adequacy are intrinsically related. As housing becomes unaffordable, households typically have no other choice but to live in inadequate housing. Housing unaffordability could therefore directly translate into housing inadequacy in some contexts. The existence of slums in many cities in developing Asia is one extreme manifestation of the problem. Substandard housing can come in various forms. The unit itself might not fulfill basic building codes or is overly crowded with residents. It could also be that the unit does not have access to electricity or to water and sanitation.

As seen in the previous subsection, the PIR is a common measurement of housing affordability. On the other hand, housing adequacy has no internationally agreed definition. UN Habitat defines housing adequacy merely by looking at affordability. An assessment on how adequate housing is across the globe is still lacking. One reason for the absence of an international definition is the fact that the perception of what constitutes adequate housing varies substantially across communities and economies.

This study, however, argues that despite various understandings, housing should fulfill a certain minimum standard to be considered adequate, irrespective of the local context. Based on the data availability, four basic criteria are considered: (i) finished roof that protects the household from the weather, (ii) sufficient living area with no more than three people sharing a bedroom, ${ }^{2}$ (iii) access to improved water with piped or spring water available in the dwelling or plot, and (iv) access to improved sanitation meaning a flush toilet or ventilated pit latrine not shared by more than two households.

2 The study acknowledges that this standard could be less critical in some Asian contexts. Since this study does not have a per person square footage information, it uses "sufficient living area with no more than three people sharing a bedroom" as a proxy of overcrowding. 
To evaluate the housing conditions in the Asia and Pacific region along these four dimensions, data from the Demographic and Health Survey (DHS) for 10 economies is explored: Bangladesh, Cambodia, India, the Kyrgyz Republic, Myanmar, Nepal, Pakistan, the Philippines, Tajikistan, and Timor-Leste. These economies account for almost half of the population in the Asia and Pacific region. Demographic and health surveys are nationally representative samples and contain detailed information on the housing conditions along the four dimensions described above. Finally, the location data of the household clusters is matched with the location data of natural cities in the 10 economies. The exact definition of each dimension and methodology can be found in Aizawa et al. (2020).

Using the information provided by the demographic and health surveys, the results show that only about $33.7 \%$ of the urban population in the study sample are living in adequate housing. This finding is consistent with the high level of housing unaffordability in cities in the region. Comparing rural and urban areas shows that urban areas offer significantly better housing conditions than rural areas, where only $13.1 \%$ in rural areas have access to adequate housing. Dividing the sample into large cities above 1 million and smaller cities below 1 million, it is observed that large cities offer significantly better housing conditions with $36 \%$ living in adequate housing compared to $30 \%$ in smaller cities.

Figure 2 presents the housing adequacy for three ADB subregions: Central West Asia, South Asia, and Southeast Asia. The figure illustrates that the economies included in the sample that represent South Asia and Central West Asia have similar levels of housing inadequacy. Only about a third of residents in large cities in South Asia and Central West Asia are living in adequate housing conditions. The level of housing adequacy is substantially higher in Southeast Asia. Even in rural areas, about one-third of the population has access to decent housing conditions. In cities, more than half are living in housing conditions that are adequate.

Figure 2: Housing Adequacy in South Asia, Central West Asia, and Southeast Asia

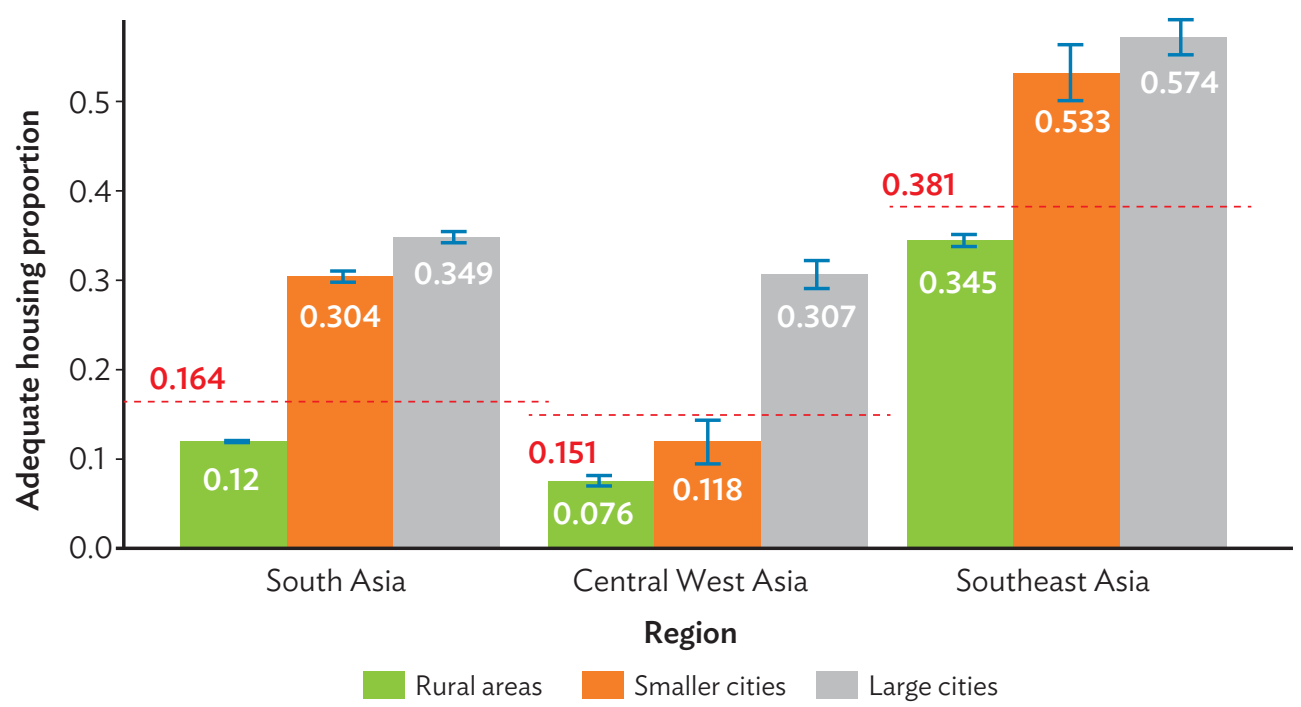

Notes: Calculations are based on data from ICF International. 2019. Demographic and Health Surveys. Rockville, Maryland (funded by United States Agency for International Development) (accessed April 2019). Economies include, by subregion, South Asia-Bangladesh, India, Nepal; Central Asia-the Kyrgyz Republic, Pakistan, Tajikistan; and Southeast Asia-Cambodia, Myanmar, the Philippines, Timor-Leste.

Source: Asian Development Bank. 
Figure 3 shows the housing adequacy along the four dimensions in rural areas and in medium-size and large cities. Large cities offer better living conditions in all four dimensions. The largest difference between urban and rural residents is observed in access to clean water and improved sanitation. However, even though living in cities allows for better access to water and sanitation, the results uncover a large gap still. Only $48 \%$ and $61 \%$ of households meet the criterion of improved water access in medium-size and large urban cities, respectively. Around a quarter of households in cities do not have access to improved sanitation. Whereas households can improve their living conditions in terms of structural quality of the dwelling and sufficient living areas, they typically rely on private or public investment to improve their access to water and sanitation.

Figure 3: Housing Adequacy in Four Dimensions and by Type of Agglomeration

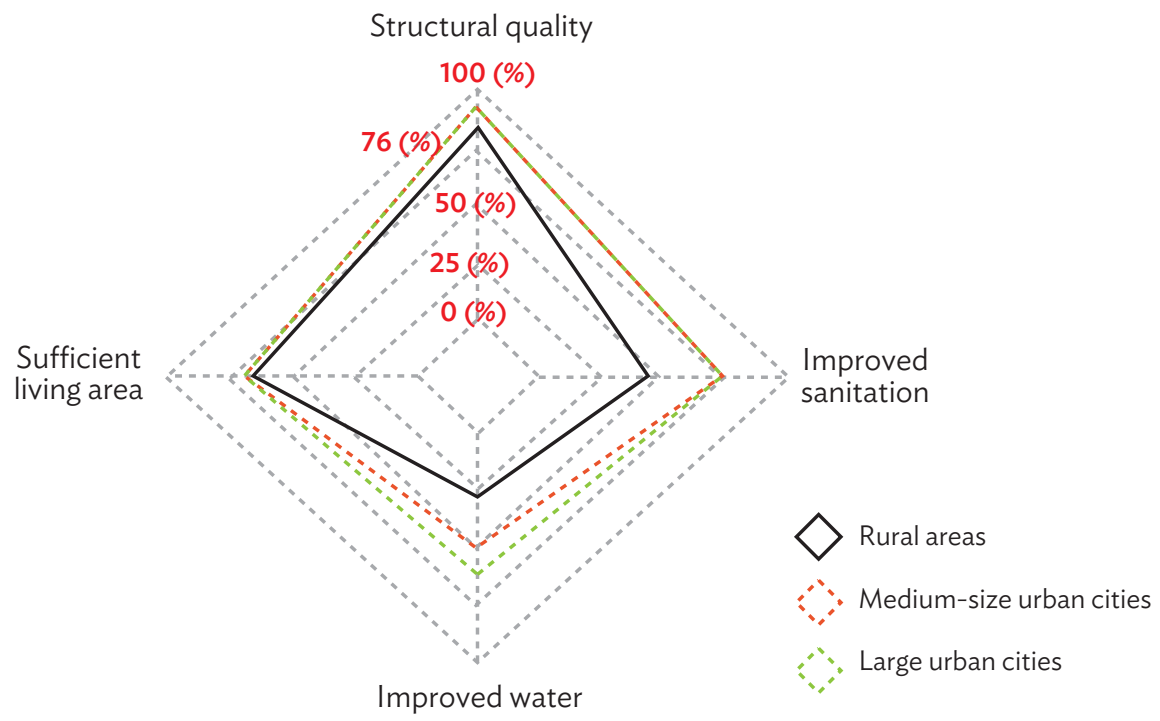

Notes: Calculations are based on data from ICF International. 2019. Demographic and Health Surveys. Rockville, Maryland (funded by United States Agency for International Development) (accessed April 2019). It covers 10 economies in the Asia and Pacific region. Economies include Bangladesh, Cambodia, India, Myanmar, the Kyrgyz Republic, Nepal, Pakistan, the Philippines, Tajikistan, and Timor-Leste.

Source: Asian Development Bank.

The demographic and health survey data allows ranking of the households according to their wealth, and thus, how housing condition differs across wealth levels can be analyzed. A simple way to quantify the inequality in housing conditions is to calculate the concentration index. It provides a measurement of the cumulative percentage of the outcome variable against the cumulative percentage of the population ranked from poorest to richest (Kakwani et al. 1997). If adequate housing is equally distributed irrespective of the household wealth distribution, then the index becomes 0 . If adequate housing is relatively more concentrated among the rich, then the index is positive.

Table 4 shows that adequate housing is more unequally distributed in cities compared to rural areas, except for the Philippines and for small and medium-size cities in Pakistan. Overall, the results thus show that while cities offer better access to adequate housing compared to rural areas, it is rather unequally distributed. Cities therefore need to ensure that their development is inclusive and offers equal benefits to all residents. 
Table 4: Concentration Index of Housing Adequacy in 10 Economies

\begin{tabular}{llcc} 
Economies & Rural & Middle-Size city & Large city \\
Bangladesh & 0.029 & 0.156 & 0.497 \\
\hline Cambodia & 0.304 & 0.535 & 0.590 \\
\hline India & 0.347 & 0.562 & 0.592 \\
\hline Kyrgyz Republic & 0.212 & 0.526 & 0.514 \\
\hline Myanmar & 0.292 & 0.553 & 0.583 \\
\hline Nepal & 0.161 & 0.479 & 0.580 \\
\hline Pakistan & 0.140 & 0.120 & 0.254 \\
\hline Philippines & 0.629 & 0.634 & 0.551 \\
\hline Tajikistan & 0.216 & 0.806 & 0.765 \\
\hline Timor-Leste & 0.403 & 0.427 &. \\
\hline
\end{tabular}

Notes: Small cities have a population of below 1 million, and large cities above 1 million. Calculations are based on data from ICF International. 2019. Demographic and Health Surveys. Rockville, Maryland (funded by United States Agency for International Development) (accessed April 2019).

Source: Asian Development Bank.

It is important to point out that adequate housing is not only about the standard of the individual unit, but also about the location. Due to data limitations, the study was only able to measure the quality of individual dwellings. However, adequate housing is only adequate if it offers reasonable access to social services (most importantly health and education), jobs, transportation, and other neighborhood amenities. Again, the definition of reasonable access varies across jurisdictions. In a study by McKinsey (2014), the authors suggest that an acceptable housing unit should be not more than 1-hour commute to the place of employment. This is in stark contrast to the reality in many megacities in Asia in which hundreds of millions of commuters spend significantly more time on their daily commute. It is also a strong reminder that more investment in urban transportation infrastructure is urgently needed.

\section{Causes of Housing Unaffordability and Inadequacy}

Housing affordability is a function of both housing and labor markets. Housing supply and demand determine housing prices, while labor supply and demand determine household ability to pay for housing (Galster and Lee 2021).

When cities have narrow administrative and geographic boundaries and strict land use regulations, housing supply tends to be less elastic and housing prices tend to be high, holding housing demand constant. An ample evidence exists - the percentage of undevelopable land around a metropolitan area has been a strong predictor of housing price inflation in major US metropolitan areas (Saiz 2010). Stricter regulations in terms of the quality of permitted housing, land use regulations, and fees associated with new developments are also correlated with lower growth in housing stock among US cities (Quigley and Raphael 2004). Some popular Asian cities face a similar issue of supply constraints. 
There is a substantial difference in housing supply elasticities among the cities in the PRC (Fan et al. 2019). In particular, stricter regulations and limited land supply in coastal cities in the PRC have led to more rapid housing price inflations in these cities compared to inland cities (Liang et al. 2016). Another factor that can influence residential construction activity is construction costs. Although construction costs, especially labor costs, have increased over time, existing empirical evidence tends to agree that housing supply is relatively elastic to changes in physical construction costs (Gyourko and Saiz 2006; Glaeser et al. 2008).

In addition to the supply-side factors, increases in housing demand drive housing price inflation. As economies undergo rapid urbanization, people are continuously moving to cities, putting upward pressure on housing demand. Some cities have also experienced endogenous growth in the number of households competing for housing due to demographic profiles of a given city (e.g., household formation of baby boomers) or changes in lifestyles (e.g., more single households). Socioeconomic stress and environmental degradation in rural hinterlands or overseas can also contribute to population in-migration to the city. For example, the extent of pollution is positively correlated with residents' emigration sentiment in Beijing (Qin and Zhu 2018). Political instability in home economies can also increase housing investment demand in seemingly more stable cities (Badarinza and Ramadorai 2018).

Another exogenous demand-side factor is changes in income distribution, which is an outcome of labor markets. If income distribution becomes more unequal, some households whose incomes have not kept pace with housing prices will face lower ability to pay and housing affordability problems (Abelson 2009).

Residential sorting is an endogenous source of housing demand. Higher income households are likely to sort into cities with better amenities, thereby increasing both housing demand and labor supply (Roback 1982). Such sorting process will increase housing prices relative to household ability to pay in these cities and eventually crowd out lower-income households who cannot afford housing (Gyourko et al. 2013).

With these supply and demand dynamics, the formal provision of affordable housing has become insufficient in many urban areas. There has also been a serious problem of spatial mismatch arising from the difference between the location of housing supply and residential location preferences of households (O'Hare et al. 1998). Coupled with inefficient urban planning decisions, these problems have led to the formation of large informal settlements in many cities in developing Asia. For example, UN Habitat (2016) estimates that around 560 million people lived in informal settlements in Asia and the Pacific in 2014, which is about $30 \%$ of the population. Although the relative ratio of people living in informal settlements has fallen in the region, the absolute number has risen by about 100 million since 1990 due to overall population growth.

\section{Consequences of Housing Unaffordability and Inadequacy}

Urbanization enhances labor productivity through agglomeration economies by attracting more people to cities (Rosenthal and Strange 2004; Behrens et al. 2014). Increased productivity translates into higher incomes in cities and thus boosts the demand for housing. If housing supply does not adequately respond to housing demand, housing prices will significantly increase. Unfortunately, as demonstrated in the previous section, many cities in Asia seem to have an inelastic housing supply and are facing a severe housing affordability crisis.

Housing unaffordability can reduce economic competitiveness of cities through three main channels. First, as housing unaffordability deters people from moving within and across cities, the labor market becomes less 
flexible, which can lead to spatial misallocation of labor. In the US, empirical studies have shown that high housing prices in highly productive cities, such as New York, San Francisco, and San Jose, have limited the flexibility of the work force and led to substantial negative impacts on economic growth of the city, impacting overall national growth (Glaeser and Gyourko 2018; Hsieh and Moretti 2019).

Research on cities in the PRC consistently reports that increasing unaffordability in superstar cities, such as Beijing and Shanghai, has reduced their attractiveness for certain population groups (Chen et al. 2017). If housing unaffordability continues to hinder urbanization processes and limits the flexibility of the work force in Asian cities, the aggregate costs of labor misallocation are likely to be similarly high.

Second, housing price inflation can lower aggregate productivity of cities through capital misallocation. Capital is another important resource for production in addition to labor. High housing prices can lead to a misallocation of capital in two ways:

- Firms are induced to invest capital resources in real estate speculation rather than in innovation and productivity enhancement (Aghion et al. 2013).

- In cities with high real estate inflation, banks tend to offer more favorable loans to those firms that hold real estate as their assets, crowding out financing to firms that hold no housing assets within the same cities (Chaney et al. 2012).

Capital misallocation across and within firms has led to lower productivity in the PRC and India compared to the US (Hsieh and Klenow 2009). Recent evidence in the PRC suggests that real estate inflation, particularly in the residential sector, leads to a significant loss in productivity through speculation and crowding out (Chen et al 2017).

Finally, housing unaffordability can lower aggregate welfare gains, and as a result, cities will lose their competitiveness. Due to housing unaffordability, the process of urbanization slows down and the agglomeration-induced productivity growth concurrently slows down. As higher nominal wages are offset by higher housing prices, especially for renters, household welfare has not improved.

Higher housing prices reducing aggregate welfare can even also happen (Glaeser and Gyourko 2018). In other words, housing price increases simply reflect higher housing demand instead of better local amenities (Moretti 2013). At the same time, if higher nominal wages are primarily caused by housing supply constraints and higher housing prices rather than further productivity growth, firms will enjoy little benefit from being located in these cities. This is what has happened in coastal cities in the PRC; they may lose their competitiveness due to increasing labor costs (Liang et al. 2016).

In addition to these macroeconomic consequences, housing unaffordability and inadequacy have substantial outcomes for households. If households overspend on housing, they are forced to reduce nonhousing consumption, including spending on education and health. As a result, household members may suffer psychologically and their children perform worse in schools (Bentley et al. 2011, 2012; Newman and Holupka 2014, 2015, 2016).

Alternatively, households may decide not to spend more on housing, but to reside in housing in physically or locationally inadequate conditions, thereby resulting in negative well-being outcomes. There is a strong relationship between inadequate housing conditions, such as physical defects or overcrowding, and children's well-being (Dockery 2013; Chambers et al. 2015). Living far from employment centers means longer commuting times, which can have detrimental mental health effects, as Wang et al. (2019) recently evidenced for cities in Latin America. 
Housing unaffordability may also influence important demographic decisions such as household formation, marriage, and fertility. Evidence from the western context suggests that housing unaffordability has led young adults to delay leaving the parental home and forming their own households (e.g., Mulder and Billari 2010; Lee and Painter 2013; Chan et al. 2019). In Asian cities, anecdotal evidence reports that young adults in the Republic of Korea; Hong Kong, China; and Taipei,China delay their marriage and give up having children due to high housing costs (Korea JoongAng Daily Online 2017). According to a survey done in wealthy OECD economies (cited in The Journal 2013), housing unaffordability is one of the strongest barriers to having more children. These individual decisions can contribute to downward pressure on fertility and demographic challenges in many Asian economies.

\section{Policy Options and Practices in Asia}

To make homes more affordable, policies should enhance a household's ability to pay and/or reduce housing prices. Policy options can be categorized as follows: (i) reduce housing prices by increasing housing supply, (ii) stabilize housing prices by decreasing (speculative) housing demand, (iii) directly control housing prices, and (iv) increase household's ability to pay for housing. Table 5 presents a summary of practices of main policy interventions in Asian economies. Most Asian economies have used a combination of several policy options listed above. ${ }^{3}$

Direct housing provision has been used in most Asian economies to increase housing supply. Government authorities or quasi-government corporations are responsible for public housing provision and management. However, there is a significant variation in the extent of public housing stock between economies (e.g., 73\% in Singapore, $7 \%$ in the Republic of Korea, 7\% in urban PRC). A variation is also found in targeted income class and tenure (e.g., ownership-oriented, middle-class in Singapore versus rentership in Hong Kong, China). Besides public housing supply, another form of direct intervention is done through slum upgrading programs specifically targeting existing residents in informal settlements. For example, in Thailand, Baan Mankong has successfully resolved problems of insecure housing and substandard living condition through community-driven approaches.

In addition, governments have provided low-interest loans, land, subsidies, or tax credit to private housing developers. This is preferred by many developing economies over public housing provision due to lower upfront cost. Examples include the Economic and Comfortable Housing Program in the PRC providing free land, the Baan Eur-Arhtorn in Thailand providing infrastructure subsidy, the Investments Priorities Plan of the Board of Investments in the Philippines providing tax exemption, and the State Bank of Pakistan subsidizing the financing of constructing new homes for low-income groups. Mandatory shares of affordable housing units in the newly developed private projects have been implemented in some economies. Well-known examples include Malaysia's affordable housing scheme, the Republic of Korea's Shift (long-term Jeonsei), and Viet Nam's social housing for workers.

Governments in Asia have also adopted a series of anti-speculation tools to decrease housing demand. Some economies have utilized macroprudential measures, which indirectly affect the cost and availability of housing mortgage credit, by tightening the loan-to-value and debt-service-to income ratios. Buyer-side taxation, especially differential purchase taxes, has been adopted by many Asian governments after 2010. This is primarily to stem the increasing foreign investment in their domestic housing markets.

3 For a detailed analysis of housing policies in several Asian economies, see Yoshino and Helble (2016). 
Table 5: Main Affordable Housing Policy Options Used in Asia

\begin{tabular}{|c|c|c|c|}
\hline Objective & Target & Measure & Examples \\
\hline \multirow[t]{8}{*}{$\begin{array}{l}\text { Reduce } \\
\text { housing prices }\end{array}$} & \multirow[t]{4}{*}{$\begin{array}{l}\text { Increase } \\
\text { housing } \\
\text { supply }\end{array}$} & Direct provision & $\begin{array}{l}\text { Cambodia; Hong Kong, China; India; Indonesia; Japan; } \\
\text { Kazakhstan; Malaysia; Myanmar; Philippines; PRC; } \\
\text { ROK; Singapore; Taipei,China; Thailand; Viet Nam }\end{array}$ \\
\hline & & Subsidizing production & $\begin{array}{l}\text { Thailand and Malaysia (subsidies), Philippines and } \\
\text { Kazakhstan (loan), Philippines, India, Indonesia, } \\
\text { Thailand (tax credits) }\end{array}$ \\
\hline & & Mandating production & Indonesia, Malaysia, ROK, Viet Nam, \\
\hline & & Providing land & Myanmar, Philippines, PRC, Singapore \\
\hline & \multirow[t]{3}{*}{$\begin{array}{l}\text { Decrease } \\
\text { housing } \\
\text { demand }\end{array}$} & $\begin{array}{l}\text { Anti-speculation through } \\
\text { taxation or purchase } \\
\text { restriction }\end{array}$ & $\begin{array}{l}\text { Singapore and Hong Kong, China (differential } \\
\text { purchase/property tax); PRC and Malaysia (purchase } \\
\text { restrictions); Singapore; Taipei,China; Philippines; PRC; } \\
\text { Indonesia; Malaysia; ROK (seller stamp duty or capital } \\
\text { gains tax) }\end{array}$ \\
\hline & & $\begin{array}{l}\text { Tax on vacant land/ } \\
\text { unoccupied units }\end{array}$ & Indonesia, Malaysia, Philippines \\
\hline & & Macroprudential & Indonesia, PRC, Singapore, ROK \\
\hline & $\begin{array}{l}\text { Directly } \\
\text { control prices }\end{array}$ & Price/rent control & $\begin{array}{l}\text { PRC and Myanmar (rent control), ROK and PRC (price } \\
\text { control), Malaysia (price discount), India (rent control), } \\
\text { Philippines (rent control) }\end{array}$ \\
\hline \multirow{6}{*}{$\begin{array}{l}\text { Increase } \\
\text { ability to pay }\end{array}$} & \multirow{2}{*}{$\begin{array}{l}\text { Direct } \\
\text { subsidies }\end{array}$} & Capital grant & Indonesia; Malaysia; Singapore; Taipei,China \\
\hline & & Allowance & Hong Kong, China; Japan; Malaysia; Singapore \\
\hline & Tax Incentives & Income tax deduction & India, Indonesia, Singapore \\
\hline & \multirow[t]{3}{*}{$\begin{array}{l}\text { Financing } \\
\text { measures }\end{array}$} & Low-interest loan & $\begin{array}{l}\text { Hong Kong, China; India; Indonesia; Kazakhstan; } \\
\text { Malaysia; ROK; Singapore; Thailand; Viet Nam }\end{array}$ \\
\hline & & Guarantee/Insurance & $\begin{array}{l}\text { Hong Kong, China; India; Indonesia; Kazakhstan; } \\
\text { Malaysia; Pakistan; Philippines; ROK; Viet Nam }\end{array}$ \\
\hline & & Savings scheme & Malaysia, Philippines, PRC, Singapore \\
\hline
\end{tabular}

PRC = People's Republic of China, ROK = Republic of Korea.

Source: Asian Development Bank.

Hong Kong, China and Singapore have notable examples which are higher taxes for their non-residents and higher taxes for additional purchases by locals. Another measure is to restrict foreigners' housing purchases only to condominiums (Singapore) and expensive homes (Malaysia). Thailand and Indonesia have introduced land purchase restrictions for foreigners. Seller-side taxation is another popular measure. Some economies like the Republic of Korea have imposed higher capital gains taxes on properties disposed within a short time and without actual occupancy. 
Recognizing many incidences of vacant homes and idle land parcels, some economies have adopted idle land taxes. The Philippines has used special levy on idle lands to discourage the proliferation of underdeveloped land and underutilized housing. Price controls has been used temporarily in the Republic of Korea along with unit size control, and in Malaysia as a form of price discount for Bumiputera home buyers.

Rent control is a policy tool that has been used to stabilize the rents, for example in the PRC and Myanmar. Another option is public rental housing with highly discounted rents. These have been offered to low-income groups to access decent housing in a number of cases, such as in Hong Kong, China; Indonesia; and the Philippines. As public rental housing usually involves substantial financial resources which may not be feasible for developing economies, incentivizing the private sector to produce more affordable rental housing is another option. For example, cities in Australia and the US have actively used inclusionary zoning, while Mumbai, India adopted the transfer of development rights as an incentivizing strategy.

Finally, to enhance the households' ability to pay, several economies have set up housing finance agencies to provide low-interest loans, either directly or through financial intermediaries. Deductions or credit for mortgage interest with respect to income taxes have been less widely used in Asian economies compared to the US or Europe. Instead, policy measures that lower household payment for housing have been more popular.

The Republic of Korea has provided low-interest loan programs for both lower-income, first-time home buyers and Jeonsei renters. In addition, state-sponsored insurances or guarantees for primary or funding market risk have been used extensively in Asian economies. In India, the National Housing Bank recently set up a mortgage guarantee company to provide mortgage insurance services. A few economies have utilized state support for savings scheme. Indonesia and the Philippines have in place compulsory savings schemes for which a certain amount from the monthly salary is deducted.

\section{Comparing Housing Policies: Lessons Learned}

For their continuing success, cities need to fundamentally improve housing affordability while maintaining agglomeration-induced productivity growth and urbanization. Figure 4 suggests the mechanisms through which policy options can improve housing affordability. It also provides a conceptual framework to comparatively assess policies used in different Asian countries discussed in the previous section.

The main lessons that can be learned from this comparative assessment include (i) the importance of holistic policy approaches that are embedded in urban planning to expand housing supply, (ii) strategies to involve private sector participation, (iii) challenges in distributing policy benefits and losses, and (iv) achieving equity across households in different income segments by combining multiple policy options. These lessons are discussed in detail below.

Asian economies have tried many policy options to increase housing supply, many of them have faced issues of limited availability of developable land. Because housing markets are embedded in urban planning, more holistic policy approaches will be useful to resolve these issues. As an attempt to increase housing supply, cities may consider relaxing land use regulations or expanding administrative or geographic boundaries. For example, in Singapore, the government provides land parcels at lower prices to private developers to build affordable housing for the middle class. In the PRC, megaregions have been formed to continue urbanization surrounding popular cities such as Beijing and Shanghai. 
Figure 4: Diagram for Mechanisms of Housing Policy Options

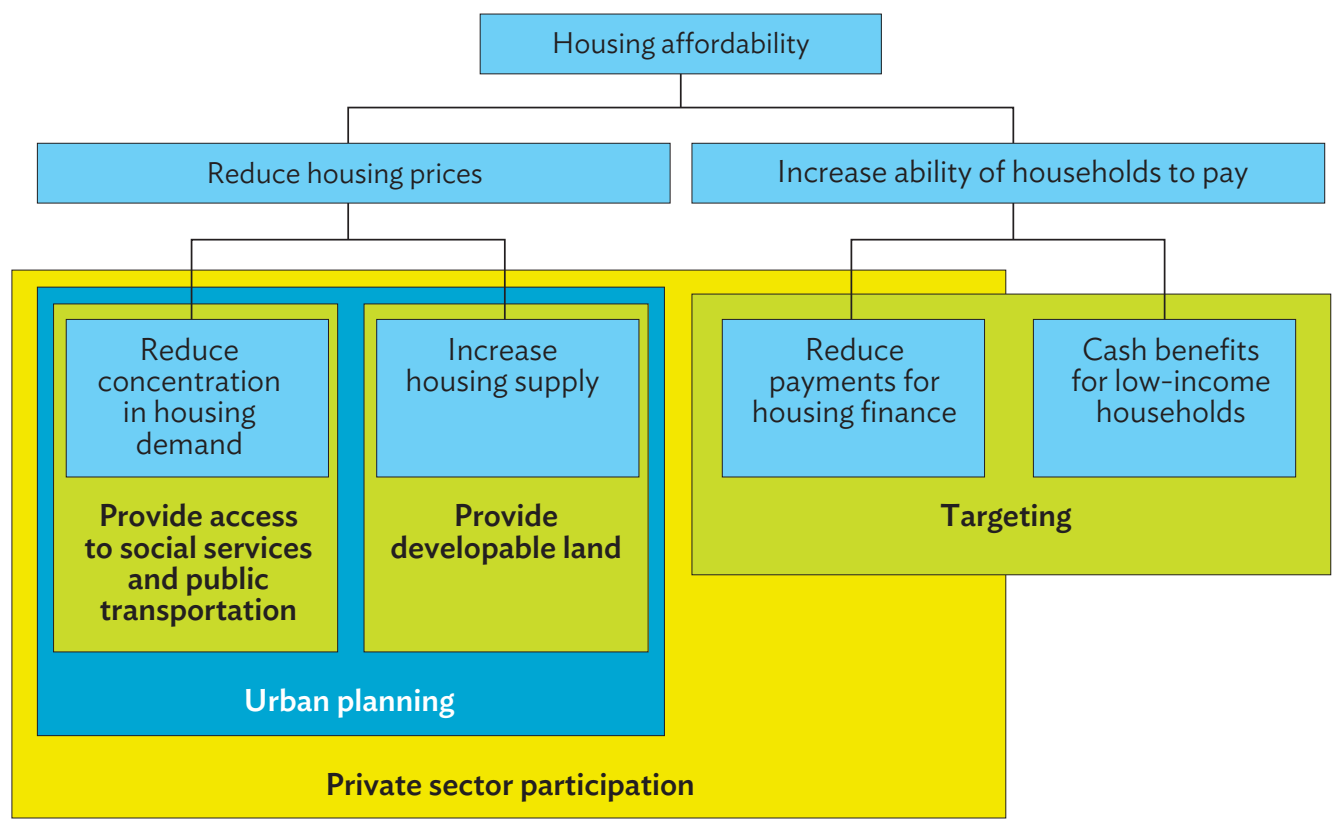

Source: Asian Development Bank.

This urban expansion, however, should integrate development of other amenities, such as transportation, jobs, education, and health care facilities. Transportation planning is related with easing housing demand in employment centers. Introducing an efficient and affordable within-city transportation system will allow people to move quickly within the city. It will also expand the potential area for commuting to jobs, which can alleviate the need for low-income groups to live in urban centers since they can have the option to move to the periphery while accessing jobs across the city.

Housing affordability crisis cannot be solved by the public sector alone, so active involvement of the private sector is essential to increase housing supply especially in developing economies in Asia. Contrary to more developed economies, however, tax credits and inclusionary zoning that aim to subsidize and mandate the private sector's participation in affordable housing production have not been very popular in Asia. As low-cost housing can involve higher risk and lower returns from the private sector's perspective, additional incentives are needed to attract more private sector investment. Financial incentives and simplified regulatory processes could also help expand private sector involvement in affordable housing supply (Sengupta 2006). At the same time, the government should actively maintain the balance between markets and community needs based on a clear institutional framework and ensure housing equity for citizens (Sengupta 2006; Parashar 2014).

Even with the best policy design, policies may not be successful if they are implemented poorly. Distribution of benefits and losses from policies is particularly challenging and involves equity concerns. The most affordable housing programs are not an entitlement, and therefore benefits from these programs are delivered only to a limited number of households. In Hong Kong, China, for example, as there is often a long waiting list for public housing due to limited supply and complicated requirements, many households who are in need but failed to fulfill the requirements do not enjoy the benefits of housing allocation (Li and Yu 1990; Chiu 2002). Sometimes, misallocation of public housing benefits can occur. 
In many economies, income eligibility is assessed only when first entering public housing, which becomes an issue as some households improve their economic situation over time. Furthermore, policies to lower speculative demand may fail, as some speculators might bribe tax assessors. To avoid these problems, policy practitioners should identify clearly their target groups, adopt stringent eligibility criteria, and be transparent in the implementation.

\section{Governments need to develop different housing policies for different income segments taking fully into} account the specificities of each group. For example, Singapore and the Republic of Korea provide financial assistance to first-time, middle-income home buyers and public rental housing for very low-income households. In Indonesia and the Philippines, community-based savings and housing microfinance organizations have assisted low-income groups to acquire land, upgrade homes, or build new dwellings. At the same time, these economies try to stimulate the housing supply by imposing an idle land tax. As the various housing segments interact, it is important to ensure the consistency between all policies. Hence, how to effectively combine different policy options is key to successful affordable housing policies.

The emphasis of many housing policies in the region has been on promoting homeownership. While homeownership offers certain advantages, such as the accumulation of a physical asset, it also carries risks, such as overborrowing. Homeownership also limits the labor mobility which is essential to reap the agglomeration benefits. Furthermore, financing the purchase of a home outstretches the financial capacity of many households. However, the rental market remains small in most Asian cities. The public rental stock is often insufficient and plagued with maintenance problems. The public rental housing stock therefore needs to be expanded and better managed and maintained. The participation of the private sector can be encouraged by providing financial incentives, such as tax exemptions or subsidies, for building private rental housing.

\section{Conclusion}

This study highlights that the Asia and Pacific region experiences a severe housing crisis. Hundreds of millions of urban dwellers spend an excessively high share of their income on housing and many live in inadequate housing conditions. The study outlines the main causes and consequences of the problem. As long as the housing market is unable to deliver, the benefits of urbanization remain limited, and even worse, such inability leads to a misallocation of labor and capital.

One prerequisite to tackle successfully the housing crisis is to have comprehensive and consistent data on the housing market and labor market in cities. Yet, as evidenced by this study, housing data is scarce. Policy makers therefore struggle to assess the magnitude of the problem or cannot assess how successful housing policies or related policies have been. Several governments in the region, such as Malaysia and the Philippines, have recognized the need for better data and introduced new programs to systematically collect more information on the housing market. As showcased in this study, new, rich data sources have become available through the latest IT developments. They can offer relatively inexpensive options to improve the understanding of the housing and labor market.

New technologies are not only a source of data; they are also transforming the housing market. Internet platforms provide an efficient tool to match demand and supply for housing and are increasingly used throughout the Asia and Pacific region. Furthermore, innovations in the area of financial technology allow for new models of housing finance. For example, in the Republic of Korea, new models of crowd financing have been proposed to help home buyers get housing. 
The increase of urban dwellers has often been very fast and has overwhelmed many cities in Asia. Cities are having difficulties in keeping up and expanding the public transportation network and social services, such as schools and hospitals. Lagging public infrastructure across the city has pushed up demand for housing and consequently increased housing prices in well-served locations. In the years to come, cities need to undertake additional efforts to create a level playing field throughout the city in terms of access to public infrastructure. Creating more equal and accessible cities would make a large contribution to addressing the housing crisis and to fully reaping the benefits of urbanization.

\section{References}

Abelson, P. Affordable Housing: Concepts and Policies. Economic Papers: A Journal of Applied Economics and Policy. 28(1). pp. 27-38.

Aghion, P., J. Van Reenen, and L. Zingales. 2013. Innovation and Institutional Ownership. American Economic Review. 103(1). pp. 277-304.

Aizawa, T., M. Helble, and K.O. Lee. Forthcoming. Housing Inequality in Metropolitan Areas in Developing Asia and the United States: Common Problems, Common Solutions? ADB Working Paper. Manila.

Asian Development Bank. 2018. Asian Development Outlook 2018 Update. September. Manila. https://www.adb. org/publications/asian-development-outlook-2018-update.

Badarinza, C. and T. Ramadorai. 2018. Home Away from Home? Foreign Demand and London House Prices. Journal of Financial Economics. 130(3). pp. 532-555.

Behrens, K., G. Duranton, and F. Robert-Nicoud. 2014. Productive Cities: Sorting, Selection, and Agglomeration. Journal of Political Economy. 122(3). 507-553.

Bentley, R., E. Baker, and K. Mason. 2012. Cumulative Exposure to Poor Housing Affordability and its Association with Mental Health in Men and Women. Journal of Epidemiology and Community Health. 66(9). pp. $761-766$.

Bentley, R. et al. 2011. Association between Housing Affordability and Mental Health: A Longitudinal Analysis of a Nationally Representative Household Survey in Australia. American Journal of Epidemiology. 174(7). pp. 753-760.

Chambers, E.C. et al. 2015. Depressive Symptomology and Hostile Affect among Latinos Using Housing Rental Assistance: The AHOME Study. Journal of Urban Health. 92(4). pp. 611-621.

Chan, S., K. O’Regan, and W. You. 2019. Geographic Mobility and Parental Co-Residence among Young Adults. Working Paper. New York: Wagner Center, New York University.

Chaney, T., D. Sraer, and D. Thesmar. 2012. The Collateral Channel: How Real Estate Shocks Affect Corporate Investment. American Economic Review. 102(6). pp. 2381-2409.

Chen, T. et al. 2017. Real Estate Boom and Misallocation of Capital in China. Working Paper. New Jersey: Princeton University. 
Chen, J., M. Hu, and Z. Lin. 2018. Does Housing Unaffordability Crowd Out Elites in Chinese Superstar Cities? Journal of Housing Economics. March. doi.org/10.1016/j.jhe.2018.03.003.

Chiu, R. L. 2002. Social Equity in Housing in the Hong Kong Special Administrative Region: A Social Sustainability Perspective. Sustainable Development. 10(3). pp. 155-162.

Demographia. 2019. 15th Annual Demographia International Housing Affordability Survey: 2019 Rating-MiddleIncome Housing Affordability. January.

Dockery, A.M. 2010. Housing and Children's Development and Wellbeing: A Scoping Study. AHURI Final Report 149. Melbourne: Australian Housing and Urban Research Institute.

Fan, Y., Z. Yang, and A. Yavas. 2019. Understanding Real Estate Price Dynamics: The Case of Housing Prices in Five Major Cities of China. Journal of Housing Economics. 43. pp. 37-55.

Galster, G. and K. O. Lee. 2021. Housing Affordability: A Framing, Synthesis of Research and Policy, and Future Directions. International Journal of Urban Sciences.

Glaeser, E. and J. Gyourko. 2018. The Economic Implications of Housing Supply. Journal of Economic Perspectives. 32(1). pp. 3-30.

Gyourko, J., C. Mayer, and T. Sinai. 2013. Superstar Cities. American Economic Journal: Economic Policy. 5(4). pp. 167-199.

Gyourko, J. and A. Saiz. 2006. Construction Costs and the Supply of Housing Structure. Journal of Regional Science. 46(4). pp. 661-680.

Helble, M., K.O. Lee, and M.A.G. Arbo. 2020. How (Un)affordable is Housing in Developing Asia? International Journal of Urban Sciences. 25 (1). 80-110.

Hsieh, C. T. and P. J. Klenow. 2009. Misallocation and Manufacturing TFP in China and India. The Quarterly Journal of Economics. 124(4). pp. 1403-1448.

Hsieh, C. T. and E. Moretti. 2019. Housing Constraints and Spatial Misallocation. American Economic Journal: Macroeconomics. 11(2). pp. 1-39.

ICF. 2019. Demographic and Health Surveys. Rockville, Maryland (funded by USAID).

Kakwani, N., A. Wagstaff, and E. van Doorslaer. 1997. Socioeconomic Inequalities in Health: Measurement, Computation, and Statistical Inference. Journal of Econometrics. 77 (1). pp. 87-103.

Korea JoongAng Daily Online. 2017. Experts Discuss Low Fertility Rate. http://koreajoongangdaily.joins.com/ news/article/article.aspx?aid=3035859.

Lee, K. O. and G. Painter. 2013. What Happens to Household Formation in a Recession? Journal of Urban Economics. 76. pp. 93-109. 
Li, S. M. and F. L. Yu. 1990. The Redistributive Effects of Hong Kong’s Public Housing Programme 1976-86. Urban Studies. 27(1). pp. 105-117.

Liang, W., M. Lu, and H. Zhang. 2016. Housing Prices Raise Wages: Estimating the Unexpected Effects of Land Supply Regulation in China. Journal of Housing Economics. 33. pp. 70-81.

McKinsey Global Institute, McKinsey \& Company. 2014. A Blueprint for Addressing the Global Affordable Housing Challenge. October.

Moretti, E. 2013. Real Wage Inequality. American Economic Journal: Applied Economics. 5(1). pp. 65-103.

Mulder, C. and F. Billari. 2010. Homeownership Regimes and Low Fertility. Housing Studies. 25. 527-541.

Newman, S.J. and C.S. Holupka. 2014. Housing Affordability and Investment in Children. Journal of Housing Economics. 24. pp. 89-100.

Newman, S.J. and C.S. Holupka. 2015. Housing Affordability and Child Well-Being. Housing Policy Debate. 25(1). pp. 116-151.

Newman, S.J. and C.S. Holupka. 2016. Housing Affordability and Children's Cognitive Achievement. Health Affairs. 35(11). pp. 2092-2099.

Organisation for Economic Co-operation and Development (OECD). 2019. Housing Costs over Income, Affordable Housing Database, Social Policy Division, Directorate of Employment, Labour and Social Affairs. (accessed 30 July 2019).

O'Hare, G., D. Abbott, and M. Barke. 1998. A Review of Slum Housing Policies in Mumbai. Cities. 15 (4). 269-283.

Parashar, D. 2014. The Government's Role in Private Partnerships for Urban Poor Housing in India. International Journal of Housing Markets and Analysis. 7(4). 524-538.

Qin, Y. and H. Zhu. 2018. Run Away? Air Pollution and Emigration Interests in China. Journal of Population Economics. 31(1). 235-266.

Quigley, J.M. and S. Raphael. 2004. Is Housing Unaffordable: Why Isn't It More Affordable? Journal of Economic Perspectives. 18(1). pp. 191-214.

Roback, J. 1982. Wages, Rents and the Quality of Life. Journal of Political Economy. 90. pp. 1257-1278.

Romem, I. 2018. Characteristics of Domestic Cross-Metropolitan Migrants. BuildZoom. 3 April. https://www.buildzoom.com/blog/characteristics-of-domestic-cross-metropolitan-migrants.

Rosenthal, S.S. and W.C. Strange. 2004. Evidence on the Nature and Sources of Agglomeration Economies. Quoted in Henderson J.V. and Thisse J.F., eds. Handbook of Urban and Regional Economics. 4. Amsterdam: Elsevier. pp. 2119-2172.

Saiz, A. 2010. The Geographic Determinants of Housing Supply. The Quarterly Journal of Economics. 125(3). pp. 1253-1296. 
Sengupta, U. 2006. Government Intervention and Public-Private Partnerships in Housing Delivery in Kolkata. Habitat International 30(3). 448-461.

Sultana, S. 2002. Job/Housing Imbalance and Commuting Time in the Atlanta Metropolitan Area: Exploration of Causes of Longer Commuting Time. Urban Geography. 23(8). pp. 728-749.

The Journal. 2013. Financial Pressures and Lack of Affordable Housing Linked to Low Fertility Rates. https://www.thejournal.ie/financial-pressures-and-lack-of-affordable-housing-linked-to-low-fertility-rates1226760-Dec2013/.

United Nations Department of Economic and Social Affairs (UN DESA), Population Division. 2018. The World's Cities in 2018: Data Booklet. ST/ESA/SER.A/417.

UN Habitat. 2001. The State of the World's Cities Report 2001. New York.

___. 2016. Urbanization and Development: Emerging Futures. World Cities Report 2016. New York.

Yoshino, N. and M. Helble, eds. 2016. The Housing Challenge in Emerging Asia: Options and Solutions. Tokyo: Asian Development Bank Institute Press. https://www.adb.org/publications/housing-challenge-emergingasia-options-and-solutions. 


\section{Earth Observation for Planning and Resilience of Livable Cities}

Paolo Manunta, Virinder Sharma, and Jiang Yi

\section{Introduction}

This section provides a basic background on Earth observation, current trends in the technology, and how it is being utilized in developing countries. The second section discusses analytical tools that utilize Earth observation technology to inform project design and development. The third section discusses practical applications of Earth observation technology, mapping the experiences of selected developing countries in climate resilience and disaster risk management, urban services improvement, flood risk assessment, and pandemic response.

As the availability of satellite data or calibrated models may vary across Asia and the Pacific, three different approaches to calculate flood risk assessment are proposed. In the Tonle Sap Basin, disaster risk is calculated with satellite flood mapping factoring in the population density. In Viet Nam and Bangladesh, very high-resolution mapping, meteorological and hydrometeorological data, and climate change simulations were combined, and final assessments downscaled to city level.

The last section outlines future directions for Earth observation technology with respect to use of artificial intelligence and open-source data.

\section{Background on Earth Observation}

Earth observation refers to collecting information on the Earth's land, oceans, and atmosphere, which involves monitoring and assessing the natural and human-made environment. In recent years, information from Earth observation has become even more accessible with the development of satellite constellations. Today's latest Earth observation instruments in orbits include not only more than 60 high-tech satellites, but many more smaller orbiting platforms that continue to be placed in orbit for scientific and experimental purposes.

These complex and continuously evolving space segments collect daily terabytes of images complemented by the Global Navigation Satellite System positioning data, which are essential for many citizens globally. In addition to these satellites built and operated by national and intergovernmental space agencies, the private sector is complementing capabilities with several large constellations to deliver and process data at very high resolution. 
Human civilization, with its large-scale industrial activities and rapid urbanization, is influencing and modifying the Earth's natural system. In this respect, Earth observation has become more important in assessing and mitigating the negative impacts. Specific cases in which Earth observations are used include:

- $\quad$ supporting prediction, adaptation, and mitigation of climate change;

- weather forecasting;

- monitoring land-use change (e.g., transport network, informal settlements, spatial analytics);

- monitoring land susceptibility and rapidly mapping of disasters, including fires, floods, earthquakes, and tsunamis;

- $\quad$ mapping energy potential, freshwater and agriculture resources; and

- addressing emerging diseases and other health risks.

There has been a significant increase in the use of Earth observation technology in addressing today's societal challenges, such as unplanned settlement growth, population growth, food and water security, and disaster risks. The collection and analysis of satellite images have advanced significantly in the last decade, developing a broad range of mature solutions for environmental management and situation awareness.

In this context, the information provided by satellite data are non-intrusive, objective, and consistent in nature, available for both the present and the past. Historical data allow models of change to be built and tested, which can explore future possibilities. The data also allow users to map and monitor change across geographies from continental to local, and over temporal daily to a decade scale. In this respect, Earth observation technology plays a significant role in shaping how cities in developing countries plan for resilience.

\section{Trends in Earth Observation}

Landsat is commonly known as the most famous Earth observation satellite. The satellites have been providing moderate resolution land surface information since 1972. Since it was first launched, Landsat series satellites have been providing valuable resources data for land use and land change monitoring. With almost 50 years of accumulated imagery, Landsat is a powerful information source for understanding urban sprawl and the development of rural and urban areas based on the land cover/land use classification.

According to the recent National Oceanic and Atmospheric Administration sponsored survey of the Asian remote sensing marketplace, Asia relies on the moderate-resolution land imaging, such as Landsat 5 and 7 because of their long history, low cost, and availability. It is followed by India Remote Sensing (IRS) Resources at IRS IC and 1D. This moderate resolution land imaging acquires data with medium resolution. This type of operation is also defined by the satellite revisit frequency and spectral characteristics. The Japanse Advanced Land Observing Satellite (ALOS) and European Space Agency (ESA) Sentinel-2 are known as typical satellites like the Landsat series.

Copernicus is the Earth observation program of the European Union. It is coordinated and managed by the European Commission. The development of the overall infrastructure for the construction and operation of the satellite constellations is assigned to ESA, and the in-situ data collection and handling to the European Environment Agency and European Union countries. The Earth observation satellites, which make up the

The National Oceanic and Atmospheric Administration (NOAA) is an attached agency of the US Department of Commerce. Its threefold objectives are (i) to understand changes in climate, weather, oceans, and coasts; (ii) to share knowledge and information; and (iii) to conserve and manage coastal and marine ecosystems and resources. https://www.noaa.gov/. 
Copernicus system, are the Sentinels. Sentinel-1, $-2,-3$, and -6 are dedicated satellites, while Sentinel-4 and -5 are instruments onboard of satellites operated by the European Organization for the Exploitation of Meteorological Satellites. Sentinel-5P, a precursor to Sentinel-5, is a dedicated satellite for studying the atmosphere and routine air quality monitoring. The two Sentinel satellites $2 \mathrm{~A}$ and $2 \mathrm{~B}$ are multispectral sensors for analyzing the Earth's land surface with a 5-day revisit time.

To enhance and standardize Copernicus data distribution and develop appropriate processing tools, the European Commission financed five cloud-based platforms known as Data and Information Access Services (DIAS). The five DIAS online platforms enable users to discover, manipulate, process, and download Copernicus data and information. All DIAS platforms provide access to Copernicus Sentinel data, as well as to the information products from Copernicus' six operational services, together with cloud-based tools (open source and/or on a pay-per-use basis).

The services provided by the platforms also include the provision of additional commercial satellites. With the DIAS platform, users only need a single access point to harness the data from Copernicus, after which they can develop and host their own applications in the cloud without having to download bulky files from various access points and process them locally.

These trends in Earth observation are supporting governments to quantify better and prepare for the unprecedented impacts of both climate change and human-induced activities on the global environment.

\section{Adoption of Earth Observation in Development Assistance}

Beginning in 2008, both the Asian Development Bank (ADB) and World Bank initiated discussions with several national space agencies on the systematic use of satellite-based Earth observation data for development assistance.

A significant number of ADB-supported projects made use of Earth observation derived maps to improve disaster and climate change resilience in project design, as well as planning and transport in an urban context. ADB collaboration with both agencies, ESA and Japan Aerospace Exploration Agency, progressed and new requests of support in operations were received and documented.

This brought forth the partnership between ADB and ESA under the Earth Observation for Sustainable Development (EO4SD) Project. ${ }^{2}$ The EO4SD initiative concentrated on nine thematic areas: (i) urban development, (ii) agriculture and rural development, (iii) water resources management, (iv) climate resilience, (v) disaster risk reduction, (vi) marine resources, (vii) fragility, (viii) conflict and security, and (ix) forest monitoring.

The EO4SD-Urban 1 focused on the design of solutions to make cities more livable. The validation approach consists of combining satellite data services, data integration, and capacity building. An overall portfolio of 12 EO-based products with various sub-products and spatial analytics were prepared (Figure 1).

2 European Space Agency. 2016. ESA and Asian Development Bank Join Forces. News release. 11 September. https://www.esa.int/ Applications/Observing_the_Earth/ESA_and_Asian_Development_Bank_join_forces. 
The approach is a sequence of four steps:

(i) selection of raw satellite data and processing with integration of ancillary data,

(ii) extraction of thematic layers starting with build-up and ending with population distribution,

(iii) production of indicators for Sustainable Development Goal (SDG) 11 and urban planning metrics, and

(iv) delivery to the developing countries via a geoportal as Spatial Data Analysis Explorer (SPADE).

Figure 1: Earth Observation-Based Products for Urban Development

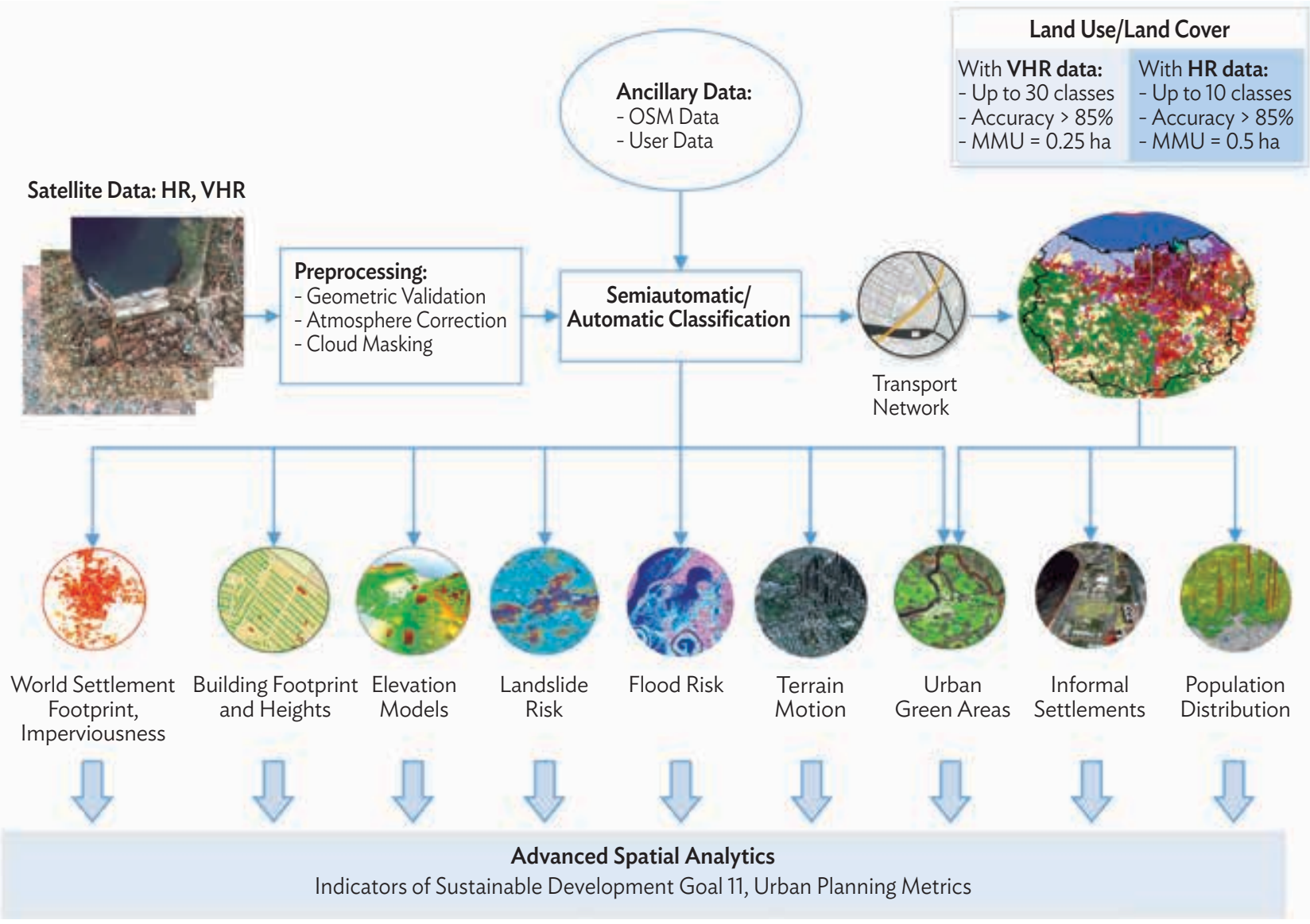

ha = hectare, $\mathrm{HR}$ = high resolution, $M M U$ = minimum mapping unit, $\mathrm{OSM}=$ open street map, $\mathrm{VHR}$ = very high resolution.

Sources: EGIS, GAF AG, German Aerospace Center, GISAT s.r.o.,GISBox, Netherlands Geomatics \& Earth Observation B.V., Joanneum Research, Systémes d'Information à Référence Spatiale. 


\section{Analytical Tools and Techniques}

\section{ADB Spatial Data Analysis Explorer}

The Spatial Data Analysis Explorer (SPADE) is an interactive, web-based geospatial platform showcasing different climate change scenarios. The platform is comprised of socioeconomic, topography, land use, and infrastructure data sets which can be used for project preparation, planning, implementation, and monitoring. Powered by open-source technology, SPADE utilizes out-of-the box solutions, such as Geonode and Leaflet, to provide user-friendly interface in accessing spatial data and viewing projects spatially, and to assist in making critical decisions in regard to climate change and hazards, among others (Figure 2).

In 2017, ADB started to develop SPADE. It was successfully launched and commissioned in June 2018 and the platform is now operational. SPADE started with data sets for five cities: Ha Giang, Hue, and Vin Yen in Viet Nam; and Bagerhat and Patuakhali in Bangladesh. Data are then gradually added to the platform, with SPADE now containing information for more than 20 cities in Bangladesh, Cambodia, India, Pakistan, the Philippines, and Viet Nam.

As SPADE uses open-source applications, it benefits from, and contributes to a public good, and can rapidly incorporate other open-source applications or innovations without the constraints of proprietary software. This web-based geographic information system (GIS) technology aims to support project planning as well as the preparation of climate risk, vulnerability, and urban system assessments. It can assist in developing regional and urban master plans and strategies, as well as in identifying opportunities to enhance the performance of infrastructure investments.

Evolution of SPADE and related tools. With SPADE, previously unwieldy and scattered, data and information becomes accessible and useful for project officers, as well as for governments and other partners. It is envisioned to be the central geospatial platform serving as a single repository of geospatial data that will make it easily accessible for future use. This will translate into savings as there would be no need to purchase the same data sets.

Through SPADE, decision makers can make informed and strategic decisions in terms of project design and investments considering climate hazards and resilience across urban and multiple sectors. Project officers and consultants can visualize how different factors can affect their project using SPADE. This platform also promotes a systemic approach that is needed to integrate disaster risk and climate change resilience into conception, design, and construction of infrastructure projects.

SPADE can store layers of information, such as socioeconomic data, population density, building footprints, and rainfall projections in 25-100 year scale, over a city map. By combining these different layers, the project team can determine the impacts of the proposed project, plan for future conditions, and incorporate these factors into project design even before any construction begins. SPADE also reinforces the thrust of the Urban Climate Change Resilience Trust Fund, which is to support cities to better plan and design infrastructure using urban resilience principles and scale up investments against hazards and other climate change impacts. The goal is to make climate change a central element of city planning.

Integrating SPADE with global initiatives is now a priority. Spatial data infrastructure (SDI) is a framework of geographic data, metadata, users, and tools that are interactively connected to provide an efficient and flexible way of using spatial data. Historically, it has always been complex and/or expensive to set up and maintain an SDI. 
Figure 2: ADB Spatial Data Analysis Explorer

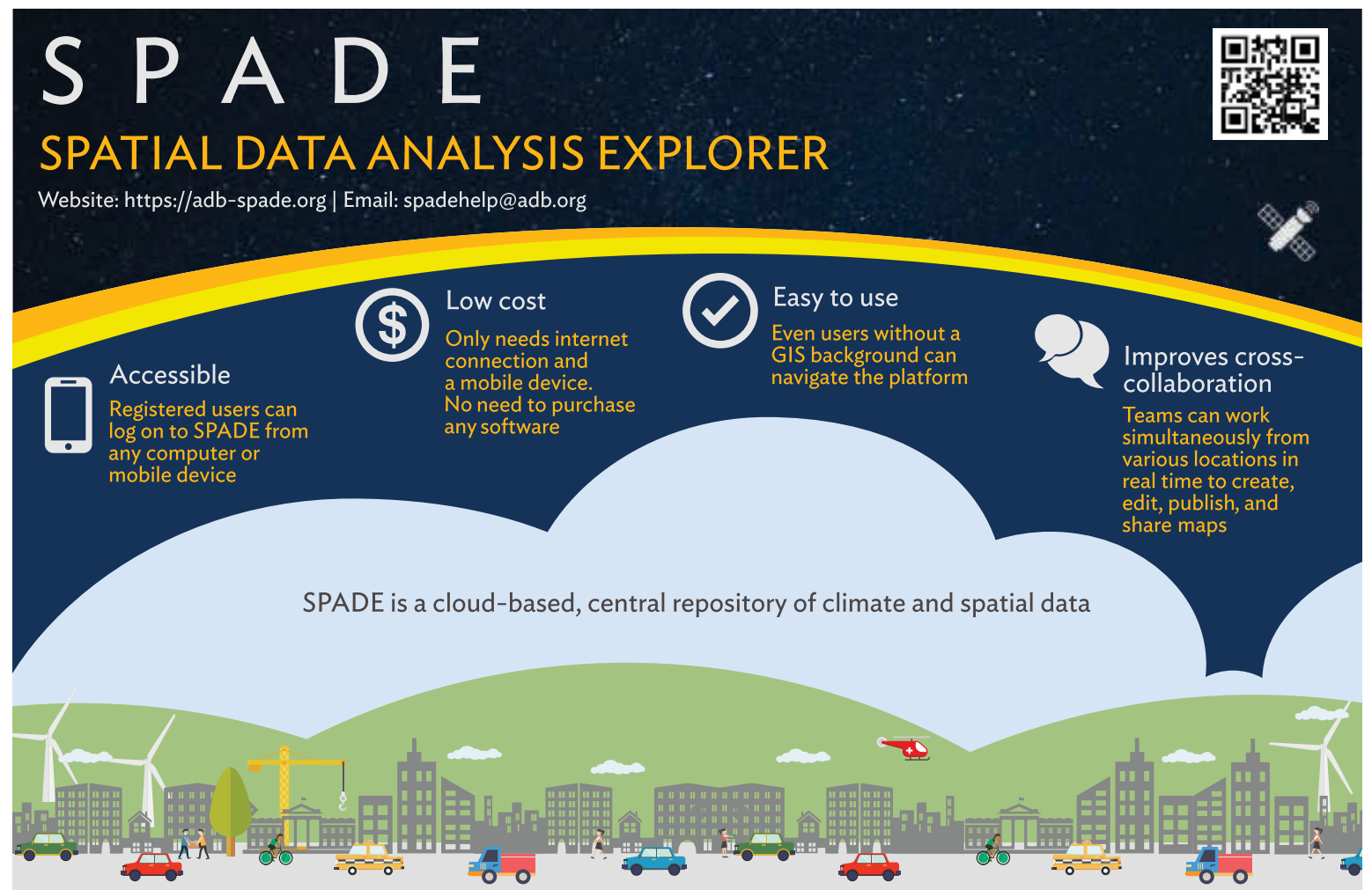

SPADE as a tool to inform strategic decisions

on project design and investment prioritization

Overlaying of climate, land

use, building and other information for analysis

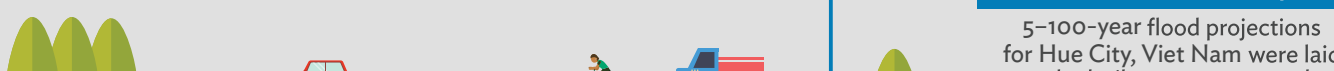
for Hue City, Viet Nam were laid different flooding scenarios and design considerations when building

\section{Mobile data collection of site conditions}

The SPADE mobile app was used to collect data on flood and rain-induced landslide hazards for a community-led project in La Trinidad, Philippine and from which produced hazard maps

to inform project design

Verifying proposed project sites are not in conflict with existing or planned projects

Paper-based maps-topography, waterways, protected areas, and land use plan-were digitized and uploaded to SPADE. These maps were overlaid to determine if the locations of projects under the Proposed Secondary Cities

Environment Improvement Project were in protected areas, along nonbuild zones, would require relocation of existing settlements, or conflicted with other utility infrastructure, such as power, water supply, or sewerage.

Source: Asian Development Bank.

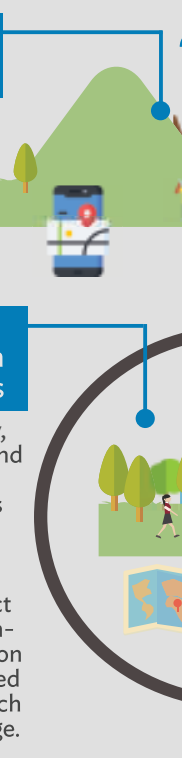

\section{If $\begin{aligned} & \text { URBAN CLIMATE } \\ & \text { CHANGE RESIIENCE } \\ & \text { THUST FURO }\end{aligned}$}

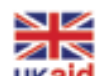

UKaid new infrastructure

SPADE can be used as a tool for conducting due diligence, project implementation, and monitoring

Monitoring progress of construction implementation

The consultant took photos and notes of the construction site during a field visit and uploaded them onto SPADE using their mobile phone. As these were geotagged, the photos showed the precise locations on the map allowing project officers to view the progress on site from their desks at the resident mission.

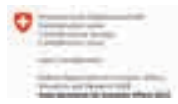

ROCKTFFITIF 
SPADE uses GeoNode, a web-based SDI that enables sharing and collaborating on geospatial data. In 2009, the World Bank and Open Geo (now Boundless Geo) initiated the development of GeoNode, aimed at making uploading, sharing, and working with data as easy as blogging. In the following years, several projects (Open DRI, Harvard World Map, Boundless Exchange) have been built on the GeoNode platform and dozens of partners have helped fund and develop enhancements to GeoNode.

Users can upload vector data such as shapefiles, edit data, and publish maps. GeoNode can also host documents such as PDF or image maps and Open Geospatial Consortium services, which streamlines integration with other systems and existing workflows. Moreover, commercial providers across the globe are supporting GeoNode with training, technical support, and development of new features.

The Annual GeoNode summit is a good opportunity to get a better understanding on the latest developments and applications of GeoNode. It was very interesting to see the work from the World Food Programme and how they combine proprietary GIS software from Esri and the open-source solution of GeoNode in their spatial data infrastructure services. Some of these organizations have created their customized GeoNode instances for their own projects (e.g., the United Nations World Food Programme, European Commission Joint Research Centre).

The World Bank's Global Facility for Disaster Reduction and Recovery (GFDRR) supports both core developments and finances localized GeoNode (e.g., GeoDash) in some of its target countries. During this summit, GFDRR representatives concluded: for all the returns already realized on GFDRR's investment in GeoNode, the most important ones may still be in the future. Open DRI has contributed to the creation of a public good, but a public good of a very particular kind. GeoNode is both a software tool and a software project, and as a project it serves as a gathering place where inter-organizational cooperation can happen with a minimum of bureaucracy and with immediately tangible results.

Where ADB SPADE stands on the GeoNode application. GeoNode is used worldwide by international organizations, national agencies, and local governments for supporting activities ranging from project planning, emergency response, to disaster risk reduction. GeoNode is becoming a popular and growing open-source project, with increasing uptake by organizations that are able to support its continued maintenance and development. With the development of SPADE, ADB has joined this movement. ADB's use of GeoNode for SPADE has now been benchmarked with other international organizations like World Bank, World Food Programme, and European Commission, which are also using GeoNode. Overall, SPADE can help cities in the Asia and Pacific region become more prepared and resilient against climate change impacts, raising quality of life for all.

\section{Asian Cities Observed with Nighttime Lights}

Data on cities, which are consistently defined and measured, are needed to help policy makers and development players better understand the urbanization status and trends across Asia and the Pacific. Such understanding enable them to gain insights on economic growth in the region. However, these data are rare partly because each country employs its own definition and measurement of cities.

There are typically four types of criteria used in official definitions of urban areas across the world: administrative boundaries, economic parameters, population size and/or density, and urban characteristics. ${ }^{3}$ Various combinations of these criteria yield 13 ways to define urban areas. The number of actual definitions of cities is

3 United Nations Department of Economic and Social Affairs Population Division. World Urbanization Prospects: The 2018 Revision. New York. https://population.un.org/wup/Publications/Files/WUP2018-KeyFacts.pdf. 
much larger as numeric thresholds applied to these criteria vary. As a result, the urban statistics collected from different countries such as those used by the United Nations in the World Urbanization Prospects (WUP) are not comparable across countries.

This case study, derived from a larger effort of understanding urbanization in Asia and the Pacific (ADB 2019), introduces a large-scale city data set developed based on nighttime light (NTL) data for the region and presents urbanization patterns and features with the data set. The primary units that constitute the data set are defined as natural cities. They are urban agglomerations defined based on satellite imagery that has captured the nighttime lights emitted by human activity, instead of by administrative or political boundaries.

Constructing the natural city data set involves three main steps:

The first step, the yearly NTL data accessed from the website of the NOAA were used to delineate human settlements in Asia and the Pacific Satellites from the United States Air Force Defense Meteorological Satellite Program (DMSP). ${ }^{4}$ The Operational Linescan System (OLS) sensors recorded the intensity of Earth-based lights from 1992 to 2013. Since 2013, the NTL was recorded by the Visible and Infrared Imager/Radiometer Suite (VIIRS), a new sensor installed on spacecraft launched under the United States (US) Joint Polar Satellite System. The VIIRS NTL data can be viewed at a higher resolution.

All pixels with positive luminosity values are considered as human settlements. The pixels with small gaps between them ( 1 kilometer [km] for DMSP-OLS data and $0.5 \mathrm{~km}$ for VIIRS data) were aggregated into one polygon as they likely belong to one human settlement, while being separated by unlit areas.

The second step, the database of the Global Rural-Urban Mapping Project (GRUMP) was utilized to identify urban areas. This is because the majority of the polygons obtained in the first step are very small and discrete, likely representing rural settlements. ${ }^{5}$ In 2000, a total of 1,964 GRUMP units were identified in Asia and the Pacific that had a population greater than 100,000. They were linked to 1,412 NTL-based polygons in 1992. These polygons were then referred to as natural cities and named after their corresponding GRUMP units or the unit with the largest population if a natural city contains multiple GRUMP units.

Some major cities in small countries may not meet the study's population criterion applied to GRUMP units. The GRUMP database could also accidentally leave out some large cities. The study team conducted manual checking and identified additional 115 polygons (natural cities) that either represent major cities in small countries (mostly in the Pacific) or had an area greater than 100 square kilometers $\left(\mathrm{km}^{2}\right)$ in 2000 . There is a total of 1,527 natural cities in the final data set, of which 680 are in the PRC, 320 in India, 92 in Indonesia, 68 in Japan, and 63 in Pakistan. The five countries account for $80 \%$ of the total natural cities in the region.

The third step is to estimate the population in the natural cities. Starting in 1998, LandScan provides global population counts at a spatial resolution of approximately $1 \mathrm{~km}^{2}$ based on a dasymetric model. ${ }^{6}$ This grid population data was filled into the delineated area of each natural city. The total population of a natural city is equal to the sum of all grids falling within the city contour or intersecting with it.

\footnotetext{
National Geophysical Data Center of NOAA. https://ngdc.noaa.gov/ (accessed 1 April 2017).

GRUMP data were generated by the Columbia University Center for International Earth Science Information Network in collaboration with the International Food Policy Research Institute, the World Bank, and Centro Internacional de Agricultura Tropical, through combining census and geospatial data sets. Socioeconomic Data and Applications Center. http://sedac.ciesin.columbia.edu/data/ collection/grump-v1. It is worth noting that the units in the GRUMP database are not from the same administrative level within, as well as across, countries.

6 Oak Ridge National Laboratory. LandScan. https://landscan.ornl.gov.
} 
Figure 3: Shares of Urban Area and Urban Population Across 43 Countries Studied

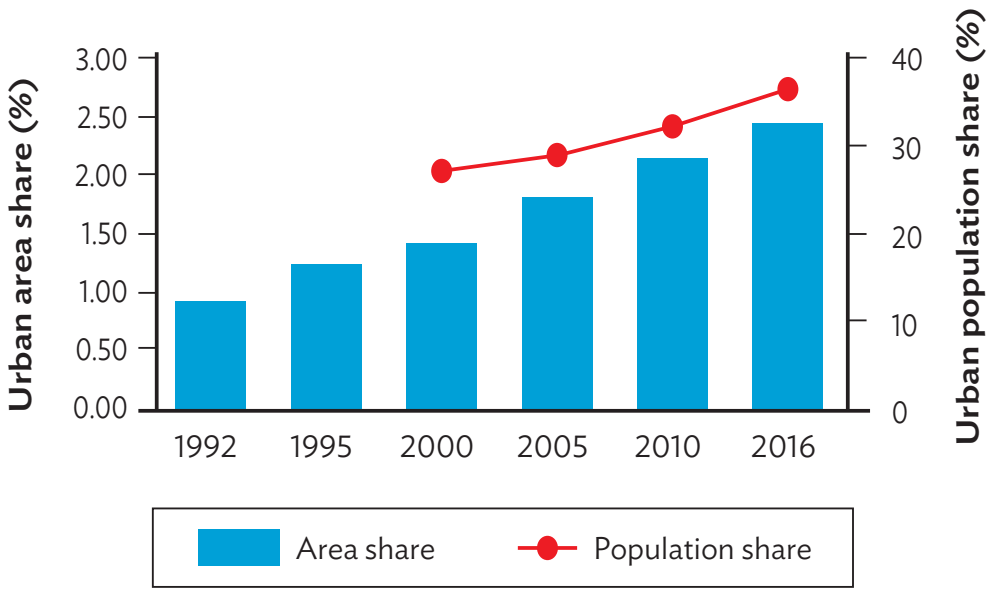

Source: Y. Jiang. 2021. Asian cities: spatial dynamics and driving forces. The Annals of Regional Science, forthcoming.

The natural city data could be used to carry out a variety of analyses. A few aspects of urbanization for the region since early 1990s are illustrated with this data in this section. Out of the 25.2 million $\mathrm{km}^{2}$ total land area of the 43 countries studied, the natural cities together account for $0.9 \%$ in 1992 and $2.4 \%$ in 2016 of the total land areas. In other words, the total area of natural cities increased from $230,000 \mathrm{~km}^{2}$ in 1992 to $610,000 \mathrm{~km}^{2}$ in 2016 , with an average annual growth rate of $4.0 \%$ (Figure 3 ).

The total population of the natural cities increased from 0.93 billion in 2000 to 1.48 billion in 2016, with an average annual growth rate of $3.0 \%$. In contrast, the overall population of the region has only increased at $1.0 \%$ per annum, from 3.5 billion in 2000 to 4.1 billion in 2016. The region's urbanization rate, the ratio of total natural city population to the total population, has risen steadily from $27 \%$ in 2000 to $36 \%$ in 2016.

These data suggests a lower urbanization rate for the region, as compared to $47 \%$ calculated with the WUP data. The gap could result from multiple difference between the two estimations. One major difference is that the WUP data adopts official city definitions that largely count urban population based on administrative boundaries. The official statistics may overstate urban population, to the extent that there are both urban and rural areas within one administrative urban unit. On the other hand, the natural city data may miss some towns and small cities due to the population criterion that this study has applied. Essentially, the natural city data is not comparable with official statistics since the two are based on completely distinct definitions of urban areas. It is preferable to view the natural city data as a new, complementary source of information on urbanization for Asia and the Pacific.

Map 1 illustrates how the footprint of each of five selected natural cities has evolved since 1992 and how it differs from the boundary of the corresponding administrative division. All five natural cities grew considerably in area from 1992 and 2016: at one end of the range, Cebu growing by 58\% and, at the other, Hai Phong growing by $930 \%$. Moreover, the spatial expansion of the natural cities was by no means constrained by the administrative boundaries (dashed lines). In 2016, each of the five natural cities had a significant portion of its area lying outside of the corresponding administrative unit. Natural city sprawl reached beyond administrative borders by $73 \%$ for Cebu City, 91\% for Muang Chiang Mai District, 46\% for Hai Phong City, 70\% for Medan City, and 64\% for the Kolkata Metropolitan Area. 
Map 1: Spatial Development

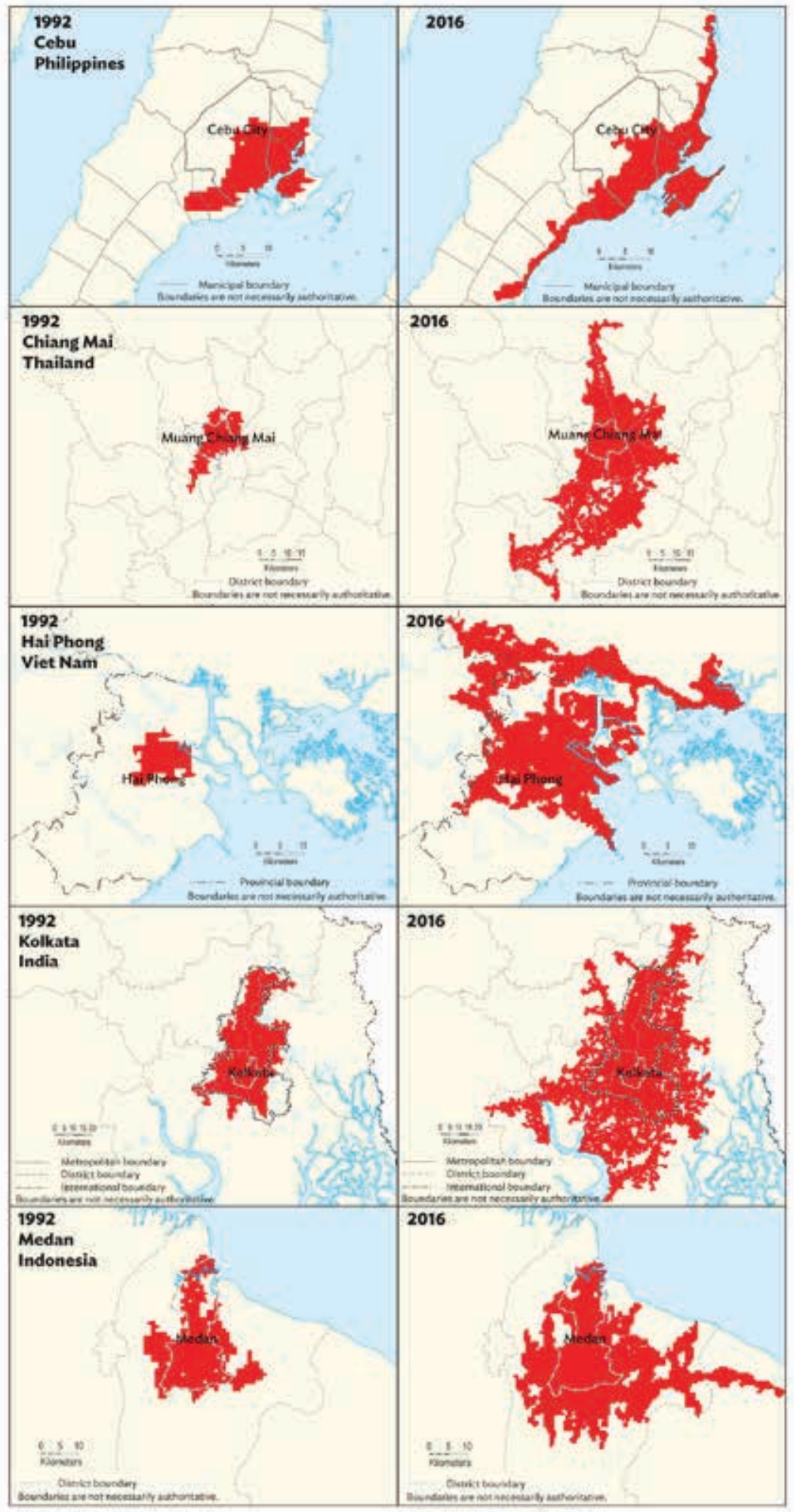

Source: Asian Development Bank. 2019. Asian Development Outlook 2019 Update: Fostering Growth and Inclusion in Asia's Cities. Manila: p.61. 
The data could also be used to examine the dynamics of an urban system. An urban system is highly dynamic as reflected by continuous changes in relative size of cities. Consequently, the size rankings of individual cities are far from being fixed, although the overall distribution of city size tends to be stable over time (Duranton 2007).

While most of the natural cities in this study's data set experienced growth in both land area and populationsubstantial growth for quite a few of them - there were also cities that contracted in land area and/or population. According to the study data, most natural cities $(1,241$ out of 1,525$)$ expanded in both area and population from 2000 to 2016. This was also true in India, Indonesia, and the PRC. However, only two cities in Japan and 17 cities in Pakistan expanded on both measures. In these two countries, the common scenario was cities contracting in both area and population.

The land area and population of a city generally move in the same direction. However, cities with the two measures moving in the opposite directions are worth noting. There were 104 cities that experienced growth in land coverage and a reduction in population, of which 47 were in the PRC. Since local governments act as a main driver of urban development process, this suggests that local officials probably have misaligned incentives to expand their urban footprints despite a net outflow of population. Another 65 cities attracted more people to settle in them while losing some urban land. Fourteen such cities are found in Japan and 10 in Pakistan. The resulting rise in density could lead to increased benefits of agglomeration and land-use efficiency but may incur additional congestion costs in these cities. Sound city governance is important to mitigate the latter.

Another way to look at city dynamics is to see how many cities in a country are changing their positions in the distribution of city size over certain time periods. If each city is assigned into a size quintile, either by population or by area, within a country, around $40 \%$ to $50 \%$ of cities are seen moving to a different size quintile from 2000 to 2016. This means nearly half of the cities have experienced significant changes in their relative size, some going up while others going down in a dynamic urban system over a 16-year period.

With the expansion of urban areas, some natural cities came closer and finally connected to form larger urban agglomerations, which are referred to as city clusters. Natural cities within a city cluster are not those connected by transport infrastructure only; they should be viewed as economically integrated as the land along the transport arteries between the cities was already developed for nonagricultural use and thus recognized by the NTL data as human settlement.

Among the 1,527 separate natural cities identified, 129 city clusters have emerged involving 489 natural cities across Asia and the Pacific by 2016 . With a total land area of $400,000 \mathrm{~km}^{2}$, these city clusters were home to 977 million people, accounting for $65.8 \%$ of the total population of all the natural cities in 2016 . Map 1 in Article $1 E$ Urban Synergies Through Coordinated City Cluster Governance shows the largest 28 city clusters across the region, each having more than 10 million in 2016. Of them, eight are in the PRC, including the largest one centered around Shanghai (Map 2); seven in India; eight in Indonesia; two each in the Republic of Korea and Viet Nam; and one each in Bangladesh; Japan; Malaysia; the Philippines; Taipei,China; and Thailand.

Overall, the natural city data set appears consistent and credible, generating novel and sensible evidence. It could be applied to studying a broad range of urban topics. More in-depth analyses using this data set jointly with other data, such as enterprise surveys with locations of firms, are desirable to foster evidence-based policy making. 
Map 2: Formation of City Cluster Centered Around Shanghai

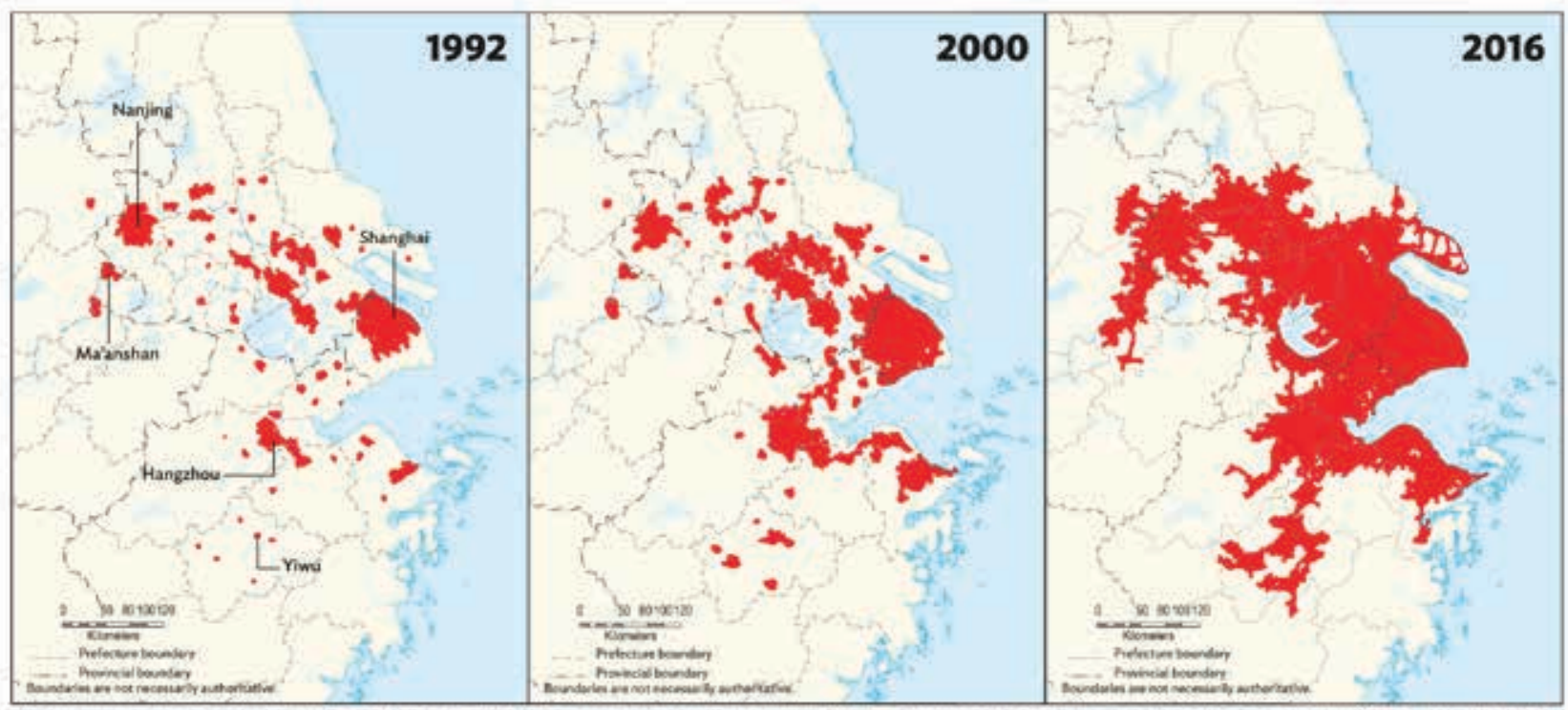

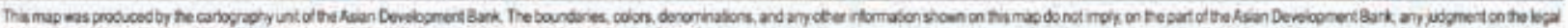

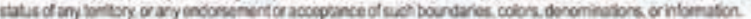

Source: Asian Development Bank. 2019. Asian Development Outlook 2019 Update: Fostering Growth and Inclusion in Asia's Cities. Manila: p.61.

\section{Practical Application and Cases}

\section{Climate Resilience and Disaster Risk Management for Cities}

This section showcases Earth observation's practical use in detecting land use/land cover with changes over time, flood risk mapping, climate resilience, and disaster response, to name a few. Land-use cases will cover city, country, and regional level applications.

Two-thirds of the world's poor are in Asia and the Pacific; these areas are among the most vulnerable regions to climate change. Much of this population is expected to be living in urban areas in the next 30 years, making it indispensable for the region's cities to become climate-resilient and more livable. Disaster risks and the effects of climate change further pose additional dimensions of challenges to infrastructure development. In areas where more frequent and intense climate events are expected, governments must plan for the effects of flooding, rains, insufficient water supply, and extreme temperatures, among others, and ensure that the infrastructure will perform under stress. These issues are further compounded in Asia, where governments must deal with rapid population growth in cities that are already saddled with deficient infrastructure networks. It is estimated that by 2025, more than 410 million people living in coastal areas in Asia will be at risk of flooding. 
Damage from floods alone is expected to worsen. According to a 2017 report from ADB, 13 of the 20 cities with the largest growth in annual losses because of inundation in the period 2005 to 2050 are in Asia. ${ }^{7}$ The process leading to more livable cities in the region starts with project preparation, planning, implementation, and monitoring of urban resilient infrastructure investments and social practices. It needs to be effective and based on reliable data-better if delivered via user-friendly geospatial platforms. Different climate change impact scenarios need to be computed considering local topography, land use, and socioeconomic factors.

The increasing intensity and frequency of extreme climate events have added a new dimension to infrastructure provision. It is no longer enough to plan for the 100-year flood. Engineers need to look at 25-, 50-, and 100-year return periods as well as historical data to better design infrastructure that can withstand such events. The use of GIS and Earth observation data has greatly improved government capacity to better design for climate change. However, the prohibitive costs of GIS software, high-resolution images, and technical capacity to utilize the information limits its application to a few, more advanced developing countries.

National space agencies, such as Japan Aerospace Exploration Agency and ESA, as part of their research and development mandates, have made available the information they have collected through their space programs to support vulnerable countries in enhancing planning for climate change and disaster risk management. At the same time, SPADE was developed as a pilot in ADB, which allows project officers, consultants, and partner agencies to view their projects spatially and make informed decisions on climate-responsive engineering designs.

\section{ADB Cases Using Earth Observation to Improve Delivery of Development Assistance}

This section presents cases on how $A D B$ is using this information to improve the delivery of development assistance. The EO4SD-Urban projects collaborated with ADB and provided six cities/towns (Kolkata, and four smaller Cambodian towns: Kampong Chhnang, Pursat, Serei Saophoan, Stueng Saen) with Earth observation-based products to support their disaster risk management activities. The collaborative activities of the EO4SD-Urban Consortium and ADB conducted in these towns are described in each of the cases below.

\section{Disaster Risk Management in the Tonle Sap Basin, Cambodia}

The EO4SD-Urban service for the four towns in the Tonle Sap basin in Cambodia was provided under the Second Integrated Urban Environmental Management in the Tonle Sap basin project initiated in 2016. As the region only had very few detailed and up-to-date spatial data and maps available, the EO4SD-Urban particularly contributed in providing a wide range of spatial products for the urban areas, including very detailed land use and land cover, settlement extent and growth, urban green area, population distribution and density analyses, and flood risk assessment.

Map 3 shows the flood risk assessment done for Kampong Chhnang in the larger urban area in the left image and in a close-up image on the right side.

The data was especially supportive as input for the urban sector assessment and as a guide for the investigation in which town to optimize investments. The data further improved the urban planning activities, including the actual infrastructure design, and led to a rethinking of the current planning approach to a more spatially based approach.

\footnotetext{
These include Guangzhou, Shenzhen, Tianjin, Zhanjiang, and Xiamen (the People's Republic of China); Mumbai, Chennai-Madras, Surat, and Kolkata (India); Ho Chi Minh (Viet Nam); Jakarta (Indonesia); Bangkok (Thailand); and Nagoya (Japan). Asian Development Bank. 2017. A Region at Risk: The Human Dimensions of Climate Change in Asia and the Pacific. Manila.
} 
Map 3: Flood Risk Assessment in Kampong Chhnang, Cambodia

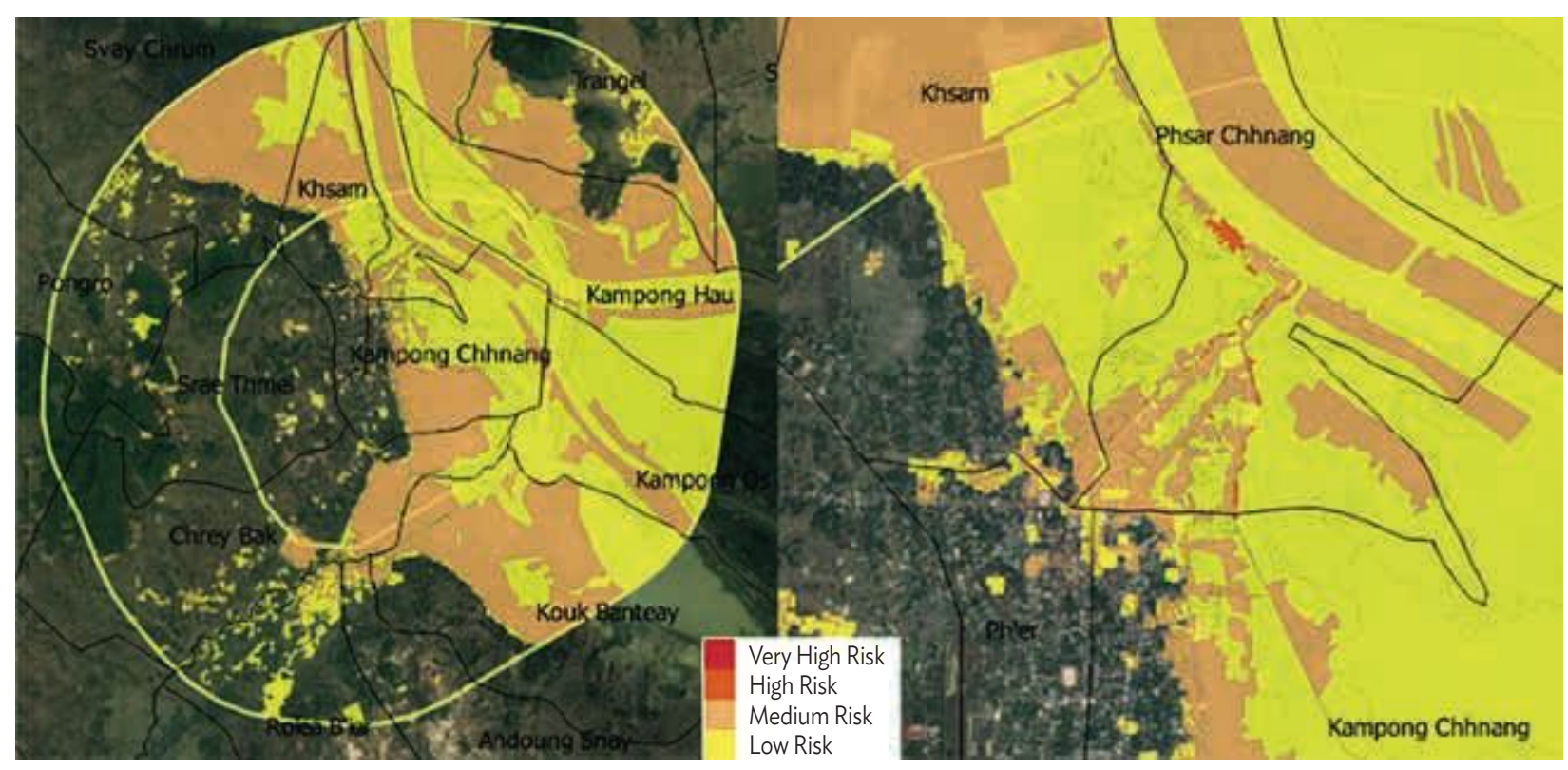

Source: Netherlands Geomatics \& Earth Observation B.V. 2017.

\section{Disaster Risk Analysis of Informal Settlements in Kolkata, India}

In Kolkata, the EO4SD-Urban consortium supported the Kolkata Municipal Corporation (KMC) with a range of products. The spatial data for KMC can be used as: (i) an add-on to the ongoing mapping exercises; (ii) support to fulfill their public service remit, including land use planning (e.g., with precise mapping of informal settlements); (iii) a tool to enable a better handling of disaster management; and (iv) a supplement to enhance urban climate change resilience.

An exemplary subset of the very detailed land use and land cover classification including informal settlements for the year 2017 is presented in Map 4.

The location and extent of informal settlements derived from satellite data were combined with, for example, transport network information to help measure, analyze, and assess the environmental conditions of these densely populated areas. Kolkata is considered worldwide as one of the most exposed cities to flood risk due to climate change, resulting in widespread sea level rise and more intense rainfall. Precisely assessing this risk not only for informal settlements but for the whole city is a vital component for making the city more resilient. For this purpose, not only the flood hazard intensity level (susceptibility) must be estimated but also the exposure level related to population and assets (vulnerability), for which land use/land cover mapping is key.

These cases briefly summarize how Earth observation data was successfully used in ADB projects. ${ }^{8}$

8 More information is available at Urban Development. Earth Observation for Sustainable Development. http://www.EO4SD-Urban.info/. 
Map 4: Subset of the Kolkata Land Use and Landcover Mapping for the Reference Year 2017

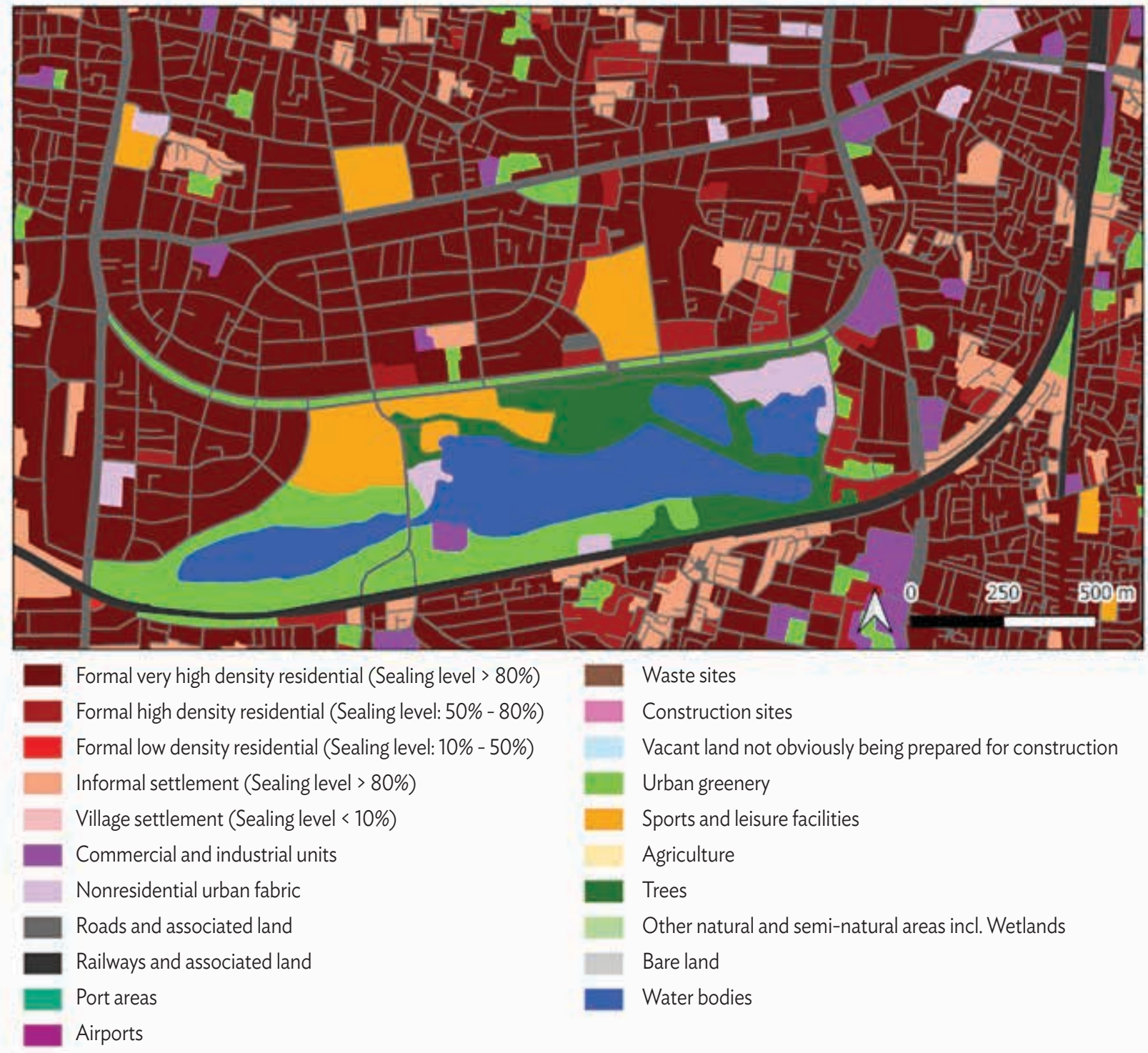

Source: Systèmes d'Information à Référence Spatiale. 2018.

\section{Capacity Building}

Within the EO4SD-Urban project, a range of capacity-building activities were done in close collaboration with ADB. One example is the training planned in Kolkata in 2021. Aside from the physical trainings, a webinar series on the basics of remote sensing, mainly on the applications of Earth observation data for urban planning activities, was done and recorded in 2019. The webinar recordings are widely available via World's Bank Open Learning Campus, ADB's k-learn platform ESA YouTube channel, and EO4SD-Urban project website. 


\section{Disaster Risk Finance in Hue City, Viet Nam}

In partnership with the University of Tokyo, the International Centre for Water Hazard and Risk Management under the auspices of UNESCO downscaled to city level the data on Earth observation, meteorological and hydrometeorological data, and climate change simulations from the DIAS. Field surveys were also done to collect socioeconomic data using a mobile application for data collection developed by the Asian Institute of Technology. Baseline data for two cities in Bangladesh (Bagerhat and Patuakhali) and three cities in Viet Nam were developed for the pilot.

Viet Nam is developing a disaster risk insurance model for public assets. This initiative, which is being pioneered in Hue city, is of immense cultural and commercial significance to the country. This city is likewise exposed to flooding and tropical cyclone risks. In Viet Nam's case, the field surveys also included noting historical flood damages to buildings. Map 5 shows the 25 -year flood projection over the city's built-up areas.

The information on Hue's building footprints, number of floors, hazards, and flood projections became part of the factors used in selecting and valuing the assets that will be recommended for the insurance. This provides decision makers information on the critical areas that may be flooded within the city in the next 25 years.

Knowing that a proposed infrastructure project falls within the critical flooded areas can prompt city managers to ensure the engineering design can withstand anticipated floods or consider relocating the facility to a safer zone.

Map 5: 25-Year Flood Projection in Hue City, Viet Nam

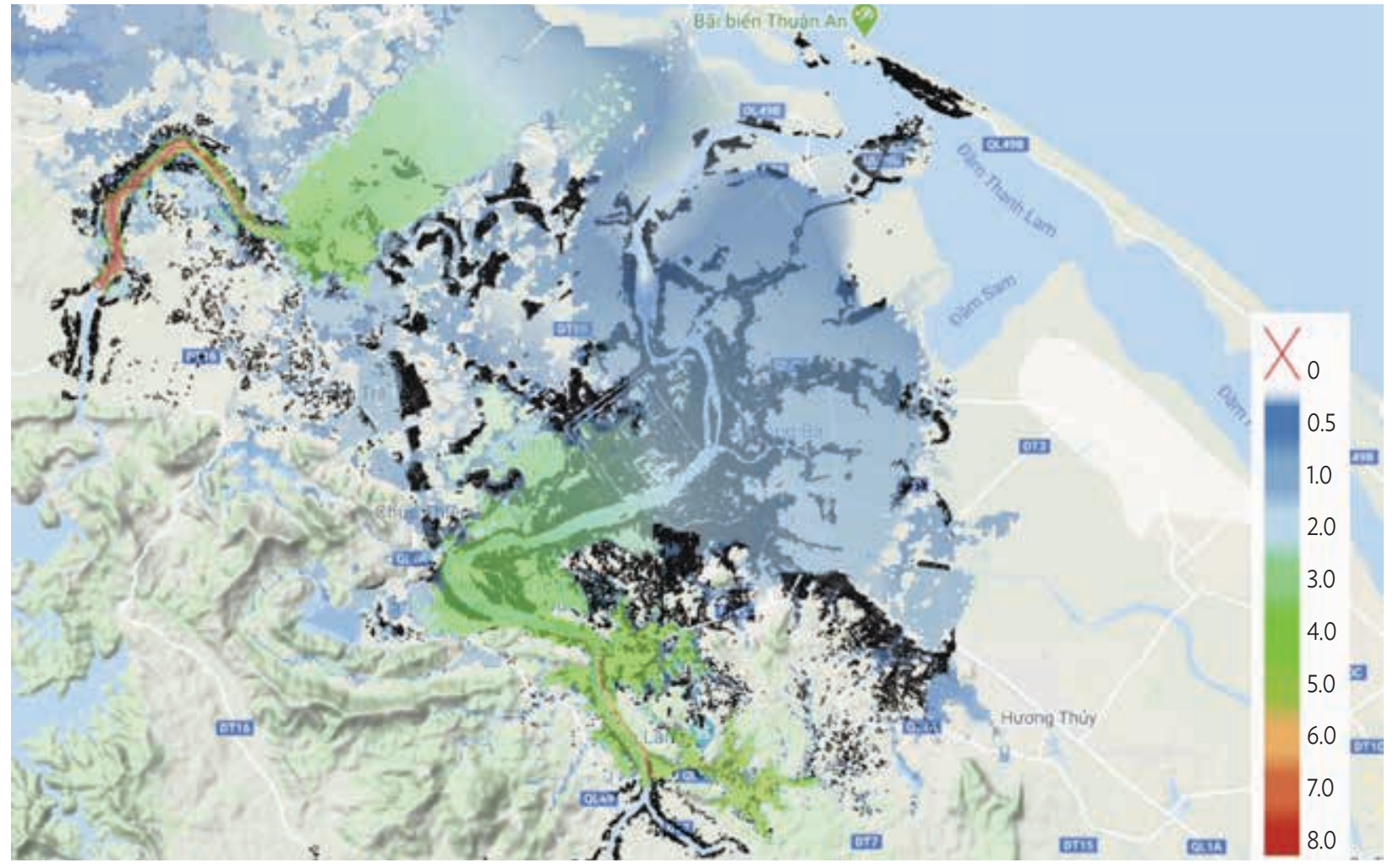

Note: Flood depth in meters, overlaid with building footprints.

Source: International Centre for Water Hazard and Risk Management under the auspices of UNESCO, Spatial Data Analysis Explorer. 
All these data are hosted on Amazon Web Services, a scalable cloud-based system where all the data are integrated and standardized. Using cloud technology, SPADE is easily accessible on both desktops and mobile phones with internet connection. There are several functions in SPADE like the ability to view data layers and upload and download maps, and nontechnical users can do simple yet useful spatial analysis.

Following the pilot, GIS and climate data from other developing country projects is hosted in SPADE to make it available for future use. This includes maps from Cambodia, India, the PRC, and Viet Nam. In Viet Nam, during a project conceptualization stage, the SPADE team converted various maps into digital format to determine if the sites of the proposed investment project fall within the protected area.

With the increasing public and private research institutions making their data available for free, SPADE can pull out geospatial information and use it on the platform to complement the data sets already available. To date, SPADE has drawn open-source data from international space agencies, such as the ESA and the National Aeronautics and Space Administration, as well as country specific projects on hazard-related data, such as the Nationwide Operational Assessment of Hazards Project in the Philippines.

In Patuakhali, Bangladesh, location and condition of sanitation facilities are mapped out, which provides valuable information to city planners and project officers for identifying targeted sanitation interventions for different parts of the city (Map 6). Data was gathered using the SPADE application, a field data collection application built on an open-source platform. The SPADE application is customizable depending on the data requirements needed. Sanitation data (e.g., composting toilet and its condition) were collected from the field and uploaded to SPADE. The application is free and downloadable from Google Play. ${ }^{9}$

\section{Case Study: SPADE and COVID-19 Mapping}

The SPADE platform was also helpful in supporting ADB's coronavirus disease (COVID-19) response efforts and mapping COVID-19 cases globally. The daily information updates collected by Johns Hopkins University on confirmed/death/recovery cases have additional layers on economic losses, health workforce, and travel restrictions, among others (Map 7). These updates provided more granular information on the situation while SPADE provided the spatial analysis to identify the highest concentrations of income poor residents in Metro Manila and who were likely most vulnerable to COVID-19. Health facilities and market accessibility were also analyzed. SPADE facilitated the mapping of hospital locations and distances to the nearest public market per village (barangay) (Map 8). Through this analysis, officials were also able to identify potential hotspots due to social distancing challenges in selected areas in Metro Manila.

\section{The Future of Earth Observation Technology}

\section{Trends in Earth Observation Toward the Use of Artificial Intelligence Sensors and Open Data}

Earth observation, as a diagnostics tool, with its ability to unlock significant data for urban planning, provide several advantages over traditional field-based surveys (such as household surveys) and/or census data normally used for urban planning. Freely available data, such as the ESA Sentinel suite, are globally available which makes it

9 ADB SPADE. Google Play. https://play.google.com/store/apps/details?id=com.gic.spade.android. 
Map 6: Location and Condition of Sanitation Facilities in Patuakhali, Bangladesh

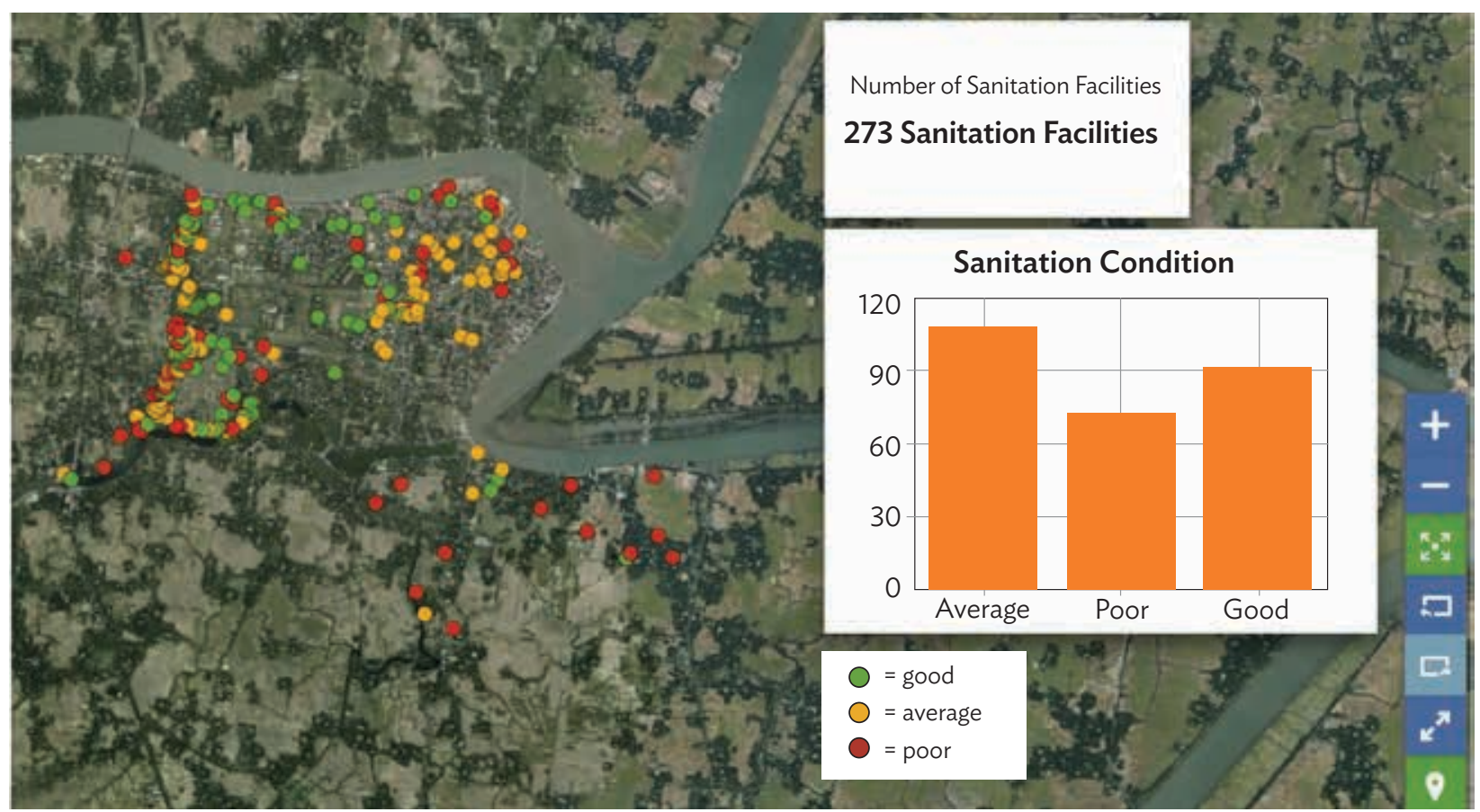

Source: Spatial Data Analysis Explorer.

Map 7: Impact of COVID-19 in Asia and the Pacific

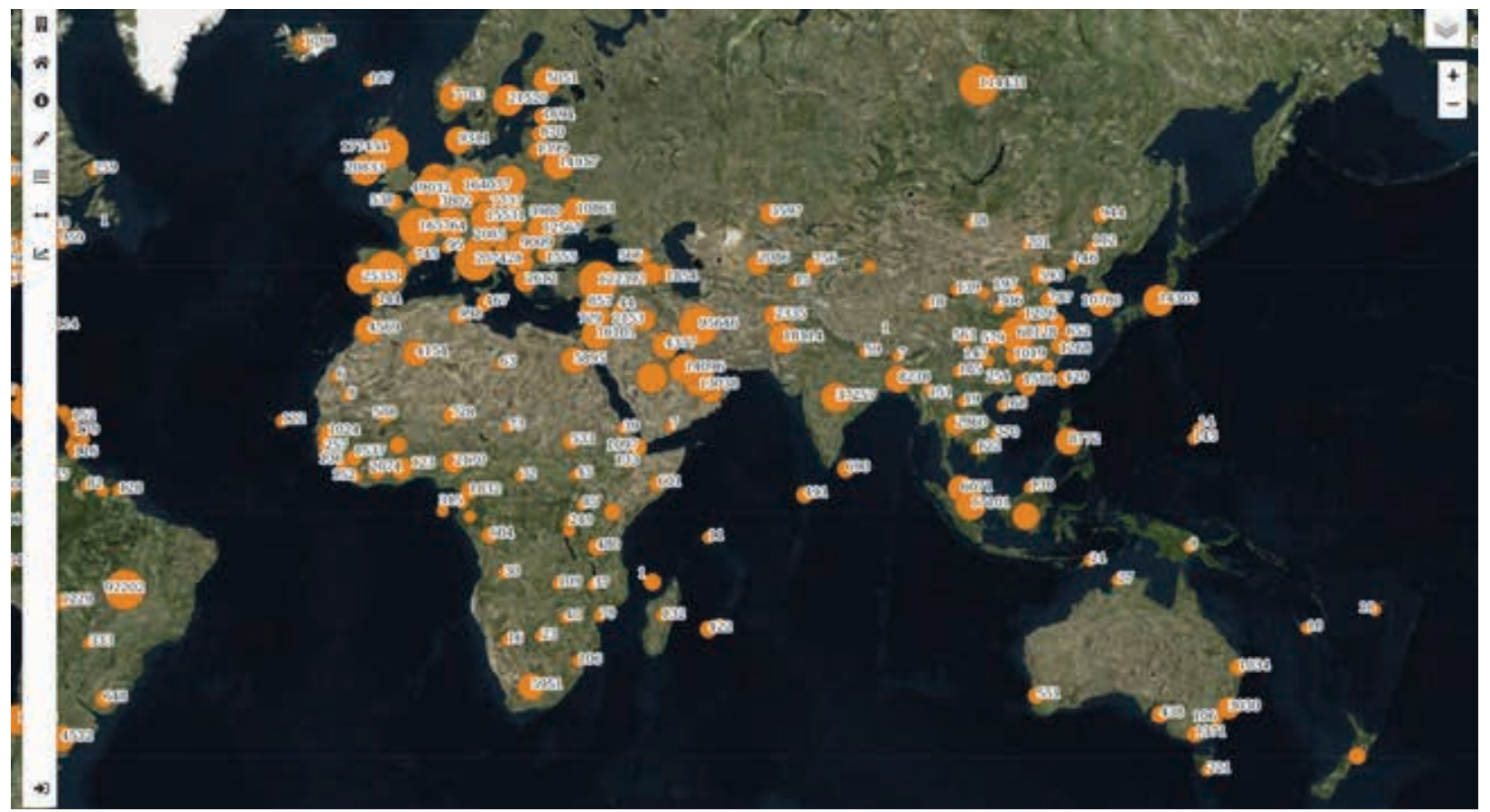

Note: Orange circles represent the number of COVID-19 cases within an area of interest.

Source: Spatial Data Analysis Explorer. 
Map 8: Hospitals and Informal Settlements in the Philippines' National Capital Region

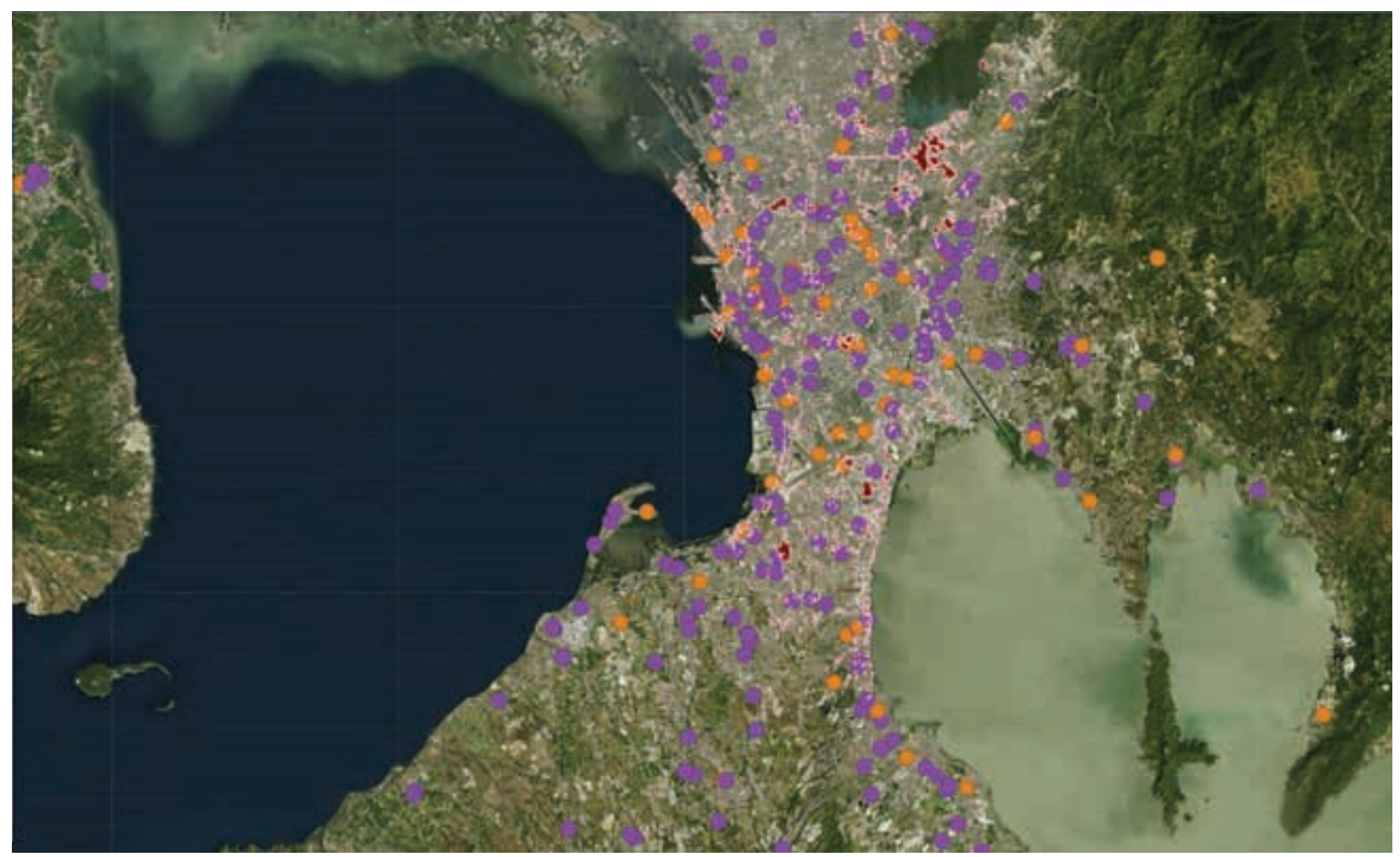

Note: Informal settlements are represented by red polygon, while government and private hospitals are represented by orange and purple circles respectively.

Source: Spatial Data Analysis Explorer.

suitable for getting information in areas that are difficult to access in cities. The timeliness and high frequency of its availability also make the data useful for the monitoring aspects of urban development. Furthermore, analysisready data are available for use soon (days or even hours) after they are acquired. Such data are useful not only for urban monitoring but also in rapid assessment for disaster response.

As noted in the Caribou Space report, the European Service Provision industry is growing. Barry and Taverner (2020) report, "The European Space Agency and the European Commission have invested $€ 250$ million in R\&D over the last decade to ensure these products are robust and accurate. The European Earth observation information services sector (private companies, government institutes, universities) has grown as a world leader, through these investments."

The experiences gained in the 4 years that the service providers implemented the EO4SD-Urban with the different multilateral development banks have generated an operational urban product portfolio that has the possibility for evolution. Stakeholders have also been provided with best practices in service delivery. The portfolio of products based on the suite of freely available Sentinel satellite data will further evolve with the growing needs and demands for geo spatial data in the urban domain. The Caribou Space study reveals that Earth observation provides benefits in four different areas: (i) urban planning and monitoring; (ii) transport 
planning and monitoring; (iii) hazard assessment, early warning, and response coordination; and (iv) monitoring of environmental issues. ${ }^{10}$

Space, in support of international development assistance, is a new joint initiative of ADB, ESA, and World Bank using satellite Earth observation for monitoring the environment. Mankind's actions are rapidly and significantly changing the world in which we live. The Earth's climate is currently entering into a state unprecedented in at least the last million years, and at a rate of change that exceeds by orders of magnitude anything previously seen.

The greatest impact will be on those societies that are the most vulnerable, like the developing countries, and will be increasingly severe and far-reaching. Consequences of these combined effects include sea-level rise due to global warming, desertification and land degradation, large-scale drought, extreme weather events, increasing frequency of natural disasters, rapid urbanization, threats to food security, natural resources depletion, and degrading air quality.

The 2030 Agenda for Sustainable Development is an action plan supported at the highest political level to take the bold and transformative steps that are urgently needed to shift the world onto a sustainable and resilient path. Importantly, it is a data- and evidence-driven agenda, containing a framework of 17 SDGs, with 169 targets, and supported by 232 indicators. The SDG Global Indicator Framework (endorsed by the UN Statistical Commission in 2017) will drive several key issues in development assistance and further underscore priorities set at national level, including data collection and reporting, establishing statistical measurement frameworks, and analysis on a variety of development finance topics (OECD, n.d.). ${ }^{11}$

To achieve a greater impact, the key challenge is to use better environmental data to understand the biggest issues facing society (i.e., climate risk, climate change-induced insecurity), and to help make better-informed, evidence-based decisions in development operations and policy making. A strategic solution has been identified-satellite Earth observation provides a wide range of environmental information that are global, comprehensive, accurate, repeatable and timely, which are key to effective planning, implementation, and monitoring and evaluation of development assistance activities.

Earth observation is a non-intrusive technology, and sometimes the only feasible method of collecting information especially for very remote or difficult-to-access regions (e.g., areas experiencing fragility, conflict, and violence). Many developing countries are lacking even the most basic mapping information, and Earth observation can deliver up-to-date mapping of natural resources across whole countries and regions.

Satellite Earth observation is well-positioned to address official development assistance priorities, such as aspects related to climate change and natural disasters, fragility, migration, food security, and environmental resilience. The development community has long been fascinated by the potential of this technology. Today, the wealth of data collected through Earth observation is easily translated into information that communities and policy makers can understand and use in their work. Consequently, better-informed management decisions have not been difficult to make.

10 N. Barry and D. Taverner. 2020. Understanding the Impact of Earth Observation for Sustainable Urban Development. United Kingdom: Caribou Space. February. https://www.caribou.space/library/adoption-and-impact-of-earth-observation-for-the-2030-agenda-forsustainable-development/.

11 Organisation for Economic Co-operation and Development (OECD) n.d. Financing for Sustainable Development. http://www.oecd.org/ dac/financing-sustainable-development/. 
Furthermore, the extraordinary circumstances and unprecedented impact that COVID-19 is having on living and working conditions, have urged the development financing community to look for new information to help in planning the response to the economic impacts of the pandemic.

Satellite Earth observation information can support development work in several ways. Social protection measures can be formulated through rapid, large-scale spatial distributions and monitoring of population densities, housing conditions, transport networks, and mass human displacements, together with mapping of environmental factors that could threaten social stability such as droughts, floods, fire, and air pollution. Satellite Earth observation can also provide information that serve as proxies to monitor activity sectors and therefore help formulate economic recovery measures.

Examples of sectors wherein satellite Earth observation can play a significant role include industry (changes around production plants, levels of atmospheric emissions); agriculture and environment (harvesting, land use monitoring); tourism (changes in resorts and facilities); and transport and trade (movement of goods by land, marine, and air).

The overall recommendation is to take advantage of these existing, proven, and available assets that Europe has already invested in over the last 2 decades (space missions, digital analytics), and use them to deliver greater impact in developing countries by growing local technical skills and capacity that can in turn support development cooperation actions.

\section{References}

Asian Development Bank (ADB). 2019. Asian Development Outlook 2019 Update: Fostering Growth and Inclusion in Asia's Cities. Manila. https://dx.doi.org/10.22617/FLS190445-3.

- - - Spatial Data Analysis Explorer. https://play.google.com/store/apps/details?id=com.gic.spade.android.

-_- 2017. A Region at Risk: The Human Dimensions of Climate Change in Asia and the Pacific. Manila. https://www.adb.org/publications/region-at-risk-climate-change.

Barry, N. and D. Taverner. 2020. Understanding the Impact of Earth Observation for Sustainable Urban Development. United Kingdom: Caribou Space. February. https://www.caribou.space/wp-content/ uploads/2020/05/Caribou-Space_GAF_ESA-EO-for-Urban_v1.pdf.

Duranton, G. 2007. Urban Evolutions: The Fast, the Slow, and the Still. American Economic Review. 97 (1). pp. 197-221. https://www.jstor.org/stable/30034391.

European Space Agency. 2016. ESA and Asian Development Bank Join Forces. News release. 11 September. https://www.esa.int/Applications/Observing_the_Earth/ESA_and_Asian_Development_Bank_join_forces.

European Space Agency. Earth Observation for Sustainable Development. http://www/eo4sd-urban.info.

EGIS. https://www.egis-group.com/. 
GAF AG. https://www.gaf.de/.

German Aerospace Center. https://www.dlr.de/EN/Home/home_node.html.

GISAT s.r.o. http://www.gisat.cz/content/en.

GISBox. https://www.gisbox.ro/.

Joanneum Research. https://www.joanneum.at/en.

National Oceanic and Atmospheric Administration. National Geophysical Data Center. https://ngdc.noaa.gov.

Netherlands Geomaticcs \& Earth Observation B.V. https://www.neo.nl/home-int/.

Oak Ridge National Laboratory. LandScan. https://landscan.ornl.gov.

Organisation for Economic Co-operation and Development (OECD). Financing for Sustainable Development. http://www.oecd.org/dac/financing-sustainable-development/.

Socioeconomic Data and Applications Center. http://sedac.ciesin.columbia.edu/data/collection/grump-v1.

Systèmes d'Information à Référence Spatiale. https://www.sirs-fr.com/sirs/en/.

United Nations. 2018. World Urbanization Prospects: The 2018 Revision. New York. https://population.un.org/wup/ Publications/Files/WUP2018-KeyFacts.pdf.

United Nations Department of Economic and Social Affairs Population Division. https://population.un.org/wup/ Publications/Files/WUP2018-KeyFacts.pdf. 


\section{Gender-Responsive and Inclusive Urban Planning}

Gillian Brown, Prabhjot Khan, and Samantha Hung

\section{Introduction}

As urban populations in Asia and the Pacific continue to grow rapidly, more women are living in urban areas, and many people live in female-headed households. Urban living may bring many advantages for women and girls, such as better access to health and education services, and work opportunities. They also benefit from increased exposure to new ideas and opportunities to socialize, which help reduce some of the sociocultural restrictions that rural women and girls face.

However, gender inequalities persist and limit the extent to which women can contribute to the social and economic life of cities. While women have greater access to jobs than their rural counterparts, many of these are in the informal economy and gender discrimination still hampers many women's efforts to find decent work. Like their rural counterparts, urban women shoulder the burden of unpaid care work. Since many have migrated to cities away from their families, they may lack the family support mechanisms that rural women turn to.

Urban women are disproportionately impacted by inadequate provision of childcare and other facilities and services that would help reduce their time poverty. Many urban women experience the additional burden of gender bias in ownership of assets; limited access to finance due to lack of security of tenure, land, or housing; long commutes; and poor water and sanitation (Pozarny 2016).

Improving gender equality brings important economic and social benefits to a country. As women's human capital is improved and as women participate in the economy, they increase the competitiveness and productivity of a country, contribute to poverty reduction and family welfare, and facilitate the human capital development of the future workforce.

Moreover, women's participation in governance, politics, and decision-making helps improve the equitable and inclusive allocation and targeting of resources, and drives urban resilience. Promoting gender equality, therefore, should be an important goal for urban planners.

\section{Gender Mainstreaming to Improve Gender Equality}

Gender mainstreaming is an approach to achieving the goal of gender equality and women's empowerment by providing a systematic way to identify the barriers and constraints, and to find solutions. Gender mainstreaming is not a goal in itself, and it does not happen automatically. It requires skills, resources, data, frameworks, and the tools to identify and analyze problems. 
Mainstreaming gender into urban planning and decision-making means ensuring that the different needs and interests of all groups are taken into account in all aspects of planning and development of a city by both public and private sectors. These groups include men and women, boys and girls, young and elderly, people with disabilities, and people of different sexual orientation and gender identities.

It takes a step further by identifying the barriers and constraints that specific groups face, especially women, and targeting resources to remove such barriers and levelling the playing field. It also requires the active participation of diverse groups of male and female stakeholders, including from the lesbian, gay, bisexual, transgender, and queer (LGBTQ) community. They should be able to engage effectively with planners and city authorities, and have access to the tools they can use to ensure accountability.

Along with participation, the collection and analysis of sex-disaggregated data is essential in mainstreaming gender considerations in planning. While some sectors such as health and education routinely collect sex-disaggregated data, others such as transport, electricity, and water supply do not. Technology and smart solutions have opened new opportunities for collecting sex-disaggregated data from nontraditional sources and for using it in innovative ways including through spatial mapping, to analyze and understand it. These technologies are being used in innovative ways to analyze and understand development issues.

\section{A Framework for Mainstreaming Gender}

A useful framework as a starting point for mainstreaming gender in urban planning and development comprises participation, access to services and facilities, livability, mobility, and safety and security (PALMS) as presented in Figure 1. ${ }^{1}$ This section discusses what each of these means from a gender perspective and how technology can be used to identify constraints and plan for solutions to achieve gender equality.

\section{Participation}

The people who are best able to describe the constraints they face are those that experience them daily. Hence the participation of women and marginalized groups from the grassroots up is at the core of this framework. ${ }^{2}$ The framework puts participation upfront, and it encompasses participation of all social groups at all levels, including women in governance, decision-making, design, and implementation.

Participation that starts in smaller activities at a project level can be amplified over time, and with the right support and resources, into longer-term sustainable influence in a city's governance structures. However, institutionalizing the participation of women and diverse groups in governance requires reforming these

\footnotetext{
ADB. 2019. Gender Mainstreaming in Urban Planning. Promoting Gender Equality and Women's Empowerment (Phase 2): Future Cities, Future Women Initiative. Consultant's Report. Manila (TA 8797-REG). This technical assistance project originally developed the MAPS framework, which has been modified for this publication. The MAPS framework refers to mobility, access, participation, and safety and security. A team from the Future Cities Lab at the National University of Singapore, supported by the Asian Development Bank (ADB) for assisting the Bandung Municipal Government in urban planning, developed the framework.

2 "Marginalized groups refer to different groups of people within a given culture, context and history at risk of being subjected to multiple discrimination due to the interplay of different personal characteristics or grounds, such as sex, gender, age, ethnicity, religion or belief, health status, disability, sexual orientation, gender identity, education or income, or living in various geographic localities." European Institute for Gender Equality. Marginalized Groups. https://eige.europa.eu/thesaurus/terms/1280?lang=en.
} 
structures and introducing the policies and processes that enable it for the long term.

There are many reasons why women and marginalized groups do not participate in specific design and planning activities. They may feel that they do not have the right to do so, or that it is not relevant for them. They may be uninformed about the process, or about what is to be discussed. Public meetings that are far away, in intimidating and unfamiliar locations, and at times that are inconvenient can discourage women from participating.

Participatory activities need to be specifically designed considering those least able to participate, and investing additional time and resources to ensure that all voices can be meaningfully heard. At the community level, participatory tools and processes can be used to ensure that the views of different groups contribute meaningfully to designs (Box 1).
Figure 1: PALMS Framework

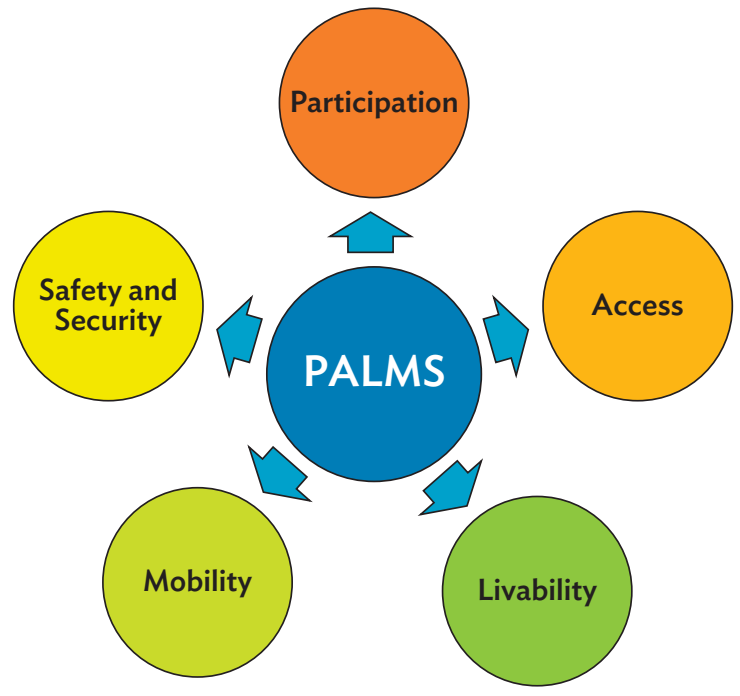

Source: Asian Development Bank.

\section{Box 1: Participatory Process in Action in Tbilisi, Georgia}

A participatory process was used in Tbilisi to enlist input from diverse groups of people in the community. They shared their ideas for the design of a local park and recreation area in a low-income residential area to be upgraded by the Department of Environmental Protection of Tbilisi City Hall.

Prior to the participatory meetings, which were organized by the local municipality (Gidani District), the district management was consulted and door-to-door interviews were held in addition to an online survey questionnaire. Leaders of local religious and social organizations and groups were approached to encourage people to attend the meetings. Posters were placed around the area and invitations sent to households. The women were sent invitations to participate in the meetings, which were held in the park that was to be redeveloped, so that it would be easy for them to get there and to bring their children along with them.

Participatory planning tools were designed, which were easy for people of all ages and abilities to engage with, and to identify their priorities and preferences. Holding the meetings outdoors, particularly in the area proposed for the park, also made it possible to practice social distancing and incorporate other risk mitigation measures during the coronavirus disease (COVID-19) pandemic.

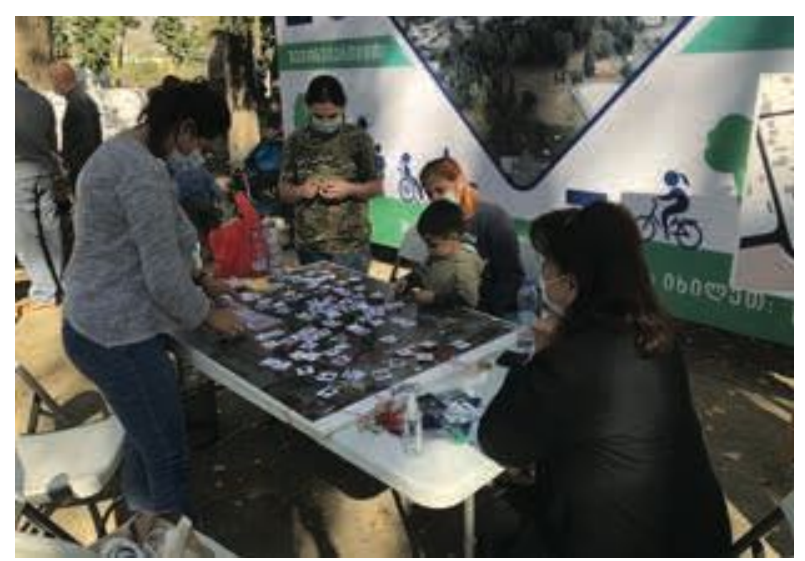

Participatory process in Tbilisi. Women in Tbilisi, Georgia participate in a "street café" activity (photo by Nana Adeishvili/ADB).

Source: Asian Development Bank. 2020. Georgia: Strengthen Local Institutions to Plan and Design Gender Responsive and Inclusive Urban Development (Future Cities Future Women Phase 2). Subproject 2. Manila. 
Carefully designed projects can provide a pathway to greater participation in decision-making, starting with encouraging women to participate actively and effectively in community planning and decision-making committees. Quotas or targets for women's participation in project-mandated committees help more women gain theexperience and confidence to participate in local governance institutions and structures. Moreover, when the community sees women representing them capably in these structures, it influences norms and perceptions about women as leaders. Ultimately, they can have greater influence when communities are willing to vote women into key decision-making positions.

Women playing the role of key decision makers, however, can take time and effort. Resources are needed to encourage participation and provide training and support to help more women understand how governance and budgets work and what their rights and duties are as representatives. Box 2 gives an example from Bangladesh where three successive projects over 17 years have incrementally built the capacity and effectiveness of women as leaders. These women are now represented in non-project governance structures, and these structures have become more responsive to the needs of citizens.

\section{Box 2: Institutionalizing Gender Equality}

The Urban Governance and Infrastructure Improvement Program has been implemented through three successive projects since 2003. From the outset, women's participation in planning and decision-making was an important result area in the Urban Governance Improvement Action Plan.

Early on, the project required creation of gender and environment committees chaired by women ward councillors (WWCs). The project also required 30\% women's representation in Town Level Coordination Committees and Ward Level Coordination Committees. The quota was exceeded after the first few years, and women members became active contributors to the pourashava (municipality) development plan and helped ensure that money was earmarked for activities that would benefit women.

Women had been initially hampered by being poorly informed about local governance systems, budgets, and resources, and about their rights. The project therefore worked with WWCs to build the skills needed to perform their duties properly and for women to become more influential. The WWCs started visiting households and holding courtyard meetings where women could meet and discuss their issues and priorities. Successive projects built on the lessons learned and extended women's participation to other local bodies, such as slum improvement committees. Over time, women started to chair many of these committees and represented the majority of members. The committees developed community action plans to improve facilities such as tube wells, toilets, drains, footpaths, and street lighting.

Through three successive projects, women have helped to strengthen the governance structures, and these structures have become more responsive to citizens' needs. Individual women have been empowered to exercise their rights and influence decision-making. Many women who participated have been elected as councilors in city corporations and pourashavas, and become members of other organizations such as local market management committees and intercity trade associations.

Source: Asian Development Bank. 2017. Institutionalizing Gender Equality: Urban Development Experience of the Bangladesh Local Government Engineering Department. Manila. https://www.adb.org/publications/gender-equality-urban-developmentbangladesh. 
Digital and online technology can be used to inform communities about planning processes and decisions and provide forums for engagement. E-governance tools such as mobile phone-based simple apps allow citizens to provide participatory feedback on any planning activities being implemented by their municipalities.

However, since women have less access to technology than men, this may exacerbate gender bias rather than provide channels for women's engagement. For example, in South Asia, a significant gender gap exists whereby $58 \%$ of women are less likely to use mobile internet than men (GSMA 2019). Closing the digital gender gap and identifying the online spaces where women can safely and effectively engage will be an important priority for the future.

\section{Access to Services and Facilities}

One of the biggest challenges that urban planners face is targeting available resources for services and facilities where they are most needed, and where they can most effectively help foster inclusive growth. Poor families, among whom female-headed households are disproportionately represented, are especially affected by the lack of access to services.

For women and girls, access to sufficient, affordable, and good quality services enables them to fully participate in economic and social life. For example, access to good quality water supply can have a significant impact on the quality of life of women since they tend to be the primary collectors and users of water. Schools with clean toilet facilities that ensure privacy and with water supply provide a conducive environment in which girls can manage their periods. In the absence of these facilities, many girls regularly miss days of school each month, or even drop out, leaving them with long-term disadvantage from engaging in economic opportunities.

In most places, the burden of unpaid care work falls on women, hence schools, health centers, and childcare services that are easy to reach and provide quality affordable services can make a significant difference on women's ability to balance unpaid and paid work.

All infrastructure services, projects, and utilities that are approved by municipalities or service providers should ensure that universal and free connections are provided to all citizens, as the critical beneficiaries of such policies will be women and children. Services can be charged at the level wherein citizens are able to pay, but access to free or highly subsidized connections is crucial to ensure that no one is left behind. An example is the West Bengal Drinking Water Sector Improvement Project, which institutionalizes access to all, and involvement of women in asset management. ${ }^{3}$

Even when facilities and services are provided, women and girls can face difficulties in accessing them due to social, economic, and cultural barriers as well as poor planning and lack of gender awareness of service providers. Inferior quality street lighting, location of public transport stops, and design of subways or street crossings can all differently affect the ease with which men and women, and boys and girls can access different services.

For service providers, there is an additional advantage in taking a gender-sensitive and responsive approach. Household spending on facilities, such as water supply and electricity, is often influenced by women members of the household. Women are therefore an important customer group for consideration. Satisfaction with services is associated with a greater willingness to pay.

3 ADB. 2018. Report and Recommendation of the President to the Board of Directors. Proposed Loan and Administration of Grant and Technical Assistance Grant India: West Bengal Drinking Water Sector Improvement Project. Manila. https://www.adb.org/projects/documents/ind49107-006-rrp. 


\section{Box 3: Small Towns Water Supply and Sanitation Sector Project in the Lao People's Democratic Republic}

The Small Towns Water Supply and Sanitation Sector Project in the Lao People's Democratic Republic has not only enhanced women's quality of life. By increasing access to water supply and sanitation, the project has also helped to promote women's employment in the water sector.

More than 150,000 residents in 13 towns benefited from improved access to piped water supply, and grants were provided for construction of household toilets. Female-headed households, which tend to have lower incomes and education levels, were specifically targeted. Many women benefited from improved quality of life as a result.

The project also identified the gap in the number of water engineers in the country as a constraint and identified women as a potential resource to fill this gap. This has helped provide women with a decent sustainable income. Women make up only $13 \%$ of engineers in the country. Men dominate the senior staff positions in the water sector.

The project's Gender Action Plan supported the improvement of (i) access of female high school graduates to educational opportunities in water supply and sanitation engineering, (ii) gender awareness in the water utilities, and (iii) gender knowledge management in the urban water and sanitation sector.

Providing scholarships for women to study environmental science and engineering have helped change perception about these as subjects and careers for men only. All who gained scholarships have obtained bachelor's degrees.

Source: Development Asia. 2020. Tapping into the Potential of Women in the Water Sector. Manila. https://development.asia/ case-study/tapping-potential-women-water-sector.

Therefore, ensuring the satisfaction of women customers and responding to their needs can have significant impacts on the financial sustainability of service providers. There is also merit in empowering women to expect a decent level of service for their tariff by reporting service outages or defects. This helps in moving beyond designing gender-responsive infrastructure and actual use of services by women.

The collection and interpretation of data on service provision and use, and against performance results, are key to efficient and effective targeting of resources. Traditionally data have been collected from, for example, health and education departments, some of which includes sex-disaggregated data. However, data from other sectors, such as water supply, electricity, and transport, rarely include sex-disaggregated data.

New technologies are paving the way for collecting different kinds of data and information that explain how services are used by different groups. Data collected from mobile phones and specially designed apps that report satisfaction or problems and complaints could raise the sophistication of gender analysis to a new level if the sex of the user was known, and if women had equal access to the technology.

Beyond analyzing data and removing gender biases of services providers, transformative change can happen simply by employing more women into management positions in service industries and challenging the gender norms attached to certain occupations. These management jobs, which tend to be more secure and provide better incomes than most traditional "female" jobs, can have significant impact on the economic prospects of the women involved. 
Moreover, by encouraging more women into employment in the water and electricity sectors, for example, gender discrimination and bias can be reduced; and greater diversity will improve both the efficiency and responsiveness of the services. ADB has a number of investments and activities where promotion of women's employment has been a specific objective (Box 3).

\section{Livability}

Gender differences also exist in terms of attitudes toward the environment, with women often being more positive about clean technologies and environmental management. In part, this is due to gender norms that place them in a primary position of managing household solid waste management and promoting good hygiene practices.They also bear the brunt of caring for family members that become sick from conditions such as intestinal diseases, dengue fever, malaria, and respiratory illnesses, which are partly caused by poor environmental management. It makes sense, therefore, to ensure that women have a leading role in the planning and implementation of livable cities strategies.

Green and recreational spaces make an important contribution to the environmental quality of urban areas as well as to the health of the population by providing spaces for exercise, play, and socialization. The design of green parks and recreational spaces should respond to the needs of different social groups of users. These users include men and women, parents or caregivers with small children, adolescent and teenage girls and boys, elderly men and women, and people with disabilities. The parks should include spaces for resting, children's playgrounds, roads, and paths for pedestrians that are also accessible for people with disabilities.

Designs can either inhibit certain groups from using the space or extend their access. Girls and boys, for example, use space in parks in different ways and designs can influence how they use them. Girls from 9 to 18 years old are less likely than their male peers to use parks due to a complex interrelation of spatial and social factors. To encourage girls to use parks and public spaces, equal consideration needs to be given to the different behavior patterns of boys and girls. The inclusion of girls-only retreat spaces, non-male sport and play areas, and calm zones for socializing encourages more girls to use the space.

Dividing large areas and ball-game areas into smaller subspaces helps prevent large areas being occupied by the 'strongest' and most assertive groups and facilitates simultaneous use by several different groups. The city of Tbilisi, Georgia developed "Fair Shared, Green and Recreational Spaces Guidelines" that take account of these different behaviors and needs, and these are being piloted in the design of a new park in a low-income residential area. ${ }^{4}$

Women and girls in low-income countries and communities tend to make up the majority of victims of natural disasters (UN Women Watch). There are many and various reasons for this. For example, in the case of floods and tsunamis, more men and boys can swim; women are more likely to be in or near poorly built homes when earthquakes hit; or their caring roles may mean they are more likely to be trying to save children or the elderly as well as themselves. Underlying these disparities are the lower socioeconomic role of women, gendered norms, and discrimination that create the situation in which gender-based vulnerabilities prevail.

On the other hand, women are also key to driving inclusive resilience strategies at the local level. Evidence from developing countries in Southeast Asia shows that women's grassroots organizations collaborate closely with

4 ADB. Promoting Gender Equality and Women's Empowerment Subproject: Future Cities, Future Women Initiative. https://www.adb.org/ projects/48206-001/main\#project-pds. 
local governments to influence how resources are allocated for resilience investments targeted at vulnerable communities. Women are increasingly playing key roles in post disaster as providers, leaders, and managers.

Given the importance of women's leadership in resilience and post-disaster strategies, it is critical that this is purposefully built in from the outset. Building on the crucial role of women in strengthening resilience, programs can invest in women's economic empowerment and leadership. Investments where women are the primary stakeholders should be prioritized (Figure 2). These might include investments that:

- have women as a starting point based on robust understanding of risk,

- address structural inequalities between men and women that lead to the persistence of women's chronic vulnerabilities,

- reduce women's time poverty and burden of care,

- generate financial returns, and

- lead to transformation (ADB 2020).

Figure 2: Examples of Women-Focused Investments in Resilience
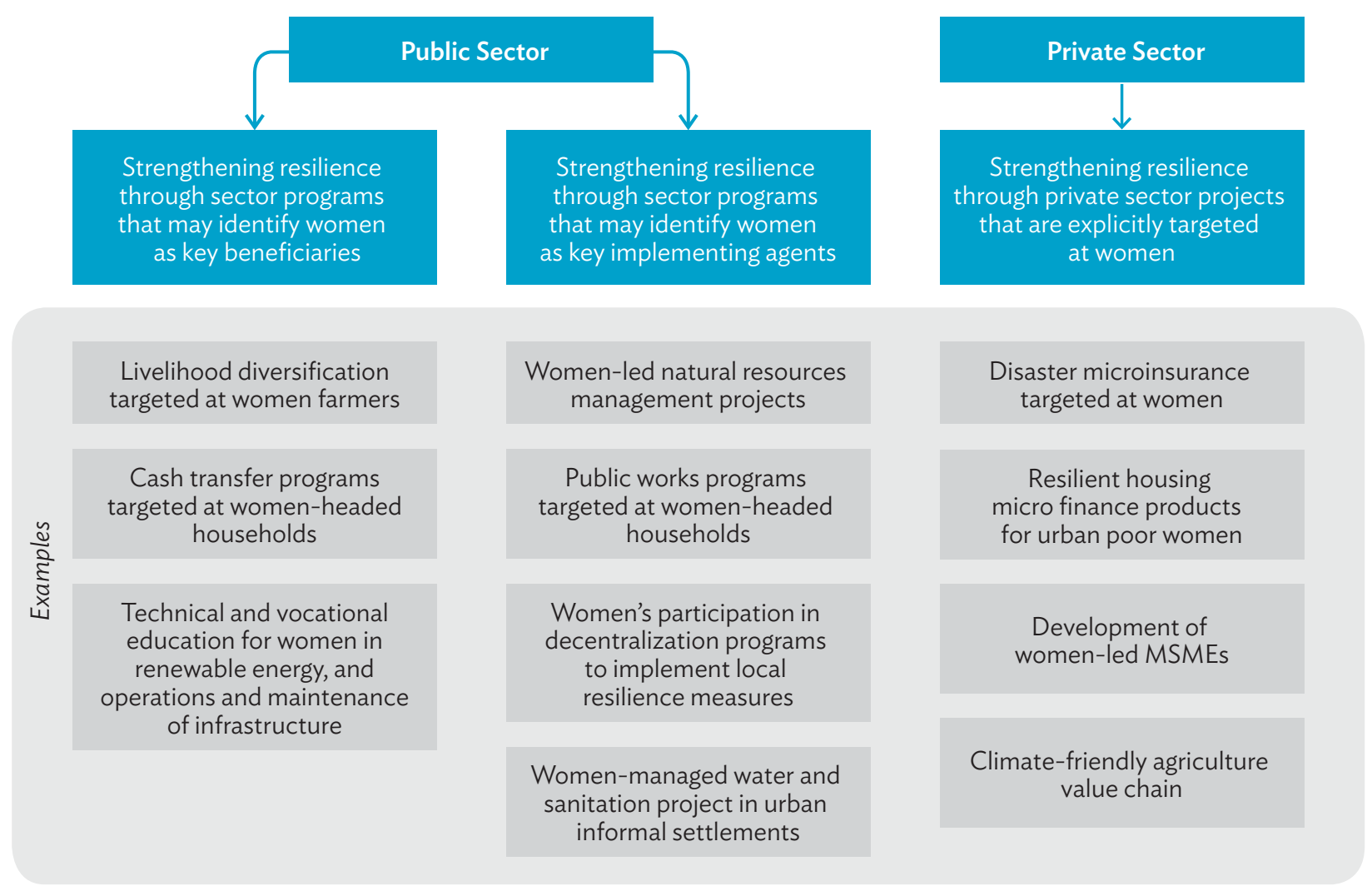

MSMEs = micro, small, and medium-sized enterprises.

Source: Asian Development Bank. 2020. Enhancing Women Focused Investments in Climate and Disaster Resilience. Manila. https://www.adb.org/publications/women-focused-climate-disaster-resilience. 


\section{Box 4: Examples of Programs Supporting Women in Urban Climate Action}

Women4Climate mentoring program. This program aims to educate and empower young women in climate action. It mentors and supports emerging women leaders from different sectors who are developing projects aimed at finding urban climate solutions with mayors, committed leaders, business sector, and civil society. Projects can be technology-based, civic initiatives, community mobilization, or research. The mentees receive training to enhance skills and enable them to address the gender barriers they face. They are also provided with the opportunity to meet other young women from different cities and countries. Women4Climate also runs a tech challenge competition designed to spark innovation and accelerate solutions from women in the tech community to address a wide range of urban sustainability issues.

Gender in urban climate change initiative. This project aims to strengthen women's leadership in urban climate action and develop gender expertise. It partners with women's organizations working on climate change and environmental issues and helps build capacity at the local level. Using a methodology called Gender Assessment and Monitoring of Mitigation and Adaptation, the project help local groups ensure that issues and priorities are systematically identified, and that local urban policies become more gender responsive. The Gender Assessment and Monitoring of Mitigation and Adaptation methodology consists of three stages: (i) assessment of the institutional and procedural framework to address climate change, (ii) gender screening of climate action programs to see if they address priority gender issues and contribute to gender equality, and (iii) gender assessment of priority policies and measures to estimate the effects of implementation on gender equality and gender relations. The program empowers women to participate in urban planning and governance processes.

Sources: Women4Climate. C40 Women4Climate Mentorship Programme. https://w4c.org/mentorship; C40Cities. Women4Climate. 2019. Gender Inclusive Climate Action in Cities: How Women's Leadership and Expertise Can Shape Sustainable and Inclusive Cities. https://w4c.org/sites/default/files/2019-02/W4C_ExecutiveSummary_EN_0.pdf.

Women are disproportionately affected by climate change and disasters; consequently, they are more likely to adopt renewable and climate-friendly technologies and drive resilience at the local level. However, they are significantly underrepresented in high-level climate negotiations, and in the sectors that contribute to and are impacted by climate change, such as urban planning, architecture, housing, energy, transport, waste management, and technology.

Increasing the representation of women in climate leadership is important to achieve gender-inclusive climate action (UNFCC 2019). Where innovative technologies have been developed and piloted, such as several of the cases quoted in this article, individual and committed women have been the driving force behind them-often in the face of skepticism and resistance. Several programs are now actively promoting and supporting more women into these sectors and into leadership on climate change (Box 4).

\section{Mobility}

Effective and reliable transport systems and services help women to navigate the city to fulfill their daily duties. Women often manage multiple daily tasks that require commuting between homes, schools, marketplaces, workplaces, and civic facilities. Poor commuting experience may impact their quality of life and productivity. 
Careful planning can help families balance their work and family care responsibilities, and children to build their independence safely. Elderly women and men, and people with disabilities need to be able to get out and about, and live healthy, independent lives. Short blocks and frequent pedestrian crossings provide easy connectivity between spaces with different functions and improve pedestrian access.

Priority should be given to public transportation to reduce private car usage and increase accessibility. Women are more likely to use public transport than men, hence transport planning and routes need to consider the way people, especially women, link their trips during the day. They may need to combine trips for multiple purposes, such as travel to work, shopping, taking children to school, and picking up medicines or visiting elderly relatives.

To facilitate trip chains, public transport needs to be well-integrated, reliable, frequent, within easy reach of residential areas, and easily accessible. Public transport should also be easily accessible for those with disabilities and mobility challenges, and those carrying heavy loads or looking after small children. Pricing policies need to reflect the variety of transport uses to ensure that women are not disadvantaged, for example, by paying for each leg in a trip chain rather than a bundled rate.

Transport use data can provide valuable insights if it can be sex-disaggregated to show the differences in the use by men and women. Apps on mobile phones using location services can track travel behaviors, including mode of travel, and help planners to ensure inclusivity. Modeling used, for example, to simulate evacuations from metro stations in emergencies would be dangerously flawed if consideration were not given to the evacuation of people with disabilities, or that are leading small children or pushing buggies. The Transformative Urban Mobility Initiative infographic shows the five principles for empowering women in transport.

\section{Safety and Security}

Safety and security are of particular concern for women and children, and people from LGBTQ communities, who may be vulnerable to gender-based violence. The movement and activity patterns of women are often shaped by their sense of safety (e.g., safe streets, public transport, and public spaces) and security (e.g., the absence of fear of criminal activities, harassment, and physical violations) in their living and working environments.

Creating a feeling of safety is especially important to girls and their parents, and elderly women. Pathways should be laid out to facilitate orientation, and in such a way to provide early sight of potential hiding places like niches, recesses, and edges of shrubs. Good sight lines into busy spaces increase the feeling of safety and the possibility of social control. Main pathways and heavily used spaces should be well-lit.

Well-maintained toilet facilities are particularly important to enable women, girls, and the elderly to stay longer in parks and recreation areas. Features like clear entrance and exit paths, visible way finding, and unobstructed lines of sight into a public space can make everyone feel more at ease and less vulnerable from being physically isolated in a park or plaza.

Designs that maintain visual and audible contact between residential apartments and open spaces help ensure the safety and protection of children and provide peace of mind for caregivers. Security of building entrances is enhanced when they are clearly visible and well-lit. Clear lines of sight and good lighting along access routes, roads, and pathways enable social control and foster security and safety.

Safety on public transport has gained attention in recent years. A survey in Baku, Azerbaijan, for example, found that $81 \%$ of female public transport users had experienced harassment, yet almost all had not reported the 


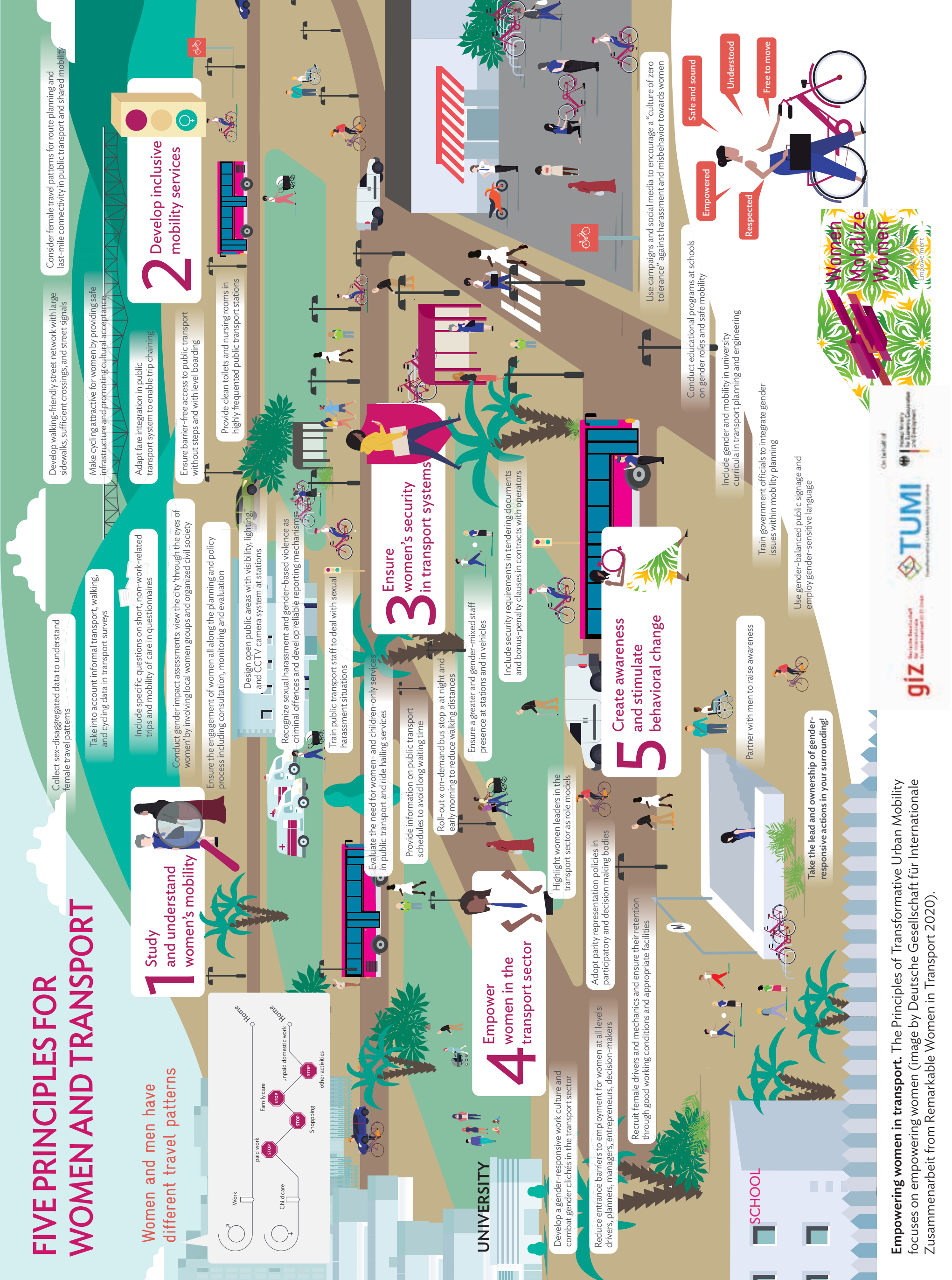


incident (ADB 2015). Around 80\% of those harassed were 18- to 30-year-old women. Of those that had been harassed, $30 \%$ said they had decreased their use of the metro and regard it now as a last option.

Harassment is not only a major concern in terms of individual safety and security, but it also carries financial costs to the transport service providers if women, who in general are more likely than men to use public transport, start to reduce their patronage as a result of feeling unsafe. Some cities, such as Delhi, Manila, and Mexico, have introduced women-only carriages in their metro systems to foster safety for women riders. Other cities have introduced different gender-friendly safety measures, such as "pink taxis" for women, as well as increased the number of women employed in the public transport sector.

Digital technologies can also be used to help make cities safer for women. Safety measures built into ride-sharing apps can promote safety for female passengers and attract more female drivers. The Safetipin app has been developed and is now used in a number of cities to map out safe routes for women through cities and collect safety-related information and make it publicly available.

In Kolkata, a social vulnerability audit of public spaces is being conducted through the Safetipin app to evaluate public spaces to make them more inclusive and improve the city's overall livability. This app, which enables assessments of perceptions of urban safety in public spaces by women, makes communities and cities safer by providing safety-related information collected by users and trained auditors. The audit is based on parameters including lighting, openness, visibility, crowds, security, walk path, availability of public transport, gender diversity, and feeling (Susantono 2020).

Another example from Armenia is the Safe YOU Mobile App which allows users to seek help during emergency situations by sending free alert messages with the user's geolocation to previously chosen personal contacts, women's support nongovernment organizations, state authorities, or the police. It also offers forums for anonymous peer-to-peer discussions within the community and consultations with vetted professionals, such as doctors, lawyers, and psychologists (Torosyon 2020).

\section{Case Study: Spatial Planning to Ensure Gender-Responsive Targeting of Services and Resources in Bandung}

The principles of the framework described in Figure 1 were used in Bandung, Indonesia to pilot the application of available sex-disaggregated data in a spatial mapping system and identify where resources should be targeted to address specific gender-related problems.

Bandung is the capital city of West Java province. The city has experienced rapid development and urbanization in recent years. It is divided into 30 districts and 153 villages and has become known as a "smart city" with its use of technology. To implement a 2000 Presidential Instruction to mainstream gender in local planning, the Bandung City mayor had formed a working group that was tasked to mainstream gender issues in the city. ${ }^{5}$ However, progress was slow due to lack of awareness of gender mainstreaming and what it meant, or knowledge about how to implement this decree. With the policy framework in place, municipality staff were keen to look for ways to enhance progress. The first step was to identify data sets that could be input into a geographic information

5 Mayor's Decision No. 260/Kep.454-DP3APM/2017 on Gender Mainstreaming Working Group and No. 260/Kep.455-DP3APM/2017 on Focal Point of Gender Mainstreaming in City Departments Planning. 


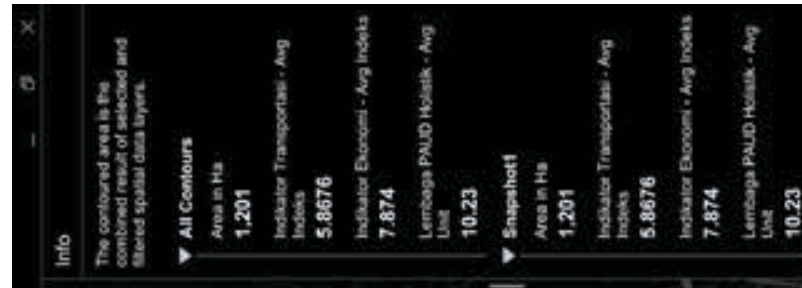

$+1000$
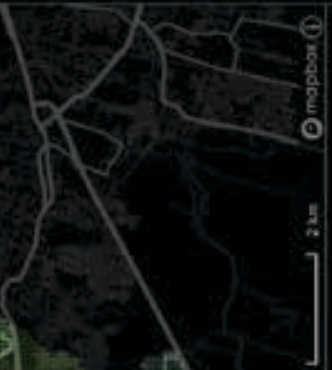

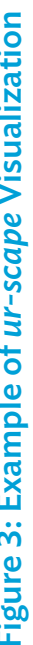

$\frac{2}{8}$

(6)

3.

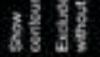

○日

(ख)
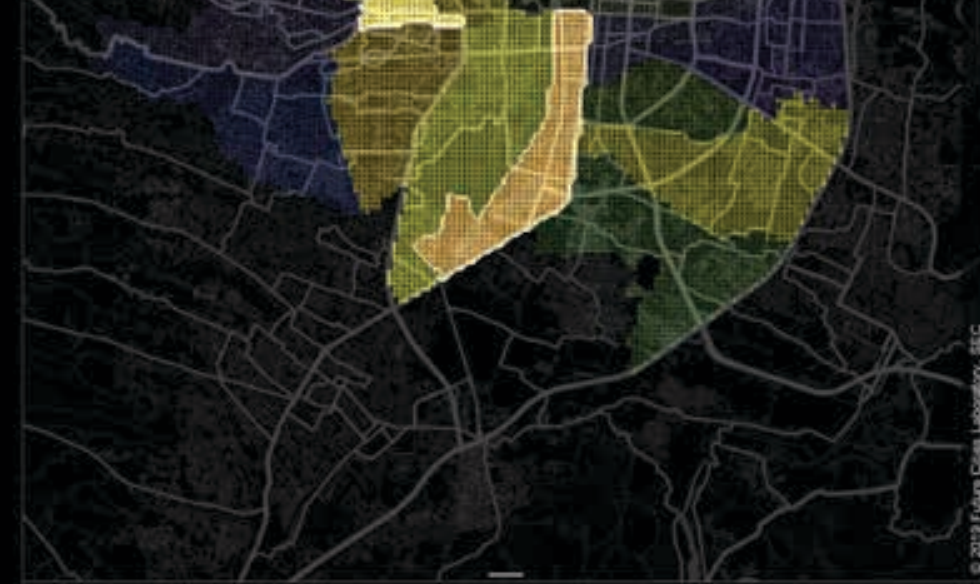

III

8

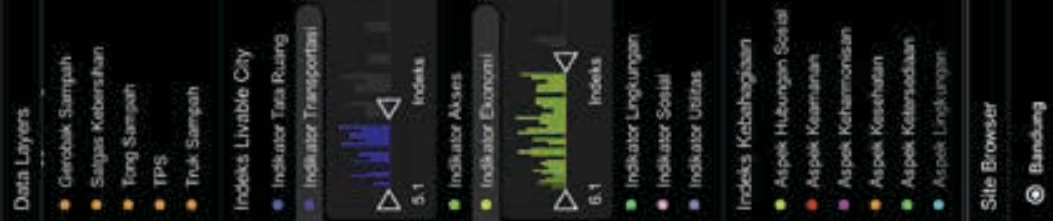

(-)

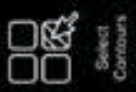
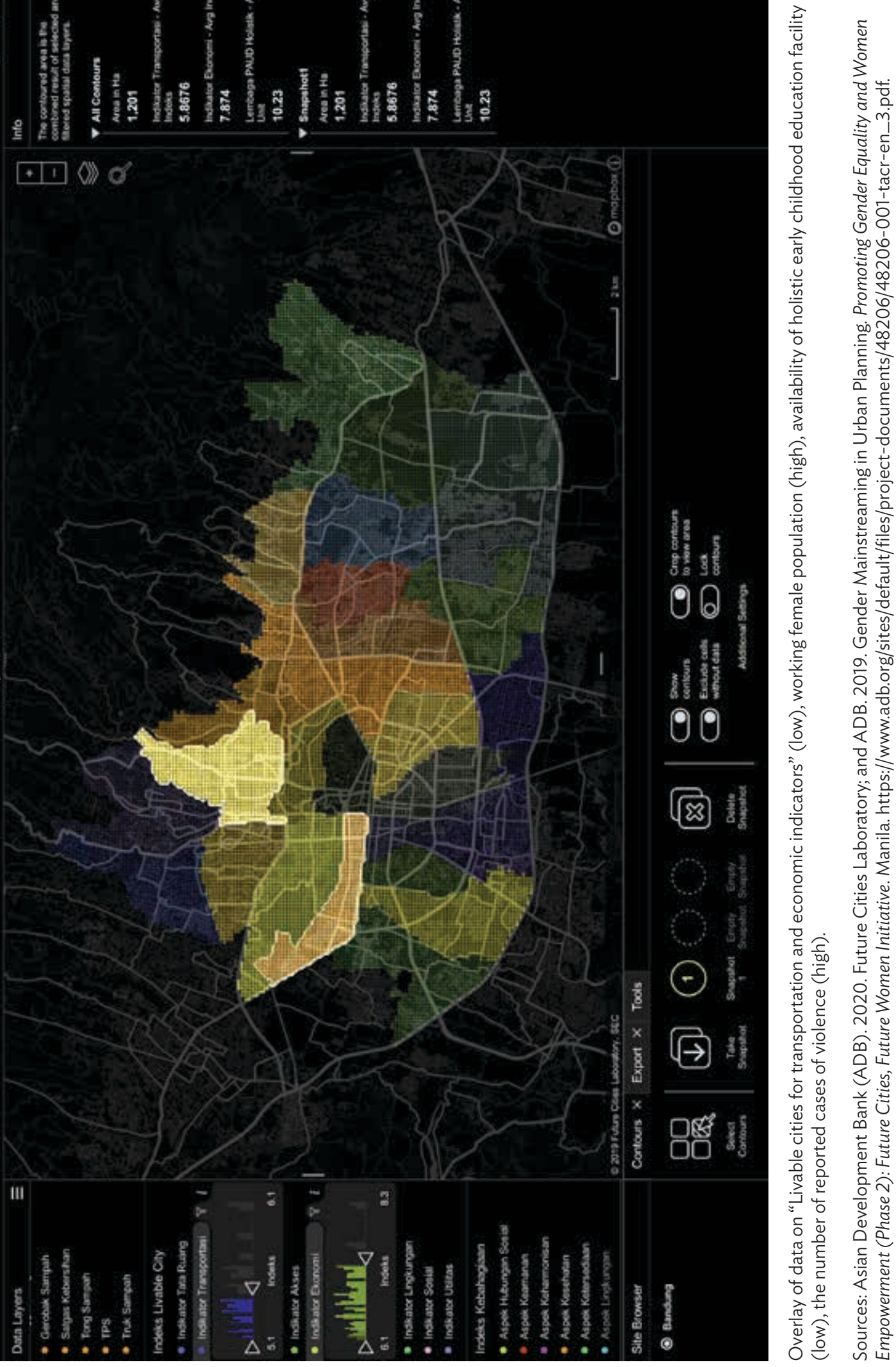
system (GIS) called ur-scape. ${ }^{6}$ The team drew together staff from a number of different agencies in the city. During their discussions, they identified several sex-disaggregated data sets that were collected at a local level and could be used for spatial mapping, including those relating to demographic profiles, land use allocation, distribution of government benefits, infrastructure, public facilities, health, and public safety.

Data could be effectively used by being aware of the types of problems that groups of women and girls face. Hence, developers had arranged meetings with civil society organizations working at the local level and with first-hand experience of some of the gender issues. The real-life experiences and challenges were developed into case studies to form the basis of pilot analyses. These case studies were used to develop scenarios that could be analyzed in ur-scape to visualize where specific interventions would be most effective.

An example scenario was the identification of areas in Bandung that were in need of basic services improvement to enable women to realize their multiple roles and have better mobility (Figure 3). Another scenario involved identification of areas where the elderly might need additional health services.

An overlay of data was performed on "Livable cities for transportation and economic indicators" (low), working female population (high), availability of holistic early childhood education facilities (low), and the number of reported cases of violence (high). The analysis showed two districts as the most vulnerable, where the city government can focus on improving mobility to support women with multiple roles.

Two implications for urban planning have surfaced from this analysis. First, increasing the number of early childhood education facilities in those districts may allow women to lessen the length of their daily commute if there were such facilities closer to their homes. Second, improving the quality, reachability, and availability of public transportation at the district level may improve the travel experience of women living in those areas and provide a sense of security for them by not having to walk far to reach the nearest available bus station.

The real value of the analysis so far has been to demonstrate the effectiveness of presenting data visually and open the door to the possibilities of using this analysis as a regular part of the planning process. The scenario presentations have been used in training and have raised awareness of the intersectional nature of gender issues in Bandung.

\section{Conclusions}

There is a strong rationale for mainstreaming gender in urban planning. It promotes gender equality and addresses gender-related issues that limit women's potential to contribute to the economic, social, and political development of cities. However, there has been a slow progress in developing the tools and approaches for mainstreaming gender. A framework such as PALMS can be useful in organizing problem identification and analysis.

A top priority is the participation and leadership of women at all levels of planning, implementation, and service delivery. Having more women in decision-making positions will likely result in more inclusive and responsive planning and service delivery. Although online and digital technologies are providing ways to engage more with

6 The Urban-Rural Systems research group at the Future Cities Laboratory at the Singapore-ETH Centre developed the GIS-based data visualization and planning tool. Further functionalities were developed for ur-scape in the context of the Bandung Smart Systems project (under ADB's technical assistance project Establishing the Future Cities Program in the Asia and Pacific region). 
the public in planning, feedback, and monitoring, digital gender gaps and lack of gender considerations in design could still act as barriers to women's participation.

Data are an essential input for gender analysis and can provide evidence to guide prioritization and targeting. New sources of data collected using mobile phones, apps, location tracking, and global positioning system (GPS) can be extremely valuable, provided the data are sex-disaggregated and comply with privacy considerations. They could be game changers in helping to understand the complex interrelationships between gendered time use, mobility, and access to services and economic opportunity.

As new technologies are developed for smart cities, continued effort is needed to explore the potential for smart technologies in promoting gender equality and inclusivity in urban areas. The possibilities are endless and the potential impacts on individuals, families, and whole cities are significant.

\section{References}

Asian Development Bank (ADB). 2015. Policy Brief: A Safe Public Transportation Environment for Women and Girls. Manila. https://www.adb.org/publications/policy-brief-safe-public-transportation-environment-women-and-girls.

- - 2017. Institutionalizing Gender Equality: Urban Development Experience of the Bangladesh Local Government Engineering Department. https://www.adb.org/sites/default/files/publication/360356/institutionalizing-genderequality-bangladesh.pdf.

-_- 2019. Fair-Shared, Inclusive and Gender Responsive Cities: Tbilisi Case Study. https://www.adb.org/sites/ default/files/project-documents/48206/48206-001-tacr-en_3.pdf.

- - 2019. Promoting Gender Equality and Women's Empowerment (Phase 2) -Future Cities, Future Women Initiative. Consultant's report. Manila. (TA 8787-REG). https://www.adb.org/sites/default/files/projectdocuments/48206/48206-001-tacr-en_3.pdf.

- - 2020. Enhancing Women Focused Investments in Climate and Disaster Resilience. https://www.adb.org/ publications/women-focused-climate-disaster-resilience.

GSMA. 2019. The Mobile Gender Gap in Asia Report: A Region of Rapid but Unequal Growth. https://www.gsma.com/ mobilefordevelopment/blog/the-mobile-gender-gap-in-asia-a-region-of-rapid-but-unequal-growth/.

Pozarny, P. 2016. Gender Roles and Opportunities for Women in Urban Environments. GSDRC Helpdesk Research Report No. 1137. Birmingham, United Kingdom. www.gsdrc.org.

Susantono, B. 2020. Leveling the Playing Field: Can Digital Technologies Address Inequity in Cities? Asian Development Blog. https://blogs.adb.org/blog/leveling-playing-field-can-digital-technologies-address-inequitycities.

Transformative Urban Mobility Initiative. 2020. Remarkable Women in Transport 2020: Female Change-Makers Transforming Mobility. https://womenmobilize.org/wp-content/uploads/2020/03/RemarkableWomen_ DINA4_2020.pdf. 
Torosyon, M. 2020. Safe YOU App: Armenian Women Use Technology to Tackle Gender-Based Violence Innovation. World Bank Blog. https://blogs.worldbank.org/europeandcentralasia/safe-you-app-armenian-womenuse-technology-tackle-gender-basedviolence?from=DigestNotification\&e=oHgz9z8FxkqlwcwbFvF_4g\&at=9.

UN Framework Convention on Climate Change (UNFCC). 2019. Gender Composition. Report by the Secretariat. https://unfccc.int/documents/200110.

UN Women Watch. Women, Gender Equality and Climate Change (derived from various resources). https://www.un.org/womenwatch/feature/climate_change/.

\section{Further Readings}

ADB. 2006. Gender, Law, and Policy in ADB Operations: A Tool Kit. https://www.adb.org/documents/gender-lawand-policy-adb-operations-tool-kit.

- In line with ADB's Policy on Gender and Development, it is important for ADB staff and consultants to recognize the gender implications of their work on law and policy reforms. The Gender, Law, and Policy (GLP) tool kit helps analyze GLP issues in proposed ADB projects. It is particularly useful in designing program and sector development loans, where law and policy reforms play a prominent role. Aside from sectors for which sectoral gender checklists have not yet been prepared, the GLP tool kit also covers the country partnership strategy process and capacity development.

ADB. 2009. Briefing Note: Project Gender Actions Plans-Lessons for Achieving Gender Equality and Poverty Reduction Results. https:/www.adb.org/sites/default/files/publication/29008/gender-briefing-note.pdf.

- This briefing note summarizes the evidences on effective approaches used by ADB to achieve benefits for women and progress toward gender equality. The findings are based on gender assessments of 12 loans in Bangladesh, Cambodia, Nepal, and Pakistan. In particular, these are five rural development loans (agriculture, rural infrastructure, and livestock), four human development and/or social sector loans (two health and two education), and three governance loans.

ADB. 2012. Good Practices in Urban Water Management. https://www.adb.org/sites/default/files/publication/29888/ good-practices-urban-water-management.pdf.

- This report presents case studies on successful Asian water utilities. The case studies provide objective, accurate, and critical analyses of urban water management practices in eight Asian cities over a 10-year period. Other local leaders throughout the developing world can use these cases to help craft their own solutions, taking into account specific local circumstances.

ADB. 2012. The Urban Governance and Infrastructure Improvement Project in Bangladesh. https://www.adb.org/ publications/urban-governance-and-infrastructure-improvement-project-bangladesh-sharing-knowledge.

- This booklet presents the project's key features and impact on pourashavas and on the lives of ordinary people. It discusses how the performance-based fund allocation strategy has proven to be effective in improving the pourashavas' capacity for service delivery, increasing citizen participation especially women, and inspiring the Government of Bangladesh and development partners to join ADB in replicating the approach.

ADB. 2013. Gender-Inclusive Approaches in Urban Development: Tip Sheet. https://www.adb.org/sites/default/files/ institutional-document/34136/files/tip-sheet-gender-inclusive-urban-development.pdf.

- This tip sheet is a quick reference guide for staff and consultants of ADB in conceptualizing and designing gender projects. It describes how to integrate gender issues in urban development planning projects. 
ADB. 2013. Gender and Urban Poverty in South Asia: Proceedings Report of the 2012 Subregional Workshop. https://www.adb.org/sites/default/files/publication/30099/gender-urban-poverty-south-asia.pdf.

- This report presents a synthesis of knowledge, experiences, good practices, and recommendations shared at the forum. The workshop aims to assist ADB and its partner agencies in planning urban development projects to facilitate gender- and socially inclusive outcomes and reduce poverty in South Asia.

ADB. 2015. Balancing the Burden? Desk Review of Women's Time Poverty and Infrastructure in Asia and the Pacific. https://www.adb.org/sites/default/files/publication/177465/sdcc-balancing-burden.pdf.

- This desk review explores the links between infrastructure development and women's time poverty in Asia and the Pacific by drawing on time-use data and reviewing existing research and evidence from impact evaluations. It finds that basic infrastructure has the potential to reduce the time spent on housework and care work and influence the gender division of labor.

ADB. 2015. Gender Equality Results Case Study, Bangladesh: Second Urban Primary Health Care Project. https://www.adb.org/sites/default/files/publication/160723/gender-equality-ban-primary-health-care.pdf.

- This case study shows how the project provided preventative and curative services, including access to immunization, reproductive health services, limited curative care, nutrition-related services, community outreach on health issues, and assistance for women survivors of violence. In project areas, there were significant improvements in key indicators, including under-5 mortality, maternal mortality, total fertility, child malnutrition, and control of sexually transmitted infections.

ADB. 2015. Gender Mainstreaming Case Study, Sri Lanka: North East Coastal Community Development Project and Tsunami-Affected Areas Rebuilding Project. https://www.adb.org/sites/default/files/publication/175341/genderequality-sri-tsunami-affected-areas.pdf.

- This case study looks at the gender dimensions of two projects focusing on the community development component that advocates community participation, social inclusion, and gender equality in community infrastructure development, and livelihood restoration processes in targeted communities.

ADB. 2015. Philippines: Strengthened Impacts of Social Protection. Consultant's report. Manila (TA 7587-PHI). https://www.adb.org/sites/default/files/project-document/161814/43407-013-tacr-02.pdf.

- This report highlights the importance of considering the needs of all members of the household, and not just those of children, are met. The needs of women who comprise the great majority of grantees are particularly important considering that successful achievement of the program's conditionalities rests on their efforts.

ADB. 2016. Mainstreaming Gender Into Climate Mitigation Activities. https://www.adb.org/sites/default/files/ publication/217771/gender-climate-mitigation.pdf.

- This publication seeks to equip policy makers with pragmatic advice on how to mainstream gender into climate change mitigation actions and funding proposals. It reflects on applications for guidelines as well as on the relationships between climate planning and funding proposals.

ADB. 2016. Vision for Gender Equality in Asia and the Pacific by 2030: Possible Future Directions for Asian Development Bank's Gender Work. https://www.adb.org/sites/default/files/institutional-document/323951/adbbgpaper-gender-2030.pdf.

- This paper explores the gender dimensions of some of the major trends and challenges facing Asia and the Pacific region. It has identified key gender-related priorities for countries in the region and possible future directions for ADB's gender work under Strategy 2030. 
ADB. 2017. Tapping the Unreached-Nepal Small Towns Water Supply and Sanitation Sector Projects: A Sustainable Model of Service Delivery. https://www.adb.org/documents/nepal-water-supply-sanitation-services.

- This booklet presents how ADB, the government, and the local communities effectively work together to reach their goal of providing clean water $24 / 7$ and sanitation to more than 1.24 million people in 69 urban centers by 2021.

ADB. 2019. India Gender Equality Results Case Study: Infrastructure Development Investment Program for Tourism in Himachal Pradesh and Punjab. https://www.adb.org/sites/default/files/publication/496446/india-gender-casestudy-infrastructure-tourism.pdf.

- This case study examines the gender aspects of the Infrastructure Development Investment Program for Tourism in Himachal Pradesh and Punjab. It also discusses the program results in three areas: human capital and economic empowerment, creation of spaces for women's voices to be heard, and promotion of equal rights. The case study affirms that a gender-inclusive design, coupled with effective implementation, gives women and men equal access to project benefits.

ADB. 2019. Operational Priority 2: Accelerating Progress in Gender Equality. https:/www.adb.org/sites/default/files/ institutional-document/495956/strategy-2030-op2-gender-equality.pdf.

- This operational priority recognizes that gender equality is critical in its own right as well as for helping realize socioeconomic development. It is imperative that ADB contributes to the efforts of accelerating gender equality outcomes in the region in five areas: (i) economic empowerment, (ii) human development, (iii) decision-making and leadership, (iv) time poverty reduction, and (v) resilience to external shocks. ADB is committed to support gender equality through gender-inclusive project designs in at least $75 \%$ of its sovereign and nonsovereign operations by 2030. 


\section{Urban Synergies Through Coordinated City Cluster Governance}

Stefan Rau

\section{Introduction and Key Messages}

Megaregions, also referred to as mega-urban regions, megacity clusters, or city clusters, have emerged around the world, and they continue to gain strength as economic magnets (Ross 2009). ${ }^{1}$ They are clustered cities with urban, suburban, and peri-urban areas in between that have been growing together across local administrative boundaries, even across national boundaries, and they are growing rapidly. Some of these urban regions are as large as nations by population, territory, and economic output. Together, megaregions and economic urban corridors accommodate more and more people and start to divide the world into high-speed and slow-speed territories - the high-performing connected city clusters on one side, while the slower, more rural and natural territories less connected and more remote on the other (Groff and Rau 2019). ${ }^{2}$

The world's 29 largest megaregions generate about one-third of the global gross domestic product (GDP) with less than $10 \%$ of the world's population (Florida 2019). In these places, more than two-thirds of innovation is produced as measured by number of patents and scientific citations (Florida et al. 2007). These city clusters are increasingly linked with each other with economic product chain relationships, as labor markets, and through connectivity, data, energy and water infrastructure. With continued urbanization, megaregions are increasingly expanding and strengthening connectivity between each other and can form even larger-scale economic corridors. Not only do they generate much of the respective countries' GDP, but they also contribute to most ecosystem loss, environmental pollution, and greenhouse gas emissions.

Megaregions continue to grow and attract people, companies, institutions, and development in developed, emerging, and developing economies (Harrison and Hoyler. 2015). In Europe, the urban corridor between Manchester, London, Paris, Netherlands, Central and Southern Germany, to Northern Italy anchored by metropolitan Milan, has a population of about 110 million and is referred to as "Blue Banana." The Tokyo-Nagoya-Osaka-Fukuoka corridor in Japan, for example, with a population of more than 70 million along 1,200 kilometers, is also referred to as Taiheio Belt or Tokaido Megalopolis. The corridor is connected by the Shinkansen high-speed train and is generating about $80 \%$ of the country's economic output. The northeast in the United States (US) from Boston to Washington has a population of about 50 million people and a GDP of $\$ 3.6$ trillion (Florida 2019).

Megaregion definitions vary. Some are based on administrative boundaries. Most international researchers are converging on agreed methods of using night time light imagery identifying contiguous built-up areas, combined with local-level detailed population data, commuting relationships (used to define functional urban areas), road and infrastructure network density, and economic output.

2 Parts of this article have been published in: S. Groff and S. Rau. 2019. China's City Clusters: Pioneering Future Mega-Urban Governance. American Affairs Journal. 20 May 2019. Some other parts are included in: S. Rau. 2021. Bridge to Future Livable and Green Cities and City Clusters in the People's Republic of China. Policy Opportunities for High-Quality Urban Development. Manila. Research contributions on data for city clusters in the People's Republic of China (PRC) are from, among others, Jianming Cai, Douglas Webster, Li Jianyi, and Han Yan. Mats Andersson contributed with peer review of this article. 
Of the largest 28 megaregions in developing Asia with more than 10 million people in 2016, eight are in the People's Republic of China (PRC), seven in India, three in Indonesia, and two each in the Republic of Korea and Viet Nam. Nineteen of these 28 clusters cut across at least two higher-level administrative boundaries like provinces (ADB 2019a, Map 1). ${ }^{3}$ In the PRC, mega-urban regions are referred to as city clusters. Some of them are as large as European countries both by population and territories, most notably the three coastal megaregions, namely Beijing-Tianjin-Hebei, the Yangtze River Delta (YRD), and the Pearl River Delta (PRD), which are defined by administrative boundaries. ${ }^{4}$ The YRD is the largest in Asia (also see Map 2 of Chapter 1 , Article 1C).

The YRD, anchored by Shanghai in the PRC, is the largest cluster, with more than 90 million people, including 53 natural cities across four province-level areas (ADB 2019a). Plans for 19 clusters in the PRC have been completed and coordination mechanisms have been initiated and, in some cases, even institutionalized since 2016. In India, the National Capital Region around Delhi, with a population of more than 46 million reaching across several states, established formal coordination in 1985. Extension is being planned adding eight districts in three states with more than 22 million people.

Across the world, city clusters are increasingly being connected on a larger scale and are promoted by various policies and investment programs. For example, ADB supports regional cooperation along several economic corridors across Asia and the Pacific region. ${ }^{5}$ Several national governments have their own programs. India supports coordinated development for 11 economic corridors linking megaregions, and the PRC engages international partners on the Belt and Road Initiative to connect continents.

Despite their massive economic output, mega-urban regions are far from being efficient as they are fragmented by administrative boundaries. They typically have weak or non-existing cluster-wide physical and institutional systems. In most cases, they have no institutional representation across the jurisdictions and no governance mechanisms that enable coordination on economic clustering, land use, transport and infrastructure planning, and environmental protection planning and management. Within these urban regions, the neighboring cities and counties are competing for residents, investments, companies, and institutions with high-paying jobs. This promotes further inefficient, sprawling carbon-extensive development.

On a smaller scale, there are many examples for coordination. Cities have their own administrations and governance systems. However, more cross-sector integration would be needed to address contemporary challenges like livability, climate change, environmental protection, natural resource management, and inclusive and sustainable urban development. On the metropolitan scale, many examples for coordinated governance, planning, and management across local administrative boundaries exist, and they offer lessons that may be applied to the megaregion scale (Andersson 2016).

3 The authors follow other recent research and efforts to unify the definition of "urban" and "city" applying the concept of "natural city" through contiguous urban areas. They use night time light intensity remote sensing data and population and road infrastructure density data to define and compare natural cities and city clusters across Asia and the Pacific region (ADB 2019a).

4 Currently, the city clusters in the PRC, as drawn by the government, are found to be too large. Some don't make it into the category of megaregion, according to international researchers, because they do not meet some of the nightime light data, population and infrastructure density, and economic output criteria. City clusters in the PRC also serve as avenues for policy programs using coordination among local governments to achieve higher efficiencies and economic, social, and low-carbon development, and enhanced environmental protection and climate resilience.

5 ADB has been supporting the Greater Mekong Subregion (GMS) and the Central Asia Regional Economic Cooperation (CAREC). See section on "Economic Corridors in Asia: Linking City Clusters to Integrate the Region." 


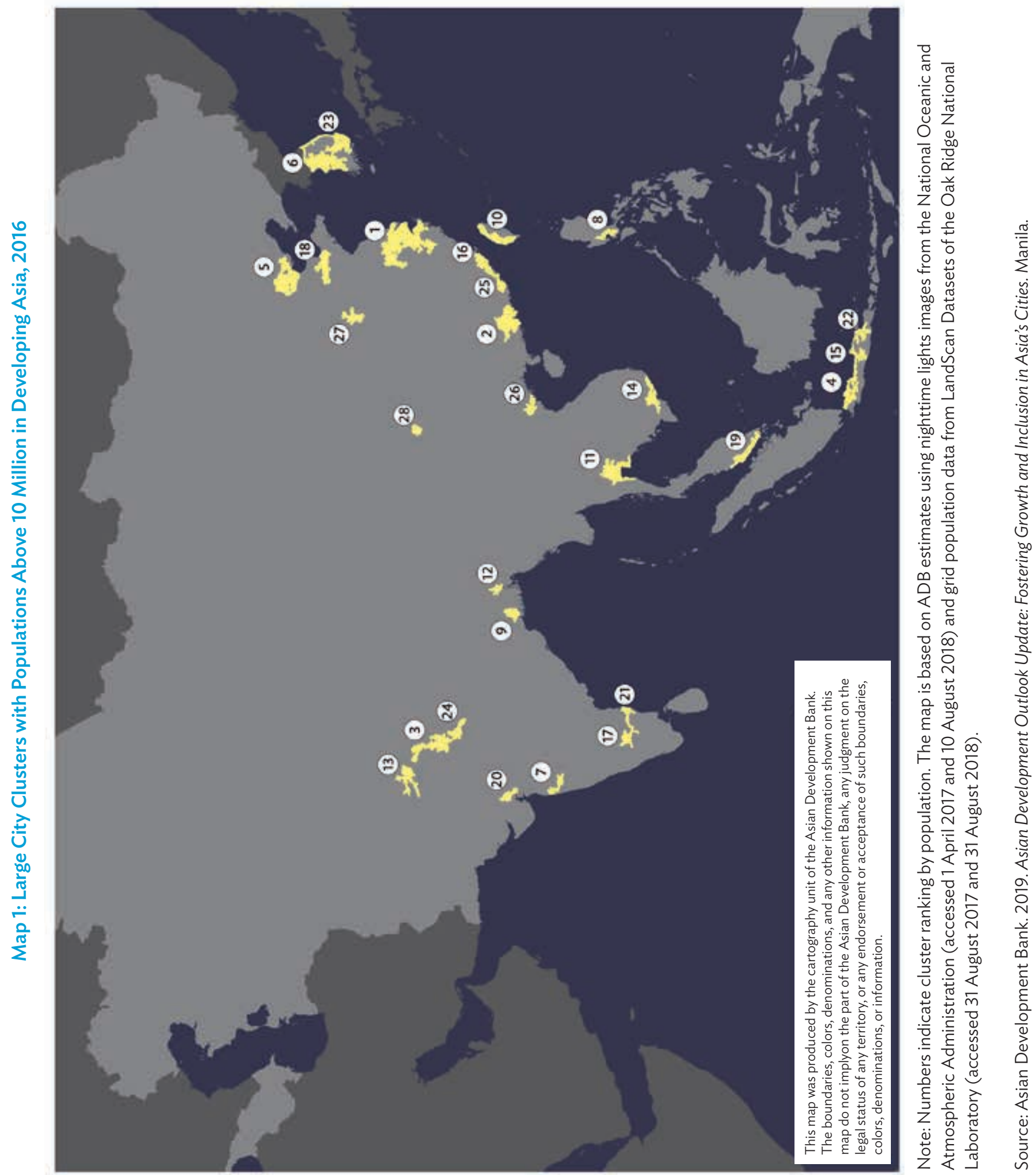


Coordination mechanisms are also in place to jointly manage single issues like airports, high-speed rail, or natural resources like water. For example, in the US, Special Districts are used as a platform to coordinate such focused areas of activities across local jurisdictions. On an even larger scale than megaregion, there are initiatives to promote regional cooperation and integration through economic corridors that connect various city clusters across large areas. These initiatives are sometimes supported by national industrial and economic development policies and infrastructure programs, and sometimes across national boundaries.

As there are still only a few examples of initial coordination on the megaregion city cluster scale, and as this is only starting, there is a lot of room for more comprehensive and closer cooperation and coordination. There is a great opportunity for institutionalizing cooperation and enabling subnational joint governance, which could create synergies for the city cluster region and a whole range of mutual benefits for the individual cities within it. They would benefit from integrated labor markets, increased productivity, improved connectivity and public transport, enhanced economic cluster and product chain links, shared investments in high-level facilities like exhibition centers, universities and research and development, connected functioning ecosystems and farmland protection forming attractive regional park systems, regional tourism development, as well as management and operation of regional transport and other affairs.

The urban-rural divide has been an increasing challenge to equitable and sustainable development all around the world. Institutionalized governance and economic cooperation at the city cluster level can benefit citizens, particularly the rural people, through increased productivity and competitiveness. To succeed, significant infrastructure investments at city cluster or even at national level might be needed, but also development coordination in a whole range of other policy areas.

Considering the further developments of city clusters and connected clusters as economic corridors, there is an urgent need to consider and design for the two speeds of human geography. Territories within city clusters at high speed of development and activities need to be strengthened to improve productivity, innovation, connectivity, and living conditions, including urban-rural linkages (physical, institutional, and socioeconomic) within the clusters. On the other hand, territories that are outside the city clusters and are developing and moving at slower speeds need a vision and definition for a different model of development. For example, the model can be based on environmental protection and high-quality ecological resource and ecosystems service delivery, like national parks. Both types of territories need to be strengthened and planned together. They should be mutually beneficial, and should be supporting, servicing, and reinforcing each other (Groff and Rau 2019).

The next section discusses some of the key challenges to coordination and provides a range of areas where coordination within city clusters can create benefits. The third section presents the case of city cluster coordination on a megaregion scale in the PRC, which is ambitious and can be considered a pioneer, having completed significant activities since 2016.

The fourth section of this article shares lessons from Organisation for Economic Co-operation and Development (OECD) countries with megaregion coordination initiatives. This section also presents lessons from metropolitan governance, single-issue coordination vehicles like Special Districts, and environmental management coordination in the form of payment for ecosystem services-which can be starting points for a more comprehensive coordination.

The fifth section highlights cooperation and coordination efforts in an even larger scale of linked city clusters within regional economic corridors in Asia, as these are increasingly defining territorial advantages and disadvantages. The last section concludes with opportunities for city cluster governance and a scenario for formalizing a territorial system of two speeds that would be mutually benefiting each other. 


\section{Challenges and Benefits of Coordination within City Clusters}

Fragmentation is a key challenge. Fragmentation of functional urban regions by many local administrative boundaries is what most experts found as a key issue that hinders more efficient and mutually beneficial development of territories and their cities, communities, and people. The most outstanding may be the fragmentation of labor markets due to physical infrastructural and institutional impediments such as limited connectivity of public transport and roads, and lack of portability of social protection systems (Bertaud 2016). Tax systems and school districts are other institutional forms where fragmentation is hindering the creation of benefits for local communities. Public transport networks sometimes end at local boundaries, and regional commuter rail is absent.

Other network and service infrastructure like electricity grids, water and wastewater management, and solid waste management are typically also limited by administrative boundaries. Economic and industry clustering is mostly self-organized by private sector product and supply chains as opposed to being facilitated and enabled across an urban region. Challenges to environmental protection and continuing ecosystem fragmentation from sprawling urban development are increasing. These challenges are serious and need to be addressed through coordination of governance for analysis; research and mapping; spatial planning and policy design; and joint finance, implementation, and operation and maintenance.

Benefits from coordination across local administrative boundaries. Effective city cluster governance and institutional development on the megaregion city cluster scale would bring a whole range of benefits. They can further economic development and urban-rural integration, thereby improving access to jobs, education, and health services. Urban culture and commerce can reach more rural residents, who can easier offer as rural products and rural ecosystems services can provide for urban residents and areas within clusters through improved physical links and institutional arrangements.

An important benefit would be improved connectivity, and social protection system reform could enable an integrated labor market, while reducing the time needed for daily commutes. Further, integration of economic clusters and regions could enhance competitive advantage through more specialized spatial development. ${ }^{6}$ City clusters have a broader economic base, yet can still market themselves with a cluster-scale, place-branding campaign to attract businesses and tourists. The coordination of connectivity, transport networks, and public transport as well as linking rural places to the fiber-optic network could contribute to better urban-rural integration and benefit rural residents. Innovative last-mile services would also help connect rural homes and villages.

$6 \quad$ K. Choe. and B. Roberts. 2008. Competitive Cities in the 21st Century: Cluster-Based Local Economic Development. Manila: Asian Development Bank. This book compiles theories on economic geography, agglomeration economy, and clustering. It offers a practical guide for cluster development and presents country cases from Bangladesh, India, and Sri Lanka. A key finding is: "Under the new model of economic development, competitive advantage results from the capacity of cities, businesses, and governments to be flexible and to improve on technologies, methodologies, products, market segments, operating strategies, and policies. The city becomes a platform for a global strategy, a place where the activities of most companies will take place. Economic development planners must therefore identify the activities that will give their city an advantageous niche, no matter how small, in the future." The authors use Michael Porter's diamond model of national competitiveness (1990) as cluster development strategy principles. Six drivers of doing business are identified as: cost of doing business, dynamics of the local economy, human resources and endowed resources, infrastructure, responsiveness of local government to business needs, and quality of life. 
Coordination of land use and transport planning could lead to more land use efficiency through more demandbased planning of residential, industrial, commercial, and institutional land. There would be less sprawl and a lesser likelihood of providing an excess of developable land by otherwise competing jurisdictions. City clusters will thus be more sustainable, livable, inclusive, and competitive. Larger, medium-sized, and smaller cities (and even towns) could be increasingly linked by intercity commuter rail transit. Meanwhile, at the micro level, compact, walkable mixed-use development could be encouraged, with an emphasis on transit-oriented development around existing and new public transit and/or regional rail stations.

Coordinated green open space planning, and environmental protection in the form of linked open space systems, could be planned and implemented. This may include parks, farmland, forests, river estuaries, and wetlands. More functioning and connected ecosystems can generate many cross-benefits from the various ecosystem services they provide. These services include habitat networks for biodiversity, recreation, agricultural production, nonmotorized transportation, as well as management of pollution and flood risk. The open space system could link ecosystems services and rural services to urban areas, and promote climate change resilience as well as agricultural production and distribution. Such services will include local recreation and improve livability.

Another benefit will come from optimizing environmental and economic sustainability. Coordination within a cluster should also contribute to a green circular economy with local product and production lifecycle considerations. This will involve balancing between centralized and decentralized local supply chains and promoting a system of reuse and recycle across economic activities and sectors, and across public and private sectors. Decentralization of services and facilities may also be beneficial (i.e., infrastructure systems and services like water and sanitation service clusters, renewable energy generation, and smart grids). The decentralized systems will benefit from a cluster-wide coordination that will ensure cluster-wide supply security by managing temporary oversupply and undersupply situations across the local systems within a region.

Mechanisms and institutionalization for megaregion governance are slowly developing, along with regulatory frameworks and technology. But the question why coordination is not happening enough, despite its many potential benefits, has no easy answer and also depends on country context. Megaregions are a fairly new phenomenon. Effective infrastructure and communication systems enabling connectivity and mobility of the workforce within these larger urban territories have only been emerging more recently. Coordination across local jurisdictions seems to happen when higher level governments request this. Such instance is seen in Germany, Japan, and the US for metropolitan governance; in the PRC for city cluster coordination to further promote urbanization and industrialization, and in India for industrial corridors to promote economic development.

It seems that certain triggers are needed to drive governance coordination. Such trigger might be an economic crisis like the downturn in the automotive sector in Sao Paolo, Brazil which prompted cooperation on economic development across local boundaries. It could also be a response to a natural disaster like an earthquake in San Salvador in El Salvador, which triggered the formation of a metropolitan agency for a large area. The coronavirus disease (COVID-19) pandemic, on the other hand, has prompted various clusters in the US to coordinate their response measures. The case of severe air pollution in the BTH Cluster in the PRC triggered coordination in the cluster, as described in the next section. Sometimes governance coordination is driven by the conviction of individuals acting as "champions" of cooperation with neighboring administrations. 


\section{Coordination of City Clusters on a Megaregion Scale in the People's Republic of China}

\section{City Clusters in the Context of Recent Urbanization and National Planning}

Urbanization and industrialization have been at the heart of the PRC's rapid economic development since the launching of the "Reform and Opening Up" policies in 1978. Around 850 million people were lifted out of poverty, and the urbanization ratio changed from $19.0 \%$ to $60.6 \%$ between 1978 and the beginning of 2020. During this period, megacities and megaregions emerged.

City clusters have been part of the PRC's urbanization strategy, at least since the PRC's National Urban System Plan in 2006. The PRC's National New-Type Urbanization Plan (2014-2020) and its Thirteenth Five-Year Plan (13th FYP) involved 19 city clusters for enhanced coordination with a mandate to complete cluster-wide plans and initiate institutional coordination mechanisms before the year 2020 (Government of the PRC, State Council 2014 and 2015). These clusters have already become population magnets, and account for more than $90 \%$ of the national GDP. However, it is important to consider the way cluster boundary lines are drawn using administrative boundaries. These also include large land areas with megacities, cities, and urban areas of various sizes, and large rural hinterlands.

Beijing-Tianjin-Hebei (BTH) has about 110 million residents, including all of Hebei (by administrative boundary), and generates about 10\% of the national GDP. Shanghai and the YRD Agglomeration, with a total population of about 152 million (by administrative boundary), is the most productive, generating about 21\% of the PRC's GDP with about $12 \%$ of its people. The newly conceived Greater Bay Area (GBA), including Guangzhou (with the PRD) and also Hong Kong, China and Macau, China, has a total population of about 70 million (by administrative boundary), producing about $12 \%$ of national GDP with about $5 \%$ of its people. It competes internationally in innovation and high technology as a new kind of Silicon Valley. Together, these three most mature clusters are referred to as BeiShangGuang (short for Beijing, Shanghai, and Guangzhou). Other significant clusters include the Chengdu-Chongqing City Cluster (ChengYu) in the upper reaches of the Yangtze River, and the Central Yangtze River City Cluster (CYR) around Wuhan.

The key 13th FYP objectives are to improve the distribution and layout of urban areas and population, as well as of natural and economic resources, by organizing city cluster development along east-west and north-south corridors. To achieve integration and efficient development within city clusters, the plan calls for proper industrial division of labor, coordination of planning and infrastructure, ecological conservation, and environmental improvement. Each city cluster, and the BeiShangGuang above all, seeks to optimize institutional innovation alongside urban-rural integration.

\section{Completion of Coordinated Plans for City Clusters}

All 19 clusters included in the PRC's 13th FYP have completed their respective formal strategy. The strategies include preliminary investment plans beginning 2016 when the 13th FYP implementation started. These plans include short- and medium-term horizons as well as recommendations for spatial structure including hierarchies, roles, and economic profiles of places within clusters. Metropolitan circles and development belts along transport corridors have also been defined. Some plans include growth boundaries, ecological zones, and green belts. 
Plans include a list of investment projects with a clear focus on transport, but some also include energy infrastructure, industrial park projects, and environmental improvement and management projects. The current challenge is that many plans are not fully integrated in the cluster level, and seem to represent the interests of individual cities rather than cluster-wide needs. As city cluster governance institutions strengthen, the plans can be revised from a more assertive city cluster perspective.

\section{Systemic Gap of City Cluster Coordination}

The PRC's achievements of improving cluster linkage have resulted primarily from top-down policies and infrastructure systems (e.g., national high-speed rail networks within clusters) and also from bottom-up governance and investments. However, there is a systemic gap in the PRC between strong national and strong municipal institutions. There is an institutional gap at the subsovereign level on the city cluster scale, which is what the government realized and aims to address through promoting city cluster governance.

Achievements from strong national policies and systems benefiting city clusters include the industrial policies discussed above, as well as a range of spatial development policies like large-scale functional zoning on a national scale. Functional zoning classifies areas ranging from development concentration zones to "green" land conservation (also known as the "environmental red line"). Strong national spatial policies also include urban-rural integration, rural vitalization, and pilots for household registration system (hukou) reform. And national infrastructure investments have significantly improved city cluster connectivity and services.

High-speed rail, highways, waterways, airport and port planning, electricity production and transmission, southto-north water transfer, and other projects have bolstered the city clusters. The high-speed rail network already connects many of the first-, second- and third-tier cities within the city clusters, and enables daily commuting for workers and students between the major centers. The rail network also provides for equally important intermittent economic travel, such as when managers travel to meet suppliers. For example, travel on the Beijing-Tianjin and Guangzhou-Shenzhen lines takes half an hour and it takes just an hour for Shanghai-Nanjing, bringing workers and companies within daily commuting distance.

Achievements from strong local level initiatives benefiting city clusters come primarily from municipal-level policies and infrastructure-including subways and road networks, water supply projects, pilots for hukou reform and social protection systems, urban-rural integration, and rural upgrading pilots that have created benefits across municipal borders. While still at the beginning, a number of accomplishments in pioneering mega urban region governance in the PRC were made, and some were led by national and/or provincial level government agencies.

\section{Coordinated Governance and Institutional Development}

The BTH city cluster has been formally cooperating since 2005. It now has regular high-level meetings and working groups on policies in areas of air pollution reduction and environmental management, industrial relocation, connectivity, and transport (Box 1). Before that, the YRD Council was established in 1992. The council assists in a variety of coordination efforts. Similar efforts are underway in the PRD and its expanded Greater Bay Area (GBA).

International development partners including ADB are supporting the Yangtze River Economic Belt national policy with a $\$ 2$ billion program from 2018 to 2020. The assistance includes projects in urban and urban-rural development, transport, environment, and agriculture and natural resources to be implemented 


\section{Box 1: The Beijing-Tianjin-Hebei City Cluster Coordination}

\section{Air Quality Improvement, Economic Clustering, Regional Rail Planning, Solid Waste Management, and Strengthening of Small Cities}

Cooperation among Beijing, Tianjin, and Hebei dates back to historic times, with Tianjin's role for the region as port city linking to the capital city and be other cities in the region. The overall objective of the Beijing-Tianjin-Hebei (BTH) plan is to intensify the cooperation within and to expand the city cluster coordination to the Bohai Rim region, reduce air pollution, and relocate non-capital functions away from Beijing to other cities and urban-rural areas within the city cluster.

BTH generates about $10 \%$ of the country's gross domestic product. It has a total population of around 42 million, and, if all of Hebei is included, about 110 million. Integration within the region has been promoted, and collective policies on air quality improvement, and improved connectivity implemented. That includes a highway network, high-speed rail from Beijing to Tianjin and from Beijing to Shijiazhuang Hebei's capital, and more planned highspeed rail connections and cross-investments between the administrative areas. The industry cluster of high-end equipment manufacturing, new information technology, and aerospace industry has been strengthened.

The Asian Development Bank (ADB), together with international development partners, has been supporting BTH to improve air quality with technical assistance and loans. ${ }^{a}$ ADB and the Government of the People's Republic of China (PRC) agreed in 2015 to establish a multiyear lending program during 2015-2020 to mutually reinforce government actions for reducing air pollution in the greater BTH region. Since 2015, under the multiyear lending program, ADB has approved about $\$ 2$ billion in loans that have been implemented successfully.

In 2015, ADB approved the first policy-based loan in the PRC under the program, which focused on policy reforms and regulatory capacity strengthening to improve air quality in Hebei Province. In 2016, the second loan was approved to establish a green financing platform for developing air pollution reduction projects in the region by enabling better access to finance. In 2017, the third loan was approved to support the adoption of high-level technologies by major polluting entities across key sectors in the region. In 2018, the fourth loan was approved to help Shandong Province adopt more efficient and advanced technologies for heat production and refrigeration by replacing coal with cleaner energy sources such as natural gas, renewable energy, and waste heat recovery.

In 2019, the fifth loan was approved to accelerate a switch from coal to natural gas and biogas for residential, commercial, and industrial uses to improve air quality in Henan Province. The Air Quality Improvement in the Greater Beijing-Tianjin-Hebei Region-Green Financing Scale up Project, approved in 2020 is the sixth loan under the air quality improvement program."b

ADB's support, amounting to $\$ 2.5$ billion from 2015 to 2020, expects an annual reduction of 5 million tons of carbon dioxide emission, a significant increase in blue sky days, and at the end of 2017, a reduction of fine particulate matter by $25 \%$ compared to 2013.

This support and the orchestrated national and local government action plan and priority triggered a profound transformation-greening of the industry and economy, particularly the public transport-and promoted a clean energy sector and energy efficiency. This can provide lessons for other regions with similar environmental and air pollution challenges.

${ }^{a} \mathrm{ADB}$ is closely coordinating with domestic programs and with the World Bank and other bilateral development partners. ${ }^{b}$ ADB. 2020. Report and Recommendation of the President to the Board of Directors: Proposed Loan to the People's Republic of China: Air Quality Improvement in the Greater Beijing-Tianjin-Hebei Region-Green Financing Scale up Project. Manila.

Source: Asian Development Bank. 
in CYR, ChengYu, urban and urban-rural development, transport, environment, and agriculture and natural resources, with the national government supporting through policies and additional funding programs.

\section{Economic Cluster Development Cooperation}

In the BTH region, industrial cooperative organizations have been formed, such as the Technology Transfer and Collaborative Innovation and Cultural Industry Development Alliance. In the YRD, the Synergy Industry Fund was founded in 2018 to support biotechnology and the Internet of Things. The YRD plan aims to make YRD a high value-added modern economic cluster with a globally competitive service economy and intelligent manufacturing. It includes investment plans for a $5 \mathrm{G}$ network across the region. The GBA plan aims to compete globally as a new digital technology region. Between 2012 and 2016, patents registration has been growing at an annual rate of 34\%, putting the GBA, especially Shenzhen-Hong Kong, China among the top three in the 2017 Global Innovation Index. The GBA is promoting the Guangzhou-Shenzhen Science and Technology Innovation Corridor, where many of the PRC tech giants are already located.

\section{Labor Market Integration and Coordination of Public Facilities and Services}

Recent achievements in the area of connectivity improvement has enabled convenient commuting for workers, employees, technical staff, and workers, especially between the large cities within the clusters. The introduction of a nationwide residence card system and policies promoting the portability of social protection schemes within BTH and YRD have been important in facilitating labor market integration.

Workers now have the opportunity to access more jobs and widen the pool of a potential workforce for companies. Still, further improvements integrating labor markets across city clusters are important for inclusive and economically beneficial development. City clusters greatly benefit from labor mobility and the coordination of higher education, technical training, health services, and transferability of social insurance, particularly those that are related to pensions. In PRD/GBA, the Guangdong Province Government provides free vocational skills training in rural areas. Health care centers have been established in all towns and villages.

Rural migrant workers are given access to insurance schemes for unemployment, retirement, work-related injury, and medical and health care throughout the PRD. Local governments in Guangzhou, Shenzhen, and Zhuhai have established a talent cooperation demonstration zone in 2012 to promote the mobility of talents so that, for example, residents of Hong Kong, China; and Macau, China can be exempted from local employment permits.

\section{Land Use Planning Coordination and Land Use Efficiency}

Nationally, there have been significant achievements in the areas of large-scale infrastructure, special economic zones, and functional zoning. However, coordination across boundaries within city clusters has still been limited. Local governments have an interest in preserving their authority over land use planning and urban expansion planning due to the important revenue source from land leases. Such interest might cause their reluctance to give up local land-based development, and may lead to some level of continued overdevelopment and sprawl. In BTH, the Land Use Master Plan for Coordinated Development (2015-2020) defines four types of regional spatial development pattern and clarifies land use principles. The PRD on the other hand has prepared the Plan for Coordinated Development of PRD Cluster (2004-2020), which includes a regional open space system. 


\section{Connectivity and Transport Networks and Public Transport Coordination}

The gap between strong national and strong municipal systems results in a transport system service gap-an area where the PRC can learn from international clusters. Beijing, Shanghai, and Guangzhou's subway systems already pass beyond the municipal boundaries. Recent BTH city cluster transport plans aim at an improved intercity railway system that connects all the prefectural- and higher-level cities. The plans encompass a seventh ring road, and include an intercity commuter rail network linking cities within the cluster.

BTH is also cooperating on closing the connectivity gaps between the high-speed rail system and the subway systems, which will eventually also link smaller cities and towns. In 2018, the YRD governments signed an agreement to promote the strategic planning of a regional railway network and coordinated development of civil aviation, including connecting all dead-end highways in the region. They plan to invest in a highly innovative Hydrogen Corridor as the first interprovincial infrastructure of its kind, to promote hydrogen energy infrastructure and hydrogen fuel cell vehicle development throughout the YRD. In GBA, both the Hong Kong-Zhuhai-Macau Bridge and seamless high-speed rail service linking Hong Kong, China with other key cities in the cluster started operation in 2018.

\section{Green Open Space Planning and Environmental Protection Coordination}

Higher-level policies and municipal-level planning have bolstered green space planning and environmental protection (See Box 2 for a case of river basin-wide water pollution and flood risk management coordination). This includes identification and implementation of national environmental red lines as well as protection of UNESCO World Heritage sites, national and provincial natural and heritage parks, water source protection areas, and farmland. Continued rapid urban expansion, however, poses a threat to natural and agricultural green land especially within city cluster areas in the PRC.

The BTH Coordinated Development of Ecological Environmental Protection Plan, released in 2015, defines open space protection for the entire BTH region, sets a limit for resource consumption, and defines its own water and air quality standards. Local governments in the BTH cluster successfully cooperate on environmental management like air pollution reduction and eco-compensation policies and projects (both with ADB support). The YRD has a quota of at least $15 \%$ of the land area to be protected open space. The PRD completed its Green Road in Nine Cities project in 2010, which won the United Nations Habitat Award in 2011. Recently the PRD started to implement its National Forest City Cluster Plan (2016-2025), aiming at ecological security and identifying many ecological projects.

City cluster coordination is embedded in the PRC's national investment programs and policies. These include industrial policies such as the decarbonization of the country's economy, and regionally differentiated industrial transformation aiming at Industry 4.0 with its program "Made in China 2025." The investment programs mainly focus on the advanced city clusters while promoting industrial upgrades inland and in resource-depleted subregions. Large-scale regional development policies - like the Belt and Road Initiative, a 21st century upgrade of the ancient Silk Road both on land and sea, and the Yangtze River Economic Belt-are also promoting development of the city clusters. The Yangtze River Economic Belt aims at subregional cooperation and integration, upgrading and relocating industries toward upstream regions of the river, and watershed-based water resource and pollution management. The results benefit more than a third of the country's population, including the three clusters of YRD, CYR, and ChengYu. 


\section{Box 2: Harbin-Changchun City Cluster and Songhua River Basin Water Pollution and Flood Risk Management Coordination in the People's Republic of China}

The Harbin-Changchun city cluster in the People's Republic of China (PRC) is part of an extended "Ha-Da" economic and transport corridor to the port city of Dalian across three provinces. Located in the northeastern region, Harbin-Changchun Cluster directly borders the Democratic People's Republic of Korea and the Russian Federation. The Harbin-Changchun Cluster includes 11 municipalities in two provinces and its total population is 46.9 million as of 2016. This region is an important national old industrial base. It has coal, fossil fuel, and natural gas resources, and is the country's largest commodity grain production base, despite long and very cold winters.

The region has been suffering from economic decline and population loss as well as environmental pollution from mining and heavy industries. In 2018, a joint plan was completed and coordination on economic development was established (i.e., industry cluster strengthening including an automotive cluster, labor market integration through education system alignment, connectivity and infrastructure including high-speed rail). Environmental management coordination includes the initiative of the Harbin-Changchun City Cluster Air Pollution Joint Prevention and Control Technology Integration and Application Demonstration project launched in 2017.

The Asian Development Bank (ADB) has been contributing through long-term and strategic support to development and revitalization of the PRC's northeast. ADB is also supporting city cluster and infrastructure development in the cities of Harbin, Jilin, and Changchun on the Harbin-Dalian corridor. A technical assistance project carried out an assessment on pollution sources and water pollution levels and prepared a master plan to clean up the river. ${ }^{a}$ This was followed by an ADB program supported the coordinated water quality improvement of the Songhua River Basin. ${ }^{.}$Projects in more than 30 cities in the river basin across two provinces include wastewater treatment. A sovereign and a private sector loan jointly supported the river environment and flood risk management. ${ }^{\top}$ The ADB-supported Songhua River Basin pollution control became a multi-project initiative, which has led to significant water quality improvements in the Songhua River.

ADB continues its support through a comprehensive revitalization and transformation project of four coal-based cities and coordination among these cities along a north-south economic corridor to the east of the cluster. The Heilongjiang Green Urban and Economic Revitalization Project helps the cities address economic decline, environmental pollution, wage reductions, unemployment, urban poverty, population loss, and improve their gross domestic product per capita, which is about half of the national average.

The project aims to generate synergies and catalyze a transformation with integrated infrastructure investments to make the cities vibrant, green, and clean. The project also promotes private sector development and green jobs creation through small and medium-sized enterprise capacity development and finance. Another key feature of the project is preparation of mining remediation road maps and pilots to clean the environment from more than 60 years of coal mining. The project has adopted lessons from some of the best practices of successful international cases of similar transformation like those in Pittsburgh (United States), Newcastle (United Kingdom), and Ruhr Valley Region (Germany). ${ }^{d}$

a Asian Development Bank (ADB). 2006. Technical Assistance Completion Report: Songhua River Basin Water Quality and Pollution Control Management. Manila.

${ }^{b}$ ADB. 2008. Report and Recommendation of the President to the Board of Directors: Proposed Loan to the People's Republic of China for the Songhua River Basin Water Pollution Control and Management Project. Manila.

c ADB. 2010. Proposed Equity Investment and Loan Songhua River Basin Water Pollution Control and Management Project Private Sector Facility (People's Republic of China). Manila.

${ }^{d}$ ADB. 2017. Report and Recommendation of the President to the Board of Directors: Proposed Loan and Technical Assistance Grant People's Republic of China: Heilongjiang Green Urban and Economic Revitalization Project. Manila.

Source: Asian Development Bank. 
However, despite the many efforts designed to make inland clusters more attractive, people continue to prefer migrating to the three coastal clusters of BeiShangGuang with more than $40 \%$ of all domestic migrants moving there in 2017. Interprovincial migrants have been changing their destination since 1978. In the 1980s and the 1990s, many moved to traditional heavy-industry areas such as the northeast, but since then they have been migrating to BeiShangGuang and more recently many preferred to relocate to BTH. Manufacturing, construction, and services were the major industries absorbing most migrants. Planners in the PRC will need differentiated approaches to policy, institutional arrangements, planning, and infrastructure investments in the coming years. Some projected clusters, especially CYR, are far beyond the 1- or 2-hour commuting circles now aimed at by planners in the PRC. Each cluster is at a different stage of development, and each has a particular scale as well as goals for a certain scope of spatial integration.

\section{Lessons from Megaregions and Metropolitan Governance in OECD Countries}

OECD countries both in Asia and around the world provide relevant lessons for city cluster coordinated governance mainly on three levels: (i) national-level urban, infrastructure, and policy planning and coordination in countries with high urbanization ratios, to promote the coordinated development and provision of services linking their functional urban areas and centers and promoting improved urban-rural linkages; (ii) metropolitan governance of many advanced forms that are either mandated by national governments or voluntary cooperation arrangements among local administrations (Andersson 2016); and (iii) single-issue cross-jurisdiction cooperation, for example, to jointly invest in, operate, and maintain infrastructure like airports, ports, or regional rail, or to protect and manage environment and ecosystems services like water resource quality and quantity. The following cases from countries and regions present the lessons from these three levels.

\section{Cases from Europe}

There are only few examples of subsovereign cooperation on the megaregion scale. However, some countries have connected functional urban areas covering large portions of their national territories. They have strong spatial planning, economic development, infrastructure, public service provision, and environmental management programs. Lessons from these national level examples of city cluster coordination can be drawn from the cases of the Netherlands and Germany.

Europe's “Blue Banana” megaregion. In Europe, the Blue Banana city cluster refers to the urban corridor, stretching from Manchester in the United Kingdom to Milan in Italy, with a population of more than 110 million. The European Union has adopted various policies on territorial cooperation including on transport infrastructure, open space protection, and urban-rural partnerships (European Union 2020). However, specific programs to coordinate local cross-border governance are weak. There have been some subregional connectivity efforts, including a seamless cargo-rail link across four countries, linking the port cities of Rotterdam in the Netherlands with Genoa in Italy. On a smaller scale and throughout Europe, there are many examples of strong metropolitan governance with various levels of integration and forms of institutional arrangements. 
Germany's functional urban areas can be considered as a megaregion within the Blue Banana. Germany has a multi-centered urban geography. It identified and mapped metropolitan regions including its economic and commuting relationships within the country. The Ministry of Construction and its subordinate research institution carry out space observation, analysis, and development programs, which are mostly also coordinated within programs of the European Union. They have been mapping the functional urban regions showing urban-rural relationships like commuting and programs like network cities and urban-rural partnerships. According to the national functional urban region map, a very large portion of the country is covered and forms a connected single ring-like territory. National infrastructure investment plans and open space protection plans coordinate connectivity, ecosystems services and functions, and public services both at the national and provincial levels, and through the provincial coordination governance body?

Metropolitan governance in Germany. In the 1920s, as major urban centers grew into metropolitan cities, the national government carried out administrative reform to enlarge the administrative areas. For instance, in Berlin and Hamburg, the government included new urban areas and sufficient surrounding space for growth, and improved urban management and future planning. Administrative reform was also done to improve infrastructure and service provision, including wetland fields for wastewater treatment. Today, metroregions in Germany typically have formal governance structures and institutions instated by national or provincial governments.

The Metropole Ruhr includes 53 cities and a total population of 5.4 million in the former coal mining and heavy industry belt. They market the subregion as a single place and cooperate on economic development, transport, open space protection and planning, and transformation from rust belt to a modern and green place. It may be a key example of a long-term cooperation starting with needed cooperation on ground and surface water management to avoid flooding of cities during the coal mining era more than 100 years ago. A national program from 1994 to 2003 promoted the cooperation and clustering of many city networks also linking third-tier cities and even across national borders to create economic, social, and environmental benefits from connectivity and coordination. ${ }^{8}$

In Germany, the Hanover and Stuttgart metropolitan regions have elected regional Parliaments governing various aspects of planning, including land use and transport for balanced and coordinated development of a road network, and public transport including regional rail. They have authority and budget allocated from local governments to operate regional rail, provide traffic management, promote open space protection, and initiate regional park development. The Stuttgart Region Association comprises 6 municipalities, 179 communities, and 2.7 million people. The regional Parliament is governing various aspects of planning for balanced and coordinated development of a road network, public transport including regional rail, traffic management, and open space protection (Verband Region Stuttgart, 2009).

United Kingdom, Greater London, and Southeast England. The United Kingdom, with Greater London and the southeast of the country, has played a pioneering role in urban planning history, including large-scale planning across administrative borders. In the early 1900s, the country envisioned and planned the development of new towns and garden cities linked by commuter rail and a green setting within farmland separated from the polluting factories. In 1944, a green belt was planned surrounding greater London (Abercrombi and Forshaw 1944).

7 Bundesamt fuer Bauwesen und Raumordnung. Bundesinstitut fuer Bau-, Stadt- und Raumforschung. Laufende Stadtbeobachtung - Raumabgrenzungen. Großstadtregionen. https://www.bbsr.bund.de/BBSR/DE/forschung/raumbeobachtung/Raumabgrenzungen/ deutschland/regionen/Grossstadtregionen/Grossstadtregionen.html?nn=2544954.

8 Regionalverband Ruhr. Metropole Ruhr. https:/www.rvr.ruhr/politik-regionalverband/ueber-uns/. 
Today, there are various forms of institutionalized cooperation including the Greater London Council. The England Green Belt plan has been famous for cooperation in the area of open space protection. The green belt covers many national- and country-level open spaces, which have been developed as large-scale green spaces allowing only a limited amount of activities and construction. London, as an early industrializing city, also pioneered many urban innovations including urban planning, subway and sewer construction, and a fabulous open space system comprising of sufficient large-scale city parks, district parks, and the famous neighborhood squares.

The Netherlands and its metroregions. In the Netherlands, eight metroregions were created as designated associations. In 1985, they were mandated by the national government with the responsibility of shared economic development policies, spatial planning, transport, and housing. They were abolished in 2015 and only the two largest cities, Amsterdam and Rotterdam, arranged their own governance coordination across their metroregions. In 2015, the Metroregion Rotterdam-The Hague was formed consolidating two previous metroregions including the two cities and 21 smaller cities and employing a total of 100 full-time staff. The scope has two main pillars, economic development and transport. About 5.5 million euros was allocated for economic development, and 480 million euros for transport, annually for 2015-2018, with most funds coming from the national government.

\section{Cases from the United States}

Population maps and economic statistics show how the entire US economy is slated to become dominated by 10 megaregions by 2050 and governance coordination for these was recommended in 2006 (Regional Plan Association 2006). There have been plans to improve infrastructure within these clusters and across the US, including high-speed rail networks. The first line is being built now in California. Coordination within the mega-urban regions has not yet been institutionalized. As early as 1961, the term "megalopolis" was coined for the northeast megaregion from Boston to Washington. It has a population of about 50 million people.

In 2007, a joint strategy plan was produced by the Regional Plan Association that was founded for the coordinated planning of the New York Metroregion in 1922. The joint strategy includes aims of sustainable and inclusive economic development, sustainable urban development reducing sprawl, improving connectivity, climate action, and environmental protection, among others. However, as there is no formal institutionalized governance, implementation remains a challenge, similarly for other clusters across the country (Regional Plan Association 2007).

Metropolitan governance. In the early 20th century, the US Census introduced the Metropolitan Statistical Area acknowledging urban and suburban growth beyond the administrative boundaries of cities. Councils of Government intended to become actual regional governments were promoted under a federal government program in the 1950s. Only the Bay Area, however, almost created a comprehensive regional government in the early 1970s. Greater New York was created as early as 1898 consolidating five counties, making it the world's largest city at the time. The Port Authority, created after the first world war, was the first of its kind as a functionbased regional governance authority. Many others responsible for regional public works, infrastructure and institutions, and even selective land use planning have followed such model of governance.

Chicago, the second-largest city in the country, prepared the famous Plan of Chicago in 1909. The local business community commissioned the regional plan. The Chicago Metropolitan Agency for Planning (CMAP) was created in 2005 and completed a comprehensive plan "Go To 2040," which includes consolidated population growth projections and economic, transport, infrastructure, and regionwide open space planning (CMAP 2014). Portland in Oregon is known for pioneering sustainable urban planning initiatives. It established an elected government for the metroregion with authority for land use and transport planning and created the legendary 
urban growth boundary. The twin cities of Minneapolis and St. Paul collaborate through their Metropolitan Council on many aspects, notably a tax-base sharing scheme designed to promote livability, competitiveness, equity, and efficient growth.

Special Districts' selective coordination on specific tasks. Lessons can also be drawn from single-issue, cross-jurisdictional cooperation. Many Special Districts had been formed in the US wherein neighboring administrations created special vehicles to jointly fund and manage infrastructure or the environment. Examples include airports, ports, rail, commuter rail, subway, toll roads, bridges, parks, water supply, irrigation, and industrial development. These are very effective forms of cooperation and may become an avenue for more comprehensive coordination. Payment for ecosystem services is another form of cooperation. An example is water quality management where, along a river basin, a downstream government pays an upstream government for achieving an agreed water quality level. This also exists in the PRC where it is called eco-compensation.

\section{Cases from Japan}

Japan has the second-largest megaregion in Asia, the Taiheio Belt (Pacific Belt), or Tokyo-Nagoya-Osaka corridor, also referred to as Tokaido Megalopolis and a three-layered governance arrangement. A Shinkansen line, Japan's high-speed train, links the cluster with more than 80 million residents (Ito et al. 1980). The most prominent metroregion within the cluster-and until recently the largest in the world both by population and GDP_-is the Greater Tokyo Area with a total of about 38 million residents, including the Tokyo Metropolitan Area, Yokohama, Kawasaki, Saitama, Chiba, and Sagamihara.

Regional planning is led by the national Ministry of Land, Infrastructure, Transport and Tourism (Ministry of Infrastructure and Transport of Japan 2006). The Tokyo Metropolitan Area is governed by the Tokyo Metropolitan Government, a regional government with 23 special wards, 26 cities, 5 towns, and 8 villages. The Tokyo Metropolitan Government unifies administration and control across the whole ward area for services like water supply, sewerage, and firefighting. This is to ensure the provision of uniform, efficient services. The wards have the autonomy to independently handle affairs close to the lives of the residents such as welfare, education, and housing.

\section{Economic Corridors in Asia: Linking City Clusters to Integrate the Region}

There are many cases of coordination of economic corridor development linking cities and city clusters in Asia and the Pacific. The Belt and Road Initiative and the International North South Transport Corridor linking India in the south, with Iran, Afghanistan, Azerbaijan, the Russian Federation, and Europe in the northwest, may be the longest linking countries and continents via land and sea. There are many other corridors in Asia. Some are arranged between a group of countries like the Central Asia Regional Economic Cooperation (CAREC), the Greater Mekong Subregion (GMS), the Bangladesh-China-India-Myanmar Economic Corridor, Brunei-Guangxi Economic Corridor, China-Pakistan Economic Corridor, and the high-speed rail corridor linking Yunnan Province in the PRC in the north with the Lao People's Democratic Republic (Lao PDR), Thailand, Malaysia, and Singapore in the south. 
Aside from the corridors across national borders, there are also many domestic corridors that create links and integration between a number of city clusters. They include corridors promoted in India, the PRC, and Thailand, among others. Key fields of cooperation are cross-border trade facilitation (which applies to both international and domestic borders between provinces or states), connectivity infrastructure and logistics, energy and data infrastructure, joint tourism promotion, and environmental management like water resource management and ecosystem protection. There are many valuable lessons to be captured from corridor coordination at the level of city cluster governance.

Central Asia Regional Economic Cooperation initiatives. CAREC coordination involves 11 countries. Six main corridors are defined with a number of sub-routes (Map 2). The countries have developed coordinated plans and strategies, such as for transport and trade facilitation; transport and logistics for multiple modes (road, rail, and air transport); and aspects of safety, investment, construction, and maintenance. There are also initiatives and plans to coordinate energy infrastructure, sustainable tourism strategy, and infrastructure investment programs (ADB 2013, 2019b, 2020). ADB has been supporting CAREC since 1996. It plays a central role as independent agent and negotiation facilitator through secretariat assistance and the establishment of the CAREC Institute. ADB has been supporting through technical planning; lending programs; and development of coordinated strategy and action plans, trade policies, and cross-border trade procedures.

Greater Mekong Subregion cooperation initiatives. The Greater Mekong Subregion (GMS) Economic Cooperation Program was established in 1992. It comprises Cambodia, Yunnan Province and Guangxi Zhuang Autonomous Region in the PRC, the Lao PDR, Myanmar, Thailand, and Viet Nam. The GMS Strategic Framework 2012-2022 (ADB 2011, 2018) provides the background policy for the Greater Mekong Subregion Strategic Urban Development Framework 2015-2022 (GMSUDF, ADB 2015). The framework includes identification of economic corridors (Figure 3) with various primary and secondary urban nodes, and scoping of national action plans and priorities. It is composed of five strategic thrusts: (i) strengthen infrastructure linkages, (ii) facilitate cross-border trade and investment and tourism, (iii) enhance private sector participation and competitiveness, (iv) develop human resources, and (v) protect the environment and promote the sustainable use of shared natural resources.

In 2012, the joint ministerial task force established a GMS Urban Development Urban Task Force, reflecting the recognition of the potential for coordinated urban development, increased rural-urban links, and spatial prioritization along GMS transport corridors. Rather than being a prescriptive or mandatory framework, the GMSUDF was designed as a tool to support coordinated urban development in GMS countries and help transform mere transport corridors into GMS economic corridors. The key objectives are to:

(i) improve national coordination and create synergies with national plans;

(ii) prioritize investments in corridor cities and local off-corridor;

(iii) apply special instruments like special economic zones, including in border areas;

(iv) provide and upgrade infrastructure in key urban areas;

(v) prepare development and spatial plans;

(vi) engage the private sector in infrastructure and services cooperation on cross-border issues; and

(vii) conduct peer-to-peer exchanges of ideas, approaches, and techniques.

GMS economic corridors are the cornerstone of ADB's investment planning. Corridor towns will be given priority for infrastructure and environmental improvements. In 2016, ADB approved a multiyear, multisector program to support economic development and poverty reduction of a cluster comprising small cities and towns in a cross-border economic corridor in Guangxi Zhuang Autonomous Region in the PRC and northern Viet Nam. 


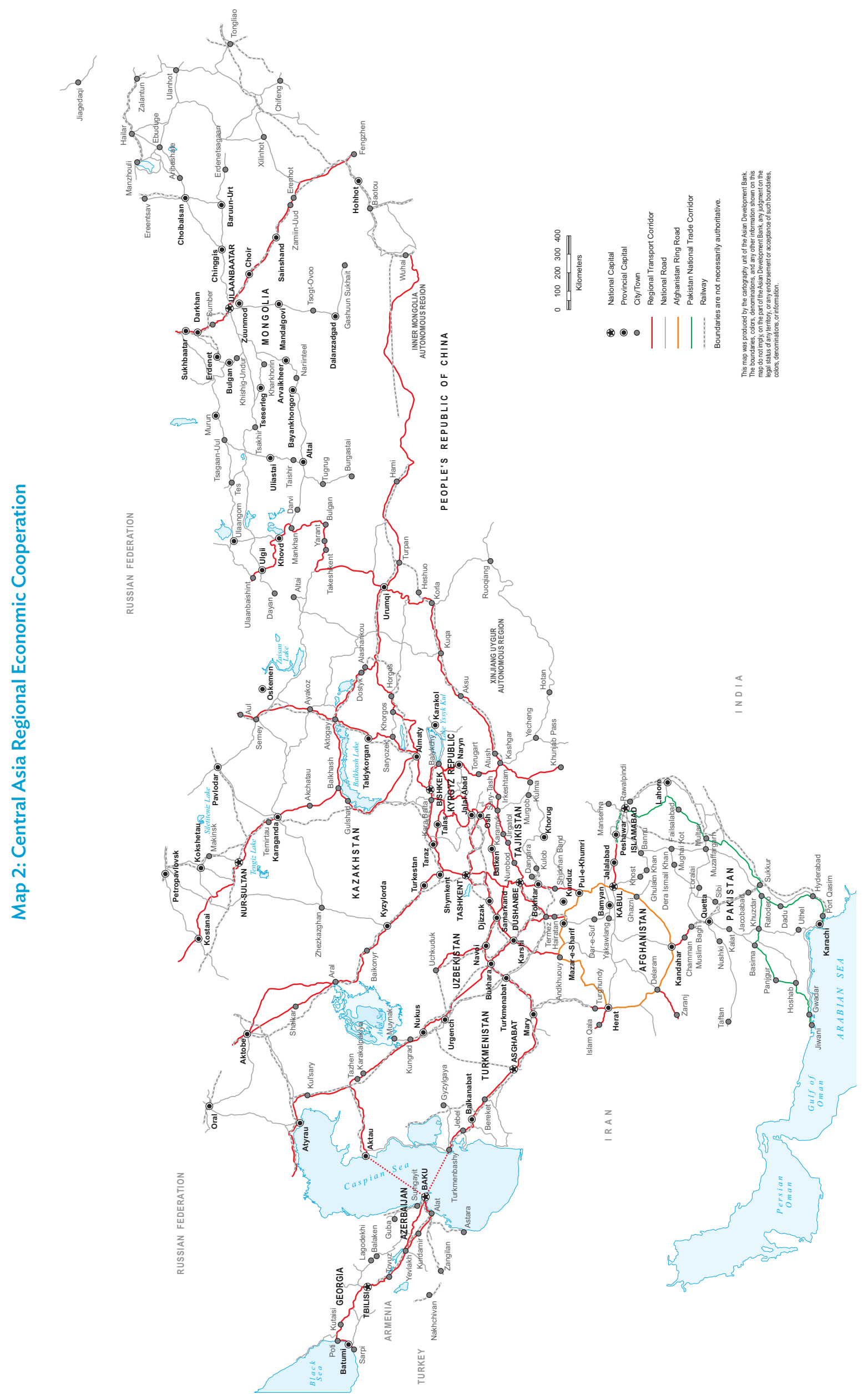

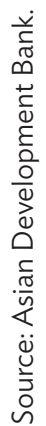


The project contributes to ADB's larger support program of regional cooperation and integration of the North-South Economic Corridor in the Greater Mekong Subregion. The project's holistic and multisector approach combines physical infrastructure improvement and trade and investment facilitation.

Since 1992, ADB has been supporting the GMS with the aim to coordinate various dimensions, such as crossborder trade and trade facilitation, improved connectivity, water resources management, and biodiversity protection. From 2012 to 2015, ADB supported urban development coordination and regional cooperation and integration. It financed a technical assistance project supporting the GMS task force in preparing the GMSUDF.

Economic corridor development in India. The Government of India promotes manufacturing, through its "Make in India" initiative, to maintain strong economic growth over the longer term and to create productive, well-paying jobs for a labor force that is growing by around 12 million people per year. Currently, manufacturing provides around 15\% of India's GDP. India's National Manufacturing Policy aims for the manufacturing industry to contribute at least $25 \%$ of GDP by 2022, similar to the levels of the PRC, Malaysia, and Viet Nam.

To support planning and implementation of the spatial and investment dimensions of the Make in India industrial policy, the Government of India established a new agency, the National Industrial Corridor Development and Implementation Trust. It coordinates the development of 11 large-scale industrial corridors linking city clusters and cities throughout the country. The aim is to strengthen productivity and innovation and attract foreign investments. The country wants the corridors to be competitors in the global manufacturing arena and generate jobs creating social and economic benefits. Major international development partners have been involved in five key corridors. ADB supports with high-level policy dialogue on national and state levels and, among others, through an investment program for the Eastern corridor (Box 3).

\section{Opportunities for City Cluster Governance and a Scenario for System of Two Speeds}

As city clusters in the scale of megaregions continue to emerge and grow and be the top economic contributors around the world, effective governance coordination efforts and cluster-level institutions at a megaregion scale are great opportunities and even urgently needed. However, national policies and policies of international cooperation agencies are currently not or not sufficiently supporting megaregional governance. The pioneering policies and plans in the PRC are innovative and ambitious. They are also often misunderstood as being primary urbanization strategies, rather than promoting coordination across local boundaries-where there was none before - to create mutual benefits. Post-industrial economies may have longer experiences from urbanization and from many forms of smaller-scale metropolitan governance. However, it can be considered that top-down national guidance for coordination, mechanisms and institutions as well as national infrastructure initiatives, along with effective industrial policies, can promote economic development and improve spatial integration within city clusters.

The PRC and other countries in Asia with stronger national governance can learn from international cases, including from OECD countries, that horizontally arranged governance can achieve good results. A good example of this are elected or appointed regional Parliaments or metropolitan agencies. While they serve smaller territories, the principles and institutions and the cooperation mechanisms can also be successfully transferred 
Map 3: New Configuration of the Greater Mekong Subregion Economic Corridors

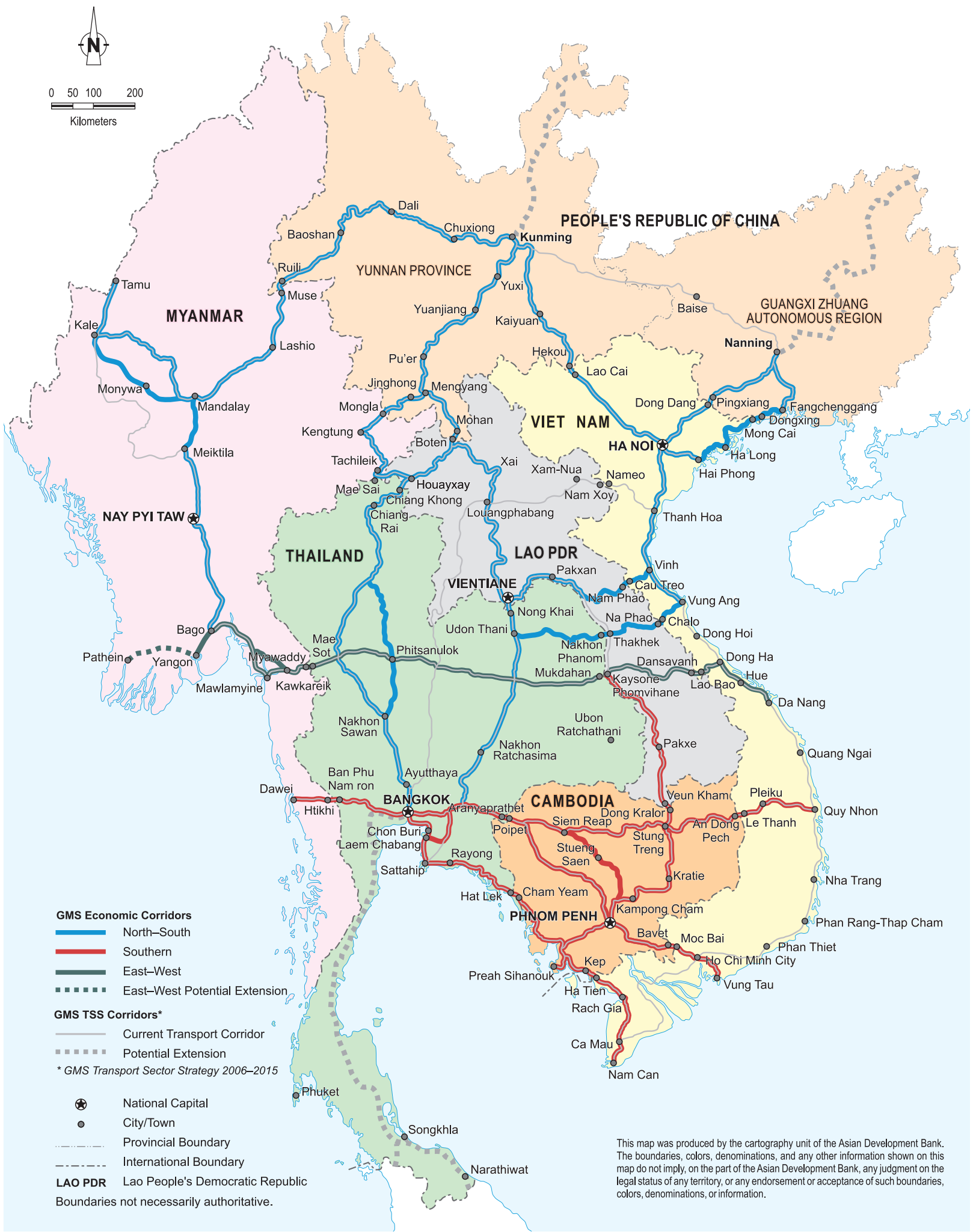

Source: Asian Development Bank. 2018. Review of Configuration of the Greater Mekong Subregion Economic Corridors. Manila. 


\section{Box 3: Visakhapatnam-Chennai Industrial Corridor along India's East Coast}

In India, the Asian Development Bank (ADB) is supporting city cluster coordination through planning and finance of the Visakhapatnam-Chennai Industrial Corridor ( VCIC) section of the East Coast Economic Corridor along 800 kilometers $(\mathrm{km})$ and connecting four economic hubs and nine industrial clusters. It is expected that by combining state-of-the-art industrial clusters, efficient transport, and reliable water and power supplies with a skilled workforce and good business policies, the Visakhapatnam-Chennai industrial corridor will become a favored investment destination. With support from ADB, the Government of Andhra Pradesh prepared VCIC's conceptual development plan, regional perspective plan, and master plan. These plans provide long-term strategic vision and a road map for investments.

The Visakhapatnam-Chennai Industrial Corridor Development Program (VCICDP) has a total investment of $\$ 846$ million. The investment includes a $\$ 500$ million lending facility from ADB, policy lending and grants to build key infrastructure, and support to industrial policies and business promotion. VCICDP complements the government's effort to enhance industrial growth, create high-quality jobs, and support priority infrastructure investments. The policy-based loan will support policy reforms and institutional development. The new infrastructure will be built in the four main centers along the corridor as well as in nearby industrial areas. It will include $138 \mathrm{~km}$ of state highways and roads, effluent and water treatment plants, $488 \mathrm{~km}$ of drinking water pipes, $47 \mathrm{~km}$ of storm drains, 10 power substations, and $281 \mathrm{~km}$ of power transmission and distribution lines. The program will also focus on increasing women's participation in the industrial workforce. Skills training for 25,000 male and female workers, entrepreneurs, and students along with an investor promotion plan is expected to help develop businesses along the corridor. The project is currently under implementation at a very high speed and with strong high-level support.

The VCIC section of the East Coast Economic Corridor, $800 \mathrm{~km}$ long and connecting four economic hubs and nine industrial clusters, will mark the first industrial corridor developed along India's coast. The East Coast Economic Corridor will ultimately extend from Kolkata in West Bengal in the northeast of India to Tuticorin in Tamil Nadu near the southern most point of the country. By 2025, annual industrial output along the corridor will increase fourfold to $\$ 64$ billion from about \$16 billion in 2015 if investment opportunities are maximized over the coming 10 years.

a ADB. 2016. Report and Recommendation of the President to the Board of Directors: Proposed Multitranche Financing Facility, PolicyBased Loan, Technical Assistance Grant, and Administration of Grant India: Visakhapatnam-Chennai Industrial Corridor Development Program.

Source: Asian Development Bank.

to the larger city clusters. Such agencies or Parliaments and their administrative units can have authority over land use, transport, and open space planning. They can also get sustainable budgets from participating local governments and with support from provincial and national governments to invest in the plans and operate and maintain infrastructure.

Countries around the world can also learn from the larger-scale economic corridor programs and the mechanisms of consensus building. They can focus on key common concerns, such as trade facilitation, connectivity, place-branding and tourism promotion, environmental protection, human resource development, and public health, which are also key concerns and highly relevant for city clusters and their coordination. 
Lessons from the specific-purpose Special Districts and payment for ecosystem services or eco-compensation can also help develop models for cooperation. Formed as legal entities and financed across administrative boundaries, Special Districts can manage resources or build and manage infrastructure like airports and ports. They often enjoy and are encouraged by additional national funding support. Western countries also exhibit more market-oriented approaches from which countries like the PRC could learn. The concept of Special Districts can also be an entry and starting point for city clusters toward a more and step-by-step comprehensive scope of cooperation among neighboring administrations.

Market-based instrument approaches suggest that interventions need to be carefully assessed to avoid inefficiencies due to limited demand for infrastructure and services. In lesser-populated, often remote subregions where infrastructure is used less, the high cost of maintenance compared to returns often results in unsustainably low economic benefits. This may apply to the PRC, while countries like the US and other Western countries are in dire need of bold infrastructure investments-following what the PRC has done, such as with its high-speed rail network construction and its effective industrial policies. Infrastructure and industrial policy are key pillars of any initiative on a national or city cluster scale. They can trigger economic transformation and better spatial integration.

National policies should create enabling environments for city clusters to establish institutions with clear authority over key areas of planning and management at a cluster-wide scale. Budgets are needed for key infrastructure, along with authority over a sustainable source of revenue. To be effective and to reap expected benefits, cluster-wide governance authorities must be responsible over a wide range of areas, such as transport infrastructure (regional intercity commuter rail, logistics centers, and intermodal transportation hubs); integrated labor markets with improved connectivity and regionalized or even nationalized social protection systems; coordinated public service facilities in higher education and health; and enhanced regional-scale land use planning to avoid leapfrogging and sprawl. Small cities, towns, and villages must be integrated within cluster economies to reduce the divides in urban-rural incomes, wealth, and services.

In city cluster strategic planning, it is important to consider short- and medium-term objectives, while fully considering long-term development scenarios. There should be realistic population scenarios taking into account some of the external factors that may be game changers like climate change and resource scarcity. In the PRC, for example, a planning period is considered up to 2035 and development objectives are even described up to 2049. Hence, an even longer-term perspective is also important, because land uses, public right-of-way systems, trunk infrastructure corridors, and asset investments as well as formally protected open spaces will remain for much longer historic periods. National plans and city cluster plans should be regionally differentiated to be strategic, robust, and flexible to adjust to these scenarios (Rau 2021).

Option for territorial system of two speeds: high-speed city clusters and slow national parks and ecosystems (Rau 2011a, Rau 2011b, Groff and Rau 2019). The world is increasingly polarized between urban and rural territories and their factors, lifestyles, and mindsets. This division may be more relevant in the future than a place's location on the globe. Natural resource availability and exposure to risks from climate change will become critical. Considering these aspects, strategies can be developed with distinct visions for both types of territories, as both need each other and both need to be strengthened to be sustainable and future-proof, as well as their relationship needs to be strengthened and mutually appreciated.

First, a high-speed system of economically performing clusters of world-class and second- and third-tier cities and their hinterlands can be facilitated, with clearly defined concentrated urban areas and restrictions on land development. This is to avoid extensive land consumption and oversupply of industrial, commercial, and residential land. 
Second, large-scale green open space systems can be preserved, consisting of protected natural, agricultural, and cultural land. They can be elevated as national and provincial parks providing a range of ecosystems services including recreation, and offering people a choice valuing not only urban but also traditional rural and more nature-based lifestyles. Both types of spaces are essential for competitiveness and well-being, and for climate resilience and low-carbon development on a large scale. As the world is increasingly divided into urban and rural geographies and populations, new forms of equitable partnerships may be needed.

A hierarchical city cluster system could be designed consisting of development zones representing a highspeed zone of urban and economic development, and a large-scale formalized protected national park system representing a slow speed of highly restricted development and natural and heritage protection. Such complementary system offers a diversity of territories and lifestyles, ecosystems services, climate resilience, and recreation-balancing on a large-scale urban development with green space protection. This balance would offer two forms of equally valuable models of development, which are mutually beneficial. An analysis could be based on bioregions, agricultural areas, cultural heritage, existing UNESCO sites, national and provincial parks and forests, and rivers and lakes.

Throughout Asia, in the medium and long term, it will be crucial to preserve scarce green land resources; effectively plan green open space systems; and protect natural environment, biodiversity habitats, wetlands, farmland, and cultural heritage. This is to ensure significant benefits are gained from functioning ecosystem networks providing a whole range of ecosystems. The increasing urbanization and concentration of urban development in the globally emerging city clusters and megacities and their linking into economic corridors will benefit from a distinct territorial system of two speeds that complement and benefit each other.

As urbanization continues rapidly in developing Asia, there is a rapidly closing window of opportunity to protect green spaces from sprawling urban development and there would be a great benefit from coordinating ecosystem preservation on the city cluster and/or larger bioregion scale. This is especially important considering increasing scarcity of natural resources and climate change, which exposes millions of people, infrastructure, assets and large territories in coastal city clusters and low-lying areas along rivers to increased risks from sea level rise, storm surges, and river flooding. This is most critical for global population hotspots like the PRC's coastal region, and India's Ganges River Region and its coastal regions. It would also be highly beneficial for Indonesia's Java island, Southeast Asia, as well as other regions in Asia.

\section{References}

Abercrombie, P. and J.H Forshaw. 1944. Greater London Plan. London.

Asian Development Bank (ADB). 2011. The Greater Mekong Subregion Economic Cooperation Strategic Framework 2012-2022. Manila. https://www.adb.org/documents/greater-mekong-subregion-economic-cooperationprogram-strategic-framework-2012-2022.

-- - 2014. CAREC Transport and Trade Facilitation Strategy 2020. Manila. https://www.adb.org/documents/ carec-transport-and-trade-facilitation-strategy-2020.

- - - 2015. Greater Mekong Subregion Urban Development Strategic Framework 2015-2022. Manila. https://www.adb.org/documents/gms-urban-development-strategic-framework-2015-2022. 
_-_. 2018. Greater Mekong Subregion: Twenty-Five Years of Partnership. Manila. https://www.adb.org/ publications/greater-mekong-subregion-25-years-partnership.

-_- 2019a. Asian Development Outlook 2019 Update: Fostering Growth and Inclusion in Asia's Cities. Manila. https://www.adb.org/publications/asian-development-outlook-2019-update.

- - . 2019b. CAREC Energy Strategy 2030. Manila. https://www.adb.org/documents/carec-energystrategy-2030.

-- - 2020. CAREC Transport Strategy 2030. Manila. https://www.adb.org/documents/carec-transportstrategy-2030.

Andersson, M. 2016. Unpacking Metropolitan Governance for Sustainable Development. Bonn, Eschborn; Nairobi: Deutsche Gesellschaft für Internationale Zusammenarbeit (GIZ) GmbH; United Nations Human Settlements Programme (UN Habitat).

Bertaud, A. 2016. China's City Clusters: The Emergence of the Largest Urban Labor Markets in the World or Just More Congestion and Pollution? Presentation at the Third World Bank-George Washington University Conference on Urbanization and Poverty Reduction. Washington, DC. http://pubdocs.worldbank.org/en/343681455906838472/ China-City-Clusters-Bertaud.pdf.

Chicago Metropolitan Agency for Planning. 2014. Go To 2040: Comprehensive Regional Plan. Chicago.

Choe, K. and B. Roberts. 2008. Competitive Cities in the 21st Century: Cluster-Based Local Economic Development. Manila: ADB.

European Union, European Commission. 2020. Ex-post Evaluation of Major Projects in Transport Financed by the European Regional Development Fund and the Cohesion Fund between 2000 and 2013. Brussels. https://ec.europa.eu/regional_policy/sources/docgener/evaluation/pdf/swd_ex_post_transport_2000_2013_en.

Florida, R. 2019. The Real Powerhouses That Drive the World's Economy. New York. https://www.bloomberg. com/news/articles/2019-02-28/mapping-the-mega-regions-powering-the-world-s-economy.

Florida, R., T. Gulden, and C. Mellander. 2007. The Rise of the Mega-Region. Toronto. https://www.creativeclass. com/rfcgdb/articles/Florida,\%20Gulden,\%20Mellander_Mega-Regions.pdf.

Government of the People's Republic of China (PRC), State Council. 2014. National New-Type Urbanization Plan, 2014-2020. Beijing.

Government of the PRC, State Council. 2015. National Economy and Social Development Thirteenth Five-Year Plan, 2016-2020. Beijing.

Groff, S. P. and S. Rau. 2019. China's City Clusters: Pioneering Future Mega-Urban Governance. American Affairs Journal. May 20, 2019.

Harrison, J. and M. Hoyler, eds. 2015. Megaregions. Globalization's New Urban Form? Cheltenham (UK) and Northampton (United States). 
Ito, T., C. Nagashima, and B. A. Hons. 1980. Tokaido: Megalopolis of Japan. GeoJournal. 4. pp. 231-246. https://doi.org/10.1007/BF00218579.

Ministry of Land, Infrastructure and Transport of Japan. 2006. White Paper on National Capital Region Development (2006). Tokyo.

Rau, S. 2011a. Proposal for Strategic Planning of China's Coastal Region Starting with No-Build Zones. In M. Schrenk, M. Popovich, and P. Zeile, Change for Stability: Lifecycles of Cities and Regions. Proceedings of the Corp 2011 Conference.

Rau, S. 2011b. People's Republic of China Coastal Region National Heritage Park Network. Potential Large-scale Cultural, Agricultural and Ecological Conservation in the World's Most Populated Region. A Proposal. A Planning Essay. Paper presented at the Academic Committee of Foreign Studies in Urban Planning of the Urban Planning Society of China's 2011 Annual Conference: Between the Old and the New-Interaction and Coordination. Tianjin. November.

Rau, S. (Forthcoming) Bridge to Future Livable and Green Cities and City Clusters in the People's Republic of China. Policy Opportunities for High-Quality Urban Development. Manila.

Ross, C. L. , ed. 2009. Megaregions: Planning for Global Competitiveness. Washington DC.

Regional Plan Association. 2006. America 2050: A Prospectus. New York.

Regional Plan Association. 2007. Northeast Megaregion 2050: A Common Future. New York.

Verband Region Stuttgart. 2009. Regionalplan fuer die Region Stuttgart vom. 22 July. Stuttgart. 



\section{CHAPTER 2 \\ Sustainable Transport}

ARTICLE 2A

Transport and Urban Form

James Leather

ARTICLE 2B

E-Mobility: Transition to Sustainable Transport

Ki-Joon Kim and Ritu Mishra

ARTICLE 2C

Planning and Design of Intelligent Transport Systems toward Livable Asian Cities

Susan Lim and Gloria Gerilla-Teknomo

ARTICLE 2D

Prospects for Mobility as a Service

Robert Valkovic, Lidia Signor, Gayang Ho, and Clémence Morlet

ARTICLE 2E

Road Safety in Asian Cities

Michael Anyala and Charles Melhuish 


\section{Transport and Urban Form}

James Leather

\section{Introduction}

Cities perform many functions. They bring people together, stimulating knowledge and economic activities. They also act as centers of commerce, government administration, and laws, and provide water supply, sanitation, and other services for the inhabitants. Such fundamentals of urban activities were as true in the ancient cities as they are in the cities of today. Transport, however, has brought the biggest change to urban function. With the influence of transportation systems, the urban form has changed over time. New modes of transport have allowed urban inhabitants to travel further, and thus stretch the urban boundaries, design, and form. It is important to understand how cities have evolved and the role that transport has played in this evolution. This article explains in depth the contemporary cities and discuss the lessons learned on the role of transport in the development of urban form.

Technological advances have allowed different transport modes to play an increasingly significant role in how people move around cities. In much of the history, urban areas were restricted in size by the limits of walking distances or horse drawn vehicles. Technologies such as steam power or combustion engine continue to play a major role in the development of cities and urban form. Increase in travel speeds and carrying capacity of new transport systems have allowed a greater number of people to travel longer distances, transforming the urban design. Perhaps more accurately, urban design was able to catch up with the advances in transport, thereby making changes in urban size and functionality.

This article explains how transport has influenced urban form throughout history until today. The next two sections examine the technological advances and the uptake of transport modes and their influence on urban form and urban form models. The fourth section looks at current urban structures and transport systems in Asia and typologizes cities to examine various development paths. Finally, the last section proposes a new paradigm for transport and urban form.

\section{Evolution of Transport Modes and Impacts on Urban Form}

In the earliest urban developments, travel was limited to foot or horses. Back then, there were no formal mass transits or public transport systems available. The earliest public transport system was the horse-drawn omnibus in Paris, which was first recorded in 1828. Eight years later, there were 16 omnibus operators covering 35 routes. The uptake of the omnibus in Paris allowed for commuting to the urban center, kicking off the transformation of the urban form. Meanwhile, in Asia, the first streetcar or tram was used in 1869 in Batavia, now Jakarta, Indonesia. 
Around the same time period, mechanical technologies, such as steam trains, were advancing and being used in transport. These trains were originally designed for freight use to move coal to feed the industrial revolution centered around northern England. Adaptation of these early mechanical transport systems quickly moved to passenger services, connecting the newly industrializing cities. The earliest passenger railways appeared in 1825 with the Stockton and Darlington Railway, followed in 1830 by the Liverpool and Manchester Railway. These early inter-urban railways started to affect urban form, as they allowed for urban conurbations which started to link several industrializing cities together. At the speed of 26 kilometers $(\mathrm{km})$ per hour, the $50 \mathrm{~km}$ journey between Liverpool and Manchester could be completed in 2 hours, a substantial reduction from the half-day horse ride or 2-day walk.

The use of steam engines in urban transport started with the Metropolitan Railway in London, which opened in 1863. This $6 \mathrm{~km}$ line ran between the large railway stations of Paddington and King's Cross. Five other stations connected both the mainline station and the growing residential areas of west London with the commercial city of London at Farringdon. The line grew in length over the next 10 years and evolved into the Metropolitan and District Railway. It followed a route very similar to the London Underground Circle Line of today. Some 150 years ago, the introduction of steam powered passenger service gave birth to the expansive London Underground system, setting the station locations, travel patterns, and urban form for modern-day London. While transitoriented design may be a recently coined phrase, its principles have been shaping urban form for a very long time.

However, the use of steam in urban areas with limited ventilation was not suitable, hence alternative power sources were being sought. The onset of mass transit could be considered to coincide with the introduction of the electric streetcar, which started operations during the 1890s. The first electric tram line was reported in Lichterfelde near Berlin, Germany in 1881. This form of mass transit allowed high-capacity movement of people along key transport corridors and thus had a major impact on urban design. From these early beginnings, mass transit systems became the skeleton around which the urban structure had been designed. To this day, the mass transit systems, integrated with bus and commuter rail services, are the central transport aspects that impact urban form and development in cities across the world.

Asian cities tend to be larger and denser. Twelve of the largest 20 megacities and 35 of the 50 most densely populated cities are found in Asia. ${ }^{1}$ The most efficient way to move such large numbers of people in limited space is via mass transit or public transport. The first electric tram system in Japan started in 1895. Over the next 30 years, many cities adopted this type of transport.

By 1932, Japan had accumulated electric tram systems in 65 cities. Around the turn of the 20th century, many other Asian countries opened electric tram systems, such as the Peking Electric Tramway (1899), Hong Kong Tramways (1904), trams in Mumbai (1907) and Delhi (1908), electric tramway in Mandalay (1904), and electric tram in Manila (1905). Across much of Asia, street cars become the dominant mode of mass transit during the 20th century. Over the century, more rail-based metro systems were introduced. The first metro line in Japan was opened in 1927 as a $2.2 \mathrm{~km}$ line between Asakusa and Ueno in Tokyo. Other cities brought in metro systems toward the end of the 20th century, such as in Beijing (1969), Seoul (1974), Kolkata (1984), and Manila (1984). Hong Kong, China had a metro line by 1979.

The rapid increase in private vehicle ownership and use has perhaps had the biggest impact on urban transport and urban form. The freedom of movement that private transport provides means urban area can grow in all

Megacities refer to cities of more than 10 million population. 
directions via the entire road network as opposed to being limited to main transport corridors using rail or bus systems. The increase in use of private vehicles has transformed many cities and given rise to urban sprawl.

The freedom that a private car provides also brings with it congestion, safety concerns, and pollution. The potential negative impacts of a private car were identified at a very early stage, most notably by Sir Colin Buchanan in his Traffic in Towns publication. Referring to a private motor car, Buchanan (1963) writes, "We are nourishing at immense cost a monster of great potential destructiveness, and yet we love him dearly." This publication (Buchanan, 1963) could be considered as the first reference to the sustainable urban transport aspirations that almost all cities are striving for today.

In Asia, a special mention should be given to both bicycles and motorcycles. The latter often functions as a family vehicle and offers even greater access than a private car. Countries across South, Southeast, and East Asia have high levels of bicycle and motorcycle use, often providing point-to-point service that no other mode of transport could provide.

While new transport technologies have allowed cities to evolve from the constraints on walking-only cities, walking is still important and is still an integral part of almost all urban trips. Most trips consist of multiple legs, with at least one leg being walking. Given this, it is surprising that relatively little attention is given to walking in cities. Very little information is collected on those who walk, or the infrastructure associated with this. In 2011, ADB released the report Walkability and Pedestrian Facilities in Asian Cities, which measured pedestrian infrastructure in selected Asian cities to develop and propose pedestrian-focused solutions (Leather and Fabian 2011).

While the overall focus of this book is the contemporary cities of Asia, it is important to have a good understanding of how cities have evolved, and the role transport has played in this evolution. Many of the issues and challenges in Asian cities today have been experienced before in cities across the world. The rapid increase in private mode of transport and the decisions taken to embrace or restrain the use of cars will have long-term implications on urban form. Similarly, throughout history, the uptake of mass transit systems, combined with bus services, has demonstrated the dramatic impact it has on urban form and the livability and function of cities. Planning, delivery, and operations of mass transit, therefore, is a task that will have fundamental and long-term implications on cities now and in the future.

\section{Theories of Urban Form and the Role of Transport}

While urban form tends to evolve, there has been a lot of research devoted to understanding and explaining its development. To better understand contemporary cities, it is worth looking at various research and perspectives on how cities and the urban form have evolved.

In the 1930s, a study on urban form tried to examine the influence of factors such as transport systems on cities. Ernest Burgess was one of the earliest to explain urban form. He predicted a series of concentric rings around a central core of a city (Park and Burgess 1925). Each of the rings has a specific function linked to a relative value. Retails and businesses in the inner core or the central business district spread out to surrounding industrial zones and to the periphery, including the residential living areas. Each ring is associated with the value of land at a diminishing rate from the center. 
Walter Christaller developed his central place theory in 1933. Similar to Burgess' theory, Christaller's (1933) theory is that the further the ring is from the center, the less value or demand it has, and thus a series of concentric rings with decreasing value surround the center. Christaller (1933) considers three principles-marketing, transport, and administrative-that influence the central place theory, distorting the homogenous landscape. The transport principle shows how efficient transport connections have distorted the distance relationship, thus influencing the urban form with greater value and demand along transport corridors.

Such generalized models have failed to fully explain the nuances and historical influences on urban form and design, and as discussed in the next section, has a heavily westernized urban form influence. Distortions are caused by many factors, but other models suggest a more complex urban form, such as the Hoyt sector model (1939) and the multi-nuclei model of Harris and Ullman (1945).

Another modeling approach to urban form and transport is the use of the gravity or spatial interaction model. The adaptation of Isaac Newton's law of gravity by social scientists to explain the attraction between urban areas - thereby increasing travel demand - contains the same basic principles of mass and distance, or trade and movement of people over distance. The use of such an approach allows the estimate of the respective influences between locations, such as movement between or within cities. Spatial interaction analysis allows for inclusion of topology, geometry, or geographic properties of urban areas.

This theoretical approach to urban form is still widely used in transport planning and forms an integral part of the transport's four-stage modeling process. The gravity model is used in the trip distribution stage of the model to estimate the interaction between two locations relating to factors such as cost, time, and distance of travel; it is also used to predict the demand for travel between areas of cities (Isard 1956).

There is clearly a range of influences on how cities develop. A combination of factors has led to current urban structures and how cities of the future may be designed. Transport and the ability to carry large urban populations over greater distances has and will continue to influence urban design.

Most of these models and approaches of urban form have a heavy European or North American influence. However, urban planning has been practiced in Asia for hundreds of years. For example, cities in the People's Republic of China have regimented urban structure and hierarchical cities culminating in the imperial city capital. Since the Han period until the imperial times and current cities, the grid patterns and urban structure are heavily influenced by regimented urban form. Other historical Asian cities, such as Angkor in the Khmer Empire, demonstrated a highly regulated urban structure as did the ancient cities in modern-day Myanmar, Thailand, and Viet Nam.

Certain types of urban areas clearly demonstrate the fundamental role that transport plays in the development and evolution of urban form. While most cities have a central business district with various land uses connected to this as they radiate away from the center, there are some cities where the transport link and access have themselves become the central business district. Cities such as Bangkok and Jakarta have become increasingly centered on the main transport corridor. The historical city centers around the Grand Palace and Chao Phraya River in Bangkok, and Kota and Batavia in Jakarta, have given way to new centers along the Rama I/Phloen Chit/ Sukhumvit Road and the Jalan Sudhirman, respectively. This pattern is true in much of developing Asia and other parts of the developing world.

Regardless of the model or formula for urban form, the need to control land use and strong implementation is essential. Without such control, urban form will evolve organically. 
Rapid urbanization, the influx of large populations, and various stages of industrialization or commercialization have resulted in cities struggling to manage the rapid and dynamic changes. The increase in population often results in large informal areas for housing, often lacking the infrastructure and services such as water supply, sanitation, schools, and hospitals that are required to ensure a reasonable quality of life. Since the 1990s, Asia has seen very large increases in urban populations with major migrations from rural to urban areas (ADB 2008). Cities across Asia have large informal urban areas, such as the Dharavi area of Mumbai, India, with an estimated population close to 1 million in the 2.1-square kilometer $\left(\mathrm{km}^{2}\right)$ area and a population density of $277,136 / \mathrm{km}^{2}$ in this area.

The densest city in the world is estimated to be Manila, with an eclectic mix of planned and informal development and a population density of $41,515 / \mathrm{km}^{2}$ (Wrights 2020). While less dense, the ger (traditional tent) areas of Ulaanbaatar also highlight the influx of large numbers to urban areas and the impact they have on urban form. In all such unplanned areas, the transport system and space allocated to movement is very small. In the informal settlements across Asian cities, the access network is primarily like the size of a footpath, which is just enough to accommodate two people walking. There is little to no formal transport or road network. As such areas become more permanent, the ability to retrofit or allocate sufficient space for transport systems becomes increasingly difficult. Such areas continue to be deprived of access to basic services, further marginalizing the poorest in the society.

Asia's urbanization can be informed by lessons from similar urban in-migration and urban transformation at other times in history, notably the Industrial Revolution in Europe of the 1800s. The informal areas of Asian cities today bear strikingly similar attributes to those of the booming industrial cities of 19th century northern England. One such infamous area was Little Ireland in Manchester. The German philosopher and industrialist Friedrich Engels describes the inhabitants of that area as "the race that lives in those ruinous cottages or in dark, wet cellars, in measureless filth and stench" (Engels 1845). Such poor living conditions led to much stricter urban planning and control with profound implications on British and European cities and even on political ideologies.

It is clear that there is no one-size-fits-all when defining an urban structure or development path. Most cities will have a blend of influences, often time-bound in terms of how people could move around a city and the respective modes of transport available. Urban form also cannot be too prescriptive and must take account of local conditions.

\section{Current Urban Form and Major Transport Challenges}

This section explores current urban dynamics of transport systems and urban form to differentiate city types and transport challenges. As cities evolve over time, technological innovations in transport have allowed cities to grow given the comparative advantages of various transport modes and systems.

Figures 1 and 2 compare the length of roads and mass transit systems with built-up areas in selected areas in Asia. Much of the Asian cities fall in a cluster with relatively limited road lengths. This has far-reaching implications on all types of travel as roads provide the main thoroughfares for all transport modes-private, public, and nonmotorized. A limited road length in urban areas means poor transport service and connectivity resulting in congestion and conflict as different modes compete for the limited space allocated for access and mobility. There are also two distinct clusters: (i) those with relatively high road lengths for city size such as Hiroshima, 
Figure 1: Road Length and Built-Up Areas

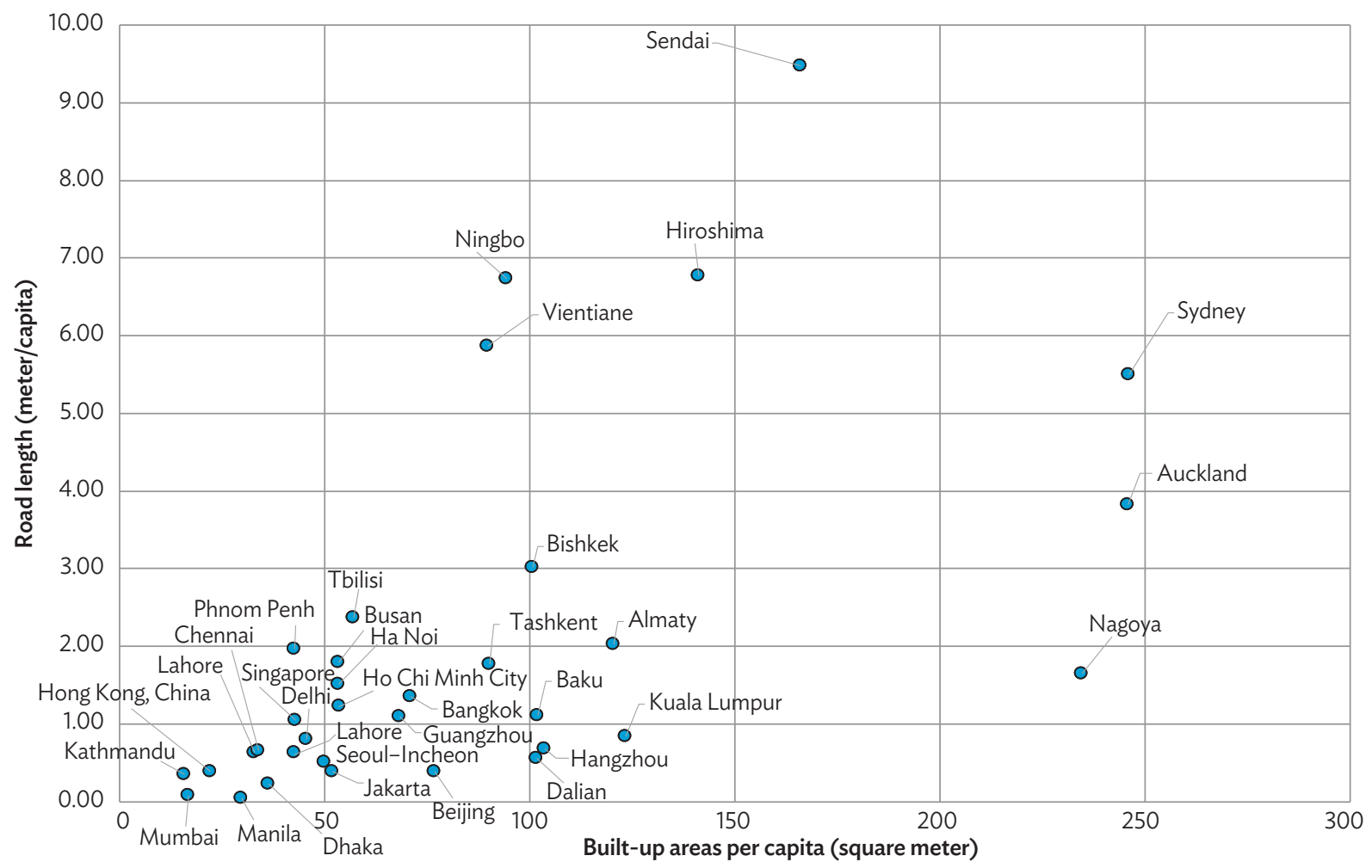

Source: Asian Development Bank. Forthcoming. Asian Transport Outlook. Manila.

Ningbo, and Vientiane, and (ii) those with relatively sparce road network for city size such as Auckland, Nagoya, and Sydney.

The length of mass transit systems, combining both metro and bus rapid transits, shows a steady pattern of longer system length in larger cities. There are a few outliers such as Beijing and Shanghai which have substantially higher mass transit system than expected.

Those cities that suffer the greatest levels of congestion are also those that give the least space to transport systems. They have lower road and mass transit lengths. Bengaluru, Kathmandu, Manila, and Mumbai fall into this category.

The largest impact on urban transport over the last 30-40 years has been the increased use of private modes of transport. Figure 3 compares car trip mode shares in selected areas in Asia against an urban sprawl index or population density in built-up areas. While wealth and access to private transport modes has a role to play in this evaluation, Figure 3 shows the bulk of areas in Asia have a private vehicle mode share of under $30 \%$. Bangkok also stands out with a relatively high private trip mode share at almost $40 \%$, but the city's urban sprawl index is very high.

During the 1990s and early 2000s, Bangkok embarked on a major expressway network development. Coupled with the historical river and khlong, the network has transformed the city form with rapid sprawl made possible by 
Figure 2: Transit Length and Built-Up Areas

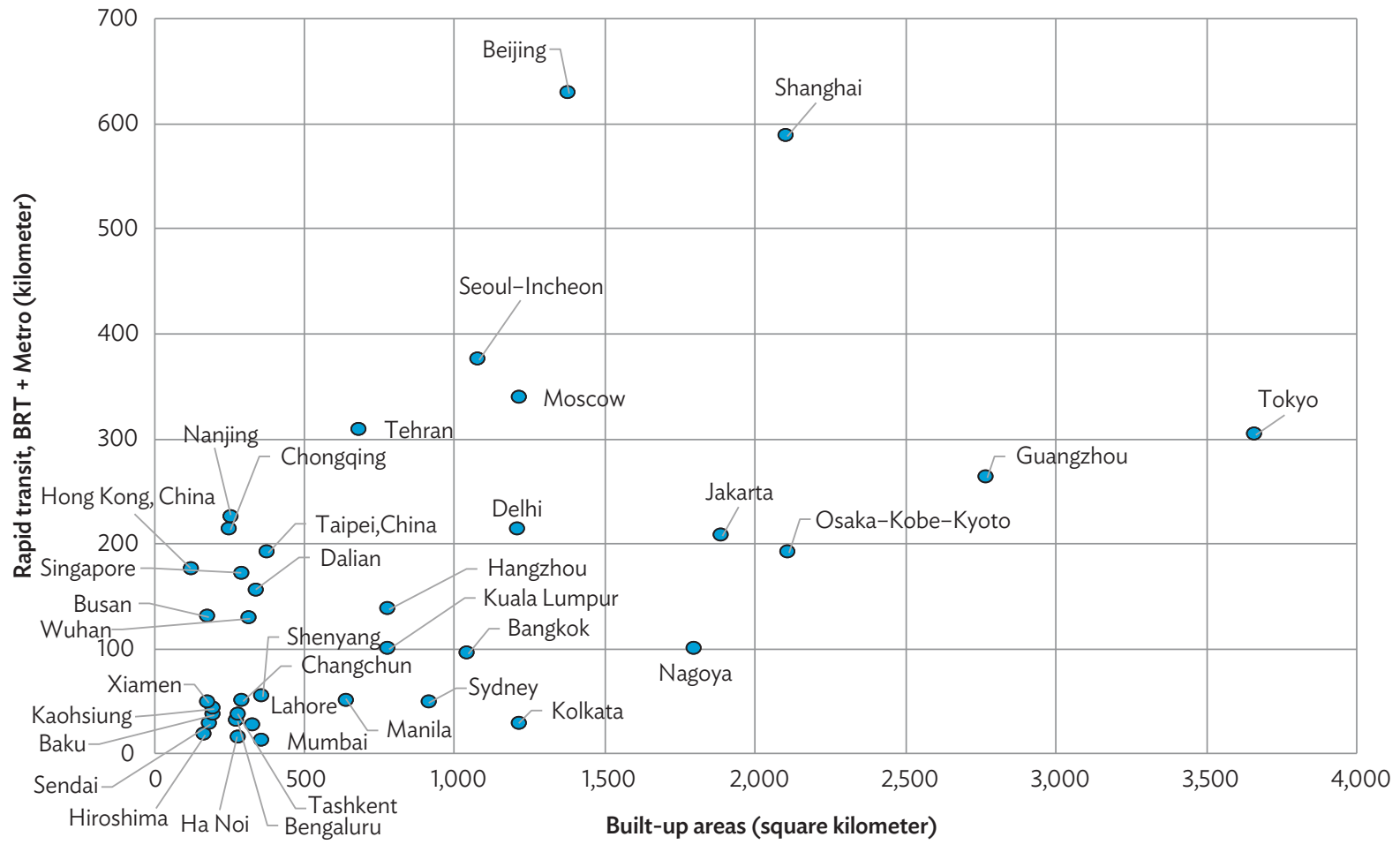

$\mathrm{BRT}=$ bus rapid transit.

Source: Asian Development Bank. Forthcoming. Asian Transport Outlook. Manila.

the access provided by the expressway network. ${ }^{2}$ It should also be noted that during this time, Bangkok was highly congested, and thus attempted to build its way out of congestion through the expressway investment program.

Mode share for urban transport trips is a good metric to assess efficient transport systems. Figure 4 shows the results of an assessment undertaken by ADB on the share of private trips (cars and motorcycles) compared to public transport and nonmotorized transport (walking and cycling). The ADB assessment aims to explore urban transport trends and to assess whether a sustainable mode share exists (ADB. 2009). The assessment report concludes that a $70 \%$ share of public transport and nonmotorized transport is a good gauge for sustainable urban transport systems. Areas that were lauded for their transport systems, such as Singapore, Seoul, and Tokyo, all fell within this range.

It is interesting that many cities in Asia's developing economies also fell within this range. Such cities have one distinct difference in that access to private modes of transport is limited. Thus, they have a relatively large transport mode share and they are the major users of public transport-motorized and nonmotorized. For many contemporary Asian cities, such characteristic is of great significance. 
Figure 3: Private Transport Modes and Urban Form

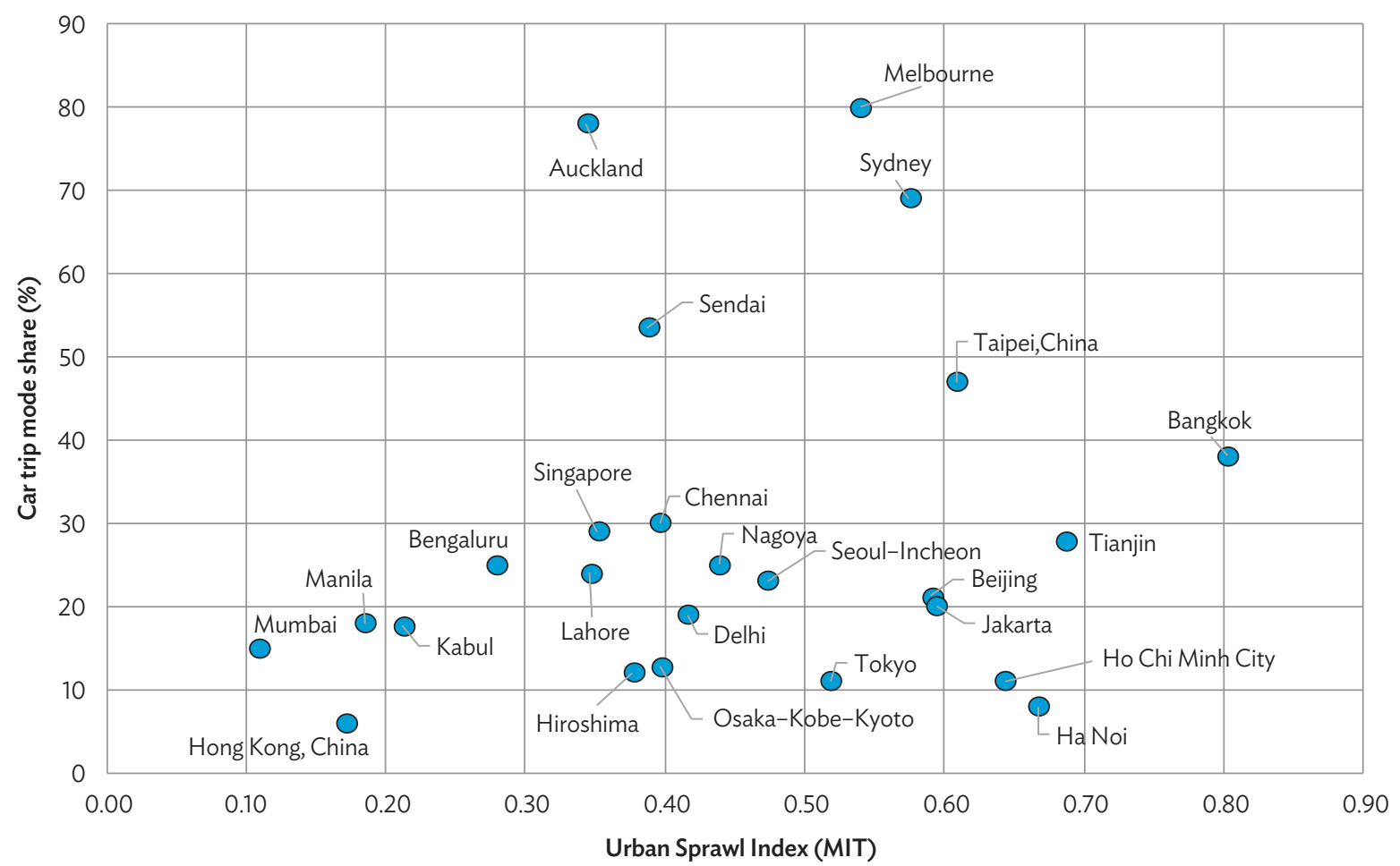

MIT = Massachusetts Institute of Technology.

Source: Asian Development Bank. Forthcoming. Asian Transport Outlook. Manila.

Figure 4: Transport Mode Share in Selected Areas in Asia

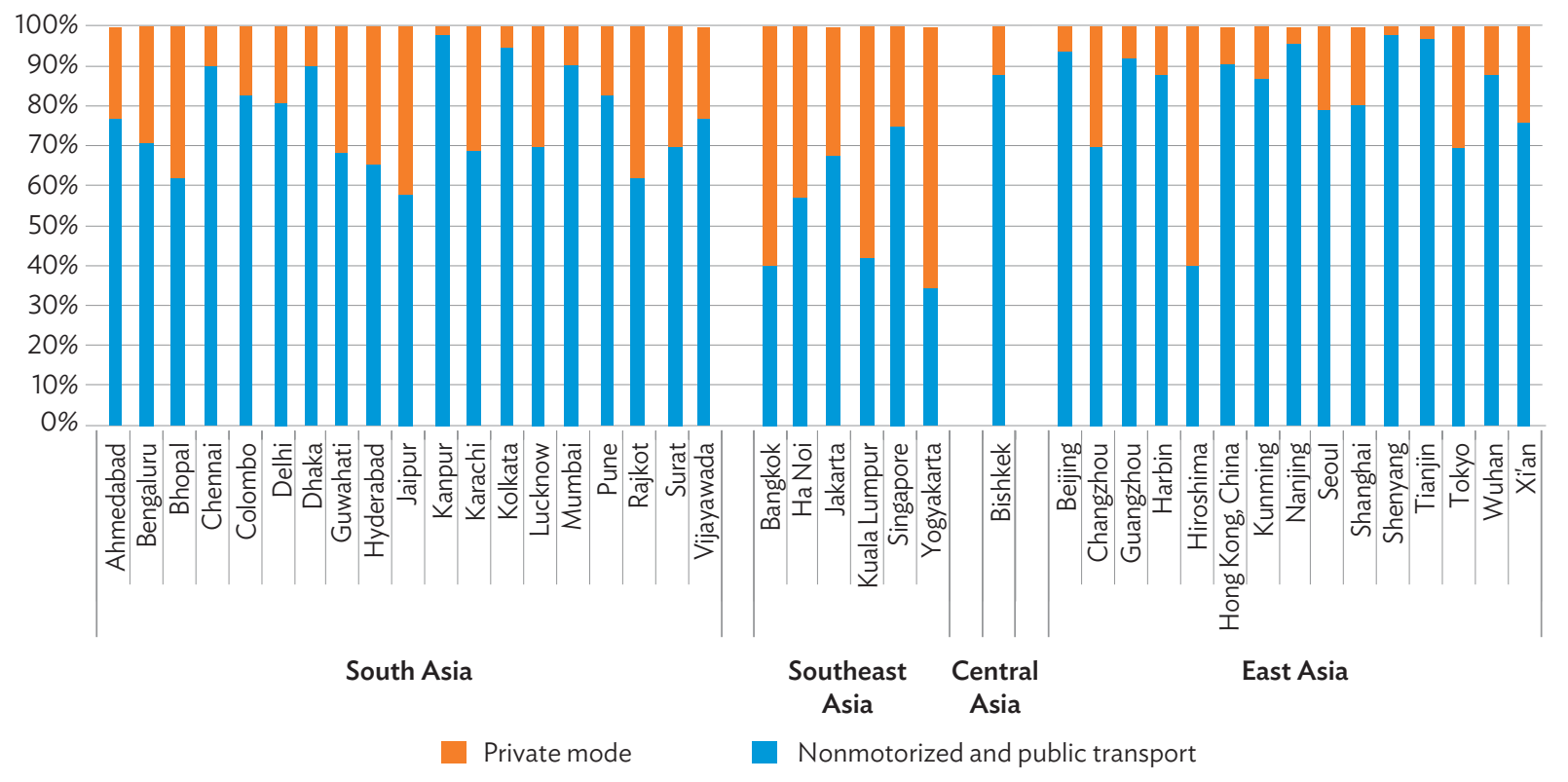

Source: Asian Development Bank. 2009. Changing Course. A New Paradigm for Sustainable Urban Transport. Manila. 
Figure 5: Barter's Transport Development Paths and City Typology

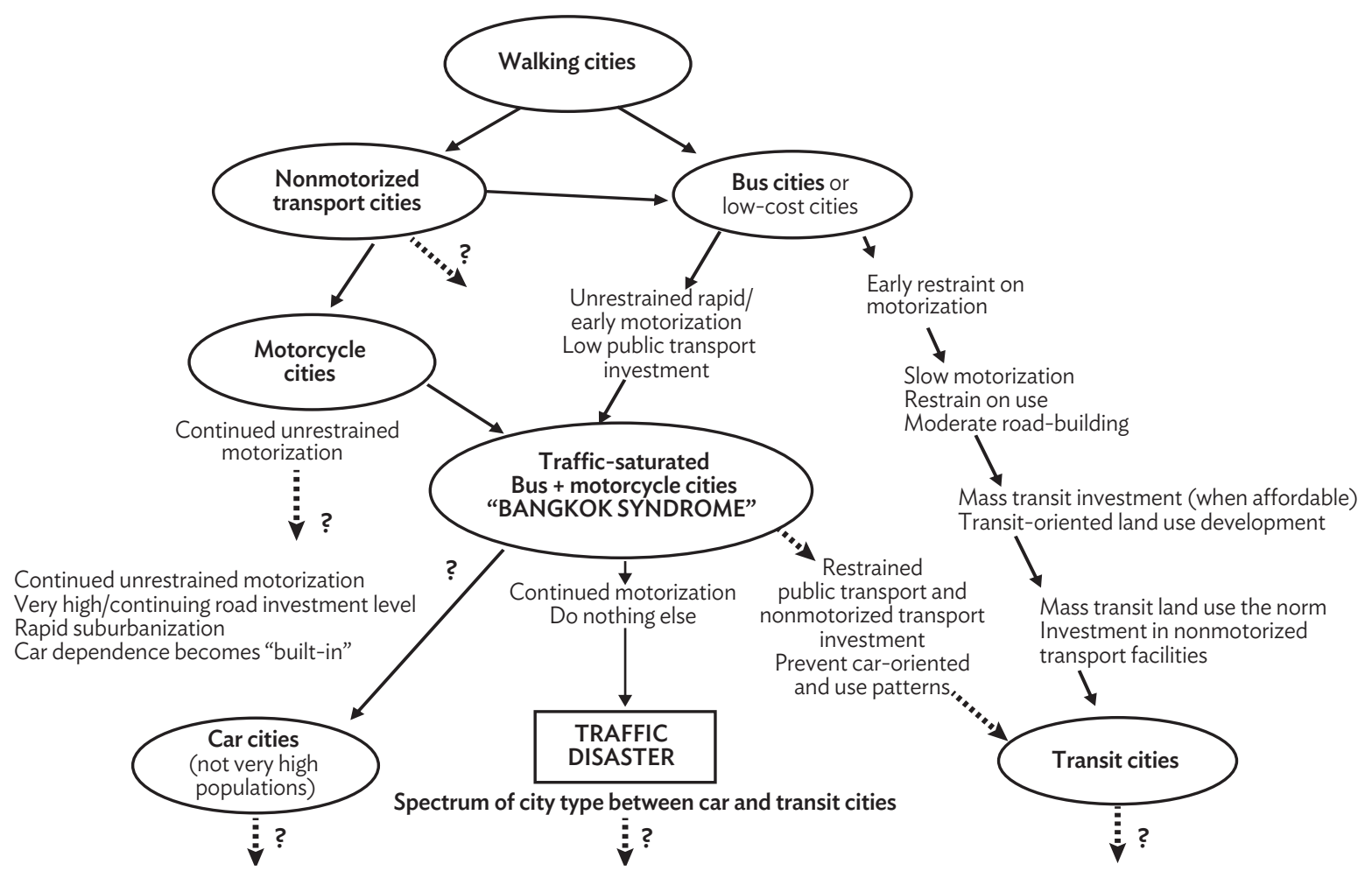

Source: Asian Development Bank. 2009. Changing Course. A New Paradigm for Sustainable Urban Transport. Manila

Over time, urban form and its transport system are determined by distinctive land use patterns, which arise in association with each new dominant transport mode. Asian cities are at a critical crossroads in their decision-making. Which direction will a city follow, that of private transport or that of public transport?

To plot such urban transport development paths and city typology, Paul Barter (2009) has developed a schematic representation of transport development paths. As above, suggests two generic transport policy options and city types: (i) one leading to "modern transit cities" based on early car restraint and promotion of public transport, and (ii) "car cities," the product of unrestrained motorization and continuing heavy road (and maybe later, rail) transport investment. All cities have choices, and depending upon their stage in urban development, these may lead to either a more, or less sustainable urban form. Cities may be seen as hybrids, having elements of more than one of these generic forms. Many Asian cities have characteristics of the congestion syndrome but have policy options to determine which path they will move-toward "modern transit cities" or toward "automobile cities." Figure 5 shows the intended or potential transport development paths for developing cities (Barter 2004).

Asian cities' rapid urbanization and growing vehicle ownership are starting to lead to urban sprawl, with worsening congestion, pollution, environmental degradation, road crashes, and declining quality of urban life. Transport contributes about $10 \%$ of greenhouse gas emissions of which $90 \%$ come from road transport. Energy usage by transport is the second highest in many countries and transport consumption of oil-based fuels is increasing rapidly. 
Fragmented institutional structures dealing with urban transport are very common in Asian countries and cities. Investment decisions and incentives have favored road investments to ease congestions for vehicles as opposed to managing transport demand to meet supply. The fragmented institutions, uncoordinated policy, and disjointed procedures and incentives have been the key reasons for unsustainable urban transport development.

Rationalized urban land use and transport planning that actively manages mobility and promotes sustainable and balanced mode shares have not been understood and realized in many Asian countries. The basic fact is that the majority of Asians travel by public transport and nonmotorized transport. However, most Asian countries have suffered from inadequate funding and operations of public transport and nonmotorized transport, while decision makers have busily engaged more investments on roads to ease traffic congestion. Urbanization sometimes has forced poor people to move further away from the urban center and thus increased the cost and time of travel. The major involuntary victims of road crashes have been those who are poor. Moreover, the lack of qualified staff at both national and local government levels to address the emerging problems is a serious issue in Asian countries.

ADB (2009) suggests that a consensus is emerging from transport practice and research and that there is no quick technological or policy fix for urban transport. Most action packages involve important trade-offs between objectives, most notably how much urban space is provided for accessibility and which specific transport modes, or combination of travel modes, should be used. Some robust "win-win" environmental strategies exist for the urban transport sector. Promotion of public transport and nonmotorized transport above private modes allows for more people to be carried in less space and with less energy use, especially if linked to improved fuel or power trains such as e-vehicles. This will result in less congestion and emissions such as greenhouse gases, sulfur oxides, nitrogen oxides, and particulate matter.

There are also some commonly agreed successful strategies and actions which would help Asian countries develop sustainable urban transport systems and build livable cities:

- Urban areas should respond to a given situation. Different cities, even in the same state or province of a country, may have different transport problems and solutions to solve them. Understanding the local conditions and needs is an essential step in selecting the most suitable development path.

- Consistency of policy, legislation, institutions, incentives, procedures, and capacity. Too often, urban planning and urban transport actions are time-bound and linked to political time frames of central or local government. Urban areas evolve over many years and the time needed to plan, implement, and start operations of major transport systems takes decades and often considerably longer than a political term. This is perhaps the biggest barrier to the development of sustainable urban transport systems in many cities.

- Prepare long-term plans based on large data sources. The use of big data sources provides knowledge of trip patterns, delivery needs, and accessibility to a level of detail that has not been possible in the past. Use of such data in the planning and operations of transport systems has been proven to deliver great results. Too often quick wins are sought or the planning process is carried out for a one-off investment. Long-term planning based on large data sources is therefore required.

- Consult all concerned agencies and transport users for any major decision. There are many agencies and stakeholders involved in the development of transport systems and urban form. City authorities, land use and transport planners, transport operators, and passengers or private vehicle users all have a role to play. Multi-stakeholder consultation is required to develop long-term development strategies that provide a balanced approach. A long-term strategy informed by large data sources and consultations allows for a shared and consistent vision toward a sustainable urban transport. 
- Prioritize public transport and nonmotorized transport over other transport modes. Due to space requirements, these forms of transport are far more sustainable than private modes of transport, especially private cars. In dense Asian urban areas, the selection of a city typology should be a forgone method as only an extensive public transport system is able to move the large volume of people that need to travel.

- Integrate all transport policies and modes. There is no single solution for urban transport issues. Almost all journeys consist of several legs, usually by different modes. Integrated planning is required to ensure the full journey is catered for.

- Improve traffic management and manage traffic demand. This is as important as providing good public transport systems and nonmotorized options.

- Start with experiments and engage in continuous evaluation and monitoring results. Urban areas evolve over time and so should the development and continual management and improvement of urban transport systems.

- Follow the "user pays" principle for full costs and externalities applied to private vehicles. Planning, implementing, operating, and managing a successful urban transport system is costly and timeconsuming. Sufficient budget is required. All revenue sources should be sought to cover such capital and operating costs.

Figure 6 provides a summary of the key success factors required to deliver sustainable urban transport as part of developing livable cities.

Figure 6: Key Success Factors for Sustainable Urban Transport

\section{Complex UT}

- Fast urbanization and motorization increasing GHG, energy and farm land

- UT planning and finance

- UT policy and procedure and incentive

- Focus on motor vehicle, but weakens poverty and social equity

- Inadequate PT and NMT

- Road equity

- Traffic congestions

- Freight transport and regional coordination

- New technology and ITS

- Inadequate capacity

\section{Ingredients for} Sustainability of UT

Based on local situations Consist of UT policy, procedure, incentive, finance

Sound analytic planning and implementation approach

- Coordinated institution and consultation with all

Prioritize PT and NMT Integration of UT

Better traffic demand management

- Experimenting and monitoring User-pays principle

\section{Livable Cities}

Better planned urban areas Better accessibility for all Less pollution Less accidents Low energy consumption Less land occupied Better environment for living Better attraction competent personnel

GHG = greenhouse gas emission, ITS = intelligent transportation system, NMT = nonmotorized transport, PT = public transport, UT = urban transport. 


\section{A New Paradigm for Transport and Urban Form}

Based on the strategies and actions provided in the previous section, the conclusion is clear that the future needs to be very different from the past. Little will happen without a major program of engagement to win the hearts and minds of influential politicians, technocrats, academics, community organizations, and business leaders. Such change poses challenges for all participants in the development process.

New thinking, based on the body of evidence, is required to set a new direction and harness the energy needed to confront the scale of the challenge ahead. This above all requires clarity about the types of cities the population wants and the decisive interventions necessary to catalyze these. Change in the mindset of many of the professionals engaged in the sector is required. New strategic thinking that is evidence-based is fundamental in ensuring a sustainable development path for urban transport and urban form.

City typology and the associated transport development paths can provide clarity on how to achieve a sustainable urban form. The strategies and actions outlined in the previous section show the most suitable and sustainable options to actively pursue and promote public transport and nonmotorized transport, while managing private modes. Such an approach provides a practical and comprehensive method for engaging with key stakeholders and presenting the key choices and possibilities open to them. The main conclusions are as follows:

- All cities have choices, but not all cities have the same choices. Past policies have created land uses and urban form that are to a considerable extent irreversible.

- Different urban types, described by their transport characteristics, exist in the real world (they result from empirical research of actual areas in Asia as shown in Figure 4). A shared vision is critical in getting into an important decision point.

- Best practices can provide an insight and understanding of where decisions taken today will lead cities over the next 10-20 years and beyond. Given the long planning and implementation period of metro or road construction, decisions taken today will only start to see the real benefits after many years in the future. Much can be learned from the development paths of urban areas across the region, and from seeing what decisions were taken when and the influences they have had on urban form.

- Urban planning and transport strategies can have a profound influence on changing the future urban form.

Creating successful transport systems for cities is a demanding challenge. A combination of several factors creates a difficult decision-making environment. Cities become locked into an urban form shaped by past decisions that are to a considerable extent irreversible. Timing is everything. The right decisions need to be taken at the right time.

Transport policy depends on the size and form of cities. Asia's developing cities display a huge variation. All are a product of their history. Some have become relatively affluent, while others remain less so. Some are developing dynamically with rapidly changing norms, while for others, change is gradual. Some are managed proactively, while for others, the government is more reactive to events. Given their diversity, it would be surprising if one transport agenda suited all cities, and indeed this is not so. The main determinants of the agenda in any urban area are their existing condition, their prospects and ambition, and their wherewithal to effect change. 
All cities grow over time. If the city is small, the transport system is necessarily modest. As the urban area grows, trips lengthen, requiring a bus system to control traffic congestion. As bus demands grow then busways become desirable, as are rail-based mass transit systems in the largest of cities.

A new paradigm for urban transport is therefore needed. The way in which decisions are taken about a city's transport system will influence its urban form now and in the future.

\section{References}

Asian Development Bank (ADB). 2008. Managing Asian Cities. Manila. https://www.adb.org/publications/ managing-asian-cities.

- - - 2009. Changing Course: A New Paradigm for Sustainable Urban Transport. Manila. https://www.adb.org/ publications/changing-course-new-paradigm-sustainable-urban-transport.

Buchanan, C. 1963. Traffic in Towns. London: Government of the United Kingdom, Ministry of Transport.

Christaller, W. 1933. Die zentralen Orte in Süddeutschland. Jena: Gustav Fischer.

Engels, F. 1845. The Conditions of Working Class in England. London.

Harris, C. D. and E. L. Ullman 1945. The Nature of Cities. The Annals of the American Academy of Political and Social Science. 242. pp. 7-17.

Hoyt, H. 1939. The Structure and Growth of Residential Neighborhoods in American Cities. Washington, DC: Federal Housing Administration.

Isard, W. 1956. Location and Space-Economy: A General Theory Relating to Industrial Location, Market Areas, Land Use, Trade, and Urban Structure. Cambridge: Technology Press of Massachusetts and Institute of Technology and Wiley.

Leather, J. and H. Fabian 2011. Walkability and Pedestrian Facilities in Asian Cities. Manila: Asian Development Bank.

Park, E. and E. W. Burgess 1925. The Growth of the City: An Introduction to a Research Project. The City. Chicago: University of Chicago Press. pp. 47-62.

Wrights, S. 2020. The World's Most Densely Populated Cities. www.worldatlas.com, https://www.worldatlas. com/articles/the-world-s-most-densely-populated-cities.html\#: :text=Manila\%20is\%20the\%20 earth\%E2\%80\%99s\%20most\%20densely\%20populated\%20city,country\%20that\%20gained\%20autonomy\%20 on\%20June\%2018\%2C\%201949. 


\title{
E-mobility: Transition to Sustainable Transport
}

\author{
Ki-Joon Kim and Ritu Mishra
}

\section{Background}

A well-functioning transport sector acts as the backbone of economic and social development. However, due to its dependence on fossil fuels, transport affects the worldwide climate through its emissions. Pollutants reduce air quality and have adverse effects on human health and ecosystems. In 2015, the transport sector emitted around 7.5 billion tons of carbon dioxide $\left(\mathrm{CO}_{2}\right)$ accounting for $18 \%$ of all anthropogenic $\mathrm{CO}_{2}$ emissions. The International Energy Agency (IEA) projects a 50\% increase of transport emissions by 2060, primarily from trucks and buses. Emissions from cars, small buses, and trucks that are less than 3.5 tons are expected to remain at current levels.

The majority of Nationally Determined Contributions (NDCs), a key achievement of the Paris Agreement, identify transport as an immediate mitigation priority. Multiple countries in Asia have made electric mobility (e-mobility) pledges. Electrification of vehicles is one of the megatrends in mobility and is vital to the decarbonization of transport.

Known as a "clean disruption," electric vehicles are rapidly emerging. They offer a promising solution for alleviating the health and environmental burdens caused by the transport sector. Electric vehicles are gaining momentum in light of recent announcements by several major car manufacturing countries to ban sales of internal combustion engine (ICE) cars in the near future, and the plans of major cities to restrict cars using diesel engines from their urban centers.

In contrast to these bans, there is increased enthusiasm for electric vehicles, with many developing countries and cities committing to electric vehicle deployment to varying degrees. Business communities are also generating business models to promote electric vehicle adoption.

Despite the growing sales of electric vehicles and announcements of policy and deployment plans by many countries and cities, the market share of electric vehicles is still very limited. It has yet to reach a critical point wherein meaningful emissions reduction takes place. Having projected to reach competitive pricing compared to ICE cars by the 2020s, global electric vehicle sales are expected to grow to 125 million by 2030.

The electrification of transport is no longer a question of "should or should not"-it is an ongoing trend. Choosing the right path can enable electric vehicles and help keep pollution and greenhouse gas (GHG) emissions in check. Achieving this requires dedicated efforts and strategic decision-making at national and subnational levels. Electrification of transport needs an industrial policy governing the manufacturing of electric vehicles, the development of charging stations, the availability of mobility services, a mix of energy supply, and interactions with financial institutions. 
This article focuses on pure electric vehicles. 'While hybrid and plug-in hybrid vehicles help reduce fuel consumption, for many countries, it is far more attractive to switch directly from fossil fuel vehicles toward electric vehicles. Fuel cell vehicles are excluded due to their large energy consumption associated with the production of hydrogen. They have roughly three times higher energy usage compared to electric vehicles. Fuel cell vehicles potentially emit higher GHG compared to fossil fuel vehicles. This article also focuses on road transport encompassing all types of vehicles. While electrification is also an option for rail, shipping, and, in the future, aviation, they are beyond the scope of this article.

\section{Electric Vehicles and their Components in Different Transport Modes}

Electric vehicles exist in all transport modes and vehicle categories. In air transport, large electric planes are only used on an experimental basis. Electric drones (e.g., for freight delivery electric planes) are already commercially available. In water transport, some electric vessels, such as cargo ships, barges, and ferries, operate basically for short-haul fluvial and lake applications. As an example, two ferries operating a four-kilometer route between Helsingborg (Sweden) and Helsingör (Denmark) are fully electric. Each vessel is 238 meters long and weighs more than 8,000 tons.

Electrification is common in rail transport, especially for urban rail transport, such as metro and light rail transit and urban cable cars. However, diesel trains are still very popular in intercity rail transport, especially for freight.

Electric vehicles used in road transport range from two-wheelers, to electric buses, to long-haul trucks. However, they have different market penetration rates. Electrification of two-wheelers (motorcycles and e-bicycles), urban buses, three-wheelers (partially), and taxis is quite popular in some countries. Meanwhile, electric trucks and electric vehicles for long-haul applications are still quite rare.

Hybrid electric vehicles (HEVs) are becoming increasingly popular. HEVs are more efficient than conventional vehicles due to their regenerative brakes that shut off the ICE during idling, and due to having two sources of onboard power allowing the ICE to be operated, more often, near its peak efficiency. According to the US Environmental Protection Agency (EPA), hybrid passenger cars reduce fuel consumption by $25 \%-30 \%$. While hybrid vehicles do have important energy savings, they still operate with fossil fuel engines and can only reduce $20 \%-30 \%$ of emissions. Hybrids today can already be financially profitable for high-mileage vehicles. However, at the end of the day, hybrids are largely perceived as an intermediate technology toward full transport electrification.

The majority of heavy-duty vehicle hybrids consists of buses and a very few hybrid trucks in operation. The major application of hybrid systems is on urban buses because the best performance, emission reductions, and cost savings of hybrids generally occur when the energy storage system is fully utilized (i.e., cycles with frequent starts and stops, low speeds, and idling which are typically prevalent in urban circumstances). The average fuel saving of hybrid buses is $20 \%-25 \%$ compared to conventional buses. Differences between cities are basically due to bus types and brands, driving conditions of cities, and different hybrid systems.

This article is a summary of J. Grütter and K. Kim. 2019. E-Mobility Options for ADB Developing Member Countries. ADB Sustainable Development Working Paper Series. No. 60. Manila: Asian Development Bank. 
Plug-in hybrid electric vehicles (PHEVs) are vehicles with a larger battery than HEVs. They can be plugged in to recharge the vehicle battery. The fuel savings and emission reductions from $\mathrm{PHEV}$ s are largely dependent on the percentage of annual mileage driven in electric mode, which again is partially dependent on how frequent PHEVs are plugged in. An ADB study (2018) was conducted in 18 cities in the People's Republic of China (PRC) that have a plug-in hybrid bus fleet of more than 10,000 units.

The study reveals that plug-in hybrid buses are not regularly recharged from the grid. Average fuel savings of plug-in hybrids are identical to those of the same size conventional hybrids in every city. Plug-in hybrid buses are not plugged in as they are equipped with a small battery size, typically 25 kilowatt-hours (kWh) for a 12-meter bus, which reduces the advantage of recharging. Bus operators purchase plug-in hybrids instead of conventional hybrids because plug-in hybrids are heavily subsidized, while subsidies for conventional hybrids have been phased out. Hence, the actual impact and cost-effectiveness of PHEVs is difficult to estimate.

Battery electric vehicles (BEVs) are full electric vehicles that include a battery or capacitor and an electric motor. A wide array of vehicle technologies exists, such as, in the case of electric buses, electric trolleybuses, opportunity charge buses, and battery electric buses (BEBs).

Fuel cell electric vehicles (FCEV) use fuel cells that - like conventional batteries-are electrochemical devices that generate electricity directly by separating positive and negative charges. An FCEV uses a hydrogen fuel cell as the power source for the drive wheels, sometimes augmented with batteries or a super capacitor. Like BEVs, these vehicles have zero tailpipe emissions, but have potential emissions from the production and distribution of hydrogen.

\section{The Electric Vehicle Market and Preliminary Assessment of Electric Vehicles' Potential in Developing Asia}

\section{Electric Vehicle Market}

By 2017, 3 million electric and plug-in hybrid cars were plying the world's roads. Electric vehicle sales are increasing worldwide, but are still disproportionally concentrated in few countries. Around $80 \%$ of all electric vehicles are sold in just three countries: the PRC, Norway, and the United States. In Norway-which is clearly ahead of other countries - a critical mass of adoption has been achieved (Figure 1). Electric vehicle passenger car sales surpassed 1 million units for the first time in 2017. By 2020, it is projected that 4.5 million electric vehicles could be sold, which is around $5 \%$ of the global passenger car sales. By 2030, this figure could reach $20 \%$ of global vehicle sales, of which 35\% is in Europe (McKinsey 2018).

Asian countries with a sizable pure electric car stock in 2017 are the PRC with 950,000 units (470,000 additional units in 2017), Japan with 104,000 units (18,000 additional units in 2017), and the Republic of Korea with 24,000 units (13,000 additional units in 2017). In 2017, India had an electric vehicle stock of 7,000 units (2,000 more than in 2016) and Thailand had 800 (300 more than in 2016). The market share of new sold electric vehicles in 2017 in the PRC was 1.8\%, in the Republic of Korea 1.1\%, in Japan 0.3\%, and in India 0.06\%. Worldwide, the electric vehicle share of new sold vehicles is $0.5 \%$. 
Figure 1: Electric Vehicle Market Adoption

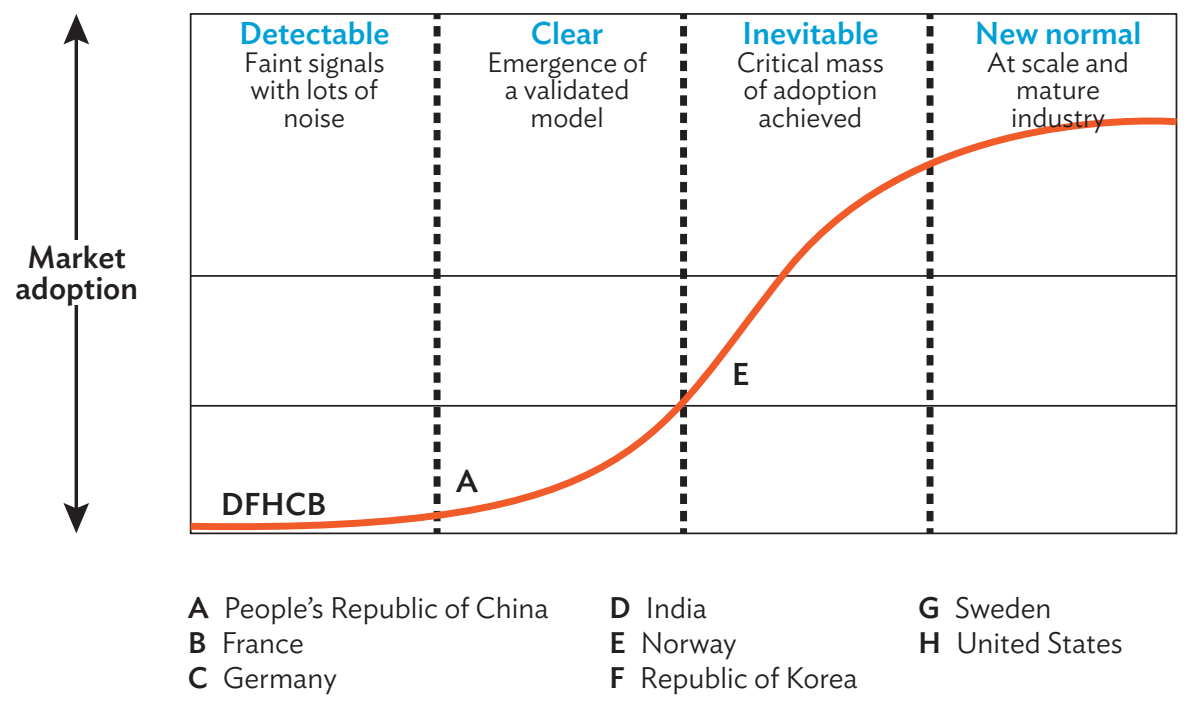

Source: C. Bradley, M. Hirt, and S. Smit 2018. Strategy Beyond the Hockey Stick. McKinsey \& Company.

Electric vehicle sales are not only concentrated in certain countries, but also in few metropolitan areas, with just 20 cities accounting for around $40 \%$ of the world's electric passenger cars. This includes various PRC cities (notably Qingdao with 11\% of new passenger car sales in 2016, that is, pure electric, and similarly Beijing with a share of $8 \%$ ); some European cities (notably Oslo with a share of $33 \%$ of pure electric and plug-in new passenger car sales in 2016, of which the majority are pure electric); and few US cities (notably San Jose with a 10\% share of new car sales in 2016, including pure electric and plug-ins).

In 2017, around 3 million chargers had been installed, of which around 330,000 units were publicly available. They comprised two-thirds slow chargers and one-third fast chargers. Publicly accessible infrastructure, especially fast chargers, is growing rapidly. The number of charging facilities, especially fast-charge facilities, is an important issue as concerns about charging facilities are among the main reasons why consumers do not purchase electric vehicles (Figure 2).

The PRC dominates the electric two-wheeler market with around 26 million units sold in 2016 and a vehicle stock estimated at 200 million to 230 million units (IEA 2017, 2018). ${ }^{2}$ This represents around $40 \%$ of the world's total two-wheeler fleet. While the PRC's share of two-wheelers is expected to drop in the future, it still accounts for a massive share of vehicle stock as well as vehicles sold in most Asian countries.

In 2017, there were around 385,000 electric buses on the roads worldwide, with $99 \%$ of the total located in the PRC (Bloomberg New Energy Finance 2018). The e-buses in the PRC made up around 17\% of the total bus fleet and $22 \%$ of new bus sales in 2017, with many cities going for electric bus fleets within the next few years. It is projected that battery electric bus (BEB) deployment will increase by three times until 2025 and reach 1.2 million units, with the large majority being operated in the PRC. Apart from BEBs, electric trolleybuses are used in many Asian countries including Armenia, Kazakhstan, Mongolia, and the PRC (Bloomberg New Energy Finance 2018).

2 The total two-wheeler sales worldwide in 2017 is around 30 million (IEA 2018). 
Figure 2: Key Concerns of Consumers on Electric Vehicles

$(\%)$

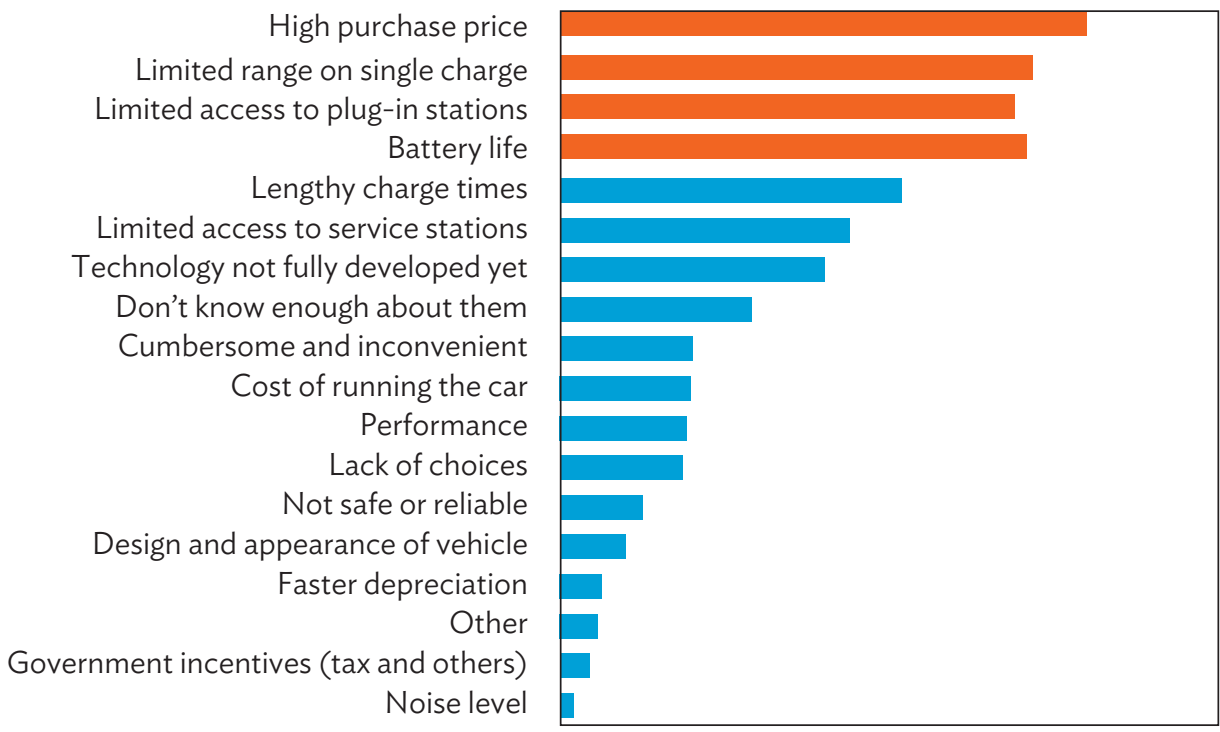

Source: UBS. 2017. UBS Evidence Lab Electric Car Teardown - Disruption Ahead? https://neo.ubs.com/shared/d1wkuDIEbYPjF/.

The PRC also dominates BEB manufacturing with Yutong (the market leader with 19\% of market share), BYD, Zhontong, and Jinlong having a combined market share of 50\% in 2016. Outside the PRC, less than 2,000 BEBs were operating as of 2017. ${ }^{3}$ However, this is expected to change rapidly in the next few years with many cities worldwide gearing up for electric buses. In Europe, for example, the International Association of Public Transport estimates that the market share of urban electric buses will exceed $50 \%$ by 2030 .

The total cost of ownership plays a more important role in the purchase of commercial vehicles compared to passenger cars. It is expected that especially for light- and medium-duty trucks, the total cost of ownership parity with diesel units will be reached in the next decade. With improved model availability, tightening of regulations especially in urban zones, and an established charging infrastructure, it is expected that after 2025, light- and medium-duty electric trucks will start to penetrate the market increasingly, followed by heavy-duty trucks (McKinsey 2017). However, $75 \%$ of freight truck GHG emissions are attributable to heavy-duty trucks.

\section{Preliminary Assessment of the Potential of Electric Vehicles in Developing Asia}

This section assesses the potential of electric vehicle uptake and its potential impact on ADB developing member countries (DMCs). The assessment is based on existing market proliferation of electric vehicles in the country, environmental criteria (GHG and local pollution impact), financial conditions, and policies in place. Table 1 shows the criteria, parameters, and benchmarks used.

3 The number of electric buses including trolleybuses was, however, much larger. In Switzerland alone, around 550 electric trolleybuses (10\% of the bus fleet) are operating. Federal Office for Statistics. Road Vehicles: Stock, Degree of Motorisation. https://www.bfs.admin.ch/bfs/de/home/statistiken/mobilitaet-verkehr/verkehrsinfrastruktur-fahrzeuge/fahrzeuge/strassenfahrzeugebestand-motorisierungsgrad.html (accessed 18 October 2018). 
Table 1: Assessment Criteria, Parameters, and Benchmarks

\begin{tabular}{|c|c|c|c|}
\hline Criteria & Relevance & Parameter & Benchmark \\
\hline $\begin{array}{l}\text { Market } \\
\text { proliferation }\end{array}$ & $\begin{array}{l}\text { A significant market share } \\
\text { of electric vehicles means } \\
\text { that a good public charging } \\
\text { infrastructure is in place and } \\
\text { that awareness of electric } \\
\text { vehicles is high, resulting in } \\
\text { faster market adoption. }\end{array}$ & $\begin{array}{l}\text { Number } \\
\text { of electric } \\
\text { vehicles in } \\
\text { the country }\end{array}$ & $\begin{array}{l}\text { - Low: less than } 1,000 \text { electric vehicles } \\
\text { excluding trolleybuses } \\
\text { Moderate: less than } 0.5 \% \text { market share or } \\
\text { limited to two- and/or three-wheelers } \\
\text { - High: more than } 0.5 \% \text { market share and at } \\
\text { least three subcategories of vehicles with } \\
\text { more than } 1,000 \text { units (buses, trucks, cars, } \\
\text { motorcycles, three-wheelers) }\end{array}$ \\
\hline GHG impact & $\begin{array}{l}\text { The potential GHG reduction } \\
\text { impact of electric vehicles per } \\
\text { replaced fossil fuel vehicle }\end{array}$ & $\begin{array}{l}\text { Carbon factor } \\
\text { of electricity }\end{array}$ & $\begin{array}{l}\text { - Low: grid factor more than } 0.8 \mathrm{kgCO}_{2} \mathrm{e} / \mathrm{kWh} \\
\text { - Moderate: grid factor between } 0.35 \text { and } \\
0.8 \mathrm{kgCO}_{2} \mathrm{e} / \mathrm{kWh} \\
\text { - High: grid factor below } 0.35 \mathrm{kgCO}_{2} \mathrm{e} / \mathrm{kWh}\end{array}$ \\
\hline \multirow[t]{2}{*}{$\begin{array}{l}\text { Local } \\
\text { pollution } \\
\text { impact }\end{array}$} & \multirow{2}{*}{$\begin{array}{l}\text { A high impact on pollution can } \\
\text { be expected in countries with } \\
\text { low vehicle emission standards. } \\
\text { The relevance of the pollution } \\
\text { impact is expressed through the } \\
\text { economic costs of pollutants. }\end{array}$} & $\begin{array}{l}\text { Emission } \\
\text { standard of } \\
\text { vehicles }\end{array}$ & $\begin{array}{l}\text { For emission standard: } \\
\text { - Low: Euro } 4 \text { or Euro } 5 \\
\text { - Moderate: Euro } 2 \text { or Euro } 3 \\
\text { - High: no emission standard }\end{array}$ \\
\hline & & $\begin{array}{l}\text { Economic } \\
\text { cost of } \\
\text { pollution }\end{array}$ & $\begin{array}{l}\text { For economic cost: } \\
\text { - Low: pollution costs in the lower } 20 \text { percentile } \\
\text { of DMCs } \\
\text { - Moderate: pollution costs between the lower } \\
\text { and upper } 20 \text { percentile of DMCs } \\
\text { - High: pollution costs in the upper } \\
20 \text { percentile of DMCs }\end{array}$ \\
\hline $\begin{array}{l}\text { Financial } \\
\text { condition for } \\
\text { electric } \\
\text { vehicles }\end{array}$ & $\begin{array}{l}\text { One of the most important } \\
\text { market conditions for the } \\
\text { adoption of electric vehicles } \\
\text { is fossil fuel price as this is the } \\
\text { major parameter influencing } \\
\text { relative operational costs } \\
\text { between electric vehicles and } \\
\text { conventional vehicles. }\end{array}$ & $\begin{array}{l}\text { Diesel and } \\
\text { gasoline price }\end{array}$ & $\begin{array}{l}\text { Low: fuel prices in the lower } 20 \text { percentile } \\
\text { of DMCs } \\
\text { Moderate: fuel prices between the lower and } \\
\text { upper } 20 \text { percentile of DMCs } \\
\text { - High: fuel prices in the upper } 20 \text { percentile } \\
\text { of DMCs }\end{array}$ \\
\hline Policies & $\begin{array}{l}\text { Policies and incentives in } \\
\text { place are core factors for the } \\
\text { uptake of electric vehicles. }\end{array}$ & $\begin{array}{l}\text { Policies and } \\
\text { incentives } \\
\text { in place }\end{array}$ & $\begin{array}{l}\text { - Low: no policies in place } \\
\text { - Moderate: initial to moderate policies in place } \\
\text { - High: moderate to strong policies in place }\end{array}$ \\
\hline
\end{tabular}

$\mathrm{DMC}=$ developing member country, $\mathrm{GHG}=$ greenhouse gas, $\mathrm{kgCO}_{2} \mathrm{e} / \mathrm{kWh}=$ kilogram of carbon dioxide equivalent emission per kilowatt-hour.

Note: The borders are determined based on the upper and lower 20 percentile of all the grid factors in Asian Development Bank (ADB) DMCs.

Source: J. Grütter and K. Kim. 2019. E-Mobility Options for ADB Developing Member Countries. ADB Sustainable Development Working Paper Series. No. 60. Manila: Asian Development Bank.

The cumulative result shows the gross potential of countries for electric vehicle promotion based on a cumulative, non-weighted summary of the criteria shown in Table 1, assigning 1 point for every low mark, 2 points for every moderate mark, and 3 points for every high mark. Low potential is given for countries with 5-7 points, moderate potential for countries with 8-12 points, and high potential for countries with 12-15 points. Considering all criteria, Nepal and the PRC have the highest electric vehicle potential, while those with low potential include Azerbaijan, Kazakhstan, Turkmenistan, and Uzbekistan. However, electric vehicles are basically promoted to 
improve the environment. In Table 2, the environmental criteria help identify countries where electric vehicles would have a significant environmental impact and countries where electric vehicles will only have a marginal environmental impact.

Considering the environmental aspects only, the countries with the highest potential to promote electric vehicles are Lao People's Democratic Republic, Georgia, and Tajikistan. Myanmar and Nepal are also of high potential. The lowest environmental impact is observed in India, where a greening of the energy grid is imperative.

Table 2: Environmental Potential of Electric Vehicles in ADB Developing Member Countries

Electric Vehicle Potential

Low environmental impact

Low to moderate environmental impact

Moderate environmental impact

Moderate to high environmental impact

High environmental impact

GHG = greenhouse gas, Lao PDR = Lao People's Democratic Republic, PRC = People's Republic of China.

Note: Based on cumulative impact on GHG reduction potential (measured with the carbon grid factor) and the local pollution impact measured by the combination of the current emission standard for fossil fuel vehicles and the cost of environmental pollution (for sulfur dioxide, nitrogen oxide, and particulate matter). High grid factor results in low GHG reduction potential of electric vehicles and vice versa. The higher the cost of pollutants, the larger the impact of electric vehicles are and vice versa.

Source: J. Grütter and K. Kim. 2019. E-Mobility Options for ADB Developing Member Countries. ADB Sustainable Development Working Paper Series. No. 60. Manila: Asian Development Bank.

\section{Charging Infrastructures and the Grid}

The number of chargers per vehicle will depend largely on the country, the density of electric vehicles, and the power of chargers. Leading electric vehicle countries have a large number of public charging points. However, there is no universal benchmark for the ratio of electric vehicles to chargers. California, for example, has 25 to 30 electric vehicles per public charger; electric vehicle owners have frequent access to home and workplace charging and thus require minimum access to public chargers. In the Netherlands, the ratio is two to seven electric vehicles per public charger; however, private parking space is limited.

Research suggests that the installed electrical capacity required to meet the demand from electric vehicles by 2030 will not be a major constraint (ADB 2018). The IEA, in its $2^{\circ} \mathrm{C}$ global warming scenario, estimates that the additional generation needed to meet electric vehicle demand represents only $1.5 \%$ of total electricity demand by 2030. However, this statement is not relevant in the case of small grids and with large electric vehicle penetration rates. For example, the electricity demand from electric vehicles for Fiji-assuming the country would only introduce electric vehicles by 2030 - would be four times higher than the current production level. 
Running 100\% electric vehicles stresses the grid in both electricity production and power demand. Electric vehicle charging can have a sizable impact on the loads applied to the grid at certain times and locations. The rise in the number of electric vehicles can be accommodated fairly by power generation facilities as long as the vehicles are charged off-peak. Faster charging during peak demand, however, can have a significant impact.

The extent to which electric vehicles will impact the electricity networks will depend greatly on technologies and charging modes used, with the bulk of charging expected to occur in low-voltage distribution grids in residential or commercial areas. Therefore, grid management is considered critical rather in terms of absolute capacities. Problems which can occur include increased peak loads and charging hotspots resulting in local network overloading.

Solutions proposed for these problems involve controlled charging and smart charging using demand-side management. The effectiveness of demand-side management can be enhanced by bidirectional "vehicle-togrid" capabilities where power can flow from the grid to the vehicle and vice versa. This could also be an attractive source of revenue for electric vehicle owners. For fast charging, managing power demand is also likely to require the deployment of stationary storage at the local level.

High-powered chargers potentially result in overloading of local grids and can lead to very high demand charges, resulting in high electricity prices. One way to resolve this problem is stationary battery storage with on-site batteries charging at lower power from the grid. When costs are lower, store the power, and release it when demand is higher (a practice called "peak shaving"). This is done, for example, on the Geneva TOSA line where buses are charged ultrafast at stations from 15 seconds to 30 seconds with $600 \mathrm{~kW}$ based on on-site batteries, which are continuously charged at lower power levels.

Increasing renewable energy penetration rates requires sufficient energy storage systems due to unpredictability of renewable sources (e.g., wind and solar) especially for small isolated island states. Electric vehicle fleets could play a role as distributed energy storage systems, thereby helping to increase the share of renewables. Second-life batteries from electric vehicles can also play an important role for storing the fluctuating supply of energy from renewable sources.

\section{Electric Vehicles and the Environment}

The emission sources of vehicles can be divided in two categories: (i) fuel- and/or energy-related emissions and (ii) other emissions. Combustion emissions occur when operating the vehicle and, for GHGs, are directly related to the energy usage of the vehicle. They are separated in direct or tank-to-wheel and indirect or well-to-tank emissions (combined well-to-wheel emissions). Emissions coming from vehicle manufacturing, maintenance, and disposal emissions are categorized as other emissions.

Electric vehicles have no direct or combustion emissions. With its indirect or upstream emissions caused by energy production and distribution, electric vehicle performance in terms of GHG emissions is directly related with electric grid. The Asian countries with the largest GHG impact from electric vehicle deployments are those with a high share of renewable electricity production, such as Armenia, Bhutan, Georgia, the Kyrgyz Republic, the Lao People's Democratic Republic (Lao PDR), Nepal, and Tajikistan. Meanwhile, deploying electric vehicles in countries with a high carbon factor in electricity production, such as India, Indonesia, Kazakhstan, Mongolia, and Turkmenistan, will only result in limited GHG. 
GHG emissions also result from the production of vehicles and their components, and specifically in the case of electric vehicles, from batteries. GHG emissions stemming from battery production can be significantly reduced because electric vehicle batteries can be reused for stationary applications after their useful life span on the vehicle terminates. Also, electric vehicles save on vehicle manufacturing-related emissions due to less usage of materials for engine manufacturing, less or no usage of oils and lubricants, and a longer vehicle life span due to less vibrations and therefore longer-lasting parts.

Upstream manufacturing emissions account for less than 5\%-10\% of total GHG emissions for buses and trucks, while for passenger cars, the figure is 15\%-30\% (depending on the electric grid). In all cases, even if including all upstream and downstream emissions, electric vehicles will result in significant $\mathrm{GHG}$ reductions if the grid factor is below 0.8 kilogram of $\mathrm{CO}_{2}$ equivalent emission per kilowatt-hour $\left(\mathrm{kgCO}_{2} \mathrm{e} / \mathrm{kWh}\right)$.

Aside from reducing GHG emissions, electric vehicles also reduce local pollutants, including particulate matter, nitrogen oxide, and sulfur dioxide. The magnitude of the impact will depend largely on the prevailing vehicle emission standards of the country and the type of vehicle replaced (fuel type and vehicle category). In general, it can be stated that pollution impacts will be significant if urban buses, trucks, diesel passenger cars, and threewheelers are replaced. Even if such vehicles theoretically comply with stringent emission standards, the practical experience is-diesel vehicles are not well maintained and real-world emissions are far higher than what vehicle manufacturers claim. In simple terms, clean air in urban areas is not achievable with diesel vehicles. Electric vehicles also have significantly lower noise levels especially during the start-and-stop, and at low speeds where engine noise dominates.

The impact of electric vehicles on GHG reductions will be far higher by deploying commercial electric vehicles instead of private units. In general, commercial vehicles have higher fuel usage, higher mileage, and longer life span. Replacing one urban diesel bus with an electric unit has the same impact as replacing 35 fossil fuel passenger cars or 300 motorcycles. Therefore, a focus on commercial vehicles maximizes the emission impact. Box 1 presents a case in Shenzhen, PRC.

\section{Electric Vehicle Economics}

The financial and economic viability of electric vehicles will depend basically on (i) the level of fossil fuel prices, (ii) the level of electricity prices, (iii) the financial incentives for electric vehicles, and (iv) the nonfinancial incentives for electric vehicles. The significant upfront subsidies in countries with high electric vehicle numbers is a clear indication that electric vehicles are currently not considered as financially profitable. As an example, Norway, which has the highest share of electric cars, subsidizes $45 \%$ of the electric vehicle price. On the other hand, the PRC, which has the largest number of electric cars, subsidizes $23 \%$ of the total price while also giving numerous other benefits.

The capital expenditure (CAPEX) of an electric vehicle can be broken down largely into the cost of its battery (40\%-50\%), electric power train (about 20\%), and other elements of the vehicle itself (30\%-40\%). The CAPEX of electric vehicles is significantly higher than that of conventional vehicles. The purchase cost remains the most cited barrier to entry of potential electric vehicle customers. Also, many electric vehicles will require battery replacement (especially buses and trucks) during their commercial life span, thus incurring a significant replacement investment. 


\section{Box 1: Electrification of Buses in Shenzhen}

In 2009, Shenzhen, a city in the People's Republic of China (PRC), was selected as one of the pilot cities for demonstration and promotion of new energy vehicles. The Government of the PRC has pushed a 100\% electrification of its bus fleets. As of 2018, Shenzhen has electrified its entire fleet of 16,359 buses.

Bus electrification have been highly positive and brought some clear benefits to Shenzhen. Fuel consumption is reduced by more than $95 \%$ in the public transport industry. Based on the daily operating mileage of 174.4 kilometers $(\mathrm{km})$ and energy consumption of 106.3 kilowatt-hours per $100 \mathrm{~km}$ in Shenzhen in 2016, it was found that energy consumption was $72.9 \%$ less than that of the diesel buses. This resulted in 366,000 tons of coal saved annually, substituted by 345,000 tons of alternative fuel, according to the Shenzhen Municipal Transportation Commission.

Looking at the impacts on the environment, there was massive reduction in carbon dioxide $\left(\mathrm{CO}_{2}\right)$ emissions. The 2017 data showed a decrease of $\mathrm{CO}_{2}$ discharge of 1.353 million tons. Also, the annual emission of pollutants such as nitrogen oxides, non-methane hydrocarbons, and particulate matter was reduced by 431.6 tons, according to the statistics from the Shenzhen Municipal Transportation Commission. Apart from that, pursuance of electric buses seems improving compared to diesel buses.

Source: Institute for Transportation and Development Policy. 2018. China Tackles Climate Change with Electric Buses. 11 September. https://www.itdp.org/2018/09/11/electric-buses-china/.

Electric vehicle costs are declining rapidly basically due to cost reductions of batteries. Not only has the battery cost per kilowatt-hour ( $\mathrm{kWh}$ ) declined, but at the same time, the battery energy density and the vehicle efficiency has increased. This results in either longer driving ranges with the same battery pack or a smaller battery pack, thus reducing vehicle costs beyond the battery cost reduction per $\mathrm{kWh}$. Another important component is that low-cost, fast-charging options have surged, thus allowing vehicles to use smaller battery packs with more frequent intermediate fast-charging.

A higher CAPEX of the vehicle can be recovered either through (i) lower operational expenditure and/or (ii) a longer lifetime of the vehicle. In the case of buses, for example, batteries are guaranteed as of 2018 by most manufacturers for 8 years with a state of charge of $80 \%$. Electric vehicles have a longer technical life span than conventional vehicles due to having less parts and less vibrations.

Compared to fossil fuel vehicles, electric vehicles have better energy efficiency and far lower energy costs. These advantages result in lower maintenance costs due to less liquids used, fewer preemptive inspections, and less wearing out on mechanical parts that require replacement (including brake pads). However, electric vehicle tire usage is 20\%-30\% higher due to increased weight and faster acceleration and de-acceleration. The spare parts tend to be more expensive due to lack of a secondary spare parts market. Standstill times are often longer and maintenance staff tends to be more expensive due to higher qualifications required. The overall maintenance costs of electric vehicles are around $60 \%-80 \%$ higher than conventional vehicles, tires included.

While fuel costs can easily be determined for fossil fuel vehicles, the same is not true for electricity costs for electric vehicles. In some countries, electricity prices depend on the time the vehicle is charged and on the power factor. An optimal system configuration of the battery pack on board the vehicle and the charging infrastructure 
is essential to reduce the costs of electric vehicles, especially for commercial operators of buses and trucks. The largest savings of electric vehicles relative to conventional vehicles is based on the relative prices of fuel versus electricity and miles driven.

\section{Electric Vehicle Policies, Subsidies, and Social Impact}

\section{Electric Vehicle Policies}

Policies are often grouped into price or financial incentives and nonprice measures. Countries with high electric vehicle uptake have been implementing both measures in a comprehensive policy package.

Financial incentives are given for vehicles as well as for charging infrastructure either as direct subsidies, fiscal incentives, or reduced energy costs. Zero emission vehicle mandate programs, such as in California, or the new electric vehicle policies in the PRC, also result in financial incentives for electric vehicles. This is because car manufacturers need to comply with specific targets, thus lowering the price of electric vehicles. Specific support for public charging infrastructure for passenger cars is required because it is difficult for private companies to produce a positive business case to justify their involvement as long as electric vehicles account only for a small share of total vehicles.

A number of cities give special incentives for fleet programs including taxis, car-sharing services, or car rentals. This has been successful in increasing the market share of electric vehicles. Fleet operators send a demand signal to the market and act as amplifiers in promoting the uptake of electric vehicles by their staff and customers. Government fleets and fleets controlled through public regulations such as service vehicles, including garbage trucks and public transport buses, are also good targets for electric fleet policies.

Nonprice incentives depend very much on the country and should be related to factors which influence purchase decisions of potential electric vehicle customers. They include

- special lane access,

- parking privileges,

- exemption from road and congestion charges,

- exemption from driving restrictions, and

- exemption from purchase restrictions.

Many of the nonprice as well as the financial incentives are of temporary nature until electric vehicles have reached a critical market share. Norway, for example, in 2016, discounted countrywide free parking for electric vehicles when a large number of such vehicles were already being used (IEA 2017).

\section{Policy Impact}

Financial incentives are clearly central and important. In the PRC, where more than $95 \%$ of all e-buses operates, battery electric buses (BEBs) cost less to operate than diesel or gas buses of the same size due to producer subsidies from the national, provincial, and local government. 
Figure 3: Fiscal Incentives and Vehicle Market Update

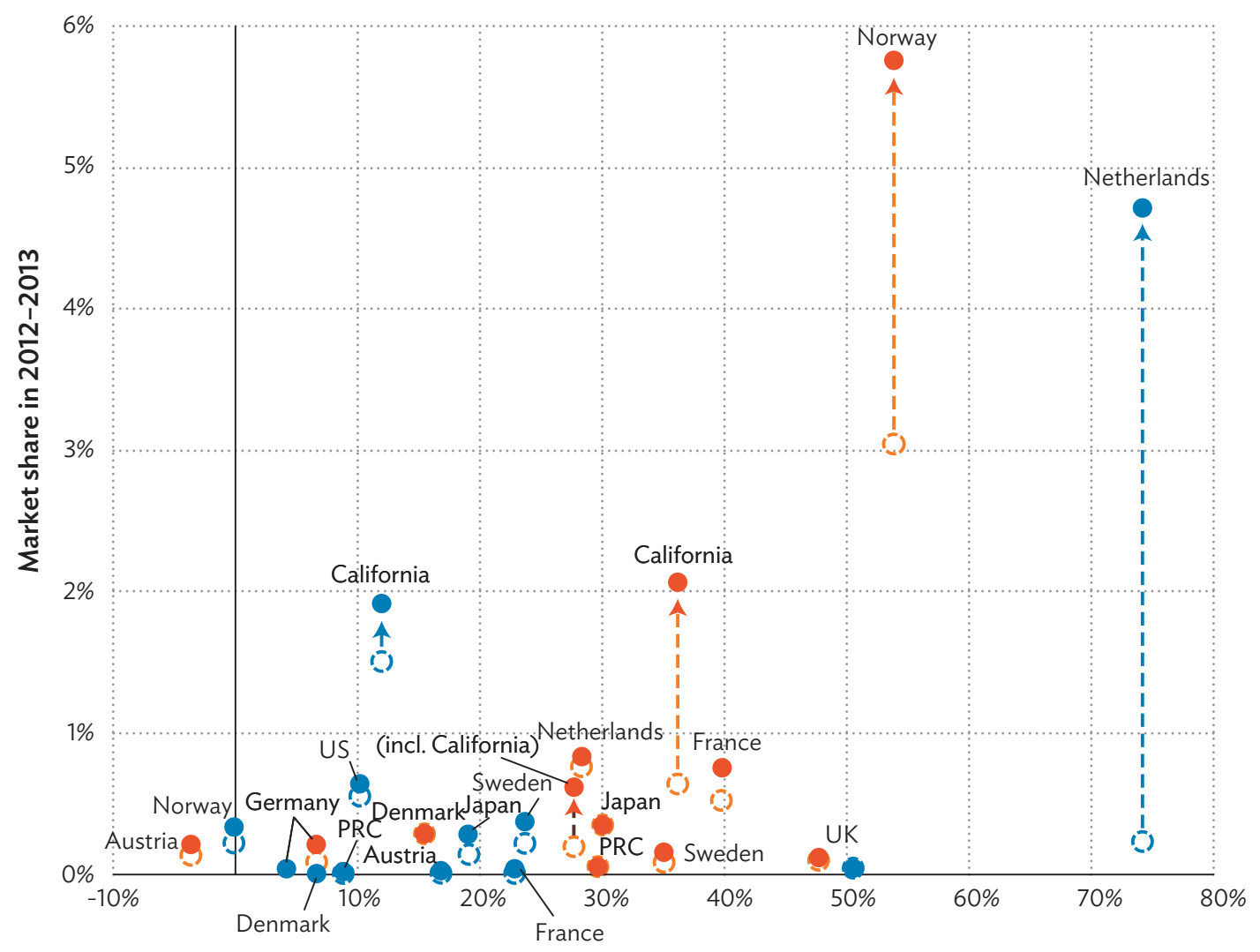

Total fiscal incentive provided (percentage of vehicle base price)

- BEV 2013 o BEV 2012 ค PHEV 2013 oPHEV 2012

$\mathrm{BEV}=$ battery electric vehicle, $\mathrm{PRC}=$ People's Republic of China, $\mathrm{PHEV}=$ plug-in electric vehicle, UK = United Kingdom, US = United States.

Source: ICCT. 2014. Driving Electrification: A Global Comparison of Fiscal Incentive Policy for Electric Vehicles. Washington DC.

National policies are basically targeted toward fiscal incentives. The largest impact from fiscal incentives is achieved if the electric vehicle purchase premium is reduced. Nonfinancial incentives are basically developed at the municipal level and result in cities having a decisive influence in the adoption of electric vehicles. Policies that have been especially successful in this context include waivers on regulations that limit the availability of license plates (e.g., implemented in many cities in the PRC), exemptions from access to restricted urban areas, and exemptions from usage fees for road networks or parking fees.

However, overall consumer benefits are the relevant criteria for the uptake of electric vehicles. This can be seen in the different level of uptakes of electric vehicles between cities in the PRC with different purchase subsidy levels, and by comparing financial incentives and electric vehicle market shares across different countries (Figure 3). Without extensive incentives (financial and nonfinancial), uptake of electric vehicles will be marginal.

A different financial structuring, such as leasing, is also a potential and an important tool for electric vehicle promotion. While capital costs are higher for electric vehicles, their operation costs are lower. Spreading out the initial investment over the commercial life span of the vehicle makes the total annual costs of an electric vehicle 
for a customer similar to a conventional vehicle. This is because higher annual vehicle costs are compensated with lower energy and maintenance costs.

An important long-term policy is also the ban on fossil fuel vehicles. Countries such as India and the PRC have proclaimed plans to ban fossil fuel vehicles. Norway, being the earliest, targets to ban fossil fuel vehicles by 2025. Many other countries have set such target from 2030 to 2040. Multiple cities have also announced plans to ban diesel vehicles, including Paris, Rome, and Madrid.

In most countries, policies are directed toward private vehicles, and limited attention is given to commercial vehicles, which would have a far bigger impact. Possible policies for promoting e-buses include

- $\quad$ requiring operators to have a gradually increasing share of e-buses in their fleets,

- requiring new licensed routes to be operated by e-buses,

- favoring e-buses in public tendering of routes,

- subsidizing charging infrastructure,

- $\quad$ implementing upfront purchase subsidies,

- limiting access to the city center to e-buses,

- $\quad$ supporting the creation of entities that purchase large fleets of e-buses and lease them to operators, and

- $\quad$ requiring all buses to be electric by a certain date.

Similar policies can also be applied to (urban) truck fleets and to taxi and shared mobility operators.

\section{Subsidies and Social Impact}

The primary justification of subsidizing electric vehicles stems from their positive environmental impact. Results will vary between countries depending on the existing vehicle fuel type, emission standards, the resulting pollution level of baseline vehicles, and the grid factor which influences the reduction in GHG.

The positive impact of electric vehicles manifests in reduced air pollution, reduced GHG, reduced noise levels, and reduced dependence on fossil fuels. The general public (non-users) also enjoys the environmental benefits of improved air quality and reduced global warming. The poor are disproportionally affected by air pollution as they tend to be located closer to its sources. At the same time, the poor contribute less to the air pollution problem as they do not own private cars. Children and the elderly are particularly vulnerable. Recent studies also reveal that women are more affected by poor air quality than men.

Incentives, including financial subsidies, to promote electric vehicle uptake can thus have positive economic and social benefits. The social impact will depend largely on the source of revenue and what types of vehicles are subsidized (Table 3).

Many countries have subsidy systems in place which gradually decline or are active for a limited time. This is based on the assumption that prices of electric vehicles decline over time. Hence pricing becomes competitive without subsidies, and more market players enter the field, increasing the attractiveness of electric vehicles by reducing their prices. Also, subsidies can reduce range constraints of buyers by establishing fast-charging infrastructure. Once sufficient electric vehicles are on the market, fast chargers can pay for themselves, but are initially loss-making ventures. Therefore, there is no need to sustain subsidies. However, the magnitude and speed of reducing subsidies is difficult to preview, but could be gradually adjusted based on market conditions. 
Table 3: Potential Impact of Electric Vehicle Subsidy Schemes

\begin{tabular}{|c|c|c|}
\hline Subsidy & Social Impact & Comment \\
\hline $\begin{array}{l}\text { For electric public } \\
\text { transport }\end{array}$ & $\begin{array}{l}\text { Users of public transport are, to a larger } \\
\text { extent, the poorer segment of society. } \\
\text { Usage of public monies, even if this implies } \\
\text { expenditure, either cuts in other areas or } \\
\text { increases taxation levels. Thus the subsidy } \\
\text { tends to have a positive social impact as the } \\
\text { poorer population benefits from reduced } \\
\text { emissions and subsidized public transport. }\end{array}$ & $\begin{array}{l}\text { A larger positive social impact can be } \\
\text { achieved if electric vehicle subsidies } \\
\text { are paid through reduced fuel subsidies } \\
\text { and/or through increased fossil fuel taxation, } \\
\text { or increased taxation of private fossil fuel } \\
\text { vehicle owners. }\end{array}$ \\
\hline $\begin{array}{l}\text { For electricity prices of } \\
\text { electric vehicles }\end{array}$ & $\begin{array}{l}\text { All electric vehicle categories profit, albeit } \\
\text { private electric vehicle owners tend to } \\
\text { consume more electricity in total and } \\
\text { thus profit more. If the subsidy is financed } \\
\text { through general government revenues, then } \\
\text { it can have a slightly negative social impact } \\
\text { depending on the tax system. }\end{array}$ & \multirow{2}{*}{$\begin{array}{l}\text { Subsidizing electricity prices for electric } \\
\text { vehicles can be paid through higher electricity } \\
\text { prices charged to residential customers. } \\
\text { This has the advantage of not increasing the } \\
\text { costs for industries. It will also be more socially } \\
\text { equitable as higher income households have } \\
\text { higher consumption levels of electricity, } \\
\text { and often, prices of electricity also increase } \\
\text { after a certain base consumption level. } \\
\text { Also, residential electricity customers profit } \\
\text { from the improved air quality. Fiscally neutral } \\
\text { policies, wherein financial incentives are paid } \\
\text { by fossil fuel vehicle owners (e.g., through } \\
\text { increased fossil fuel taxes and/or increased } \\
\text { vehicle taxation levels) have a positive } \\
\text { environmental and social impact. }\end{array}$} \\
\hline $\begin{array}{l}\text { For private electric } \\
\text { vehicles or taxis }\end{array}$ & $\begin{array}{l}\text { If the subsidies paid are not fiscally neutral } \\
\text { (e.g., tax rebates which are not paid through } \\
\text { higher taxes on fossil fuel vehicles), then } \\
\text { this subsidy scheme will have a negative } \\
\text { social impact as private vehicle owners } \\
\text { are the "wealthy" members of society and } \\
\text { expenditure cuts in other areas or increased } \\
\text { taxation levels will affect also the poor. }\end{array}$ & \\
\hline
\end{tabular}

Source: Asian Development Bank.

\section{Recommendations and Support Policies}

This section discusses the recommendations and required support policies for developing countries.

\section{Recommendations for Actions}

It is recommended to structure electric vehicle policies and instruments around three principles: focus, optimization, and incentives.

Focus should be on high-mileage vehicles, on cities, and on large fleets. High-usage electric vehicles lead to a significant impact on the environment, particularly on lowering GHG emissions. The financial profitability of such electric vehicles is better as the higher CAPEX is compensated quicker with lower operational costs due to the high mileage. This means targeting buses, trucks, taxis, mobility-as-a-service providers, car sharing, and rickshaws. A focus on electric vehicles in cities reduces the need for costly charging infrastructure and provides for the biggest impact on air pollution and noise, as these are main concerns in urban areas. Focusing on fleet managers and on large fleets also reduces the costs. Electric vehicle deployment can be more efficient through 
leasing companies and vehicle aggregators, especially in countries where transport service providers are small companies.

Optimization refers to charging infrastructure, battery usage, and greening the grid. Optimizing the charging infrastructure together with the vehicle configuration reduces costs. Options include assessing the optimal mix between battery pack and charging type (slow, fast, or ultrafast), solar charging systems, and especially for small island states, linking renewable grids with electric cars on a vehicle-to-grid base.

Batteries can be a problem, but they can also be a possible solution. Second-life options of electric vehicle batteries are potentially an interesting source of revenue. Lead batteries, which are still often used in twoand three-wheeler electric vehicles, have a very limited life span and recycling them is often related to a large environment and health impact. Thus, incentives for lead-powered electric vehicles should be phased out. At an early stage, battery recycling and re-usage policies should be put in place, obliging vehicle vendors to take back batteries and use them in secondary applications or recycle them. An upfront recycling charge could be lifted on the sale of batteries, which then feeds into a recycling and re-usage fund.

In countries with a grid factor of more than $0.8 \mathrm{kgCO}_{2} \mathrm{e} / \mathrm{kWh}$, greening the grid should be a priority. The impact of electric vehicles on $\mathrm{GHG}$ reduction in such countries will be small with high marginal abatement costs. Starting first with electric vehicles or greening the grid in parallel to promotion of electric vehicles is not considered an effective strategy since grid greening, in general, takes a lot of time due to the long life span of energy production units.

Appropriate incentive structures include financial and nonfinancial incentives as well as a creative packaging of incentives. Financial incentives are critical toward reducing upfront costs and establishing charging infrastructures. However, an important parameter affecting electric vehicle profitability is also the fossil fuel price. Reducing fossil fuel subsidies and putting environmental taxes on fossil fuels will promote the shift toward electric vehicles. This is equitable as it follows the "polluter pays" principle.

Cities have multiple instruments at their disposal to promote electric vehicles, such as city access restrictions, preferential lanes and parking access, preferential access for electric vehicles, and demanding increased shares of electric vehicles in transport fleets. Such incentives can turn business models based on electric vehicle fleets profitable.

For motorcycles, financial incentives have proven to be important, but not decisive. Even if electric scooters (e-scooters) have the same price tag as conventional motorcycles, customers will still be reluctant to purchase them due to anxieties over range, speed, power, and reliability. The core nonfinancial incentive to promote e-scooters is clearly to ban fossil-powered motorcycles from entering cities.

Incentives should be targeted toward vehicles with high impact and toward sustainable business models. Subsidizing public charging infrastructure in cities is a good start. Incentives are often too much targeted toward private vehicle owners, which have a limited impact and a high cost. Linking subsidies to vehicle usage and mileage is more efficient. Access to capital, guarantee schemes, and nonfinancial incentives should be explored next to traditional upfront subsidies, which have proven to be effective (if sufficiently high), but very costly. Financial subsidies to private electric vehicle owners should be fiscally neutral and financed from levies on fossil fuel car owners (i.e., gasoline taxes) such that it internalizes negative social impacts associated with fuel consumption. 


\section{Recommended Policies for Commercial Vehicles}

In most countries, policies have been directed toward private vehicles with limited attention being given to commercial vehicles, although the latter would have a far bigger impact with a lower price tag. Policies which could be deployed for different commercial vehicle categories to foster adoption of electric vehicles include the following:

Buses. To optimize electrification in buses, it is essential to have policies requiring operators to have a certain share of electric vehicles in their bus fleet, which gradually increases until reaching 100\%. New licensed routes should be promoted to operate by electric buses. Electric buses should be favored in public tendering of routes. Also, free charging infrastructure and/or reduced price of electricity as compensation for improved air quality and reduced noise (public goods) with upfront purchase subsidies could be added to the policy package. Electrification of vehicles could also be enhanced through policies that limit access to city center to electric buses, support the creation of entities which purchase large fleets of electric buses and lease them to operators, and increase diesel tax. Long-term vision such as requiring all bus fleets to be electric by a certain date will boost the use of electric buses.

Taxis, car-sharing organizations, and shared mobility. To increase electrification in shared mobility services, it is important to support the establishment of public fast chargers at multiple locations and free charging infrastructure. An additional incentive is reducing the price of electricity as compensation for improved air quality and reduced noise (public goods). Other policies that can boost electrification are increments in diesel and gasoline tax, reduction of taxes on electric vehicles, and banning of fossil fuel vehicles in the city.

\section{Recommended Electric Vehicle Support Policies}

Support for electric vehicles needs to be country- or city-specific. However, some general recommendations should be taken into account when drafting an electric vehicle policy package.

The greener and less carbon-free the electricity grid, the larger the impact of electric vehicles. Electric vehicle support measures thus clearly make more sense in countries where the grid is greener and where there is a larger share of renewables in the energy mix. In countries with a grid factor of electricity production of more than 0.8 kilogram of carbon dioxide equivalent emission per kilowatt-hour ( $\mathrm{kgCO}_{2} \mathrm{e} / \mathrm{kWh}$ ), using electric vehicles will result in only a very minor GHG impact. In such countries, policies could rather be directed toward greening the grid and not toward aggressively promoting electric vehicles.

Countries with a predominantly renewable energy production combined with air pollution problems are ideal candidates for promoting electric vehicles. They can achieve a large GHG impact, improving local air quality and reducing dependency on fossil fuels. Electric vehicle support should therefore focus on such countries.

The largest impact concerning GHG reduction and air quality improvement can be achieved with commercial vehicles. Also, the cost-benefit ratio of commercial electric vehicles tends to be far better due to high mileage and energy usage than that of private vehicles. Commercial electric vehicles include buses, taxis, ride-sharing vehicles, and urban trucks. Support policies for electric vehicles should thus be geared toward these vehicle segments. Transport programs, especially if conducted within countries with favorable circumstances should include components on e-mobility, including charging infrastructure. 
Cities play an important role in the adoption of electric vehicles as they experience air and noise pollution problems, which can be alleviated by electric vehicles. Cities also have a large concentration of commercial vehicles. Many cities are also concerned about their $\mathrm{CO}_{2}$ footprint. Urban development programs, especially urban transport programs, offer ideal entry points to include electric vehicle support policies and programs. Electric vehicle policies can include subsidies but should be as fiscally neutral and socially positive as possible. This needs to be included when formulating electric vehicle support policies.

\section{Conclusions}

The electric vehicle market is growing strongly, albeit from a low base level. Growth is concentrated in relatively few countries and cities. The PRC has by far the largest electric vehicle market. Cities are a good starting point for promoting electric vehicles as they accommodate large numbers of commercial vehicles including buses, urban trucks, and taxis, as well as car-sharing facilities, all of which can be converted to electric vehicles at lower cost than private passenger vehicles. Cities are also prone to high levels of air and noise pollution where electric vehicles can make a real difference.

A major barrier to the widespread adoption of electric vehicles is the high upfront investment. Most countries that invested in electric vehicles have only partially recovered their investment with lower energy and maintenance costs. The lack of charging points is also a major barrier especially for private cars, while questions concerning the technology's reliability are more important for commercial customers.

The environmental impact of electric vehicles manifests in reduced greenhouse gas (GHG) emissions. In particular, substituting fossil fuel vehicles with electric vehicles can reduce air pollution and noise. The GHG impact of electric vehicles is positive with most electricity grids, even if upstream manufacturing emissions of the vehicle and battery are included. However, greening the grid is important for countries that have levels of more than $0.8 \mathrm{kgCO}_{2} \mathrm{e} / \mathrm{kWh}$ as the impact of electric vehicles will only be limited.

Vehicle and charging technology, policies, and business models are distinctly relative to the vehicle category. Policies in most countries focus on and favor private cars, basically through tax exemptions, even though commercial vehicles could have a much larger impact on reducing GHG emissions and pollution. Commercial vehicles in general have high mileage and, in the case of buses and trucks, high energy consumption. Also, especially for buses, the total cost of ownership for electric vehicles is nearly equal to conventional fossil fuel units in many countries. Hence, vehicle electrification does not require massive subsidies, instead, it requires new business models based on, for example, vehicle leasing models or separation of vehicle ownership and vehicle operations allowing for the introduction of less costly units.

Most countries already have low tax levels for all types of commercial vehicles, such as buses, trucks or taxis, and therefore electric vehicles do not profit much -in contrast to private cars. Sound policies are therefore required to stimulate commercial electric vehicles, such as compensation for their impact on air pollution and noise, preferential access to urban centers, preferential licensing (i.e., for taxis), or obligations to operate a certain share of electric vehicles (i.e., for buses), which can be gradually increased.

Electric two-wheelers and three-wheelers have been taken up in many countries, albeit with problems. The electric units deployed are often of low quality, equipped with lead batteries with a very short life span, and with environmental disposal problems, and vehicle convenience is not the same with gasoline or diesel or compressed 
natural gas (CNG) units in terms of power, driving range, and speed. While the low purchase price of such electric units makes them an attractive option, users need to invest in costly new batteries after around 1 year.

Electric vehicles are also not as comfortable as conventional vehicles. However, they become attractive to a certain customer segment, such as students in the case of e-scooters, as no license is required. Comparable electric vehicles of the same vehicle category (with a similar power, speed, and driving range) are equipped with lithium-ion batteries and have higher-powered motors, resulting in significantly higher costs and clearly surpassing conventional vehicles.

Conventional motorcycles, meanwhile, have a very low purchase and operational cost, making them more affordable and convenient. Electric units with comparable features are far costlier to purchase and the energy cost savings will not be impressive for a client. The experience of Taipei,China also shows that even with purchase subsidies, it will be very hard to achieve significant shares of electric motorcycles or e-motorcycles. For this category, it is important to have policies in place that either ban fossil fuel units or create very strong nonfinancial incentives which clearly favor e-motorcycles (such as exclusive access to the city center or exclusive parking spaces). Cost parity for e-motorcycles might not provide for a sufficient incentive to switch.

\section{References}

Asian Development Bank (ADB). 2018. Sustainable Transport Solutions: Low-Carbon Buses in the People's Republic of China. Manila. https://www.adb.org/publications/sustainable-transport-solutions-peoples-republic-china.

Bradley, C., M. Hirt, and S. Smit. 2018. Strategy Beyond the Hockey Stick. McKinsey \& Company.

Bloomberg New Energy Finance. 2018. Electric Buses in Cities. https://about.bnef.com/blog/electric-buses-citiesdriving-towards-cleaner-air-lower-co2/.

ICCT. 2014. Driving Electrification: A Global Comparison of Fiscal Incentive Policy for Electric Vehicles. Washington DC.

International Energy Agency. 2017. Global EV Outlook 2017. Paris.

International Energy Agency. 2018. Global EV Outlook 2018. Paris.

Grütter, J. and K. Kim. 2019. E-Mobility Options for ADB Developing Member Countries. ADB Sustainable Development Working Paper Series. No. 60. Manila: https://www.adb.org/publications/e-mobility-adb-developingmember-countries.

McKinsey. 2017. What's Sparking Electric-Vehicle Adoption in the Truck Industry? https://www.mckinsey.com/ industries/automotive-and-assembly/our-insights/whats-sparking-electric-vehicle-adoption-in-the-truck-industry.

McKinsey. 2018. The Global Electric-Vehicle Market is Amped Up and on the Rise. https:/www.mckinsey.com/industries/ automotive-and-assembly/our-insights/the-global-electric-vehicle-market-is-amped-up-and-on-the-rise.

UBS. 2017. UBS Evidence Lab Electric Car Teardown - Disruption Ahead? https://neo.ubs.com/shared/d1wkuDIEbYPjF/. 


\title{
Planning and Design of Intelligent Transport Systems toward Livable Asian Cities
}

\author{
Susan Lim and Gloria Gerilla-Teknomo
}

\section{Introduction}

Intelligent transport systems (ITS) apply information and communications technologies in the transport domain to improve safety, efficiency, and convenience for all users of the transport network. ITS can offer unique advantages in many ways, such as automatically detecting potential dangers, giving timely reminders and warnings to drivers, advising passengers arrival and departure times of buses and trains, and assisting drivers to control vehicles. Wirelessly connecting vehicles and infrastructure to control, manage, and distribute information to improve transport outcomes is called cooperative ITS (C-ITS or V2X communication for vehicle-to-vehicle, vehicle-to-infrastructure, and vehicle-to-passenger communication). Cooperative systems require that all parties involved are able to communicate.

Having a robust, comprehensive ITS framework boosts economic growth by enabling citizens and governments to better manage their resources. Developing such systems to connect multiple modes of transport, facilitate travel demand management, mitigate traffic congestion, and reduce accident risks are all crucial for continued economic growth and sustainable urbanization. If strategically implemented, ITS tools can improve efficiency, traffic safety, productivity, and network operation resilience. People also can make more informed decisions about when and how to travel, which in turn mitigates traffic congestion.

Various ITS technologies are already well integrated into modern life. Examples are intelligent traffic signal control systems at intersections; automatic enforcement equipment; apps which help people to manage their travel patterns, like Waze for deciding which route to take, or Uber and Grab for ride sharing, and apps that highlight the fastest bicycle routes or show which train lines are in service. Other examples of ITS elements include transportation management centers, field equipment (e.g., detectors, closed-circuit television or CCTV cameras, dynamic message signs, and weather stations), vehicles with ITS equipment (e.g., private vehicles, buses, commuter trains), and traveler equipment (e.g., mobile devices).

Asian cities are increasingly turning to ITS solutions to manage traffic and provide passengers with more efficient public transport modes. The safe, reliable, convenient, and comfortable movement of people and goods is important for the operation and growth of cities. This is the primary objective of any transportation investment. ITS can save time, money, and lives if they are properly planned and implemented. ITS includes the data processing and data communication systems that support the operation and maintenance of all transportation modes. It aims to improve safety and efficiency in transporting people and goods.

Several countries and regions are currently advancing rapidly in terms of readiness for, and deployment of, C-ITS and other ITS building blocks. For example, the US is preparing legislation to mandate connected cars, Europe is introducing eCall (rapid motorists assistance), and Japan has a national beacon-based infrastructure for C-ITS. 
There are also many international research studies, pilot trials, and international standards being developed. The European Union/United States/Japan Task Force on connected vehicles has been established to exchange information and experience.

ITS projects are complex due to many interacting components and information that must be collected and analyzed. Not only are ITS projects complex, but they also have high uncertainties in terms of project costs, schedule, and systems requirements at the onset. Technology changes quickly, and ITS involve multiple stakeholders. If the ITS planning, design, and implementation are not well executed, the expected outcomes will not be met, and investments will be wasted.

This article provides a basic understanding of how to plan, design, and implement ITS projects for a city to minimize ITS project risks and meet the needs of users. It documents the methodologies and results of the conceptual design process using a recently approved project in the People's Republic of China as the case study: the Guizhou Gui'an New District New Urbanization Smart Transport System Development Project (ADB 2019).

\section{Box 1: Gui'an New District's Smart Transport System Development-A Project Case Study}

The State Council of the People's Republic of China (PRC) established Gui'an as a new city in January 2014, with the objective of making it the economic development driver in Guizhou and neighboring provinces. The key strategies for Gui'an include developing a high-level technology innovation hub to attract talent and business, encouraging innovation and high-tech industrial development, conserving the natural environment to ensure a healthy green city, and fostering ecotourism. They are in line with the PRC's new direction on urban development, which places increasing importance on innovation and coordination, eco-friendly policies, and people-centered development and urbanization.

Gui'an will be designed and built into a safe, orderly, smooth, accessible, low-carbon, sustainable, and smart city. Among the ways to achieve this growth include the (i) deployment of intelligent transport systems, which incorporate advanced information processing technology, data communication technology, electronic sensing technology, control technology, Internet of Things, and cloud computing methods in a big data center, among other technologies; (ii) promotion of environment-friendly public transport with the use of battery electric buses to support mobility; and (iii) advancement of the pilot study on intelligent connected vehicles system, an emerging industry which makes use of the information and communication technology revolution.

The intelligent transport system (ITS) conceptual design developed for Gui'an has integrated the different elements of the ITS project and reduced the complexity of the project. It clearly shows the different needs of multiple stakeholders and connects them seamlessly. It also provides a clear guide in developing a detailed project design.

Source: Asian Development Bank. 2019. Conceptual Design of The Intelligent Transport Systems Project-Case in Gui'an New District. Manila. 


\section{Planning and Design of Intelligent Transport Systems Projects}

There are many integration risks inherent in designing and deploying transportation systems. The process involves new and complex technologies and interoperation between transportation systems deployed by different institutions. Thus, the planning, design, and implementation of ITS requires a systematic approach that follows a globally accepted ITS framework architecture.

Developing an ITS conceptual design should meet the specific transportation needs of the stakeholders. This systematic approach is embodied in the systems engineering process. Systems engineering processes keep projects being procured on budget and on schedule, and meet all the needs and objectives originally intended for the project. Such processes may also help substantially reduce the number and severity of defects in complex ITS. The different stages of the systems engineering process for ITS projects are briefly discussed below.

ITS framework architecture. The ITS framework architecture provides a common basis for planners and engineers to conceive, design, and implement systems using a common language as a basis for delivering ITS. It is the standard national architecture of a country. It provides a systematic basis for planning ITS implementation, facilitating their integration using standardized interfaces for information sharing when multiple systems are to be deployed, and ensuring near- and long-term interoperability of stakeholders' systems.

Regional ITS architecture. The ITS framework architecture is then tailored and customized for the specific surface transportation needs of a specific region, called the regional ITS architecture. The regional ITS architecture identifies the integration opportunities that should be implemented and are agreed to by the stakeholders. The regional ITS architecture includes identification of open standards or local protocols agreed to by the stakeholders, which will be used to encode the information flows between ITS elements, when those standards or protocols are available. The relationships between the generic framework architecture, the specific regional ITS architecture, open standards, and the ITS projects for a region is illustrated in Figure 1.

ITS analysis. When complete, the regional ITS architecture should be used as input to the ITS Feasibility Study Report (ITS FSR) which should contain the ITS analysis. The ITS FSR should include or reference the ITS stakeholder elements and their functional requirements as well as information dependencies on other ITS stakeholder elements in the regional ITS architecture. The ITS FSR should then provide additional analysis such as detailed cost and benefits estimates, and high-level technology choices for the ITS elements. The analysis should be guided by local environmental and institutional considerations.

High-level versions of these analyses are included in the ITS conceptual design. There should be full bidirectional traceability between the ITS FSR and the functional and information dependency requirements in the regional ITS architecture of the ITS conceptual design. The FSR should also state the measurable objectives of the ITS, which can be used later to validate whether the deployed ITS has satisfied all the objectives. The ITS FSR is then used as input to the detailed design process, starting with a complete system requirements analysis.

Requirements development. The system requirements involve the functional, performance, and environmental requirements of each stakeholder project that makes up the overall ITS. The system requirements should not depend on the selected technologies. They should trace back to the high-level objectives in the ITS FSR and should be useful as verification tests on the final ITS before it is released to operations. The purpose of the system requirements, where every requirement is testable, is to verify that the system has been built correctly. This is complementary with, but different from, the validation testing based on the ITS FSR, which should be 
Figure 1: Relationships between Framework and Regional Architectures, Intelligent Transport Systems Standards, and Intelligent Transport Systems Projects

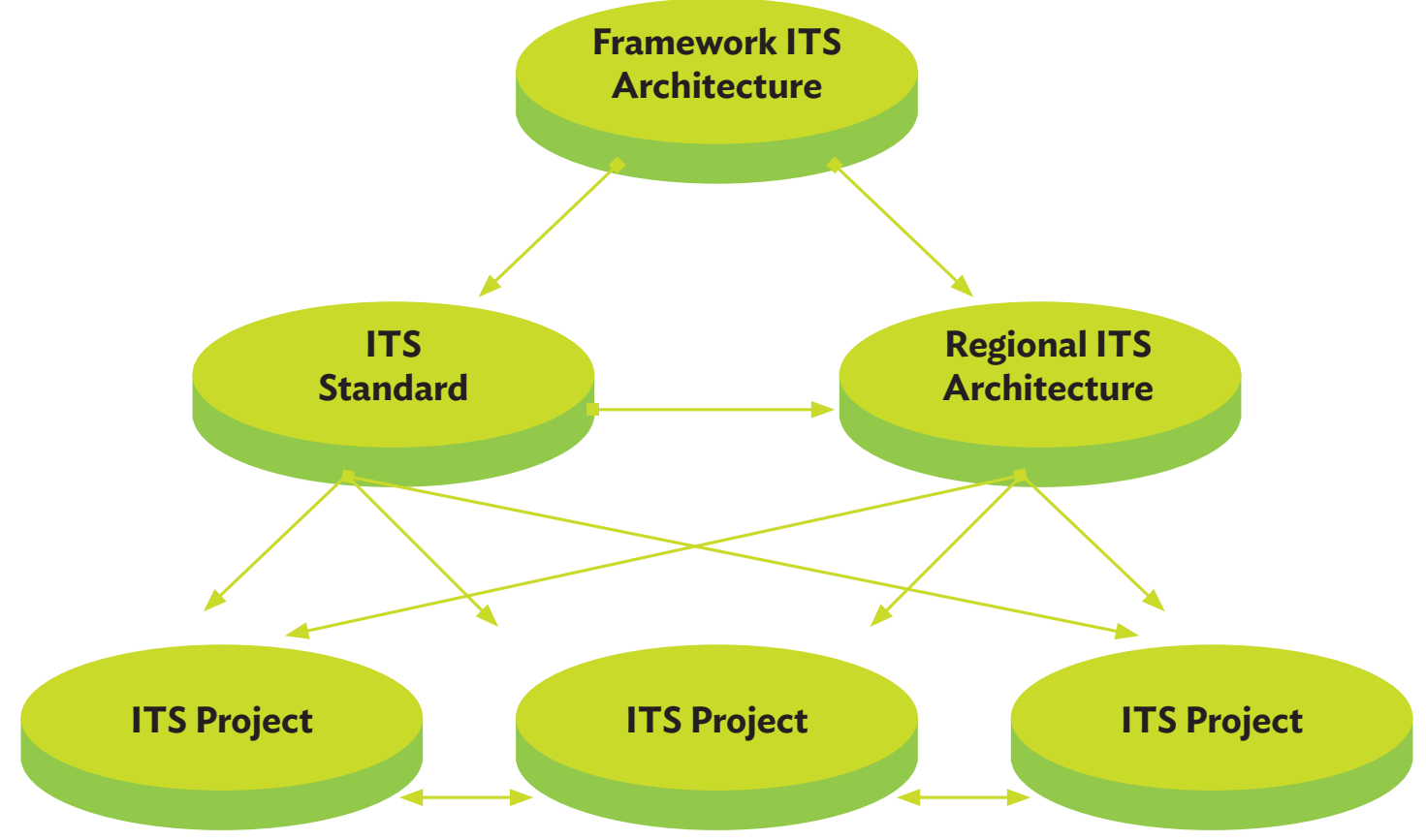

ITS = intelligent transport systems

Source: Asian Development Bank. 2019. Conceptual Design of the Intelligent Transport Systems Project-Case in Gui'an New District. Manila.

used to confirm that the system meets the needs and objectives originally intended (i.e., the system requirements verify that the overall system is built right, and the ITS FSR needs/objectives validate that the right system was built).

The focus of the functional requirements in the FSR is on the functional impact on the users, operators, and maintainers outside the ITS. On the other hand, the functional requirements of the system requirements focus on the functional operations of the ITS. For each objective in the ITS FSR, there should be traceability to one or more requirements. Upon inspection, the report should persuade the reviewer that the ITS FSR objectives will be satisfied by the ITS requirements and that, conversely, each system requirement contributes to satisfying at least one objective.

High-level design and detailed design. Once the ITS functional, performance, and environmental requirements are defined, they can be used to select the technologies to be applied in the ITS. Each selection should be supported by trade studies as necessary to justify the selection of the "best" technologies. This set of selected technologies are included in the "high-level design," not in the system requirements. Next, the ITS detailed design proceeds, which includes the development of all the specifications necessary to implement the selected technologies for the full ITS. Each of the detailed specifications is tested upon the integration of the ITS modules as they are built or procured. ITS modules can be either hardware and/or software. 
Implementation and testing. Once the specific technology specifications have built up into a complete detailed design for the ITS, the actual build or procurement of hardware and software for the ITS begins. Individual hardware elements and software modules of the ITS are integrated, tested, and combined to produce a complete ITS. The next steps are to verify whether the system was built correctly and tested to meet all requirements, then to put the system into operation, and finally to validate whether the needs are all met.

Manage, operate, and maintain. After the system deployment or during its operation, validation can be conducted to check whether all the needs or objectives initially intended have been met. After a period of operation, upgrades and changes may occur, and eventually replacement and/or retirement.

Between subsequent steps in the process, a traceability analysis is conducted. The analysis verifies whether the subsequent level of analysis, design, or build, completely meets all the objectives, requirements, or specifications of the previous step. Further, there are three additional testing phases: (i) unit/device testing against specifications, (ii) system verification against system requirements, and (iii) system validation against needs/objectives. All this traceability analysis and testing are intended to detect defects soon after the systems are created, when they are least expensive to repair.

Finally, it is necessary to assess in advance if all the stages of the systems engineering process are necessary for a project. The assessment should look at where the risks in the ITS to be deployed exist. If there are only a few risks during an analysis stage-for example, because that stage of analysis is similar to a prior project that was successfully procured and deployed - then the traceability and/or testing of that stage might be unnecessary, or at least the analysis/testing can be abridged. These decisions should be made by staff experienced in systems engineering and should be documented in a systems engineering management plan (SEMP) for the project. The SEMP should become a part of the project management plan (PMP) or a parallel document to the PMP.

The development of an ITS conceptual design at the very beginning of a regional transportation technology project seeks to avoid very costly interoperability (or institutional integration) defects later in the project procurement, operation, and maintenance. Such an approach complements the two overall objectives of systems engineering process - to keep projects within budget and on schedule and meet all the needs of the project scope.

\section{Steps in Developing the Intelligent Transport Systems Conceptual Design}

The ITS conceptual design guides the development of an ITS suitable for financing. The conceptual design development requires a series of steps summarized in Figure 2. The conceptual design is undertaken with the support of relevant stakeholders that will develop, operate, maintain, or depend on ITS.

\section{Step 1: Develop ITS objectives.}

Identification of ITS objectives is an important step in determining the ITS services suitable for any city or region, in this case, Gui'an. ITS objectives should be based on the government's ITS plan. Objectives are statements of the impact that the ITS deployment will have on the non-ITS transportation infrastructure after deployment. Objectives should be specific and measurable so that they can be used to validate whether the deployed ITS has brought the intended benefits. 
Figure 2: Steps in Developing the Intelligent Transport Systems Conceptual Design

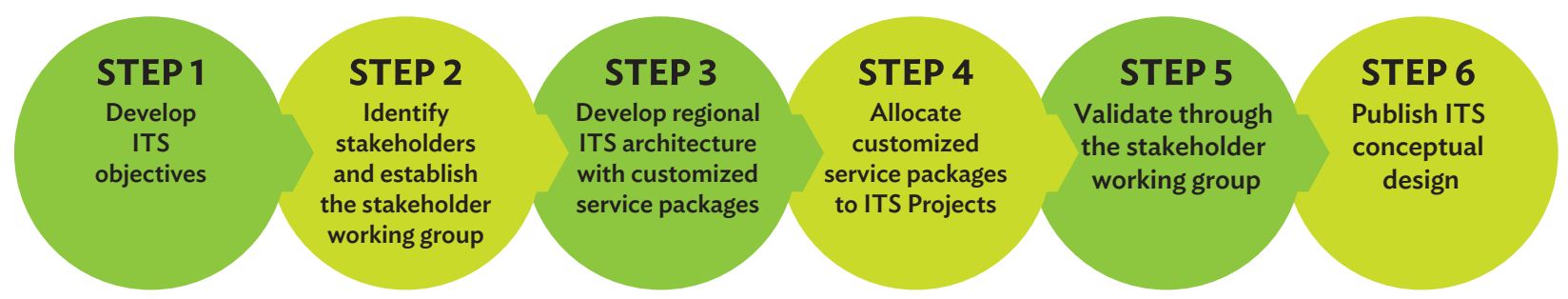

ITS = intelligent transport systems

Source: Asian Development Bank. 2019. Conceptual Design of the Intelligent Transport Systems Project-Case in Gui'an New District. Manila.

The objectives for the Gui'an project were based on the development plans and were refined by conducting interviews with the stakeholder working group members. The objectives were used as the starting point to select and customize services for the Gui'an Regional ITS Architecture. Since there is currently no virtual ITS deployed in Gui'an and much of the future non-ITS transportation infrastructure is still to be deployed, an assumption is made on the level of improvement of operations or maintenance of the future transportation infrastructure, by estimating the changes that may have occurred with ITS deployed versus without ITS deployed. In the end, 24 objectives were identified and organized into four objective groups representing the overall needs categories: mobility convenience and efficiency, safety, low carbon, and intelligence.

The key performance metrics can be influenced by any of the ITS services. For example, for the first mobility objective, "Improve (shorten) the travel time of public transit," this can be improved by one or more of the following:

- off-board electronic payment to shorten the bus dwell times at bus stops,

- transit signal priority to shorten the average time it takes a bus to travel through an intersection, and/or

- $\quad$ automated bus lane enforcement to shorten the time buses spend to travel on dedicated bus lanes by reducing the number of non-transit vehicles using the dedicated lanes.

In most cases, the reported actual key performance indicators or KPI improvements were based on one specific ITS service, and do not take into consideration the improvements due to multiple ITS services that may have been deployed before or after the performance evaluation. To ensure that the right objectives are identified and measured meaningfully, stakeholders should be engaged.

\section{Step 2: Identify stakeholders and establish the stakeholder working group.}

One of the most important attributes of a successful ITS project is the engagement of a group of senior individuals who represent each transportation mode or support services in a region. The purpose of such engagement is to validate the project objectives and know whether the ITS to be deployed is consistent with the conceptual design, and whether it would meet the needs of the senior individuals.

In Gui'an, the ITS working group was formed for the project. It was made up of stakeholder representatives from major institutions that will operate and maintain ITS services in the Gui'an New District. The Gui'an ITS working 
group was made up of seven stakeholder institutional representatives covering all ITS services and modes, with one or two stakeholder representatives from each. All the stakeholder representatives were responsible for reviewing

- the Gui'an ITS objectives early in the project,

- the ITS customized service packages (CSPs) that their ITS elements participated in, and

- the ITS conceptual design analysis results toward the end of the project.

The ITS stakeholder representatives need to critically review the ITS conceptual design to make sure whether the system meets the requirements specified in the conceptual design, and whether the system would meet the stakeholders' needs.

\section{Step 3: Develop the regional ITS architecture with customized service packages.}

The regional ITS architecture is central to conceptual design development. Once the objectives are in place, the framework ITS architecture is used as a "menu" of possible generic ITS services, and the selected ITS services from that menu are then customized based on the actual stakeholders in Gui'an and their actual stakeholder elements.

(i) Framework Intelligent Transport Systems Architecture

The framework ITS architecture is based on generic ITS element subsystems (Figure 3). In this diagram, the generic ITS element subsystems are organized into five groups: (i) center subsystems, which can be located anywhere; (ii) field subsystems located on or near the roadway or right-of-way, (iii) vehicle subsystems located on or in a vehicle; (iv) traveler subsystems located with a traveler, like a smartphone, or a public information device such as a kiosk that a traveler can use; and ( $v$ ) support subsystems that are usually located in a data center and are present to support multiple elements. ${ }^{1}$

Each of the subsystems has functional requirements defined for them, depending on which service packages they belong. A subsystem can be used in many different service packages. It also can have different functional requirements based on each service package. The functional requirements of the subsystems are usually factored into the regional ITS architecture and used as a starting point to identify the detailed system requirements during the ITS design stage. The framework ITS architecture includes a set of more than 100 generic ITS services covering all surface transportation modes.

\section{(ii) Development of Customized Services Packages}

After the Gui'an ITS objectives were developed and validated with the members of the ITS working group, the generic service packages were identified for customization. There were 72 generic service packages identified and organized into 12 ITS service areas. Service packages represent slices of the physical view that address specific services like traffic signal control. A service package collects different physical objects including systems and devices and their functional objects and information flows that provide the desired service.

Each of the areas has one or more service packages to support one or several related services that fall into the "ITS Service Area." Some service packages can be viewed to support more than one area, but in this area, sorting each service package appears only once, and a decision is made to place the service package in one

Each of the subsystems in the groups is defined in more detail at US Department of Transportation. Architecture Reference for Cooperative and Intelligent Transportation. https://local.iteris.com/arc-it/ (The website is updated regularly). 

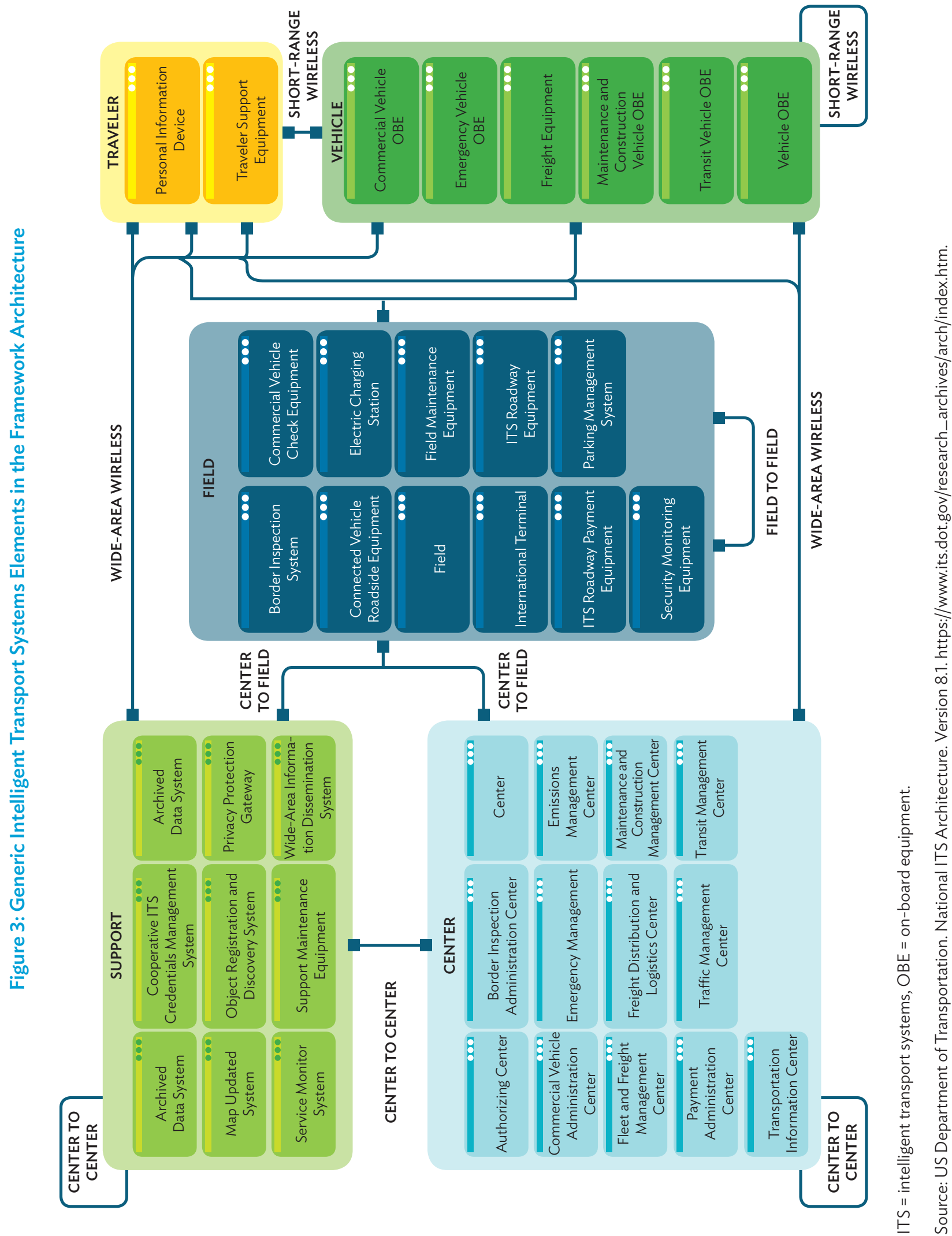
area or another. Once a generic service package was selected for Gui'an, it was added to a task list and its customization scheduled in the project plan.

The service package customization process involves deciding which stakeholders will be involved in a service and replacing the generic ITS elements in the Architecture Reference for Cooperative and Intelligent Transportation (or ARC-IT) framework with specific stakeholder elements in the Regional Architecture Development for Intelligent Transport (or RAD-IT) development tool (footnote 1).

The information flows between and among the stakeholder ITS elements in the customized service packages (CSPs) are developed in coordination with each stakeholder in the ITS working group (Figure 4 provides an example of information flows). The Cultural Tourism Investment (CTI) Enterprise Group is the stakeholder responsible for public transport operation and taxi operation. Each public transport vehicle has an onboard equipment which will communicate with the transit management center.

Figure 4 shows the roll-up of information flows between the CTI Enterprise Group Transit Vehicle On-Board Equipment, and the CTI Transit Management Center, based on multiple CSPs, each containing a subset of the information flows. In addition to information flow diagrams showing the information flows between two stakeholder ITS elements, a context diagram can be developed for each stakeholder element.

The functional requirements of each CSP are also defined to apply the appropriate information flows. This is found in the list of ITS element functional requirements. In this case, there are functional requirements for each of the customized ITS services participated in by this element. For example, the Transit Vehicle Passenger Counting yields four functional requirements:

- The transit vehicle counts the number of passengers getting on and off.

- The passenger counts are related to location to support association of passenger counts with routes, route segments, or bus stops.

- The passenger counts are time-stamped so that ridership can be measured by time of the day and day of the week.

- The transit vehicle sends the collected passenger count information to the transit center.

These are just a subset of the many functional requirements allocated to the CTI Transit Vehicle On-Board Equipment.

(iii) Customizing Service Packages

While the ITS service packages were customized for the objectives in Gui'an, in parallel, the stakeholder inventory was developed as elements were needed to populate the CSPs. Like the framework ITS architecture, the CSPs are organized by the same areas. Some of the framework service packages have been skipped since they are not relevant to Gui'an stakeholders, and others have more than one instance for meeting the needs of Gui'an. As an example, there are three instances of the generic Transit Vehicle Tracking service package:

- Tracking buses in support of multiple services, including bus arrival traveler information.

- Tracking taxis in support of more efficient taxi dispatching.

- Tracking bicycles to verify, and potentially enforce parking in designated locations. 
Figure 4: Information Flow Context Diagram for Cultural Tourism Investment Transit Vehicle On-Board Equipment

\section{CTI Transit Management Center}

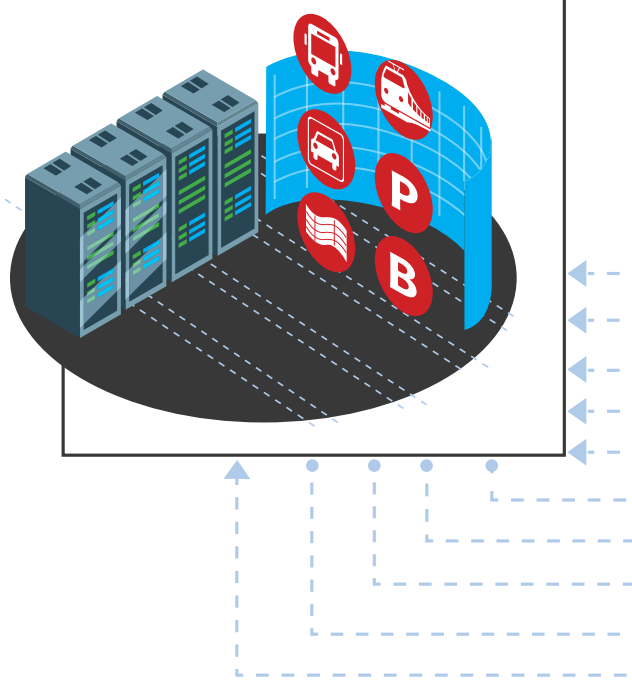

alarm notification

fare collection data

transit vehicle loading data

transit vehicle location data

transit vehicle schedule performance

dispatch command-ud.

fare management information

remote vehicle disable

transit vehicle operator information

transit schedule information

CTI Transit Vehicle Operator

CTI Transit Vehicle

On-Board Equipment

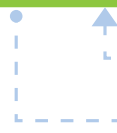

transit vehicle operator display

transit vehicle operator input

Planned

Source: Asian Development Bank.

Figure 5 shows an example of a CSP for traffic surveillance. The CSP uses video- and detector-based surveillance of roadways to analyze congestion and support detection of, classification of, and response to incidents by the Traffic Management Bureau's Traffic Management Center (TMC). The TMC shares the road network conditions such as link congestion and nonrecurring incidents with the Bureau of Economic Development in Gui'an New District Public Transport Office Transport Information Center . 
Figure 5: Customized Service Package for Basic Traffic Surveillance

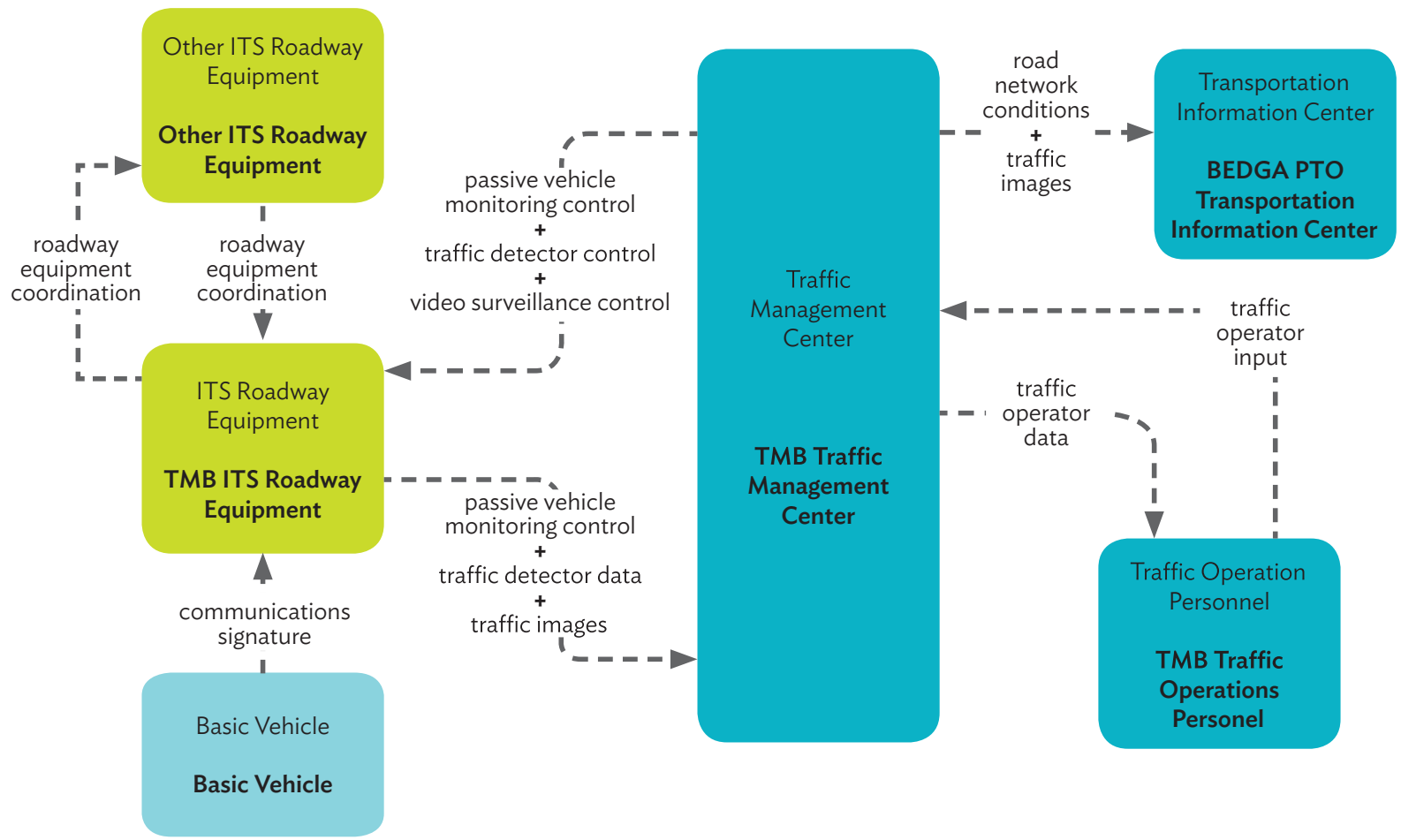

BEDGA = Bureau of Economic Development in Gui'an New District, ITS = intelligent transport systems, PTO = public transport office, $\mathrm{TMB}=$ traffic management bureau.

Source: Asian Development Bank. 2019. Conceptual Design of the Intelligent Transport Systems Project-Case in Gui'an New District. Manila.

\section{Step 4: Allocate customized service packages to ITS projects.}

There are about 76 CSPs developed to meet all the Gui'an New District ITS objectives. Each CSP was allocated to an actual ITS project to be designed and then built. The nine projects, along with their major systems, are as follows:

(i) Real-time traffic and road-weather monitoring system
a. Road operation monitoring based on video
b. Full view video detection
c. Traffic flow detection
d. Information collection based on Internet of Things and electronic vehicle tags
e. Transportation security early warning based on cooperative vehicle infrastructure system
f. Transportation weather and environment monitoring

(ii) Big Data Service Center

(iii) Multimodal Transportation Systems Management and Operations Center
a. Intelligent public transport management system
b. Integrated taxi management and service system
c. Intelligent parking management system 

d. Intelligent bicycle management system
e. Dynamic operation supervision system for passenger vehicle (transit vehicle and taxi)
f. Dynamic operation supervision system for commercial vehicle
g. Integrated transportation hub information management system
h. Multimodal travel information service system
i. Traffic and transportation law enforcement management system
j. Maintenance and construction management system

(iv) Electric Vehicle Application and Service System

(v) Integrated Traffic Operations, and Security and Emergency Management System
a. Integrated traffic operation monitoring platform
b. Transportation security and emergency management platform
c. Decision support and information service platform

(vi) Demonstration application of driverless vehicles and cooperative vehicle infrastructure system
a. Demonstration application of driverless vehicles
b. Demonstration application of cooperative vehicle infrastructure system

(vii) Traffic Management Center

(viii) Fleet and Freight Management Center

(ix) Weather Management Center

Once the projects have been identified and provided with CSPs, additional analysis can be done as needed. For example, in the case of Gui'an, the estimated cost, estimated benefits, communication requirements, and other analyses for each project were prepared.

\section{Step 5: Stakeholder validates the customized service packages.}

After the initial draft of the complete set of CSPs were prepared, the working group members, in a series of individual meetings, reviewed each of the CSPs participated in by their ITS elements. The working group members also at that time revisited their needs, objectives, key performance indicators, and scope. Each CSP was also deliberated in detail with each working group member. These meetings took from a few hours to multiple days in some cases. The meetings involved training for the working group members to explain the ITS services and the full scope of the possible ITS services that their function might participate in or lead. The draft CSPs were then edited to remove and/or add functionalities that the working group members deemed best suitable for their function in Gui'an.

\section{Step 6: Publish ITS conceptual design.}

The ITS conceptual design was published on the internet using an extensive cross-referenced methodology. This is the most ideal way to publish the ITS conceptual design due to the very large amount of information that will be used by the developers of the formal ITS Feasibility Study Report (FSR). This report includes the detailed design requirements for the ITS projects, selected technologies, and the specifications. 


\section{Challenges of Implementation}

ITS projects tend to be extremely challenging due to many modern and complex technologies involved. Also, many stakeholder entities have their respective ITS elements that may need to be interoperable, and wherein they may need to share information across institutional boundaries. Sharing information may create risks if there are multiple development processes involved in the implementation of the regional ITS elements. Misunderstandings on which information will be shared and how information will be encoded can contribute to the risk, thus the intended ITS services may partially work or not work at all.

An ADB study on ITS shows that there is currently no single deployment model (ADB 2016). This presents an opportunity to both learn from and share the different international approaches. Given the rapid technology development within ITS and consumer electronics, there are challenges in predicting future capabilities and in terms of the time frame for deploying different services. While the pioneer services have already been identified, other services may become much more attractive in a shorter period than initially thought, and it would seem prudent to continue research and monitoring of development in all prospective ITS areas.

(i) Vehicles

After many years of slow growth of in-vehicle ITS, vehicle manufacturers are beginning to respond to consumer expectations for connected in-car services. One of the challenges is having a fragmented market, with many suppliers in the value chain and few similarities in how services are implemented. Automotive manufacturers use different suppliers, service providers, and service architectures. This situation means that achieving standardization of interfaces within a company's various offerings is difficult, if not impossible.

Another potential issue with achieving standardization of ITS interfaces for safety applications is that the market for ITS currently concentrates on infotainment applications. Some manufacturers feel that there is little perceived market advantage to safety-related ITS applications; other market surveys suggest this has been increasingly important to consumers. Nevertheless, some "push" from government could help increase focus on safety-related applications, particularly where there is no consumer awareness.

\section{(ii) Communications Technologies}

In regard to supporting communications technologies, the automobile industry is largely technology agnostic on the issue of cellular versus dedicated short-range communications. However, the fact that cellular coverage is largely ubiquitous means that there is a perceived advantage in using cellular on the basis that it already exists. On the subject of vehicle-to-vehicle communications (V2V), the industry seems to be taking a "wait-and-see" approach, which means that there may be a window of opportunity to influence the industry toward common goals and standards.

The communications network is critical in the development of C-ITS services. Cooperative systems require V2V data communications or vehicles-to-infrastructure (V2I) communications. The actual communications protocol falls to the cellular networks, which are suitable for $\mathrm{V} 2 \mathrm{I}$ communications, and to wireless local area networks, which can be used for $\mathrm{V} 2 \mathrm{I}$ and $\mathrm{V} 2 \mathrm{~V}$ communications. There are time-critical services such as collision warning or mitigation where the latency of cellular communications would be problematic, and roadside beacon density would be insufficient. For such services there are two options, the use of $\mathrm{V} 2 \mathrm{~V}$ communications between the vehicles involved in the maneuver, and the use of on-board sensors. 
The use of on-board sensors can be a robust solution in a situation where other vehicles are not equipped with $\mathrm{V} 2 \mathrm{~V}$ services. Thus, the case for $\mathrm{V} 2 \mathrm{~V}$ is weakened by the "rollout" issue. Autonomous sensing provides immediate and progressively increasing benefits as vehicles are equipped, whereas $V 2 \mathrm{~V}$ does not provide benefits until most vehicles are equipped. Eventually, $\mathrm{V} 2 \mathrm{~V}$ might be a cheaper solution, since the deployment of on-board sensors is difficult. With the $5 \mathrm{G}$ technology available, the decision of which communication technology may be more suited would highly depend on costs and functions.

(iii) Stakeholders and Business Models

To accelerate the deployment of ITS, governments should spearhead the update and dissemination of state-of-the-art national ITS architecture and deployment plan for all stakeholders. Industry stakeholders are ready to develop more ITS services if suitable business models are available. Business models require customers who want the services, and a value chain capable of delivering those services such that the chain supports all the participants in a way that provides affordable services. Similarly, there is an increasing interest in integrating smartphones within the vehicle ecosystem; although, again, there are many approaches and options. The automotive industry is not able to finance the installation of beacons providing a dedicated communication channel to vehicles. Consequently, they are pragmatically basing V2I services on cellular communications.

Industry stakeholders have indicated that they are looking at governments to take the lead in establishing a market for $\mathrm{V} 2 \mathrm{I}$ and $\mathrm{V} 2 \mathrm{~V}$ services. They are not anticipating direct or continued government funding for ITS, but they see the government's role as stimulating market demand and identifying solutions that can become self-funded and sustainable in the longer term. Several approaches to stimulate ITS deployment are available. One such approach is for the government to sponsor research, trials, or pilot projects to undertake work on standards and autonomous vehicles. The insurance industry could also have a role in deploying ITS, as technology can reduce accident risk and/or monitor higher risk drivers. All existing routes appear to be suitable for stimulating deployment of ITS. Market solutions should be encouraged for ITS such as floating vehicle data collection, dynamic route guidance, in-vehicle signage, and hazard warning ahead.

(iv) Skills and Experience for Cooperative Intelligent Transport Systems Deployment

Higher education and university academic teaching, including postdoctoral research, are needed for the deployment of ITS. Technical visits and discussions with various stakeholders have also provided evidence for high-level skills and capabilities within the industry. Nevertheless, ITS is a rapidly developing area which calls for continuous professional development, in which engineering institutions would play a key role. Professional registration and ongoing formal skills development are critical to support future growth.

(v) Longer-Term Cooperative Intelligent Transport Systems Development

Given the rapid technology development within ITS and consumer electronics, there have been challenges in predicting future capabilities and in terms of the time frame for deploying different services. While the pioneer services have already been identified, other services may become much more attractive in a shorter period than initially thought, and it would seem prudent to continue research and monitoring of development in all prospective ITS areas. 


\section{Conclusions and Recommendations}

Considering the varying stages of ITS development across Asia and the Pacific, it is important to promote sharing of experiences, best practices, and innovation. Knowledge sharing has been increasingly becoming important, especially in critical areas, such as regional public goods, climate change, urbanization, regional cooperation initiatives, as well as emerging social issues, such as aging. Development partners can proactively seek ways to promote the use of advanced technologies across their operations and provide capacity-building support to developing member countries. They are also in a good position to mainstream advanced technologies in infrastructure operations that reduce life cycle costs and increase durability, improve efficiency, and maintain the quality of services, while minimizing negative environmental and social impacts.

The systems engineering approach to developing and implementing high-technology projects is a good tool for ITS development, because it focuses on managing the risks in the design, deployment, and maintenance of complex interacting elements over their life cycles. The bulk of this article discussed the ITS conceptual design, which is part of the feasibility study or concept exploration phase of the systems engineering process. The conceptual design is essential as it fully illustrates the needs of stakeholders. The ITS is planned and designed based on stakeholders' objectives. The conceptual design is also an important part of the whole process-from planning to implementation of an ITS project.

An ITS conceptual design that was based on stakeholder needs and objectives had been developed for the do Gui'an New District. The conceptual design includes a regional architecture that shows the stakeholder elements and their information-sharing interfaces with other elements. It aims to ensure that implementation of ITS services meets all the stakeholders' objectives. The ITS architecture in the conceptual design is a technology-neutral representation of the ITS services, and it should be used to guide the detailed design, construction, and testing of the ITS elements.

The development of a conceptual design in a project can enable future system operators, maintainers, and users to plan ITS services based on existing best practices that meet the specific transport safety and efficiency needs of the Gui'an New District. Its development at the very beginning of a regional transportation technology project is intended to avoid very costly interoperability (or institutional integration) defects later in project procurement, operation, and maintenance.

To increase the chances of success in developing a comprehensive and sustainable ITS, it is important to invest in a regional architecture conceptual design. Once this is developed and identified, city or municipal governments can ensure that the ITS projects they finance will be able to adapt to changes, such as frequent equipment and technology advancements.

Encouraging the development of a proper regional architecture or conceptual design is also important for development partners before investing in an ITS project to avoid costly and piecemeal ITS investments. Doing so will help ensure investment returns and allow for knowledge sharing. In Asia and the Pacific, development partners should further support the development of regional architecture like cooperative ITS that requires cross-border collaboration, including institutional and legislative agreements.

Increased ITS deployment will bring about safety improvements which will lead to other benefits. Accidents will be reduced, which in turn leads to a reduction in traffic delays. Ultimately, the use of ITS will yield economic and environmental benefits. Economic or efficiency benefits arise from reduced journey times and improvements in 
journey time reliability for both travelers and goods. Environmental benefits are gained through smoothing out of vehicle flows, which reduces fuel consumption, emissions, and noise. A robust ITS, therefore, can improve road safety, increase transport efficiency and comfort, and promote sustainable growth.

\section{References}

Asian Development Bank (ADB). 2016. Safety and Intelligent Transport Systems Development in the People's Republic of China. Manila. https://www.adb.org/publications/safety-and-intelligent-transport-systemsdevelopment-prc.

- - . 2019. Conceptual Design of the Intelligent Transport Systems Project-Case in Gui'an New District. Manila. https://www.adb.org/publications/intelligent-transport-systems-guian.

- - . 2019. Report and Recommendation of the President to the Board of Directors: Proposed Loan to the People's Republic of China for the Guizhou Gui'an New District New Urbanization Smart Transport System Development Project. https://www.adb.org/projects/documents/prc-51366-001-rrp. 


\section{Prospects for Mobility as a Service}

Robert Valkovic, Lidia Signor, Gayang Ho, and Clémence Morlet

\section{Introduction}

Urban mobility has traditionally been developed from the perspective of individual modes or even operators. Services are frequently poorly integrated, even if designed to be implemented at the planning stage. Sometimes integration is augmented through operational initiatives and government regulatory framework and regulations. While strategic or holistic objectives like modal share may exist through city transport masterplans, these are rarely effectively implemented. There is often a mismatch between modal share targets and the planning or investments needed to achieve urban mobility. The end result is usually a poorer public transport system and services that both discourage their use and create more favorable conditions for private vehicle usage, such as cars and motorbikes.

For most of its history, urban mobility has been largely a static system in terms of new developments - the same basic modes are still being used now as 100 years ago. However, over the last decade or so, the application of technology has resulted in some significant changes to many modes, particularly from a user's perspective. At the same time, high urbanization rates, particularly in developing countries, have exacerbated several problems in cities. Accelerated traffic volume growth - well in excess of increasing land space for transport-resulting in higher pollution, greenhouse gas $(\mathrm{GHG})$ emissions, and congestion, continues to plague many cities around the world.

The world has seen an advancement of mobility technologies, creating a variety of traditional mobility choices, such as car-sharing, bike sharing, on-demand transport, and ride hailing in recent years. New innovations have been introduced in the area of shared micro-mobility like scooters, electric bikes, electric scooters, and electric mopeds. However, these modes are only meeting a very small percentage of transport demand. Additionally, even the emerging 4th industrial revolution modes, such as electric/alternate fuel cars and autonomous vehicles, or other trends like higher e-commerce that have indirect mobility impacts, have been projected to have a negative impact on transport if left as independent modes. ${ }^{1}$

These modes have created a far more complex mobility environment than in the past-far too complex for an average user to easily determine the optimal modal mix for a trip. Hence these services need to be well-integrated to shift to a multimodal optimization of the transport system.

Mobility as a service (MaaS) has emerged in the last decade to meet this new complex mobility demand as technology has allowed greater access to data and devices, such as smart mobile phones. MaaS systems (e.g., Uber, Lyft, Ola) were originally and mainly developed as a single platform to facilitate private sector-led

The growth of e-commerce sales has resulted in substantive increase in delivery services, thus exacerbating congestion. Autonomous vehicles will promote convenience and increase trips per person. Electric vehicles will lower vehicle operating costs, encouraging more and longer trips. The net impact of these measures has been estimated to increase transport demand by $50 \%$ to $100 \%$. 
initiatives. To date, the concept of MaaS has expanded to integrate various forms of transport services into a single mobility service which is accessible on demand. MaaS also assists city planners and decision makers in achieving public transport usage targets. MaaS has the potential to provide an attractive and efficient alternative to private car use and to promote a shift toward sustainable public transport modes. This will result in transport networks being more efficiently used, thereby reducing congestion, and in the long term, can decrease the level of investment in transport for the same demand.

The potential transport constraints and the need for efficient and effective mobility in cities cannot be overstated to avoid the potential transport constraints that cities will face in the future. Congestion will continue to increase despite improvements of vehicles, options in types of urban mobility modes, and investment in infrastructure. MaaS, coupled with an effective public transport system and a core capacity in active mobility, is critical. ${ }^{2}$ It will reduce congestion, promote equal access to services, and mitigate the negative environmental impacts of air pollution and GHG emissions. MaaS will eventually contribute to more sustainable mobility and toward achieving livable cities in the future.

The next two sections review the basic principles of MaaS. The fourth and fifth sections discuss the different beneficiaries and how to create an equitable framework for each city, which is necessary to ensure a holistic forward-looking system can be established. In the section "Mobility as a Service Topology and Levels," this article examines the different dimensions of MaaS and how they have been evolving throughout the world. The next section focuses on MaaS in developed and developing countries in the Asia and Pacific region. Finally the last section briefly examines how the coronavirus disease (COVID-19) crisis has impacted and expected to impact MaaS in the future.

\section{Defining Mobility as a Service}

MaaS has no commonly agreed definition although its concept has received high levels of interest in the urban mobility sector, both from the public and private sector. There is also regional bias on whether the private or the public systems have led to its development. MaaS can be misunderstood or oversimplified as a mobile application (an app) or as all the services that come with an app, such as ride-hailing services like Uber, Grab, and Lyft. This perspective is clearly a deviation from the more advanced concept of MaaS.

Today, MaaS is more holistically understood as a multimodal framework that enables optimum and people-centered transport choices, based on integrated multimodal information, booking, ticketing, and payment functions that make it easier to satisfy people's needs (Figure 1). This framework would be the basis for all private and public transport systems in a city, albeit some MaaS apps can still serve the needs of a subset of a city's total requirements.

The MaaS Alliance (2017) shared the first definition of MaaS with public and private organizations:

MaaS is the integration of various forms of transport services into a single mobility service, accessible on demand. For the user, MaaS offers added value through the use of a single application to provide access to mobility, with a single payment channel instead of multiple ticketing and payment operations.

2 Active mobility refers to all modes of nonmotorized transport, such as walking and cycling. 
Figure 1: Individual Urban Modes versus Holistic Mobility as a Service Model

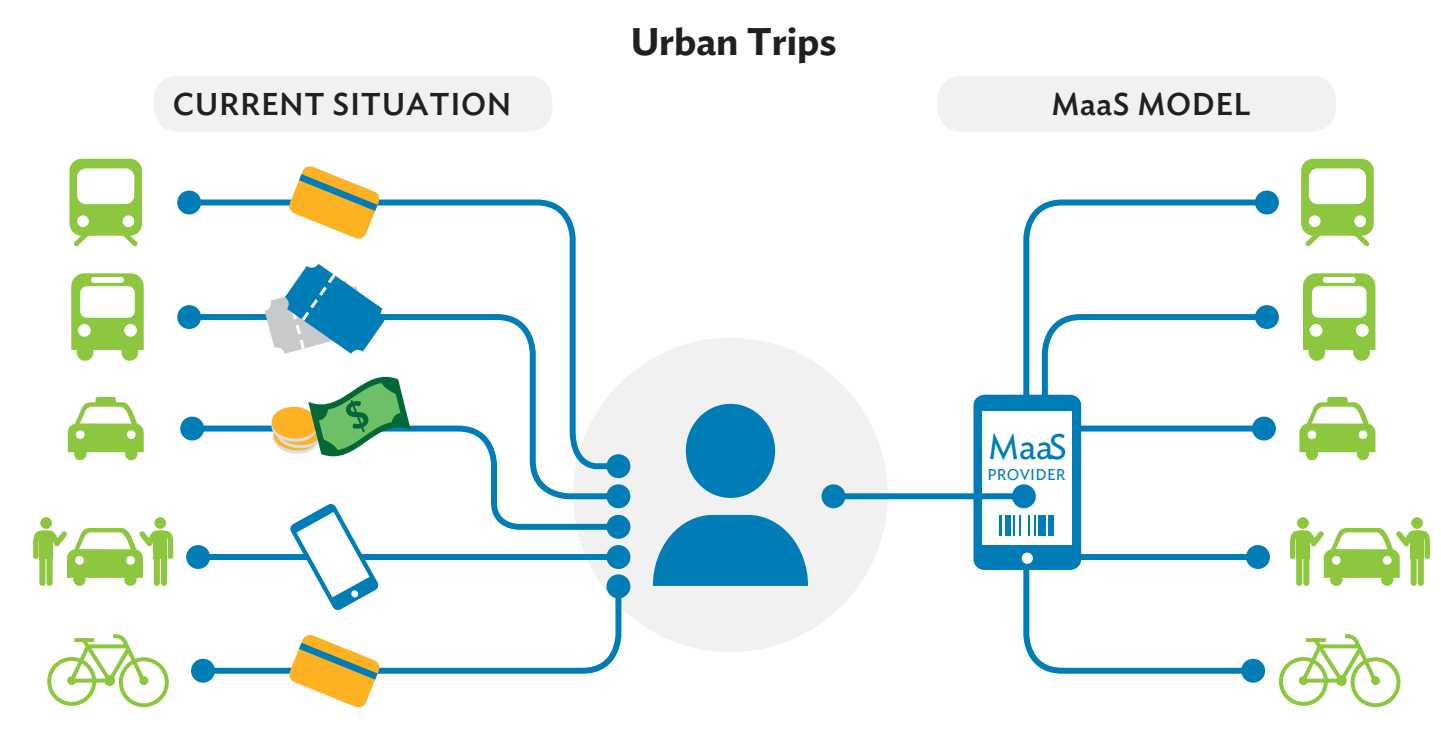

MaaS = mobility as a service.

Source: International Association of Public Transport (UITP). 2019. Report: Mobility as a Service. https://cms.uitp.org/wp/wpcontent/uploads/2020/07/Report_MaaS_final.pdf.

On the other hand, the International Association of Public Transport (2019) defines MaaS within the context of the overall urban transport system:

Mobility as a Service (MaaS) is the integration of, and access to, different transport services (such as public transport, ride sharing, car sharing, bike sharing, scooter sharing, taxi, car rental, ride hailing, and so on) in one single digital offer, with active mobility and an efficient public transport system as its basis. The tailor-made service suggests the most suitable solutions based on the user's travel needs. MaaS is available anytime and offers integrated planning, booking, and payment, as well as en route information to provide easy mobility and enable life without having to own a car.

One of the main objectives of MaaS is to provide transport users an alternative to private cars, which is just as convenient and more sustainable. This will help reduce congestion and constraints in transport capacity, and is even more economic than using private modes. ${ }^{3}$

The concept has emerged with the development of technological possibilities brought about by mobile data and the Internet of Things (loT). The development of MaaS will accelerate as 5G, artificial intelligence, and automation/on-demand systems become more ubiquitous in modern society. MaaS is also a product of societal megatrends, such as changes in behavior and attitudes (e.g., sharing economy), increasing urbanization and pressure on the transport networks and on public space as a scarce resource, as well as climate change and health crisis.

3 Total costs include vehicle maintenance, real parking costs, and indirect ownership charges-not simply daily operating costs. 
Following the appetite of worldwide businesses for the pool of money that is today spent on private cars, the policy potential of MaaS as a better alternative to private car use has also rapidly gained traction. In 2019, under the ERTICO-ITS Europe initiative, a guide for urban mobility planners, Mobility as a Service (MaaS) and Sustainable Urban Mobility Planning, was released as a collective effort of different organizations in coordination with the European Commission. ${ }^{4}$ The guide presents MaaS as a tool for planners to achieve sustainable urban mobility. At the same time, the International Association of Public Transport (UITP) MaaS Report (2019) stresses the importance of having active mobility and an efficient public transport system as the basis of a MaaS solution to "enable life without having to own a car."

The association of European Metropolitan Transport Authorities developed its vision of a "sustainable MaaS ecosystem that creates public value for society and can contribute its part to meeting our region's and city's mobility challenges," and furthermore noted that "MaaS also generates insights into demand, needs and travel behavior for cities and authorities, allowing for more targeted and effective adaptations of services and investments in infrastructure" (EMTA 2019).

Therefore, to deliver on its promise, MaaS is certainly composed of an on-demand, real-time platform that can include any combination of transport modes such as public transport, car and bike sharing, taxis, and car rentals/ leases, which cater to consumers' needs from travel planning to payments (Figure 2). However, the real focus (and challenge) is on the mobility ecosystem, including access to transport-related data sources (the so-called "big data"), and its governance to make it open and inclusive, efficient, and resilient, while reducing its negative externalities.

Figure 2: Urban Mobility Services

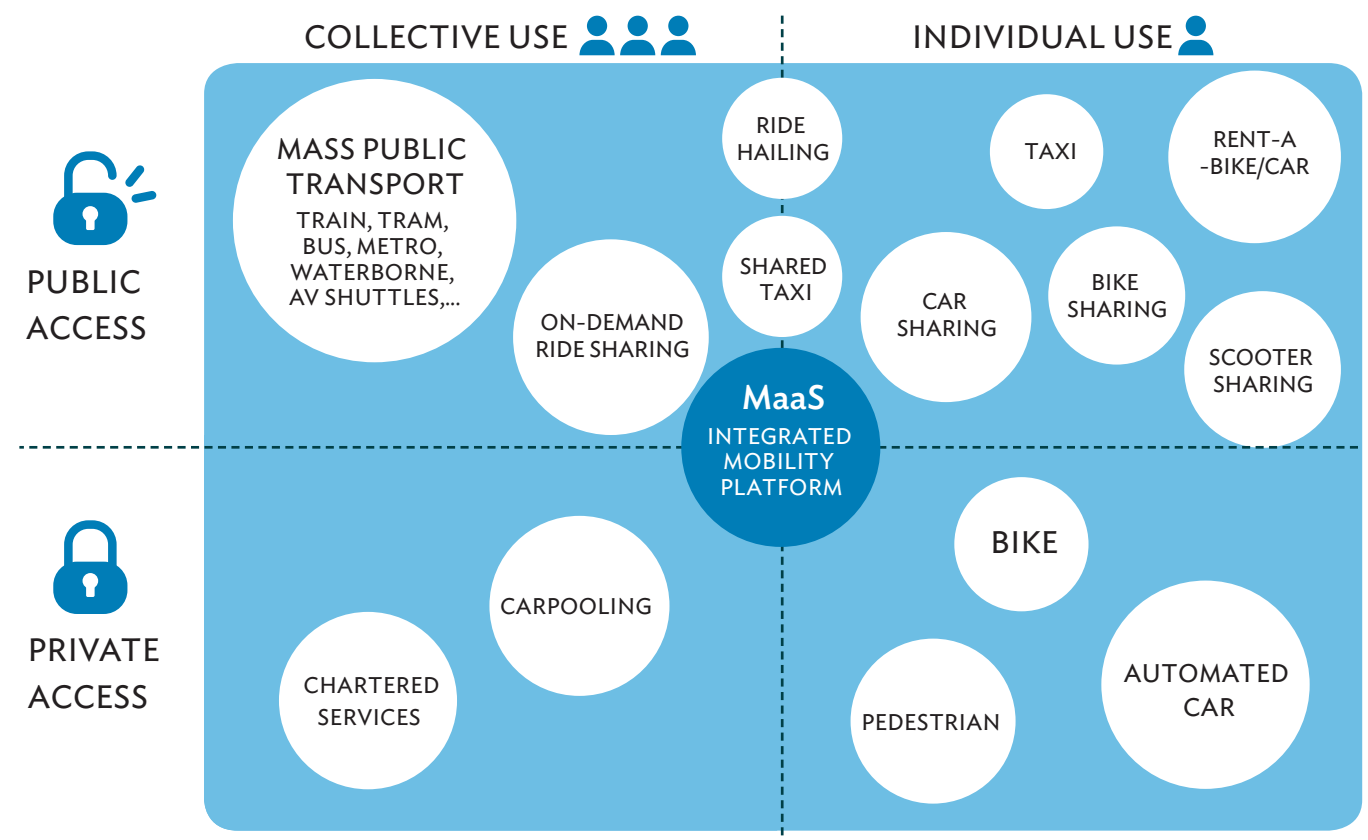

MaaS = mobility as a service.

Source: International Association of Public Transport (UITP). 2019. Report: Mobility as a Service. https://cms.uitp.org/wp/wpcontent/uploads/2020/07/Report_MaaS_final.pdf.

4 ERTICO-ITS Europe (ed.). 2019. Mobility as a Service (MaaS) and Sustainable Urban Mobility Planning. https://www.eltis.org/sites/default/ files/mobility_as_a_service_MaaS_and_sustainable_urban_mobility_planning.pdf. 
MaaS requires a business ecosystem where multiple stakeholder organizations involve users in the co-creation and collaboration beyond the traditional boundaries of business sectors and companies as well as public and private entities.

At its core, the integration and the unified service provision given to the user are undertaken by intermediaries that are between the supply and the demand. The MaaS integrator is called the MaaS platform provider, while the service provider is referred to as the MaaS operator. They may belong to the same or different entities. The supply includes transport operators and infrastructure owners as well as advanced traveler's experience providers. Within MaaS, public transport operators have an essential role as backbone of urban mobility. It is important to note that for each definition given, there is an assumption that an effective and efficient active mobility and a public transport system exists in a city. However, this is not the case in many of the cities in developing Asia.

For MaaS to thrive in those cities, actions are required to support the development of public transport in combination with other complementary services within any given city. MaaS does not intend to create new transport capacity, but to integrate and coordinate with the current capacity of the existing transport mode options in a city. Shared mobility and on-demand services can serve as either a solution for total travel or just the first- and last-mile connectivity. They can supplement traditional public transport services which are not sufficient to meet the users' various travel needs.

The co-existence of MaaS platforms in different geographic regions will likely take place as market efficiencies occur in national and even international systems. ${ }^{5}$ Similarly, the appeal of MaaS will likely result in offers that are targeted to groups with less mobility, such as people with disabilities, elderly or children.

While the concept of MaaS has been defined clearly, the actual MaaS systems are being driven by various physical, operational, and regulatory regimes that exist in cities or countries. In this environment, combined with the fluent and dynamic nature of global MaaS development, there are several types of models that are evident: commercial integration, open platform, public transport integration, and network mesh.

\section{Commercial Integration}

The commercial integration model is structured around marketplace agreements between MaaS providers and transport operators (UITP 2019a). It provides competition through multiple MaaS providers and functions in a largely free and unregulated market (Box 1).

This modal is perceived to provide more customer-oriented and innovative

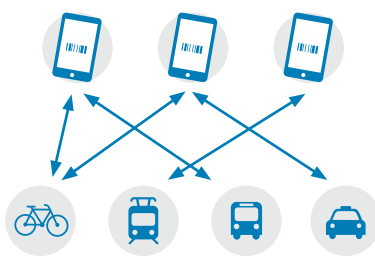
solutions, but its competitive nature would likely preclude it from being socially inclusive due to operational priorities of the business models. It is unlikely that the MaaS providers' data would be shared with public authorities, which means it is not possible to improve existing public transport services and planning through data analytics. There is also a high risk of bias in the presentation of transport options for individual needs. This model could be suboptimal and may provide travel options that are based around the interest of MaaS providers' partners.

In 2016, the Netherlands had a nascent MaaS platform (for public transport only) that covered the entire country, wherein a single card or app could be used in any city or town. 
Box 1: Zipster-Asia's First Integrated Mobility as a Service App and Payment Wallet in Singapore

MobilityX Pte Ltd, a start-up backed by SMRT and Toyota Tsusho, has launched Zipster, which provides a single point of access to multimodal transport options throughout Singapore. This includes public transportation (metro rail transit and buses), private-hire vehicle services, shared mobility devices, and car-sharing services, among others.

Providing a seamless door-to-door transport experience to commuters, Zipster grants the user access to an integrated mobility as a service (MaaS) payment wallet across multiple modes of transport. As part of the wallet, MobilityX will also launch a Zipster card trial.

MobilityX has partnered with AXA Insurance Singapore to protect Zipster users across their multimodal journey. This protection covers personal accident, accident medical reimbursement, and personal liability.

With the introduction of MaaS in Singapore, MobilityX aligns with Singapore's Land Transport Master Plan 2040 and the land use Master Plan 2019. MobilityX plans to strengthen the integration of the entire transportation network and meet the growing travel needs of commuters.

Source: International Association of Public Transport (UITP). 2019a. Mobility as a Service. Brussels. https://cms.uitp.org/ wp/wp-content/uploads/2020/07/Report_MaaS_final.pdf.

An example of a commercial integration model is the Whim service provided by MaaS Global in Helsinki, Finland. The service offers both pay-as-you-go solutions and packages for the existing public transport services, under the "Whim To Go" or "Whim Urban" offers. It has been successful in capturing the majority of users.

\section{Retail Model}

The retail model relates to how the system will be packaged to users rather than to the fundamental system structure. A MaaS offer could be tailored to special needs, like a post-paid telecom contract, or a pay-as-you-go offer like a prepaid telecom contract. Like telecom, it seems there could be a need for both options in a MaaS offer.

A package can offer special conditions, discounts, and new pricing models that can be very cost-effective for a user. It also can enhance attractiveness for the customer and propose new business models for the provider. However, monthly fees or long-term subscriptions for these packages have been barriers to a customer, especially for those who are not experienced in using new mobility services and do not adequately understand the benefits they could gain from the services. Flat rate-style packages can be problematic for the provider and the customer, as they will require setting a reasonably high basic fee for longer lock-in period, given that travel needs may vary throughout a year.

Thus, for the moment, a pay-as-you-go offer or small (low-priced) bundles seem to be better received from a customer's perspective, as the benefits are more intuitively visible. For this type of bundle, it is also important to reduce the entrance barrier for customers. Special short-term packages can be offered to customers to give them the opportunity to learn, and from there, move on to long-term packages at a later stage. 


\section{Open Platform}

In an open platform model, different MaaS providers build their own service based on a common open platform set up by a public entity with rules determined by a public authority (UITP 2019-a). In effect, the platform serves as public infrastructure on which different actors could build a MaaS solution. Thus, the platform acts as a relay between operators and providers. The platform also requires all mobility service providers to open up their application programming interface (API) so that data will flow freely. The competition in this modal is on the front side with the MaaS providers, who need to provide value to users to get and maintain a market share.

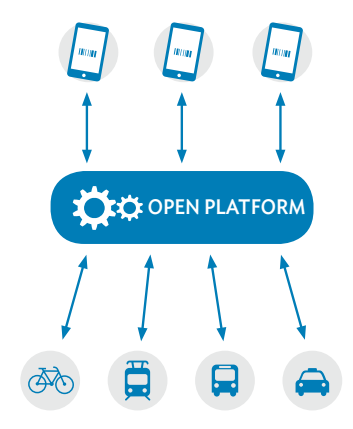

This model is usually considered to enhance features by offering a customer-oriented, innovative, and impartial service, and leads to conditions where local transport providers are more likely to be integrated. However, as the platform is established and operated by a public entity, there is a need to address its initial and long-term financing. The platform may be financed through an appropriate cost-sharing mechanism, as well as keeping up with technological innovation and evolution (which will enable it to attract sustainable financing).

\section{Public Transport Integration}

In this model, the MaaS is run by a public transport entity which has the prerogative to select mobility services and set all the rules for operation (UITP 2019a). The more extensive services the public transport entity controls, the better. Other mobility service providers may have to open up their API to be included under the public transport MaaS system.

Since the public transport entity has the largest customer database, and provides a city's core urban transport system, its role of leading the city-wide integration of all urban transport service options is just logical. Public transport remains relevant to existing customers and appears more attractive to new ones by becoming a real mobility provider. This model is also perceived as being able to achieve the highest increase in sustainable mobility, being socially inclusive, and being best aligned with public policy goals (as data would be shared with public transport). However, as only public entity-led, this means it is perceived as providing a less customer-oriented and innovative service.

This model has garnered high acceptance in Europe, where public transport providers are commonly both multimodal and reasonably well integrated due to prior government reforms to reduce inefficiencies and decrease subsidies.

One of the first real MaaS by a public transport operator was established in Hanover, Germany by Üstra. In February 2016, Üstra launched the "Mobility Shop" that offers multimodal registration, routing, booking, and invoicing for all public transport (car sharing, bicycle, taxi, and local German rail services) within the Hanover region. Üstra holds the "umbrella" contract with the clients and offers special discounts for other mobility services and flexible registration for all services. At the end of the month, Üstra does the multimodal billing, provides customers with a joint invoice, and redistributes revenues. It is a major step toward becoming a true multimodal provider that offers MaaS to the city's public transport users.

Another example is in Vienna, Austria. The city public transport authorities, Wiener Linien and Wiener Stadtwerke, established a subsidiary, Upstream, as the entity to develop an urban transport platform for the city. Upstream created the necessary digital infrastructure for all transport management in line with public policy goals, including social objectives. The digital infrastructure provided a centralized access to all mobility services in Vienna. This platform is the back-end platform onto which different MaaS solutions can be built, but it was not open. 
In June 2017, the mobility app WienMobil was launched. It provided simple and convenient access to bus, tram, and metro, and to all other publicly available mobility services, such as e-loading stations, parking garages, taxis, bike sharing, car sharing, and car rentals. The WienMobil has become a one-stop mobility shop that enables the user not only to access real-time information, but also to buy tickets, book, reserve, and pay for other combined transport for an "end-to-end" mobility solution.

While a MaaS app like WienMobil can provide a largely fair and efficient selection of mobility options in Vienna, an inherent risk comes with it. Since it is closely linked to public transport agencies, which are traditionally dominated by technocrats, its design could be less innovative and less creative than those normally managed by the private sector and entrepreneurs or those led by multisector or gender aware teams.

Another variation of this model is in Japan. During its first stage of development, the MaaS in Japan focuses more on data integration and lesser on other integration areas. MaaS Japan acts as a common data platform, wherein all MaaS providers build their service offerings. Figure 3 illustrates an example from the EMot app, currently piloted by the Odakyu Group in Japan.

Figure 3: Japan's Common Data Platform-MaaS Japan

- MaaS Japan is an open common database for MaaS in Japan

- MaaS Japan provides integrated API and data connection service

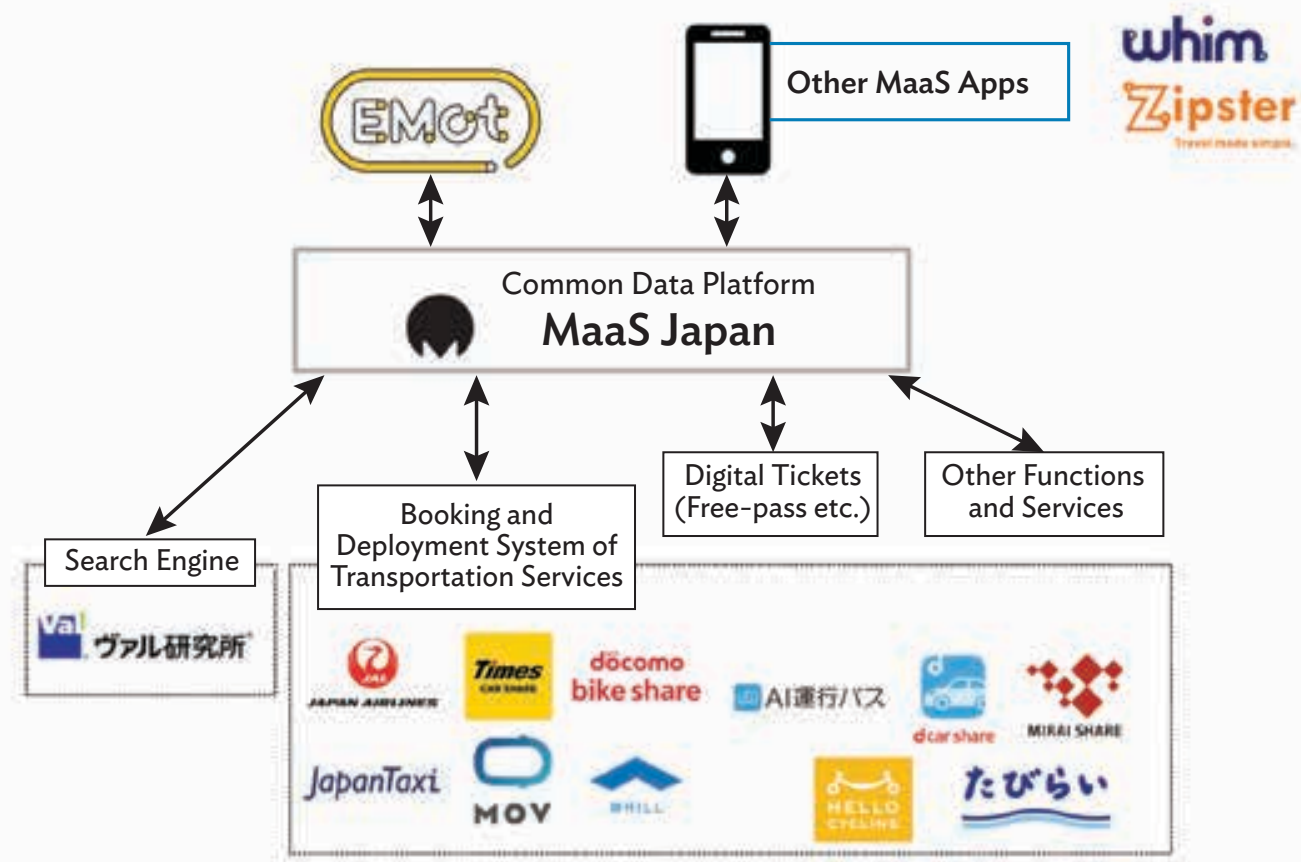

$\mathrm{API}=$ application programming interface, $\mathrm{MaaS}=$ mobility as a service.

Source: Odakyu News Release. 2019. Common Data Platform “MaaS Japan” Cooperating with Global MaaS apps Odakyu Electric Railway Company. https:/www.odakyu.jp/news/o5oaa1000001necq-att/o5oaa1000001necx.pdf. 


\section{Network Mesh}

This model is a relatively new concept and has no common MaaS platform (as described in prior models). The interface of the mobility data is on a peer-to-peer basis (UITP 2019a). This means that each of the individual mobility service vehicles is constantly exchanging information on its status with all other (nearby) vehicles, rather than going through a central database for each mode or mode provider.

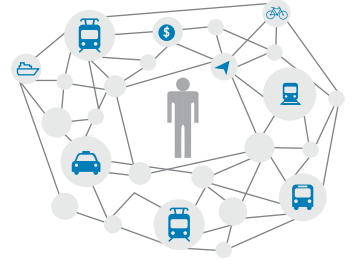

The technology framework used to establish this model is blockchain, which provides suitable security (e.g., identity and data management), speed of payment and data transactions, and scalability. All stakeholders work on a shared platform via a decentralized ledger technology. In this model, a central entity coordinating the platform would not be necessary, since a coordinated mobility ecosystem is already built in the model.

As a new model, there are only pilot systems emerging from start-up companies at a relatively fast pace. However, it is not yet a proven technology and no large-scale implementation has been established yet.

\section{Why is Mobility as a Service Important and Relevant?}

Both developed and developing cities have seen the trends and complexity in mobility development in recent years. In this regard, MaaS is an important and a necessary step in building a better mobility system. The number of mobility services, alongside the enhancement of mobility modes, will continue to increase in the future. As new services gain acceptance and begin to grow out of their niches, it is likely that customer expectations will continuously evolve and create a different mobility landscape in the future. The arrival and expansion of automated vehicles will be the ultimate game changer, enabling ride-sharing and ride-hailing services become a common reality.

Technology allows mobility services to merge to form a continuum of different options, and "end-to-end" solutions. Consequently, the traveler's choice will depend more on the total price and performance (e.g., quality, comfort, flexibility, time) than on individual mobility modes. However, with the increasing complexity of mobility options, there is a need to help users understand the differences in value of the modes and enable them to make a better choice. Mobility services should be organized in a smart and coordinated approach from a street design and urban space allocation perspective. MaaS is key to changing travel behavior toward more sustainable urban mobility options. It can reduce private car use and provide better and more affordable mobility for all users, including diverse and vulnerable groups.

From the users' perspective, users are looking for reliable and accessible urban mobility solutions from door to door. They wanted to enjoy the total freedom that mobility offers without having to pay for, maintain, and park a car. It is expected that once people realize the improved service through MaaS, they will reconsider car ownership and be more inclined to change their mobility habits toward more sustainable modes. However, a thorough understanding of travel and human behavior of different user groups in different contexts is essential to form the basis of any serious development of MaaS solutions.

According to the UITP MaaS Report (2019), from a transport operator's perspective, MaaS is also offering its travelers a better service with a wider range of options that will attract more customers. MaaS is a tool to improve customer loyalty and provide better value for money. It is clear that any business stakeholder in the MaaS ecosystem will pursue the goal to grow their business, but it is still unclear which business models will emerge to 
capture the value created by MaaS. Nevertheless, it is a great opportunity for public transport operators to gain a positive and more modern image, while adding more services to their portfolio and leading the ecosystem toward the creation of a more sustainable public transport system for a city or region.

As explained in the previous section, from a city authority and mobility policy perspective, one specific objective to pursue MaaS is to shift citizens' travel behavior toward more sustainable modes and offer better service and affordable mobility to reduce car ownership, while offering similar flexibility and convenience. This would support the broader objectives of reducing congestion, increasing accessibility, lowering air pollution, and contributing to the reduction of GHGs. However, cities and regions engaging with MaaS need to have a clear strategic vision. Cities also need to ensure allocation of sufficient financial and human resources. Their vision can be used to guide MaaS solutions, tackle key missing enabling elements, and improve public-private partnerships. To avoid unfavorable mode shifts, cities and regions should ensure that a MaaS system aligns with their policies and broader goals. ${ }^{6}$

Studies about the impact of car sharing show that car ownership shapes mobility habits. For instance, the 2014 Ubigo pilot in Gothenburg involved 70 paying households under real conditions for 6 months. The arrangement was that each household paid their transport costs upfront, while earning a bonus for making sustainable choices. Researchers at Chalmers University have published many papers based on this pilot's evaluation (Karlsson et al. 2016). The results clearly show that there has been a shift to more sustainable transport modes, as private car use has been reduced by $50 \%$.

A car parked in front of one's door will influence mobility habits and choices in its favor because it is easily accessible and the cost of owning a car is not known. Indeed, fixed costs are already paid, and year-long excellent marketing techniques ensure people are also emotionally attached to their cars. Car ownership is the greatest obstacle to a flexible, context-oriented choice between modes. This means the conversion of car owners is key to changed mobility behavior in developed countries and reduced growth of car ownership in developing countries. One of the bigger potential impacts of MaaS could be achieving a shift from individual car ownership to shared and other sustainable mobility modes.

For cities and authorities, MaaS is also an opportunity to gain precious insights on real demands, needs, and travel behavior. It allows for more targeted and effective adaptations of services and investments in infrastructure. Data analytics based on data usage, including demand data, from the MaaS operator, can provide transport operators with valuable insights on how to adjust their network or service to best match the demand. This can be done by relocating stops, redefining certain routes or schedules, or offering additional services. This means data analytics has many benefits. It helps enhance the overall service quality of all transport services and enables a better response to a traveler's needs. The data value lies in the analysis and service trends in real time that can be extracted from the generated data, which provides the following indirect benefits:

- $\quad$ Service trends allow the MaaS operator to improve the service by providing more personalized services and to optimize the business with a holistic view on usage and needs.

- Data analysis gives the transport operators better knowledge of their customers and helps them improve their offer and optimize their costs.

- Real-time data enables city authorities to have a better view on their territories and to improve infrastructure and urban planning.

6 MaaS Maturity Index. https://www.MaaSlab.org/MaaSindex. 
By using MaaS, travelers could save money and get a better service (Box 2). They experience flexibility and convenience, while helping achieve their cities' socioeconomic and environmental sustainability goals. However, it is still not clear which mechanisms can successfully operate to allow value capture from the operators, especially the MaaS operator as intermediary. This is particularly true in a market where profits are already very low, public transport is subsidized, and many new mobility services are running on venture capital without making a profit. One potential mechanism could be the sale of bundled mobility services made available to individual customers, like in the case of MaaS Global in Helsinki.

\section{Box 2: The Potential of Mobility as a Service-The Low-Tech Pilot of Great Manchester, United Kingdom}

In 2018, the Transport for Greater Manchester and the Atkins/SNC-Lavalin tested whether mobility as a service (MaaS) could shift commuters out of their cars, either onto public transport or toward active travel options such as walking and cycling to work. The experiment adopted a very customer-centric and human-centered approach from the outset.

In a live trial, there were 39 participants from across the city who were all working in Salford. The immersive research captured rich data from the participants through in-depth interviews and ride-alongs with passengers. This provided insights on day-to-day issues affecting commuters. Seven modes of travel were offered in the personalized journey plans: buses, trams, car share, taxi, bike share, on-demand shared mini bus, and walking.

Extensive analysis showed that MaaS could be a significant tool in achieving the Transport for Greater Manchester's objectives. About $26 \%$ of the participants were more willing to use public transport, and $21 \%$ were more willing to cycle and walk. This indicates that MaaS has the potential to create more sustainable travel behaviors (active travel modes and ride sharing), which can help address the challenges local authorities face in urban areas. Six months following the trial, $82 \%$ of the participants interviewed wanted MaaS back. One-third of car owners wanted to give up their vehicle following the research, and the majority of participants were willing to pay an increase in their monthly travel expenses for MaaS.

Source: International Association of Public Transport (UITP). 2019a. Mobility as a Service. Brussels. https://cms.uitp.org/ wp/wp-content/uploads/2020/07/Report_MaaS_final.pdf.

Today, a variety of business models are experimented worldwide, including bundling of services that go beyond pure mobility and embrace other needs, such as those of the employers, retailers, housing promoters, and tourist service providers. The more visible and evolved mobility services seem to be more connected to the general technology-enhanced disruptions - using technology to fill transport deficiencies-and evolutions seen in society and all sectors of economy (acceptance of shared economy supports shared mobility). The world has seen many businesses that were originally only a mobility provider that moved into other complementary and even non-related areas to improve their financial viability. Examples are Uber now providing Uber Eats and other services or Grab now providing financial services in some countries. Thus, the world is now moving toward "Living as a Service" business model. 


\section{Making Mobility as a Service Work: Stakeholder Aspirations}

How each MaaS system (or systems) develops in a city will be heavily influenced by various key stakeholders. At a functional level, the key stakeholders will be governments (at all levels), operators (physical and MaaS providers), and urban mobility users. While there may be strategic policies and regulatory mechanisms in place-which should promote equitable, inclusive, and sustainable public mobility - they usually are neither comprehensive nor effectively addressing the changing urban mobility trends. Stakeholders are rarely a homogenous group and each of them have their own priorities, interests, and approaches. Additionally, as MaaS has a heavy technology component, some stakeholders (the "disruptors") might use the outdated regulations that have gaps for urban mobility system operations as an excuse not to push forward with the sustainable public mobility agenda.

Stakeholder mapping is an important first step to develop an effective MaaS system and creating the right policy and regulatory framework for a city. Stakeholders for a major city typically include

- government and authority,

- public transport operators,

- car-sharing operators,

- bike-sharing operators/micromobility

- urban mobility users,

- MaaS operator, and

- business partners.

Government authorities will need to support the city population's daily activities without the need to own a car by providing suitable sustainable mobility options. They have the ability to reach segments that public transport providers cannot attract and win by themselves. This will secure the role of the public transport sector in providing a reliable mobility platform for people living outside the cities. The government's key responsibilities are to establish a citywide mobility vision or strategy and develop the regulatory framework to establish this strategy. On an ongoing basis, the government needs to ensure the improvement of service efficiency and long-term network planning.

The public transport operators (PTOs) should value customer relationship, with the intent of getting new clients through the MaaS operator and ensuring suitable, cost-effective quality of service to maintain this customer relationship. To ensure business viability, they need to ensure they will receive a fair share of MaaS-generated revenue based on the actual usage of their services. This will be achieved through effective use of their transport data, use of shared accounts, data sharing, and reciprocity and data deals with other stakeholder operators. The PTOs will need to ensure their operational and usage data is open for everyone. They should be transparent on the whole trip demand of their users to ensure fair usage by all stakeholders. The PTOs will be responsible for liability for the whole journey and in ensuring there is sufficient customer focus with provision of services that suits their requirements. To maximize benefits, the PTOs will need to ensure their brand is visible to users too.

Car-sharing providers (CSP) will expect gaining new customers through the MaaS operator, which will increase turnover and profit. Importantly, by being a part of a common stakeholder group, the CSP will better understand that it is a low-margin business. This can benefit other stakeholders by removing the typical competitive behavior of a CSP against public transport modes. The CSP data will leverage other stakeholders' data to run their operations, create a data-sharing community, and provide customer service during the trip. The full data will ensure CSPs can provide vehicle availability in a cooperative manner. Due to their competitive nature (some CSPs will not be stakeholders but competitors), CSPs will need contract flexibility to react to the changing environment and the MaaS operator should not compete with CSPs. 
Bike-sharing/micromobility providers (BMPs) will gain benefits from a much wider data for operational procedures, from access to a bigger market and from obtaining a higher market rate price for their service. BMPs would expect to have an influence in the MaaS app mode choice and mode hierarchy structure and how BMP services are presented to ensure effective promotion of these newer service modes, such as the health benefit and sustainability features. Similar to CSP, the tariffs need to be flexible and respect a degree of autonomy to firmly establish this option as a viable alternative. The BMPs will need to provide a rigorous customer service to ensure these outcomes can be effectively achieved.

Individual urban mobility users (UMUs) should be considered in the human-centric perspective of traveler or commuter. They need to trust that all service providers will provide high-quality services with real-time information, strong reputation and branding (consistent across their services), and high reliability (extremely low non-service occurrence). The MaaS app should be simple with an easy, user-friendly interface and harmonized services across providers to ensure high levels of convenience. The app should provide an impartial choice of options and high flexibility for UMUs to switch between services.

The MaaS operator should have a high emphasis on outreach to ensure the MaaS app is a desirable system for all UMUs and to attract maximum customers for maximum benefits. They will need to set up an integrated mobility platform that creates value and satisfies customer expectations, and develop strong partnerships with different transport operators. The MaaS operator can be any suitable entity, a major public transport provider, a new government agency, or a public-private partnership, depending on the local city context.

The MaaS business partners, which may include operators, expect the system to be a neutral, independent, innovative, and stable integrator of services. All MaaS business partners should be treated equally and nondiscriminatory. They should be an effective mediator to ensure operators understand and respond to each other's needs. They expect the MaaS system solution to be very user-friendly and highly attractive to UMUs to ensure long-term growth and business viability.

In addition to the challenges and barriers that the competing interests of key MaaS stakeholders present, there are also inherent critical issues in establishing and operating public transport systems that need to be overcome to create a successful and financially viable MaaS ecosystem. How they need to work in coordination should be addressed in parallel.

The MaaS ecosystem challenges inherent to public transport provision emanate from a low- and high-margincost market in cities, which is based on high volumes and low revenue. It is also difficult to integrate "public" transport in a commercial service due to its low viability (commonly resulting in operational subsidies); thus, attracting different providers to join the market can be challenging. Other key non-system challenges are deployment of car sharing (to support public transport), expansion of UMU base, and establishment of suitable data protection regulations.

Some of the typical barriers and obstacles to the MaaS ecosystem perceived by operators are the risks of cannibalization of their UMUs, degradation of brand by other operators, and losing existing customer relationship. A new MaaS system can face a lack of shared vision and lack of understanding among key stakeholders of what MaaS is and what it can do, especially the MaaS business case. Many operators have a fixed view of their existing roles and identities, which can also create value misalignment within organizations. Furthermore, many operators lack suitable key competencies and adequate entrepreneurial mindset. There can be a lack of understanding about what UMUs want or prefer and who are their key segments. Due to prolonged exposure to the traditional market, operators may struggle to know UMUs' real willingness to pay and what is the actual market demand for MaaS services. 
Reducing the impact of these challenges can be a difference between establishing a successful and financially viable MaaS solution, or, setting up a failed MaaS or one that does not serve the entire public transport system and all users.

\section{Mobility as a Service Governance Framework}

For MaaS to effectively function and achieve the mobility visions and goals that may be set by city authorities, it is necessary that relevant mobility policies and regulatory conditions exist in a city. Regulatory measures should create an equitable, socially acceptable, and sustainable physical and legislative framework. The governance of this framework needs to be embodied in these laws and regulations. Such framework should be developed, established, and monitored/validated to ensure maximum transparency, fairness, and openness in competition among MaaS providers, mobility service operators, and transport users.

In terms of the physical environment framework, it is assumed that for MaaS to be successful, an effective and efficient active mobility and public transport system should exist in a city. Unfortunately, financial and legislative bias is not uncommon, resulting in overinvestment in private vehicle infrastructure (that is inconsistent with the stated mobility master plan targets) as well as in car-friendly policies and regulations like low-cost or no parking and less risky areas for pedestrians. In many cases, this results in a poor public transport system, particularly in cities of developing Asia. A more holistic, integrated MaaS model cannot be created if the critical multimodal linkages do not exist. At the same time, "MaaS-like" solutions are being developed in these same cities, mostly taking advantage of public transport deficiencies and creating private ownership models, like Grab and Ola.

Hence it is important to develop both physical and (MaaS) software elements that are consistent with each city's mobility options. They should be developed in a holistic and coordinated manner to avoid imbalanced solutions to become entrenched in a city. This means ensuring a more balanced allocation of finances to balance infrastructure improvement with public transport goals. Regulatory biases and hidden subsidies that support private vehicle usage should also be removed.

Local context significantly matters when designing a legislative framework to encourage MaaS, as both established systems and growth directions vary. Replicating MaaS systems to achieve similar results in different cities can become problematic and difficult. Experts have noted that there is no single perfect MaaS solution that fits every environment. Each city and region would need to evaluate which option works best for them, taking into consideration the important aspects, such as local conditions, relationship between public and private sector actors, existing structures or arrangements that create biases, available resources, and mobility policy objectives.

The coexistence of MaaS platforms of different geographic footprints (e.g., local, national, global or multi-local) is likely to become a reality. These platforms can have various offerings that cater to different customer segments (e.g., persons with reduced mobility, elderly) as well as non-frequent customers. In most cases, city authorities may find it simpler to start at a local level and remain within their legal jurisdiction to avoid issues that can either derail or significantly delay the establishment of a MaaS system. This will also help prevent potentially serious and difficult issues, like "MaaS-friendly" common ticketing systems. Although many times, common ticketing can be difficult to achieve even across many modes in a city, in the Netherlands, they achieved a countrywide common ticketing system for all public transport services in 2016. This allowed for the accelerated deployment of MaaS apps throughout the country's cities in the succeeding years. 
There is also a need to ensure that governance frameworks are consistent and appropriate for the varying levels of government in a country-national, state/province, and cities. Each of them can have their own mobility priorities that can impact MaaS development. National government's MaaS-related requirements tend to be at a higher level. They may set common targets or principles that are aligned with their international commitments (e.g., reduce GHGs in transport) or social objectives (e.g., affordability for vulnerable groups through subsidy).

For states and provinces, there may be more financial and transparency/corruption-based requirements to reduce potential financial burden (future subsidies) or to avoid preference for short-term demands over long-term needs. At a city level, the requirements can easily become more complex and competing, which can be addressing congestion problems, improving air quality, or improving services (to selected city areas). Preference for the least-cost investment solutions over socially inclusive solutions may also occur at the city level.

Private sector entities, being the main drivers of MaaS as a new mobility approach, have the advantage of both more profit-oriented business models and human resource capabilities to implement and manage their systems. Most often, public authorities are at a disadvantage to these private sector entities. Public entities may experience nontransparent development or agreements made without sufficient knowledge on how to ensure equitable solutions. Thus, there is a need to ensure that suitable governance criteria are established to ensure the government side is not at a disadvantage during the establishment of MaaS regulations or specific agreements. The minimum staff capability levels should also be determined.

Furthermore, the governance frameworks for MaaS need to be flexible enough to enable the development of the different models identified, as each will have differing regulatory and legislative requirements. Given the importance of the country regulation, it is important for cities to analyze their regulatory environment to appreciate both the real benefits and inconveniences of this model, as well as the actions required.

How these factors influence the different MaaS models depends on how models are structured and how they operate in each city, although the following common impacts can be seen:

Commercial integrator. As the commercial integrator model involves many MaaS providers and service operators as market players, public authorities need to ensure that its role as a public transport regulator (and by default, MaaS oversight) is not compromised by unfair or unequal agreement. This could include a policy to ensure access to data for public authorities (to ensure fairness in pricing of services).

Retail model. The retail model is largely a user interface payment option that would be very similar to most countries' telecom regulatory environment (if they have postpaid and prepaid options), thus this model is unlikely to require special governance conditions.

Open back-end platform. As this platform is set up by a public entity with rules determined by the public authority, the governance framework would need to ensure the platform is created fairly and that access is given to all potential MaaS providers. Appropriate conditions and criteria should also be in place to maximize the potential of a customer-oriented, innovative, and impartial approach, and to integrate the local mobility providers while ensuring scalability. The policy will also need to establish how financial contributions are made by MaaS operators for both the establishment and long-term maintenance and operation. Sufficient resources should be secured as technology develops and advances.

Public transport as integrator. Similar to open back-end platform, in this model, the public transport operator is the integrator and in charge of setting up the rules. This should not disadvantage the city authority from its role as regulator of all public transport. There should also be principles that encourage the public transport operator to 
integrate new mobility (private sector) partners that can help advance sustainable mobility, and that are socially inclusive and can best align with public policy goals. Involvement of the private sector should allow for more customer-oriented and innovative services to adopt a forward-looking approach. Furthermore, to prevent public monopoly, private actors may create their MaaS services without the integration of public transport. They can adopt more car-based services that are likely to scale up beyond the local authority's jurisdiction.

\section{Further Institutional and Regulatory Considerations}

There are very few cities that come close to the idealistic framework described in this section. Much debate remains in the realms of think tanks that are trying to define suitable guidelines, although they are influenced by their own perspective on which approaches suit their underlying cultural influences.

In addition to the general governance framework features described above, elements that need to be considered in the institutional and regulatory framework to promote MaaS and sustainable mobility include a range of supportive measures (UITP 2019b):

Cities' policy goals. To achieve more sustainable mobility systems, the regulatory framework needs to ensure that high-capacity public transport and active mobility are at the heart of all MaaS solutions. Their algorithms and business agreements should not create negative modal shifts. The data derived from MaaS should be given to authorities to help them improve the use of existing infrastructure and enhance sustainable mobility, including service efficiency and network planning. Authorities must get involved to ensure the mobility policy for the city is both achievable and trends are heading into the right direction.

Incentives for less car usage. This means that wrong incentives (e.g., free parking or subsidized company cars) can hinder MaaS' ability to attract car drivers' need to be given up. On the positive side, tools to control car traffic and car usage such as access restrictions, road user charging, parking restrictions, and charging car ownership need to be considered.

Incentives for more usage of combined mobility. As an example, the creation of multimodal interchanges offering visibility to all mobility options is essential to promote combined mobility.

Gamification and nudging. Nudging and heuristics (meaning approaches and elements of motivational techniques, such as bonus schemes) to encourage the traveler to use more sustainable modes are often underestimated in terms of the influence they can have on people's behavior and perception of different options available to them. Using MaaS as a tool to steer travel behaviors into more sustainable modes also means to use more nudging to maximize its potential.

Institutional coordination and multimodal urban planning. Different regulations and management for the diverse transport modes and services are often the source of missing coordination. There is also a mismatch between the transport modes, urban space allocation, and street design. MaaS might be a digital gateway to different mobility services but these services also need to be integrated from a physical point of view to become really attractive. Institutional fragmentation should be tackled to ensure the quality of MaaS solutions.

Regulations, data sharing, and standards. The quality and consistency of the shared data and the data format are essential for MaaS. It must be easy for all transport operators, large and small players alike, to plug in the MaaS solution. A standard for sharing data should be set up, to which every actor could adapt voluntarily. At the core of MaaS, there should be trust and a collaborative approach. New forms of regulation should be taken into 
consideration (e.g., the possibility for public authorities to establish a "public data cache" for mobility data and to regulate input and output). Public authorities therefore need to have the necessary capabilities and resources to understand and manage the risks and stakes from an IT and data analysis perspective. It is also essential that data is shared back to authorities to enhance overall mobility coordination and planning. From the operator's point of view, there must be questions addressing the financing of the adaptation in data and APIs as well as the common fear of losing customers if they open their data.

Building trust. To build trust among all partners, their different perspectives, interests, and risks should be considered. They can be addressed through having the MaaS integrator propose fair business rules (terms and conditions for the reselling of transport services), through a clear reselling contract such as a share-alike license set by the transport operators, and by having a suitable regulation. Mapping of stakeholders is also essential, as discussed in making mobility as a service work section.

\section{Asian City Considerations}

While the institutional and regulatory considerations, as discussed above, can influence the development and growth of MaaS in a city, in many developing Asian cities, a variety of constraints exists. This includes the level of sophistication of their urban mobility system (low use of high technology), low levels of financing leading to under investment in sectors, weak regulatory and policy environment, and poor basic services. Knowledge of complex MaaS issues is likely to be non-existent, creating further challenges to effective development. Additionally, many countries typically have a city management with short-term visions that could be subject to vested interests.

These conditions, however, do not necessarily preclude the emergence of MaaS systems. In many ways, weaknesses can lead to better conditions, especially for private sector entrepreneurs. Grab was first established in Singapore, which provided a good environment to establish and grow a stable core. It has quickly expanded into other countries like Philippines, Thailand, Malaysia, Japan, and other Association of Southeast Asian Nations member countries. It became successful enough to take on and force Uber into reaching a cooperation agreement. Over time, the more basic car-sharing service has expanded into a wider variety of choices and other micromobility modes. Grab Singapore even went into banking and has proven to be a good source of profit-which may result in having banking as the main business of the company in the future and diminish its efforts on urban mobility.

Much of the success can be traced back to exploiting actual and perceived weaknesses in a city's transport system. However, this service has now subsumed-exclusively in some cases-mobility options that would be under a comprehensive set of MaaS services, thereby capturing the group of transport users that may find these services more affordable. This would hinder the development of new competing services and create an artificial hurdle, which discourages the investment of necessary large start-up capital in less developed Asian cities where affordability for transport services decreases significantly across the different user groups.

This does not mean good MaaS systems cannot emerge in difficult developing Asian cities, but they may become less common and become dependent on operator management that has a wider vision beyond their own singlemode infrastructure development. In Kochi, India, as part of the establishment of a new metro, the Kochi Metro Railway Limited has established an app for users that has many non-mobility features, making the service more attractive. Similar innovative MaaS-like services have been established with other new Indian metros; however, the vast majority have not included support for citywide MaaS services and have left improving integration of other modes unaddressed. 
In other countries, the development of multimodal MaaS solutions can be hindered by other key modes, particularly buses which are operated by government-owned entities that have their own established mechanisms. Such mechanisms could be resistant to change and modernization, despite their reliance on subsidies. However, even in these cases, there have been some success for MaaS systems, and other necessary model efficiency improvements have been developed by pitching solutions not only to the operator but to the overlying financier providing the subsidies. In Tamil Nadu state, India, as part of an effort to eliminate high subsidies, the Department of Finance supported a modernization program that included a range of improvements that is expected to eventually lead to a statewide MaaS system.

While MaaS systems tend to be predominant in developed countries, including developed Asian countries, their growth in more challenging developing Asian countries and cities has occurred and is expected to expand as lessons learned are shared among developing cities.

\section{Mobility as a Service Topology and Levels}

According to the MaaS topology developed by Sochor, Arby, Karlsson, and Sarasini (2018), there are four levels of MaaS differentiated based on the types of integration:

0 if no integration (single, separate services)

1 for integration of information (multimodal travel planner, price information)

2 for integration of booking and payment (single trip-find, book, and pay)

3 for integration of the service offer (bundling contracts with responsibilities)

4 for integration of societal goals (governance and public-private partnership)

This topology enables the positioning of services along the MaaS spectrum (Table 1). According to the authors, "it also deepens the understanding of why MaaS can take time to establish and can help support the development of action plans in terms of what needs to be done depending on what type of MaaS one wants to develop" (Sochor et al. 2018).

A level 0 MaaS could be an app of a public transport operator that provides information on the timetables of the lines of an urban public transport network. In some cities, it also includes payment or management of subscription to the public transport services. Alternatively, a level 0 MaaS could be an app by a mobility provider for their private transport mode, car rental, car sharing, bike sharing, and micromobility providers, among others. The app allows to book a vehicle and/or manage a subscription to this service only. For level 1, MaaS include apps such as Google Maps, Citymapper, and Axon Vibe. For level 2, MaaS include WienMobil, Hannovermobil, and Jelbi. Level 3 MaaS apps have fewer well-established and good examples such as the Ubigo and Whim (Box 3). Level 4 MaaS is relatively rare, and a good example of this is UMAJI+ (Initiated by the Ministry of Transportation and Communications, Taipei,China). 
Table 1: Features of Mobility as a Service Levels

\begin{tabular}{|c|c|c|c|c|c|}
\hline Features & Level 0 & Level 1 & Level 2 & Level 3 & Level 4 \\
\hline Target group & $\begin{array}{l}\text { Depending on the } \\
\text { service }\end{array}$ & $\begin{array}{l}\text { People without } \\
\text { a car }\end{array}$ & $\begin{array}{l}\text { People without } \\
\text { a car }\end{array}$ & $\begin{array}{l}\text { Car owners } \\
\text { or potential } \\
\text { car owners: } \\
\text { households }\end{array}$ & Service provider \\
\hline $\begin{array}{l}\text { Value for } \\
\text { the users }\end{array}$ & $\begin{array}{l}\text { Simply get from A to B } \\
\text { Manage subscription } \\
\text { of each service (public } \\
\text { transport, car sharing) }\end{array}$ & $\begin{array}{l}\text { Find the best } \\
\text { way from } \\
\text { A to B }\end{array}$ & $\begin{array}{l}\text { Perform the } \\
\text { best mobility } \\
\text { mode trip }\end{array}$ & $\begin{array}{l}\text { Replace car } \\
\text { ownership, meet } \\
\text { household's } \\
\text { mobility needs }\end{array}$ & $\begin{array}{l}\text { Incentives- } \\
\text { improved level } \\
\text { of service }\end{array}$ \\
\hline Value to TSP & NA & $\begin{array}{l}\text { Exposure to } \\
\text { new users }\end{array}$ & New ad hoc users & $\begin{array}{l}\text { Reaches new } \\
\text { customer segment } \\
\text { and increases } \\
\text { efficiency }\end{array}$ & $\begin{array}{l}\text { Partnership } \\
\text { between regional } \\
\text { and local } \\
\text { authorities } \\
\text { Wide database }\end{array}$ \\
\hline Value to MSP & NA & $\begin{array}{l}\text { Advertising } \\
\text { or public } \\
\text { financing }\end{array}$ & $\begin{array}{l}\text { Commission or } \\
\text { reseller discount }\end{array}$ & $\begin{array}{l}\text { Improves } \\
\text { procurement and } \\
\text { packaging options }\end{array}$ & $\begin{array}{l}\text { Forward incentives, } \\
\text { access to data }\end{array}$ \\
\hline Sustainability & $\begin{array}{l}\text { Ensured if } \\
\text { well governed }\end{array}$ & $\begin{array}{l}\text { Limited effect } \\
\text { on those that } \\
\text { need to be } \\
\text { reached }\end{array}$ & $\begin{array}{l}\text { Cars are used less } \\
\text { Mix of transport } \\
\text { modes is easier } \\
\text { for users }\end{array}$ & $\begin{array}{l}\text { Less space for and } \\
\text { use of cars }\end{array}$ & $\begin{array}{l}\text { Governing } \\
\text { both MaaS and } \\
\text { individual providers }\end{array}$ \\
\hline Governance & $\begin{array}{l}\text { Terms and conditions } \\
\text { in license, dynamic } \\
\text { road pricing }\end{array}$ & $\begin{array}{l}\text { Forcing all } \\
\text { TSP to open } \\
\text { access and } \\
\text { standardization }\end{array}$ & $\begin{array}{l}\text { Forcing all TSP to } \\
\text { open access and } \\
\text { standardization }\end{array}$ & $\begin{array}{l}\text { Terms and } \\
\text { conditions in } \\
\text { public transport } \\
\text { reseller agreement }\end{array}$ & $\begin{array}{l}\text { City creates } \\
\text { market for MaaS } \\
\text { through parking } \\
\text { policy, congestion } \\
\text { charging, and city } \\
\text { planning }\end{array}$ \\
\hline Analogy & NA & Tourist fair & Travel agency & $\begin{array}{l}\text { Packaged } \\
\text { charter trips }\end{array}$ & $\begin{array}{l}\text { Eco tourism, } \\
\text { accessible } \\
\text { destination }\end{array}$ \\
\hline Responsibility & NA & $\begin{array}{l}\text { Quality of } \\
\text { information }\end{array}$ & $\begin{array}{l}\text { Valid booking/ } \\
\text { ticket and payment }\end{array}$ & $\begin{array}{l}\text { Quality of } \\
\text { actual services }\end{array}$ & $\begin{array}{l}\text { Merit of the service } \\
\text { product }\end{array}$ \\
\hline
\end{tabular}

MaaS = mobility as a service, $M S P=$ MaaS service provider, NA = not applicable, $\mathrm{TSP}=$ transport service provider.

Sources: Asian Development Bank and International Association of Public Transport (UITP).

\section{Mobility as a Service in Asia and the Pacific}

As discussed in mobility as a service important and relevant section, MaaS systems have been developing across the world in response to the increasing number of mobility services. The wide adoption of new technologies, such as smartphones, has facilitated the development of MaaS. 


\section{Box 3: The Whim System in Helsinki, Finland}

In Helsinki, the company MaaS Global launched its service under the brand Whim in 2017. It offers both pay-asyou-go solutions and packages. In early 2019, the large majority of clients has adopted the Whim To Go (pay-asyou-go) and Whim Urban offers (package). Today, Whim in Helsinki proposes different packages or plans, beyond the pay-as-you-go.
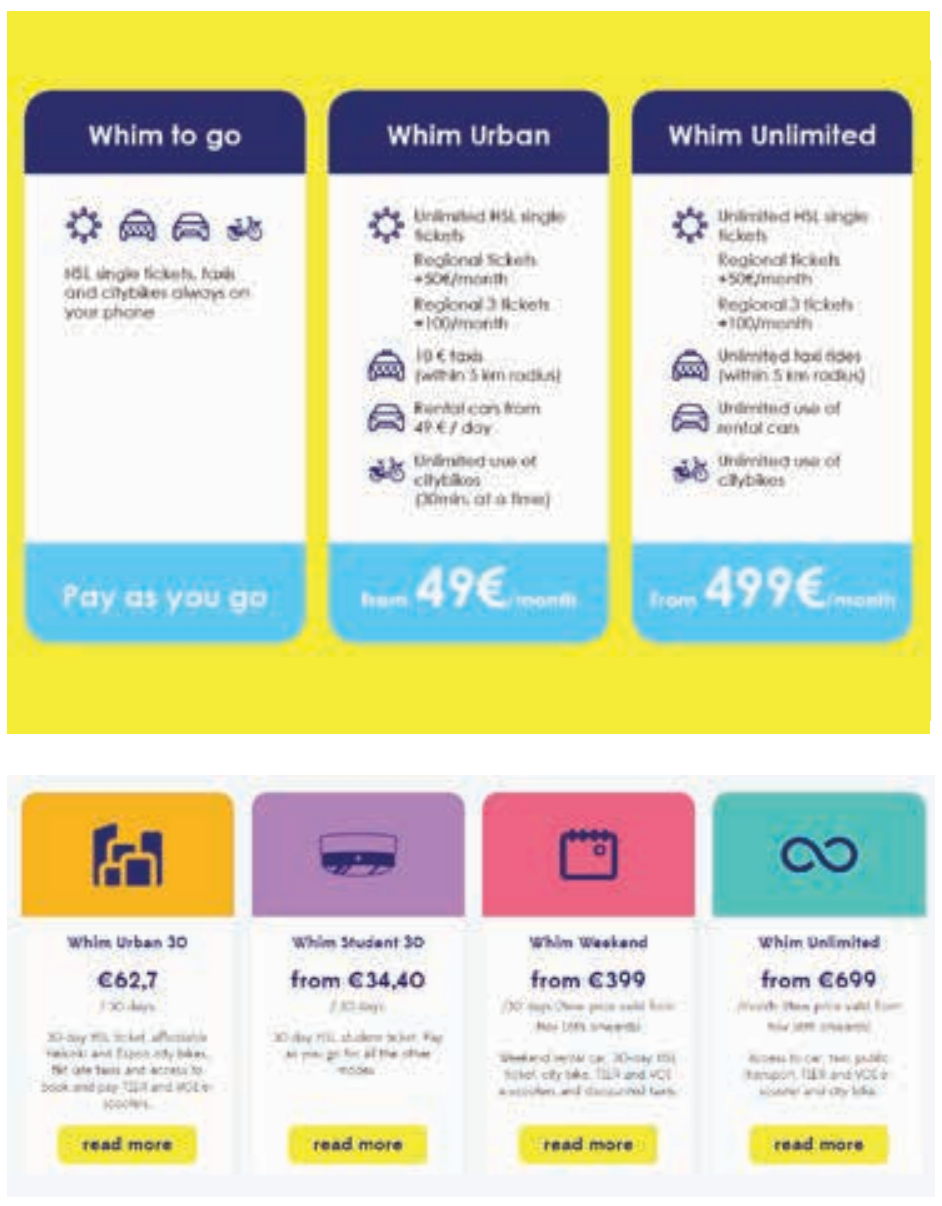

Packages: A package can offer special conditions, discounts, and new pricing models which can enhance attractiveness for the customer and propose new business models for the provider.

- Monthly fees or long-term subscriptions for these packages are also barriers to the customer, especially for those who are not experienced in using mobility services.

- Flat rate-style packages seem to be very difficult, both for the provider and the customer, as they will require a high basic fee.

Pay-as-you-go: For the moment, a pay-as-you-go offer or small (low-priced) bundles seem to be better received from a customer's perspective. It also helps reduce the entrance barrier for customers and could be used to learn and move to other packages at a later stage.

More research and feedback experience on the effectiveness of different packaging is needed.

Source: International Association of Public Transport (UITP). 2019a. Mobility as a Service. Brussels. https://cms.uitp. org/wp/wp-content/uploads/2020/07/Report_MaaS_final.pdf.

Most MaaS systems have been created in developed countries, including developed Asia. Examples of MaaS in Singapore and Japan are provided in the defining mobility as a service section. Taipei,China is in the midst of developing UMAJI+, a MaaS platform expected to reach Level 4 (Box 4). This will make the economy as having one of the unique and pioneer cases of MaaS at Level 4.

MaaS is also finding its way in Asian developing countries. Grab's "Trip Planner" is an example of a commercial MaaS integrator that makes the MaaS solution easily scalable due to the multicity operations of Grab (Box 5). 


\section{Box 4: UMAJI+ - A Mobility as a Service Platform in Taipei,China}

The Ministry of Transportation and Communications (MOTC) of Taipei,China is the funding agency responsible for the development and delivery of UMAJI+. This platform follows the mobility as a service (MaaS) business model wherein the public transport acts as the integrator.

UMAJI+'s goal is to facilitate urban and intercity sustainable door-to-door journeys in Taipei,China so as to reduce congestion levels by minimizing the use of single-occupancy vehicles and scooters.

Following a competitive process, the MOTC appointed Metropia to build the UMAJI+ MaaS platform called MaaS\&T. The figure presents the relationships between the stakeholders of the UMAJI+ MaaS ecosystem.

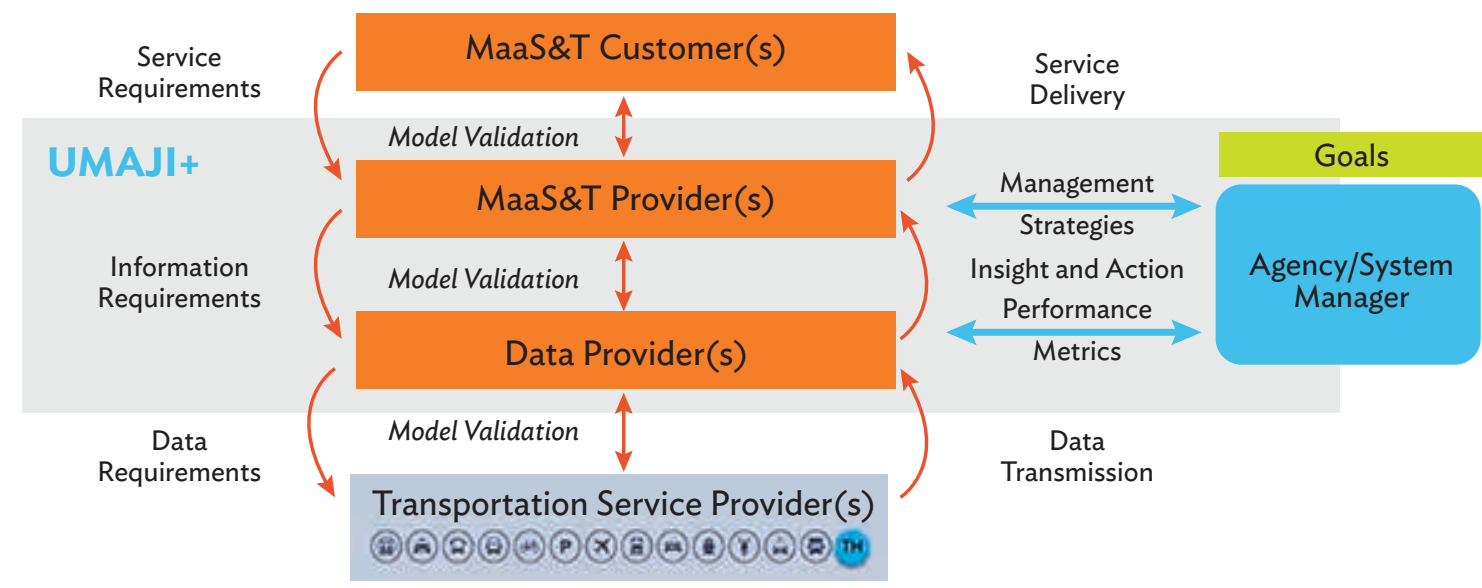

Released in two cities in 2020, UMAJI+ is targeting a Level 4 MaaS. The service includes intermodal trip planning, real-time traveler information, intercity transport ticketing, and integrated mobile payment options. The MOTC and Metropia are closely collaborating. Both the authority and the MaaS\&T provider work together on artificial intelligence and machine learning algorithms to build behavior-changing strategies and promote contextual mobility option recommendations to support intermodal exchange toward sustainability.

Source: Metropia.

Ownership and governance of a MaaS platform is driven either by a public agency or a private operator. Both have their own merits depending on the organization of public transport market and market competitiveness. In a Level $4 \mathrm{MaaS}$, wherein the government is the driving force, the platform is motivated by societal goals which extend beyond coordinating between supply and demand of mobility services (Harm et al. 2018). Often, the mobility options presented to users are endorsed by public agencies and aligned with other public policies. One of the biggest challenges in Level $4 \mathrm{MaaS}$ is justifying and securing a large amount of public funding for the initial investment and sustainable resources to support the system. On the other hand, where the MaaS model is operated by a private organization, red tape is less likely to occur and funding is from private investment. One of the challenges is to ensure the platform offers a full range of mobility service options with little to no biases. Otherwise, instead of directing users to options that align with public policies, it may encourage mobility behaviors that compete with public services and/or against societal goals. 


\section{Box 5: Grab’s Trip Planner-A Commercial Mobility as a Service Option in Southeast Asia}

Grab, a provider of ride-hailing services in Southeast Asia, initiated a new feature Trip Planner embedded into its Grab application that can be classified as a Level 1 MaaS. Trip Planner was made available in March-April 2019 in the cities of Bangkok, Jakarta, Singapore, and Kuala Lumpur.

When users enter an itinerary in Grab's Trip Planner, they will be provided with public transport options including real-time information on arrivals and departures, walking routes, and Grab's first- and last-mile services (such as GrabBike or JustGrab) to and from public transport stations. Although booking is only available for Grab services, Trip Planner aims to facilitate seamless door-to-door multimodal journeys in providing integrated and timely information.

Source: Grab Press Center. 2019. Grab Integrates Public Transportation Options into its App, First in Thailand to Introduce 'Mobility As A Service' (MaaS) Solution for Mass Market Consumers. 23 April.

Regardless of the approach, MaaS will only be feasible and successful if public transport systems and active mobility are the backbone of urban mobility. In some developing Asian cities, the first step is to build these sustainable networks of mobility. The physical integration of modes and services in the urban environment is also a prerequisite to enable digital integration. According to a study by the Netherlands Institute for Transport Policy Analysis (Harms et al. 2018), given the goal of significantly shifting mobility patterns from private or personal vehicles to public and shared mobility services, the success of MaaS requires the following:

- The platform should offer autonomy and flexible options, reliable services, and be available anytime and anywhere.

- MaaS should be an added value in relation to the current situation with the "4 Cs" notion (costs benefits, convenience, choice, and customization).

- Current mobility behavior needs to be factored in. Not all cities will be suited with MaaS because every city's mobility behaviors are dependent on a number of factors such as ease of travel, car ownership (necessity and luxury ownership), cultural acceptance, and public safety.

MaaS is still at the early stages of adoption in cities of developing Asia and the Pacific as many cities are challenged by the governance framework. In many Southeast Asian cities, where the public transport market is fragmented, and relatively less mature and less regulated compared to developed cities, MaaS may not be the solution to existing urban mobility challenges. Long-term effectiveness and efficiency of MaaS systems need to be built on solid, conducive, and equitable policy and regulatory conditions. Regardless of whether cities are considering MaaS or not, it is clear urban mobility is moving toward the trend of on-demand customization, and the trend of having the demand drive mobility options (rather than having the supply dictate mobility behaviors, as in the past). To prepare for transforming the urban mobility landscape, cities should review their current regulatory frameworks and economic environment for the following:

- Data-sharing models and standards. This is increasingly becoming a critical topic for cities, especially in the context of MaaS, where data sharing can better facilitate the integration of modes and ensure authorities can benefit from data generated through MaaS for planning and policy purposes.

- Stakeholder collaborations. An integrated public transport system, with or without MaaS, require multi-stakeholder collaborations. The establishment of trust and alignment of goals underpins such collaborations. 
MaaS in developing cities in Asia and the Pacific should not be viewed as a short-term trend. An opportunity for these countries is to integrate the digital infrastructure that will enable MaaS at a later stage-as early as the construction of the physical infrastructure. In some developed parts of the world, the upgrade of legacy systems with digital technologies is a critical challenge.

\section{The Future of Mobility as a Service}

As the world-especially the public transport sector-has been hard hit by the COVID-19 pandemic, the future of MaaS is uncertain. Will the investment on MaaS accelerate or decline? With cities placed in full or partial lockdown, the mobility sector is largely disrupted and the trust in public transport as a safe mode of travel has been eroded.

Here are some of the trends that are evident during the COVID-19 pandemic. They are likely to continue to support the growth of MaaS:

Increased need for mobility options. Public transport has a been disrupted with the growing trend of on-demand mobility services. Many cities have been grappling on how to balance mass public transport (a public good) and individual mobility services (which may or may not be aligned with mobility policies). As COVID-19 has swept across cities and as authorities encourage social distancing measures, cities are faced with limited mobility options and are challenged to keep essential works and services afloat. The pandemic has caused cities to review their urban mobility options and ensure that they are adopting the right mix as social distancing may continue or may be needed in the event of another pandemic.

Investment growth in technology. Although COVID-19 has devastating impact on many sectors, the technology sector has benefited from the pandemic as internet and telecommunications have been key to enabling the community and the workplace thrive in cyberspace. The growth of advanced technologies is likely to influence MaaS' continued development. For example, during the pandemic, the use of artificial intelligence has intensified in key areas, such as digital assistance in customer service, optimization of operational efficiency through predictive analysis of mobility demand, autonomous dispatching and operations to better meet the increasing demand and the dynamic environmental changes, effective preventive maintenance operations, and preventive safety and security management using video analytics powered by artificial intelligence (Schweiger 2020). Together with the growing use of blockchain, MaaS platforms are expected to perform more effectively in optimization and security.

Traceable payment systems. The pandemic has encouraged the growth of digital payment for better convenience and hygienic transactions. Like in some cities, when Wuhan reopened after lockdown, it encouraged traceable payment systems as a way to safeguard public safety. In the event a commuter is infected with COVID-19, a number of people they have interacted can be traced. The integrated payment system is one of the advantages of MaaS and the acceptance of digital payments will help the growth of MaaS.

Urban mobility is clearly the lifeline of cities and MaaS has promising social, environmental, and economic benefits to a city. Whether matured MaaS systems (Level 3 or Level 4) could be a trend in Asia, especially Southeast Asia, is still to be seen. It is important to note that effective and efficient data sharing and governance of transport services are the foundation of a sustainable MaaS platform. 


\section{References}

European Metropolitan Transport Authorities (EMTA). 2019. A Perspective on MaaS from Europe's Metropolitan Transport Authorities. https://www.emta.com/spip.php?article1319\&lang=fr.

Harms, L. et al. 2018. Exploring Mobility-as-a-Service. The Hague: Netherlands Institute for Transport Policy Analysis (KiM), Ministry of Infrastructure and Water Management. https://MaaS-alliance.eu/wp-content/ uploads/sites/7/2018/11/MaaS-brochure-ENG.pdf.

Karlsson, M. A. I, J. Sochor, and H. Stromberg. 2016. Developing the 'Service' in Mobility as a Service: Experiences from a Field Trial of an Innovative Travel Brokerage. Gothenburg.

MaaS Alliance. 2017. Guidelines and Recommendations to Create the Foundations for a Thriving MaaS Ecosystem. White Paper. https://MaaS-alliance.eu/wp-content/uploads/sites/7/2017/09/MaaS-WhitePaper_final_040917-2.pdf.

Schweiger, C. 2020. How has COVID-19 Impacted 2020's Mobility Trends? Intelligent Transport. 22 April. https:/www.intelligenttransport.com/transport-articles/98257/how-has-covid-19-impacted-2020s-mobilitytrends/.

Sochor, et al. 2018. A Topological Approach to Mobility as a Service: A Proposed Tool for Understanding Requirements and Effects, and for Aiding the Integration of Societal Goals. https://www.sciencedirect.com/ science/article/abs/pii/S2210539518300476.

International Association of Public Transport (UITP). 2019a. Mobility as a Service. Brussels. https://cms.uitp.org/ wp/wp-content/uploads/2020/07/Report_MaaS_final.pdf.

UITP. 2019b. Policy Brief: Ready for MaaS? Easier Mobility for Citizens and Better Data for Cities. Brussels. https://cms.uitp.org/wp/wp-content/uploads/2020/07/Policy-Brief_MaaS_V3_final_web_0.pdf. 


\section{Road Safety in Asian Cities}

Michael Anyala and Charles Melhuish

\section{Introduction}

In the mid-1990s, road safety was recognized as a serious issue in Asia and the Pacific following a major regional review of road safety covering 23 countries. Subsequently, the Road Safety Guidelines for the Asian and Pacific Region was published in 1998. 'The World Report on Road Traffic Injury Prevention highlights road safety as a global issue (WHO and World Bank 2004). Furthermore, the United Nations (UN) General Assembly resolution has recognized the scale of the problem and established a formal structure led by the World Health Organization (WHO) and the UN regional commissions to address the issue.

Road safety issues are influenced by increasing urbanization and motorization that underpins the rapid economic growth in the region. The rapid gains in per capita incomes registered from 1980 to 2000 led to large increases in vehicle fleets and created markets that were increasingly dependent on personal mobility. These shifts in the role of transport while supporting socioeconomic development also resulted in deteriorating road safety conditions across the region.

In the 1990s, vehicle fleets in many developing countries were increasing at rates between $5 \%$ and $10 \%$ a year, effectively doubling the fleet in less than a 10-year period. This trend represents a phenomenal growth rate compared to the experience of the Organisation for Economic Co-operation and Development (OECD) countries. Moreover, many of the vehicles were not passenger cars but two-wheeled motorcycles - which implies a significant difference in terms of safety. Motorcycle fleets had shown steep growth in Malaysia and Thailand in the 1980s and demonstrated explosive growth in the 1990s in Bangladesh, Indonesia, India, Malaysia, Pakistan, Sri Lanka, Thailand, and Viet Nam (International Transport Forum 2002, 2020). The motorcycle has become the dominant vehicle in many Asian countries and is used both as a family vehicle and a "workhorse" hauling multiple goods. Motorcycles are also used to provide transport and delivery services in urban areas.

Simultaneous with the fleet increase was the acceleration in urbanization across the Asia and Pacific region. Many rural dwellers have moved to towns and cities, attracted by the increasing availability of jobs, higher incomes, and better quality of life. The Asian region in particular has witnessed a phenomenal change. In 1966, more than $80 \%$ of the population was residing in rural areas and dependent on agriculture. By 2018 , about $50 \%$ of the population was classified as rural, and this is projected to decrease further to $40 \%$ by 2030 .

The move to towns and cities is forecast to continue at pace, and the number of cities exceeding 500,000 population, numbering 631 in 2018, will increase to 778 by 2030 (UN 2018). In effect, one new city with 500,000 people is being created each month. The urban areas with robust economic activities create opportunities,

Asian Development Bank (ADB). 1998. Road Safety Guidelines for the Asian and Pacific Region. Manila. 
facilitated through ownership of motor vehicles, improved public transport, and greater mobility for all. In this respect, greater attention will need to be given to addressing road safety issues in towns and cities. This comes with the underlying need to address road safety as a national issue if the number of road-related deaths and serious injuries are to be mitigated in the future.

Global research has shown that one of the negative impacts of economic growth is the consequential increase in road trauma (WHO and World Bank 2004, World Bank 2017). As economic growth increases, the rise in per capita incomes results in increasing vehicle ownership, leading to a surge in crash risks on national road networks. Japan in the 1970s and the Republic of Korea and Australia in the 1980s exhibited this trend. Following the comprehensive measures enforced by national governments, these countries were able to flatten the road fatality curve as economic development continued to mature. These examples clearly demonstrate that road safety risks can be abated by implementing a series of complementary measures which are designed to reduce the number of fatalities and injuries occurring on national road networks.

This article discusses the road safety situation in the Asia and Pacific region with particular emphasis on urban areas. It also sumarizes the plans to reduce the very high number of deaths and injuries being incurred on the region's road networks and to meet global road safety targets. Following the introduction, the next section describes the regional trends in road safety and illustrates the magnitude of the issue in the Asia and Pacific region. The next section focuses on measures that were adopted by global institutions to tackle road safety on a global basis. These measures prioritized the adoption of the safe systems approach to road safety and prepared the global plan of action that was implemented to mitigate road crashes. The plan envisaged a 10-year implementation period termed the Decade of Road Safety 2011-2020, targeting a reduction of road fatalities by $50 \%$. The target was considered achievable as it primarily consisted of using successful evidence-based solutions adopted earlier by OECD countries.

The article concludes with an assessment of the 2030 road safety targets set by the Sustainable Development Goals. The conclusion also points out the need to focus on investing in road safety across the region, the supporting role of the Asia Pacific Road Safety Observatory, and the contribution of road safety to improved quality of life in urban areas.

\section{Regional Trends in Road Safety}

Approximately, half of the world's crash victims are located in Asia and the Pacific. While the crash rate is not as high as in Africa, it is of concern that despite the awareness of the issue, many developing countries do not prioritize road safety. Various research studies have shown that countries in the region commonly lose about $3 \%$ of their gross domestic product (GDP) to road crashes each year (ADB 1998, Wismans et al. 2017). However, the Global Road Safety Facility has recently calculated that low- and middle-income countries incur losses amounting to about $6.6 \%$ of their GDP (World Bank 2019).

While it is difficult to substantiate the actual loss due to data imperfections and shortcomings, it is evident that the economic and social costs of road crashes exhibit a substantial toll on individual countries in the region. The magnitude of the loss has not yet attracted the attention of policy makers despite the high economic returns that can be gained when they invest in remedial measures. In many developing countries, sufficient budgets and resources have yet to be invested in road safety. 
Since 2004, the WHO has regularly reported on the global road safety position and the latest statistics for the Asia and Pacific region (Table 1). The WHO (2018) reveals that the overall recorded number of fatalities in the region have increased by about 18,000 between 2010 and 2016, from about 300,000 to 318,000, over a 6 -year period. These figures, which are based on official national records, have shown a small decline in several countries, but this has been outpaced by large increases in several countries, especially those in South Asia.

Official statistics, however, do not necessarily demonstrate the size of the problem. WHO (2018) has undertaken an analysis on each country which not only includes official crash statistics, but also information from hospital records, data from other entities, and information based on statistical modeling using regression analyses. The results of this analysis indicate that in many developing countries, the likely estimated number of fatalities has significantly increased, compared to those reported from official records. Overall, the total number of estimated deaths in the region has more than doubled to 749,000 , which is equivalent to about $57 \%$ of the global deaths from road crashes.

In several developing countries, the number of fatalities significantly exceeds official data. This is particularly important in countries that have large and growing numbers of two-wheeled motorized transport such as Bangladesh, India, Pakistan, and the People's Republic of China. It also extends to other countries such as Cambodia, Myanmar, the Philippines, Thailand, and Viet Nam. The WHO considers this figure to be likely representative of the true picture of road safety in Asia and the Pacific.

Table 1: Road Crash Fatalities in Developing Countries in Asia and the Pacific

\begin{tabular}{|c|c|c|c|c|c|}
\hline \multirow[b]{2}{*}{ Region } & \multirow[b]{2}{*}{ Country } & \multicolumn{2}{|c|}{ Country Reported Fatalities } & \multicolumn{2}{|c|}{ Estimated Fatalities } \\
\hline & & 2010 & 2016 & 2010 & 2016 \\
\hline \multirow{14}{*}{$\begin{array}{l}\text { East Asia } \\
\text { and Pacific }\end{array}$} & Cambodia & 1,816 & 1,852 & 2,431 & 2,803 \\
\hline & China, People's Republic of & 70,134 & 58,022 & 275,983 & 256,180 \\
\hline & Cook Islands & 2 & 5 & 2 & 3 \\
\hline & Fiji & 52 & 60 & 54 & 86 \\
\hline & Indonesia & 31,234 & 31,282 & 42,434 & 31,726 \\
\hline & Kiribati & 6 & 5 & 6 & 5 \\
\hline & $\begin{array}{l}\text { Lao People's Democratic } \\
\text { Republic }\end{array}$ & 767 & 1,086 & 1,266 & 1,120 \\
\hline & Malaysia & 6,872 & 7,152 & 7,085 & 7,374 \\
\hline & Micronesia, Federated States of & 2 & 2 & 2 & 2 \\
\hline & Mongolia & 477 & 484 & 491 & 499 \\
\hline & Myanmar & 2,464 & 4,887 & 7,177 & 10,540 \\
\hline & Papua New Guinea & 269 & 158 & 892 & 1145 \\
\hline & Philippines & 6,739 & 10,012 & 8,499 & 12,690 \\
\hline & Samoa & 55 & 17 & 30 & 22 \\
\hline
\end{tabular}


Table continued

\begin{tabular}{|c|c|c|c|c|c|}
\hline \multirow[b]{2}{*}{ Region } & \multirow[b]{2}{*}{ Country } & \multicolumn{2}{|c|}{ Country Reported Fatalities } & \multicolumn{2}{|c|}{ Estimated Fatalities } \\
\hline & & 2010 & 2016 & 2010 & 2016 \\
\hline & Solomon Islands & 12 & 11 & 79 & 104 \\
\hline & Thailand & 13,365 & 21,745 & 26,312 & 22,491 \\
\hline & Timor-Leste & 99 & 71 & 219 & 161 \\
\hline & Tonga & 6 & 18 & 6 & 18 \\
\hline & Vanuatu & 4 & 9 & 39 & 43 \\
\hline & Viet Nam & 11,859 & 8,417 & 21,651 & 24,970 \\
\hline & Subtotal & 146,234 & 145,295 & 394,658 & 371,982 \\
\hline \multirow{9}{*}{$\begin{array}{l}\text { Central and } \\
\text { West Asia }\end{array}$} & Armenia & 285 & 267 & 558 & 499 \\
\hline & Azerbaijan & 1,202 & 759 & 1,202 & 845 \\
\hline & Georgia & 685 & 581 & 685 & 599 \\
\hline & Kazakhstan & 3,379 & 2,625 & 3,514 & 3,158 \\
\hline & Kyrgyz Republic & 850 & 812 & 1022 & 916 \\
\hline & Tajikistan & 442 & 427 & 1,244 & 1,577 \\
\hline & Turkmenistan & - & 543 & - & 823 \\
\hline & Uzbekistan & 2,731 & 2,496 & 3,107 & 3,617 \\
\hline & Subtotal & 9,574 & 8,510 & 11,332 & 12,034 \\
\hline \multirow[t]{9}{*}{ South Asia } & Afghanistan & 1501 & 1565 & 6209 & 5230 \\
\hline & Bangladesh & 2,872 & 2,376 & 17,289 & 24,954 \\
\hline & Bhutan & 79 & 125 & 96 & 139 \\
\hline & India & 130,037 & 150,785 & 231,027 & 299,091 \\
\hline & Maldives & 6 & 4 & 6 & 4 \\
\hline & Nepal & 1,689 & 2,006 & 4,787 & 4,622 \\
\hline & Pakistan & 5,192 & 4,448 & 30,131 & 27,582 \\
\hline & Sri Lanka & 2,483 & 3,003 & 2,854 & 3,096 \\
\hline & Subtotal & 143,859 & 164,312 & 292,399 & 364,718 \\
\hline Overall & Total & 299,667 & 318,117 & 698,389 & 748,734 \\
\hline
\end{tabular}

Source: World Health Organization. 2018. Global Status Report of Road Safety 2018. Geneva.

The significant divergence between official and estimated numbers of road fatalities illustrated in Table 1 needs to be addressed if remedial road safety action plans are to be meaningful, evidence-based, and successful in reducing crash rates. Box 1 describes the work undertaken in Thailand to help resolve the issues concerning the road fatality database. 


\section{Box 1: Harmonization of Data on Road Fatalities in Thailand}

In Thailand, actions have been taken to reduce the disparity between traffic police records. Traffic police, health authorities, and insurance companies have worked together to understand the complexity of problems and issues. Police records often do not document all road fatalities as many casualties do not die at the crash site, but succumb later to injuries received. Police authorities may not have the time or inclination to keep checking at hospitals to see whether injured persons survive. Health records do not always show all road fatalities, especially wherein the death does not occur in a health facility and insurance records only report those persons who are adequately covered by insurance policies. The analysis reviewed all data systems to identify where they recorded the same death and where they did not. From this assessment, algorithms were developed to analyze the data from multiple sources. The overall harmonization of the data resulted in an improved estimate of the number of persons fatally killed by road crashes. While the overall result is still below the estimate, the rationalized database provides a better estimate of road fatalities than just relying on the official traffic police record.

Source: N. Tantitham., P. Srisuwan, and P. Singkham. 2018. Thailand Road Traffic Data Integration. Workshop on Improving Road Traffic Deaths in Africa. Accra.

Globally, more people die from road traffic injuries than from HIV/AIDS, tuberculosis, and diarrheal diseases. From 2021 to 2030, approximately 7.5 million persons in the Asia and Pacific region are projected to die as a result of a road crash, representing more than 62,000 persons a month (WHO 2018). It is commonly estimated that the number of serious injuries from road crashes amount to between 10 and 15 times the number of fatalities (iRAP 2020). Using the lower number of the two estimates suggests that more than 620,000 persons suffer a serious road crash injury each month in Asia and the Pacific, which places a large burden on the region's health systems and facilities. These numbers clearly indicate the scale of carnage occurring on the region's road network each month.

Crash statistics are not usually disaggregated by urban or rural areas. They require a detailed assessment of national data to ascertain the impact of road fatalities. However, analysis of the national data reveals the underlying trends that have important policy implications. The first of these is that road crashes generally have the largest impact on the economically active population. Fatalities are most common in the 15- to 44-year-old group which contains the bulk of the working population in most countries. For the young age group between 5 and 29 years old, road accidents are the main cause of deaths, particularly in developing countries where roads are often used as playgrounds and young people operate powered two-wheelers, often without using helmets. Overall, road fatalities are globally the eighth leading cause of death.

While global and national data are not usually disaggregated to specifically identify the type and scale of urban road safety problems, there are certainly features of the data that are of more concern in urban areas. One example is the problem associated with speed management which is of particular concern in urban areas as there is greater conflict between vehicle movements and cyclists and pedestrians. A key issue in many ADB developing member countries (DMCs) is the inappropriate speed regulations applied on urban roads that lead to unnecessary increases in fatalities and serious injuries. Speed limits applied on urban roads in some countries are well above the 30 to 50 kilometer per hour ( $\mathrm{kph}$ ) limit, depending on road hierarchy (Figure 1). A reduction in these limits would result in fewer road crashes and particularly save lives and prevent serious injuries. 
Figure 1: Maximum Default Speed Limits for Urban Roads in Asia and the Pacific

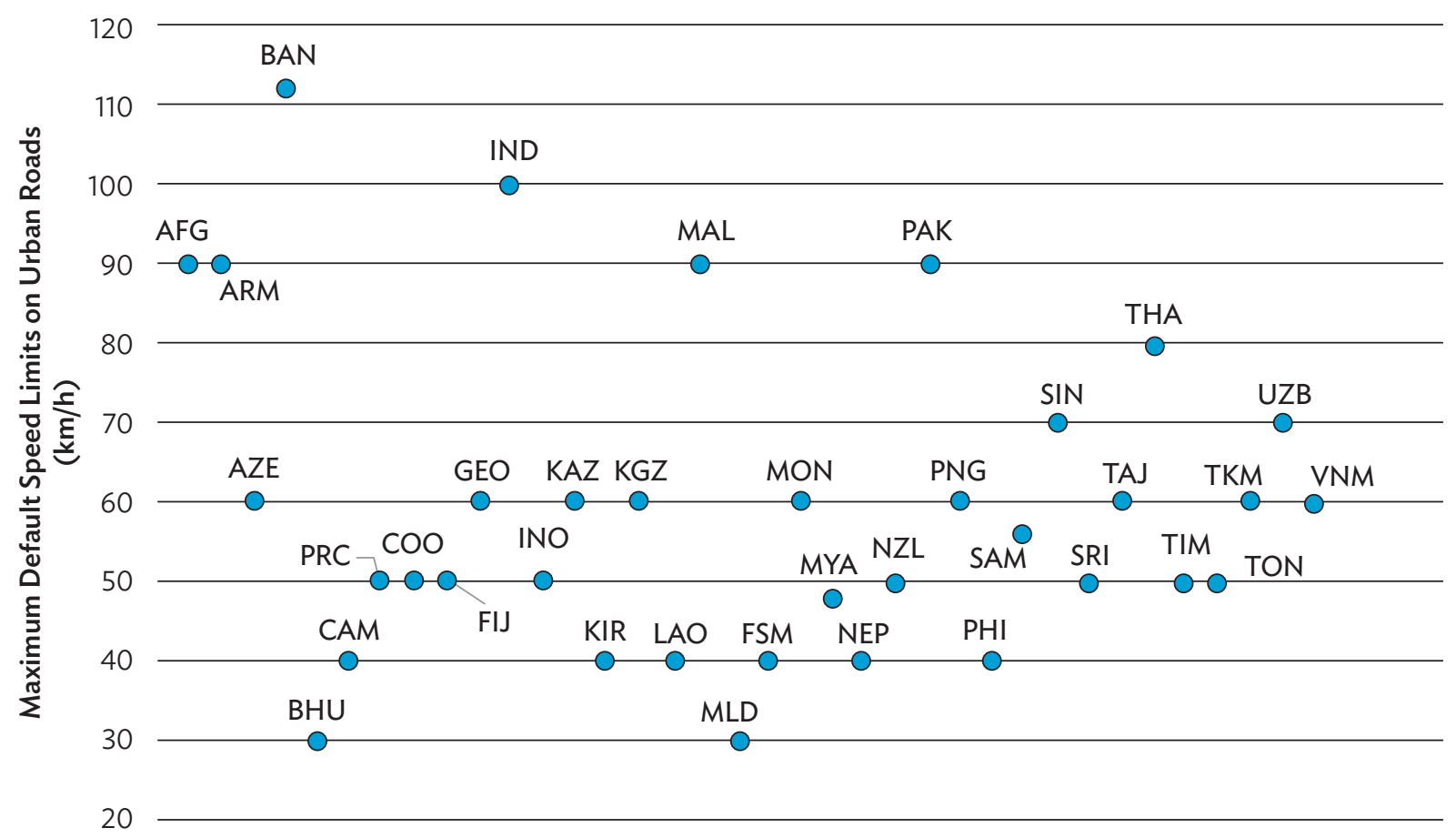

$\mathrm{AFG}=$ Afghanistan, $\mathrm{ARM}=$ Armenia, $\mathrm{AZE}=$ Azerbaijan, $\mathrm{BAN}=$ Bangladesh, $\mathrm{BHU}=$ Bhutan, $\mathrm{CAM}=\mathrm{Cambodia}, \mathrm{COO}=\mathrm{Cook}$ Islands, $\mathrm{FIJ}=$ Fiji Islands, $\mathrm{FSM}=$ Federated States of Micronesia, $\mathrm{GEO}=$ Georgia, IND = India, INO = Indonesia, KAZ = Kazakhstan, KGZ = Kyrgyz Republic, KIR = Kiribati, LAO = Lao People's Democratic Republic, MAL = Malaysia, MLD = Maldives, MON = Mongolia, MYA = Myanmar, NEP = Nepal, NZL = New Zealand, PAK = Pakistan, PHI = Philippines, PNG = Papua New Guinea, PRC = People's Republic of China, $S A M=$ Samoa, SIN = Singapore, SRI = Sri Lanka, TAJ = Tajikistan, TIM = Timor-Leste, TKM = Turkmenistan, THA = Thailand, TON = Tonga, UZB = Uzbekistan, VNM = Viet Nam.

Source: World Health Organization. 2018. Global Status Report on Road Safety 2018. Geneva.

Most developing countries in the region enact and encourage policies and legislation to promote safe mobility through greater use of public transport and increased investment in public transport modes. Some countries and individual cities also encourage walking and cycling as part of their policy to promote sustainable transport which includes safe mobility. A significant portion of the region-countries when combined consist of more than 2 billion people-does not yet promote walking and cycling as part of their sustainable transport policies.

Relatively few countries have adopted adequate design standards for pedestrians and bicycle networks. A small number of countries have not yet promoted the use of public transport over private transport modes. Adoption of these and other related policies is required in all urban areas to achieve safer mobility. It is incumbent on city planners, managers, and policy makers to ensure that urban streets are safe for all.

Another key fact is the impact that road crashes have on low-income groups. In many DMCs, road crashes have a disproportionate impact on lower income persons. A high proportion of fatalities are attributable to riders of powered two-wheeled motorcycles, pedestrians, and cyclists rather than other road users. While few countries have detailed figures, several countries in South Asia and Southeast Asia where motorcycles dominate the vehicle fleet have high rates of two-wheeled fatalities. 
Figure 2: Proportion of Fatalities by Road User

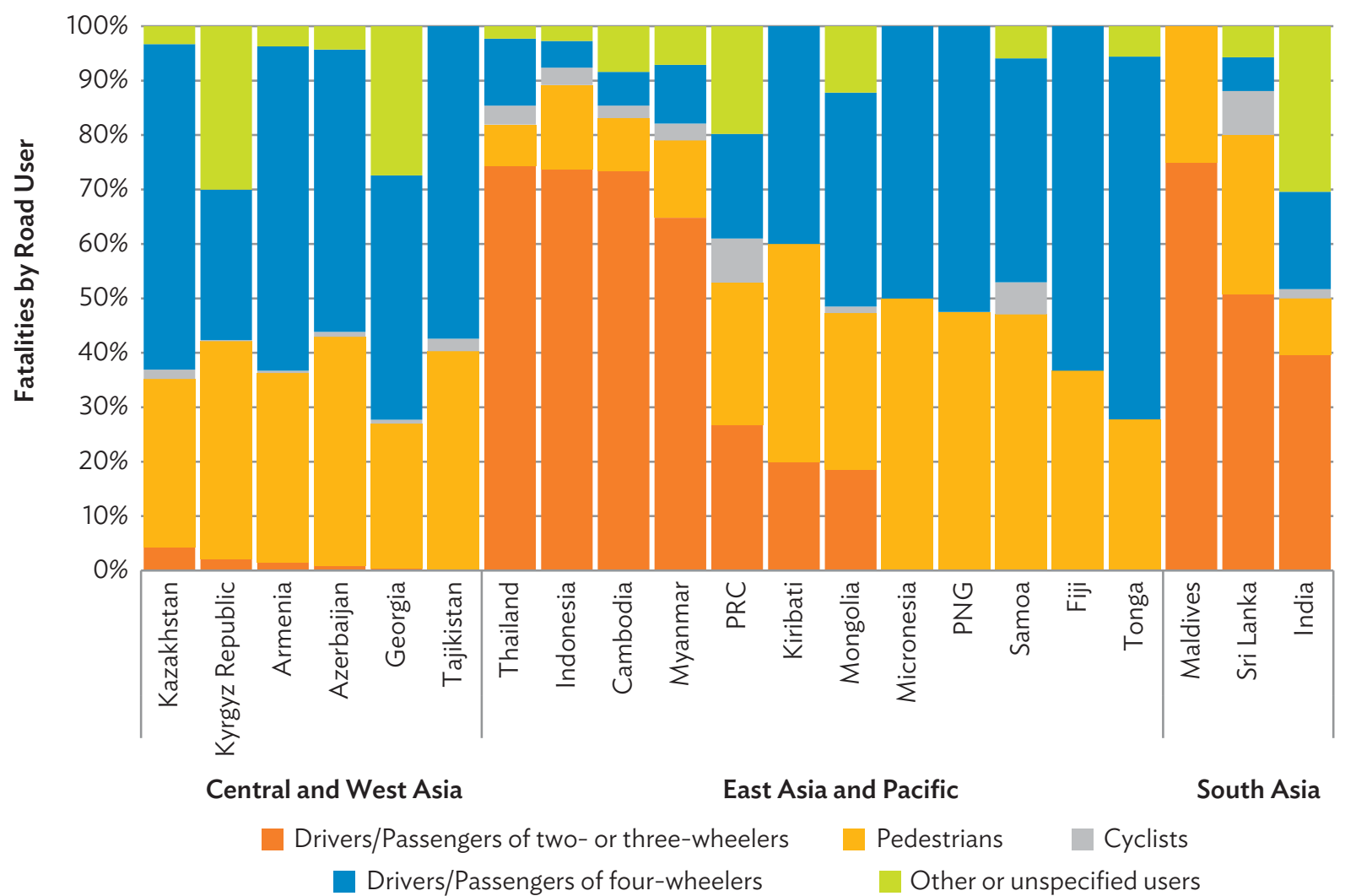

PNG = Papua New Guinea, PRC = People's Republic of China.

Source: World Health Organization. 2018. Global Status Report on Road Safety 2018. Geneva.

Cambodia, Indonesia, Maldives, and Thailand all attribute more than $70 \%$ of fatalities to motorized two-wheeled transport modes (Figure 2). Pedestrian fatalities mostly occur in several smaller countries including Armenia, Azerbaijan, Federated States of Micronesia, Fiji, Kazakhstan, Kiribati, Papua New Guinea, Tajikistan, and Tonga. Cyclists regularly suffer $2 \%$ or more of the fatality toll in many DMCs. These figures indicate that the impact of road crashes often affects the less well-off categories of the population, and many of these groups are not well covered by insurance or medical safety nets. Moreover, safety considerations of these groups are often neglected by road system designers who pay more attention to motorized vehicles using the road network.

Perhaps the most obvious point concerning road safety in the Asia and Pacific region is that crash rates are high per 100,000 population, largely falling in the range of 10 to 22 fatalities. In some developing countries, these fatality rates are exceedingly high. Countries with high fatality rates need to be compared with those countries that successfully implemented an integrated road safety action plan. Good practices in mitigating high fatality rates have been demonstrated by several countries in Europe, including Norway with a fatality rate of 2.7, Sweden 2.8, and United Kingdom 3.1 (Figure 3). These examples demonstrate the high potential in the Asia and Pacific region, wherein individual developing countries could reduce their crash fatality rates by over 5 to 6 times. If achieved, this would represent almost 600,000 lives saved a year across the region. 
Figure 3: Gross Domestic Product Per Capita and Road Fatality in Selected Countries

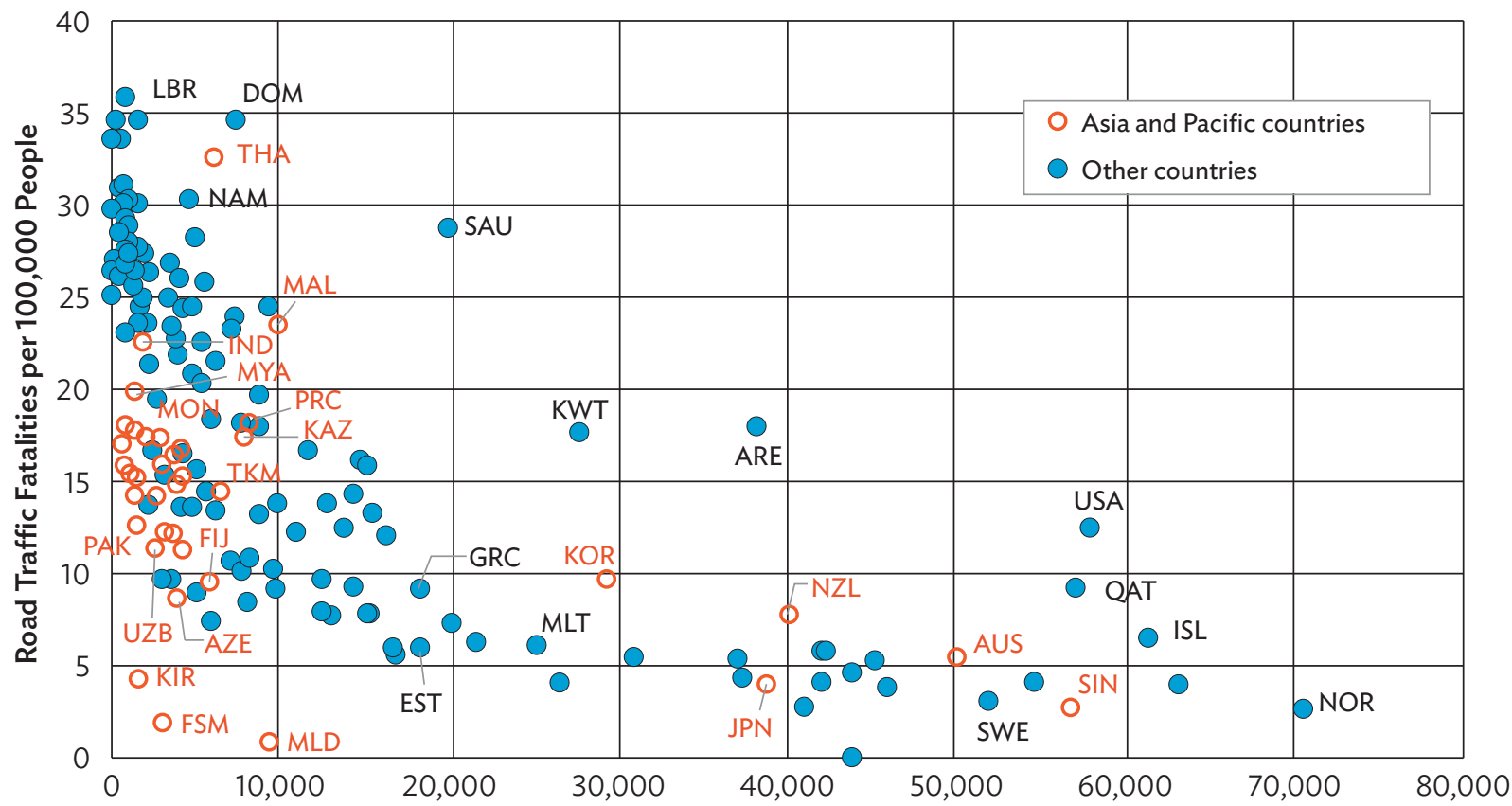

Gross Domestic Product per Capita (\$)

$\mathrm{ARE}=$ Argentina, $\mathrm{AUS}=$ Australia, $\mathrm{AZE}=$ Azerbaijan, $\mathrm{DOM}=$ Dominican Republic, $\mathrm{EST}=$ Estonia, $\mathrm{FIJ}=$ Fiji Islands, FSM $=$ Federated States of Micronesia, GRC = Greece, IND = India, ISL = Israel, JPN = Japan, KAZ = Kazakhstan, KIR = Kiribati, KOR = Republic of Korea, $\mathrm{KWT}=$ Kuwait, $\mathrm{LBR}=$ Liberia, $M A L=$ Malaysia, $\mathrm{MLT}=$ Malta, $\mathrm{MON}=$ Mongolia, $\mathrm{MYA}=$ Myanmar, NAM = Namibia, NOR = Norway, NZL = New Zealand, PAK = Pakistan, PRC = People's Republic of China, QAT = Qatar, SAU = Saudi Arabia, SIN = Singapore, SWE = Sweden, THA = Thailand, USA = United States, UZB = Uzbekistan.

Note: Based on 2016 data from the World Health Organization and the World Bank.

Source: World Health Organization. 2018. Global Status Report on Road Safety 2018. Geneva.

\section{Addressing the Road Safety Crisis}

\section{The Safe System Approach}

The concept of the safe system approach has its origins in Sweden in the 1990s. Sweden adopted a road safety policy based on "Vision Zero" which envisages a road system where there are no deaths or serious injuries. The principles underpinning the safe system approach acknowledge that people make mistakes. The blame for crash fatalities and injuries is shifted from road user behavior to a shared responsibility wherein the various elements of the road network should be fair to users who are always susceptible to making mistakes and prone to errors. The core of the system is the fact that the human body has a defined physical ability to withstand crash forces, and that any impact above $30 \mathrm{kph}$ increases the risks of fatality from a crash incident.

The approach also embodies the principle of shared responsibility where everyone has a role in a crash riskfrom those that plan and design roads to those who build, operate, and use the road system. Subsequently, all components of the road system need to be strengthened to reinforce each other so that if one component 
fails, the other will remain to lessen people's risks. In this respect, all stakeholders need to adopt an integrated safe approach to each of the core components of the road system that comprise safe roads, safe vehicles, safe speeds, and safe community as vulnerable road users. The end result is a safe and magnanimous road system.

The safe system approach is considered more effective than the traditional approach. The old approach primarily emphasized education and enforcement and did not focus on infrastructure and system issues. This narrower approach is considered less effective in dealing with the multiple complex issues between the various variables that generally contribute to road safety outcomes.

\section{The Global Plan of Action and Decade of Road Safety}

The World Report on Traffic Injury and Prevention (WHO and World Bank 2004) reveals that the annual global road deaths total up to 1.2 million a year throughout the initial decade of the millennium. This is due to a range of factors, notwithstanding the significant increases in rising per capita incomes and motorization, especially in less-developed countries. The UN then adopted the Decade of Action for Road Safety 2011-2020 primarily to reduce global road fatalities and serious injuries by $50 \%$ by the end of the decade. It was the first time that the UN had adopted a mandate to promote road safety and save the lives of millions of people worldwide.

To address the issue, $\mathrm{WHO}$ and the UN authorities prepared a global plan of action which was designed to be adopted by countries as an outline plan to tackle their individual national road safety situations. ${ }^{2}$ The core of the plan was based on the safe systems approach and the integration of five principles also known as pillars of action:

- Road safety management

- Safer roads

- Safer vehicles

- Safer road users

- Post-crash response

Many developing countries in the Asia and Pacific region do not have effective road safety management systems. In most countries, a multidisciplinary approach involving multiple agencies is essential in promoting harmony and inclusiveness among all agencies involved in road safety. Traditionally, institutions such as road authorities and police, education, health, statistics, and legal agencies do not commonly work together. Therefore, it is essential that an organization is created to address the problem holistically rather than in piecemeal.

Oftentimes such organizations are under the office of the country's President or Prime Minister for national programs, or under city mayors for city programs, as they require supra-authority over a number of co-equal partners. The key objectives of this organization are to prepare and implement a road safety action plan, ensure sufficient funds are available to implement identified actions, exchange information and knowledge between agencies, and monitor the outcomes and impacts of remedial actions.

Roads are at the core of road safety as they are the arteries used by people to conduct economic and social activities. While roads are designed using criteria normally regarded as providing safe infrastructure, the use of roads by both motorized and nonmotorized users may not result in safe outcomes. Road networks often

2 United Nations. 2010. Global Plan for the Decade of Action for Road Safety 2011-2020. New York. 
have black spots where crashes are more frequent, and these locations need to be identified and assessed to determine the reasons for numerous crashes.

It is also important to ensure that new and improved roads are also designed to have safe outcomes. Undertaking road safety audit of designs can often prevent future blackspots. It is considerably cheaper to change a design document than to adjust physical infrastructure once built. Roads should also be inspected during construction to ensure safe concepts were maintained and reviewed prior to use. Adoption of safer roads concepts such as these will result in safer infrastructure and reduce future crashes.

In terms of operation, it is important to ensure that safe speeds are adopted on each stretch of road and are maintained by effective information and enforcement programs. Review of design principles is particularly important in considering urban roads and the role of the road within the urban framework. A major artery or strategic road needs to be considered differently from a district or local road that performs a different function. Safety considerations need to be adjusted for different road types. There are a number of street guides that identify the safety priorities relating to different urban roads. These need to be consulted and applied to ensure safe urban environment results. ${ }^{3}$

Safer vehicles have an important role in reducing road trauma. While many developing countries do not physically manufacture vehicles, it is important that their safety regulations meet high international standards and technologies to either prevent a crash or mitigate crash forces to help prevent deaths and injuries. Not all vehicle models are created equal. Safety devices such as seat belts, airbags, anti-skid braking, and electronic stability control devices can all help to reduce crash risks. It is up to regulators to ensure that vehicles include the highest safety features in their jurisdiction. Vehicles also need to be inspected regularly to ensure that they are properly maintained. Special attention must be given to inspecting those aspects that might compromise safety during operation.

"Safe people" refer to everyone who uses the road and road corridor. It does not only cover drivers and passengers of vehicles, but also those who use nonmotorized modes such as bicycles, rickshaws, and push carts. It includes also pedestrians who use the sidewalks, cross the roads, and might be using the sidewalk for non-transport movements such as dining, socializing, and marketing wares. All users need to behave in a safe manner, but some people will make mistakes at times. Safe road users are a core component of a safe road system.

Post-crash care is an important element of a safe road system. After a road crash, the availability of effective post-crash care involving emergency diagnosis, treatment, and trauma care has an important role in reducing the risks of death and serious injuries. Four countries in Asia and the Pacific (India, Indonesia, Papua New Guinea, and Viet Nam) do not have at least one telephone number with a national coverage to activate emergency care.

\section{Evidence-Based Solutions are Available}

As noted earlier, the road crash database is often unreliable in many developing countries, which makes the detailed assessment of safety risks less accurate. While it is true that data are often missing or perhaps not accurate, this should not hamper the delivery of appropriate road safety actions and programs. Fortunately, there

3 For example, see National Association of City Transportation Officials (NACTO). 2020. iRAP Star Ratings of NACTO-GDCl's Global Street Design Guide. New York. https://globaldesigningcities.org/wp-content/uploads/2020/10/iRAP-Star-Ratings-of-the-GSDG.pdf; World Resources Institute. 2015. Cities Safer by Design. Urban Design Recommendations for Healthier Cities, Fewer Traffic Fatalities. https://files.wri.org/s3fs-public/CitiesSaferByDesign_final.pdf. World Health Organization. 2020. Promoting Walking and Cycling. https://www.who.int/activities/promoting-walking-and-cycling. 
is global evidence that can be used to develop programs that will deliver appropriate results. Individual countries do not have to undertake their own research or develop special techniques to save lives. A plethora of evidence is available in the following areas that can be immediately harnessed to deliver safety benefits.

- Use of seatbelts. Research in developed countries during the 1960s and 1970s was undertaken to identify the benefits of wearing seatbelts for both front- and rear-seat vehicle riders. While the majority of all vehicles are sold with seatbelts, governments need to make sure that they have the necessary legislation in place to enforce the use of seatbelts by drivers and passengers in front and rear seats and create the enforcement mechanisms to ensure that seatbelts are actually worn. For front-seated riders, seatbelts will lower the risks of fatality and serious injuries by $45 \%-50 \%$ while for rear seats, the risks are lowered by $25 \%$ (WHO 2009).

- Child restraints. Nearly all developing countries in Asia and the Pacific (except Cambodia, Fiji, Kazakhstan, and Lao PDR) have no legislation in place that requires children to use child-restraint devices. It is common in some countries to see unconstrained children, often on their parent's lap in front seats, exposed to significant safety risks. Enforcement also needs to be strengthened to ensure that drivers have the responsibility to ensure children are adequately restrained.

- Wearing helmets. The wearing of a properly designed helmet is essential for those travelling on a powered two-wheeled vehicle such as a motorcycle or motorized bicycle. The major safety risk associated with this vehicle type is head injuries, the most vulnerable part of a human body. It is essential that legislation exists to ensure that users of powered two-wheeled vehicles are properly equipped with helmets (with the correct safety specifications) in both urban and rural areas. Enforcement needs to be strictly maintained. The wearing of a helmet decreases the risk and severity of injuries by about $78 \%$ and decreases the likelihood of death by up to $39 \%$ depending on speed. Use of a helmet also reduces health care costs associated with motorcycle crashes (WHO 2006).

- Driving under the influence of alcohol or drugs. Substantial evidence exists about the lethal impacts of driving under the influence of alcohol and/or drugs. Their impact is not only on vehicle users but on innocent pedestrians and bystanders who, at times, are the ones adversely affected. Evidence from several studies shows that alcohol impairment has a significant effect on crash risk and is widely reported as one of the most serious contributing factors to road crashes. Studies in the US indicate that as blood alcohol concentrations (BAC) increase, so does the relative crash risk. With BAC levels of between 0.04 and .010 grams per deciliter $(\mathrm{g} / \mathrm{dl})$, the crash risk increases by 5 compared to a zero level; while with a BAC of $0.24 \mathrm{~g} / \mathrm{dl}$, the crash risk rises to 140 (WHO 2007). Increasingly, many developing countries have enacted legislation to curb driving under the influence of alcohol, but enforcement needs to be strengthened to ensure that it is effective and produces results.

- Speeding. Excess speed is a major risk factor in road crashes. Increasing speed directly influences the severity of injuries that result from a crash. Police crash records suggest that speed is one of the major causes of crashes in the region with more than $50 \%$ of crashes reported. ${ }^{4}$ Thus, the corollary is also true that controlling vehicle speed can reduce both the risk of a crash and its severity.

4 Police records may not fully reflect the real cause of the crash, but evidence suggests that over speeding is a major cause of many crashes. World Bank. 2019. Guide for Road Safety Opportunities and Challenges: Low and Middle Income Country Profiles. Washington, DC. 
WHO speed advice states that the higher speed of the vehicle, the shorter the time it has to stop and avoid a crash. An increase in speed of $1 \mathrm{kph}$ typically results in a 3\% higher risk of a crash involving an injury, and 4\%-5\% increase in crashes that involve a fatality (Global Road Safety Partnership 2008). Passengers of a vehicle crash at $80 \mathrm{kph}$ have 20 times increase in risk of death compared with the same crash at $30 \mathrm{kph}$. The relationship between speed and injury severity is particularly important for vulnerable road users such as bicyclists and pedestrians.

Evidence suggests that a pedestrian struck at $30 \mathrm{kph}$ has a $90 \%$ chance of survival, but at $45 \mathrm{kph}$, the chance is reduced to $50 \%$, and at $80 \mathrm{kph}$ the chance is practically zero. Managing speed is therefore a key part of maintaining the road network. This requires active enforcement, including the use of speed cameras, setting speeds in line with safe infrastructure, use of traffic calming measures particularly in those areas and zones that have high vehicle-pedestrian conflict, and paying special attention to those zones where transition to slower speeds is desirable.

- Infrastructure. Poor quality infrastructure is often a major impediment to safe use by pedestrians and nonmotorized users. In urban areas where the safety of nonmotorized users is paramount, the segregation of pedestrians from motorized traffic is a vital safety consideration. The provision of sidewalks, safe road crossings, and the overall separation of pedestrians from motorized traffic is essential to promote safety and security in urban areas.

For streets that are primarily for pedestrian use such as shopping, commerce, and business activities, measures to reduce and dissuade motorized traffic from using such streets can promote safety and enrich the urban environment by reducing pollution from road vehicles. In areas where land use is more mixed and through traffic is common, the simple provision of sidewalks can provide the necessary separation from traffic and protect pedestrians.

This list of actions acknowledges that there are many ways to reduce the number of fatal and serious injuries on a road network regardless of the country or location. Ample evidence is available in many countries to demonstrate that the imposition of these measures, together with adequate enforcement and community information campaigns, can produce immediate positive results by saving lives.

\section{Saving Lives: Priority Components and Interventions}

In 2017, the WHO developed a package of road safety components and interventions that could be easily adopted by a country. It has a high probability of addressing the fatality and serious injury rates in a country. This package combines the pillars of action underpinning road safety described in "The Global Plan of Action and Decade of Road Safety" and adopts the measures in which global evidence demonstrates will save lives (see previous section). Table 2 illustrates the 6 components and 22 interventions that comprise the Save LIVES program.

Adoption of the Save LIVES program either in total or in part will save lives if implemented. The individual components do not require separate justification as they are based on concepts and programs that have been shown to work elsewhere. It will be necessary for the individual application-whether it be a national, local, or city plan-to be tailored to the situation at hand to ensure that the individual components address the existing issues. 
Table 2: Save LIVES Priority Components and Interventions

\begin{tabular}{|c|c|}
\hline Speed management & $\begin{array}{l}\text { - Establish and enforce speed limits laws nationwide, locally and in cities } \\
\text { - Build or modify roads which can calm traffic } \\
\text { - Require car manufacturers to install new technologies, such as intelligent speed } \\
\text { adaptation, to help drivers keep to speed limits }\end{array}$ \\
\hline Leadership on road safety & $\begin{array}{l}\text { - Create an agency to spearhead road safety } \\
\text { - Develop and fund a road safety strategy } \\
\text { - Evaluate the impact of road safety strategies } \\
\text { - Monitor road safety by strengthening safety systems } \\
\text { - Raise awareness and public support through education and campaigns }\end{array}$ \\
\hline $\begin{array}{l}\text { Infrastructure design } \\
\text { and improvement }\end{array}$ & $\begin{array}{l}\text { - Provide safe infrastructure to all users including sidewalks, safe crossing, refuges, } \\
\text { - Pverpasses, and underpasses } \\
\text { - Mut in place bicycle and motorcycle lanes } \\
\text { - } \text { - Design safer intersections } \\
\text { - Separate access roads from through roads } \\
\text { - Prioritize people by putting in place vehicle-free zones } \\
\text { - Restrict traffic and speed in residential, commercial, and school zones } \\
\text { - Provide better, safer routes for public transport }\end{array}$ \\
\hline Vehicle safety standards & $\begin{array}{l}\text { - Establish and enforce motor vehicle safety standard regulations related to seat belts, } \\
\text { seat belt anchorages, frontal impact, side impact, electronic stability control, pedestrian } \\
\text { protection, and ISOFIX child restraint points } \\
\text { - Establish and enforce regulations on motorcycle anti-lock braking and daytime running lights }\end{array}$ \\
\hline Enforcement of traffic laws & $\begin{array}{l}\text { Establish and enforce laws at national, local, and city levels on drinking and driving, } \\
\text { motorcycle helmets, seat belts, and child restraints }\end{array}$ \\
\hline Survival after a crash & $\begin{array}{l}\text { - Develop organized and integrated prehospital and facility-based emergency care systems } \\
\text { - Train those who respond to crashes in basic emergency care } \\
\text { - Promote community first responder training }\end{array}$ \\
\hline
\end{tabular}

Source: World Health Organization. 2017. Save LIVES: A Road Safety Technical Package. Geneva.

While the Save LIVES program has been construed to meet a wide range of road safety situations, the program can be adapted to better address the safety situation required in urban areas. In urban locations, the safety of pedestrians and nonmotorized road users is more important as the density of people and vehicles rises and as safety risks increase. An assessment of $15,000 \mathrm{~km}$ of roads classified as urban in Southeast and East Asia, using the iRAP assessment methodology, reveals that $78 \%$ of the road length has no formal footpaths or sidewalks, and traffic in these locations is flowing at $40 \mathrm{kph}$ or more (iRAP 2020). The safety risks are high, and the simple addition of footpaths would significantly enhance the safety of these locations by lowering crash risks.

Within urban areas, greater attention needs to be given to enhancing the urban environment. This generally implies that people areas need to be separated from motorized traffic to provide an area that is risk free from crashes and that has less air pollution. Significant emphasis is now placed on protecting central locations where people congregate-away from moving vehicles. The creation of both vehicle-free streets and limited-access streets are common solutions in many towns and cities. Safety can also be enhanced by encouraging public transport trips rather than private car and motorcycle trips as public transport is a safer mode of transport than the private vehicle. The provision of cycle facilities such as cycle lanes, turning priorities, and parking facilities can also facilitate safety and promote a better urban environment. 
Box 2: Lessons from Asia and the Pacific Experiences in Addressing Road Safety

A review of the Asian Development Bank (ADB) transport sector portfolio covering 2010 to 2018 indicates that approximately half of the 173 road projects include a road safety component. The key findings are as follows:

- Greater focus should be given to sector and program assistance for road safety in addition to including components under road and urban transport projects. While the latter can deliver specific project-related benefits, stand-alone operations focusing wholly on road safety can provide comprehensive assistance across the spectrum of activities and agencies tackling road safety and can eventually deliver greater impact.

- Greater effort needs to focus on delivering road safety as a national priority. Despite the global plan of action, few countries placed priority on delivering road safety through the national budget and few resources were allocated for this purpose. As a public good, it is important for national and city authorities to take a leading role in delivering and achieving road safety outcomes.

- The delivery of road safety does not have a prominent role in the transport sector assessment of many developing countries. Policy discussions on this topic need to be strengthened and reflected in the country operational business plans of development partners.

- Road safety is an important aspect of many transport projects and not just those associated with road construction or improvement. All transport projects involve the movement of people and freight, and the delivery of safe services is a priority requirement. Public transport, including rail-based systems, need to ensure that passengers are able to access and egress safely at all stations along the route. Safe interchange between modes, including nonmotorized transport and pedestrian facilities, should be promoted. Safety should be adopted holistically across all transport projects and modes to ensure that safe travel and safe journeys are promoted at all times.

Source: Asian Development Bank, Independent Evaluation Department. 2020. Sector-wide Evaluation: ADB Support for Transport 2010-2018. Manila.

\section{Meeting the 2030 Global Targets}

A key challenge in the 2020s is the ability to meet the core targets of the Sustainable Development Goals (SDG). Within the SDG plans in many developing countries, there is an important role for delivering better and more comprehensive road safety.

\section{Sustainable Development Goals}

There are two SDGs related to road safety. The first of these is SDG 3.6 which sets a target of halving road fatalities by 2030 relative to the level in 2010. This goal was originally set as a 2020 target of the Decade of Action, but despite considerable awareness raising at the global and national levels, the target was not met. The number of estimated fatalities globally in 2010 was 1.35 million and the actual number for 2020 will only be known in 2022 as there is a normal 2-year lag in assembling data at the global level. However, based on the WHO 2018 assessment, global statistics show that the number of fatalities has stabilized at about 1.3 million mark, but have yet to see a downturn in the figures. About $57 \%$ of the global road crash fatalities occurs in the Asia and Pacific region, and this significantly influences the global trend. Hence, greater efforts are needed to 
address road safety problems, which will require greater investment by governments in road safety together with improvements in each of the road safety pillars described in "The Global Plan of Action and Decade of Road Safety".

Recently, the UN General Assembly has recommended the continuation of the global effort to address road safety by proclaiming the period 2021 to 2030 as the Second Decade of Action of Road Safety. ${ }^{5}$ Meeting the global target will be challenging, particularly for the Asia and Pacific region where the bulk of road fatalities occur (see "Regional Trends in Road Safety"). This will require a reduction of approximately 375,000 estimated deaths each year across the region. Such target is only attainable if individual countries adjust their vision, attitude, and political willingness to address road safety significantly different from the previous decade. This is likely to be a considerable challenge.

The second SDG target relating to road safety is SDG 11 which aims to provide access to safe, affordable, accessible, and sustainable transport for all. A greater proportion of people will reside in towns and cities as urban areas increasingly become the economic engines of the region. The global response does not specifically identify urban road safety as a critical area, but by inference, urban areas contain concentrations of people and vehicles and thus generate greater mobility demand. This mix of factors suggests that urban road safety has an important role in delivering the global target reduction in road-related deaths, requiring special attention from urban managers and transport authorities to address road safety comprehensively.

Within urban areas, greater attention needs to be given to implementing safe systems and Vision Zero approaches to road safety without limiting road safety to specific aspects of road investments and projects. This requires incorporating safety as a component in all projects and programs and not just those with a specific focus on roads. Investments in public transport, including rail-based systems, should also address road safety. The public transport systems and modes need to be safely accessible by all, which implies that safe access by all, including cyclists and pedestrians, need to be considered in project designs. It will be necessary, therefore, to address road safety issues from a wide perspective and not only limit actions to those projects with investments in road infrastructure.

\section{Refocusing the Emphasis on Safety}

If the Second Decade of Action is to be effective, it will require a change in focus. Experience during the first decade shows that awareness raising is not sufficient to change the course of road safety impacts. Indeed, as the region gains wealth, the demand for travel and desire for mobility will increase at a rate that is likely to outstrip economic growth. The popular personal mode of transport in most developing countries of the Asia and Pacific region is the motorcycle, which is inherently a vehicle with higher crash risks. In urban areas, this will be coupled with new forms of mobility such as e-scooters and e-bikes, which, because of their higher speeds, will also add to crash risks. The increasing mobility demand and a surge in crash risks will potentially add to the general safety risks associated with the use of roads. These factors point to the need to refocus the emphasis on safety, not just on road safety but on the overall mobility safety.

There is a need to adopt a new vision of safety if the SDG target is to be realized. For many developing countries, a new approach in tackling safety issues and greater investments for safety purposes are required. A change in the level of investment in road safety will be one of the major determinants of success. As a public good, it is

5 United Nations General Assembly. 2020. Improving Global Road Safety. New York. 18 August. 
necessary for the public sector to take a lead role in investing in safety and in saving lives. Support from the private sector will be important, but will always take a secondary role when public benefits are concerned. It is anticipated that projects and programs generated by the private sector will increase substantially following the lead by the public sector. The involvement of civil society will also be energized by greater involvement of national and local governments.

Resource allocations are not the only requirement. People's attitudes toward safety also need to change as safe road user behavior will need to adjust in line with the new focus. A multisector approach (involving a wide spectrum of sectors) should continue, and communication tools need to be developed to increase the awareness of users on safety concepts.

If the Second Decade of Action is to be realized, then there is a large need for regional, national, and local efforts to enhance road safety activities and outcomes. Historic levels of investment in road safety have been small and often inconsequential with limited impact. The support for safety will need to take on a new thrust and should become a significant component of transport sector development. While supporting road safety components under road and urban transport investments will continue, programmatic approaches and stand alone investments in safety are required to deliver greater impact. With the global coronavirus disease (COVID-19) pandemic currently suppressing economic and social activities across the region, the increased emphasis on safety will be difficult to achieve over the next 2-3 years as budget resources are limited and other areas of the economy take priority.

Given the realities over the 2021-2023 period and the focus on economic recovery, the transport sector needs to use the time to rethink its position on sector priorities in individual country operations. Investment in transport infrastructure is expected to be a major component of economic stimulus packages. Such programs need to also encourage and include safety components. Safety should be an important element of the "new" demand for transport.

Rather than take up traditional investments and components for road safety, the future should encapsulate broader-based view of safety and mobility requirements in investments. This should not restrict investments to hard infrastructure, but should also include health, education, communications, and related skills to develop the broad safety needs of future mobility especially in towns and cities of the region. This modified approach will not only help achieve both SDG 3.6 and SDG 11, but will also strongly align with the efforts to develop more livable and safer communities.

The Asia Pacific Road Safety Observatory (APRSO) was launched in February 2020 at the Global Ministerial Conference on Road Safety Minister's meeting held in Stockholm, Sweden. It was established by a group of international development organizations and its core membership comprises countries in Asia and the Pacific. ${ }^{6}$ The APRSO is designed to collect, manage, and analyze a regional database on road safety indicators and provide a forum to assist member countries in assessing road safety in their jurisdictions, promote good practices in road safety policies and strategies, and help countries reduce crash risks. It is expected to help raise the awareness of road safety across the region and promote additional activity and investment in road safety to save lives. The operation of the APRSO will motivate countries to invest in saving lives through strengthened road safety action plans and exchange of information and knowledge between member countries. It will also encourage the enactment and enforcement of laws and regulations that promote safer road use.

6 The organizations are Asian Development Bank (ADB), World Bank Group, Federation Internationalede'Automobile (FIA), International Transport Forum (ITF), and UN Economic and Social Commission for Asia and the Pacific (ESCAP). ADB serves as the secretariat of the APRSO. 
Meeting the 2030 road safety targets is a tough challenge. Experience of the previous Decade of Action 2011-2020 is that success is not assured even with considerable support from global organizations. The number of estimated fatalities in the region is of pandemic proportions with more than 62,000 deaths and up to 620,000 serious injuries each month. Despite this magnitude of death and carnage on the region's road networks, the scale of adverse economic, social, and health impacts has not raised road safety as a priority among the key policy makers in most countries.

A key to achieving better national performance in road safety is to address the current low level of investment allocated to saving lives in most national budgets. Experience in many developed countries provides ample evidence of a plethora of remedial measures - many of which are low-cost-that do not require significant time for planning and designing. Their implementation will definitely result in lives saved. Countries need to realize that moderate levels of investment will save considerable lives and will contribute to better living conditions and better lives for many residents and communities across the region.

Experience shows that investments in the road sector take time to generate outcomes and even longer to attain impact. A 5-year implementation period for a road sector project or program is fairly standard suggesting that impacts typically occur only after a time frame of 5-7 years. With only a decade till 2030 , there is an urgent requirement to accelerate investments in road safety to meet national and global targets. The time to prepare investment opportunities, implement, and obtain outcomes and impacts suggests that road safety activities are already on the critical path.

Road safety is less often discussed in its subsets of urban and rural situations. While many of the remedial actions are similar, the inferences are different between the two. The rising urbanization and densities of towns and cities in the region will continue to increase the probability of conflicts between people and vehicles, unless better planning and remedial actions are taken to minimize zones of conflict. Mobility is central to a better quality of life in future cities.

As per capita incomes rise, the demand for movement will also increase. The end result is that road safety in its broadest terms needs to expand and the awareness of urban planners should increase to ensure that people zones are free of vehicles and that areas with conflicts are treated carefully to minimize crash risks. Road safety should perhaps be better termed mobility safety as crash risks permeate across all modes including pedestrian and nonmotorized transport. The concept of safer people zones in urban areas should be a priority and is an important concept toward achieving a better living environment.

\section{References}

Global Road Safety Partnership. 2008. Speed Management: A Road Safety Manual for Decision Makers and Practitioners. Geneva.

International Road Assessment Program. 2020. Vaccine for Roads. http://vaccinesforroads.org (accessed 15 December 2020).

International Transport Forum. 2002. World Road Statistics Data, 1963-1990. Geneva.

International Transport Forum. 2020. World Road Statistics Data 2013-2018. Geneva. 
Tantitham, N., P. Srisuwan, and P. Singkham. 2019. Thailand Road Traffic Data Integration. Workshop on Improving Road Traffic Deaths in Africa.

United Nations. 2010. Global Plan for the Decade of Action for Road Safety, 2011-2020. New York.

- - . 2018. The World's Cities in 2018. New York.

United Nations General Assembly. 2020. Improving Global Road Safety. New York. 18 August.

Wismans, J. et al. 2017. Economics of Road Safety: What Does it Imply under the 2030 Agenda for Sustainable Development? 10th Regional Environmentally Sustainable Transport (EST) Forum in Asia. Vientiane.

World Bank. 2017. The High Toll of Traffic Injuries: Unacceptable and Preventable. Washington DC.

_-_. 2019. Guide for Road Safety Opportunities and Challenges: Low and Middle Income Country Profiles. Washington D.C.

World Health Organization (WHO). 2006. Helmets: A Road Safety Manual for Decision Makers and Practitioners. Geneva.

-_- 2007. Drinking and Driving: A Road Safety Manual for Decision Makers and Practitioners. Geneva.

-_-. 2009. Seat-Belts and Child Restraints: A Road Safety Manual for Decision-Makers and Practitioners. Geneva.

-_- 2017. Save LIVES: A Road Safety Technical Package. Geneva.

-_- 2018. Global Status Report on Road Safety 2018. Geneva.

World Health Organization and World Bank. 2004. World Report on Road Traffic Injury Prevention. Geneva. 


\section{CHAPTER 3}

\section{Sustainable Energy}

ARTICLE 3A

Sustainable Energy Solutions for Livable Cities

David Elzinga and Okju Jeong

ARTICLE 3B

The Role of Microgrids in 21st Century Urban Development

Susumu Yoneoka and Dan Millison

ARTICLE 3C

Waste, Waste-to-Energy, and the Circular Economy

Stephen Peters and Keshan Samarasinghe 


\section{Sustainable Energy Solutions for Livable Cities}

David Elzinga and Okju Jeong

\section{Introduction}

Cities are home to more than $55 \%$ the world's population and account for $80 \%$ of gross domestic product (GDP). Cities need energy to power their economic activities, provide livable habitation, and support virtually all aspects of daily life. As a result, cities consume more than two-thirds of the world's energy (C40 Cities 2012).

Energy production and use is the largest contributor to global greenhouse gas (GHG) emissions. The huge amount of energy that cities use means that cities account for more than $70 \%$ of global carbon dioxide $\left(\mathrm{CO}_{2}\right)$ emissions, but they can also play an important role in its mitigation. The Intergovernmental Panel on Climate Change (IPCC) Special Report on Global Warming of $1.5^{\circ} \mathrm{C}$ (SR1.5) confirms this and identifies cities as one of four critical global systems that can accelerate and upscale climate action (C40 Cities Climate Leadership Group and Global Covenant of Mayors 2018). It underscores six areas where city, national, and regional governments can focus to unlock $1.5^{\circ} \mathrm{C}$-safer future. These are urban energy systems, buildings, transport and urban planning, green infrastructure, sustainable land use, and water management. Action in these areas will bring considerable co-benefits including improved public health and reduced air pollution.

Fast-growing cities in the Asia and Pacific region should be decisive in addressing the region's energy future and its carbon footprint. The share of people living in cities in developing Asia and the Pacific is currently more than $50 \%$, lower than the global average, and much lower than the region's developed countries, like Japan (92\%), Australia (87\%), and New Zealand (84\%) (ADB 2020a). This indicates that the future urbanization in the region will be led by rapidly growing cities in developing countries. Hence, their urban energy systems and climate resilience will be even more important to the entire region's sustainable development pathways.

The vision for urban energy systems will vary widely from country to country and even from city to city. The scale of ambition for cities to evolve to more energy- and resource-efficient livable cities will depend on many factors. The vast diversity of energy consumption patterns depends on the economic and functional characteristics of cities and their development stage. Other factors include whether improvements are considered for an existing city with an existing layout of buildings, roads, and infrastructure, or for a newly planned city where a sustainable vision can be more easily realized from the onset of the development.

The size of the cities and their proximity to heavy industry will play an important role in how they can develop. In some cities, heavy industry accounts for a major share of energy consumption-wherein waste energy could be used in meeting heating needs. On the other hand, other cities are very much based around trade and banking, and energy consumption is more due to buildings and transport. This illustrates that there is no single model that fits all cities, and the application of innovative technologies and policies will vary from country to country and city to city. 
Energy for cities is typically imported from outside urban centers through distribution systems or networks.

Urban energy systems function similarly to any other energy supply system; however, urban energy systems are unique because of the intensive economic and social activities behind them (IRENA 2020). In the case of power, electricity is typically generated at centralized plants, carried through transmission system and then distribution systems to end users. In the same way, natural gas uses a network of pipelines that can bring it into cities from where it is extracted from wells or is re-gasified from ships transporting liquefied natural gas. Additionally, thermal energy (for both heating and cooling) can directly be piped to buildings; but usually the distance between the production of either the cooling or heating energy is much shorter than electricity or natural gas networks since energy losses are too great at long distances. Other fuels, such as oil products for transport and solid fuels for heating or cooking, are brought into cities using various forms of transport.

In general, demand for energy comes from buildings (residential and services), transport (passenger and freight), heat and power, industry, and urban services such as water and waste treatment. The characteristics of these components can further vary based on their specific locations within an urban geographical area, ranging from high-density urban cores to lower-density peri-urban areas (IEA 2016).

Figure 1 highlights the key elements that can be considered in sustainable urban energy systems. These elements include traditional approaches in importing energy, opportunities to produce energy within cities, reducing energy demand through higher levels of energy efficiency, and managing energy better to optimize supply and demand. Examples are highly efficient building shells and appliances with integrated solar power production and use of waste energy linked to distributed energy generation through waste-to-energy technology (see Article 3C).

Figure 1: Key Elements of Sustainable Urban Energy Systems

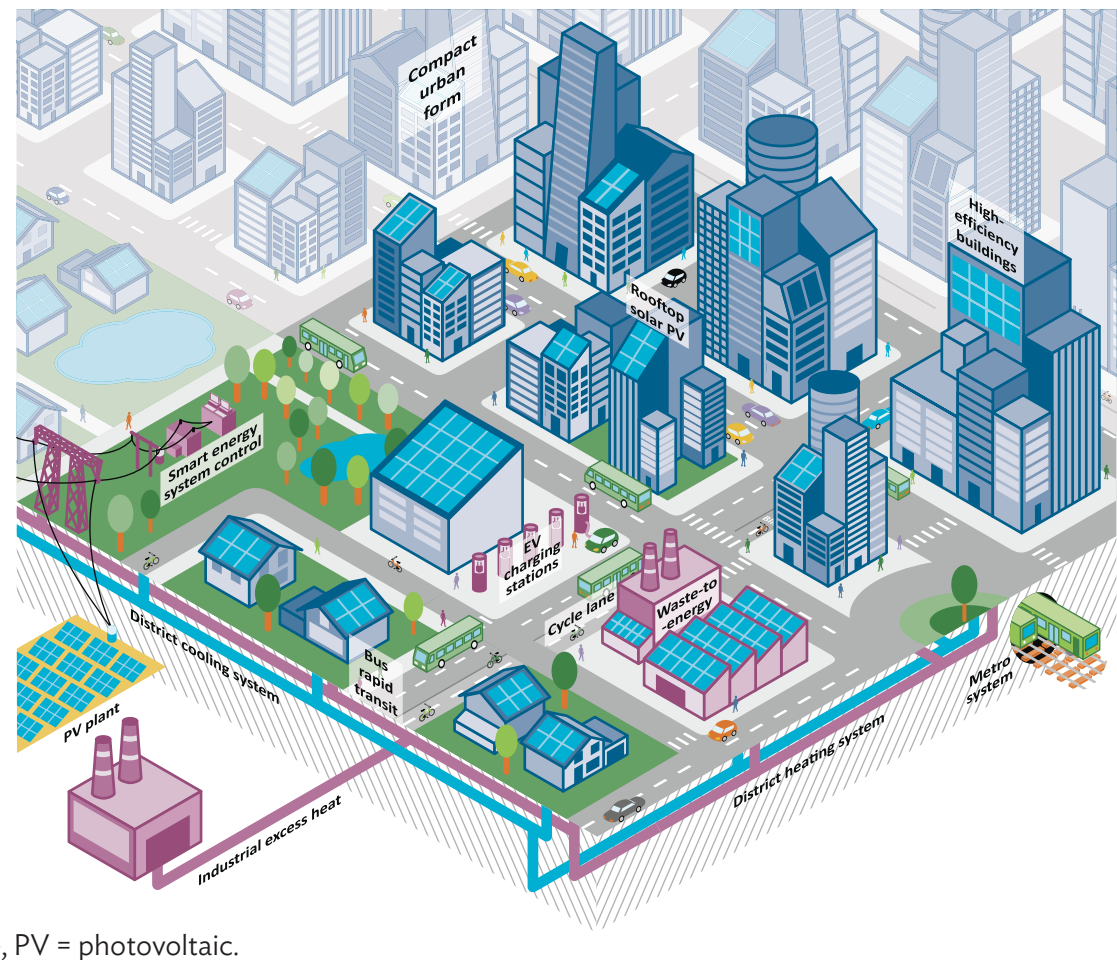

$\mathrm{EV}=$ electric vehicle, $\mathrm{PV}=$ photovoltaic.

Source: International Energy Agency. Energy Technology Perspectives 2016. Paris. https://www.iea.org/reports/energy-technologyperspectives-2016. 
The various elements of urban energy systems in cities can influence each other. Increased deployment of energy-efficient and smart buildings, distributed energy system, electric mobility, and other smart technologies will require greater interconnectedness. Electric vehicles and smart buildings can help balance variable renewable energy production from solar photovoltaics through systems connected by information and communication technologies (ICT) and market models to incentivize the provision of such services. The digitalization of energy systems, together with energy planning and energy efficiency measures, are overarching and essential to optimize all energy sector technologies. Integrated approaches that link energy supply, management, and demand technologies within the energy sector are instrumental in maximizing the self-reinforcing benefits, managing potential trade-offs among technologies, and achieving the broader global agendas such as the Paris Agreement and the Sustainable Development Goals (SDGs).

Against this backdrop, this article looks into several key energy solutions that contribute to the current and future energy challenges in sustainable urban development (Figure 2). The scaling up of frontier technologies, including ICT and energy efficiency technologies, along with enhanced urban energy planning, are emphasized as essential and overarching approaches to creating sustainable energy pathways for developing countries and cities. The key energy solutions discussed in this article include distributed clean energy technologies, energy-efficient building and housing, e-mobility, and smart street lighting systems. These technologies are not a complete set of interventions that are available or needed for sustainable development in cities; but they have been selected as a set of solutions that apply in virtually all cities, and they offer substantial and no regret benefits. In addition to the topics covered in this article, the publication also discusses treatment of electric vehicles in Article $2 \mathrm{~B}$, microgrids in Article 3B, and waste-to-energy in Article 3C.

Figure 2: Framework of Chapter Aligned with Interconnected Urban Energy Systems

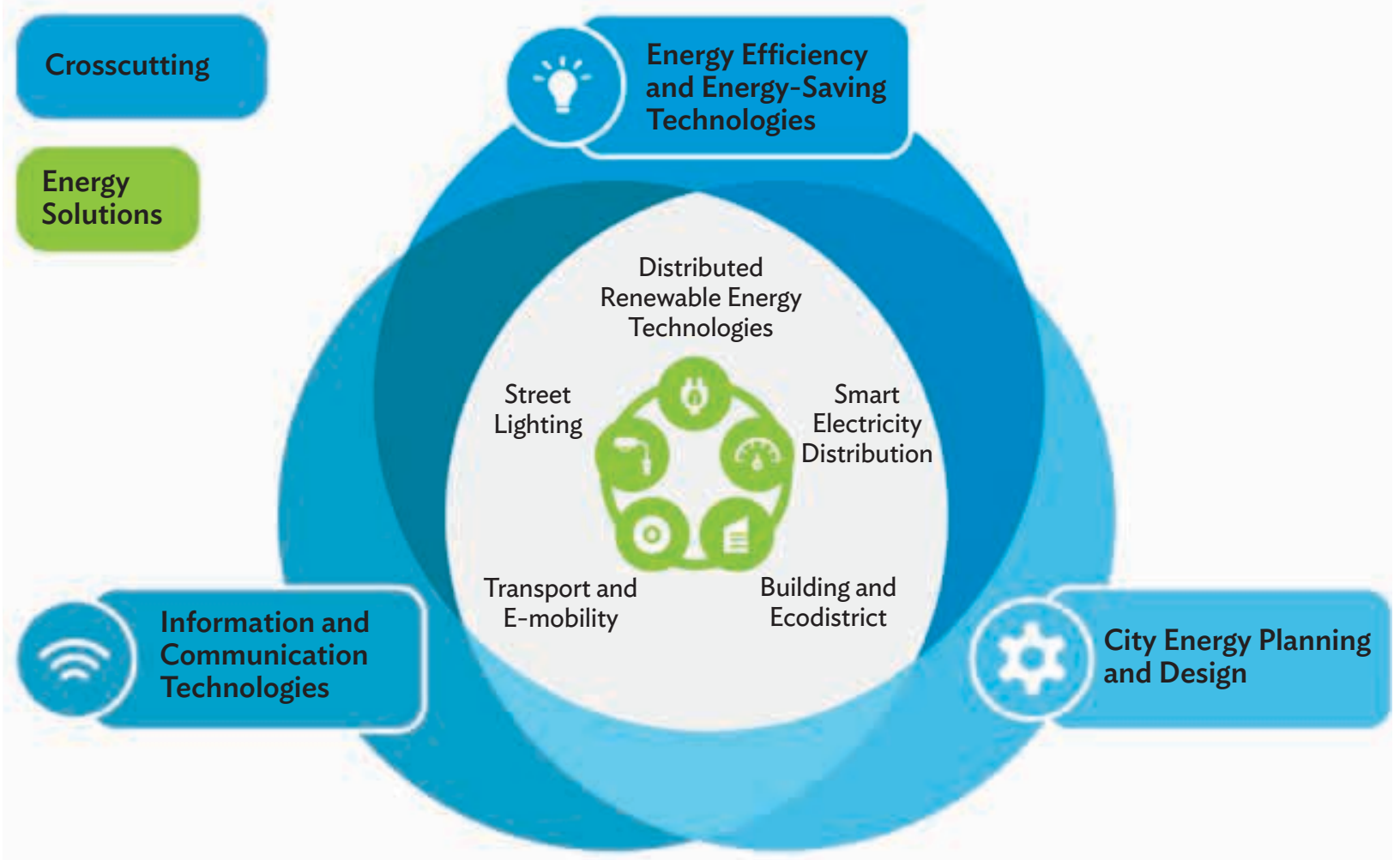

Source: Asian Development Bank. 
For each energy solution, selected cases are presented as examples to demonstrate the potential of ongoing efforts. They highlight the specific urban and energy contexts, the benefits and challenges of addressing energy system issues, and the need for cross-sector integrated planning and stakeholder engagement.

Each of the following sections elaborates on key energy solutions for future livable cities:

A. City energy efficiency planning and implementation. Investments in energy efficiency are widely deemed as the most cost-effective options in the short to medium term. Many cities are taking the lead in mainstreaming energy efficiency on a citywide scale as a critical part of their own development pathway and to support national energy efficiency objectives. This section highlights the critical role of the city government and the public sector in transforming energy systems through coordinated planning and actions.

B. Urban distributed clean energy production. Cities are major consumers of energy. They typically import energy from centralized production and distribute it through grids or networks to consumers. While the density of cities and resultant energy demand can rationalize distribution infrastructure, it is typically difficult to find the space to install energy generation and productions. This section discusses how to address the limitation for using distributed energy resources. It emphasizes the need to consider the specific context of a city to find opportunities for energy generation and production that will contribute to meeting the overall energy demand.

C. Urban smart electricity distribution systems. Smart electricity distribution systems in cities can play an essential role in enabling cities to improve energy efficiency, integrate renewables, and ensure reliable provision of power. This section discusses how electricity distribution systems tie together many other smart technologies such as e-mobility, smart street lighting, building power use, and other areas to improve the operation of the entire system.

D. Energy-efficient buildings and eco-districts. Investments in energy efficiency play a vital role in the life span of a building or building blocks, from construction to operation, renovation, and deconstruction and recycling. This section examines the energy intensity of the building sector and looks at diverse technical solutions and policy means that can decrease costs and environment impacts, while improving the overall livability of an urban-built environment.

E. Urban e-mobility. Transportation infrastructure is essential in enabling cities to function as places to live, work, and conduct business. Transport services, however, consume a large share of energy, and therefore produce a high share of $\mathrm{CO}_{2}$ emissions. Fossil-fueled vehicles are also producing significant amounts of air pollution. This section discusses the opportunity for e-mobility in the urban context and the potential energy system impacts and benefits of electric vehicles.

F. Smart and energy-efficient street lighting. Street lighting has multiple social and economic benefits. It makes cities more attractive, resilient, and safer, and therefore more livable. Also, street lighting is a significant consumer of electricity in cities, and often perceived as a low-hanging fruit in terms of urban energy saving potential. This section discusses the trajectory of street lighting becoming more energy-efficient and connected. It also highlights the potential of smart street lighting as a core element of smart city development.

Overarching perspectives of urban energy solutions for current and future urban development are provided in the last part of the article along with recommendations for decision makers. Sustainable energy system interventions have become pivotal in the urban context in terms of increasing the livability of cities and contributing to global 
sustainable development goals. National governments and cities are taking the lead in transforming their own energy systems through effective energy planning and implementation.

This article was developed to provide guidance to governments, policy makers, and other stakeholders from a high-level perspective and will be of most value to those with generalist level energy sector experience. Given a high-level treatment of a specific set of sustainable energy aspects, it is expected additional topics will require further investigation and that evidence-based research is needed to support full policy implementation.

\section{Implementing Energy Solutions}

\section{City Energy Efficiency Planning and Implementation}

Energy efficiency is a key solution to meeting energy and economic challenges in developing Asia. It is often defined as delivered energy service per unit of energy supplied into a system. Within cities, a key value of energy efficiency is grounded upon its ability to meet increasing end-user needs (demand-side energy efficiency) requiring less or no expansion of energy supply or distribution infrastructure (Table 1).

Table 1: Supply-Side versus Demand-Side Energy Efficiency

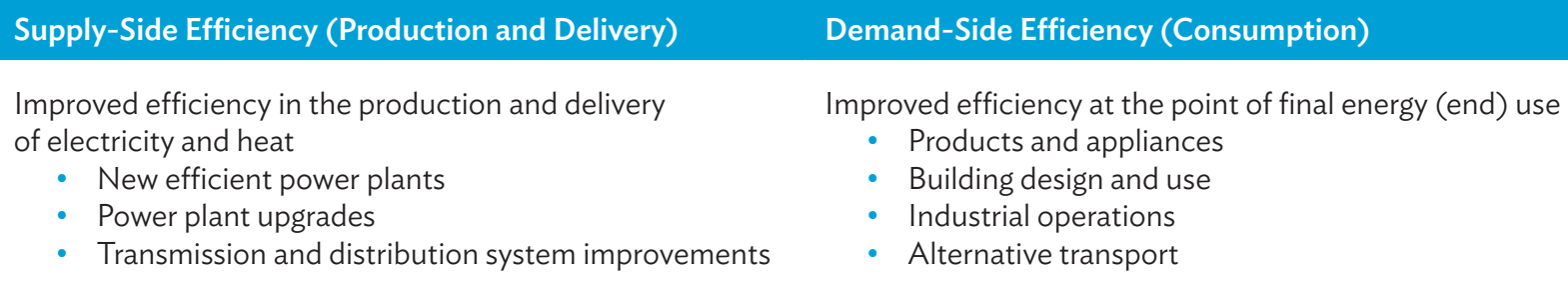

Source: Asian Development Bank. 2013. Same Energy, More Power: Accelerating Energy Efficiency in Asia. Manila.

Investments in energy efficiency are widely deemed as the most cost-effective options in the short to medium term. The Asian Development Bank (ADB) estimates that a 1\%-4\% investment in energy efficiency, as a share of overall energy sector investment, can meet as much as $25 \%$ of the projected increase in primary energy consumption in developing Asian countries by 2030 (ADB 2013). As Asia continues to urbanize, integrated energy planning for urban infrastructure can combine the use of renewable energy, new public transport options, and more efficient vehicles to maximize efficiencies across the built environment for mixed-use development. Together, these changes promise to capture the next level of dramatic energy savings, which can bring vast economic and environmental gains (ADB 2013).

Both the national and subnational governments have significant leverage in addressing both the supply and demand side of energy efficiency. If national governments choose to set up nationwide energy-focused frameworks, the responsibilities of cities and local governments over energy use will increase due to political decentralization and their direct access to citizens and businesses. They are often responsible for a range of measures, including urban planning, transport investment decisions, land use and zoning, building requirements, property taxes and transfers, and economic and workforce development. They are also a major energy consumer and an asset owner. 
Cities and the urban public sector can drive market transformation toward low-carbon technologies and services, and promote community participation through "leading by example." By improving the energy efficiency of public facilities and operations, such as water, wastewater, waste, transport, electricity, and other energy distribution infrastructure, they can demonstrate the effectiveness and value of energy efficiency interventions (ACEEE n.d.). Improved energy efficiency and avoided costs can, in turn, decrease or prevent increases in local taxes or utility rates.

Figure 3 shows an institutional mapping of three cities: Da Nang, Viet Nam; Surabaya, Indonesia; and Cebu City, Philippines. It illustrates the principal agencies and actors involved in the delivery and management of services that affect the city's energy efficiency and GHG emissions. It shows that each city generally has control of investment, budgets, and several local energy efficiency activities, as well as certain aspects of public lighting, public buildings, and wastewater treatment and water tariffs. In most other energy-related areas, there is a mix of influence concentrated at the city level. This situation reinforces the need for city governments to be aware of their local circumstances so as to tailor their plans to their own needs and governance structures (World Bank 2012).

Establishing partnerships is another important requirement for cities to effectively plan and implement cross-sector urban energy efficiency. Not all actions are under the city's control, especially since the majority of urban electricity is supplied from the national grid. As shown in the cases of three cities in Figure 3, city authorities' influence relating to power supply and electricity tariffs is exceedingly limited. Utilities, private enterprises, financial institutions, and different levels of governments and public agencies are all pursuing energy management with respective priorities and responsibilities. Promoting integrated urban energy management to improve energy efficiency will require cities to work together with multiple stakeholders and strengthen their capacity to coordinate actions.

Figure 3: Level of Influence of City Government in Various Urban Sectors

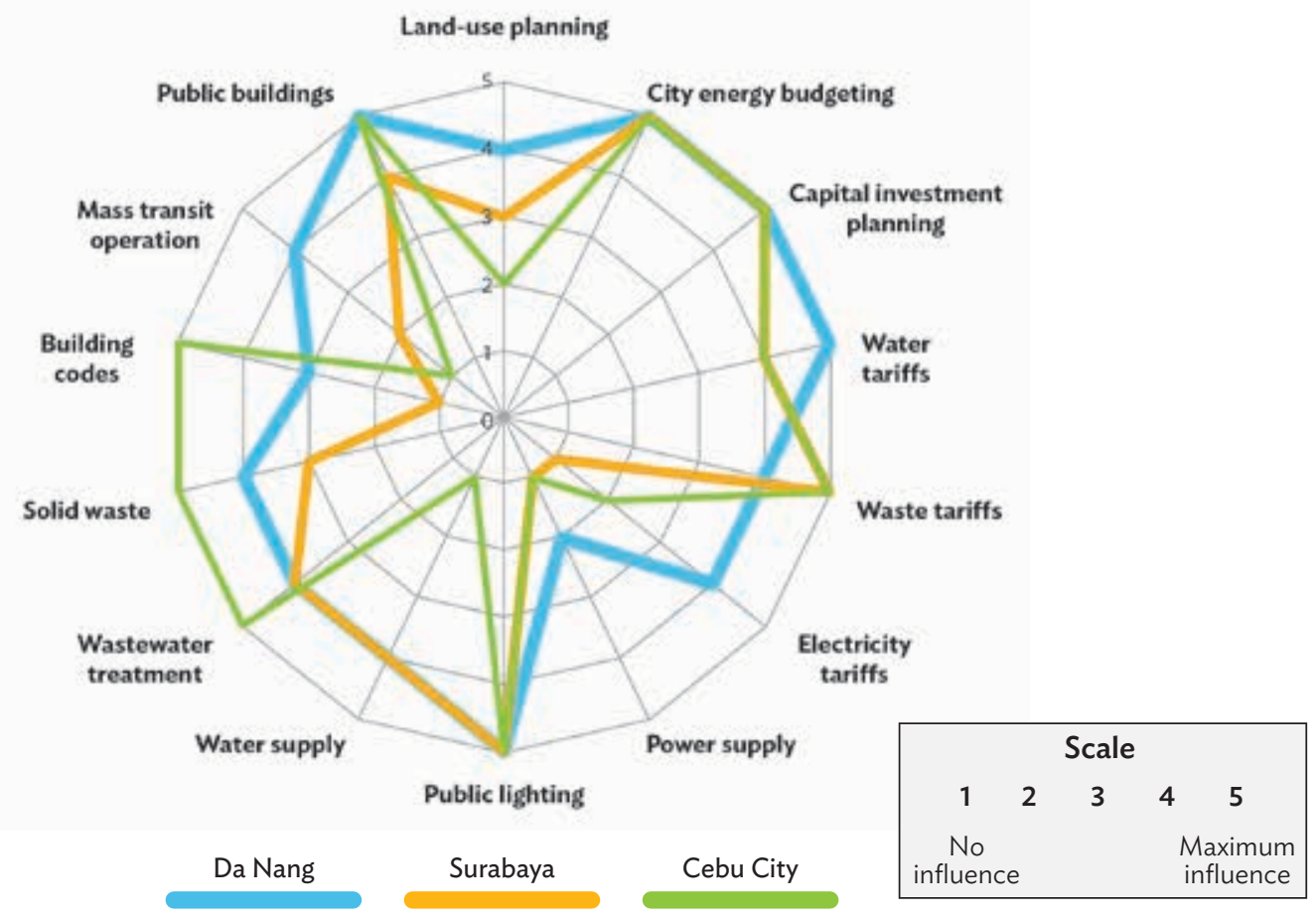

Source: World Bank. 2012. Energizing Green Cities in Southeast Asia: Three City Synthesis Report. Washington DC. p.18. 
The proven benefits of energy efficiency measures, including economic, social, environmental, and climate resiliency, also offer value beyond the energy sector alone and make the adoption of targeted policies and investments a compelling and cost-effective means to achieve various development goals. Many cities are taking steps to integrate energy efficiency on a citywide scale as a critical part of their development pathway (see Box 1). Initially, the formulation of a near-term and long-term energy plan to coordinate actions is needed. It is essential to include a clear political commitment to energy efficiency and savings, and set out the vision, targets, and key actions for near- to long-term planning and investment decisions in the sector.

A vital step is to understand the city energy balance by collecting energy information about energy use, demand and supply by sector, and fuel type. Because the latter is directly related to the intensity of GHG emissions, the energy audit process can be easily combined with GHG emissions assessment and used to identify the highest GHG emitters and priority areas for mitigation projects. Urban energy planning is therefore an integral part of climate action planning.

A recent Energy Efficiency and Conservation (EE\&C) law in the Philippines, enacted in 2019, demonstrates how cities and local governments can work together with the national government to improve their energy planning and implementation. In alignment with a National EE\&C Plan and a National EE\&C Database, local government units (LGUs) are now responsible for developing and implementing their local energy efficiency and conservation plans and reducing their own energy consumption. LGUs are also tasked to monitor compliance to the EE\&C

\section{Box 1: Tackling Air Pollution and Climate Change-Study for Energy Master Plan of Ulaanbaatar}

The capital of Mongolia, Ulaanbaatar, with its 1.37 million inhabitants, depends largely on fossil energy. Mongolia's energy sector is coal-based resulting in high levels of carbon dioxide $\left(\mathrm{CO}_{2}\right)$ emissions and air pollution. Particularly during the winter period, the city suffers from extremely high air pollution caused by five combined heat and power (CHP) plants and heating and cooking using raw coal in districts of informal settlements. A number of different policies, strategies, and actions have been adopted and implemented in the past, but have not been sufficient to solve the dramatic health and environmental problems. There was a need for a substantiated analysis of all possible options for action and the identification of basic potential solutions for the systematic transformation of Ulaanbaatar's energy system.

The final study report, presented in October 2018, includes the current and future energy demand and assumptions until 2050, the generic energy system structure, and the available renewable energy sources around Ulaanbaatar City. The study recommends the step-by-step establishment of a sustainable energy system relying mostly on renewable energy sources such as photovoltaic, wind turbines, and CHP plants (coal and waste incineration).

In Mongolia, a green development policy was adopted in 2014. The policy aims to improve the energy system efficiency by $20 \%$ until 2030, and increase the share of renewable energies by $20 \%$ in 2020 and by $30 \%$ in 2030 . The Energy Conservation Law was adopted in 2015 to improve the legal framework for energy efficiency projects. In 2016, Mongolia ratified the Paris Agreement on Climate Change with the objective to reduce greenhouse gas emissions by $14 \%$ in 2030 .

Sources: Sector Network Tuewas. Energy Master Plan for Ulaanbaatar, Mongolia. https://tuewas-asia.org/2017/07/05/ energy-master-plan-for-ulaanbaatar-mongolia/; German Cooperation, GIZ, UN-ESCAP, The Urban Nexus. Case Study Flyer: Energy Masterplan, Ulaanbaatar (UB), Mongolia. https://www.unescap.org/sites/default/files/Flyer_MN_Ulaanbaatar_ EnergyMasterPlan_2017.pdf; German Cooperation. 2018. Ulaanbaatar, Mongolia's Capital City Plans to Go Green by 2050.16 October. https://www.thai-german-cooperation.info/en_US/ulaanbaatar-mongolias-capital-city-plans-to-go-green-by-2050/. 
obligations of the designated establishments within their jurisdiction. Government financial institutions are mandated to offer concessional financing and provide incentives through the Local Investment Incentives Plan. ${ }^{1}$

Similarly, a structured planning process across national, provincial, and city levels is also being implemented in Viet Nam. The Viet Nam Energy Efficiency Program (VNEEP 2005-2015) was set up for the first time in 2006 as the country's comprehensive plan to improve energy efficiency across the energy sector. After years of continued efforts, energy efficiency gradually took roots, until the third VNEEP (2019-2030) was approved in 2019. Among others, the VNEEP's third phase of the program requires all Viet Nam's provinces and cities to prepare their Energy Efficiency Action Plans by 2030. The efforts of local governments are essential to achieve the national goals and targets set out by the national government, as the former can more effectively tap into local resources and capacity. This demonstrates that effective planning and implementation requires an inclusive approach by combining both top-down and bottom-up processes.

Local governments can also benefit from international development collaboration where they are increasingly recognized as a lead actor in global development. Viet Nam's Ministry of Industry and Trade encourages provincial and city governments to work with international and regional partners. This will help expand the opportunities for local governments to learn from global experiences and enlarge their development perspective on global initiatives, such as the Paris Agreement and SDGs.

\section{Urban Distributed Clean Energy Production}

The urban context offers both opportunities and challenges to energy generation and use. The population density in cities and resultant demand can rationalize infrastructure, such as electricity and natural gas distribution or district heating and cooling networks. However, this density can also make it difficult to find the space to install energy generation and production. As a result, cities as major consumers of energy typically import energy from centralized production and distribute it through grids or networks to final demand.

Depending on the context, local energy sources within cities can help meet overall energy needs. Even if available local low-carbon energy resources are not sufficient to cover all energy needs and self-sufficiency is not possible, these resources can make a meaningful contribution (IEA 2016). Additionally, peri-urban areas near cities can provide the needed space for such deployment near the concentrated load. With energy being transported at a lesser distance can result in lower distribution losses.

There are several main criteria for evaluating the prospects of distributed energy production in the urban context. ${ }^{2}$ The density of a city, or parts of the city, often as a direct result of the height of the buildings and land use, not only increases the amount of energy required per unit of area, but also limits the available space for deployment of energy generation or production technologies. Secondly, high-rise buildings create significant shading which has a major impact on technologies like building-integrated photovoltaics.

ADB. 2019. ADB, DOE, and EU-ASEP Brief Philippine LGUs on Energy Efficiency and Conversation Law. https://www.adb.org/ news/adb-doe-and-eu-asep-brief-philippine-lgus-energy-efficiency-and-conversation-law; IEA. Act 11245: The Energy Efficiency and Conservation Act. https://www.iea.org/policies/7402-act-11245-the-energy-efficiency-and-conservation-act; ICLEl. Visayas Stakeholders Convened to Promote Energy Efficiency and Conservation. https://icleiseas.org/index.php/2020/03/26/visayasstakeholders-convened-to-promote-energy-efficiency-and-conservation/.

2 Renewable energy resources in the urban context must fit within the limited space available and be able to operate in the presence of a dense population. Hence, renewable power technologies typically include solar photovoltaics and waste-to-energy (which can also be designed and operated as a combined heat and power plant). Heating technologies typically include geothermal (with vertically drilled thermal wells) and solar thermal. Small-scale wind power can be deployed on buildings in many situations, and larger wind turbines in some situations, such as where cities are next to large water bodies. However, the density of populations and buildings can limit wind energy deployments. 
Other considerations are the age of the city and whether its design has considered the availability of local energy resources. For example, older and more established cities typically did not consider the orientation or placement of buildings to take advantage of solar energy. Also, in cooling-dominated climates, older cities did not consider how to reduce solar gains to minimize cooling loads. Additionally, building and appliance efficiency is likely lower in older cities and therefore requires increased amount of generation or supply technology to satisfy a meaningful share of demand. District heating and cooling technologies that involve piping networks installed underground are best deployed during construction of buildings or infrastructure as their subsequent installation will be highly disruptive.

In the case of developing Asia where many cities are yet to be built, newly planned cities have the advantage to significantly tap local renewable energy resources using the best-in-class technologies. Streets and buildings can be oriented in the best direction to take advantage of solar energy, and to maximize solar gains for winter heating and domestic water heating, or to generate electricity. Best practice on building design and construction can be used to minimize energy demand and space since infrastructure can be planned and implemented during the construction phase and district heating and/or cooling networks can be integrated in the overall design of the city.

Rooftop solar photovoltaics (RTSPV) is a key technology that can be deployed on a range of buildings including residential dwellings as well as commercial and industrial buildings in cities (Box 2). Programs usually differentiate between residential-based applications or commercial and industrial roof spaces due to inherent size of available

\section{Box 2: Rooftop Solar Photovoltaic Power Generation Systems in Sri Lanka}

Sri Lanka has substantial solar energy potential as it is situated close to the equator and has abundant sunlight year-round. For over two-thirds of the land mass, solar radiation is in the range of 4.0-4.5 kilowatt-hours (kWh) per square meter per day, which is considered high. However, the development of a solar power generation market has been limited in the past. As of November 2016, there were 4,200 customers with net-metered renewable energy facilities, adding up to a cumulative generating capacity of about 30 megawatts (MW).

Almost all of these facilities are solar photovoltaic installations on rooftops, except for a few small hydro electric facilities. About $95 \%$ of net-metered customers are households, while the others are institutional customers. In September 2016, the government announced the Battle for Solar Energy program. The government's strategic goal is to increase solar photovoltaic capacity to $200 \mathrm{MW}$ by 2020 and to 1,000 MW by 2025. The program envisages boosting clean power generation through net metering, net accounting, and micro solar power producer (net plus) schemes to connect rooftop photovoltaic installations to the network.

To support the ambitions in Sri Lanka, the Asian Development Bank is providing long-term debt financing for the installation of rooftop solar photovoltaic power generation systems. The loan will be provided to public financing institutions, including public and private sector banks, for financing qualified rooftop solar systems based on available business models. Associated technical assistance will also support establishing technical guidelines and standards for rooftop solar systems; subproject screening, implementation, monitoring, and compliance activities; and stakeholder capacity and market development.

Source: Asian Development Bank. Sri Lanka: Rooftop Solar Power Generation Project. https://www.adb.org/ projects/50373-002/main\#project-overview. 
roof space as well as customer objectives. ${ }^{3}$ Smart inverters that convert the direct current electricity created by the photovoltaic panels to grid quality-alternating current electricity are also sometimes now required to operate in a manner that provides voltage or frequency support that can increase the reliability of not only the solar photovoltaic (PV) system, but also the grid itself.

Peer-to-peer trading with storage is also a newly evolving approach with RTSPV systems and has been piloted in Thailand (see the next subsection on urban smart electricity distribution systems). Despite global experience and demonstrated success of RTSPV, local challenges in developing countries for such deployments typically include lack of local capacity for installation and maintenance, difficult access to financing to pay upfront capital cost, and lack of local policy and regulations for grid connection.

While many cities are not able to provide sufficient land availability for large-scale PV deployments, many are next to water bodies that could be suitable for floating solar deployments. Floating solar is a relatively new concept (Box 3). The biggest advantage is that the installations do not require land space. It can also help in water resource conservation by shading the body of water and reducing evaporation.

Waste-to-energy is a technology that is well suited to the urban context. The population density in cities results in a significant amount of solid waste production. Once recyclable materials are recovered from the waste stream, there is typically a significant amount of organic material that must be disposed of and there can be significant limitation in the urban context for such disposal. Alternatively, the remaining waste can be converted to energy.

While much of the renewable energy discussion focuses on power technologies, there is a significant need to support heating applications in many Asian cities. District heating together with geothermal energy can offer a cost-effective, efficient, and renewable solution. The attractiveness of geothermal heating is based primarily on its lower operational costs, superior emissions profile, and potential for sustainable operation - given an effective resource management. However, capital costs are higher, which requires that planners account for longer-term benefits, including environmental externalities, and applications with economies of scale.

In the northern People's Republic of China (PRC) and in developed areas more generally, heating is provided mainly by centralized district systems at the neighborhood or district level. These involve large-scale and small-scale co-generation, heat-only boilers fired by coal or natural gas, or larger-scale heat pumps. Distributed units at the building or individual household level are used as supplement, and may involve gas and coal boilers, small-scale heat pumps, and electric heaters. This presents options for improvement and the need for GHG-reducing technologies.

As part of the initiatives to mitigate air pollution, the Government of the PRC is promoting more energy-efficient and lower-emissions heating systems. In its 13th Five-Year Plan (2016-2020), the government has ambitious plans to develop district heating based on renewable resources, especially geothermal energy, with immediate focus on newly urbanizing or highly polluted areas. ADB is lending up to $\$ 200$ million to Sinopec Green Energy Geothermal Co. (SGE) in the PRC for the construction, acquisition, rehabilitation, and operation of a series of urban district heating systems based on geothermal energy. ${ }^{4}$ SGE focuses on medium-temperature $\left(<150^{\circ} \mathrm{C}\right)$ hydrothermal energy to supply district heating systems in several cities in northern provinces, reducing reliance on fossil fuels. ${ }^{5}$

3 Residential customers may deploy rooftop solar for various reasons, such as energy savings and environmental benefits, whereas commercial/industrial customers are largely driven by cost savings alone.

4 ADB. China, People's Republic of: Geothermal District Heating Project. https://www.adb.org/projects/51186-001/main\#project-overview.

5 The most common geothermal resource type in the PRC is hydrothermal-especially resources of low temperature $\left(<90^{\circ} \mathrm{C}\right)$ and medium temperature $\left(90^{\circ} \mathrm{C}-150^{\circ} \mathrm{C}\right)$ - of which the PRC has the world's largest resource base. 


\section{Box 3: Grid-Connected Solar Floating Photovoltaic Power Project in Visakhapatnam, India}

Visakhapatnam is an industrial metropolis of Andhra Pradesh state. It is one of the fastest-growing cities in India. With a population of 1.88 million (2011 census), the city needs a huge amount of energy for its economic activities and urban growth. Visakhapatnam has been also identified as a "Smart City" as part of the Government of India's national program on smart cities.

The city is highly exposed and vulnerable to climate extremes. Climate resilience is one its priorities. Multiple initiatives and projects are being implemented to build climate-resilient urban infrastructure. The city's flagship projects include a 3-megawatt (MW) grid-connected solar floating photovoltaic (PV) power project in the Meghadrigedda reservoir area, currently being implemented under the Visakhapatnam-Chennai Industrial Corridor Development Program. The project is financially supported by the Asian Development Bank (ADB) Urban Climate Change Resilience Trust Fund.

The floating solar plant will only take up a fraction of the reservoir space ( 0.05 square kilometers out of the 5.015-square kilometer reservoir area). The panels are best-in-class solar PV crystalline panels and the floats are made from polypropylene with foam which is a durable material and cannot be punctured. Notably, the Greater Visakhapatnam Municipal Corporation, the city's chief governing body, has learned lessons from the existing $2 \mathrm{MW}$ solar floating that they have installed in Mudasarlova reservoir under Smart City funds. The solar floating plant will reduce greenhouse gas emissions (1,500 tons carbon dioxide equivalent per annum averted), reduce evaporation losses from the reservoir, and provide additional energy to the city's water utilities.
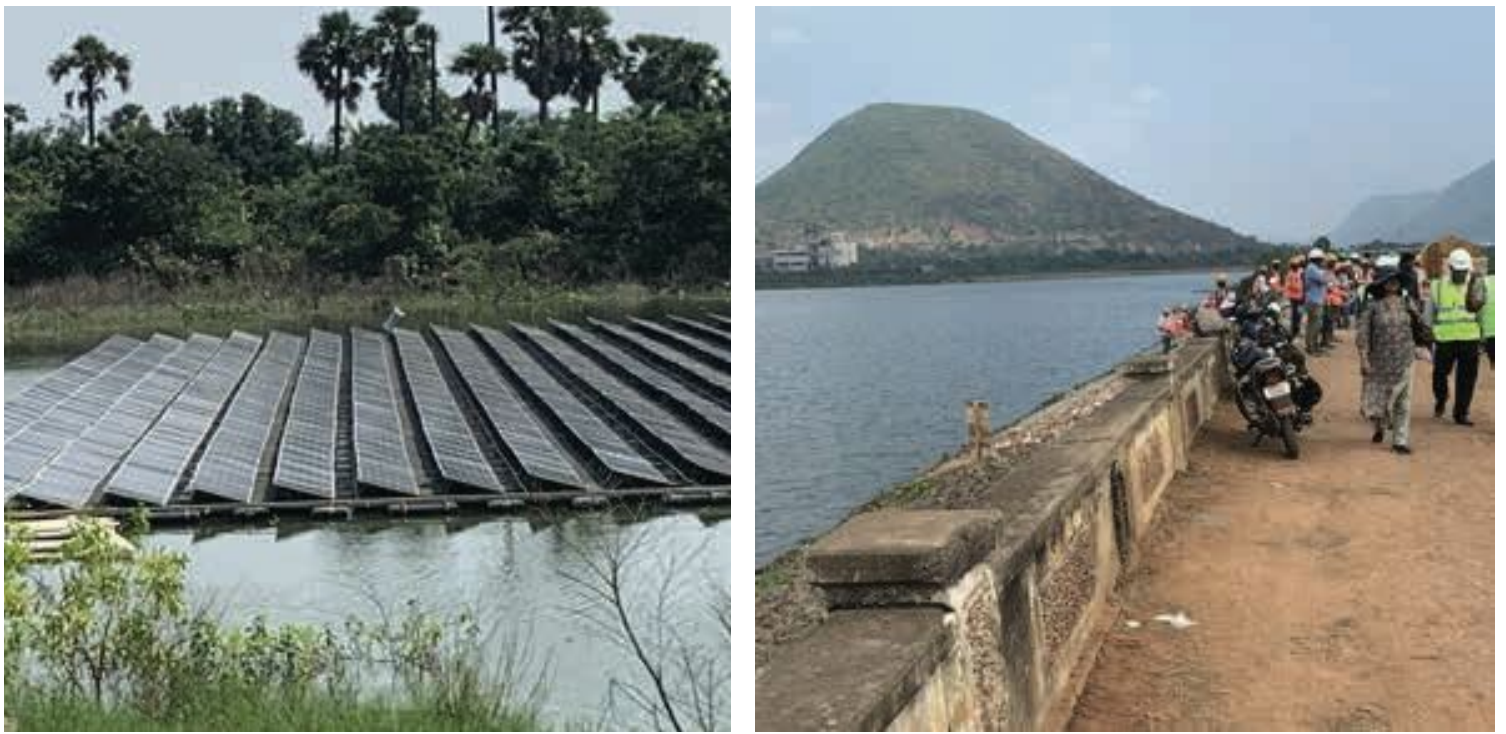

Floating solar plant. (Left) $2 \mathrm{MW}$ floating solar panels are installed in Mudasarlova reservoir; (Right) Meghadrigedda reservoir is host to a $3 \mathrm{MW}$ grid-connected solar floating PV power. Supported by the Urban Climate Change Resilience Trust Fund, the preparation work is in progress (photos by Virinder Sharma/ADB).

Source: Asian Development Bank. India: Visakhapatnam-Chennai Industrial Corridor Development Program, Project 1. https://www.adb.org/projects/48434-003/main\#project-overview. 


\section{Box 4: Waste-to-Energy Plant in Greater Malé}

Greater Malé and its neighboring 32 outer islands-which host 86 tourist resorts - suffer from severe environmental pollution and deteriorating livability due to inadequate collection and haphazard disposal of solid waste. More than 830 tons per day (tpd) of solid waste are generated in the area and dumped or burned at the 10-hectare dump site on Thilafushi island. Established in 1992, this dump site has no pollution control measures. The site contaminates the surrounding environment. Consequently, it has become a public health issue and an environmental hazard threatening fisheries and tourism.

The Asian Development Bank (ADB) is supporting a project that will establish a waste-to-energy (WTE) plant with a capacity of $500 \mathrm{tpd}, 2$ treatment lines of $250 \mathrm{tpd}$ each, an 8-megawatt electricity surplus energy recovery facility, an air pollution control system, and a landfill for safe disposal of air pollution control residues and nonmarketable incineration bottom ash. The WTE treatment process minimizes land requirements for waste disposal and produces renewable energy, thereby addressing the critical land and electricity constraints of developing small island countries like Maldives.

All facilities will adopt disaster- and climate-resilient features to respond to future disaster and climate change threats, such as sea level rise. The WTE plant will be implemented through a design-build-operate modality with the private sector, with a 15 -year operation and maintenance period.

The project will also strengthen the institutional capacity of the Ministry of Environment and Environmental Protection Agency to supervise WTE operations, enhance operation and maintenance cost recovery, and improve public awareness on sustainable waste management practices.

Source: Asian Development Bank. 2020. ADB Approves $\$ 73$ Million Package to Develop Waste-to-Energy Facility in Maldives. News Release. 12 August. https://www.adb.org/news/adb-approves-73-million-package-develop-wasteenergy-facility-maldives.

\section{Urban Smart Electricity Distribution Systems}

Smart electricity distribution systems in cities play an essential role in enabling cities to improve energy efficiency and integrate renewables and in ensuring reliable power supply. The definition of smart grids in power distribution systems is very broad. ${ }^{6}$ Smart electricity distribution systems can tie together many other smart technologies, such as e-mobility, smart street lighting, and building power use. ${ }^{7}$

Historically, distribution systems were deployed in a manner described as "fit and forget," wherein demand for power was estimated based on the typical needs of a given building structure or consumer, and the requisite distribution system was deployed to meet this need. This approach has generally been very effective. However, as supply and demand for electricity evolves, this approach can be greatly improved, addressing present issues such as financial and environmental sustainability, and preparing for the future.

6 The European Union Commission Task Force for Smart Grids defines a smart grid as "an electricity grid that can cost efficiently integrate the behavior and actions of all users connected to it-generators, consumers, and those that do both-to ensure economically efficient, sustainable power system with low losses and high levels of quality and security of supply and safety. A smart grid employs innovative products and services together with intelligent monitoring, control, communication, and self-healing technologies."

7 A number of smart electricity distribution grid features, such as smart metering, can be applied to other networks, such as natural gas or district heating. 
For example, concentrations of grid-connected PV systems can result in reverse flow of electricity along certain feeders, voltage rise, or other anomalies during the day, and then revert typical demand patterns during the evening. Increased demand for power due to electric vehicles may result in power demand in excess of design. Addressing these issues can be very challenging and costly, if not impossible, for conventional distribution systems.

In many electric utilities, the operation of the electric distribution system is being transformed from mostly manual, paper-driven business processes through the introduction of electronic, computer-assisted decisionmaking. Advances in control and communication technology now permit the automatic or semiautomatic and remote operation of distribution equipment and facilities that in the past could only be operated manually (Madrigal et al. 2017).

The deployment of smart distribution systems can also enable advanced operating approaches and business models that can benefit both system operators and end users. Increased provision of usage data for all customers can enable targeted energy efficiency programs and reduce demand (and resultant costs). Smart metering can enable peak and off-peak pricing structures, which can improve the operational efficiency of the system. Automated demand response at the commercial and industrial sectors, and at the residential sector, can modulate demand per agreed parameters, which allows reliable grid operation at very low costs.

Smart distribution systems can also integrate technologies like battery electric storage to address supply and demand situation. They can support electricity trade between "prosumers." Smart distribution grids can also be designed to identify problems in the systems before the system fails. They help prevent identity and power theft and enable the distribution system to operate more resiliently during inclement weather.

"Smartening the distribution grid" or distribution grid modernization also brings the benefits of improved asset utilization (allowing operators to "squeeze" more capacity out of existing assets) and workforce productivity. These benefits can provide more than enough monetary gain for electric utility stakeholders in developing countries to offset the cost of grid modernization. Some of these core smart grid benefits may be achieved by electric distribution utilities that have not yet advanced very far in their process of grid modernization. For example, lowering the voltage set point on an existing electromechanical voltage regulator can reduce electrical demand and improve the overall efficiency of the distribution system (Madrigal 2017).

The cases in Box 5 highlight the various ways that smart grids can be deployed throughout the distribution systems. It should be noted that these potential applications of smart grids do not make up an exhaustive set of examples. These cases demonstrate the value in using the available ICT to deliver reliable, sustainable, and cost-effective power to end users.

\section{Energy-Efficient Buildings and Eco-Districts}

Buildings are places where people live and work, and consume energy, water, materials, and natural resources. The building sector encompasses a diverse set of energy end-use activities, such as space heating and cooling, lighting, and appliances and equipment. Building designs and materials have also a significant effect on energy consumption. In many countries, buildings consume more energy than the transport and industry sectors.

According to the International Energy Agency (IEA), the buildings and construction sector accounts for 36\% of final energy use, and $39 \%$ of energy and process-related $\mathrm{CO}_{2}$ emissions. In terms of $\mathrm{CO}_{2}$ emissions, buildings

8 A prosumer is a customer that both produces and consumes electricity. 
Box 5: Cases of Smart Electricity Distribution Technologies in Differing Applications

\section{Meghalaya Power Distribution Sector Improvement Project in India}

The project will strengthen and modernize the power distribution grid, reduce technical and commercial losses, and improve the power quality of the distribution grid in Meghalaya State. The project will support the provision of 24/7

power for all households, industries, commercial businesses, public needs, and other electricity-consuming entities. ${ }^{a}$

The project has several technical deployment outputs. As its first output, the project will construct new substations, and renovate and modernize substations, including modern control room equipment and protection systems. To improve the reliability of power distribution, auto-reclosers and fault passage indicators will be installed. New distribution lines will be set up and three village distribution grids are to be renovated. For the project's second output, the automated metering infrastructure will be deployed to improve billing and collection, and reduce electricity theft. Other outputs for the project will support planning by developing a distribution sector road map to help meet existing and future power needs and build capacity to systematically plan, design, and manage the distribution grids.

\section{Powell Energy Efficiency Enhancing System with Energy Storage System, Demand Response, and Factory Energy Management System the Republic of Korea}

Smart distribution systems have the ability to link several technologies to provide combined benefits to consumers. In the Republic of Korea, the Powell sewage treatment plant was facing high costs due to peak electricity demand charges. The Factory Energy Management System (FEMS) continually manages the plant's energy demand pattern and then charges/discharges the battery based on this analysis. By managing energy demand through the FEMS and using stored energy when required, the facility can modulate its electricity demand, while still providing adequate sewage treatment, therefore reducing peak demand. This approach allowed the facility to participate in a demand resources trading market, reducing its net energy costs. This complex operation is only possible through interactions between the end user and the grid, including all associated market settling information. ${ }^{b}$

\section{Peer-to-Peer Electricity Trading in Thailand and Bangladesh}

Power Ledger, a blockchain developer based in Perth, Australia, has partnered with BCPG, a Thai renewable energy business, to launch a peer-to-peer (P2P) renewable energy trading trial at the T77 urban precinct in Bangkok, Thailand. A P2P approach uses a business model based on an interconnected platform that serves as an online marketplace where consumers and producers "meet" to trade electricity directly without the need for an intermediary (like a utility). P2P electricity trading is also known as the "Uber" or "Airbnb" of energy, as it is a platform that allows locally distributed energy generators to sell their electricity at the desired price to consumers willing to pay that price. ${ }^{c}$

The trial also includes a partnership with a Thai utility, Metropolitan Electricity Authority, which has allowed access to its grid for the physical transaction of energy between participants. Approximately 700 kilowatts of photovoltaics are deployed across an international school, apartment complex, shopping center, and dental hospital, including a co-located battery storage. It is expected to cover $20 \%$ of the community's overall electricity needs. ${ }^{d}$

P2P trading can be also done at a very small scale to support access to energy. SOLshare, a small German company, has successfully piloted the world's first information and communication technology (ICT)-enabled P2P electricity trading grid for rural households with and without solar home systems in Shariatpur, Bangladesh. SOLshare's implementation partner is a nongovernment organization, the Upokulio Biddutayan O Mohila Unnayan Samity. Its financing partner is the Infrastructure Development Company Limited, and its research partner is the United 
Box continued

International Universit-Centre for Energy Research. Along with its partners, SOLshare combines solar home systems and centralized mini-grids to enable more rural households to access renewable electricity at a lower cost. While this application is applied in a rural setting, it could also be deployed in an urban context.

The trading grid interconnects households via a low-voltage DC grid and controls power flows through bi-directional metering integrated with an ICT back end, which handles payment, customer service, and remote monitoring. Each SOLshare meter enables the user to buy and sell renewable electricity with neighboring households, businesses, and rural industries. ${ }^{\text {. }}$

${ }^{a}$ Asian Development Bank. India: Meghalaya Power Distribution Sector Improvement Project. https://www.adb.org/ projects/51308-004/main\#project-pds.

b International Smart Grid Action Network. Powell Energy Efficiency Enhancing System with ESS+DR+FEMS http://www.iea-isgan.org/ess-case-korea-5/.

c International Renewable Energy Agency. 2020. Innovation Landscape Brief: Peer-to-Peer Electricity Trading. Abu Dhabi.

${ }^{d}$ M. Maisch. 2018. Power Ledger Launches P2P Solar Trading Trial in Bangkok. PV Magazine. 22 August. https://www.pv-magazine-australia.com/2018/08/22/power-ledger-launches-p2p-solar-trading-trial-in-bangkok/; Power Ledger. https://www.powerledger.io/client/bcpg-mea/.

e ME SOLshare: Peer-to-Peer Smart Village Grids, Bangladesh. https://unfccc.int/climate-action/momentum-for-change/ ict-solutions/solshare.

Source: Compiled by the authors.

were responsible for $28 \%$ of global energy-related $\mathrm{CO}_{2}$ emissions in 2019 , which makes decarbonizing the sector essential to achieving the Paris Agreement commitment (IEA 2020a). Consequently, a total of 136 countries have mentioned buildings in their Nationally Determined Contributions (UNEP 2019).

Despite the significant technological advancement and resulting improvement in building energy efficiency, the total energy demand from the sector continues to rise. Multiple factors are associated with this rise, including increased access to energy in developing countries and greater use of energy-consuming devices especially for space cooling.

Space cooling is an area of significance for Asia and the Pacific. Its current levels of ownership in ADB's developing member countries varies quite broadly. The PRC has experienced significant growth over the last 10 years to the point where, now, $60 \%$ of households have at least one air conditioning unit, whereas in India, the level is at only 4\% (IEA 2018). In Southeast Asia, it is reported that less than $15 \%$ of households have an air conditioner (IEA 2019a).

These numbers indicate a huge potential for future growth in major markets in Asia, driven by increasing temperatures and higher income. While efficient cooling technology is available and can significantly decrease the energy demand, the cost of ownership, and the associated emissions from ownership and use, a customer will often choose less expensive and low-efficiency appliances (air conditioning, refrigerators) that have higher operational costs and energy demand.

A fundamental cause related to the need for space cooling and heating is the rapid growth in floor areas of buildings. Coupled with urban growth and economic development, as a building's floor area per person increases, its energy use becomes higher. Building envelopes and systems have not improved enough to offset this growth (Figure 4) (IEA 2020a). 
Figure 4: Changes in Floor Area, Population, Buildings Sector Energy Use, and Energy-Related Emissions Globally, 2010-2018

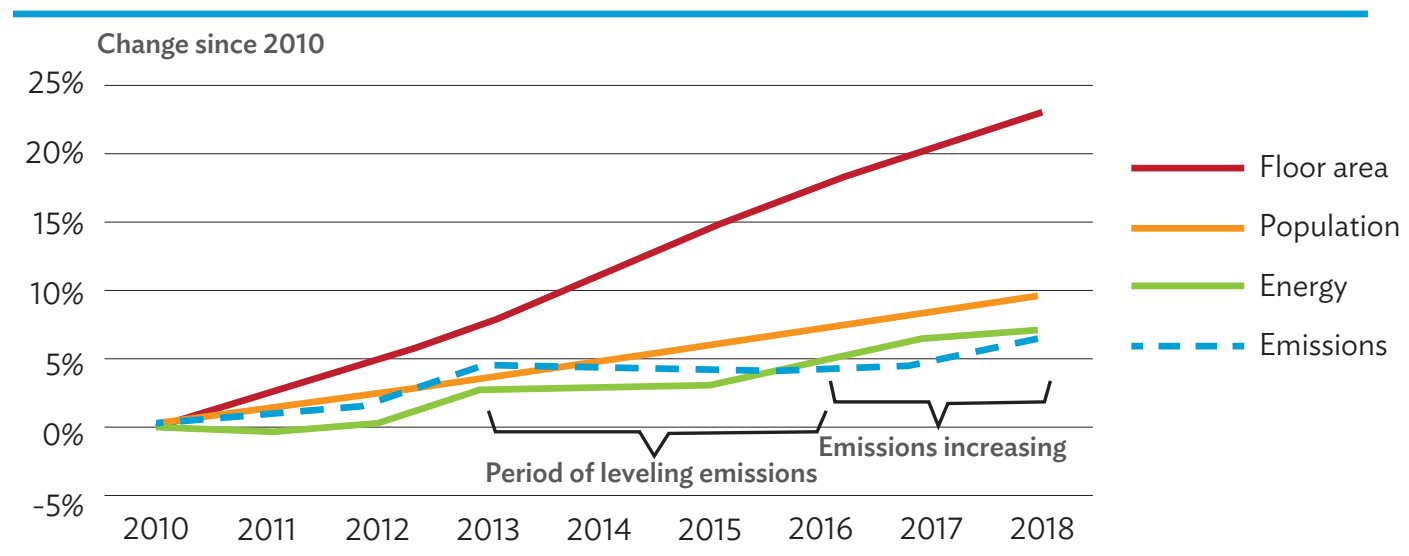

Source: Global Alliance for Buildings and Construction, International Energy Agency and the United Nations Environment Programme. 2019. 2019 Global Status Report for Buildings and Construction: Towards a Zero-Emissions, Efficient and Resilient Buildings and Construction Sector. Paris. p. 9.

The need for more buildings in developing countries, including both residential and commercial, presents a tremendous opportunity to transform the sector to become more energy-efficient, low-carbon, and climateresilient. The global building stock is set to double by 2050, and emissions from buildings will double by that year if conventional approaches continue, largely because of new floor spaces. ${ }^{9}$ This will serve as a unique opportunity to promote solutions and technologies in the building stock through making new buildings energy-efficient and retrofitting the existing ones.

Experience from developed countries shows there are multiple contributing elements to support the transition to highly efficient buildings. These include renewable energy for building energy use, smart and energy-saving technologies for building operations, locally available construction materials, passive building design, private sector investment, and green financing. An energy-efficient building should not only be confined to having energy-efficient appliances and building shells; significant benefits can be gained with broader considerations, such as water and waste management, materials and resource efficiency, and indoor environment quality improvement, which together can contribute to the overall resource efficiency of the building system.

Multiple policy options have been tested and applied for wider uptake of energy efficiency measures. They include regulations and legislations, awareness raising, incentive and financing, and research and development. Among the various policy measures, regulations and legislation (including green building codes) are considered as the most cost-effective means, if effectively implemented. Very often, financial cost is seen as the first barrier to the adoption of energy-efficient technologies, due to higher upfront costs for more efficient equipment. Financial incentives in the form of direct grants and subsidies, preferential loans, funds, tax incentives, or indirect incentives (e.g., granting larger floor area, higher density) can contribute to offsetting the upfront costs and promoting market and behavioral changes.

9 United Nations Environment Programme, Global Alliance for Buildings and Construction, and International Energy Agency. 2019. Global Status Report for Buildings and Construction: Towards a Zero-Emission, Efficient and Resilient Buildings and Construction Sector; World Resources Institute. 2019. News Research Shows Zero Carbon Buildings are Possible Where You Might Least Expect Them. 17 September. https://www.wri.org/news/2019/09/release-new-research-shows-zero-carbon-buildings-are-possible-where-you-might-least. 
Box 6: Innovative Private Initiatives as Leverage to Energy Efficiency in the Building Sector

Private companies can contribute to the greening of the building sector by offering expertise in sustainable building design and construction, innovative technical concepts, sustainable building materials or financial resources.

ADB Ventures, an initiative of the Asian Development Bank (ADB), helps early-stage companies scale technology into the Asia and Pacific region to achieve sustainable development impact. Given the importance of the building sector in climate and energy challenges in the region, ADB Ventures organized the Building Energy Challenge 2020 in partnership with the New Energy Nexus. The Building Energy Challenge 2020 aims to introduce start-ups with innovative energy efficiency technologies for buildings to commercial property groups and energy-intensive corporate partners.

To enable potential commercial pilots and partnerships, ADB Ventures provides seed funding for the pilots and invests in some of the start-ups. Focus areas include low-cost cooling, energy management, façade solutions, and other building solutions such as smarter and more efficient building usage, which have the highest potential and impact on green business.

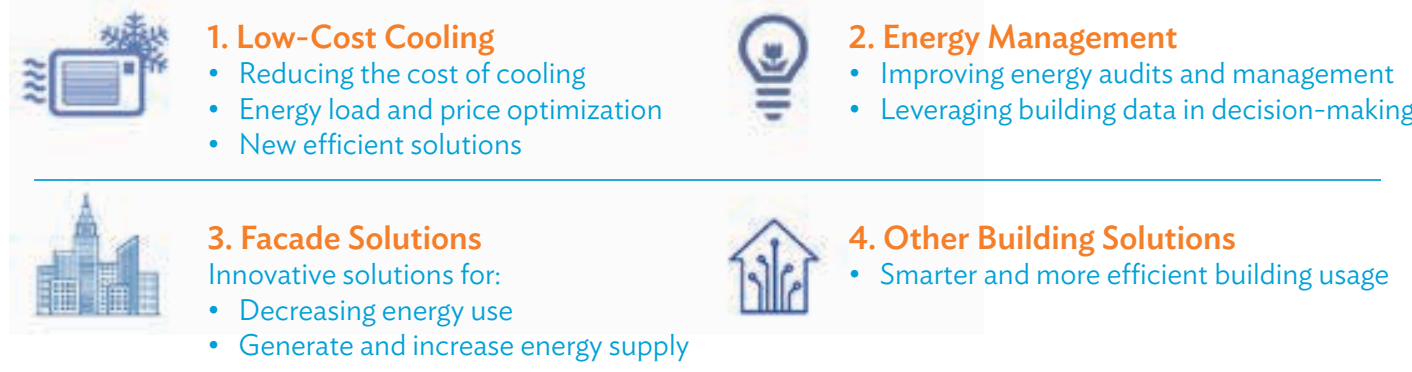

Sources: ADB Ventures. https://ventures.adb.org/; New Energy Nexus. Building Energy Challenge 2020. https://www.newenergynexus.com/program/building-energy-challenge/; GFSE. 2016. Private Sector Involvement in Sustainable Development: Green Buildings. https://www.gfse.at/fileadmin/files/Links/Publications/GFSE_PB2_Private_ Sector_Involvement_Green_Buildings.pdf.

In a developing country context, the catalytic role of public stakeholders should be fully utilized especially through "building it right" and helping expand private markets where the industry is still adherent to conventional building practices. Examples are retrofitting public buildings to ideally low energy consumption levels, and constructing public buildings or social housings that are energy-efficient and climate-resilient. Since the building sector is driven mainly by the private sector in most countries, creating the enabling environment for private investment, including financial, technical, and compliance mechanisms, is another leverage toward achieving energy efficiency.

Urban spatial and land use planning is an effective structural way the city authorities should harness. Apart from the energy used in buildings, an integrated approach to urban, energy, and transport planning enhances the overall energy efficiency of a city. The urban spatial structure comprising physical and functional parameters, is a key determinant of urban energy consumption. It influences residential patterns, demands for transport and mobility, and distribution of human activities. According to the research study of World Resources Institute (2019), the shift to net zero carbon buildings is more achievable when the intervention is expanded beyond the boundary of a building to allow the use of off-site clean energy or to have consideration across a portfolio of district or municipal buildings. 


\section{Box 7: Ulaanbaatar Green Affordable Housing}

The project aims to deliver 10,000 affordable green housing units and redevelop 100 hectares of ger areas into lowcarbon, climate-resilient, mixed-use, and mixed-income eco-districts. Ger areas are traditional and informal districts in Mongolia that often lack basic electricity, water, and waste infrastructure. International and local experiences show that a complete solution-integrating housing, infrastructure, urban development, and financing support to both the supply and demand sides - is the best way to create a paradigm shift to improve access to green affordable housing, and resilient and low-carbon urban development.

Green housing maximizes climate mitigation measures using resource-efficient and energy-efficient building technique and materials, renewable energy systems, and operation and maintenance that ensure building performance and occupational health. In terms of climate change adaptation, it is expected to reduce the vulnerability of ger area residents to harsh winter, flood events, hot summer, and soil pollution.

Sources: Asian Development Bank. Mongolia: Ulaanbaatar Green Affordable Housing and Resilient Urban Renewal Sector Project. https://www.adb.org/projects/49169-002/main.

An ADB project in Ulaanbaatar, Mongolia demonstrates the integrated actions adopted for highly climate-vulnerable expanding cities (Box 7). This case shows that renewable energy represents a low-carbon and climate-resilient energy solution for buildings and housings, and that it constitutes an integral part of sustainable urban development.

\section{Urban E-Mobility}

Transportation infrastructure is essential in enabling cities to function as places to live, work, and conduct business. The overall global transport sector consumes nearly $30 \%$ of all final energy demand and is responsible for $24 \%$ of direct $\mathrm{CO}_{2}$ emissions from fuel combustion (IEA 2019b). Road vehicles (cars, trucks, buses, two- and three-wheelers) account for nearly three-quarters of transport $\mathrm{CO}_{2}$ emissions (IEA 2020b). In addition to $\mathrm{CO}_{2}$ emissions, many of the vehicles used produce significant amounts of air pollution from the use of fossil fuels. This can be exacerbated by the lack of needed infrastructure and poor planning that results in major congestion, as well as the use of old and poorly maintained vehicles. While this article discusses aspects in transport related to the energy sector, a full discussion on e-mobility is covered in Article 2B.

An increasing number of transport modes within the urban context are being considered for electrification. Beyond light duty passenger vehicles and two- and three-wheelers, buses and services vehicles are all being considered in the global context. Local air pollution can be eliminated with electric vehicles, contributing to improved urban air quality. Since conventional power plants will still create GHG emissions when producing the electricity to power electric vehicles, the $\mathrm{CO}_{2}$ emissions from transport can only be fully mitigated with zero emission power generation. But, even with conventional power production using fossil fuels and with electricity systems having high emission factors, efficiency gains in electric vehicles can still result in GHG emission reductions (Figures 5 and 6 ). For example, it is estimated that with grid emission factors below 1.05 tons of $\mathrm{CO}_{2}$ per kilowatt-hour, a standard urban electric bus will produce less well-to-wheel emissions than a conventional fossil-fueled bus. 
The cost of imported transportation fuels can also lead to significant impacts on public finances for countries. Countries with clean indigenous power production can reduce the costs from importation of fuels and reduce GHG emissions by electrifying and using nationally produced power. This also provides the benefit of improving security of energy supply by being less dependent on imports. It is estimated that the global operational electric vehicle fleet has prevented the use of almost 29 million tonnes of oil equivalent (Mtoe) ( 0.6 million barrels per day) in 2019.

With the growth in deployment of electric vehicles, based on current projections, the amount of displaced fossil liquid fuel is expected to be between 120 Mtoe (2.5 million barrels per day) and 210 Mtoe (4.2 million barrels per day) of diesel and gasoline by 2030, depending on the scenario (IEA 2020c). Despite the potential benefits

Figure 5: Energy Usage for 12-Meter Bus

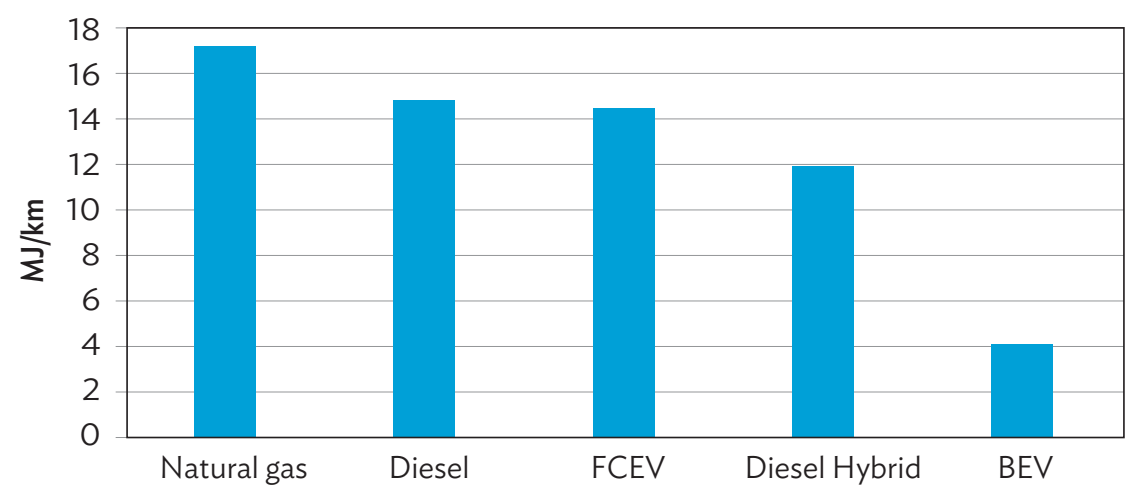

$\mathrm{BEV}=$ battery electric vehicle, $\mathrm{FCEV}=$ fuel cell electric vehicle, $\mathrm{MJ} / \mathrm{km}=$ megajoules per kilometer.

Source: Asian Development Bank. 2018. Sustainable Transport Solutions: Low-Carbon Business in the People's Republic of China. Manila. https://www.adb.org/publications/sustainable-transport-solutions-peoples-republic-china.

Figure 6: Benchmark Power Grid Factors That Result in Lower Electric Vehicle Carbon Dioxide Emissions

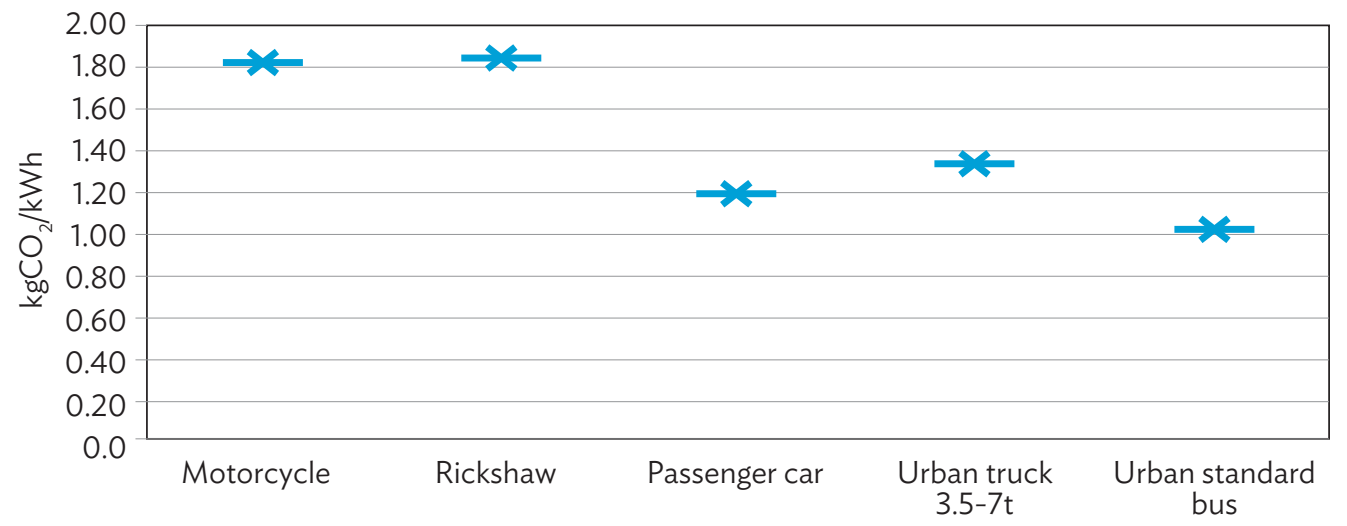

$\mathrm{kgCO}_{2} / \mathrm{kWh}=$ kilogram of carbon dioxide per kilowatt-hour, $\mathrm{t}=$ ton .

Note: In countries with a grid factor above this benchmark, electric vehicle usage increases carbon dioxide emissions.

Source: Asian Development Bank. 2019. E-Mobility Options for ADB Developing Member Countries. Manila. https://www.adb.org/publications/e-mobility-adb-developing-member-countries. 
that electrification of transport can provide to countries and the urban context, less than $10 \%$ of Nationally Determined Contributions as part of the Paris Agreement address this topic (Fransen et al. 2019). The growth of electric vehicles globally and the price reductions, especially in battery technology, are increasing the costeffectiveness of these solutions.

The increased use of electric vehicles and charging infrastructure will have significant impacts on the power grid, especially on the distribution grids in cities. The challenge for existing grids to accommodate this new load will depend on a number of factors. For developed economies, there is the possibility that energy efficiency measures across multiple electricity consumers will reduce the overall power demand in the future, or at least limit its growth. This means that the annual use of power for transport will be a beneficial additional load to power system actors and will maintain or increase the value of the system.

Alternatively, in developing economies, the per capita electricity demand is quite low. With increased economic development, electricity demand per person is expected to rise, especially with the projected increased demand in air conditioning in both residential and commercial sectors. In this context, it is expected that the upgrading of distribution systems will be needed to enable electric vehicle deployment (Box 8). For new distribution systems, upfront planning for electric vehicle usage will need to be considered in the design phase.

In all cases, it is important to manage the charging of electric vehicles to limit the peak demand on the distribution grid. There are three main factors that influence the impact on peak demand from electric vehicles: the number of vehicles charging, the size of respective charges, and the time of the charging relative to other demands on the system. ${ }^{10}$ In an unmanaged charging situation, the charging schedule for light-duty passenger vehicles may follow a cycle where charging will begin after the work day when people return from work. The typical peak period for power demand in the residential sector is when people turn on their cooling or heating systems, and when they begin to cook and/or use electricity for other needs.

The charging in this case can be managed through a range of approaches. Time-of-use tariffs combined with timers can encourage electric vehicle users to charge their vehicle at night during off-peak periods that will not stress the power system. Advanced systems in a smart distribution grid could respond to market signals when there is lower demand on the system or excess renewable power generation available to charge the electric vehicles (Box 9). If vehicle-to-grid approaches are employed, the electric vehicles could also send power back to the grid, providing voltage or frequency support or balancing supply and demand when numerous vehicles are aggregated to make a substantial contribution. In this context, electric vehicles could move from being a load on the distribution grid, to being a resource for power and operational support.

\section{Smart and Energy-Efficient Street Lighting}

Street lighting is a citywide key public service. Improved lighting infrastructure is much appreciated by citizens as it considerably enhances the safety of residents at night, beautifies public spaces, promotes economic activities and tourism, and therefore increases the overall attractiveness and livability of cities.

10 Level 1 chargers that have a capacity typically under 2 kilowatts $(\mathrm{kW})$ are not expected to cause problems, but level 2 chargers can have capacities of up to nearly $20 \mathrm{~kW}$, equal to the peak size of a connection to a small house in North America. Direct current charges can have much higher capacities and will typically have dedicated feeders. 


\section{Box 8: Successful Operation of Electric Bus Fleet in Kolkata, India}

The city of Kolkata has more than 900 bus routes, of which 348 are operated by the city (the other routes are operated by private operators). There are more than 1,550 buses of various makes and models. Buses make up the highest amount of pollution compared to other forms of transport, primarily due to the age of the existing diesel fleet. As part of a pilot project, the city procured 80 buses through the Faster Adoption and Manufacturing of (Hybrid \&) Electric Vehicles (FAME) initiative under a cost-sharing scheme. The Government of India provided $60 \%$ of the funding and the state governments shared $40 \%$ for the buses and associated infrastructure.

The 80 buses were integrated successfully but they had faced some challenges. The charging infrastructure experienced frequent tripping of chargers and grid synchronization issues during the initial phases (up to 4 to 5 months); however, these issues were rectified through software reconfigurations. Regular monitoring of bus charging and impact on the local distribution grid was needed. Accordingly, it was also essential to monitor and analyze the power quality parameters for e-bus chargers on a regular interval to ensure proper functioning of the electric grids. While the initial 80 buses could be accommodated within the existing routes and bus depot infrastructure, a significant scale-up would require a much larger space to accommodate charging infrastructure.

Despite some challenges, the project demonstrated the potential of electric buses in Kolkata. The strength and capability of the power distribution system will be an important consideration for scale-up. Strengthening the distribution system and reducing the carbon content of the grid power will ensure that electric buses can meet the transport objectives reliably, while significantly reducing greenhouse gas and air pollution impacts.

Source: The Energy and Resources Institute. 2020. Successful Operation of Electric Bus Fleet: A Case Study of Kolkata. New Delhi. https://iea.blob.core.windows.net/assets/db408b53-276c-47d6-8b05-52e53b1208e1/e-bus-case-studyTERI-Kolkata.pdf.

\section{Box 9: Electric Vehicle Provision of Power System Ancillary Services in Delaware, United States}

PJM, a region transmission organization that is part of the Eastern Interconnection electric transmission grid in the United States, has been exploring vehicle-to-grid technology (V2G) since 2007. In a pilot project together with the University of Delaware, they demonstrated the capability of an electric car to respond to signals from the grid operator to provide electricity to the grid (also known as V2G).

Currently, the pilot is demonstrating the potential for electric vehicles to act as mobile storage devices that provide services to the wholesale market and PJM. Based on signals from the PJM control room used to stabilize the power grid, the cars can both charge and discharge, and earn revenue, similar to a generation asset. The V2G-enabled cars charge and discharge in response to the PJM frequency regulation signal and can earn approximately $\$ 100$ per month per car for their services.

PJM and BMW North America explored electric vehicle interaction with wholesale electricity pricing signals, and vehicle owner battery-charging habits. Managing electric vehicle charging based on pricing signals, either wholesale or dynamic retail rates, not only ensures vehicles are charged when the grid is less stressed, but also reduces the already low fuel costs of plug-in vehicles.

Source: Partnerships Advancing Electric Vehicle Technology. https://learn.pjm.com/energy-innovations/plug-in-electric.aspx. 
It is also one of the most expensive responsibilities of a municipality. It can account for up to $38 \%$ of energy consumption and GHG emissions in some cities. For example, in India, public lighting accounts for more than $1 \%$ of the total national energy consumption; in particular, street lighting has the savings potential of more than $60 \%{ }^{11}$

It is widely perceived that energy efficiency in street lighting is a relatively easy, noncritical, and fast path to implement as a low-hanging fruit. However, in most developing countries, switching into more energy-efficient lighting technology at scale is slow or only on a small-scale pilot basis. According to an ADB pilot project in Indonesia, the greatest challenge was its high initial capital cost and the requirement for governments to procure the lowest upfront cost products, which result in the purchase and use of older and less-efficient technologies (ADB 2017). The lack of knowledge, standards, testing facilities, and measurement equipment applicable to the new energy-efficient lighting proved to be another important barrier.

Apart from the lack of public funds, options for private financing are generally limited. In the case of Viet Nam, there have been multiple initiatives from cities that still use outdated and inefficient technologies, including sodium lamps, mercury vapor, and fluorescent lamps. The efforts of moving to a more energy-efficient and environment-friendly lighting system, however, have been delayed due to the complexity of options.

The government's capacity and experience to determine the right contract or organize the appropriate public-private partnership bidding process was an important challenge for such a sector where the payback period is long due to high equipment costs and low electricity tariffs. Only a few projects in Ha Noi, Da Nang, and Ho Chi Minh City have the public lighting system using light-emitting diodes (LED) at scale (Box 10). The use of LED lamps represents only less than 1\% of total lighting across the country (IEEE 2019).

In terms of new lighting technologies, LED lighting is the latest technological advancement worldwide. The use of LED lighting has been growing across a wide range of applications. ${ }^{12}$ LED is by far the most energy-efficient among the existing lighting technologies. A pilot street lighting project in selected municipalities in Indonesia demonstrated reductions in the peak electricity demand of up to 59\% through streetlamp retrofits using LED. In Copenhagen, the installation of 20,000 connected LED streetlights resulted in energy savings of $65 \%$, which is critical in achieving the city's ambition to become carbon-neutral by $2050 .{ }^{13}$

LED lighting also has important advantages other than energy efficiency, due to its great flexibility when combined with a variety of "smart" applications. Coupled with sensors installed, LED lighting can adapt to the time of night, detect movements by cars and pedestrians, and adjust lighting levels accordingly. The entire system can be automated, remotely monitored, and controlled through online applications. Overall, the smart LED lighting can provide considerable operation and maintenance savings, improved service, and reduced energy consumption. It can contribute to about $70 \%$ of electricity savings compared to a traditional fluorescent lighting system, and about $20 \%$ savings compared to a regular LED lighting system without smart applications.

Smart lighting systems, as a network of sensors, can interact with other smart devices. Communication between devices generate various real-time data including air pollution, temperature, traffic, parking, security and crimes, and other urban services, which can support decision-making by public and private stakeholders and citizens.

1 The Climate Group under the British High Commission supported the project on LED street lighting. The Climate Group. 2015. Identifying Challenges in the Implementation of LED based Street Lighting System in Municipal Corporations. https://cdkn.org/wp-content/ uploads/2017/07/Up-LED-street-lighting-in-India-1.pdf.

12 Stouch Lighting. 15 Advantages of LED When Compared to Traditional Lighting Solutions. https://www.stouchlighting.com/blog/top-15advantages-of-led-lighting; Lifehack. Top Eight Benefits of Using Led Lights. https://www.lifehack.org/533944/top-8-benefits-using-led-lights.

13 Smart Citylab. Lighting the Road to Smart Cities and Sustainability. https://www.smartcitylab.com/blog/urban-environment/lighting-theroad-to-smart-cities-and-sustainability/. 


\section{Box 10: Challenges to Upscale Smart and Energy-Efficient Street Lighting in Viet Nam}

The Government of Viet Nam promotes smart and efficient lighting systems as a key instrument to meet energy efficiency targets and sustainability objectives, such as smart city development and green growth. The Viet Nam National Energy Efficiency Program identifies public lighting as one of the top five sectors that has the highest energy saving potential. Many provinces and cities, including Ha Noi City, stipulate smart and efficient street lighting system as a priority in their action plans.

Every year, Ha Noi City spends about $\$ 5.4$ million for electricity and $\$ 5.6$ million for expansion, operation, and maintenance of its street lighting system. In 2013, the city prepared a street lighting project of $\$ 140$ million to retrofit old lamps with light-emitting diodes (LEDs) and smart components, expand serviced areas, and beautify parks and bridges with LED lamps. It did not materialize, however, due to lack of public funds and difficulties in attracting private sector investors. The use of an energy savings performance contracting approach also encountered obstacles because there were no specific regulations or clear guidance for energy service company (ESCO) business operations and for energy performance contracting or asset management in Viet Nam.

Some of the key challenges include perceived high risk of energy efficiency projects, unfamiliarity with technologies, high upfront capital costs, and lack of suitable financing models. Capacity and awareness building are necessary for all the stakeholders concerned including government policy makers and practitioners, and the energy efficiency industries such as ESCOs and the banking sector.

Source: Asian Development Bank. Southeast Asia Energy Sector Development, Investment Planning and Capacity Building Facility. https://www.adb.org/projects/52096-001/main.

This is why connected LED street lighting is considered as "a foundation for a smart city" and "should be the first step" to realize the vision of smart city development.

Implementing a full-scale smart street lighting represents challenges for many of the developing countries where smart city concepts are still at early stage of development. In the short and medium term, there are several issues to be addressed that are largely related to the nature and scale of innovation in the street lighting sector, such as the following:

- What are the main objectives for rolling out available technologies?

- How to deal with social demands and challenges at the same time?

- How to make a successful pilot as an effective entry point?

- How to manage the key risks inherent to public procurement to integrate new and evolving technologies?

- How to build new operating business models and technical specifications?

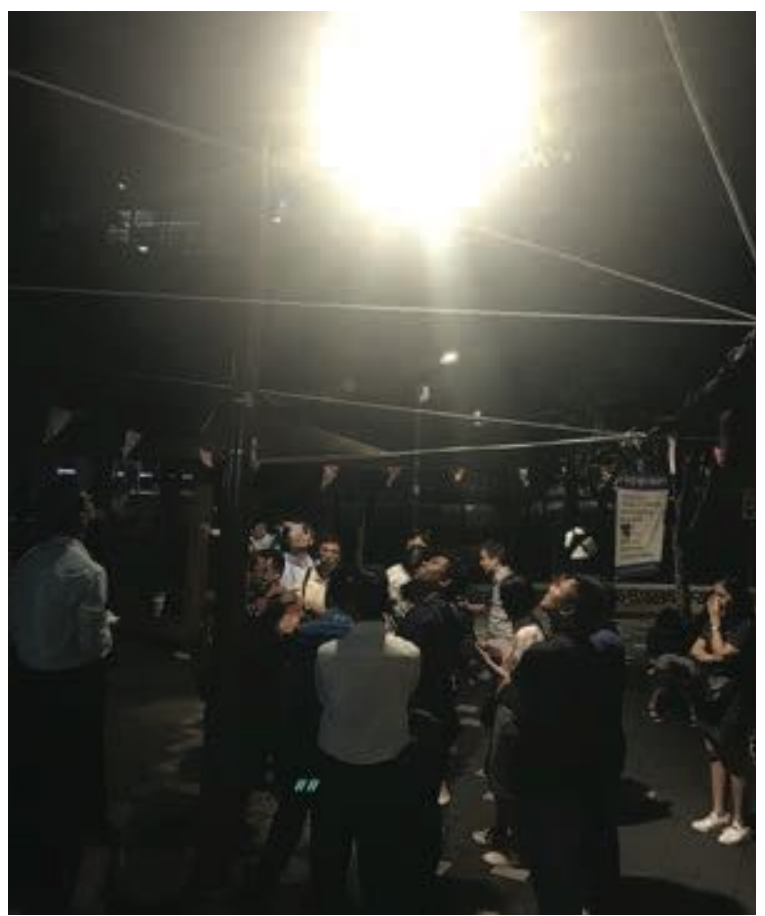

Seoul's LED street lighting. LED lighting is energy-efficient, brighter, and environment-friendly (photo by Okju Jeong/ADB). 
The solutions to these issues within the lighting sector can be applied to other areas in the urban context. They can help build a long-term vision and actions as an integral part of sustainable and smart urban development.

\section{Conclusion and Recommendations}

The development of sustainable energy systems in the urban context has far-reaching benefits for societies. Significantly lowering pollution while delivering essential services (e.g., potable water and transportation) and providing comfort in both residential and commercial spaces are just a few examples of the enabling value of energy in the urban context.

Sustainable urban energy systems are a key enabler to making cities more livable. They can significantly contribute to the collective efforts of reducing carbon emissions to meet targets under SDG 7 and the Paris Agreement. As cities evolve and develop, given their limited resources, it is essential to balance individual interventions, while looking for synergies across energy supply and demand and other sectors such as waste management, building construction, and transport.

Gradual retrofitting of existing urban areas and optimizing energy supply and demand for newly expanded urban areas from the onset of development need to go hand in hand to improve overall urban energy efficiency. In reality, dealing with this two fold approach is challenging because of the accelerating speed and scale of urbanization in most developing countries. Although resources are limited, urban stakeholders must find ways to make progress.

This article highlights the potential and importance of overarching efforts across city-scale energy planning, ICT, and various energy technologies. The specific energy solutions presented include distributed renewable energy, smart distribution grids, energy efficiency in buildings, e-mobility, and smart street lighting. This article also demonstrates how energy solutions can help cities shift to a higher efficiency and lower carbon energy system while coping with increased energy demand from growing urban centers.

The following are the overarching reflections and key directions for decision makers:

- A wide range of technological options are already available for the transition to clean and low-carbon urban energy systems (as shown by the case studies presented in this article). Cities can be brought closer to net zero by using technologies and adopting practices that are already technically and commercially feasible. Low-carbon measures have the potential to cut emissions from key urban sectors by almost $90 \%$ by 2050 . Such measures also offer financial benefits by generating annual savings worth $\$ 2.80$ trillion in 2030 - while the required investments would be only $\$ 1.83$ trillion (about $2 \%$ of global GDP) per year..$^{14}$

- As many low-carbon technologies are decreasing in cost and improving in capability, there is now a compelling case for cities to make progress by deploying clean energy solutions, learning by doing, and evaluating best practices internationally to adjust strategies as new approaches and technologies become viable. In particular, a successful pilot will serve as an effective entry point and will motivate

14 Coalition for Urban Transitions. 2019. Urban Climate Emergency, Urban Opportunity. https://urbantransitions.global/wp-content/ uploads/2019/09/Climate-Emergency-Urban-Opportunity-report.pdf. 
innovation. It can considerably facilitate further uptake of innovative and unproven technologies by providing lessons and testing regulatory and business models for investments.

- Harnessing and scaling up those technologies will require a combination of tailored solutions and sustained effort. Tapping into new technologies involves strategic planning and practical solutions, which can balance short-term requirements for meeting immediate energy need, and long-term imperative that is consistent with low-carbon pathways to meet global commitments such as the Paris Agreement. Such a complexity reinforces the need for locally optimized solutions, for which stakeholders are conscious about their development context, capacity, and implementation needs when setting the goals and prioritizing key actions.

- The potential of a single energy solution can be maximized when it is implemented as a part of an integrated systems approach. Integration with other technologies and sectors (i.e., distributed energy production with eco-development design or increased low-carbon power generation together with electric vehicle deployments) will expedite the transition of the entire energy system. It will also help take advantage of available synergies and better manage trade-offs among different technological solutions. The critical role of smart digital technologies needs to expand as a key enabler of synergies across sectors. Enhancements in energy generation, distribution, storage, and use can be optimally integrated and managed involving digital technologies to facilitate the shift to modern energy infrastructures. ${ }^{15}$

- The concept of integration builds on interconnection, which goes beyond energy goals. Low-carbon energy solutions are inherently crosscutting and closely linked to environmental sustainability and to the use of broader urban resources, such as water. They also contribute to social and economic development objectives that address issues of inclusiveness, air quality, urban health, urban wealth, and competitiveness. For example, the rapid emergence of renewable energy has a job creation effect, which can be a leverage toward urban development. According to a study, global jobs in the power sector can rise from 21 million in 2015 to 35 million in 2050 (Ram et al. 2020). Despite the remarkable economic growth in Asia, there are still millions of people living in urban slums and informal settlements in the region who lack access to affordable, reliable, and clean energy, in particular, electricity. Providing affordable, reliable, and clean electricity to those living in urban slums and vulnerable people in cities is not only crucial to reducing poverty, but also to achieving broader development goals such as job creation, education, and improving air quality. Strategic energy planning and implementation will require significant focus to deliver both near-term and future value for sustainable urban development. Decision makers should look across sectors and prioritize options which can create broader development benefits.

- Integrated urban energy system requires a new energy governance and institutions that build on partnerships and interconnectivity. Traditionally and vertically integrated utilities may need to unbundle and allow private investments if they are to grow and change at the pace demanded by the economy and society. Power systems, particularly at the distribution level, need to transform and modernize to meet the new demand for cooling, e-mobility, and eventually the Internet of Things (ADB 2020b). The combination of top-down and bottom-up approaches, decentralized energy governance, and effective collaboration between public and private stakeholders are key to modernizing urban energy governance.

15 Smart Energy Systems Overview. https://www.frontiersin.org/research-topics/15554/smart-energy-systems. 


\section{References}

American Council for an Energy-Efficient Economy (ACEEE). n.d. Energy Efficiency Policies for Local Governments. https://www.aceee.org/files/pdf/fact-sheet/local-govt-ee-policy.pdf.

Asian Development Bank (ADB). 2013. Same Energy, More Power: Accelerating Energy Efficiency in Asia. Manila. https://www.adb.org/publications/energy-efficiency-asia-untapped-resource.

- - - 2017. LED Street Lighting Best Practices: Lessons Learned from the Pilot LED Municipal Streetlight and PLN Substation Retrofit Project (Pilot LED Project) in Indonesia. https:/www.adb.org/publications/led-lighting-bestpractices-indonesia.

- - . 2020a. Key Indicators for Asia and the Pacific. Manila. https://www.adb.org/sites/default/files/ publication/632971/ki2020.pdf.

- - 2020b. ADB Energy Policy and Program, 2009-2019. Manila. https://www.adb.org/documents/sectorwide-evaluation-adb-2009-energy-policy-and-program-2009-2018.

- - - India: Visakhapatnam-Chennai Industrial Corridor Development Program, Project 1. https://www.adb.org/ projects/48434-003/main\#project-overview.

C40 Cities. 2012. Why Cities? Ending Climate Change Begins in the City. https://www.c40.org/ending-climatechange-begins-in-the-city?fbclid=IwAR18Sy2T2ZM9OY6E_rT_lk4ZnsSIRw3119q3tCgTtPgS3b7n-_iUrGPXiUU.

C40 Cities Climate Leadership Group and Global Covenant of Mayors. 2018. Summary for Urban Policy Makers: What the IPCC Special Report on Global Warming of $1.5^{\circ} \mathrm{C}$ Means for Cities. https://www.ccacoalition.org/en/ resources/summary-urban-policy-makers-what-ipcc-special-report-global-warming-15\%C2\%B0c-means-cities.

Fransen, T. et al. 2019. Enhancing NDCs: Opportunities for Transport. Working Paper. Washington, DC: World Resources Institute. www.wri.org/publication/enhancing-ndcs-transport.

Institute of Electrical and Electronics Engineers. 2019. Development and Implementation of Smart Street Lighting System based on Lora Technology. https://ieeexplore.ieee.org/abstract/document/8921028.

International Energy Agency (IEA). 2016. Energy Technology Perspectives. Paris. https://www.iea.org/reports/ energy-technology-perspectives-2016.

- - . 2018. The Future of Cooling. Paris. https://www.iea.org/reports/the-future-of-cooling.

-_- 2019a. The Future of Cooling in Southeast Asia. Paris. https://www.iea.org/reports/the-future-of-coolingin-southeast-asia.

-——. 2019b. World Energy Outlook 2019. Paris. https://www.iea.org/reports/world-energy-outlook-2019.

-_- 2020a. Tracking Buildings 2020. https://www.iea.org/reports/tracking-buildings-2020.

-_- 2020b. Tracking Transport 2020. Paris. https://www.iea.org/reports/tracking-transport-2020. 
-—-.2020c. Global EV Outlook 2020. Paris. https://www.iea.org/reports/global-ev-outlook-2020.

International Renewable Energy Agency. 2020. Rise of Renewables in Cities: Energy Solutions for the Urban Future. Abu Dhabi.

Madrigal, M., R. Uluski, and K. M. Gaba . 2017. Practical Guidance for Defining a Smart Grid Modernization Strategy: The Case of Distribution. Revised Edition. World Bank Studies. Washington, DC: World Bank.

Ram, M. et al. 2020. Job Creation During the Global Energy Transition Towards 100\% Renewable Power System by 2050 in Technological Forecasting and Social Change. p. 151. https:/www.sciencedirect.com/science/article/ pii/S0040162518314112.

United Nations Environment Programme, Global Alliance for Buildings and Construction, and International Energy Agency. 2019. Global Status Report for Buildings and Construction: Towards a Zero-Emission, Efficient and Resilient Buildings and Construction Sector. https://www.worldgbc.org/sites/default/files/2019\%20Global\%20 Status\%20Report\%20for\%20Buildings\%20and\%20Construction.pdf.

World Bank. 2012. Energizing Green Cities in Southeast Asia: Three City Synthesis Report. Washington, DC.

World Resources Institute. 2019, Accelerating Building Decarbonization: Eight Attainable Polity Pathways to Net Zero Carbon Building for All. Working Paper. https://www.wri.org/publication/accelerating-buildingdecarbonization. 


\title{
The Role of Microgrids in 21st Century Urban Development
}

\author{
Susumu Yoneoka and Dan Millison
}

\section{Introduction}

Cities are centers of work and play. Regardless of geographic size, shape, location, and population, cities are hubs of trade, finance, and culture. With the rapid growth of urbanization around the world, cities will continue to use huge amounts of energy and other resources, which yield greenhouse gases (GHGs) and other harmful pollutants. The built environment, which includes urban areas, accounts for two-thirds to three-fourths of global resource consumption and pollutant emissions, including GHGs, the primary source of global warming.

As rural-to-urban migration continues, sustainable cities will require sustainable energy systems. Reducing pollutant emissions and decarbonization requires more flexible, resilient, and efficient energy systems which allow people in cities to work, play, and grow without harming the environment. It will also minimize the health costs as much as at present. Sustainable energy requires high-value urban energy interventions, such as managing distributed renewable generation on distribution lines, developing energy-efficient buildings ("green" buildings), reducing petroleum fuels for urban transport to reduce street-level pollution, and recovering waste from municipal waste management systems.

Since the 1900s, most cities around the world receive electricity supplies from large-scale electricity grids and centralized power plants. In the late 1800s, electricity distribution started off local and decentralized, with a patchwork of conventional microgrids operating across cities. The early microgrids were powered by coal, using design advances on existing heating systems, and were noisy and dirty. These microgrids were later integrated and centralized. With the advent of alternating current, long-distance transmission became possible and much larger power plants were built outside of urban areas. The urban microgrid model was largely abandoned.

However, recent innovations in distributed renewable generation, energy storage, energy-efficient controllable loads, and information and communication technology (ICT) can now help centralized systems become decentralized - a part of the process known as energy transition.

Microgrids are a critical innovation in helping realize flexible, resilient, and efficient decentralized systems. A microgrid is a localized group of interconnected loads and distributed energy resources within clearly defined electrical boundaries that act as a single controllable entity within a regional or a national electric grid (macrogrid). It can operate in "island" or isolated mode. Five broad categories of components are needed to build a functioning, grid-connected microgrid: local generation, energy storage, end-use loads, utility interconnection, and a microgrid control system. These must be carefully chosen to maintain a balance between supply and demand using intelligent controls. Achieving sustainability goals means that urban microgrids need to run primarily on renewable energy, with fossil fuel used for backup generation as a last resort. Figure 1 shows the general design concept and components of the 21 st century microgrids. 
Figure 1: Urban Microgrid Conceptual Design and Key Components

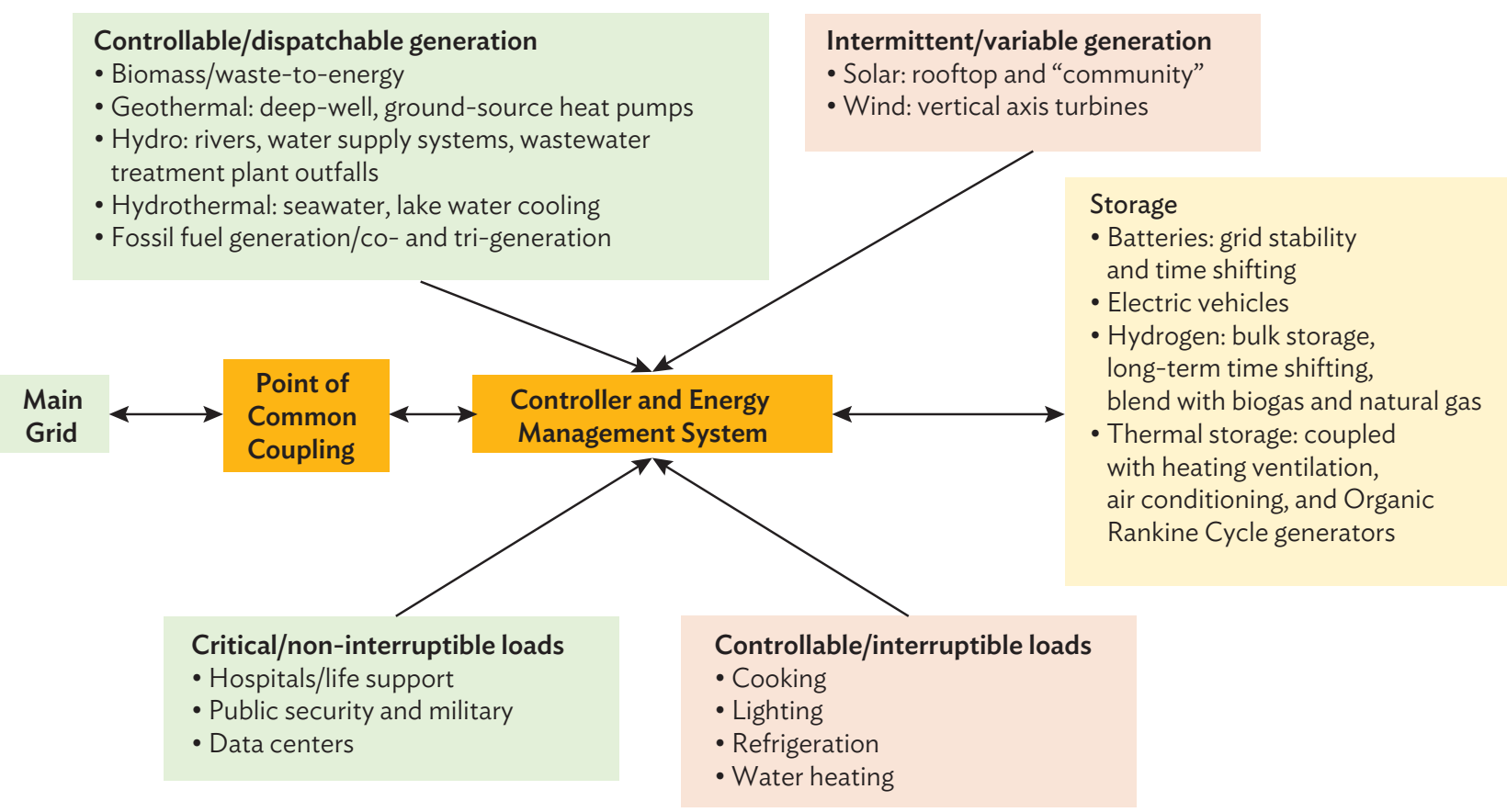

Source: ENEA Consulting. 2017. Urban Microgrids: Overview, Challenges, and Opportunities. https://www.enea-consulting.com/wpcontent/uploads/2017/02/Urban-Microgrids-Public-report_VF3.pdf.

A major challenge in urban microgrid design is matching renewable resources to end-use applications with appropriate energy technologies in a cost-effective system. Multiple renewable resources may be present in urban areas and everything should be considered at the conceptual design stage. A simple mnemonic is suggested for easy reference: "BiGSHOW" which stands for biomass (including waste), geothermal, solar, hydrogen, ocean, and wind. Solar and wind provide intermittent or variable output, while the other resources are controllable and coupled with BESS (battery energy storage system), which can provide firm and reliable power on demand. Biomass can be converted to biogas or pelletized and stored indefinitely.

Biogas can be used in internal combustion generation sets and biomass pellets can be used in conventional boiler-turbine plants, both of which can be configured for combined heat and power production. Geothermal energy is often overlooked in the urban context but can be harnessed for space heating and cooling using groundsource geothermal heat pumps. Deep-well, low-enthalpy reservoirs have been commercially deployed for district heating in Europe and the People's Republic of China (PRC).

Solar photovoltaic (PV) systems exhibit good load-following characteristics; rooftop solar is becoming popular to support afternoon peak demand (mainly from air-conditioning loads) and can be deployed over parking areas for electric vehicle charging. ${ }^{1}$ Cities in mountainous and hilly areas may have good hydropower resources. ${ }^{2}$ Lowhead hydropower can be installed at the outfalls of sewage treatment plants. Solar thermal systems can provide hot water for multiple uses, including space heating. Deep-water source cooling has been used in cities adjacent

Floating solar may also be viable in urban areas. Singapore is in early stages of deploying $50 \mathrm{MW}$ of floating solar on water supply reservoirs.

Many cities around the world were developed where hydropower was readily available to power mechanical mills. 
to large lakes and ocean coasts. ${ }^{3}$ Wind power has not gained much traction in urban areas, but new vertical-axis wind turbines are promising with respect to low-noise, low-vibration operations.

A second significant challenge for microgrids is the use of energy storage for "island" mode. Batteries are probably the most common option, but other technologies are rapidly evolving. The use of electric vehicles for storage are being considered, especially for microgrids at public transport facilities (e.g., airports).

Urban microgrids in developing countries can provide significant gains solely beyond providing energy access offered by remote off-grid minigrids. One key advantage that is often overlooked by policy makers is the reliability and resiliency of electricity supply that grid-connected microgrids can provide, especially for commercial and industrial applications, not to mention voltage and frequency regulation of power supply. Power outages are estimated to cost African countries 1\%-2\% of gross domestic product (GDP), with Tanzania taking the lead at 15\%. In Latin America, India, and several ASEAN countries, weak unreliable grids affect commercial and industrial companies, often resulting in excessive rental rates in enclaves for reliable backup, usually provided by expensive diesel generators.

Installing microgrids is also important as a disaster resilience strategy, particularly in developing countries in the context of increased risk of natural disasters due to climate change.

\section{Benefits of Microgrids}

In the urban context, microgrids are grid-connected setups of varying scales that can still generate electricity and provide reliable supply to end users, even if the connection to the main grid is cut off, a feature known as "islanded" or "isolated."

Most of the microgrids in the world today are serving consumers in non-utility or non-grid connected areas, such as remote islands and communities. In these applications, the microgrid provides a scaled-down version of services that the traditional electric utility would typically provide. However, in terms of the fast-expanding, grid-connected segment, there are traditionally three core value propositions for the end user. The exact combination of value drivers varies from case to case but is usually a combination of the following:

Reliability. The most common objective of a microgrid, especially in commerce and industry and other mission-critical sectors (e.g., health care services), is to be more reliable and resilient than the utility so that the energy end user continues to have uninterrupted service even during extreme circumstances (e.g., earthquakes, storms, or power grid outages from faults on the utility grid). The "high 9" applications, referring to the level of availability ranging from 99.9\% to $99.999 \%$, are usually in hospitals, data centers, military bases, and laboratories, among others.

For applications that require a high 9 level of reliability, the microgrid's cost is viewed as secondary to the purpose of maintaining energy supply to the facility even under extreme conditions. In such situations, the value of electricity may be several multiples of the capital and operating cost. Alternatively stated, the "sticker price" may be high but the delivered value makes the microgrid "cheap." In practice, reliability requires backup generation and/or energy storage, with storage often representing the largest additional cost of the system.

3 For example, the city of Toronto uses cold water from Lake Ontario for cooling in 3.7 million square meters of commercial building space. See Deep Water Source Cool. https://en.wikipedia.org/wiki/Deep_water_source_cool. 
Cost savings. Another objective for microgrids is to supply cheaper power than that from the utility. In this case, the microgrid produces and manages an energy supply with its internal generation and storage resources, to provide electricity at lesser (or at least competitive) cost compared to that which would be charged by the utility for similar service levels. A simple instance of this might be a customer-owned net metered solar PV system.

However, these are usually more sophisticated, especially if installed for providing cheaper electricity than the local utility. This is because achieving lower electricity cost needs cost-effective generation sources, demand-side management, ${ }^{4}$ and if possible, the trading of electricity as a "prosumer" at the microgrid point of common coupling to the utility. A prosumer is someone who consumes and produces a product, in this case electricity. When trading electricity, the microgrid may also have other types of generation like natural gas turbines or microturbines, as well as storage, to leverage time-of-use arbitrage opportunities that might be available with the grid.

Environmental benefits. Renewable energy is the fastest-growin resource for environmental and, increasingly, cost considerations (Lilienthal 2018). While renewable energy has been successful in reducing fossil fuel use for electricity generation, the intermittence and variability of sources like solar and wind limit the amount that can go into a system unless energy storage is deployed. ${ }^{5}$ Hence, many microgrids now include energy storage to integrate high penetrations of clean renewable power. Advanced distributed energy storage management, as well as demand-side management, potentially allows for not just the integration of higher amounts of renewable energy, but also for better reliability than what can be achieved via larger-scale centralized storage.

\section{Types, Design, and Operating Modes}

Microgrid configurations depend on their application and involve varying degrees of technological complexity and ownership structure (Figure 2). There are five key categories of interest, discussed in more detail below.

(i) Rural and remote microgrids. This segment accounts for the largest number of microgrids operating currently, but has the smallest average size. Remote microgrid communities are typically connected to the rural distribution system in weak grid areas where it is prohibitive to bring in new transmission lines for backup due to distance, cost, or physical barriers, such as mountainous terrain or islands. The main benefits of these microgrids include reliable energy supply and integration of low-carbon renewable energy, such as biomass, hydropower, solar PV, and wind power.

They can minimize fuel dependency, energy costs, and pollution. Many of the remote, off-grid microgrids were initially set up with only diesel generation and now are being "hybridized" with small-scale renewable generation. As they become larger, these remote microgrids start to experience operational constraints that can be alleviated by microgrid management and optimization techniques. Minigrids, which typically serve off-grid areas (as opposed to "weak grid" areas referred to in this category) are a subset of this category.

Demand-side management is the ability to control loads to optimize usage of generation resources.

Storage can take many forms. Microgrids have commonly utilized batteries which allow time-shifting of electricity output for a few days. Conversion of surplus electricity to hydrogen via electrolysis, then back to electricity via fuel cells, is gaining interest because hydrogen can be stored indefinitely. Electricity can also be "stored" by using it in productive, but interruptible applications such as ice making and water heating; the commercial viability of such applications is site-specific. 
Figure 2: Microgrids Classified by Technology Complexity and Ownership Structure

Technology Complexity

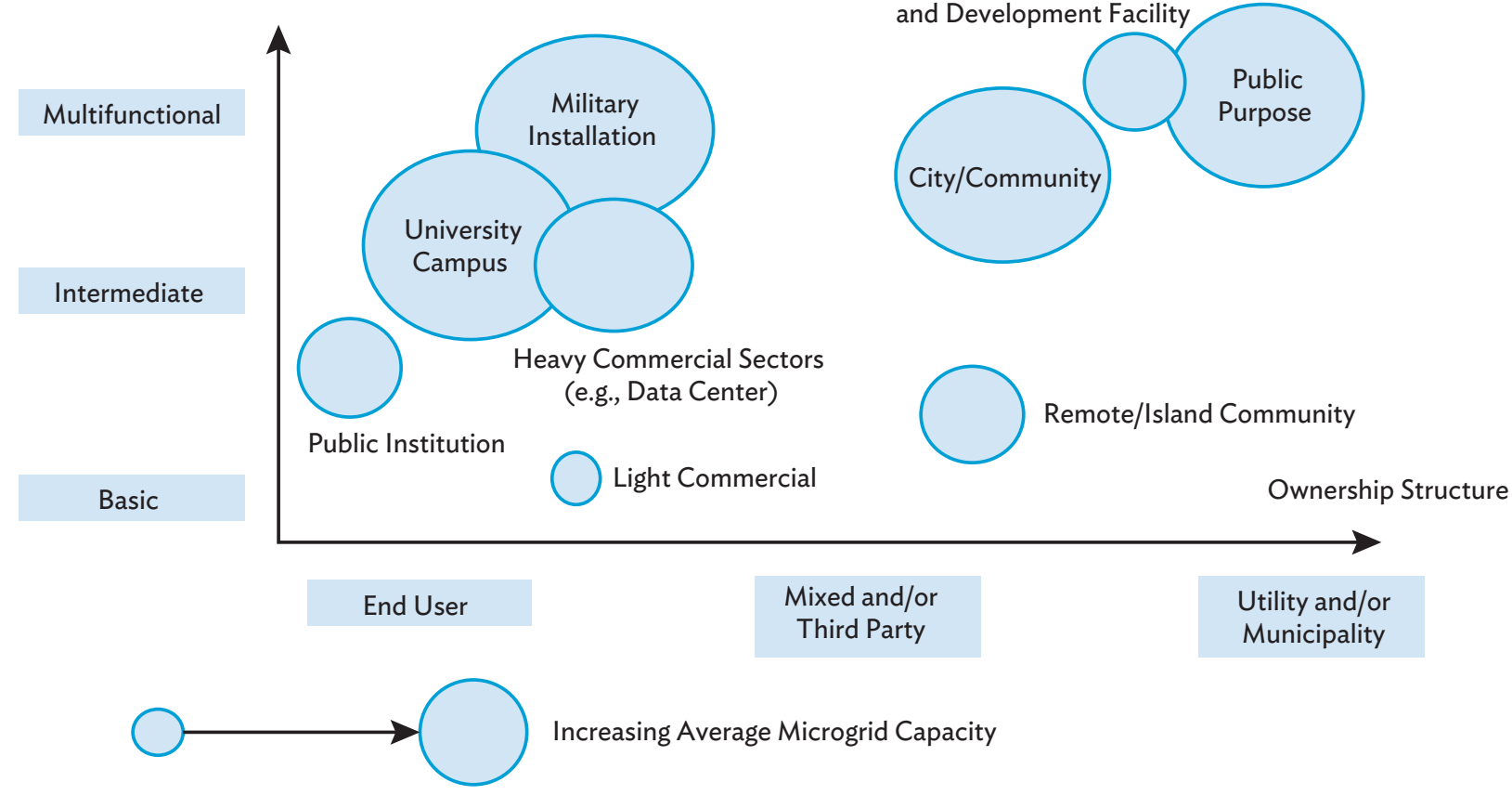

Source: GTM Research. 2016. U.S. Microgrid Tracker. https://microgridknowledge.com/us-microgrid-market-gtm/.

(ii) Commercial and industrial microgrids. These are either commercial centers or manufacturing zones with critical loads. These microgrids are often multi-owner, driven primarily by security and affordability, and are expected to grow substantially in the coming years. They are built to minimize costs by reducing energy consumption during normal operation and providing $24 / 7$ availability to insure against grid outages.

Shopping malls may be very good candidates for microgrids, if solar PV can be deployed on rooftops and over parking areas, with solar for electric vehicle charging, electric vehicles providing energy storage, and ground-source heat pumps supporting space heating and cooling. Industrial parks may also be good candidates depending on available renewable resources, such as process heat and waste-to-energy.

(iii) Community and city microgrids. These aim to improve the reliability of critical infrastructure and deferred asset investment, achieve emission and clean energy targets, and foster community engagement. This category comprises primarily residential customers and is driven mainly by the needs of affordability and security. However, to attain widespread commercial traction, additional standards need to be in place and certain regulatory barriers should be removed.

(iv) Campus and public institutional microgrids. This market segment offers good near-term development opportunity, and may have the best potential to develop sophisticated advanced microgrids. This market segment accounted for $40 \%$ of the United States' pipeline of microgrids, adding $940 \mathrm{MW}$ 
of new capacity valued at $\$ 2.76$ billion by 2015 (Devi and Babu 2017). Broadly, future growth is expected in two areas:

- Research laboratories and campus housing, which comprise large heating and cooling demands with good opportunities to reduce energy consumption, costs, and emissions. These facilities usually occupy large land areas and may also function as emergency shelters during extreme events such as cyclones, earthquakes, and forest fires. Many campuses already have distributed generation systems and controllable loads, so microgrid technology can be overlaid to link them together and enjoy the additional benefit of being able to sell excess power back to the grid.

- Public health and safety facilities, such as hospitals, police stations, fire stations, wastewater treatment plants, schools, and public transit systems, to improve reliability and lower energy consumption and cost. ${ }^{6}$

(v) Mission-critical microgrids. This is currently the smallest market segment, but is growing. Typical installations are for "high 9" applications such as data centers, hospitals, and military bases. Military microgrids focus on high reliability for mission-critical loads, strong cybersecurity, physical security requirement, "non-operationally ready" energy cost reduction, and GHG emission reduction goals at the operating bases. These installations generally present a strong case for integrating distributed renewable energy generation to secure energy services without depending on the grid or on any supplied fuel.

\section{Operating Modes}

There are two operating modes for a grid-connected microgrid. The normal operating mode is enabled when it is connected to the grid. However, when a power interruption or disturbance on the main grid takes place, the microgrid will be disconnected and shift to "island" or "isolated" mode. Whether planned or unplanned, the disconnection will not affect the microgrid's operation. These transitions, along with maintenance of system stability and fault detection, are the three critical aspects of proper microgrid operations.

From a project management perspective, the conceptualization, evaluation, design, construction, and commissioning of a microgrid follow the same broad stages as other infrastructure projects with similar stakeholders.

In the case of an existing facility or a brownfield microgrid, the pre-project evaluation begins with the assessment of current situation, followed by a high-level assessment for both brownfield and greenfield projects. The subsequent project feasibility study should consider applicable policy and regulatory frameworks, renewable energy resource assessment, assessment of site conditions and site selection, technical and financial viability, and financing structure. Microgrids can be designed for deployment in stages. For example, an airport system may start with rooftop solar only, then add vehicle-to-grid (V2G) systems for electric vehicle charging and energy storage.

6 Like shopping malls, airports are also good candidates for distributed renewable energy, where large areas are available for solar PV installation, and electric vehicle charging can be deployed. Several airports in India now use solar energy, although most of these may not yet be true microgrids. For example, the Cochin International Airport in the state of Kerala now hosts 80 MW of solar PV (rooftop and ground-mounted), which provides about twice the daily electricity demand. Excess solar is exported to the grid during the day, and electricity is imported from the grid at night under a net metering arrangement. See CIAL Solar Power Project via https://cial.aero; and https://en.wikipedia.org/wiki/CIAL_Solar_Power_Project, https://cial.aero/. 
Three case studies provide perspective on the challenges and benefits of developing and operating microgrids in urban areas. The Nagoya landfill microgrid illustrates a land area that is not suitable for construction can be utilized for renewable energy generation, in this case, with solar energy plus energy storage (Box 1). The Sendai Microgrid is one of the best examples of how microgrids can be effective sources of power supply in times of natural disasters (Box 2). The microgrid enjoys diverse power sources, being equipped with gas engines and solar PV with battery backup, allowing it to operate in an island mode following an outage. Meanwhile, microgrid deployment in developing countries has been mostly in remote areas which are unserved by centralized grids. Urban microgrid development has been quite limited in developing Asia, and one of the only documented cases is in the greater urban area of Delhi, India (Box 3).

\section{Box 1: Case Study-500-Kilowatt Microgrid at the Nagoya Landfill, Japan}

As described in the Microgrid Analysis and Case Studies Report by the California Energy Commission, the 2-acre host site is a landfill. As most types of construction were not possible on such a site, a microgrid installation was the most appropriate and efficient use of this land. In addition, with a tightly regulated electricity market, utilities and regulators in Japan were at the opposite ends of the spectrum - both had to cut dependence on fossil fuels and nuclear power plants on one hand, and encourage the uptake of renewable energy on the other. However, given the intermittent nature of renewable energy, it is difficult to integrate renewable power assets into the grid. With the Nagoya microgrid fulfilling both the needs of the utility - to have renewable energy and peak demand capacity provided by battery power - the additional element for project viability was the feed-in tariff (FIT).

The landfill microgrid facility in Nagoya, Japan has a 500-kilowatt (kW) solar generation unit and a $200 \mathrm{~kW}$ battery storage system. Developed by Optimal Power Solutions of Australia, the microgrid was built to enhance the value of the landfill for its owners (who also own the microgrid). With its 0.2-megawatt/1.2-megawatt-hour battery enabling long-duration dispatch of solar photovoltaic (PV) energy, this microgrid provides robust capacity to the grid during peak demand periods. In case of grid outage, the facility provides a resilient power source to serve local loads.

Since Japan had sought to reduce reliance on imported fossil fuels and phased out nuclear power plants, the distributed solar PV became a top priority for utilities and regulators. Given strong support for solar PV, a special FIT was agreed was agreed for installations such as these. Moreover, a one-directional inverter has been installed, since importing electricity from the grid was not allowed. During the peak net load periods, typically between 4 p.m. to 9 p.m., and sometimes as late as 2 a.m., the battery bank provides electricity to the grid. The battery bank is labeled with a rating of 6 hours, but can provide power for 8 to 10 hours.

Due to their low cost at the time of design, lead-acid batteries were chosen, but the project owners envision replacing the battery bank at the end of its life (approximately 6 years after initial commissioning) with lithium-ion batteries, given their rapidly falling prices.

Navigating through the intricacies of Japan's utility interconnection requirements was one of the biggest challenges for the developer and owners, given the nature of distributed energy resources and their high occurrence in Japan's grid.

The microgrid's additional key value propositions are renewable energy integration, resiliency, future transactive energy revenue, provision of energy and capacity services, provision of ancillary services, reduction of carbon footprint, and future linkage to virtual power plant.

Source: California Energy Commission. 2018. Microgrid Analysis and Case Studies Report. August. https://ww2.energy. ca.gov/2018publications/CEC-500-2018-022/CEC-500-2018-022.pdf. 


\section{Box 2: Case Study-The Sendai Microgrid in the Aftermath of the Tohoku Earthquake}

The Sendai microgrid was set up by the New Energy and Industrial Technology Development Organization (NEDO) under the Ministry of Economy, Trade, and Industry (METI) in Japan. It is located in the campus of Tohoku Fukushi University in Sendai City in Japan's Tohoku district. This microgrid was built to supply multiple power quality levels of alternating current (AC) as well as direct current (DC) power to various consumer loads at the same time.

The microgrid was completed in October 2006 and operated and monitored under NEDO supervision until 2008. After completion of the NEDO demonstration phase, some changes were made to the microgrid. Today, it continues to operate as a university-owned installation. The project was estimated to cost $\$ 25$ million (capital expenditures, operating expenditures, and monitoring costs) and was almost entirely funded by NEDO.

Following the 2011 Tohoku earthquake (also referred to as the Great East Japan Earthquake), the Sendai microgrid functioned successfully in island mode during a 2-day blackout. It provided uninterrupted DC power to sensitive loads in a local hospital as well as AC power to other loads. It successfully reconnected to the grid and continued to function until the natural gas supply was disrupted 2 weeks later due to further complications from the earthquake.

The Sendai Microgrid is one of the best examples of how microgrids can be effective sources of power supply in times of natural disasters. The microgrid enjoys diverse power sources, being equipped with gas engines and solar $\mathrm{PV}$ with battery backup up, allowing it to operate in island mode following the outage.

Sources: K. Hirose, J. T. Reilly, and H.Irie. 2013. The Sendai Microgrid Operational Experience in the Aftermath of the Tohoku Earthquake: A Case Study. NEDO. https://www.nedo.go.jp/content/100516763.pdf; J. Romankiewic et al. 2013. International Microgrid Assessment: Governance, Incentives, and Experience (IMAGINE). The European Council for an Energy-Efficient Economy's 2013 Summer Study on Energy Efficiency. European Council for an Energy-Efficient Economy. http://etapublications.lbl.gov/sites/default/files/imagine-eceee.pdf.

\section{Box 3: Case Study-Microgrid in Delhi, India}

Microgrid deployment in developing countries has been mostly in remote areas which are unserved by centralized grids. Urban microgrid development has been quite limited and one of the only such documented cases is in the greater urban area of Delhi, India. BSES Yamuna Power Ltd. (BYPL) is one of the three distribution companies (DISCOMs) serving the National Capital Territory of Delhi area.

BYPL has implemented four pilot microgrid installations on their premises, one of which has been the subject of detailed analysis (Tyagi et al. 2020). This case study is for a system installed at the BYPL business office consisting of a 7-kilowatt (kW) rooftop solar photovoltaic (PV) system coupled with a 10-kilowatt-hour (kWh) behind-themeter lithium-ion battery energy storage system (BESS); the connected load is $1.5 \mathrm{~kW}$. The case study covers the 2018-2019 period.

This microgrid is a good example of a developing country's urban context given the ongoing challenges of rapid electricity demand growth, variations in seasonal and daily electricity demand, severe urban air pollution, and national commitments to renewable energy expansion and energy efficiency. In the BYPL service area, the annual peak demand in 2018-2019 was 1,185 megawatts (MW), the minimum (baseload) demand was 289 MW, and average demand $827 \mathrm{MW}$. The maximum daily demand was 1,166 MW in the afternoon and at night, with minimum demand of $800 \mathrm{MW}$ in the morning. At the BYPLY microgrid, the annual peak demand was $1.2 \mathrm{~kW}$, minimum demand was $0.1 \mathrm{~kW}$, and average demand was $0.6 \mathrm{~kW}$ (vs. maximum connected load of $1.5 \mathrm{~kW}$ ). 
The BYPL microgrid arrangement is grid-interactive. The rooftop solar output can be fed into the grid, directly to consumers, and the BESS can be charged from the grid and can send power into the grid. The analysis covers four operational scenarios (which implicitly represent a phased deployment schedule) and cover impacts of microgrid operations from three different perspectives (impacts on consumer demand management, impacts on DISCOM revenue, and impacts on BYPL consumers); the analysis assumes that consumers pay for the microgrid system upfront (Tyagi et al. 2020).

Scenario 1: PV. This contains the rooftop PV system and excludes BESS, demonstrating the impact of the grid-connected PV system on the DISCOM.

Scenario 2: PV-BESS. This contains PV and BESS connected to the grid, with the restriction that the battery cannot charge on the grid and can only export stored electricity to the grid. Hence, this scenario illustrates the resiliency of the PV system in maintaining battery operations, the contribution of the BESS to the performance of the PV system, and the resulting impact on DISCOM operations.

Scenario 3: PV-BESS-Grid. This contains the PV system, BESS, and the grid, which work in synergy to meet consumer and DISCOM demand. The difference between Scenario 2 and Scenario 3 is that there is no restriction on battery and grid interaction. The battery can charge on both the PV system and grid. This scenario represents the actual configuration of the installed microgrids.

Scenario 4: Optimized PV-BESS-Grid. This is an optimized version of Scenario 3 which modeled the battery charge-discharge cycles as per the DISCOM load profile to achieve greater support from the microgrid. Other interactions from Scenario 3 remain unchanged.

Key observations on consumer demand management:

- The rooftop PV system had an annual capacity utilization factor of $18 \%$, with a maximum of $25 \%$ in summer and $12 \%$ in winter.

- More than $80 \%$ of solar output was self-consumed by the consumer, directly and via the battery.

- In the current configuration, on an annual basis, the battery only drew $1 \%$ of electricity from the grid (i.e., the BESS did not act as a load on the grid).

- The microgrid supported about $59 \%$ of consumer's annual demand, which is not unexpected, considering that the PV capacity of $7 \mathrm{~kW}$ is almost five times that of the $1.5 \mathrm{~kW}$ connected load.

Key observations about impacts on DISCOM revenuer:

- The DISCOM benefits the most in Scenario 4, gaining $\$ 0.0147 / \mathrm{kWh}(1.08 / \mathrm{kWh})$, in which the urban microgrid is optimized to reduce the overall peak demand of the DISCOM.

- Greater export of solar electricity to the grid during the DISCOM peak hours (70\% in Scenario 1 and $65 \%$ in Scenario 4) results in a net benefit to the DISCOM.

- Increased self-consumption of solar electricity by consumers (87\% in both Scenarios 2 and 3) results in a net loss to the DISCOM, as local peaks are different to and smaller than system peaks. The key conclusion is that using the microgrid to reduce local peaks does not significantly impact DISCOM operations, but does significantly affect DISCOM revenues.

Key observations on impacts of microgrids on consumers:

- The consumer benefits the most from directly consuming the solar electricity in Scenario 2, instead of a redirected use via the battery as in Scenarios 3 and 4. 
Box continued

- Earnings under the net metering regulation increase with the export of solar electricity to the grid and reduced self-consumption.

- Inclusion of the battery significantly increases the consumer's payback period. The maximum savings and shortest payback period are possible in Scenario 2 which does not include the battery.

- Prioritizing battery usage for grid support in Scenario 4 reduces consumer savings by $37 \%$.

Overall conclusions of the economic analyses:

- The benefit to the DISCOM increases by almost four times with battery storage. In Scenario 1, solar generation alone offers a net benefit of $\$ 0.0037 / \mathrm{kWh}$ (₹0.27/kWh), improving to $\$ 0.0147 / \mathrm{kWh}$ (₹1.08/kWh) in Scenario 4 with BESS optimized for grid application. This is achieved by scheduling electricity export during peak hours and battery charging during off-peak hours simultaneously through the grid and solar.

- Financial burden may be imposed on consumers. Under the assumed purchase model, including energy storage, prioritizing the export of solar electricity during the DISCOM's peak hours over self-consumption by consumers decreases consumer savings by $37 \%$, increasing the payback period of the microgrid investment to a little over 9 years.

- Urban microgrids can reduce DISCOM peak demand. Urban microgrids with energy storage can reduce peak demand by $21 \%$ of the rated solar PV capacity, as compared to $18 \%$ reduction without energy storage. This is achieved by prioritizing the export of solar electricity to the grid during peak hours and altering the consumption patterns of consumers. The export of solar electricity to the grid helps the DISCOM minimize power procurement costs, both from short-term purchases and variable components of scheduled procurements under long-term power purchase agreements. Savings from avoided power procurement costs represent $55 \%$ of the cumulative benefits to the DISCOM.

- Battery storage may yield a net loss to the DISCOM if not optimized for grid application. Energy storage brings additional benefit to DISCOMs by increasing solar export during DISCOM peaks. However, in the case of an afternoon DISCOM peak, using energy storage lowers the overall benefit due to a loss in battery efficiency.

- Enhanced self-sufficiency of consumers. Urban microgrids with battery storage significantly improve the self-sufficiency of consumers and reduce their grid dependence. Consumers can satisfy $66 \%$ of their total demand with storage, as compared to $59 \%$ with solar generation alone. The battery provides consumers the flexibility to store and later utilize solar electricity.

The case study indicates that proliferation of urban microgrids is contingent on various support policies and innovative market frameworks. Key recommendations include implementing the following:

- Regulatory provisions to support dispatch from behind-the-meter storage. The energy storage system of the microgrid is placed behind the meter in the consumer's premises and are grid-interactive (i.e., importing and exporting electricity from and to the grid). Many of the individual Indian states' regulations recognize such grid-interactive systems, but none explicitly mentions export from the battery to the grid. Therefore, regulations supporting dispatch from behind-the-meter storage would support urban microgrid deployment.

- Grid tariff for battery charging and export to the grid. Time-of-use/time-of-day tariffs for all consumer categories can be designed to incentivize consumers to export electricity to the grid during peak hours or charge batteries on the grid during off-peak hours.

- Redesigning the restrictions on the authorized PV capacity of urban microgrids. At present, most Indian states have restrictions on permissible installed PV capacity based on the authorized load. Solar generation from rooftop systems normally is not enough to meet consumer demand and restricts the utilization of solar energy for the DISCOM's benefit. The restrictions on authorized load could be revised in the case of urban microgrids, and they could be imposed on the overall export of solar power. Further, the time-of-day concept, based on the overall DISCOM load profile and seasonality, can also be used to restrict export of electricity. 
- New business models. The high upfront cost of batteries drastically increases the payback period for consumers, as compared to investing in a solar PV system alone. DISCOMs could develop new business models to ease the financial burden of microgrids on consumers. Such business models could include cost-sharing and leasing.

- Value-stacking the benefits. Urban microgrids offer numerous applications to DISCOMs. Battery discharge can be scheduled to suppor tload leveling (peak shaving), minimize short-term power procurement from expensive sources, or defer network upgrades. For each of these factors, systems need to be configured and sized depending on the local or overall load profile. DISCOMs should undertake multiple scenario analyses (as outlined above) to ensure the deployment of urban microgrids with optimal benefits.

- Strategic dispatch from the battery. In the BYPL case study, there is a conflict of interest between DISCOM and consumers in terms of the benefits derived from urban microgrids. Prioritizing self-consumption of solar electricity benefits consumers more than DISCOMs, which benefit from the maximization of solar export. Hence, a cautious choice needs to be made to optimally schedule dispatches from the battery, based on time-of-use/time-of-day tariffs, to benefit both stakeholders equitably.

Source: A. Tyagi, N. Kuldeep, and A. Dave. 2020. Are Urban Microgrids Economically Feasible? A Study of Delhi's Discom and Consumer Perspective for BYPL. Delhi, India: Council on Energy, Environment, and Water (CEEW).

\section{Challenges to Scaling Up Microgrids}

There are currently several potential barriers to scale up the implementation of microgrids, for which solutions are still evolving. Some of these challenges are discussed below.

\section{Limited Number of Scalable Prototype Installations and All-in-One Deployments}

- Most deployments are customized and incrementally installed with organic increase in need. Consequently, the conceptualization and design can be time-consuming relative to the value of energy services provided. This is compounded by the general lack of utility leadership in encouraging microgrids. A programmatic approach should consider standardized "grid-in-a-box" designs with plug-and-play architecture. A modular approach would allow factor mass production and some manufacturing economies of scale (especially for battery storage systems).

- Many microgrids are brownfield to the extent that existing generation and load assets need to be integrated. ${ }^{7}$ While this can help reduce upfront capital costs, it may place limitations on optimal design.

\section{Lack of Translatable Microgrid Performance Metrics}

- While installation-specific microgrid performance metrics are often documented, these may not be identical to the metrics at another installation due to customization and the uniqueness of each microgrid architecture and layout. Thus, they are not easily translatable across installations. Every microgrid business case has to, in a way, reinvent the wheel, build a first-principles business case (rather than rely on proven outcomes at other installations), and navigate the same early-adopter risks.

- Consequently, the building of effective business cases, which relies on streamlined documentation of quantitative and qualitative microgrid benefits, is hampered.

Brownfields are existing sites or assets which are redeveloped, rehabilitated, and/or expanded for new productive uses, typically with private investment. 


\section{Limited Microgrid Financing Models}

- Most of the current projects are end-user- or utility-financed with limited access to a third party, especially private capital, mainly because microgrid projects are often not bankable from a financier's perspective. This is due in large part to the lack of translatable performance metrics and the uncertainties associated with fully capturing the myriad of microgrid value streams and risks.

- To address these financing challenges, stakeholders will have to develop a programmatic approach toward microgrid financing, with clearly defined benchmarks and standards that will allow potential investors to compare the relative bankability of candidate projects. Ideally, microgrids will then develop into a distinct asset class from an investor's perspective, and the financiers in this arena will develop standardized processes to evaluate potential investments (Strahl et al. 2015).

\section{Restrictions from Utility Franchise Rights and Limited Retail Market Access}

- There is lack of regulatory familiarity as well as utility experience with microgrids. Therefore, understanding how to justify them as a grid asset can be challenging. Business case examples that clearly demonstrate value to both participants and nonparticipants from a regulatory perspective are limited. For example, there are limited instances of ability to quantify and value resilience.

- In an increasing number of cases, microgrids today are producers and consumers of electricity (prosumers), but in many cases they are still not fully integrated with utility generation, and sale of power to third parties using the utilities' transmission and distribution infrastructure (open access) infringes the latter's franchise rights. Regulations with specific open-access provisions will enhance the financial viability of microgrids.

\section{Cybersecurity Concerns}

- Security-sensitive applications in grid-connected operation are vulnerable in the absence of cybersecurity standards, architectures, and devices. Common points of vulnerability are wired, and wireless communications networks are used to control, monitor, repair, and reboot processes of the system or equipment within it. For example, the communications ports in smart home controllers, common in microgrids, are a weak link. While utility-scale grid management systems routinely scan for malicious elements trying to hack into the macrogrid, microgrid control systems need to achieve a similar standard of security on smaller budget with fewer equipment, sensors, and less analytics.

\section{Limited Standards and Interconnection Protocols}

- Given the large variety of processes in a microgrid, several standards are applicable to microgrids for different purposes. However, many microgrid function specifics are still not comprehensively covered in interconnection protocols, and enhancements are still being made.

\section{Technical and Operational Challenges}

- These include power quality (e.g., harmonics management, voltage and/or frequency control), grid synchronization, control strategies, control architecture, energy management, energy optimization, stability, protection protocols (e.g., during grid synchronization, transitions from island- to grid-connected operation modes), initial design process of the microgrid, and the additional skill sets required of the operators. 


\section{Policy and Regulatory Enablers}

Microgrid policies and regulations vary across Asia. Some countries, such as Japan, the PRC, and Thailand, have supportive policies and/or piloted programs for urban and industrial microgrids, whereas others have yet to introduce such policies. Several countries such as Bangladesh, Cambodia, India, Indonesia, Maldives, Myanmar, Nepal, and the Philippines have developed and implemented microgrid policies for increasing access to energy in off-grid areas.

Some of the key policy and regulatory enablers for urban and industrial microgrids are discussed below.

- Specific urban and industrial microgrid policy. A specially defined policy for urban and industrial microgrids would help facilitate private and public sector investments. This policy should clearly define the goals of deploying urban and industrial microgrids; provide technical specifications and standards; identify eligible consumers; and determine grid interconnection norms, tariffs, and licensing and documentation requirements. So far, only developed countries, such as Japan and the Republic of Korea, and upper middle-income countries such as the PRC and Thailand, have defined such policies or programs in Asia. Other developed countries such as the US and a few European countries have also defined such policies and programs.

- Net metering or gross metering policies. Net metering or gross metering policies enable microgrids to be connected to the national grid and allow the export of excess electricity to the grid. Such policies enable urban and industrial renewable energy-based microgrids to use the grid instead of relatively expensive energy storage solutions to increase their autonomy. This will also improve their economics by supplying excess electricity to the grid for economic considerations (net- or gross-metered). While net or gross metering for stand-alone, single-customer rooftop or ground-mounted solar installations are available in many developed and developing countries in Asia, these have not yet been defined for microgrids in most countries.

- Technical standards and specifications for grid interconnection. This would allow microgrids to be designed and planned according to specified technical standards; hence, grid interconnection technical design and costs can be managed more reasonably. While grid interconnection norms for stand-alone, single-customer rooftop or ground-mounted solar installations are available in many developed and developing countries in Asia, these have not yet been defined for microgrids in most countries.

- Open access or contestable consumer model. Open access policies and regulations allow electricity consumers - typically only large commercial and industrial consumers (known as contestable consumers) - to choose their electricity service provider, rather than being confined to purchasing electricity from a government-owned or regulated monopoly utility. Such contestable consumers are often served by open access developers or merchant power plants that develop and install these assets either remotely or locally (e.g., on-site rooftop solar or microgrid installations). The national grid transmission and distribution infrastructure is used to supply electricity. Countries such as India, the PRC, the Philippines, and Singapore have such regulations in place, whereas countries such as Viet Nam are in the process of introducing similar policies. Nevertheless, treatment of open access and/ or contestable consumers by on-site microgrids is still not defined in most countries of Asia, and such clarity would enable more microgrid investments.

- Simpler electricity generation and distribution licensing. In many countries, electricity generation and distribution are still highly regulated. Licensing involves complex documentation and approval processes for microgrid developers to obtain such licenses (in some countries, a microgrid might require separate licenses for generation and distribution). Simplifying these regulations would increase developers' interest in setting up microgrids. 
- Financial incentives and instruments. Life cycle costs, including the avoided costs of grid outages, make a compelling case for microgrid deployment (as noted in the Sendai microgrid case in Box 2). However, upfront capital costs may be a barrier to development, especially if battery storage is included. In the absence of standardized "microgrids in a box," there is no inherent manufacturing economy of scale for microgrids; although the costs of some components (i.e., smart meters, solar PV, and storage) may continue to decline with scaled-up deployment. It is generally possible to quantify the higher life cycle economic benefits of a microgrid investment; but in practice, it is difficult to monetize those benefits in the form of upfront project financing and deliver a microgrid which is revenue-neutral or revenue-positive to the owners and users. Financial incentives, such as tax benefits and feed-in tariffs, have been used widely for renewable energy development, but new instruments may be useful to accelerate microgrid investments. For example, a standby capacity payment that awards a microgrid owner for the ability to switch to island mode would partly monetize this public goods benefit provided by the microgrid. Considering the limited understanding and interest from commercial banks and lenders in many developing countries, risk-sharing mechanisms, such as credit guarantees or blended finance structures, could help microgrid developers raise debt finance at affordable interest rates for "first-mover" projects.

\section{Future Development}

\section{Decarbonization, Digitalization, and Decentralization}

Microgrids are poised to play a substantial role in the electricity ecosystem of the future that has decarbonization, digitalization, and decentralization (or collectively referred to as 3D) as key attributes. They could help address current energy challenges and provide an optimized way to access reliable, resilient, and clean energy. This sustainable energy can replace the need for specific equipment upgrades, such as new transmission lines or transformers, by reducing the load at the substation or circuit level.

At the same time, the strategic addition of high-voltage transmission connections should not be completely ignored. If renewable energy (especially intermittent renewable) is to become the backbone of the electricity system, several factors should also be considered. Renewable energy resources are found "as is, where is" which is not necessarily where the energy is needed. Land availability can be a constraint, with perceived conflicts over land use for energy or food production. It is possible to co-locate solar and agriculture (including via advanced solar-powered greenhouse agriculture). However, there is limited experience in co-locating solar and agriculture compared to co-locating wind and agriculture. As outlined in the introduction, the full spectrum of renewable resources (BiGSHOW) should be considered, and these resources should be matched to end-use applications using appropriate technologies. For example, seawater may be available for space cooling and geothermal energy for space heating, using heat pumps to move the thermal energy resource to the point of use.

As a holistic strategy, if the goal is to increase the renewable energy penetration in the grid, adding transmission capacity needs to be considered in the context of, and as a complement to, grid-edge investments in distribution networks and microgrids. Lastly, electrification of the transport sector will require grid augmentation, including additional transmission capacity. 


\section{Key Relevance to the Transportation Sector}

Urban microgrids can serve as key enablers for electrification of transport, since electric vehicles are in effect mobile storage units. Apart from the electricity supply sector itself, the electric vehicle transportation ecosystem is a foundational sector that deserves specific highlight, as this is an area where microgrids have an enormous transformational ability. This is partly because of the sheer size of the sector. Transportation worldwide consumes more than $30 \%$ of primary energy, and electrifying only a small percentage of transportation in the coming years would translate to a huge capacity.

To ensure adequate energy, new charging infrastructure will have to be installed on the utility grid in combination with grid-edge technologies, like distributed energy resources and energy storage. In cases where utility support might not be possible, microgrid infrastructure can fill the gap to enable charging stations to cater to the charging demand. In addition, a decentralized infrastructure will allow the many actors in the electric vehicle ecosystem to capitalize on the flexibility of electric vehicles. One promising way to do this is through "vehicle-to-grid" (V2G), wherein electric vehicles can sell demand-response services to the power grid, either by throttling their charging rate and/or returning power to the grid.

One of the fundamental impediments to growth of the electric vehicle ecosystem is the lack of better-aligned business models and pricing structure associated with the sale of electricity. This results in the paucity of readily available charging stations. The current electric vehicle charging infrastructure is only as clean or as "dirty" as the local grid mix, and new energy solutions, including renewable energy, energy storage, and microgrids, if integrated, can enable a more robust, widespread, and cleaner electric vehicle charging infrastructure.

To truly enable a vibrant electric vehicle ecosystem, a reliable charging infrastructure that microgrids can enable is something that needs to be widespread and readily available. In addition to workplaces and communities, electric vehicle charging stations will need to be developed in three key locations: at destination points, along highways, and near public transportation nodes like airports, bus, and train stations.

\section{Relevance of Microgrids to the Current Power System Situation in Developing Countries}

The current power system situation, in terms of both technology level and regulatory frameworks, varies significantly across developing countries. In general, end users in developing countries typically do not have access to high-quality, reliable power and must contend with frequent power outages, in contrast to their counterparts in developed countries. Developing countries also often have weak grid infrastructure due to underinvestment, poor management, and irrational electricity pricing. All these contribute to high power losses and theft, thereby hindering the success of business and industry and depriving people of a better quality of life. In developing countries, grid-connected microgrids offer the possibility of greater participation by consumers in energy services, including generation with rooftop solar and other distributed generation (prosumer). The lack of a level playing field in the provision of electricity is the reason why the indirect costs of the status quo outweigh the huge initial investment required to change it. Further, grid-connected microgrids are the building blocks of smart grids and smart supergrids, which have the potential to help developing countries leapfrog, by revolutionizing the power sector, similar to what the internet has done for information services. 


\section{Approaches to Promote Grid-Connected Microgrids and Replicate Pilots}

From a technology and application perspective, as developing countries develop from low-income to middleincome countries, the various drivers for microgrids are beginning to align with what is being seen in developed countries. Many of the drivers for microgrids in developing countries are similar to the motivations for operational microgrids in the US. This line of thought should guide the replication of microgrid pilots in developing countries, especially for grid-connected systems. The overall benefits can be maximized with the adoption of a high-level architecture that involves a "federation of microgrids," each solving as best as they can the needs of their own localized off-takers, but sharing and harmonizing what they can in a centralized fashion throughout the grid, which is often emerging or weak.

From a policy and regulatory standpoint, governments and policy makers in developing countries should aim to include microgrids (both on-grid and off-grid) in their power system planning and design. Specific policies and regulations to clarify microgrid as a distinct power asset class and their technical standards in terms of grid interconnection will go a long way in incentivizing microgrid investments. Pilot and demonstration microgrids have been installed in nearly all developing countries in Asia and the Pacific, although most of them are rural off-grid, with focus on energy access.

Only a few countries such as Japan, the Republic of Korea, the PRC, and the US have installed multiple on-grid pilot and/or demonstration microgrids. The installation of more of these systems in developing countries, funded by government and/or development capital, could also play an important role in demonstrating the role of microgrids in their future power systems. Clarity on tariffs, licensing, and permitting for microgrids would also be beneficial, while targeted concessional lines of credit and financial risk-sharing facilities from development financial institutions such as ADB would help increase access to finance.

\section{Transactive Energy}

Transactive energy can be described as an electricity ecosystem comprised of multiple participants (e.g., decentralized generators, loads, and storage) interacting with each other, with potentially competing goals and objectives. They are bound by a set of common economic and control mechanisms to facilitate a dynamic balance of supply and demand across the entire energy infrastructure using value as a key operational parameter. Transactive energy techniques may be localized to managing a specific geographical (e.g., microgrid), or functional (e.g., residential demand response for the utility grid) part of the power system. In addition, studies and pilots have also proposed transactive energy for managing end-to-end (generation to consumption) activity at the larger electric power system level.

With the increased proliferation of distributed energy resources, demand-side management, energy storage, and decentralized networks such as microgrids in the evolving smart grid, there is significant potential for reducing cost and increasing efficiency.

Resource utilization could also be improved through enabling market-based transactions between energy producers and consumers. 


\section{Internet of Things, Data Analytics, and Artificial Intelligence}

The Internet of Things (loT) is a large global dynamic network infrastructure of internet-enabled, always on, web services-enabled entities. Smart grid is an important application of loT, which along with data analytics and artificial intelligence, are ongoing research areas that have the potential to translate into significant incremental benefits for microgrid capabilities, resulting in a microgrid's techno-commercial viability.

Essentially, microgrids are composed of equipment that requires a huge amount of sensors, connectivity (both constituents of loT), and self-learning (attained via data analytics and artificial intelligence), to perform at its best. The type of data that could be gathered, analyzed, and acted upon, includes energy usage patterns, grid tariff rates, solar PV output, and weather predictions. Examples of applications wherein these data and capabilities could be used are the following:

- Improved fault detection, reliability, and resilience

$>$ Optimizing line voltage to minimize energy losses and line damage

$>\quad$ Locating the source of line sags, surges, and outages

$>$ Improving load balancing, restoring services faster, and making safer override decisions

$>$ Identifying the source of technical and nontechnical losses in the system, reducing the costs of service

$>\quad$ Lowering outage investigation times by isolating fault locations

$>$ Improving asset management, and preventive and predictive maintenance with artificial intelligence.

- Improved energy management

> Smart battery charging and discharging systems that use a self-learning algorithm with artificial intelligence to optimize performance

$>$ Improved demand-side management and demand response programs that incorporate artificial intelligence to deduce predicted market/customer behavior

$>$ Monitor distributed energy resources generation along with emissions, storage, and consumption, among others, and predict the electricity requirement

$>$ Integrate with electric vehicle management systems.

- $\quad$ Artificial Intelligence in microgrid controllers

$>$ Improved control, drawing on historical and real-time data from microgrid sensors, meters and other equipment, as well as from weather stations and weather data feeds.

\section{References}

California Energy Commission. 2018. Microgrid Analysis and Case Studies Report. August. https://ww2.energy. ca.gov/2018publications/CEC-500-2018-022/CEC-500-2018-022.pdf.

Devi, P. and M. Babu. 2017. Implementation of Proportional Power Sharing in Hierarchical Droop Control for Reactive Power Sharing in Microgrid. International Journal of Advanced Research in Electrical Electronics and Instrumentation Engineering. 6 (2). February. http://www.ijareeie.com/upload/2017/february/26_REACTIVE_ JOURNAL.pdf. 
ENEA Consulting. 2017. Urban Microgrids: Overview, Challenges, and Opportunities. https://www.enea-consulting. com/wpcontent/uploads/2017/02/Urban-Microgrids-Public-report_VF3.pdf.

GTM Research. 2016. U.S. Microgrid Tracker. https://microgridknowledge.com/us-microgrid-market-gtm/.

Hirose, K., J. T. Reilly, and H. Irie. 2013. The Sendai Microgrid Operational Experience in the Aftermath of the Tohoku Earthquake: A Case Study. NEDO. https://www.nedo.go.jp/content/100516763.pdf.

Lilienthal, P. 2018. Microgrid Value Propositions Revisited: Part One. Homer Microgrid News.

https://microgridnews.com/microgrid-value-propositions-revisited-part-one/.

Strahl, J., E. Paris, and L. Vogel. 2015. The Bankable Microgrid: Strategies for Financing On-Site Power Generation. December. Navigant Consulting. https://www.navigant.com/-/media/www/site/downloads/energy/2015/ powergen_bankablemicrogrid_dec2015.pdf.

Tyagi, A., N. Kuldeep, A. Dave. 2020. Are Urban Microgrids Economically Feasible? A Study of Delhi's Discom and Consumer Perspective for BYPL. Delhi, India: Council on Energy, Environment, and Water (CEEW).

\section{Further Readings}

ABB. n.d. GTM Microgrid Paper. https://library.e.abb.com/public/0356a68f668647599efce1d156ee6c7d/ GTM\%20Microgrid\%20paper_v4.docx.

ABB. 2017. Innovative Business Cases for the Deployment of Microgrids. State Energy Conference of North Carolina. https://d3n8a8pro7vhmx.cloudfront.net/rtcc/pages/44/attachments/original/1493135223/Microgrids_ Panel_Combined_Presentations.pdf?1493135223.

ABB. 2017. Microgrids Case Study: Longmeadow, South Africa. ttp://search.abb.com/library/Download.aspx?Docum entID=9AKK107045A3118\&LanguageCode=en\&DocumentPartld=LoRes\&Action=Launch .

Asian Development Bank (ADB). 2017. Deployment of Hybrid Renewable Energy Systems in Minigrids. Manila. https://www.adb.org/documents/deployment-hybrid-renewable-energy-minigrids.

- - - 2017. Developing Renewable Energy Mini-Grids in Myanmar: A Guidebook. Manila. https://www.adb.org/ sites/default/files/institutional-document/391606/developing-renewable-mini-grids-myanmar-guidebook.pdf.

- - - 2017. Improving Lives of Rural Communities Through Developing Small Hybrid Renewable Energy Systems. Manila. https://www.adb.org/documents/improving-lives-rural-communities-hybrid-renewable-energy.

-_- 2017. Microsoft Excel-Based Tool Kit for Planning Hybrid Energy Systems: A User Guide. Manila. https://www.adb.org/documents/microsoft-excel-based-tool-kit-hybrid-energy-systems-guide.

- - - 2018. Handbook on Battery Energy Storage System. Manila. https://www.adb.org/sites/default/files/ publication/479891/handbook-battery-energy-storage-system.pdf.

-_- 2019. Guidebook for Deploying Distributed Renewable Energy Systems: A Case Study on the Cobrador Hybrid Solar PVMini-Grid. Manila. https://www.adb.org/publications/deploying-distributed-renewable-energy-systemsguidebook. 
Anam, F., A. Sahito, and A. Shah. 2018. Comparison of AC and DC Microgrid Considering Solar-Wind Hybrid Renewable Energy System. Engineering Science and Technology International Research Journal. March. http://www.estirj.com/Volume.1/6Faiza21.pdf.

Arup. n.d. Five Minute Guide to Microgrids. https://www.arup.com/perspectives/publications/promotionalmaterials/ section/five-minute-guide-to-microgrids (accessed 28 September 2019).

Brattle Group. 2019. Additional Transmission Investment Needed to Cost-Effectively Support Growth of Electrification in North America. 8 March. https:/www.brattle.com/news-and-nowledge/news/ brattleeconomists-additional-transmission-investment-needed-to-cost-effectively-support-growth-ofelectrification-in-north-america.

Elizondo, L.R., ed. 2018. Solar Energy Integration of Photovoltaic Systems in Microgrids. TU Delft. https://ocw.tudelft.nl/courses/solar-energy-integration-photovoltaic-systems-microgrids/.

Faisal, M. and S. B. Islam. 2017. Planning, Operation, and Protection of Microgrids: An Overview. Energy Procedia. 107. February. pp. 94-100. https://doi.org/10.1016/j.egypro.2016.12.137.

George, S. and S. Chauhan. 2015. An Investigation into Centralized and Decentralized Micro-grid Systems with Synchronization Capability and Flywheel. International Journal of Enhanced Research in Science Technology \& Engineering. 4 (5). May. pp. 225-248. https://pdfs.semanticscholar.org/068b/ e24d624ddfe09e4043deeac2ea72c6655499.pdf.

Ghasempour, A. 2019. Internet of Things in Smart Grid: Architecture, Applications, Services, Key Technologies, and Challenges. Inventions. 4 (22). 26 March. doi:doi:10.3390/inventions4010022.

Giraldez, J. et al. 2018. Phase I Microgrid Cost Study: Data Collection and Analysis of Microgrid Costs in the United States. National Renewable Energy Laboratory (NREL), Juwi Americas, Navigant Consulting. www.nrel.gov/ publications.

GreenTechMedia. 2014. Microgrids 2014 and Beyond: The Evolution of Localized Energy Optimization. GridEdge. 13 March.

HDBaker. 2016. What are the Components of a Microgrid? https://www.hdbaker.com/article/what-are-thecomponents-of-a-microgrid-.

HDBaker. 2016. What are the Value Propositions for Microgrids. http://www.hdbaker.com/article/what-are-thevalue-propositions-for-microgrids-.

Honghua, X. 2015. Status and Challenges of Micro-Grid Demonstration in China. https://events.development.asia/ system/files/materials/2015/05/201505-status-and-challenges-microgrid-demonstration-china.pdf.

Iansiti, M. and K. Lakhani. 2017. The Truth About Blockchain. Harvard Business Review. January-February. https://hbr.org/2017/01/the-truth-about-blockchain.

Justo, J. J. and F. Mwasilu. 2013. AC-Microgrids versus DC-Microgrids with Distributed Energy Resources: A Review. Renewable and Sustainable Energy Reviews. August. https://www.researchgate.net/ publication/270831774. 
Kawahara, T. ed. 2019. Distributed Renewable Energy in Emerging Countries.Tokyo: Bloomberg NEF. 1 March.

Lawrence Berkeley National Laboratory. 2019. Microgrids at Berkeley Lab. About Microgrids.

https://buildingmicrogrid.lbl.gov/about-microgrids-0.

Li, G. et al. 2016. HELOS: Heterogeneous Load Scheduling for Electric Vehicle-Integrated Microgrids. IEEE Transactions on Vehicular Technology. PP (99):1-1. December. https://www.researchgate.net/publication/311502708_ HELOS_Heterogeneous_Load_Scheduling_for_Electric_Vehicle-Integrated_Microgrids/stats.

Microgrid Resources Coalition. 2017. Microgrid Features. https://www.districtenergy.org/microgrids/ aboutmicrogrids $97 /$ features.

Nandapawar, H. 2018. Blockchain: Smart Disruption for Clean Energy Deployment. ACEF, ADB.

Navigant Research. 2017. Non-Wires Alternatives: Nontraditional Transmission and Distribution Solutions. https://www.peakload.org/navigant-publishes-report-on-non-wires-alternatives

Organisation for Economic Co-operation and Development (OECD) Directorate for Financial and Enterprise Affairs. 2019. Blockchain Technologies as a Digital Enabler for Sustainable Infrastructure. Paris.

Planas, E. et al. 2015. AC and DC Technology in Microgrids: A Review. Renewable and Sustainable Energy Reviews. 43. March. 726-749. https://doi.org/10.1016/j.rser.2014.11.067.

Romankiewic, J. et al. 2013. International Microgrid Assessment: Governance, Incentives, and Experience (IMAGINE). The European Council for an Energy-Efficient Econfxomy's 2013 Summer Study on Energy Efficiency. European Council for an Energy-Efficient Economy. http://eta-publications.lbl.gov/sites/default/files/imagineeceee.pdf.

S\&C Electric. 2018. The Long and Short Term Care of Your Microgrid. June 11.

Sabzehgar, R. 2017. Overview of Technical Challenges, Available Technologies and Ongoing Developments of AC/DC Microgrids. In Cao W.P. and Yang J. 2017. Development and Integration of Microgrids. doi:10.5772/ intechopen.69400.

Samad, T., E. Koch, and S. Petr. 2016. Automated Demand Response for Smart Buildings and Microgrids: The State of the Practice and Research Challenges. Proceedings of the IEEE. 104 (4). April. pp. 726-744. doi:10.1109/ JPROC.2016.2520639.

Santos, A. Q. et al. 2018. Framework for Microgrid Design Using Social, Economic, and Technical Analysis. Energies. 11 (2832). https://www.mdpi.com/1996-1073/11/10/2832.

Scauzillo, S. 2016. Metropolitan Water District Saving Money Lost During Drought by Investing in Solar. SGV Tribune. August. https://www.sgvtribune.com/2016/08/10/metropolitan-water-district-saving-money-lostduringdrought-by-investing-in-solar/.

Schneider Electric. 2016. How Microgrids Contribute to the Energy Transition.

Scott, N. 2016. Microgrids: A Guide to their Issues and Value. Highlands and Islands Enterprise in Partnership with Scottish Government. 
Smart Electric Power Alliance (SEPA). 2019. Transactive Energy: Real World Applications for the Modern Grid. https://sepapower.org/resource/transactive-energy-real-world-applications-for-the-grid/.

Shahnia F. et al. 2014. Interconnected Autonomous Microgrids in Smart Grids with Self-Healing. In Hossain J. and Mahmud A., eds. 2014. Renewable Energy Integration, Challenges and Solutions. Singapore: Springer Singapore. pp. 347-381. https://eprints.qut.edu.au/69798/.

Tam, C.W. ed. 2019. Urban Microgrids: Enabling Utility and C\&I Towards Green Digital Future. ACEF, ABB. June.

The Metropolitan Water District of Southern California. http://www.mwdh2o.com/.

The Metropolitan Water District of Southern California. 2016. Solar Power: Metropolitan's Investment in Renewable Energy. August. http://www.mwdh2o.com/PDF_NewsRoom/solar_7\%2025\%20final.pdf.

Thurstan, C., ed. 2018. Microgrid Cybersecurity Tightens With Standards Adoption. CleanTechnica. 28 December. https://cleantechnica.com/2018/12/26/microgrid-cybersecurity-tightens-with-standards-adoption/.

United States Environmental Protection Agency. Sustainable Water Infrastructure: Energy Efficiency for Water Utilities. https://www.epa.gov/sustainable-water-infrastructure/energy-efficiency-water-utilities.

Wanshan Archipelago. https://en.wikipedia.org/wiki/Wanshan_Archipelago.

Wikler, G. et al., eds. 2018. Are Non-Wires Solutions the Next Big Thing? Navigant Research. https://www.navigant. com/-/media/www/site/downloads/energy/2018/pages-from-aesp-magazine-2018navigantarticle.pdf.

World Business Council for Sustainable Development. 2017. Microgrids for Commercial and Industrial Companies. https://docs.wbcsd.org/2017/11/WBCSD_microgrid_INTERACTIVE.pdf.

Zhang, F. 2019. In the Dark: How Much Do Power Sector Distortions Cost South Asia. Washington DC: The World Bank.

Zhou, J. et al. 2019. Design and Analysis of Flexible Multi-Microgrid Interconnection Scheme for Mitigating Power Fluctuation and Optimizing Storage Capacity. Energies. 12 (2132). 1 June. doi:10.3390/en12112132. 


\section{Waste, Waste-to-Energy, and the Circular Economy}

Stephen Peters and Keshan Samarasinghe

\section{Introduction}

Asian megacities struggle with planning and managing waste, notably in developing sufficient infrastructure facilities. It is estimated that Asian cities will generate 1.8 billion tons of municipal solid waste (MSW) annually by 2025 (UNEP 2017). Rising populations, growth of economic activity, and rapid urbanization result in changing consumption patterns and increasing per capita solid waste generation. The Asian Development Bank (ADB) estimates that developing countries in Asia and the Pacific need to invest $\$ 1.7$ trillion annually for infrastructure to support sustainable development, eliminate poverty, and respond to the effects of climate change (ADB 2017).

MSW creates severe environmental problems due to its accumulation in ecosystems from improper disposal. Globally, $37 \%$ of MSW is disposed in landfills, while $33 \%$ is dumped in the open environment. Only $19 \%$ of MSW is recovered though recycling and composting. Incineration accounts for about $11 \%$ of MSW. In high-income countries, $39 \%$ of MSW is disposed in landfills, while $35 \%$ is treated by recycling and composting and $22 \%$ is incinerated. Low-income countries collect about $48 \%$ of MSW in urban areas and only $26 \%$ of MSW outside of urban areas (World Bank Group 2018).

Cities often seek a "magic bullet" to deal with crucial waste issues. This can result in poorly planned, end- of-life facilities that crowd out recycling and upcycling. Recycling is the process of converting used materials (waste) into reusable materials. Upcycling is converting a product to a new functional condition or finding an alternative use for it (Oyenuga and Bhamidimarri 2017). Many developing country governments have limited budgets to support transformation in the waste industry.

Large-scale waste-to- energy facilities are built through private sector investments, while governments assure the supply of large volume of waste. However, these plants often do not receive a consistent and adequate amount of waste due to waste supply chain issues and lack of consistent waste management practices. Rightsizing waste management solutions is a key step toward smart cities with resilient urban footprints.

Several solutions and actions can be considered to improve waste management outcomes. These may include sustainable consumption and production, and development and implementation of necessary policies, laws, and regulations. Developing a circular economy is a more sustainable solution in the longer term. The circular economy model is an alternative to the traditional economy. Its goal is to optimize the use of resources, minimize waste generation, and keep resources in use for as long as possible. 


\section{The Role of the Circular Economy}

The circular economy model provides a sustainable response to Asia's waste crisis in the longer term.

The concept foresees a sustainable consumption and production system where wastes are reused, recycled, and/or recovered (Eygen et al. 2017). Realizing the circular economy requires extensive product and business process redesign to facilitate recycling and reuse of material at the end of its life. Major multinational companies are playing catch up due to consumer demand for a circular economy.

Influenced by product and business process redesign, waste management infrastructure will change from centralized infrastructure to a more distributed waste management model to allow for waste transformation and recovery. By creating smaller circular waste processing steps closer to the source of waste generation, more expensive, end-of-life solutions can be rightsized and higher resource recovery rates can be achieved-from $10 \%$ up to $80 \%$.

Realizing the circular economy entails emerging policies, business models, investment opportunities, and community behavior that are all geared toward less polluting, more prudent, and resource-efficient activities, underpinning global civilization. Many developing countries currently follow a "buy and throw away" linear economy resulting in poor waste separation, lack of waste collection infrastructure, unsustainable product design, poor regulatory framework, and social factors associated with the informal sector (Lalitha and Fernando 2018). Several developing countries such as Maldives, the People's Republic of China (PRC), and Viet Nam are currently transitioning from the linear economy to a recycling economy as they see the benefits from recycling markets and from reducing dependency on other countries' resources (ADB 2018a).

\section{Solutions for Developing Countries in Asia}

Transition from linear to a more circular economic model will require communities and governments to implement new ways and means of managing waste.

\section{Improve the Waste Collection Efficiency}

Well-developed innovative technologies are available in the market to improve waste collection efficiency. Smart sensor technology is one of the best inventions to strengthen the waste collection system. Sensors can be installed in waste bins to indicate when a specific bin should be collected. They can be combined with global positioning systems (GPS), a tracking system using geographic information systems (GIS), and a collection algorithm to optimize truck routes (SynchroniCity 2020). This reduces the impact of high-axle loads on roads, while reducing the prevalence of uncollected bins.

This approach is a quick "smart" improvement in the most populous cities. These GIS can be augmented with application software for citizens to alert the city when waste needs collection in an urgent situation. This can be implemented for an additional increase in collection costs of $\$ 2$ to $\$ 5$ per ton. GIS provide a net saving in transport fuel and maintenance costs. Waste collection development projects, such as sensors and Internet of Things, can optimize collection and reduce operating costs. 
Singapore has piloted its centralized pneumatic waste collection and sorting systems. Pneumatic collection solutions add significant cost to the collection of waste which relies on a high-value recycling market to become economically viable. This suits Singapore's highly urbanized demographic. This type of solution is applicable in middle- to high-income countries with densely populated urban environments.

\section{Digitize Recyclable Waste Collection System}

Planning for collection interventions often assume the status quo in householder sorting behavior, which is typically segregating waste at source. Households in Asia traditionally sort their waste and supply recyclable waste to the informal neighborhood recyclable waste collection centers. The informal sector has not been resourced, policed, and funded to ensure the maximum financial and economic benefit from waste. Governments have been cautious in dealing with the informal sector and generally tolerate them without significant engagement.

Zero waste communities are sadly regarded as similar to the informal sector. To differentiate themselves, several zero waste communities are experimenting with applications for the collection, tracking, and trading of waste, but they are yet to gain wide traction. These applications allow waste generators and collectors to maximize value creation and create verified data maps of waste generation. This waste mapping assists in de-risking investment in recycling and upcycling industry. Some of the net benefits of waste mapping are minimizing collection and/or treatment costs for cities by increasing the segregation at source and ultimately reducing waste to landfills.

Amazon has announced a collaboration with Plastics Bank, which has developed its own waste application (Andresen 2018). Other smaller start-ups are developing their own applications with a local flavor. A proprietary study carried out in a city in the National Capital Region estimates a 30\% saving to the community in recyclable tin-cans waste collection process (Barrie and Pagdanganan 2018). The collection cost is about $\$ 2$ per ton of aluminum cans. Stakeholders benefit from this platform and marketplace to sell collected, segregated waste.

\section{Build Intermediate Material Recovery Facilities}

Larger cities often have material recovery facilities (MRFs) to sort recyclable waste materials with higher value plastics and metals. Removing these materials provides extra revenues for large concession collectors since these facilities are typically priced in the overall waste collection charge. San Francisco has an excellent MRF which is operated by the waste collector, Recology Inc. This MRF contributes to the $80 \%$ landfill diversion (recycling) rate achieved in the city and avoids the need for a waste-to-energy facility (Eberlein 2016).

\section{Build Waste-to-Energy Facilities}

Often seen as a "magic bullet" to reduce waste volumes and maintain public hygiene, modern waste-to- energy (WTE) facilities have superior flue gas emissions technology that meets stringent international standards. These facilities can handle the most difficult wastes. WTE facilities produce heat which can be used for district heating (and cooling) and converted to steam for power generation. WTE technology is now well established and widely used in Japan, the PRC, the Republic of Korea, and Singapore. In many cities, WTE facilities are lodged within residential areas to reduce transport costs. A separation barrier can often be landscaped to provide public space and reduce the visual impacts. Handling of fly ash from air purification control systems poses a pollution concern which requires further technical innovation. Operating WTE facilities costs $\$ 28$ to $\$ 55$ per ton depending on the plant capacity, availability of a hazardous waste landfill to receive air pollution control residues, and land value. 


\section{Build and Operate a Sanitary Landfill}

Landfills in Asia are often uncontrolled dumpsites with open burning of waste and uncontrolled discharges of polluted effluents. Many public health problems are associated with uncontrolled dumpsites. By converting these dumpsites to sanitary landfills, effluents (leachate) can be treated, and methane gas can be captured to generate power. The waste handling costs for dumpsites can be as low as $\$ 2$ per ton of waste, excluding transport and environmental costs. Sanitary landfill costs are higher at $\$ 8$ to $\$ 25$ per ton, depending on the size of the landfill and land costs. The landfill recently completed in New Clark City in the Philippines has set a high standard of design and construction with a higher cost of disposal reflecting a higher service level (Navarro 2012).

\section{Build Zero Waste Community Centers}

Zero waste communities rely on the efforts of local nonprofits and engage citizens to recycle as much as possible. These communities are small-scale, localized MRFs utilizing a higher waste recovery rate with little or no waste sent to landfill. The operations rely on strong community empowerment and leadership (Box 1). The funding for zero waste communities is reliant on the sale of recyclables or other craft revenues, as cities rarely provide support. Cities prefer centralized facilities which are under direct control. The greater community benefits from zero waste communities, leading to a deeper understanding of consumption and waste. However, higher social interactions can result in internal conflict among the community members. Communities are increasingly requesting and supporting this approach due to concerns about a cleaner low-carbon future. ${ }^{1}$

\section{Box 1: Community Empowerment with Private Sector Participation}

Community empowerment projects have created a lasting impact on changing the traditional participation of private sector investment to support small and medium-sized enterprises (SMEs) in the waste sector. Larger, fast-moving consumer goods companies can create significant change in public goods to meet the Paris Accords and the UN Sustainable Development Goals if governments can provide incentives. A good example for community empowerment is the EKOCENTER project of The Coca-Cola company.

The project has committed to develop materials recovery supply chain through changing the product design and building PET bottle recycling facilities. Overall, it aims to strengthen SMEs and support sustainable development. The project has also facilitated the sites for micro level eco-industrial parks that have complete community empowerment infrastructure (telecoms, training areas, start-up space for solar energy, recycling, and upcycling). One of its subprojects in Dong Thap Province, Viet Nam has created a momentum for SMEs in the recycling supply chain. The allocated sites have become well established through the project. Zero waste communities have been formed and the utility values are very high. This can be replicated in large and medium cities in ADB developing member countries by energizing communities with the dedicated involvement of the private sector.

Source: Asian Development Bank.

SAAHAS Zero Waste of Bengaluru is an excellent example of a community-empowered organization. The company has achieved significant results in a challenging environment, especially by empowering women in the industry. Saahas Zero Waste. Breaking the Tech Ceiling in WM. https://saahaszerowaste.com/blogs/breaking-the-tech-ceiling-in-wm/. 


\section{Develop Eco-Industrial Parks}

Landfills, WTE facilities, and MRFs have a high concentration of sorted materials ready for recycling and upcycling to higher-value materials. By providing additional space for innovative technologies, waste can be transformed and landfill rates can decrease substantially. These initiatives are net revenue creators, allowing concessionaires to diversify their revenue model. Reduction of overall waste-related costs to cities can be up to $\$ 3$ to $\$ 10$ per ton. The following activities can be carried out at a local, municipal or regional level:

- Micro eco-industrial parks. MRFs are being transformed to biological and mechanical treatment facilities where organic materials are converted to biogas for power, fuel, or heat applications. The fuel applications include use for bus fleets (Lowry 2016). A project doing this is in the feasibility stage for the Behns Colony in Karachi, Pakistan which aims to fuel the Bus Rapid Transit (BRT) Redline. ${ }^{2}$

- Eco-industrial parks. WTE facilities can incorporate waste heat recovery for other processes including desalination and drying of materials for upcycling. Technologies have been introduced to convert plastics to fuels or resins, while reducing the chlorine content of the waste. This can partially avoid the risk of toxicity in the air purification control residues (fly ash) from WTE plants. Recycling of glass into water filter media, conversion of aluminum cans to hydrogen and alum, and waste gasification to make biochar are well suited for eco-industrial parks.

- Green ports. The aggregation of materials from shipping operations allows co-location of treatment facilities. This is especially relevant in small island developing states or countries with large inland shipping activities. Backloads of sorted wastes in green ports can be consolidated at eco-industrial parks to treat more efficiently.

\section{Extend Producer Responsibility}

One of the earliest recycling schemes were deposits for glass bottles. Once a bottle's contents were consumed, the bottle could be returned to the retailer or company for a small refund. This concept was introduced by a Swedish academic, Thomas Lindhqvist, and eventually evolved into the broader concept of extended producer responsibility (EPR). The EPR is an environmental protection strategy to decrease the total environmental impact of a product. The manufacturer is responsible for the entire life cycle of the product, especially for the take-back, recycling, and final disposal (Box 2).

Taipei,China has an area of 36,000 square kilometers $\left(\mathrm{km}^{2}\right)$ and a population of 23.2 million-a highly dense population in a small land area-which makes resource conservation and recycling an important strategy to achieve sustainable development. MSW generation has rapidly increased as a result of rapid urbanization and economic development. Consequently, policy initiatives were introduced to improve the waste management sector. Figure 1 shows the summary of policy initiatives which have been taken from 1987 to 2005, and the performance of the recycling industry.

Initially, only a market-driven recycling industry was initiated to manage a small portion of recyclable waste. In 1987, a polluter-pays principle was introduced so that producers were physically and financially responsible for recycling. Based on the producers-pay principle, eight recycling funds were created to collect recycling fees. The Environmental Protection Administration (EPAT) administers the funds. Based on EPAT statistics,

2 Green Climate Fund. 2018. Green BRT Karachi. Karachi, Pakistan. 
Figure 1: Resource Recycling Management Policy

1987

Polluter-pays principle introduced
1997

Four-in-one recycling program

1990

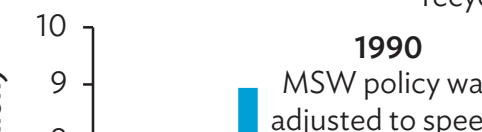
adjusted to speed up incineration

\section{Recyclin enterprises} were set up

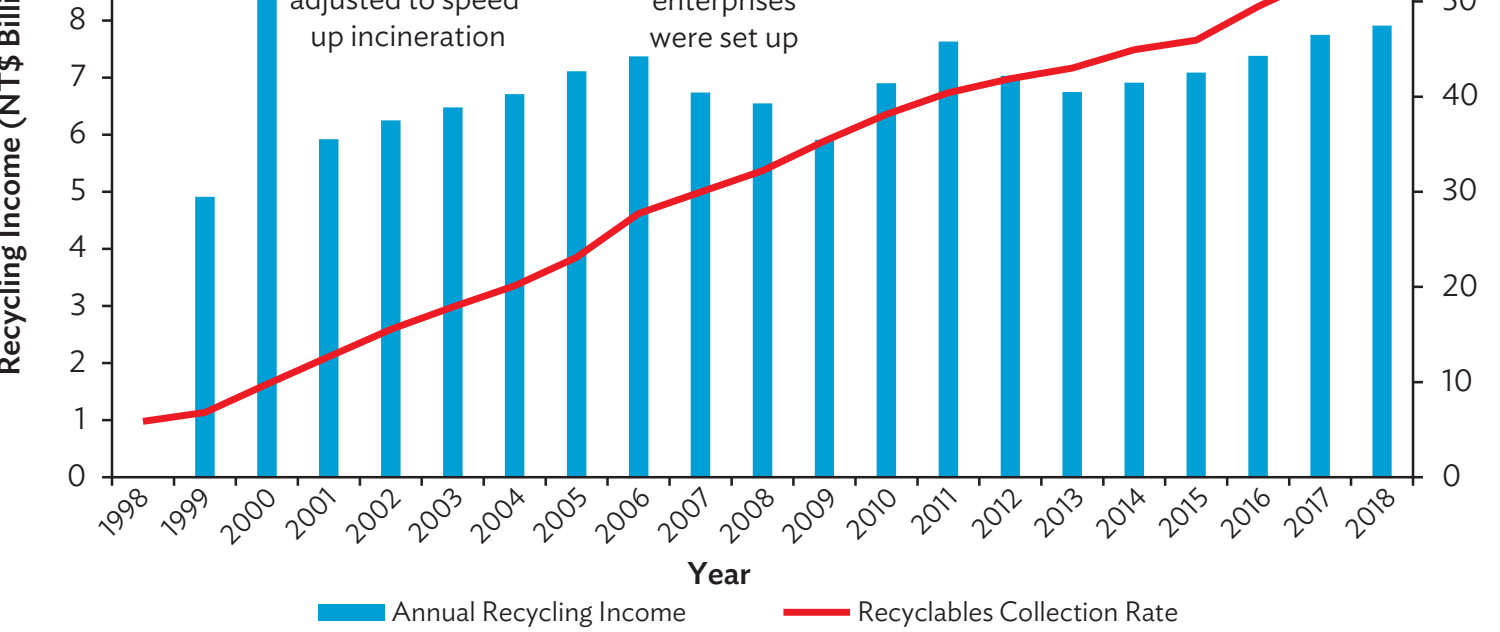

2004

\section{Zero waste policy}

2002

Resource recycling act initiated

2005

Mandatory garbage sorting $[60$

MSW = municipal solid waste, NT\$ = NT dollar.

Note: Exchange rate was NT\$1.00 $=\$ 0.033$ at end of 2020 .

Source: Asian Development Bank.

the recyclables collection rate increased by $47 \%$ over the past 20 years. The recycling industry generated an annual revenue greater than $\$ 2$ billion, and $10 \%$ of income is generated from the recycling fund.

Resource recycling management regulations were put in place to strengthen the waste management sector. Management measures for manufacturers and importers were introduced to calculate the amount of regulated recyclable waste (RRW) products that are being sent to the local market. Standards were implemented for waste collection, transportation, storage, and recycling of RRW. Attractive subsidies were given for RRW collection and recycling through an application review process. Transparent registration, monitoring, certification of RRW, auditing, and cancellation of registration were carried out to encourage enterprises and investors.

The EPAT "Four-in-One Recycling Program" focuses on the municipal government, manufacturers, consumers, and recycling enterprises. Community-based recycling organizations promote waste segregation at source and recover recyclable materials from MSW. In addition, recycling enterprises regularly collect recyclable materials from households, commercial places, and municipalities. A recycling fund is raised which is financed by waste generators and manufacturers under the EPR policy. All industries that manufacture RRW products are responsible for the end-of-life waste treatment. Thus, the industries provide financial support to recyclers through the recycling fund. As a result of having enough funds for recycling, Taipei,China has a well-developed recycling sector. EPAT returns about $20 \%$ of its revenues to the government. The remainder goes to the operations of the waste management supply chain, subsidies to recyclers, and operations costs. Because of the EPR initiative in last 30 years, the segregation efficiency of MSW is higher in Taipei,China than in other locations around the world. 


\section{Box 2: Digitization of Extended Producer Responsibility Schemes}

The e-EPR technology supports the tracking of waste from waste generation to waste treatment processes, such as reuse, upcycling, and recycling. Further development in digitized extended producer responsibility (EPR) schemes can be linked through apps. Linking existing waste collection applications to digitized EPR platform will allow implementation of an EPR fund to capture products entering a market, levy an EPR fee, track transactions on waste, subsidize recycling and end-of-life treatments, regulate the market, and guarantee sanitation. Through the e-EPR, the informal sector can access online banking, manufacturers can find a reliable source to buy recycled materials, and the government will have a new tool to fund infrastructure and enhance urban sanitation. Like Uber and Grab in the taxi industry, waste trading applications are looking to increase collection efficiency and enhance the performance of the informal sector.

Several start-ups have implemented stand-alone trading applications, notably Xianyu by Alibaba in the People's Republic of China. These applications have mostly focused on trading high-value items, ignoring low-value waste materials. Tracking of commonly recycled materials have not yet tapped the information technology sector since the waste is hard to quantify and the margins on trades are small. Therefore, private sector involvement is needed in the waste sector because digitization will facilitate the implementation of EPR principles for which developed economies have taken 20 to 30 years to implement.

The consumer-facing applications interfaces can be customized to suit local conditions and practices.

The e-EPR applications can link industries to improve the entire supply chain such as recyclers, waste collectors, manufacturers, or importers. By linking every stakeholder to the waste supply chain, it is expected to create an efficient waste management sector, generate new revenue source for governments, create more job opportunities, minimize waste transportation cost, improve higher resource recovery and utilization, and help empower the informal sector.

Source: Asian Development Bank.

\section{The Role of the Private Sector}

Governments can facilitate consumer value creation from MSW instead of sending waste to landfills which are often mismanaged (Bugge et al. 2018). Informal waste sector can be formalized to improve the recovery rate of recyclable materials from MSW. High-quality nonrecyclable waste can be utilized in upcycling or through WTE facilities instead of landfilling. The private sector is best suited to realize this value, or valorize waste (Ferronato et al. 2019). Financial institutions, private and government organizations, and bilateral and multilateral institutions can make a significant contribution in the Asia and Pacific region in reducing waste pollution, while strengthening the circular economy through private sector investment. This is possible by adopting public-private partnership (PPP) investment models (ADB 2018b).

City governments often struggle with the investment and operation requirements of waste management. PPP arrangements have struggled in some cities due to lack of funding and capacity. The PRC has enacted a few laws under the "Ecological Civilization" approach to sustainability. This represents a comprehensive plan to create public goods. One such law specifically relates to the circular economy. ADB recently approved funding for SUS Shanghai Environment to implement three projects using an eco-industrial park model where material recovery is 
maximized under this law. ${ }^{3}$ These types of eco-industrial parks can be smaller and distributed at community level with the private sector participation.

\section{Implementation Challenges}

Developing countries need support to realize their circular economy aspirations. They can be supported through awareness creation, capacity building, investment in infrastructure, technology availability, law enforcement and policy implementation, international collaboration, PPP, fiscal policy support, and industry formalization (Gunarathne et al. 2019). The key problems facing the waste management sector are presented in Table 1.

Table 1: Implementation Challenges and Way Forward

\begin{tabular}{|c|c|c|}
\hline Challenges & Description & Solutions \\
\hline \multirow{3}{*}{$\begin{array}{l}\text { Lack of } \\
\text { environmental } \\
\text { management } \\
\text { and monitoring plan }\end{array}$} & \multirow{3}{*}{$\begin{array}{l}\text { The key development risk is low institutional } \\
\text { capacity. Inspection, monitoring, reporting, } \\
\text { and initiating corrective actions and measures } \\
\text { are not taken at the right time. Therefore, } \\
\text { unexpected environmental and social issues } \\
\text { occur throughout the implementation and } \\
\text { operation period. }\end{array}$} & $\begin{array}{l}\text { Provide training on environmental } \\
\text { management }\end{array}$ \\
\hline & & $\begin{array}{l}\text { Appoint qualified project } \\
\text { implementation consultants }\end{array}$ \\
\hline & & $\begin{array}{l}\text { Conduct proper monitoring } \\
\text { and mitigation arrangements }\end{array}$ \\
\hline \multirow{2}{*}{$\begin{array}{l}\text { Political interference } \\
\text { and limited } \\
\text { community } \\
\text { engagement }\end{array}$} & \multirow{2}{*}{$\begin{array}{l}\text { Political interference typically impedes the } \\
\text { adoption of new models to protect existing } \\
\text { relationships in the waste management sector. } \\
\text { Often new initiatives are shrugged off as "not } \\
\text { for profit" to minimize importance. There is a } \\
\text { perception that new business models disrupt } \\
\text { existing relationships and cashflows. }\end{array}$} & $\begin{array}{l}\text { Create independent revenue- } \\
\text { generating agencies }\end{array}$ \\
\hline & & $\begin{array}{l}\text { Interact with all stakeholders to engender } \\
\text { visibility. General community awareness } \\
\text { programs create expectations wherein political } \\
\text { interference can be minimized, while aligning } \\
\text { the political agenda with community attitudes. }\end{array}$ \\
\hline \multirow[t]{2}{*}{ Unskilled labor } & \multirow{2}{*}{$\begin{array}{l}\text { Recycling operations often employ unskilled } \\
\text { labor. These employees require basic training } \\
\text { and close supervision, especially in regard to } \\
\text { safety. Waste-related operations tend not to } \\
\text { adequately invest in training. }\end{array}$} & $\begin{array}{l}\text { Provide basic training and up-to-date safe } \\
\text { operations descriptions to motivate staff }\end{array}$ \\
\hline & & $\begin{array}{l}\text { Engage employees in working toward achieving } \\
\text { operational targets }\end{array}$ \\
\hline $\begin{array}{l}\text { Lack of industry } \\
\text { expertise }\end{array}$ & $\begin{array}{l}\text { Many equipment operators do not know } \\
\text { how machinery works and how to keep it } \\
\text { running. Sometimes, it takes a long time to fix } \\
\text { a small issue or the issue can be a reason for a } \\
\text { catastrophic event in a plant because of lack } \\
\text { of knowledge. }\end{array}$ & $\begin{array}{l}\text { Hire experienced equipment operators and } \\
\text { expertly trained workforce to control the } \\
\text { process and minimize operational issues. } \\
\text { This requires the management to move beyond } \\
\text { the day labor market model. }\end{array}$ \\
\hline
\end{tabular}


Table continued

\begin{tabular}{|c|c|c|}
\hline Challenges & Description & Solutions \\
\hline $\begin{array}{l}\text { Poor quality } \\
\text { waste stream }\end{array}$ & $\begin{array}{l}\text { In the Asia and Pacific region, waste } \\
\text { segregation is poorly practiced at the source } \\
\text { of generation. Most of the recyclable waste } \\
\text { is contaminated with impurities due to } \\
\text { co-mingling. It is difficult to clean and use } \\
\text { segregated material in mechanical and } \\
\text { chemical recycling processes. Calorific value } \\
\text { of MSW is low due to high moisture content }\end{array}$ & $\begin{array}{l}\text { Segregate waste at generation point to } \\
\text { have better quality waste stream for WTE } \\
\text { facilities. Consistency in waste stream helps } \\
\text { run the WTE plant smoothly and improve } \\
\text { its efficiency. Also, the recyclable waste } \\
\text { fraction can be further increased by avoiding } \\
\text { contamination of recyclable waste with } \\
\text { impurities and by collecting uniform materials. }\end{array}$ \\
\hline & $\begin{array}{l}\text { of organic wastes. Therefore, many WTE } \\
\text { operators face difficulties in applying imported } \\
\text { systems when using poor quality waste stream. } \\
\text { This requires additional cost for pre-sorting. }\end{array}$ & $\begin{array}{l}\text { Use segregated non recyclable and } \\
\text { combustible waste with a high calorific value } \\
\text { for power generation in WTE facilities. }\end{array}$ \\
\hline
\end{tabular}

MSW - municipal solid waste, WTE = waste-to-energy.

Source: Asian Development Bank.

\section{Conclusion}

This article provides a snapshot of the emerging waste management trends in developing countries. The sheer amount of waste requires updating of outdated waste management practices to create more value and amenity for communities. Achieving a sustainable waste utility involves decentralizing processes to create value closer to the community, building material recovery facilities, developing eco-industrial parks, and making collection more efficient.

The transition from linear (or buy and throw away) economic model to one with higher recycling rates is underway in many developing countries. This is the first step to a circular economy. Zero waste communities have been demonstrating that a circular economy is possible. During this transition, there will be waste that cannot be recycled and upcycled. Planning for the end of life of products will require landfills and waste-to-energy facilities in the medium term. Determining the right capacity for these facilities and planning for their end of life will be related to how quickly a circular economy is realized. Funding for the required infrastructure is beyond the resource capacity of most developing country governments. Private sector funds can be deployed under PPP arrangements to meet these needs. Implementation of extended producer responsibility schemes can reduce risks and provide a subsidy mechanism for this infrastructure.

Digitization of the waste management supply chain and EPR mechanisms will serve as a monitoring means that is necessary in enforcing regulations. Visibility of the digitized process will help raise awareness within communities and align the interests of all stakeholders. The regulation and administration of these processes needs to be both independent and revenue positive to the government. A well-managed supply chain with EPR at its core has achieved this already and is considered a best practice. 


\section{References}

Asian Development Bank (ADB). 2017. Meeting Asia’s Infrastructure Needs. https://www.adb.org/publications/ asia-infrastructure-needs.

—-_. 2018a. Viet Nam: Municipal Waste-to-Energy Project. Manila. https://www.adb.org/projects/50371-001/main.

-- - 2018b. Creating an Enabling Environment for Public-Private Partnerships in Waste-to-Energy Projects. https://www.adb.org/publications/ppp-waste-to-energy-projects.

- - - 2019. ADB Expands Circular Economy With SUS's Low Carbon Eco-Industrial Parks In China. News release. 8. April. https://www.adb.org/news/adb-expands-circular-economy-sus-s-low-carbon-eco-industrial-parkspeople-s-republic-china.

Andresen, S. 2018. Plastic Bank: Blockchain Tackles Global Poverty and Ocean Plastic. https://www.borgenmagazine. com/plastic-bank-blockchain/.

Barrie, M. and A. Pagdanganan. 2018. An Introduction to Solu. Manila.

Bugge, M. M., A. M. Fevolden, and A. Klitkou. 2018. Governance for System Optimization and System Change: The Case of Urban Waste. Oslo, Norway.

Eberlein, S. 2016. A Mighty New Recycling Beast at San Francisco’s Pier 96. California, US.

Eygen, E., D. Laner, and J. Fellner. 2017. Circular Economy of Plastic Packaging: Current Practice and Perspectives in Austria. Vienna, Austria.

Ferronato, N. et al. 2019. Introduction of the Circular Economy Within Developing Regions: A Comparative Analysis of Advantages and Opportunities for Waste Valorization. Varese, Italy.

Green, Climate Fund. 2018. Green BRT Karachi. Karachi, Pakistan.

Gunarathne, A. D. N., T. P. Y. C. Tennakoon, and J. R. Weragoda. 2018. Challenges and Opportunities for the Recycling Industry in Developing Countries: The Case of Sri Lanka. Colombo, Sri Lanka.

Lalitha, R. and S. Fernando. 2018. Solid Waste Management of Local Governments in the Western Province of Sri Lanka: An Implementation Analysis. Colombo, Sri Lanka.

Lowry, M. 2016. Biogas Buses are the Green Solution for Cities. https://euinmyregion.blogactiv.eu/2016/07/04/ biogas-buses-are-the-green-solution-for-cities/\#: :text=Although\%20the\%20average\%20age\%20of,and\%20 have\%20chosen\%20biogas\%20buses.

Navarro, C. 2012. Metro Clark Sanitary Landfill Gears Up for New Clark City. New Clark City, Philippines.

Oyenuga, A. and R. Bhamidimarri. 2017. Upcycling Ideas for Sustainable Construction and Demolition Waste. Management: Challenges, Opportunities, and Boundaries. Colombo. 
Saahas Zero Waste. 2020. Breaking the Tech Ceiling in WM. https://saahaszerowaste.com/blogs/breaking-thetech-ceiling-in-wm/.

SynchroniCity. 2020. Quamtra Smart Waste Management. https://synchronicity-iot.eu/project/quamtra-smartwaste-management/.

United Nations Environment Programme. 2017. Asia Waste Management Outlook. https://wedocs.unep.org/ handle/20.500.11822/27289.

World Bank Group. 2018. What a Waste 2.0: A Global Snapshot of Solid Waste Management to 2050. Washington DC. 


\section{CHAPTER 4 \\ Financial Innovation}

ARTICLE 4A

Advancing the Financial Sustainability of Asian Cities

Manoj Sharma, Sarah Hui Li, and Renard Teipelke

ARTICLE 4B

Urban Housing Bond Market Development in Asia

Heejoon Jeong, Bambang Susantono, Donghyun Park, and Shu Tian

ARTICLE 4C

Enhancing Infrastructure Investment through Value Capture Abdul Abiad, Kathleen Farrin, Chris Hale, Matthias Helble, and Grant Stillman 


\title{
Advancing the Financial Sustainability of Asian Cities
}

\author{
Manoj Sharma, Sarah Hui Li, and Renard Teipelke
}

\section{The Importance of Financial Sustainability of Cities}

The Asian Development Bank (ADB) estimates that developing Asia and the Pacific requires $\$ 26.2$ trillion between 2016 and 2030 - \$1.7 trillion annually - to meet its infrastructure needs to maintain growth, eradicate poverty, and respond to the changing climate (ADB 2017b). Power and transport sectors will comprise the largest share of investment needs, requiring $\$ 14.7$ trillion and $\$ 8.4$ trillion, respectively. The costs for telecommunications will reach $\$ 2.3$ trillion, followed by water and sanitation infrastructure investment at $\$ 800$ billion. Much of the infrastructure finance is likely to be needed in rapidly urbanizing cities in the region.

From the 1950s to 2018, urban populations in Asia and the Pacific increased from about $20 \%$ to $48 \%$ of the region's population. By 2030, cities in Asia and the Pacific are projected to house about 2.5 billion people, $55 \%$ of the region's population (ADB et al. 2019). Accordingly, Asian cities require considerable resources to provide facilities and services to growing urban populations, and to address existing infrastructure deficits. Moreover, external shocks and crises, such as the coronavirus disease (COVID-19) pandemic, further emphasize the importance of quality urban infrastructure and building resilience of cities (ADB 2020a). Cities need to provide, among others, adequate health infrastructure; proper solid waste management including medical waste management; water, sanitation, and hygiene (WASH) services; affordable housing for all, including the vulnerable people; and appropriate transportation systems that allow efficient movement of people and goods without overcrowding urban spaces.

The growing urbanization and the considerable infrastructure investment need to underscore the importance of financial sustainability of cities. Cities should have the capacities, systems, and processes to effectively and efficiently manage their revenues and expenditures, and to attract investments to meet the growing demands for recurrent expenditures and capital investments (ADB 2019d).

This article presents a snapshot of the challenges and opportunities for enhancing financial sustainability of cities in Asia and the Pacific.

\section{Acknowledgments}

Robert Guild, chief sector officer, ADB Sustainable Development and Climate Change Department; Go Nagata, David Aaron Robinett, and Ma. Antoinette Figurasin from ADB's Governance Thematic Group; Sung Su Kim from ADB's Finance Sector Group; Ranen Banerjee from PwC; Sunil Kumar Goyal, a former officer from the Government of Rajasthan, India; and Cerin Kizhakkethottam from AECOM provided valuable comments and inputs to this article. 
The first section begins with a brief analysis of the current municipal financial performance. Municipalities and subnational governments in the region often struggle with maximizing the potential of all sources of revenues, especially property taxes. Weak expenditure management is also a major concern, which involves challenges on resource allocation mechanisms and effective spending prioritization. Cities require better fiscal management capacity, enhanced governance, and the ability to be smart and utilize technology to facilitate sustainable and inclusive urban development.

The second section discusses options for municipalities to improve and maximize common revenue sources. Taxes, particularly property taxes, are still underutilized, although they have the most potential to generate revenue if well designed, managed, and executed. Land value capture can be an effective mechanism to derive revenues from one of the most important assets in urban development-land. As a means of cost recovery, tariff and user charges highlight the importance of sufficient funding allocation for infrastructure operations and maintenance. Intergovernmental transfers from higher-level governments, while being useful, come with shortcomings for municipalities including limited discretion for local needs.

The third section analyzes the mechanisms for catalyzing additional revenue sources at the local level. These mechanisms include public-private partnerships (PPPs) for city infrastructure, which are expected to contribute to the improvement and efficacy of urban service delivery notably in the housing, water supply, solid waste management, and transport sectors. Bonds are a viable instrument particularly for revenue-generating projects. Municipal development funds, on the other hand, provide a useful pooling vehicle to make financing more accessible and affordable to municipalities of different sizes and capabilities. In any case, increased creditworthiness of municipalities is essential to attract additional investments. It also brings benefits such as enhanced financial transparency, enforced spending discipline, and improved fiscal management and governance.

The last section concludes by reflecting on the previous sections and offering recommendations to advance sustainable municipal finance in ADB's developing member countries (DMCs) across Asia and the Pacific.

\section{Current Municipal Fiscal Performance: Revenues and Expenditures}

\section{Revenues}

Over the years, governments have become more aware of the need to mobilize their revenue to fund infrastructures and public services. OECD (2019) affirms that taxation provides a predictable and sustainable source of government revenue. However, at the country level, many DMCs in Asia and the Pacific, particularly in Southeast Asia and South Asia, have an overall tax-gross domestic product (GDP) ratio below or around 15\%. This is now widely regarded as the minimum level required for sustainable development in the absence of other sources of revenue, which is significantly below the OECD average tax burden of $34 \%$.

At the local level, municipal and subnational governments often struggle with maximizing the potential of all sources of revenues. Local government revenue remains below $20 \%$ of GDP in DMCs (Figure 1). In most DMCs, local government revenues are below $10 \%$ of GDP compared to about $10 \%$ to $35 \%$ among high-income European countries (OECD-UCLG 2020). The potential to increase the local revenues in DMCs such as Cambodia (1.2\%) and Sri Lanka (2.3\%) is huge. In general, local governments, including advanced economies, such as Japan and the Republic of Korea, still rely on intergovernmental transfers (or grants) as an important revenue source. Governments have been making efforts to reduce the relative share of such transfers in recent years. This aims to both reduce the national fiscal burden and support decentralization efforts more broadly. However, in most DMCs, municipal bodies' own sources of revenue are meager because of inadequate collection of local taxes, 
Figure 1: Local Government Revenue as Percentage of GDP, 2019 or Latest Available Year $(\%)$

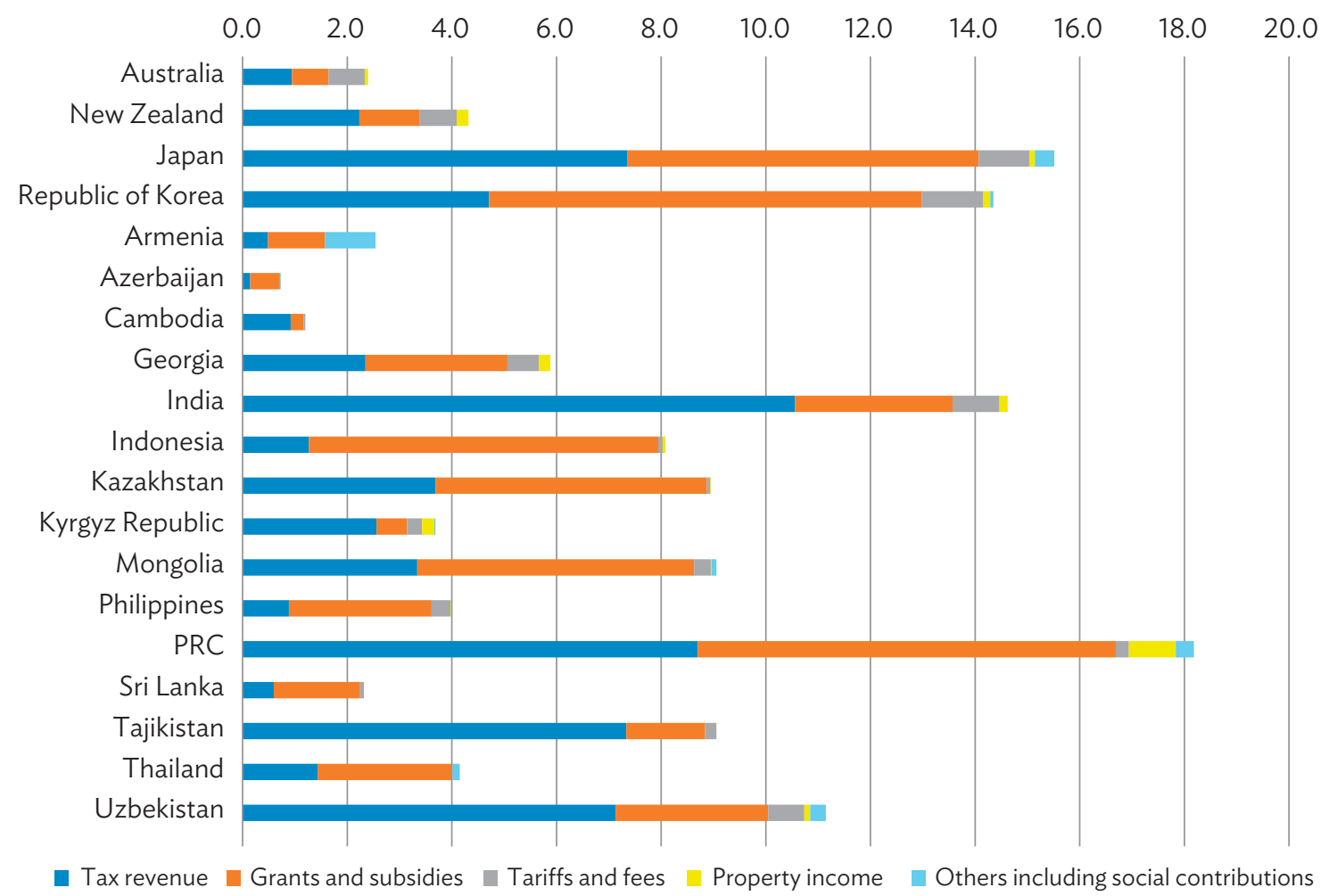

GDP = gross domestic product, $\mathrm{PRC}=$ People's Republic of China.

Note: Local government data for India is not available, instead state government data is shown.

Source: OECD-UCLG. 2020. World Observatory on Subnational Government Finance and Investment. http://www.sng-wofi.org/data/ (accessed 6 April 2020).

such as property taxes, and disorganized or repressed real estate sectors (UNESCAP 2019). While the types of taxes levied by local governments vary among countries, property tax is usually the most prominent contributor to the revenues from taxes levied by local governments. Moreover, in general, the realization of property tax, when compared to its potential, remains low for local governments in DMCs due to administrative inefficiencies in the property tax system.

\section{Expenditures}

The government's budget is a financial mirror of agenda setting and development priorities. Apart from collecting resources from the economy in a sufficient and appropriate manner, allocating and using those resources responsively, efficiently, and effectively is as important for the government to perform its roles in infrastructure and service delivery.

However, resource allocation is a fundamental issue for public sector budgeting, especially revenue and expenditure budgeting, due to limitations in resources. In general, among local governments in Asia and the Pacific, local government expenditure as percentage of GDP remains below $18 \%$. The local government's 
Figure 2: Local Government Expenditure as Percentage of GDP, 2019 or Latest Available Year $(\%)$

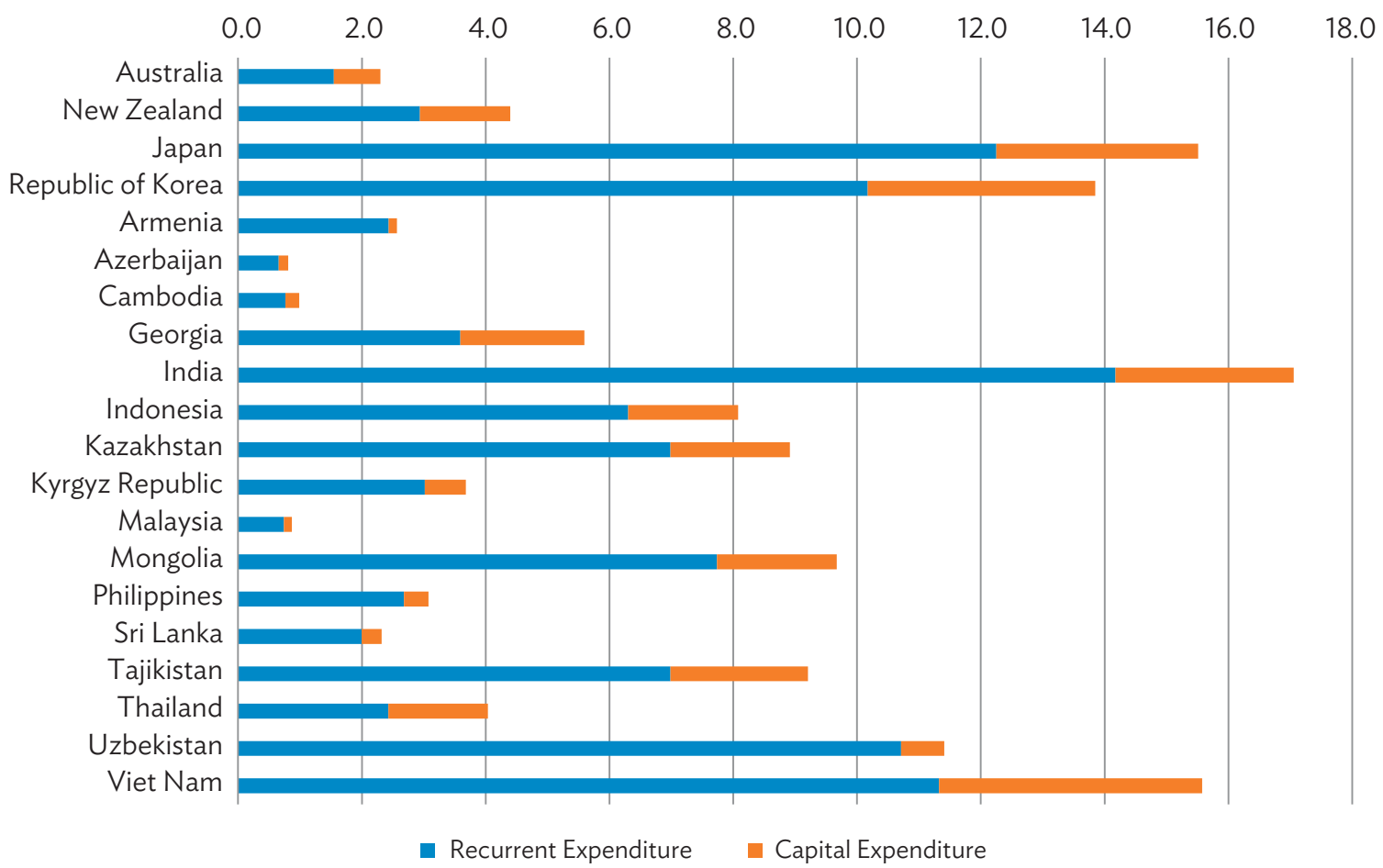

Note: India has no data for local government, instead state government data is shown.

Source: OECD-UCLG. 2020. World Observatory on Subnational Government Finance and Investment. http://www.sng-wofi.org/data/ (accessed 6 April 2020).

recurrent expenditure significantly outweighs its capital expenditure (Figure 2). The biggest recurrent expenditure items, among others, are employee compensation, grants, subsidies, and social benefits. According to OECD (2019), subnational governments tend to spend more on education, social protection, and general public services, compared to areas such as health, housing, and environmental protection.

\section{Challenges in Municipal Financial Management}

\section{Revenues}

If local governments are to take on more responsibility for financing infrastructure, they must have both the mandate and capacity to generate local revenue. However, these are currently lacking across most countries in Asia and the Pacific. Despite decentralization, local governments in DMCs still experience considerable constraints in raising local revenue. Local tax revenues, for example, have been limited due to disincentives caused by intergovernmental transfers, fear of losing political positions, and regulations from central governments. Property tax is one of the most underutilized revenue sources. This is because of incomplete data, ineffective institutional arrangements, improper land and property registration system, and inaccurate value assessment methodologies, among others. Realization of tariffs and user charges, on the other hand, are constrained by low willingness to charge, political pressure to keep tariffs low, underestimated costs of 
infrastructure operations and maintenance, cumbersome collection system, and revenue losses such as from nonrevenue water. More significantly, too many municipal enterprises and commercial assets, especially real estate, lack professional management and effective governance. In terms of additional finance resources such as through PPP, bonds, and municipal funds, cities often lack a robust legal framework and transparency, do not hold a credit rating, and can do more for an enabling environment to attract external investments for urban infrastructure and services.

\section{Expenditures}

Cities and municipalities in developing Asia and the Pacific are not only experiencing challenges on revenue generation, but also on their expenditures. Some of the expenditure management issues they face are weak expenditure estimation and budgeting, improper classifications of income and expenditure heads, decoupled expenditure from resource realization, and quantity over quality and effective spending. Most local revenues are used for the operations of city governments with very little allocation for capital expenditure (Figure 2). While a proportion of own-source revenues can be set aside for capital development expenditures, in practice, most are funded through central grant transfers. ' Such funding, however, is dependent upon the central government's commitment, which can be made based on formulas, agency priorities, or political expediency instead of local needs (ADB 2012).

Other important expenditure challenges are the absence of resource allocation mechanisms and effective spending prioritization. Urban infrastructure projects should be based on necessity, cost-effectiveness, and availability of funds. Such projects should be identified after assessing various techno-commercial options, and comparing capital expenditure and operation and maintenance costs of each option. In many municipalities, the common drawback is that sometimes the projects are selected based on political or personal preference without accounting for the local government's capacity to bear the cost of operation and maintenance in addition to capital expenditure. Meanwhile, for cities to be more livable, besides critical infrastructure such as water supply and waste management, they should also enhance their capacity to assess and prioritize projects such as energyefficient and climate-resilient infrastructure.

\section{Fiscal Management}

Since cities need to raise more funds themselves, improve efficiencies, and reduce costs, they need to enhance their governance systems and build their capacity, particularly through utilizing smart technologies. To generate sufficient revenue, municipalities need to improve their fiscal management capacity, such as tax administration and investment planning. This could be achieved through technological means such as e-governance and geographic information systems or GIS, staff training, and the necessary regulatory reforms. Strengthened fiscal management can contribute to accountability and transparency. This, in turn, helps municipalities use their scarce resources as seed money and tap available private finance and blend it with public resources through effective risk sharing. Meanwhile, for cities to mobilize different types of financing modalities, enabling factors such as ease of implementation, relevance, affordability, expected impact, as well as secondary impact should be evaluated based on local contexts (Table 1). The next two sections will further discuss common and additional finance resources of municipalities in detail.

\footnotetext{
Fiscal transfers generally make up more than $50 \%$ of local government revenues. In some countries, such as Pakistan, they can reach as
} high as $95 \%$. 
Table 1: Factors Impacting Availability of Financing Modalities

\section{Criteria}

Ease of implementation (resourcing/regulations)
Criteria Subcategory

Enabling regulatory

framework

\section{Description}

Degree to which the financing mechanism relies on a relatively complex set of enabling rules and regulations to be put into places to be effective

Administration Expected human capacity requirements and/or institutional requirements burden imposed for the financing mechanism to be implemented effectively

\begin{tabular}{|c|c|c|}
\hline \multirow[t]{3}{*}{$\begin{array}{l}\text { Relevance to } \\
\text { intermediary cities }\end{array}$} & $\begin{array}{l}\text { Applicability to } \\
\text { intermediary cities }\end{array}$ & $\begin{array}{l}\text { Degree to which the inputs and outputs of the financing } \\
\text { mechanism are expected to be suitable for smaller cities } \\
\text { (i.e., the mechanism is relatively easy to implement and } \\
\text { the scale of funding requirement is relatively small) }\end{array}$ \\
\hline & $\begin{array}{l}\text { Decentralization } \\
\text { requirement }\end{array}$ & $\begin{array}{l}\text { Extent to which the financing solution requires or does not } \\
\text { require local government to have a high degree of autonomy }\end{array}$ \\
\hline & Absence of a solution & $\begin{array}{l}\text { Degree to which the financing solution might be expected to add } \\
\text { to the range of funding mechanisms currently utilized by a city }\end{array}$ \\
\hline \multirow[t]{2}{*}{$\begin{array}{l}\text { Affordability/financial } \\
\text { sustainability }\end{array}$} & Financial burden & $\begin{array}{l}\text { Extent to which the financing option directly imposes a financial } \\
\text { burden on local government versus the degree to which this } \\
\text { burden can be shared with other parties }\end{array}$ \\
\hline & $\begin{array}{l}\text { Contribution to financial } \\
\text { sustainability }\end{array}$ & $\begin{array}{l}\text { Consideration of the degree to which the financing option can help } \\
\text { cover operational expenditure (and potentially the capital costs) }\end{array}$ \\
\hline \multirow[t]{2}{*}{$\begin{array}{l}\text { Expected scale/ } \\
\text { relevance of impact }\end{array}$} & Scale of expected impact & $\begin{array}{l}\text { Degree to which the financing solution potentially targets and/or } \\
\text { addresses the needs of a wide range of stakeholders (i.e., poorer } \\
\text { households, women and children, marginalized groups) }\end{array}$ \\
\hline & Level of need & $\begin{array}{l}\text { Degree to which the financing mechanism is targeted at providing } \\
\text { a solution to a critical infrastructure shortage }\end{array}$ \\
\hline \multirow[t]{2}{*}{$\begin{array}{l}\text { Positive secondary } \\
\text { impact }\end{array}$} & Externalities & $\begin{array}{l}\text { Consideration of whether the financing mechanism will result } \\
\text { in any positive or negative impacts outside of its direct intended } \\
\text { purpose (e.g., improved institutional coordination) }\end{array}$ \\
\hline & $\begin{array}{l}\text { Link with other } \\
\text { key themes }\end{array}$ & $\begin{array}{l}\text { Degree to which the financing solution is reliant upon and/or } \\
\text { helps deliver advances in governance, technology, and planning }\end{array}$ \\
\hline
\end{tabular}

Source: UNESCAP. 2019. The Future of Asia and Pacific Cities 2019: Transformative Pathways Towards Sustainable Urban Development. Bangkok.

\section{Improving and Maximizing Municipal Revenue}

Cities in Asia and the Pacific must utilize a blend of public and private finance as revenue sources for their recurrent expenditures and investments. Revenue sources can be broadly categorized into own-source revenues, intergovernmental transfers, debt, and equity (Table 2). Understanding the various revenue instruments, evaluating their suitability and availability, and utilizing and managing them can be challenging. Therefore, municipal staff and decision makers should be capacitated to better understand and manage related fiscal processes. 
Table 2: Exemplary Source of Municipal Finance

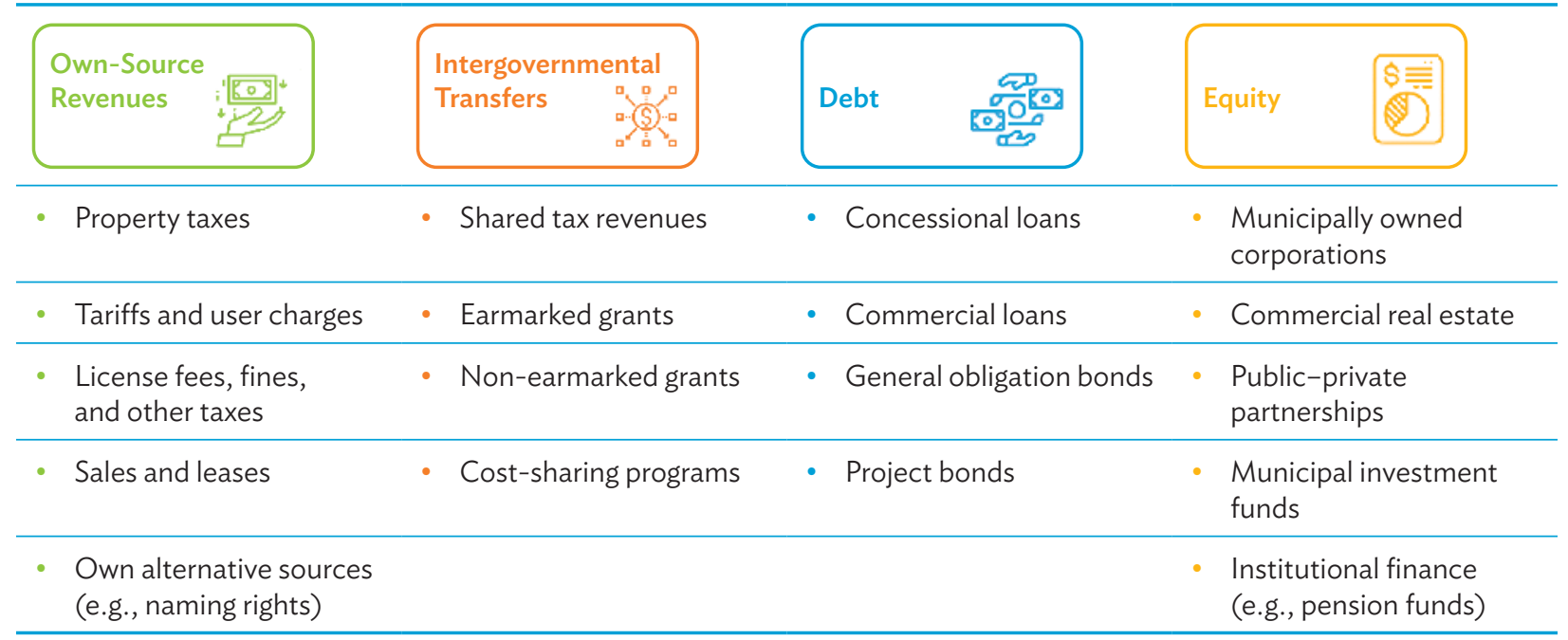

Source: Asian Development Bank.

\section{Taxes}

Local taxes have significant and predictable revenue potential, allowing greater local discretion, and in turn, a better response to local policy objectives. They also often provide for a much clearer linkage between payments and local service delivery when compared to intergovernmental transfers. However, many central governments of lower- and middle-income countries decentralize fewer revenue sources than what would be justified based on fiscal principals and subnational needs. While subnational governments in high-income countries raise $30 \%$ of total public revenues through local taxes, their counterparts in low-income countries raise less than $8 \%$ (Smoke 2019).

Hindered by current fiscal regimes and regulations, many local tax systems lack economies of scale for efficient collection and broader revenue base. Even where subnational governments are encouraged to raise their own revenue, they often underutilize this opportunity. This can be due to many causes. Intergovernmental transfers can create disincentives for subnational revenue generation, particularly where they are the default option for a municipality's finance. Local decision makers may be reluctant to impose additional taxes or other charges onto their residents in fear of political opposition. Also, central governments may control and unduly regulate the taxation of public services delivered by municipalities to sustain dependence, clout, and influence on subnational governments.

To achieve greater compliance and stricter enforcement for local tax revenue, cities can introduce simplified electronic tax-filing and electronic payment systems that improve efficiency and reduce the opportunities for corruption. Also, the local governments need to recognize that residents are willing to pay their share of taxes if services can be improved. In parallel, the promotion of local economic development may contribute to cities' tax revenues by using targeted progressive taxation. For instance, new entrepreneurs or micro and small enterprises enjoy lower taxation rates that can help them further their businesses, while local markets and supply chains are sustained by fostering competition with larger/external market players (Akitoby 2018). 


\section{Property Taxes}

As one of the most crucial sources of municipal taxes, cities turn to property taxes given its potential to generate a stable and predictable revenue stream. ${ }^{2}$ Generally, the property tax system aims to align expenditure responsibilities with the revenue allocated at the local level, reduce inequalities in the provision of public goods, and foster local government ability to provide urban services. Related to property taxes are value-capture methods in the form of property transfer, sale, and inheritance taxes that raise income for the municipality when property titles are passed on or sold from one holder or entity to another. Taxing land and properties allows city authorities to capture the enormous wealth generated by urbanization and use it for the public good. As such, it provides for a strong taxation rationale.

Property taxes are a significant source of recurring local tax revenues and are often a primary revenue for local governments in Australia, the United Kingdom, and the United States (US), while the case in developing Asia is much more mixed (Figure 3) (ADB 2014). Apart from country-level differences, property tax collection rates also differ depending on the size and development level of cities. Major cities with more sophisticated land-use planning, digitized title registration system, and stronger tax administration tend to have higher collection rates for property taxes. Property taxes, if well designed and executed through an efficient administrative system, have numerous advantages such as:

- facilitating longer-term budgeting and infrastructure development planning;

- $\quad$ fiscal revenue resilience during downturns due to their limited cyclicality;

- $\quad$ economic efficiency resulting from low administration costs;

- $\quad$ transparency and high collection success rates due to the tax being difficult to evade; and

- $\quad$ improved growth inclusiveness, if the tax is designed in a progressive way (ADB 2014).

Figure 3: Property Taxes Share of Total Revenues of Local Government, 2019 or Latest Available Year $(\%)$

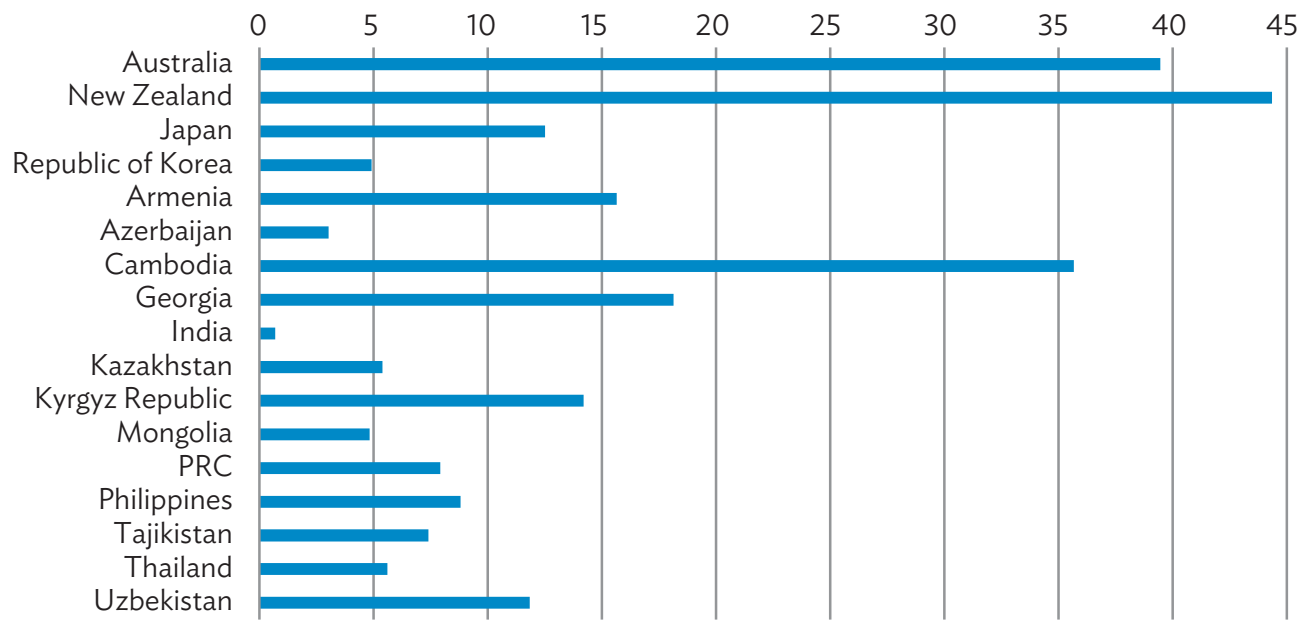

PRC $=$ People's Republic of China.

Note: India has no data for local government, instead state government data is shown.

Source: OECD-UCLG. 2020. World Observatory on Subnational Government Finance and Investment. http://www.sng-wofi.org/data/ (accessed 6 April 2020).

2 For further guidance, see Government of India, Ministry of Housing and Urban Affairs. 2020. A Toolkit for Property Tax Reforms. New Delhi. 
However, without effective institutional arrangements and set-up, property taxes can be costly and cumbersome to administer and often lead to unsatisfactory revenue mobilization. As a very visible tax, it tends to be not well-received by taxpayers and might raise suspicion and mistrust when levied against unrealized increase of housing/land value that does not directly trickle down to the property owner. This can lead to the unintended consequence that property tax rises as a proportion of a property owner's income, forcing lower middle-income owners to sell their property, monetize the increased housing/land value, and move to the outskirts of urban areas, which in turn creates knock-on effects in terms of increase commuting traffic and corresponding burdens on municipalities' infrastructure system.

Municipalities across Asia and the Pacific are challenged with undervalued properties, wherein a significant discrepancy exists between the price on the formal title and the actual value of ownership or at point of sale. As an example, the collection rate of property tax in the Mumbai municipal corporation covers only $45 \%$ of the taxable base and accounts for about $22 \%$ of all own-source revenues (UNESCAP 2017b). To combat this situation of under-assessment and under valuation, property tax rates should, in general, be low and applied over a broad base of taxpayers to yield significant revenue.

Open disputes between the local government and the property owner on regularization and approval processes for changing the use of a property should be resolved quickly. A two-pronged approach can be adopted-finding consensus and relaxing procedures without undermining the necessary rules. For instance, design changes can be tailored to the approved use of the property. In general, executing a simplified, transparent, and quick dispute resolution mechanism increases the willingness and timeliness of paying outstanding and future property taxes. Revenue bodies must uphold systems of checks and balances and related codes of conduct by operating in a fair and impartial manner that demonstrates their performance accountability (ADB 2018).

There are four main methods of land and/or property valuation that can be deployed to assess values and set taxes (IGC 2018).

(i) Capital market value assessment. This is based on sales of similar pieces of land and properties, such as residential, agricultural, or industrial land, or on the cost of the buildings' construction for immovable properties in isolated locations. The assessment requires data on land and property sales, as well as related attributes to capture the true taxable value. Additionally, characteristics such as access to main roads and critical infrastructure influence the price base. Although this method has been found to result in a high accuracy (e.g., 90\% in Japan), its collection, maintenance, and analyses of the required market transaction information on characteristics of plots is costly and requires trained staff. The method is inherently less transparent and needs significant investment in public awareness to mitigate appeals from taxpayers against the value assessment.

(ii) Rental value assessment. This establishes the typical rent required to occupy a particular land or property. Mainly used in Australia, the People's Republic of China (PRC), and India, this method reflects the current market value. Although it requires a significant amount of data, information on rental values are usually easier to obtain. Cities in India like Bengaluru, Chennai, Hyderabad, Indore, Kolkata, Patna, and Pune have introduced a self-assessment system. In this system, the rental values of the properties are determined based on the property information provided by the owners (Chattopadhyay and Kumar 2019). The self-assessment system is genuinely an appealing procedure with little administrative capacity, but the possibility of underestimation can produce significant revenue losses. If not the typical rent but the actual rent is taken as the baseline, the rental value assessment can lead to disputes between the local government and the property owner where the rental value is far below the market value. This assessment method would not be applicable on non-rentable or industrial properties that are commonly not on the rental market. As this assessment identifies the current rental value, 
it disincentivizes the sale of land for more efficient uses than for renting. Also, rental controls, used for example in India, distort the true value of land and property.

(iii) Area- and location-based assessment. This values land taxes based on land area, location, and land use, whereas property taxes are assessed based on the building area or volume. This method does not require huge amounts of data. It is more transparent and comprehensible to communicate to taxpayers. It is also easier to administer. Cities like Delhi and Chennai in India, or Kuala Lumpur in Malaysia, are using a self-declaration approach to identify the location-based value. While the assessment method has shown to improve property tax collection rates significantly for different areas of a municipality, it does not accurately reflect the actual value of land and property, potentially undervaluing the land/ property leading to unequal distribution of taxation.

(iv) Points-based assessment. This is a hybrid between an area-based and market-based valuation system using the surface area of land and observable characteristics, such as access to paved roads, train stations, electricity, or criminal records of the neighborhood. The characteristics, if affecting market value, are given negative or positive points based on a rough judgment. This method is less precise and more complex than the capital market or rental value assessment, but is not as data-intense, is easy to administer, has high potential to be automated, is more transparent, and can be communicated fairly easily to the public. It also allows for quick assessments of new or upgraded buildings. Not many cities in the Asia and Pacific region adopted the points-based assessments; but outside the region, it increased local revenues, for instance, in Sierra Leone's cities of Bo, Kenema, and Makeni, where local revenues rose by $200 \%$ to $450 \%$ between 2007 and 2011 (IGC 2018).

Exemptions to the property tax system should be minimized as much as possible as they increase the burden for nonexempt taxpayers, contribute to government revenue losses, and exacerbate the lack of transparency over the authority to confer exemptions. A 2015 study of Punjab province in Pakistan estimates that bringing the exempt owner-occupied property fully into the tax base would triple the level of property tax revenues (Bahl et al. 2015). However, it is common to provide exemptions to properties with less floor area, nonprofit entities, communitybased or faith-based organizations, as well as for welfare programs, for example, to support or keep affordable social services and housing for low-income populations.

Often, local governments lack the administrative capacity to generate, procure, and manage property data of their jurisdictions. Computer-assisted mass appraisal systems coupled with solid legal principles-preferably set at the national level consistent across all subnational governments-and valuation assessment criteria can help secure the data system and ensure consistency, accountability, and fairness among property taxpayers (Box 1). Local governments in Kanpur, India, for example, expanded the registered property tax base by $50 \%$ using geospatial technology and e-surveys to collect data on physical characteristics of properties and their occupiers (Pokhrel and Majumder 2017).

Another way to provide a secure data system ensuring transparency and accountability is through blockchainbased land registry systems that are used, for instance, in Georgia and Fij. Such systems reduce the transaction costs and time required to register and transfer property and provide government and individuals the ability to audit transactions quickly (ADB 2019-a). Due to its accuracy and low cost, other countries, including India and Japan, are rolling out blockchain for land value registration.

\section{Land Value Capture}

While not being a tax in the traditional sense, land value capture combines tax, charge, and sale instruments through a land-linked financial policy mechanism used to leverage the increment in land value due to public investments. Land value capture shares the cost of infrastructure among beneficiaries, allows greater spatial 
Box 1: Property Tax Innovations in Jharkhand, India

For many years, Jharkhand in India was struggling with low-capacitated and under-resourced urban local bodies. They could not increase the rate of property tax collection due to an outdated legal framework and collusion among households and tax collectors. In the early 2010s, a self-assessment system and a scientific method of determining the annual rental value were introduced. The property tax recovery and collection rules were made more stringent. To increase the professionalism and efficiency of tax collection, a public-private partnership started with the appointment of three tax collection agencies and a project management unit across 41 urban local bodies. Based on a self-assessment form, a digital system linked to property tax and water connection registry was developed. Cross-mapping municipal license data with property tax data and water user charge data then allowed for a gap assessment and corresponding reduction in unassessed households by more than $35 \%$. To facilitate payments, rebates were offered for payments at decentralized collection centers and online. Within just 5 years, property taxes increased from $\$ 1.36$ million to $\$ 13.87$ million, while their share among own-source revenues more than doubled from $19 \%$ to $51 \%$.

Source: S. A. Singh. 2018. Property Tax Innovations-Jharkhand (Privatization of Property Tax Collection). Municipal Finance-Resource Management: Issues and Options; Government of India, Ministry of Housing and Urban Affairs. National Workshop on Municipal Finance and Urban Planning. 26 November. http://mohua.gov.in/cms/ NationalWorkshoponMunicipal.php.

development control by local governments, increases their fiscal independence, provides for a faster recovery of externality values created by public investments, and links more strongly revenue generation and local service provision.

As land value capture closely correlates with economic growth, in theory, it creates a virtuous cycle of increasing revenue, while at the same time promoting more responsible land-related investments and providing a disincentive for land speculation. On the downside, land value capture faces implementation/enforcement challenges, long-term sustainability concerns due to underrating and mis-evaluation of land value, and potential public resistance to service charges.

Broadly, six forms of land value capture instruments can be differentiated (UNESCAP 2019).

(i) Leveraging public real estate assets. Cities often have substantial, underutilized public commercial assets such as real estate. While an approach of isolated one-off sales of such assets generates some revenues, this is not an instrument for substantial and sustainable returns. An effective approach is to identify and assess public commercial assets and place them under professional management with effective governance systems (Detter 2020).

(ii) Development charges. Development rights can be granted to developers on the requirement for cash or in-kind payments as compensation for the provision of public infrastructure in the wider development area. This instrument is particularly useful where new development areas are opened up or where land use changes in an underdeveloped community. Development charges can be utilized to improve local equity through better service provision.

(iii) Sale of development rights. Increase in population density, or the intensity of usage in an area, puts more burden on the infrastructure system. As such, the sale of development rights can provide for revenue to scale up infrastructure in a particular area. 
(iv) Land pooling/readjustment. In areas that lack a cohesive transport network or are characterized by a previously highly informal development, land readjustments and pooling can help roll out infrastructure and services, while improving the layout of neighborhoods. Landowners have to agree to contribute part of their land to accommodate such infrastructure development. Also, the readjustment of plots can provide for 'premium' pieces that can be sold, for instance, to businesses, resulting in revenues for infrastructure development as well as improved provision of services and amenities.

(v) Special assessments/betterment levies. In recognition of expected property value increases due to infrastructure development, this instrument can recoup investment costs through added property or sales taxes. It is dependent on effective communication and buy-in of landowners.

(vi) Tax increment financing. Somewhat similar to betterment levies, tax increment financing is an instrument whereby the increased tax value following infrastructure developments is used to serve as a collateral and then for refinancing of loans that were originally used for infrastructure upgrades. It relies on a very careful assessment of the value increase expected from the investment.

\section{Alternative Tax Revenues}

As urban growth advances and urban investment needs increase, cities also look into alternative approaches for revenue generation. One such example is the temporary letting of vacant public lots and facilities before their refurbishing/repurposing. Cities have also tapped revenues from selling naming rights of metro stations, sports arenas, and similar venues. Although not without controversy, leasing advertising space in public spaces provides additional revenue for municipalities. Two tax-related examples of alternative revenue sources are further explored below.

Motor vehicle tax. Cities in Asia and the Pacific are facing a rapidly increasing number of motor vehicles and related impacts on traffic, air pollution, and economic and environmental damages (ADB et al. 2019). The pace of this motorization is faster than the related provision of transport infrastructure. This trend is expected to continue as middle-class populations grow. One way of disincentivizing the rapid increase in private vehicle use is motor vehicle taxes. They can be designed in more progressive ways, whereby the ownership of a second or third car per household is taxed at a higher rate. Singapore is an example where a whole package of taxes and charges (e.g., registration fees, annual road taxes, parking fees, and electronic road pricing) aims at disincentivizing private car ownership and use in favor of public transportation and more equivalent pricing of road infrastructure costs.

Local consumption taxes. Most consumption taxes are imposed at the point of sale as gross receipts tax, therefore being rather indiscriminate and potentially putting municipalities in a disadvantaged position in terms of inter-municipal economic competition. However, there have been some innovations within local consumption taxes to achieve specific policy goals, while collecting additional local revenues to fund certain programs. One such example are sugar (or soda) taxes, which have been introduced, for instance, in Brunei Darussalam, India, Malaysia, the Philippines, and Thailand. Outside of Asia and the Pacific, municipalities in the US illustrate the use of this instrument at the local level. Although the tax by itself does not necessarily result in significant revenue streams, there has been evidence suggesting that it can have positive effects on prevention or control of obesity. This, in turn, comes with multiple co-benefits for individuals and societies, such as a decrease in municipalities' indirect costs for social service provision in the health sector (Thavorncharoensap 2017). On the downside, a local consumption tax can lead to evasions if there are large rate differences between neighboring local governments leading people and wholesale buyers to cross borders to avoid the local consumption tax in a particular area. 


\section{Tariffs and User Charges}

While cities deliver urban basic services, such as water, power, and sanitation, user charges and tariffs for public services are an effective way to maintain the financial viability and quality of public utilities supplying the services (ADB 2004).

Tariffs and user charges are first and foremost a means of cost recovery aiming to raise revenue through fees to fund a city's current operations and future investments. According to ADB (2001), cost recovery should also allow for income redistribution, minimization of waste generation, containment of demand, and efficient management of utilities. As a tool of public policy, tariffs and user charges can be used for a variety of social, economic, and financial purposes to help manage the facility benefiting from the tariff.

User charges are meant to collect payments from people using certain amenities or services at an equivalent cost ratio. The fee can be on a per-use basis (e.g., toll roads and congestion charges), periodic flat rate (e.g., annual public zoo membership), consumption rate (e.g., parking ticket for a certain time), or hybrids of these. Beyond revenue generation, user charges have underlying social and environmental effects. If invested into better mobilization and connectivity of the city, urban congestion charges, for instance, can influence car-dependent behavior by shifting travel by time, mode, and route, as well as reducing overall travel demand while simultaneously reducing congestion-related emissions (UNESCAP 2019).

The key debate around tariffs and user charges is the political decision whether the delivered service has an element of a public good or human right, and thus, should be provided at a very low cost or even for free. If the municipality acts as a monopoly supplier or the service is mandatory (e.g., with registration fees), user charges and tariffs should follow a progressive and differential structure keeping the rates low and affordable for the poor and low-income consumers, thereby freeing them from a disproportionate economic burden. Furthermore, there is a striking difference among many cities in regard to the set user charges and tariffs and their actual collection rate. Setting tariffs can be guided by five core principles, of which balance should be negotiated between decision makers, service providers, and consumers: (i) cost recovery, (ii) operating efficiency, (iii) fairness (distributive justice), (iv) affordability, and (v) economic efficiency (Mclntosh 2014).

It is a false assumption to believe that good affordable services automatically require low tariffs (World Bank Group 2017). Where such low tariffs are heavily subsidized by local governments, they tend to lack cost recovery measures and result in poor service delivery, which in turn can inhibit infrastructure access and supply. Thus, there is a need to adjust tariff setting with the purchasing power parity of residents within a city and then apply fixed (standing) charges, consumption-based charges, or (increasing/decreasing) block charges to match different groups' consumption patterns and ability to pay. ${ }^{3}$ User charges and tariffs can also be made more affordable through the use of technologies and improved operational performance, which can increase resource use efficiency while reducing operation costs. ${ }^{4}$ On the flipside, the COVID-19 pandemic has underscored how the lack of affordable services (e.g., health and WASH services) can severely impede cities' ability to cope with sudden shocks and take adequate preventive measures to control such diseases (UNICEF 2016).

3 Sustainable Sanitation and Water Management Toolbox. 2019. Water Pricing-General. https://sswm.info/sswm-solutions-bop-markets/ improving-water-and-sanitation-services-provided-public-institutions-1/water-pricing---general.

4 See the Manila Water case in Box 2 or the case of the Dhaka Water Supply and Sewage Authority in ADB. 2017. The Dhaka Water Services Turnaround. Manila. https://www.adb.org/publications/dhaka-water-services-turnaround. 
Beyond the tariff setting, the replenishment of maintenance budgets for urban infrastructure services is a challenge in Asia and the Pacific (Mclntosh 2014). Often, maintenance allocations are reduced during times of financial shortfalls, as the consequences of low funds for maintenance are usually not felt immediately or very visibly. However, studies on preserving infrastructure assets show that for every $\$ 1$ spent, for example, on regular road maintenance can save more than $\$ 5$ on refurbishing and rebuilding of roads (UNESCAP 2017a). The Government of Viet Nam reformed its underfunded road maintenance structure by establishing a Road Maintenance Fund per Decree 18/2012/ND-CP. The fund generates 35\% of automobile fees paid to the local budget, while the remainder goes to the central budget to upgrade local roads.

Data for both developed and developing economies in Asia illustrate how insufficient tariff and user charges mostly still are (Figure 4). The importance of allocating sufficient funding for infrastructure maintenance is underscored by the still dire state of water supply networks in many places across Asia and the Pacific, where nonrevenue water (i.e., water that is pumped and then lost or not accounted for) often has a share of $30 \%$ to $50 \%$ of water supply (ADB 2016). Related revenue losses due to nonrevenue water in Southeast Asia have been estimated at around $\$ 1.5$ billion per annum (ADB 2010).

Figure 4: Tariffs and Fees Share of Local Government Total Revenues, 2019 or Latest Available Year

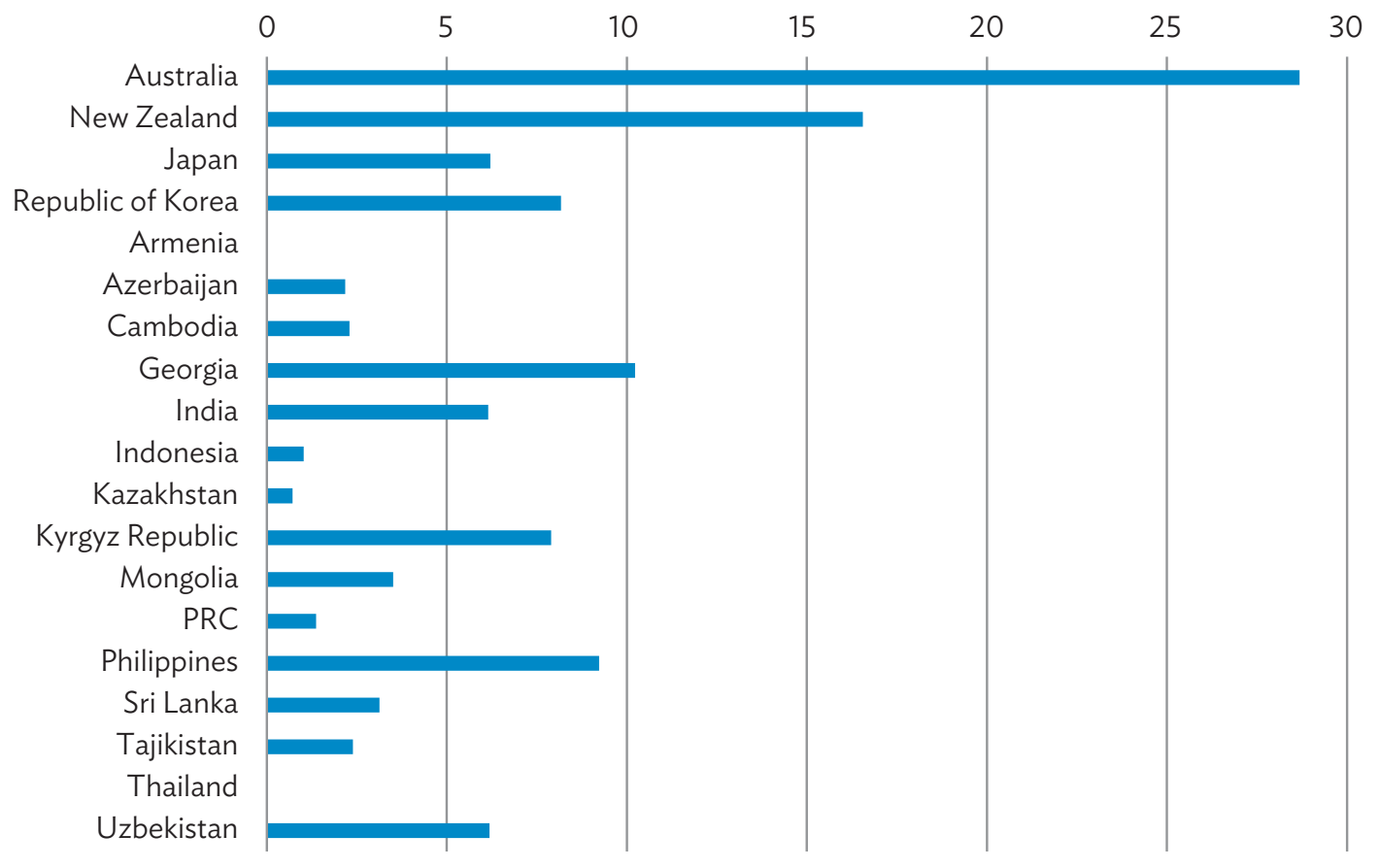

PRC = People's Republic of China

Note: India has no data for local government, instead state government data is shown. Tariffs and fees in this figure relate directly to charges the local government levies for services such as land certificates or toll roads. It may not be comprehensive in terms of recognizing tariffs and fees charged by municipally owned corporations providing services such as for water supply or waste management.

Source: OECD-UCLG. 2020. World Observatory on Subnational Government Finance and Investment. http://www.sng-wofi.org/data/ (accessed 6 April 2020). 


\section{Intergovernmental Transfers}

Almost all city governments receive financial resources from higher-level governments (particularly the national government) in the form of shared tax revenues, matching funds, or earmarked grants (for particular purposes) and unconditional grants (non-earmarked). Transfers can also come in the form of subsidies (Lindfield and Teipelke 2017). The allocation mechanism for intergovernmental transfers varies from ad hoc (often projectspecific) to recurrent ones, which can be indiscriminate of needs (derivation approach) or formula-based (i.e., targeted at equalizing certain shortfalls or disadvantages between municipalities).

In developing countries, intergovernmental grants play a dominant role in infrastructure finance, local service provision, and recurrent government expenditures (Figure 5) (Smoke 2019). Intergovernmental transfers can be a useful financial source for planning urban development, reducing the financial burden for residents (otherwise hit by local fees or taxes), and enabling cities to become champions for national reforms.

However, intergovernmental transfers also come with dependence on aligning local expenditures with capital/ donor objectives and interests with limited discretion for local needs. The dependence on intergovernmental transfers can also demotivate local governments from generating internal sources of revenue. Further, the timing of the transfers can be unpredictable, which does not allow a flexible response to market cycles, demographic shifts, policy changes, or an adequate response to shocks and stresses, such as disease epidemics or natural disasters that increasingly arise because of climate change.

Figure 5: Grants and Subsidies Share of Local Government Total Revenues, 2019 or Latest Available Year $(\%)$

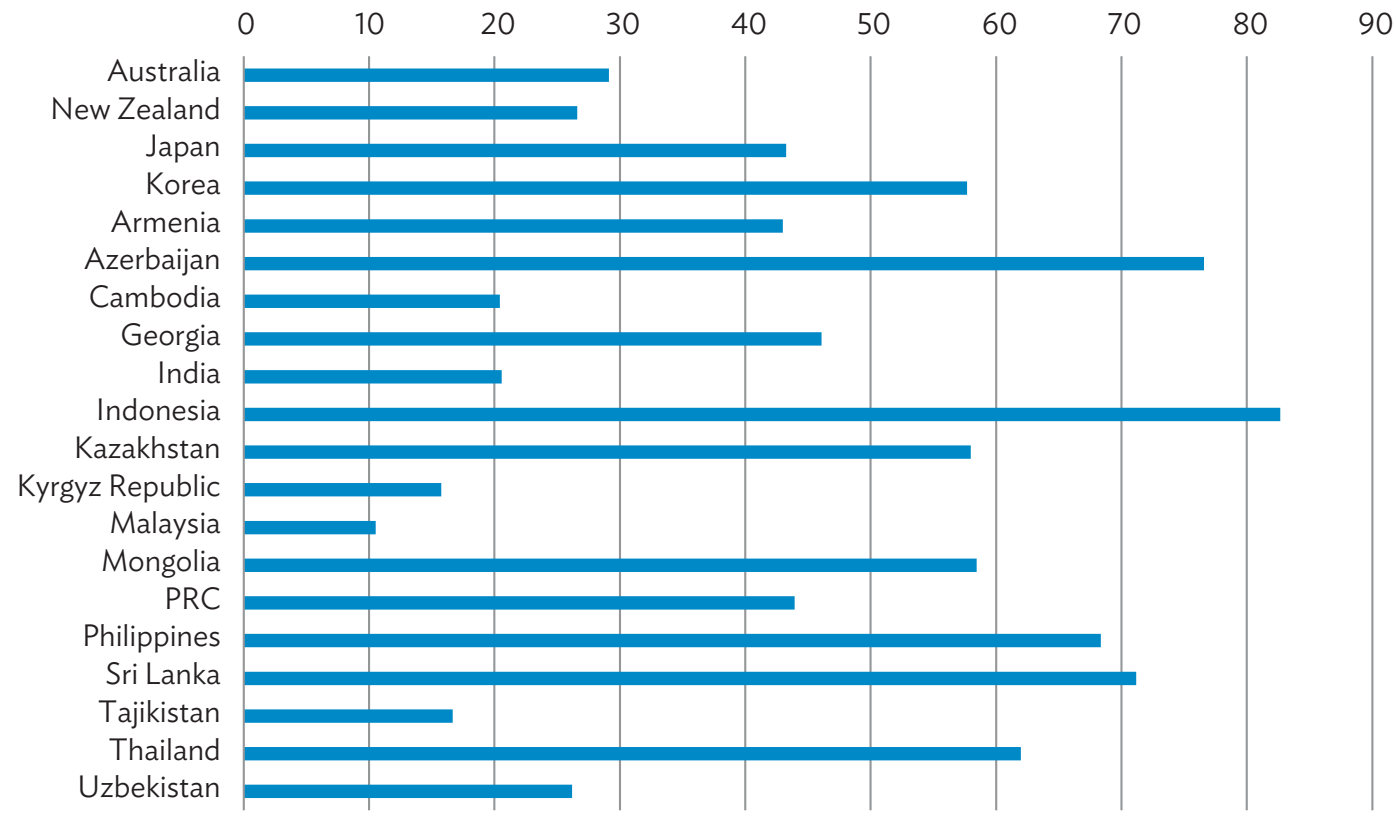

PRC = People's Republic of China

Note: India no data for local government, instead state government data is shown.

Source: OECD-UCLG. 2020. World Observatory on Subnational Government Finance and Investment. http://www.sng-wofi.org/data/ (accessed 6 April 2020). 
Intergovernmental transfers can be contentious when national and subnational governments are from different political parties, and/or disagree in their agenda setting and investment prioritization due to restrictions on the type of expenditure. If tied to a rather indiscriminate distribution mechanism, intergovernmental transfers can fall short in both addressing specific needs of weaker or particularly challenged municipalities and recognizing above-average performance of municipalities. As a result, the usefulness of the instrument may be low in terms of ensuring fiscal sustainability and targeted policy implementation.

Top-up grants and competitive grants as a subcategory of conditional grants, however, do address some of these shortcomings. Top-up grants provide an incremental grant in addition to the base funding, allowing the extension of a project or further technical support where needed. Competitive grants provide additional finance for proposed projects/initiatives that align best with the grants' funding objectives (which are usually in line with national development strategies), or for self-reliant/revenue-earning projects. The advantage of competitive grants is that they define the intended outcomes without dictating the use of specific solutions, methods, or tools. This enables greater pooling of local knowledge and stakeholder engagement informing a location-tailored design of projects and investments. On the downside, larger entities with greater capacity may often find it easier to successfully apply to such funds, while resource-stricken small administrations may simply not have the personnel or time to consider those additional funding avenues.

An innovative way to promote local economic development and mobilize higher tax collections is linking tax collections to intergovernmental transfers. Central governments can adopt policies to transfer to the local governments a part of their collection of income tax and consumption tax, which in turn, incentivizes local governments to boost local economic development through increasing local production, income, and expenditure, among others. The consequent higher tax revenues in a local government's jurisdiction are used by the central governments to enhance the amount of intergovernmental transfers to that local government. Since 2010, the Republic of Korea has applied this approach, which not only successfully strengthened local economies, but also produced positive effects for local governments' fiscal independence and creditworthiness.

\section{Catalyzing Additional Revenue Sources}

The investment needs of local governments are often greater than their annual operating surplus. Therefore, it is critical for local governments to attract external funding from grant, debt, and equity sources, further supported by risk mitigation instruments (Lindfield and Teipelke 2017). These sources can then be used to finance priority projects aligned with the city's capital improvement/investment plan. Capitalizing both public and private resources should be balanced with the expected revenue flow from investments to avoid liquidity shortfalls.

\section{Public-Private Partnerships}

In Asia, public-private partnerships (PPPs) in delivering public services have grown fast over the last 30 years. PPPs have substantially contributed to the improvement and efficacy of urban service delivery notably in the housing, water supply, and solid waste management sector (ADB 2019b). PPPs can be adopted across multiple project stages - from planning, financing, construction, to operation and maintenance. PPPs are used as a procurement and delivery method for better-quality and more viable infrastructure services in cities. Table 3 illustrates some service areas focusing on city-level PPPs. 
Table 3: City-Level Public-Private Partnership Areas

\begin{tabular}{lll}
\hline Transportation & & \\
&
\end{tabular}

Source: CDIA. 2010. PPP Guide for Municipalities. https://cdia.asia/wp-content/uploads/2014/09/PPP-guide-for-municipalities.pdf. p. 12.

An increasing number of cities in the Asia and Pacific region embed social and environmental aspects in their PPP concessions. Across the region, ADB DMCs have been adapting principles such as the 'quality infrastructure investment' to the context of subnational PPPs. ${ }^{5}$ For instance, in Manila, Philippines, a light rail transit extension was developed under a PPP arrangement, which resulted in fiscal benefits of $\$ 512$ million and is estimated to reduce 40,000 tons of carbon dioxide emissions per year (IFC 2018). An example of environmental services can be found in Indonesia, where Unilever successfully bid for a PPP concession with Jakarta and 16 other Indonesian cities. The project aims to provide waste bank facilities to improve solid waste management capacities of target cities (IFC 2018). ${ }^{6}$ In the housing sector, the Shukhobrishti Housing PPP project in New Town Rajahat of Kolkata, India, specifically caters to the housing needs of more than 100,000 low-income and middle-income citizens through a cross-subsidy approach. Under a PPP, the below-market sale of public land to the private developer allowed the developer to use parts of the land for commercial (office space) units, while committing to construct low- and medium-income housing units in parallel.

Viability gap funding is an instrument that can facilitate PPPs in the form of grants or concessional debt. It can help finance projects of particular social or environmental impact or those that deploy new technologies, which would otherwise not receive sufficient affordable public or private sector financing (ADB 2017a). The potential of this instrument is illustrated by the Umbulan Water Supply System Project in East Java, Indonesia. A private consortium and local governments could only finance $60 \%$ of the project cost. Given the importance of water provision in that part of Indonesia, the national government, through the PT Sarana Multi Infrastruktur's Project Development Facility, supported project transaction preparation and execution. A viability gap funding scheme ensured that water would be accessible by the local community at an affordable tariff (Zen 2018).

Principle 3 of the Global Infrastructure Hub Quality Infrastructure Investment. 2019. Output Specification for Quality Infrastructure. Sydney. Unilever. Environment Programme: The Need of Waste Management. https://www.unilever.co.id/en/about/unilever-indonesia-

foundation/environment-programme.html. 
Box 2: The Manila Water Story

To benefit from a reliable, efficient, and equitable operation of public services through public-private partnerships (PPPs), local governments must monitor PPPs carefully to ensure that performance targets are met and that risks are allocated to the party best suited to manage them. In the Philippines, for example, a dedicated unit of the government, the Metropolitan Waterworks and Sewerage System of Metro Manila, initiated the 1997 reforms for the water service through PPPs. The government invited the private sector to bid for a 25-year concession model for the east and west part of Metro Manila. The concession granted exclusive rights for the winning bid "to manage, operate, repair, decommission and refurbish the facilities in the Service Area, including the right to bill and collect for water and sewerage services supplied." The government remains the owner of the water utility - its asset base and all additional assets invested by the concessionaires that will be turned over at the end of the concession period. As the institutional framework for the establishment of PPPs was still weak at that time, the Government of Manila adopted a "regulation by contract" framework that clearly defined that activities would be monitored and assessed by the Regulatory Office based on a pre defined set of key performance indicators and business efficiency measures. These and many more measures led to a commercially viable operation of the water supply system throughout Metro Manila.

Source: V.C. Rivera, Jr. 2014. Tap Secrets: The Manila Water Story. The Case Study of Manila Water Company: An Exercise in Successful Utility Reform in Urban Water Sector. Manila: ADB and Manila Water Company.

The sharing of risks through PPPs provides incentives to avoid failure of projects and to deliver timely and costeffective physical infrastructure and services. The PPP holds all parties accountable, hence enforces good urban governance structures. It has also the potential to improve regulatory policy frameworks incentivizing private investment in the city beyond the PPP project (Box 2). While the risk-sharing characteristic of PPPs makes this modality more attractive than a traditional procurement, the legal complexity defining roles and responsibilities of PPPs is an obstacle to these partnerships. ${ }^{7}$ Countries in developing Asia and the Pacific-also affecting their cities-receive low rankings on the quality of their legal and institutional environment. Establishment of PPPs are constrained by lack of policy cohesion, redundant contract processes, unpredictable changes in laws and regulations, corruption, and political instability (ADB 2019b). It is estimated that the global infrastructure investment via PPPs is still less than 10\% of global public investment in advanced economies and less than $25 \%$ of global public investment in emerging market and developing economies (OECD 2018).

To utilize subnational PPPs, local governments need to develop a PPP framework. This framework should articulate how skills and capacities are resourced and maintained, and outline the common language, goals, and the appropriate expectations from PPPs. Useful tools, such as the PPP Certification Program Guide and the Certified PPP Professional (CP3) credential, have been developed by ADB, European Bank for Reconstruction and Development, Inter-American Development Bank, Islamic Development Bank, Multilateral Investment Fund, and the World Bank Group. These tools further define the underlying principles and elements of good practice that are applicable in most circumstances in emerging markets and developing economies, while recognizing the need for local variations. ${ }^{8}$

7 The COVID-19 pandemic has illustrated how demand for some PPP services, for instance in the transport sector, can drop dramatically leading to severe revenue shortfalls, which, in turn, triggers minimum revenue guarantees and additional liability on the public partner.

$8 \quad$ APMG International. PPP Certification Program Guide. https://ppp-certification.com/ppp-certification-guide/about-ppp-guide. 
Once in operation, subnational PPPs are either financed by available payments of local governments, revenues such as user fees, or a hybrid of both. As a word of caution, it is important to note that availability payments can be a substantial long-term liability for the municipal budget, reducing the flexibility for future investments. User fees, on the other hand, tend to lack the robustness of accurate revenue forecasts. Thus, PPPs are justified when they represent greater value for money compared to a traditional procurement, but they are not a means to bypass fiscal constraints (OECD 2018).

\section{Bonds}

Debt financing from bonds provide for a range of products and sources for municipal finance, with a particular focus on financing infrastructure. Traditionally, a specific infrastructure project with a clear revenue stream during its operation can be financed through a project (revenue) bond. Where such revenue stream may not be there, a municipality may commit to the repayment of a bond through its general revenues. As such, it could use the instrument of a general obligation bond. Where bond issuance is allowed at the subnational level, it often comes with the requirement that the legal and commercial responsibilities are secured in a separate entity. In those cases, municipalities can secure finance for investments through corporate bonds issued by/for a separate municipally owned company. The bond market at the subnational level has matured in countries like the US where almost two-thirds of the cities' infrastructure is funded through municipal bonds. In 2019, almost 50,000 state/local government entities could issue bonds with $\$ 3.85$ trillion outstanding in municipal bonds, much of which is owned by retail investors. The US municipal bonds market has significant lessons for the development of similar markets in DMCs:

- Increased ease of doing business due to well-established legal and market structures following the principles of transparency, disclosure, and accountability, and freedom to issue and invest anywhere without any controls and federal approvals.

- Higher attractiveness due to tax-exempt nature of municipal bonds.

- Enhanced efficiency through the use of technology, data analytics, and free flow of information to investors and issuers through instruments such as electronic municipal market access.

- Investors find the municipal bonds attractive because of acceptable returns for the risks, and complete and accurate information (e.g., standardized legal disclosures, agreed-upon standards of accounting and auditing).

- Issuers find the municipal bonds acceptable because of tolerable borrowing costs (tax exempt, huge competition), flexibility, and credit quality.

- Debt obligations match with infrastructure periods with bonds issued for periods as long as 30 to 50 years.

One innovative debt financing approach is a long-term infrastructure floating bond, combined with the application of positive spillover taxes to increase the rate of return on infrastructure investments (Yoshino 2019). Conventional fixed-rate bonds are generally unattractive for investors as infrastructure projects generate low or no returns during early development stages. A floating bond, of which the yields can be adjusted in line with returns from the projects, utilizes spillover tax revenues generated from the infrastructure project to enhance the returns in later development stages. For example, a new highway project can bring economic opportunities and increase land and property values in the region, generating higher income taxes and property taxes, among others. To harness these increased tax revenues, governments may support businesses and auxiliary infrastructure, such as housing and other social facilities. Increased revenues contribute to the yields of the bond, compensating for the initial low returns at early stages of the infrastructure development-making a floating bond more suitable 
for such infrastructure projects. Moreover, governments and private investors can share the additional revenues equally or agree on a "cap," over which the additional revenues can just be kept by the government.9

Countries in Asia and the Pacific, such as Indonesia and the Philippines, are now increasingly using bonds for infrastructure financing, although often through national-level vehicles (OECD and APEC 2019). Where legal restrictions may prevent local governments from issuing bonds, other pathways are through municipally owned utility companies or special purpose vehicles (Climate-KIC et al. 2016). Either way, revenue-generating projects need to be identified; risks need to be well understood; and transaction costs for underwriting, guarantee fees, and other expenses need to be taken into account, preferably mediated through upper-level government support, such as through tax breaks on municipal bonds (SBI Mutual Fund 2018).

In regard to creditworthiness, bond financing at the subnational level remains only realistically available either to sufficiently large municipal entities with self-reliant, economically viable projects, and robust financial management systems, or to above-municipal, regionally pooled vehicles such as infrastructure investment funds (Smoke 2019).

It is worth mentioning that the bond market has evolved in recent years with products specifically tailored to more sustainable finance and investment. This can be seen in the tremendous growth of the green bond market, and in innovative bond issuance for achieving social impact or the UN Sustainable Development Goals (SDGs) (Lindfield and Teipelke 2017). One such example is the Seoul Metropolitan Government, which in 2016, issued Asia's first Social Impact Bond for a child welfare program. The service provider, verified by a third-party evaluator, is reimbursed for its expenses and receives a bonus if it can effectively achieve the program objectives. The transfer of the bond contract to investors was also facilitated through blockchain technology for improved transparency. ${ }^{10}$

Although bonds are not directly attainable by all municipalities in developing countries, their provincial or national governments can consider those instruments as a way to prioritize investments into certain sustainable or climate change agendas. In this way, the needed resources can be allocated to subnational governments' targeted projects and programs. Furthermore, even cities that are not able to issue green bonds, for instance, can align their project portfolio with the performance criteria of other green bond issuers, such as international finance institutions. This can allow those institutions to invest in a city's green bond-aligned projects and use several of such projects to issue a packaged green bond themselves (Climate-KIC 2016).

\section{Municipal Development Funds and Pooled Financing}

Municipalities are often not allowed or sufficiently capacitated to access capital markets or other external financing options from private investors. However, municipal development funds and similar vehicles have proven to be useful for cities to finance infrastructure investments (Box 3). Similar vehicles are governmentowned development financing institutions, such as the Development Bank of the Philippines or provincial development banks in the PRC.

9 More details on methodologies for setting the rate of return for a floating bond can be found at N. Yoshino. et al. 2019. Innovative Financing for City Infrastructure Investment by Increasing the Rate of Return from Spillover Tax Revenues. ADBI Working Paper 979. Tokyo. https://www.adb.org/sites/default/files/publication/514256/adbi-wp979.pdf; and N. Yoshino and M. Nakahigashi. 2020. Role of Digital Education to Help Long-Term Growth Recover Under Covid-19. Tokyo.

10 Seoul Metropolitan Government. 2016. Seoul Implementing SIB for the First Time in Asia. 28 April. http://english.seoul.go.kr/seoulimplementing-sib-first-time-asia/; and Pan-Impact Korea LLC. 2018. The Combination of SIB and Blockchain. 7 February. http://panimpact.kr/first_smart_sib/. 


\section{Box 3: Pooled Financing in Tamil Nadu}

A prominent example of municipal development funds that deploy pooled financing is the Tamil Nadu Urban Infrastructure Financial Services Limited in India. It manages the Tamil Nadu Urban Development Fund, the Water and Sanitation Pooled Fund (focusing on less-resourced municipalities), and two dedicated grant funds to support project preparation and poverty alleviation. As a public-private financial intermediary, it illustrates how vehicles at the subnational, provincial level can access funding from international finance institutions, the government, and the private sector. Effective risk matching allows for long-term, affordable, and stable credit to municipalities. Another advantage of such funds is they come often with grant resources for project identification, preparation, and implementation, and additional support in terms of capacity development.

Source: Asian Development Bank. 2016. GrEEEn Solutions for Livable Cities. Manila. https://www.adb.org/publications/ greeen-solutions-livable-cities.

Linked to municipal development funds is the approach of pooled financing. This mechanism acknowledges the limited financial capacities of individual municipalities and allows smaller entities to join forces to access the capital market or obtain loans at better rates. They can achieve this through pooling, which basically deconcentrates the default risk of individual municipalities. Pooled financing at the subnational level has shown to reduce the costs for local infrastructure projects through economies of scale, and domestic capital markets are strengthened through these 'market-making' instruments (FMDV 2017). There is also a useful exchange of knowledge and learning involved between local governments of different capacities.

Sometimes, pooled financing is combined with a revolving fund, whereby infrastructure investments, for instance, for extended household wastewater connections are implemented incrementally. This allows for a step-by-step financing of the infrastructure instead of requiring a large one-off capital availability. At the same time, it enables loan back-payments by those serviced first, which replenishes a (pooled) fund for later investments and roll out of the infrastructure to other areas. One successful example is the Philippine Water Revolving Fund set up in 2008. The fund used initial concessional seed financing through official development assistance with a standby credit line, domestic public funds, and commercial financing to make local water and wastewater projects attractive to private institutional financing. This has been achieved through lower borrowing costs, lower investment risks due to credit enhancements, and a multilayered approach with finance and risk accordingly matched with each party's appetite (World Bank 2016).

It should be noted that many of these alternative revenue sources depend on risk mitigation to lower the cost of capital and make the instruments attainable to cities. Such risk mitigation can come in the form of national government-backed credit enhancement and underwriting, the provision of guarantee funds and loan loss reserves by multilateral development banks and development finance institutions, as well as loan syndication (i.e., several banks backing a loan) (OECD and ASEAN 2020).

\section{Creditworthiness}

To attract additional investments from the private sector and capital markets, cities need to be creditworthy (Table 4). The creditworthiness of a municipality describes its potential to default on its debt obligations (C40 2016). Independent international and national rating agencies are tasked to assess the voluntarily disclosed key financial data of a city and provide a score based on a quantitative and a mathematic ratio analysis. 
Table 4: Illustrative Subnational Government Financing Arrangements

\begin{tabular}{|c|c|c|c|}
\hline \multirow{2}{*}{$\begin{array}{l}\text { Type of } \\
\text { Investment }\end{array}$} & \multicolumn{3}{|c|}{ Subnational Government Income Level/Creditworthiness } \\
\hline & Low & Medium & High \\
\hline Self-financing & $\begin{array}{l}\checkmark \text { Transfer } \\
\checkmark \text { Loans (possibly subsidized) } \\
\varnothing \text { Bonds }\end{array}$ & $\begin{array}{l}\varnothing \text { Transfer } \\
\checkmark \text { Loans (possibly subsidized) } \\
\checkmark \text { Bonds (if feasible) }\end{array}$ & $\begin{array}{l}\varnothing \text { Transfer } \\
\checkmark \text { Loans } \\
\checkmark \text { Bonds }\end{array}$ \\
\hline $\begin{array}{l}\text { Partially revenue- } \\
\text { generating }\end{array}$ & $\begin{array}{l}\checkmark \text { Transfer } \\
\checkmark \text { Loans (likely subsidized) } \\
\varnothing \text { Bonds }\end{array}$ & $\begin{array}{l}\checkmark \text { Transfer } \\
\checkmark \text { Loans (likely subsidized) } \\
\varnothing \text { Bonds }\end{array}$ & $\begin{array}{l}\checkmark \text { Transfer (if justified) } \\
\checkmark \text { Loans (possibly subsidized) } \\
\varnothing \text { Bonds }\end{array}$ \\
\hline $\begin{array}{l}\text { Non-self- } \\
\text { financing/ } \\
\text { Social purpose }\end{array}$ & $\begin{array}{l}\checkmark \text { Transfer } \\
\varnothing \text { Loans } \\
\varnothing \text { Bonds }\end{array}$ & $\begin{array}{l}\checkmark \text { Transfer } \\
\checkmark \text { Loans (possibly subsidized) } \\
\varnothing \text { Bonds }\end{array}$ & $\begin{array}{l}\checkmark \text { Transfer (if justified) } \\
\checkmark \text { Loans (possibly subsidized) } \\
\varnothing \text { Bonds }\end{array}$ \\
\hline
\end{tabular}

Source: P. Smoke. 2019. Improving Subnational Government Development Finance in Emerging and Developing Economies: Toward a Strategic Approach. Tokyo: Asian Development Bank Institute. p. 15. https://www.adb.org/publications/improving-subnationalgovernment-development-finance-emerging-developing-economies.

The analyses typically include the assessment of (i) the state of the local and national economy, (ii) the debt structure, (iii) the financial conditions, (iv) the demographic factors, (v) the management practice of the local government, and (vi) the legal policy framework (World Bank 2014). Nonetheless, a rating is not a scientific evaluation, and subjective judgment plays a fundamental role in the rating assigned. In addition to the mentioned assessment criteria, international rating agencies also focus on a city's ability to service debt in foreign hard currencies. The credit rating for a municipality is globally comparable, recognized, and as such, can open the door to international investments if allowed by a country's specific legal framework.

Though more desirable, international credit ratings are much more difficult to obtain for a municipality and borrowing in foreign currencies increases the risks associated with fluctuating foreign currency exchange rates, unless risk mitigation instruments are effectively utilized. Therefore, municipalities would typically opt first for a national credit rating, with a focus on borrowing from local banks and capital markets. This would usually limit cities to borrow in their local currency which reduces the pool of potential investors/lenders. However, local currency markets play an important role and are currently a relatively untapped finance source (Box 4).

The credit rating of a municipality helps investors determine the risk related to a potential investment. Typically, the higher the rating, the more finance will be available at more preferential rates (i.e., lower interest rate, longer grace period, or smaller bond coupon payment). As such, creditworthiness is interlinked with the existing infrastructure finance gap and the large investments needed to realize the SDGs and the international climate agenda. As the World Bank's Low-Carbon Livable Cities (LC2) Initiative states, "every dollar invested in the creditworthiness of a developing country city is likely to mobilize more than USD100 in private sector financing for low-carbon and climate-resilient infrastructure" (World Bank 2013).

Along with a city's effort to obtain a credit rating often come also other benefits in terms of enhanced transparency of municipal finances, enforced fiscal discipline, improved management, and good governance (C40 2016). Beyond financial aspects, the assessment of a municipality's creditworthiness also identifies infrastructure gaps and urban development issues, which can help prioritize targeted investments and inform medium- to long-term planning. Such a strategic approach for urban development not only attracts outside investors but also eases and accelerates the lender's decision-making process. However, less than $20 \%$ of the 


\section{Box 4: Advancing Local Currency Markets in Asia and the Pacific}

Developing local currency markets to leverage additional finance for much needed infrastructure investments is a key concern of developing member countries in Asia and the Pacific. The Association of Southeast Asian Nations (ASEAN)+3 Asian Bond Markets Initiative concluded on the following set of key recommendations to advance local currency markets:

- Comprehensive and robust legal framework.

- Full, accurate, and timely accounting and financial reporting.

- Comprehensive credit assessments for creditworthiness measurement.

- $\quad$ Availability of information and market transparency.

- $\quad$ Safe and efficient trade, payment, clearing, and settlements systems.

- Smooth communication between market participants.

- Market liquidity.

- Clear and consistent tax policies.

- Creation of a specialized market for professional investors.

- Cooperation among stakeholders and market participants to implement remaining reforms.

Sources: P. Smoke. 2019. Improving Subnational Government Development Finance in Emerging and Developing Economies: Toward a Strategic Approach. Tokyo: Asian Development Bank Institute. https://www.adb.org/publications/improvingsubnational-government-development-finance-emerging-developing-economies. Asian Development Bank. 2019. Good Practices for Developing a Local Currency Bond Market. Lessons from the ASEAN+3 Asian Bond Markets Initiative. Manila. https://www.adb.org/publications/developing-local-currency-bond-market.

largest 500 cities in developing countries were deemed to be creditworthy in 2013 (World Bank 2013). The lack of credit ratings for municipalities results in low investor confidence and corresponding limitations in the type and scale of external finance available to subnational governments.

\section{Infrastructure as an Asset Class}

The premise of additional revenue sources outlined in this section is that public sector-dominated financing is insufficient to meet the infrastructure investment needs in the coming years (ADB 2017-b). Infrastructure as an asset class asserts that any municipally owned asset can generate an income, if professionally managed. The critical pillars for this include (i) diagnosis of initial inventory, (ii) classification of assets, and (iii) capital investment plans for the use of asset wealth. These pillars help cities identify their asset holdings, assess private and public obligations, and improve participation and accountability in the use of municipal assets (IGC 2009). ${ }^{11}$

11 In a quite exceptional approach in the region, the city state of Singapore has incorporated its public asset portfolio into public wealth funds delegated to holding companies responsible and accountable for managing public commercial assets. The public wealth funds of Temasek and the Government of Singapore Investment Corporation have driven economic development of the city state and provided almost $80 \%$ of its population with affordable and well-maintained public housing. To date, the joint market value of Temasek and GIC (Government of Singapore Investment Corporation) exceeds Singapore's public liabilities and is more than 1.7 times the annual gross domestic product (GDP) of Singapore-improving the net worth and financial flexibility of the government, while supporting its high creditworthiness. See ADB. 2020. Public Commercial Assets: The Hidden Goldmine. The Governance Brief. 44. Manila. 
There are large pools of private savings in Asia and the Pacific that are mostly untapped for infrastructure investments. It is estimated that institutional investors (e.g., pension funds, insurance funds, and sovereign wealth funds) manage around \$120 trillion in assets globally (McKinsey Global Institute 2016). For those savings, institutional investors are looking for secure investments aligned with their relatively long-term liabilities and the need to diversify their portfolios and distribute investment risks (PwC 2018). For such investments, certain infrastructure assets are suitable, as they can provide steady cash flow and predictable returns that are less sensitive to business cyclicality.

However, there are still numerous obstacles that make infrastructure as an asset class a difficult equation, particularly at the subnational level. There is a lack of bankable infrastructure projects sufficient in size for institutional investors. Infrastructure assets are very heterogeneous in terms of sector, geography, and regulations. And there is still limited data and knowledge about specific infrastructure's risk-return profile in relation to their performance over a lifetime, especially in light of climate change impacts and the deployment of innovative technologies (OECD 2019a). These obstacles are further compounded for DMCs in Asia and the Pacific and their cities. They may not possess the same features as developed economies have, such as:

- $\quad$ high credit ratings;

- low sovereign risk exposure;

- $\quad$ stable and mature regulatory frameworks;

- $\quad$ well-structured projects;

- clear planning, structuring, and implementation procedures and standards;

- corresponding capacities and experience; and

- $\quad$ established capital markets (OECD 2019a).

However, there are regional examples of infrastructure funds that were successful in obtaining local and international private sector investments. An example is the BTS Mass Transit Growth Infrastructure Fund, whose proceeds through securitization are linked to the fare box revenues from the Core BTS Sky Train System in Bangkok, Thailand (PwC 2018).

By fitting different investors' risk appetite with different investment finance types and stages, risk mitigation can help manage some of the challenges in infrastructure investments. Risk mitigation is applicable to most of the alternative revenue sources presented in this section. It allows for a lower cost of capital and 'insurance' against project performance, finance, and political risks. It can come, for instance, in the form of national governmentbacked credit enhancement and underwriting, the provision of guarantee funds and loan loss reserves by multilateral development banks and development finance institutions, as well as loan syndication (i.e., several banks backing a loan) (OECD and ASEAN 2020).

Asia has been emerging as "the new frontier for blended finance" (Convergence 2019). Blended finance vehicles are specifically supported by bilateral development agencies, multilateral development banks, and other global funds, such as the Green Climate Fund. Such vehicles have been emerging as a way to crowd in private finance, while accelerating the implementation of international development agendas (e.g., Paris Agreement and the SDGs). Blended finance vehicles aim to leverage private sector finance with concessional financing and guarantees, thereby pooling in different investors according to their risk and return expectations. The case of the Shandong Green Finance Facility shows how innovative approaches are piloted at the subnational level (Box 5). The facility focuses on enhancing sustainable and climate-resilient investments in cities (ADB 2019c). 
Box 5: Blended Finance Applied in the Shandong Green Development Fund

The objective of the Shandong Green Development Fund (SGDF) is to implement an innovative, replicable, and scalable form of financing facility that will tap new funding sources, both public and private. It aims to use catalyst concessional sources of finance as a leverage for creating a pipeline of viable climate-resilient and low-emission investments. The SGDF ensures that the fund addresses priority climate impacts and vulnerabilities in Shandong, People's Republic of China. It incorporates a project development facility to develop a pipeline of sustainable and replicable subprojects that will support project sponsors in achieving high levels of performance based on the Green Climate Fund (GCF) investment criteria. The SGDF also includes structures for financially incentivizing highly performing subprojects based on the GCF investment criteria, and leveraging private, institutional, and commercial (PIC) finance. Using a "cascade financing" approach, private financing will be leveraged at both the fund and project levels. A fund of approximately $\$ 1.5$ billion (CNY10 billion in 2019) is expected to leverage at least another $\$ 2.5$ billion in PIC funds. Adaptation investment is to be at least $25 \%$ of SGDF's portfolio. The fund has developed a methodology for benchmarking the portfolio composition against the priority sectors for adaptation interventions as defined by a climate vulnerability analysis (specifically coastal protection, flood control, water resilience and greening/heat island) prioritized based on the number of people under threat.

Sources: Asian Development Bank. 2019. Report and Recommendation of the President to the Board of Directors: Proposed Loan to the People' Republic of China-Shandong Green Development Fund Project. Manila; Green Climate Fund. 2019. Funding Proposal FP082: Catalyzing Climate Finance (Shandong Green Development Fund). Incheon, China: Asian Development Bank (Decision B.23/09).

\section{Advancing Financial Sustainability of Cities}

Countries in Asia and the Pacific are too diverse to adopt a single approach to sustainable municipal finance. Each country and each municipality need to develop a tailored approach to their capacities, legal framework, distribution of authorities and responsibilities, governance regimes, and related processes. Informed by Operational Priority 4 in ADB's Strategy 2030 on making cities more livable, the following recommendations provide guidance on the different expenditure and revenue areas that should be adjusted to specific local contexts (ADB 2019d).

\section{Recommendations for Municipal Expenditures Management}

\section{(i) Allocation Efficiencies}

- Allocate budget based on the concepts of equity and priority. The identification and prioritization of infrastructure projects should be informed by an assessment of their necessity, cost-effectiveness, finance availability, operations and maintenance expenditure prospects, and their role in furthering livable cities (i.e., through increased disaster resilience or reduced air pollution).

- Expand contingency budgeting in specific areas like disaster recovery, ad hoc repair, or unexpected price volatility (e.g., inflation or currency exchange fluctuations) to enable a municipality's swift response to unforeseen circumstances, while safeguarding other budget lines dedicated to often equally important spending areas.

- Reengineer existing welfare schemes, or establish new ones, for simpler and faster flow of funds to vulnerable populations. Municipal direct benefit transfers to target beneficiaries will 'cut the middleman' and reduce delays of disbursement, which in turn can increase their willingness to pay for urban services. 
(ii) Technical Approaches

- Strengthen budget formulation and control techniques with more focus on correct estimation. This should be reflected in medium-term expenditure frameworks that consider central and public investment commitments, and tools for budget formulation and stricter expenditure monitoring.

- Structure proper classification for expenditure heads informed by clearly formulated budget manuals for local governments, including further subdivisions/specifications under general areas of personnel, goods and services, and investments/capital spending. Transfers from one subhead to another during a budget year should be closely scrutinized.

- Incentivize cost analyses and reductions by changing the way how and for what period allocated budgets for particular subsectors are being made available. This could entail, for instance, the use of saved expenditure budgets for additional investments or the recognition of municipal staff who were able to achieve cost savings in their programs.

- Upgrade and reform accounting and procurement systems to achieve clearer record-keeping, easier monitoring, and more transparency, as well as improved efficiencies in handling payments, tendering, and contracting. This will not only strengthen a local government's daily work, but also increase the private sector's trust and willingness to invest locally and collaborate on joint projects.

(iii) Fiscal Strategies

- Carefully study and address the reasons for deficit financing. Although quite common in some municipal finance systems, cities should identify budget shortfalls and devise more sustainable spending avenues in preparation of taking on more responsibilities in the future.

- Employ rolling multi year budgeting, as it can enable longer-term planning and secured funding for initiatives that require sustained efforts. It also avoids the perverse end-of-year spending spree common in departments who would otherwise lose their unspent funds or even face decreased budgets in the following year as a result of underspending.

\section{Recommendations for Municipal Revenues Management}

(i) Revenue Impact

- Maximize internal revenue sources by striking a balance between taxes, tariffs, and transfers. Confirm their appropriateness in terms of social inclusion and calibrate their price levels and collection methods to ensure effective realization of corresponding revenues. This process should be supported by electronic filing/collection systems. Municipalities should also scope 'creative' revenue streams, which may nudge behaviors of people and firms toward more environmentally sustainable practices.

- Strengthen the impact of intergovernmental transfers by providing, for instance, outcome- or performance-based grants and local economy-linked transfers. These would allow and motivate municipalities to devise a locally appropriate approach to implementing related activities. Recurrent transfers from higher-level governments would also benefit from more predictability, and accountability in spending.

(ii) Planning and Design Effectiveness

- Manage tariffs and user charges holistically. Strike a balance between different functions, from cost recovery to affordability. At the same time, look into collection effectiveness and sustainable operation regimes in terms of network performance and the targeted maintenance and its budgeting.

- Harness the potential of property taxes, starting from low but broad-based rates to yield significant revenue. This should be based on a value assessment method that is suitable for a city 
government's capabilities and access to the required data. Adopt simple and clearly communicated taxation principles, with exemptions being avoided where possible. Strengthen property title and tax management using enabling technologies, such as computer-assisted mass appraisal systems and blockchain-based land registry systems.

- Promote land-based financing-beyond simple, one-off land sales-as a tool to capture increments in land values from public and private investments, particularly for urban regeneration, spatial expansion, and mass transit projects. Conduct an appropriate project appraisal to accurately identify beneficiaries and quantifiable benefits.

- Take a whole-lifecycle approach to local asset management. Treat infrastructure as an asset class that can attract multiple investors. This will help create various finance types at different stages of an infrastructure asset's lifetime, including provision of maintenance services. Leveraging private finance for infrastructure investments will depend on improved project preparation. Emulate international good practices and models in project structuring and contracting. Conduct a close monitoring of infrastructure performance to collect more detailed asset-level data for better decision-making and more accurate risk return profiling.

(iii) Instrument Opportunities

- Join forces through pooled financing and municipal development funds. These instruments can lower the cost of capital, reduce the default risk, provide access to additional finance sources, leverage that finance (e.g., in combination with a revolving fund mechanism), and encourage city governments to share knowledge and learn from each other.

- Support public utilities and service providers to develop public-private partnerships (PPPs). Strengthen administrative capacity and regulations, expand upstream pipeline development, invite private sector solutions to tackle urban development challenges, and deploy strategic environmental and social features in PPP concessions to ensure benefits to the public good. PPPs are particularly relevant to contexts where private sector expertise for urban services is well developed. ${ }^{12}$

- Increase capacities to potentially utilize bonds, particularly for revenue-generating projects with climate/green and social impacts, for which investor interest is rapidly growing. Where legal circumstances prevent local governments from issuing bonds directly, utility companies and special purpose vehicles can provide avenues for bond issuances. Related to that, strong efforts should be dedicated to improving creditworthiness of local administrations to broaden potential capital access and strengthen local financial management systems.

- Take advantage of climate finance and safeguard investments. Prioritize infrastructure and services that strengthen the resilience of city governments, citizens, and firms to climate change shocks and stresses. This, in turn, will ensure that assets are designed to future needs and qualify for concessional climate and green finance from international funds and multilateral development banks.

These core elements will define the opportunities toward each municipality's financial sustainability. However, implementing the recommendations to improve the management of local expenditures and revenues will depend on several enabling actions. To achieve financial sustainability, municipalities should strengthen the local capacities in fiscal management; use long-term strategic investment planning; and ensure effective project preparation, implementation, and operations and maintenance.

12 The Municipal Public-Private Partnership Framework, developed by World Bank, is a helpful tool for municipal practitioners. It presents a series of fundamental questions concerning the municipality's institutional capacity and the applicable legal and regulatory framework to provide a basic assessment of the municipality's readiness to pursue a PPP project or program. World Bank. 2019. Municipal Public-Private Partnership Framework. Washington DC. 
Many of the recommendations will benefit from, or are even only possible with, the support of national governments and conducive legal and regulatory frameworks. Sustainable municipal finance equally concerns local, provincial, and national governments. It also entails a dialogue between public sector, citizens, and firms, who are key contributors of municipal revenues and important (potential) investors for new infrastructure projects.

Many cities in developing Asia and the Pacific aim to transform their economies through higher-value production and services and to create well-paying jobs for their relatively young populations. Smart investments in quality infrastructure and services are critical to equipping cities with the physical, financial, and human capital resources to manage this transformation successfully.

The global COVID-19 pandemic has exposed the vulnerability of urban infrastructure and services and underscored the value of proactive investments in resilient cities (ADB 2020b). The options and practices discussed in this article will help cities in scoping revenue sources, finance instruments, and good expenditure practices. As such, cities can make well-informed choices, build up contingencies for extraordinary events, and create more livable cities.

\section{References}

Asian Development Bank (ADB), African Development Bank, European Bank for Reconstruction and Development, and Inter-American Development Bank. 2019. Creating Livable Cities: Regional Perspectives. Manila. https://www.adb.org/publications/creating-livable-cities.

ADB. 2001. Guidelines for the Financial Governance and Management of Investment Projects Financed by the Asian Development Bank. Manila. https://www.adb.org/documents/guidelines-financial-governance-and-managementinvestment-projects-financed-adb.

- - . 2004. Beyond Cost Recovery: Setting User Charges for Financial, Economic, and Social Goals. Manila. https://www.adb.org/publications/beyond-cost-recovery-setting-user-charges-financial-economic-and-socialgoals.

-_- 2010. The Issues and Challenges of Reducing Non-Revenue Water: Philippines. Manila. https://www.adb.org/ publications/issues-and-challenges-reducing-non-revenue-water.

-_- 2012. Subnational Finance for Infrastructure: Potential Roles and Opportunities. Manila. https://www.adb. org/sites/default/files/publication/29768/adb-wp20-subnational-finance-infrastructure.pdf.

- - - 2014. Property Taxation in the People's Republic of China. Manila. https://www.adb.org/publications/ property-taxation-peoples-republic-china.

- - 2 2016. Asian Water Development Outlook 2016: Strengthening Water Security in Asia and the Pacific. Manila. https://www.adb.org/publications/asian-water-development-outlook-2016.

- - . 2017a. Catalyzing Green Finance: A Concept for Leveraging Blended Finance for Green Development. Manila. https://www.adb.org/publications/green-finance-catalyzing-facility. 
_-_. 2017b. Meeting Asia's Infrastructure Needs. Manila. https://www.adb.org/publications/asia-infrastructureneeds.

-_- 2017. The Dhaka Water ServicesTurnaround. Manila. https://www.adb.org/publications/dhaka-waterservices-turnaround.

- - . 2018. A Comparative Analysis of Tax Administration in Asia and the Pacific. Manila. https://www.adb.org/ publications/comparative-analysis-tax-administration-asia-pacific.

-_- 2019a. Distributed Ledger Technology and Digital Assets Policy and Regulatory Challenges in Asia. Manila. https://www.adb.org/publications/distributed-ledger-technology-digital-assets-asia.

- - . 2019b. Realizing the Potential of Public-Private Partnerships to Advance Asia's Infrastructure Development. Manila. https://www.adb.org/publications/potential-ppp-asia-infrastructure.

-_-. 2019c. Report and Recommendation of the President to the Board of Directors: Proposed Loan to the People's Republic of China-Shandong Green Development Fund Project. Manila. https://www.adb.org/projects/documents/ prc-51194-001-rrp.

-_-. 2019d. Strategy 2030 Operational Plan for Priority 4: Making Cities More Livable, 2019-2024. Manila. https://www.adb.org/documents/strategy-2030-op4-livable-cities.

-_- 2020a. Guidance Note: Livable Cities_Post-COVID-19 New Normal. Manila. https://www.adb.org/sites/ default/files/institutional-document/624566/guidance-note-livable-cities-post-covid-19.pdf.

- - . 2020b. The Economic Impact of the COIVD-19 Outbreak on Developing Asia. ADB Briefs.128. Manila. https://www.adb.org/publications/economic-impact-covid19-developing-asia.

Akitoby, B. 2018. Raising Revenue: Five Country Cases Illustrate How Best to Improve Tax Collection. Finance \& Development. 55 (1). Washington, DC: International Monetary Fund.

Bahl R., M. Cyan, and S. Wallace. 2015. The Potential of Provincial Taxation. Oxford: Oxford University Press.

C40. 2016. Good Practice Guide: Creditworthiness. London.

Chattopadhyay, S. and A. Kumar. 2019. Tapping the Revenue Potential of Property Tax in India. Chicago: Tata Center for Development.

Climate-KIC, CPI, South Pole, ICLEI, CBI. 2016. Green Bonds for Cities: A Strategic Guide for City-Level Policymakers in Developing Countries. London.

Convergence. 2019. The State of Blended Finance 2019. Toronto/Nairobi.

Detter, D. 2020. Public Commercial Assets: The Hidden Goldmine. The Governance Brief. 44. Manila: Asian Development Bank. https://www.adb.org/publications/public-commercial-assets.

Global Fund for Cities Development (FMDV). 2017. The Potential Catalytic Role of Subnational Pooled Financing Mechanisms. Paris. 
International Finance Corporation (IFC). 2018. Climate Investment Opportunities in Cities. Washington D.C.

International Growth Centre (IGC). 2009. Improving Asset and Debt Management in Developing Cities. https://www.theigc.org/blog/improving-asset-and-debt-management-in-developing-cities/.

IGC. 2018. Land and Property Taxes for Municipal Finance. London.

Lindfield, M. and R. Teipelke. 2017. Explainer: How to Finance Urban Infrastructure. London (C40).

McIntosh, A.C. 2014. Urban Water Supply and Sanitation in Southeast Asia: A Guide to Good Practice. Manila: Asian Development Bank. https://www.adb.org/publications/urban-water-supply-and-sanitation-southeast-asiaguide-good-practice.

McKinsey Global Institute. 2016. Bridging Global Infrastructure Gaps. Singapore.

Organisation for Economic Co-operation and Development (OECD) and Asia-Pacific Economic Cooperation (APEC). 2019. Financing Infrastructure in APEC Economies. APEC/OECD Report on Selected Effective Approaches. Paris.

OECD and Association of Southeast Asian Nations (ASEAN). 2020. Commercial Risks Mitigation. http://rmid-oecd.asean.org/project-risks-mitigation/risk-mitigation-instruments/commercial-risk-mitigation/.

OECD-United Cities and Local Governments (UCLG). 2020. World Observatory on Subnational Government Finance and Investment. http://www.sng-wofi.org/data/ (accessed 6 April 2020).

_-_. 2018. Subnational Public-Private Partnerships: Meeting Infrastructure Challenges. Paris.

- - . 2019. 2019 Report: World Observatory on Subnational Government Finance and Investment. Paris.

_-_. 2019. Revenue Statistics in Asian and Pacific Economies 2019. Paris.

-_- 2019a. The G20 Roadmap to Infrastructure as an Asset Class. Paris.

Pan-Impact Korea LLC. 2018. The Combination of SIB and Blockchain. 7 February. http://panimpact.kr/first_ smart_sib/.

Pokhrel, N. and S. Majumder. 2017. India: Smart Partnerships Making Kolkata a Smart City. Asian Development Blog. May. https://blogs.adb.org/blog/india-smart-partnerships-making-kolkata-smart-city.

PwC. 2018. Investing in the ASEAN Infrastructure Asset Class. Infrastructure Series Report 3. Singapore.

SBI Mutual Fund. 2018. Municipal Bonds Market in India: Perspectives from Investor Viewpoint. Government of India, Ministry of Housing and Urban Affairs. National Workshop on Municipal Finance and Urban Planning. 26 November. http://mohua.gov.in/cms/NationalWorkshoponMunicipal.php.

Seoul Metropolitan Government. 2016. Seoul Implementing SIB for the First Time in Asia. 28 April. http://english. seoul.go.kr/seoul-implementing-sib-first-time-asia/. 
Smoke, P. 2019. Improving Subnational Government Development Finance in Emerging and Developing Economies: Toward a Strategic Approach. Tokyo: Asian Development Bank Institute. https://www.adb.org/publications/ improving-subnational-government-development-finance-emerging-developing-economies.

Sustainable Sanitation and Water Management Toolbox. 2019. Water Pricing-General. https://sswm.info/sswmsolutions-bop-markets/improving-water-and-sanitation-services-provided-public-institutions-1/water-pricing--general.

Thavorncharoensap, M. 2017. Effectiveness of Obesity Prevention and Control. ADBI Working Paper Series No. 654. January. Tokyo: Asian Development Bank Institute. https://www.adb.org/publications/effectiveness-obesityprevention-and-control.

World Bank. 2013. Liveable Cities - Planning and Financing Low-Carbon Cities. Washington D.C.

_-_. 2014. Municipal Finances: A Handbook for Local Governments. Washington DC.

_- - 2016. Water Revolving Fund in the Philippines. Washington DC.

_-_. 2017. The Status of Infrastructure Services in East Asia and Pacific. Washington, DC.

UN Economic and Social Commission for Asia and the Pacific (UNESCAP). 2017a. Infrastructure Financing Strategies for Sustainable Development in South-East Asia. Bangkok.

United Nations Economic and Social Commission for Asia and the Pacific (UNESCAP). 2017b. Metropolitan City Finances in Asia and the Pacific Region. Bangkok.

UNESCAP. 2019. The Future of Asia and Pacific Cities 2019: Transformative Pathways Towards Sustainable Urban Development. Bangkok.

United Nations International Children's Emergency Fund. 2016. Strategy for Water, Sanitation and Hygiene, 2016-2030. New York.

Yoshino, N. et al. 2019. Innovative Financing for City Infrastructure Investment by Increasing the Rate of Return from Spillover Tax Revenues. ADBI Working Paper 979. Tokyo. https:/www.adb.org/sites/default/files/ publication/514256/adbi-wp979.pdf.

Zen, F. 2018. Public-Private Partnership Development in Southeast Asia. ADB Economics Working Paper Series No. 553. Manila. https://www.adb.org/publications/ppp-development-southeast-asia. 


\section{Urban Housing Bond Market Development in Asia}

Heejoon Jeong, ${ }^{1}$ Bambang Susantono, Donghyun Park, and Shu Tian

\section{Introduction}

Securing a stable living space is essential to living a decent life. Demand for housing, which is a physical living space, is influenced by population, income, urbanization, and household structure (Doling et al. 2013). Due to rapid urbanization and income growth, housing demand is inevitably higher in Asia than in other regions.

However, housing prices are often so expensive that households cannot afford them with only their labor income earned and saved over a short period. This is especially true in urban areas, where houses are more expensive. For example, in the urban areas of the Republic of Korea, where the urbanization rate increased from $40.7 \%$ in 1970 to $81.6 \%$ in 2015, there has been a chronic shortage of housing supply and a sharp rise in the housing prices. Amid rising affordability burdens, a mortgage system enables households to purchase homes if they have a stable source of income to make future mortgage payments. Since there is a high proportion of households with stable income in the urban areas, development of a mortgage system can greatly contribute to housing stability in the urban areas and ultimately benefit the country as a whole. Because traditional financial intermediaries acting as mortgage lenders relied on savings to finance mortgage loans, only limited loan amounts and maturities were available to home buyers in the earliest form of a mortgage system. Providing housing opportunities to more households required a differentiated housing finance system, capable of increasing mortgage lending and managing the resultant risks.

Money raised through mortgages is used as a factor of production in real sectors such as housing construction (supply side). But even so, there may be a timing gap between the demand for large-scale funding from the construction sector and the fund inflows from mortgages. For a properly functioning housing market where supply meets demand, housing finance should play a role in reducing the time friction that may exist between the demand and supply of finance in the housing construction sector.

To that end, it is necessary to enhance the role of financial intermediaries, mainly banks. Also, it is critical to invigorate housing bond finance based on the capital market. In developed economies with active housing bond markets, housing finance sources include not only financial intermediaries, but also investors, both institutional and individual, in capital markets. As a result, the smooth supply of housing finance has stimulated the construction and financial services industries, leading to job creation and income generation, and ultimately contributing to economic growth. The developed housing finance markets, especially housing bond market, provide the historical experiences that showed high efficiency in large-scale housing finance in urban areas. 


\section{Housing Finance and Housing Bond Market}

Within any economic system, the demand for stable housing comes not only from individuals but also from the society as a whole. Thus, a system that ensures stable housing for all is indispensable for the maintenance and growth of the society. Houses are long-lived durable goods; therefore, buyers need a large sum of money to purchase a house. The essential necessity of housing finance arises because many home buyers face difficulties securing sufficient funds at their desired time of purchase.

Housing finance is generally known as the operation of the mortgage market in the form of housing loans or mortgage loans that enable consumers who wish to have their own home to borrow against the value of their housing asset. It allows consumers to spread the required payments over the period of the loan to own that asset (Lude and Whitehead 2016).

Housing finance is actually a much broader and more diverse concept. This is because houses - the purpose that housing finance is used for-vary in shape and size (e.g., single-family and multifamily houses, and more recently, share houses). Housing may be acquired through purchase or other ways (e.g., rental or long-term lease) since the users of housing finance may have varying needs in terms of amount, maturity, interest rate, and early redemption method, among others; while different types of financial institutions may meet user needs in a variety of ways.

The International Union for Housing Finance stresses that housing finance can be defined in diverse ways. It describes the nature of housing finance as follows: "Housing finance brings together complex and multisector issues that are driven by constantly changing local features, such as a country's legal environment or culture, economic makeup, regulatory environment, or political system" (International Union for Housing Finance n.d.).

However, the meaning of housing finance, which is defined based on the perspective of housing demand, tends to neglect finance for housing supply. Although the funds borrowed from the mortgage market flow into the supply side of the housing market, namely the construction sector, there may be a timing mismatch between when funds are needed and when they are available. Therefore, the concept of housing finance, in a broad sense, needs to include the funding needs of the supply side to ensure the timely delivery of housing.

In spite of the complexity and scalability of the concept, housing finance also needs to achieve the primary purpose of finance, which is to efficiently mobilize the capital needed for financial consumers (Goldsmith 1969). In addition, it should be a system that can reflect the characteristics of housing in the financing process.

In the early stages of economic growth in most advanced economies, including the United States (US), housing finance was bank-based finance. Banks provided loans secured by real property (mortgage loans), and short-term deposits were their main source of funding for mortgage loans. As a result, early mortgages had a short-term variable rate that could not fully satisfy mortgagors in need of long-term financing (McConnell and Buser 2011). Furthermore, financial intermediaries had to take on various risks - such as credit risk, liquidity risk, and prepayment risk -in the process of asset transformation for housing finance.

Against this backdrop, the advent of a housing bond market brought about fundamental changes to the structure of housing finance. For banks, which were the major provider of housing finance, long-term mortgages were illiquid assets. Therefore, once a mortgage loan was made, a new mortgage could not be made until the existing loan was repaid or unless new money inflows occurred. Furthermore, fluctuations in market interest rates, alongside nonperforming loans (NPLs), could cause substantial losses to banks with large holdings of long-term, fixed-rate mortgages. 
Such a situation necessitates a financial system that provides protection against losses from mortgages held by banks and ensures the liquidity of mortgage assets. A mortgage guarantee or mortgage payment insurance scheme could be introduced to protect lenders against mortgage losses. A mortgage refinance agency funded by the public sector could also be established to facilitate asset liquidity.

Mortgage refinance agencies or entities, however, do not have limitless funds available. Therefore, they have to raise funds on their own by issuing bonds and notes. Also, they need an effective funding vehicle to meet mortgage refinancing needs above and beyond the amount of funds raised. The most popular instruments are mortgage-backed securities (MBS), which give investors the right to receive cash flows from mortgages and are tradable in capital markets. MBS are the core product in the housing bond market. Covered bonds, also known as mortgage-backed bonds, are also housing bonds that are structurally similar to MBS in terms of the underlying asset pool, except that covered bonds are issued by different types of entities.

MBS and covered bonds are financial instruments created through the process of securitization so that they can be traded in the capital markets. Investors trading in MBS or covered bonds can be institutions or individuals. Thus, the securities can be used to expand the base of funding for housing finance to include all investors at home and abroad.

The housing bond market refers to a capital market in which debt class instruments are issued and sold to raise funds for housing. Housing bonds are a type of bond classified by the purpose of issue, like social bonds and green bonds, rather than traditional standards such as the type of issuer or method of repayment.

In addition to MBS and covered bonds, there are various types of housing bonds. Government corporations issue debt securities to finance their operations, for example, refinancing existing mortgages, buying mortgages and issuing MBS, and providing guarantees or insurance for mortgages and MBS. These agency bonds are housing bonds as well.

Both central and local governments may use proceeds from the issuance of government bonds to provide housing finance for housing stability. However, it is difficult to consider these bonds as housing bonds because government bond proceeds are used for various purposes. If the government issues bonds solely for the purpose of implementing housing finance policy, then the bonds can be regarded as housing bonds.

\section{Products and Investors}

MBS are generally considered debt securities (or bonds) in the capital market, though they can take different forms other than traditional debt securities (Fabozzi 2016a). The simplest form of MBS are pass-through securities whose structure involves borrowers, a bank (originator), a mortgage servicer, and a special purpose vehicle (issuer of MBS). Investors are entitled to receive cash flows from a pool of mortgages in proportion to the face value of the MBS they own.

A pass-through MBS may be different from plain vanilla bonds that produce constant cash flows until maturity. This is because the cash flows of MBS vary depending on the method of determining the interest rates of the underlying mortgages and principal payment rate per period. Furthermore, MBS are subject to high cash flow uncertainty as mortgages are often paid off before maturity, and sometimes are in default. 
There are a wide range of MBS products in which different techniques are employed to reduce the uncertainty of cash flows. The most popular are collateralized mortgage obligations and stripped MBS.

Backed by a pool of mortgage loans, collateralized mortgage obligations are structured with multiple tranches separated by credit quality and maturity. Stripped MBS are favored by investors who do not wish to face reinvestment risk arising from multiple cash flow streams from the securities.

MBS use guarantees from guarantee institutions to mitigate credit risk. In this case, guarantees provide protection from investment risk, but the guarantee fees charged reduce the rate of return on the investment.

Unlike MBS, which allow the originator to move the underlying mortgages off its books by selling them to the special purpose company, covered bonds are securities backed by a pool of mortgages that remain on the books of the originator. Accordingly, in contrast to MBS whose cash flow stability is determined by the quality of the underlying assets or external credit enhancement, covered bonds are an investment whose creditworthiness is based primarily on the issuer's credit quality and secondarily on the nature of collateral (that is, the underlying assets).

In other words, the issuer of covered bonds pays principal and interest as in the case of nonguaranteed, uncollateralized corporate bonds. When the issuer goes bankrupt, cash flows from the designated ring-fenced pool of assets, on which the bondholders have a priority claim, are used to pay the principal and interest on the covered bonds. While MBS have evolved mainly in the US, covered bonds have developed primarily in Europe.

Another investment product in the housing bond market are agency bonds issued by public corporations established to support MBS issuance. Most of these enterprises are explicitly government-funded, but some are privatized. Nevertheless, a dominant view in the capital markets is that housing agency bonds are guaranteed by the government. At the same time, agency bond yields tend to be a little bit higher than government bond yields.

Because a stable housing market is the backbone of the economy, the government (both central and local) usually covers housing-related expenditure, especially for low- and middle-income households, by means of taxation or government bond issuance.

In general, the proceeds of government bonds are used to fund not only housing projects, but also other public projects. For some economies, however, governments issue bonds to fund housing projects only. These bonds are also government bonds, and thus they receive the same credit rating as that of the sovereign bond. If the bonds are different in liquidity from other government bonds, their market price may differ as well.

Also, bonds may be issued by local governments to finance housing projects. Among them, obligation bonds can hardly be classified as housing bonds since local governments use tax revenues to repay the municipal bonds. On the other hand, revenue bonds whose interest and principal payments are funded by cash flows generated from housing projects can be regarded as housing bonds (Fabozzi 2016b).

Housing bonds, which comprise one class of bonds, are financial products issued and traded in the capital markets. This means that these can be an investment alternative for all investors pursuing returns. As with other major bonds, housing bonds tend to be traded in large volumes by institutional investors.

Non-institutional investors with sufficient capital above a minimum investment threshold are allowed to directly buy and sell housing bonds in the wholesale market. Because MBS provide higher divisibility than mortgages due to securitization, investors can make small investments through institutional investors acting as housing 
bond dealers. Moreover, investors can invest indirectly in housing bonds by purchasing beneficiary certificates of investment trusts or mutual funds that include housing bonds in their portfolios.

The main investors in MBS and covered bonds are pension funds and insurance companies. This is because mortgages themselves are basically long-term loans, and structured securities backed by underlying mortgage pools are also issued for longer maturities. Also, pension funds and insurers with long-term debt obligations have strong demand for long-term bonds because of asset liability management.

Hedge funds and asset management firms generally invest in financial instruments with relatively high expected returns (Berliner et al. 2016). These institutional investors tend to invest primarily in non-agency MBS.

Investors in housing agency bonds are not much different from those in other agency bonds. Agency bond investors are nearly the same as government bond investors. Given that most investors who want to hold risk-free assets invest in government bonds, investors in housing agency bonds, in practice, include both institutional and individual investors.

Apart from the institutional investors mentioned earlier, commercial banks, asset management companies, and securities companies (investment banks) also invest in housing bonds. Meanwhile, housing bond investment can also be undertaken as part of socially responsible or social impact investing, which has received increased attention in recent years.

\section{Rationale for Developing the Housing Bond Market}

Housing finance increases access to home ownership, thereby contributing to the well-being of people through residential stability. It also enables households to acquire properties that can generate long-term rental income. Housing construction is also known to affect employment, savings, investment, and productivity (Harris and Arku 2006). Funds raised through housing finance system generate demand in the real economy, including the housing construction sector, thereby becoming an important driver of economic growth. Therefore, housing finance development facilitates the growth of the economy.

From a historical point of view, housing finance relies primarily on private sector capital, mostly bank loans. Such a phenomenon tends to be more pronounced in developing economies, especially those with bank-based financial system. Even in the US, where the housing finance system is most developed, the housing finance sector in its nascent stage was dominated by banks. Currently, however, the US has the world's most developed housing bond market.

Implications for the housing bond market can be drawn out from the rationale and direction of development - primarily from the historical experiences of the US economy, which has overcome many obstacles.

In the US, mortgage lending was funded by short-term deposits in the early 1900s. Early mortgages were short-term, renewable loans that were secured by collateral. The availability and pricing of mortgages varied across regions, making them insufficient to satisfy the financing needs of potential home buyers. Meanwhile, the default rate for home mortgages originated by banks soared in the aftermath of the Great Depression. During the financial catastrophe that accompanied the Great Depression, bank-based housing finance revealed its limitations in terms of scalability and risk management. 
To resolve these issues, the Federal Home Loan Bank (FHLB) was founded in 1932, and the Home Owners' Loan Corporation was established in 1933 pursuant to the Home Owners' Loan Act. The Home Owners' Loan Corporation was directed to help home owners refinance existing mortgages to reduce the rate of foreclosure. In response, it introduced long-term, fixed-rate, and self-amortizing mortgages. Although these two government agencies assisted the US in overcoming the crisis posed by the Great Depression, they played only a limited role in improving the intended functions of the housing finance system.

Major milestones that reshaped the housing finance system include the enactment of the National Housing Act in 1934, which launched the Financial Housing Administration insurance to protect approved lenders against losses from mortgage defaults. By enhancing the stability of mortgage loans, these steps paved the way for widening the mortgage supply base.

The creation of Fannie Mae in 1938 resulted in an epoch-making expansion of sources of mortgage funding in the US. Fannie Mae was established as a federal government agency to provide a liquidity facility for mortgage lenders in the secondary mortgage market by buying, holding, and selling mortgages.

In 1952, Fannie Mae became a public-private mixed ownership corporation. In 1968, the Housing and Urban Development Act split the old Fannie Mae into a private, shareholder-owned company known as Fannie Mae, and a government-owned corporation, the Government National Mortgage Association, or Ginnie Mae (Weiss and Jones 2017).

Ginnie Mae was created to guarantee the timely payment of principal and interest on privately issued MBS backed by government-insured or guaranteed mortgages. In 1968, the very first MBS were issued and guaranteed by Ginnie Mae (McConnell and Buser 2011). For the earliest MBS, the underlying assets were mostly single-family mortgages before gradually diversifying into multifamily mortgages.

The issuance of MBS by Fannie Mae and Freddie Mac, which was founded in 1970, led to the issuance of private-label MBS (also called non-agency MBS). Private-label MBS refer to securities backed by non-conforming mortgages that do not meet Fannie Mae's or Freddie Mac's creditworthiness standards.

The emergence of MBS was a breakthrough event that not only expanded the supply side of housing finance from various institutional investors to include the investing public, but also provided risk management tools to mortgage originators.

Promoting housing finance by developing the structured finance market requires the involvement of various capital market entities that carry out a mortgage valuation, provide credit enhancements, undertake MBS issuance activities (including multitranche structuring), collect mortgage principal payments and transfer cash flows to investors, and provide marketing services. For the entities to perform their respective roles properly, it is imperative that a well-developed housing bond market exists.

In many economies, housing finance agencies are increasing the share of funding through bond issuance in total funding. Given this, housing bond markets are becoming increasingly important across the world. Finally, the development of a housing bond market, which should be preceded by the adoption of advanced financial products and techniques, is very important for the growth of the real economy as well as the financial sector, including housing finance. 


\section{Housing Bond Markets in Advanced Economies}

Despite differences in the development process, housing bond markets in most developed economies were created with the securitization of cash flows from loans extended by mortgage originators. The roles of the housing bond market are to expand the supply side of housing finance by providing a wide range of investors with access to the market, and to provide risk management tools to mortgage originators. Notably, MBS have grown to become a substantial part of the US housing bond market, whereas covered bonds have driven growth in the European market.

In the US, which is home to the world's most developed MBS market, the volume of agency MBS outstanding grew steadily for decades, reaching nearly $\$ 4.1$ trillion in 2002 before slowing in subsequent years in the wake of the subprime mortgage woes and the global financial crisis (Figure 1). As the US rode out the crisis through the mid-2010s, agency MBS outstanding volume rebounded to reach $\$ 8$ trillion at the end of 2017.

In contrast, non-agency residential mortgage-backed securities (RMBS) grew faster than agency MBS in the pre-crisis period and peaked at $\$ 2.7$ trillion in 2007 , just before the onset of the global financial crisis. However, non-agency RMBS outstanding have since declined sharply, falling to $\$ 0.8$ trillion at the end of 2017 , reflecting the fact that the increase in and securitization of non-agency RMBS were major triggering factors that led to the crisis.

Among housing agency bonds, the outstanding volumes of those issued by Fannie Mae and Freddie Mac reached their peak during the global financial crisis. Since then, they have declined steadily. On the other hand, FHLB bonds outstanding decreased from 2008 until 2012 before rising again. In 2018, FHLB bonds comprised the largest proportion of total housing agency bonds. As a result, the proportion of FHLB bonds traded in the secondary market has been on the rise as well.

Figure 1: Housing Bonds Outstanding in the United States (\$ billion)

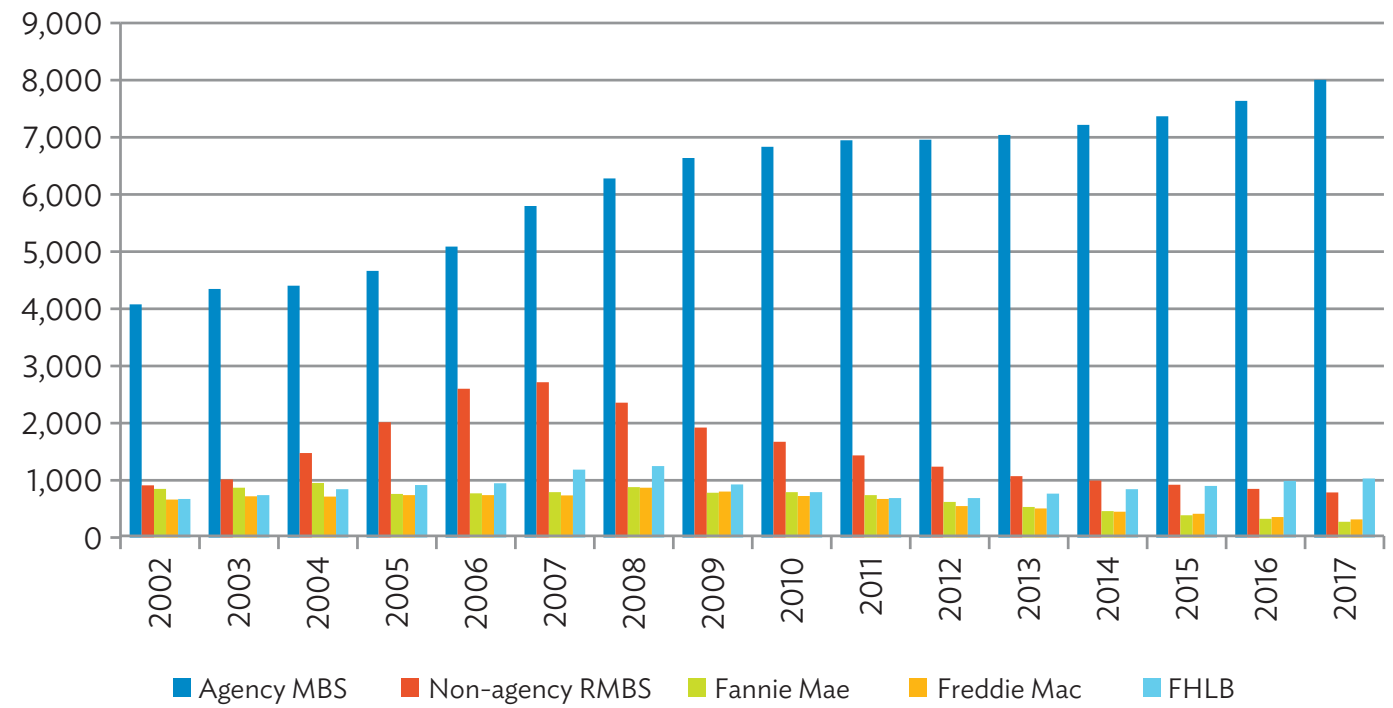

FHLB = Federal Home Loan Bank, MBS = mortgage-backed securities, RMBS = residential mortgage-backed securities . Source: United States Securities Industry and Financial Markets Association. 
In Europe, where the role and proportion of covered bonds in the housing bond market has been significant, 26 out of 28 European Union economies had covered bond legislation as of 2014 (Lunde and Whitehead 2016). The total volume of covered bonds outstanding in Europe even increased during the global financial crisis, but subsequently dropped after reaching a peak in 2012. Nevertheless, the outstanding volume of covered bonds backed by mortgages has rebounded since 2015.

Among European economies, Germany has the covered bond market with the longest history, and it uses a variety of asset classes as underlying collateral. The German financial market produces covered bonds backed not only by mortgages, but also by underlying assets such as ships and assets in the public sector, among others. Recently, Denmark became the largest market in Europe for covered bonds backed by mortgages; outstanding covered bonds backed by mortgages accounted for $98.8 \%$ of the total covered bond market in Denmark in 2016 (Figure 2).

The main issuers of covered bonds in Europe are financial institutions acting as mortgage originators. Since the bonds issued by financial institutions are generally classified as corporate bonds, it would be difficult to segment the European housing bond market into agency bonds and non-agency bonds in the same way that the US housing bond market is divided.

In Europe, MBS were introduced in the mid-1980s and have become an important source of funding, especially in Ireland and the United Kingdom. The growth in the use of MBS was supported by the subsidiaries of US financial institutions. The market almost collapsed after the global financial crisis because of the problems experienced in the US, which was only beginning to recover in 2014 (Scanlon and Whitehead 2011; Lundea and Whitehead 2016).

Figure 2: Outstanding Covered Bonds in European Union, 2016

\section{(€ billion)}

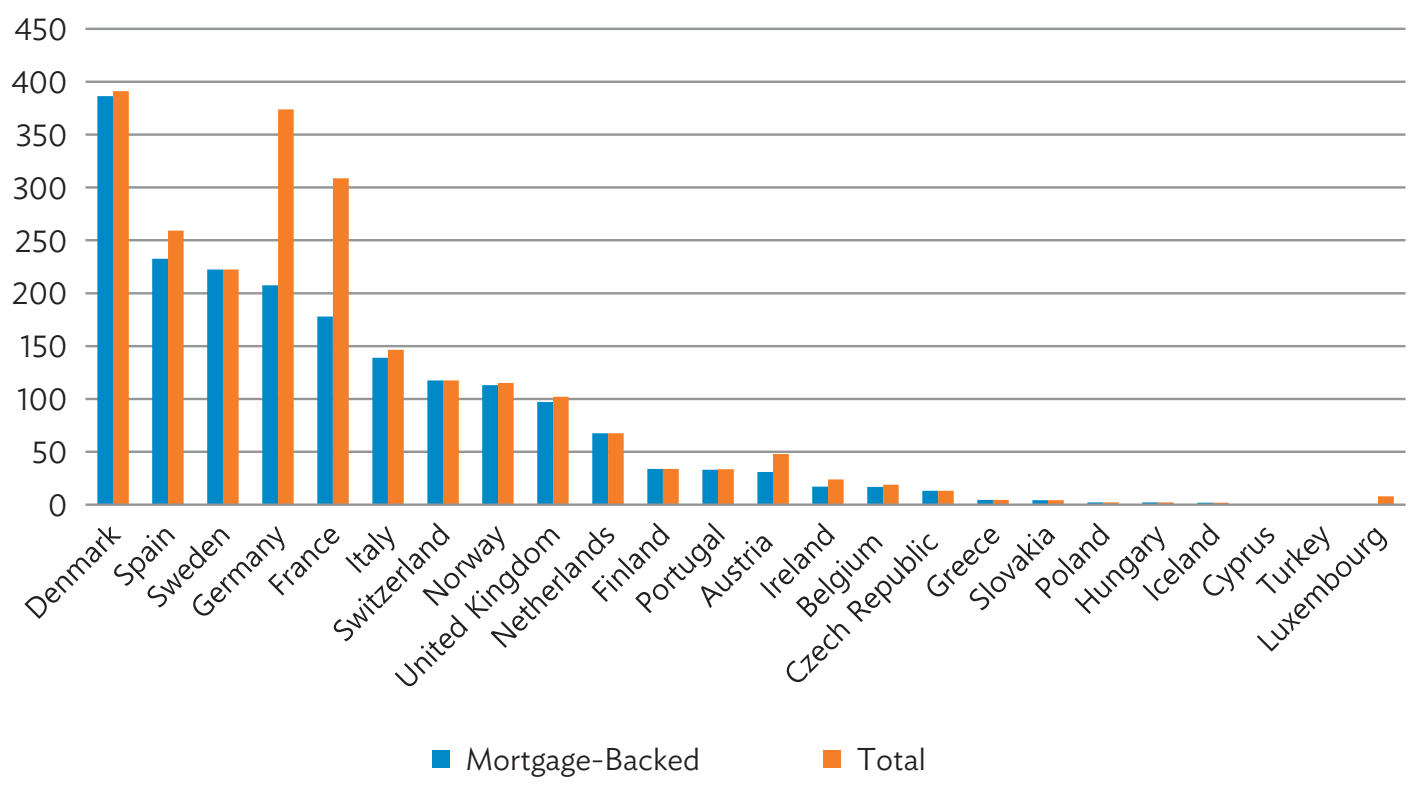

Source: European Mortgage Federation-European Covered Bond Council. 2017. ECBC Covered Bond Fact Book 2017. Brussels. 
Japan was the first economy in Asia to establish a government housing finance agency, the Government Housing Loan Corporation (GHLC), in 1950. The GHLC provided long-term, fixed-rate mortgages to households through loan originators. Its sources of funding were borrowings from the Fiscal Investment and Loan Program and proceeds from the issuance of agency bonds. The GHLC also provided mortgage insurance to households.

In 2003, the GHLC began to participate directly in the housing bond market with a shift in its business focus to the issuance of MBS backed by mortgages from private mortgage originators. In addition, the GHLC started to guarantee the timely payment of principal and interest on MBS issued by financial institutions. It was renamed the Japan Housing Finance Agency (JHF) in 2007.

The MBS issuance of JHF has steadily increased over the past decade. The outstanding amount of MBS doubled from about $¥ 6.8$ trillion at the end of 2007 to $¥ 12.7$ trillion at the end of 2017 (Figure 3), accounting for $10.1 \%$ of the total value of mortgages in Japan ( $¥ 125.9$ trillion).

The increase in the amount of agency bonds outstanding has been remarkable. In terms of total bonds outstanding, agency bonds are smaller than MBS but their average annual growth rate between 2007 and 2017 was about $31 \%$, expanding from only $¥ 0.3$ trillion in 2007 to $¥ 3.2$ trillion in 2017 . However, this impressive growth rate gradually decreased during the review period. The proportion of other bonds issued by JHF, property accumulation saving scheme-tied housing bonds, and housing land bonds has also gradually decreased.

The share of housing bonds in Japan's bond market, which is dominated by government bonds, is very small. However, the share, which was about $1.1 \%$ at the end of 2007 , rose to $1.5 \%$ at the end of 2017 , as the importance of housing bonds in the overall bond market is gradually increasing.

Figure 3: Growth of the Housing Bond Market in Japan

(¥ trillion)

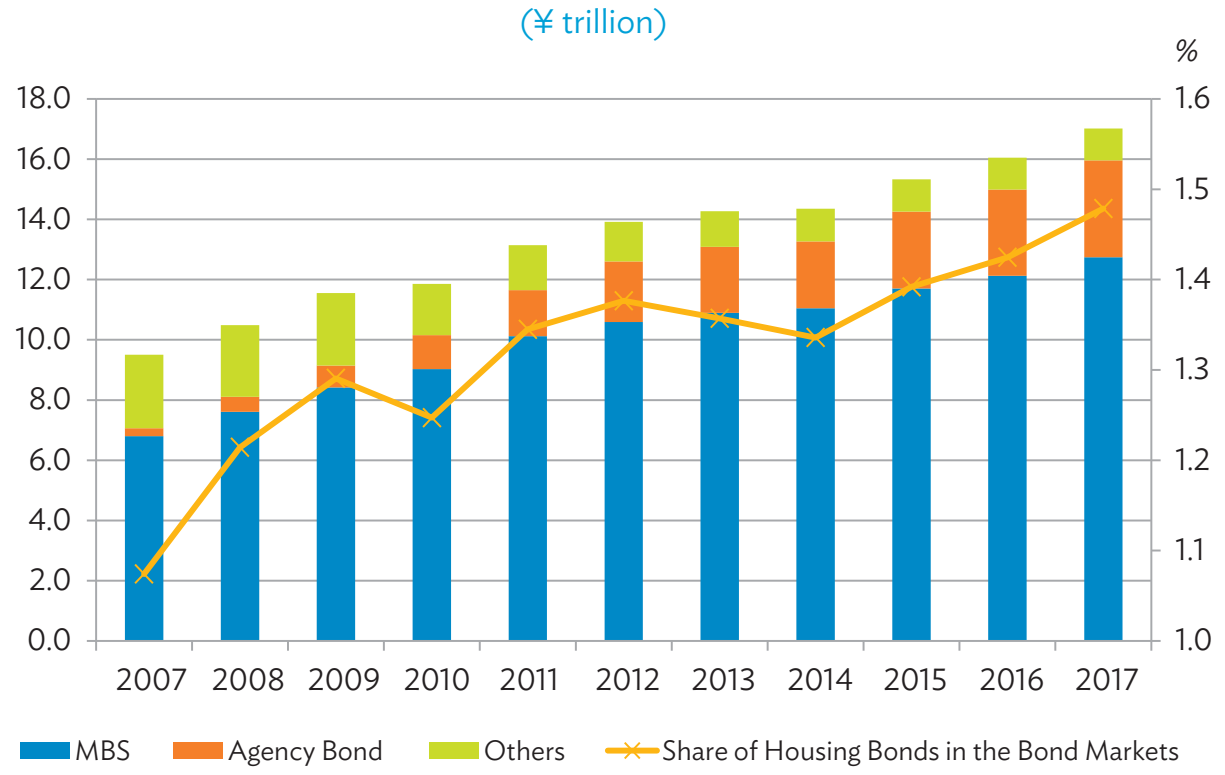

MBS = mortgage-backed securities

Sources: Japan Housing Finance Agency, Japan Securities Dealers Association. 


\section{Asian Housing Bond Markets}

While per capita incomes in Asian economies, especially in East and Southeast Asia, are growing faster than those of other parts of the world, the urban population as a percentage of the total population in many countries is lower than on other continents. Combined with continued economic growth, the future rate of urbanization in Asia is expected to be relatively high (World Bank, United Nations 2014). Accordingly, such a phenomenon is likely to accelerate housing demand in Asia.

However, in the Asian economies where capital market development is relatively low, housing finance is indirectly channeled by way of commercial bank loans. Such a system is structurally limited in meeting the housing finance needs of home buyers.

The amount of total housing loans tends to be proportional to the gross domestic product (GDP) of each economy, but the amount of individual housing loans actually available to meet housing demand is affected by the level of development of the financial market, especially the capital market. In East Asian economies, as shown in Figure 4, a relatively higher level of capital market development leads to higher per capita housing loans.

Figure 4: Per Capita Housing Loans in East Asia

$(\$ 000)$

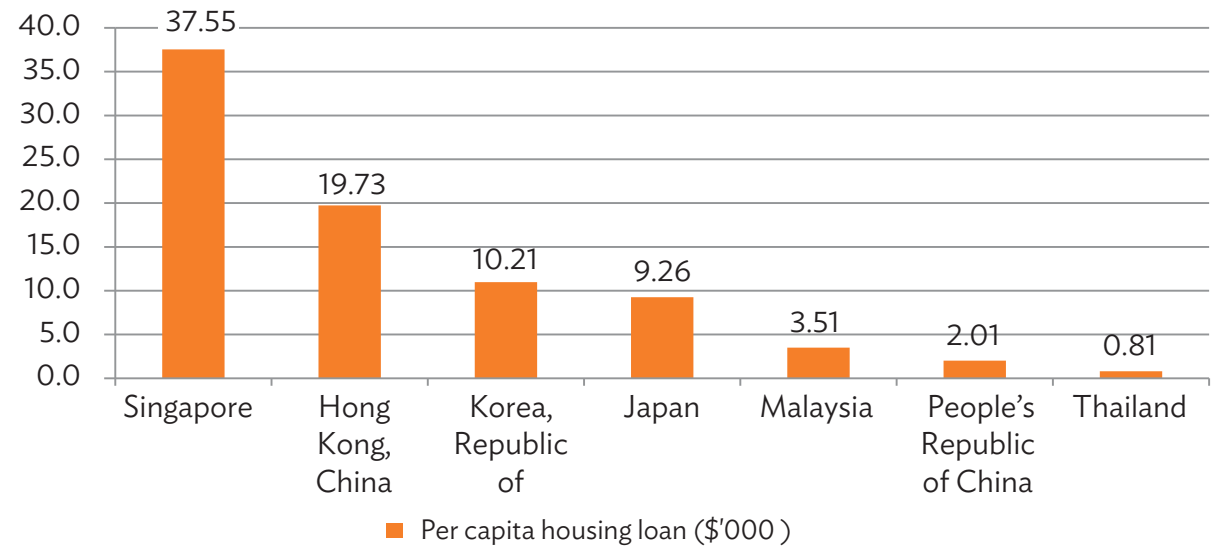

Sources: Total housing loan data from the central bank of each economy.

\section{Benefits of Housing Bond Market Development in Asian Economies}

Capital markets are the mechanisms in which large amounts of long-term funds are raised from a large number of unspecified investors, thereby diversifying investment risks. When a housing bond market, one part of the capital market, develops, it enables financial intermediaries to attract more sources of funding and to transfer and diversify relevant risks through securitization and sales of mortgages to investors. In particular, long-term mortgages could satisfy investment demand from pension funds and insurance companies, which mainly invest in long-term instruments. In the case of MBS, mortgage assets are moved from the originator's books, which can help the financial institution better manage its liquidity and risks. Thus, the development of the housing bond market will lead many Asian economies with bank-oriented housing finance to have a balanced and improved housing financial system. 
The development of the housing bond market can have several effects on the economy. First, it creates more funding sources for mortgages in Asian economies, which are currently limited to short-term bank savings. The scope of financing sources can be broadened to include all investors at home and abroad, thereby meeting the funding needs of many more home buyers.

Second, the funds raised through the housing bond market are also used to finance the supply of housing, leading to expansion in housing construction and an increase in labor demand and income. This ultimately contributes to economic growth. For several decades, academics have regarded housing as an important contributor to economic growth (Harisa and Arku 2006, Tibetaijuka 2009).

Third, the housing bond market, along with its contribution to the growth of the real economy, can contribute to overall financial development by enabling economies with less developed capital markets to experience the benefits of a capital market as a good place to raise large-scale, long-term funds over a relatively short period.

Fourth, with the development of the housing bond market, investors are provided with financial instruments with predictable cash flows and high credit quality. This allows investors to have relatively high expected rates of return and provides risk diversification.

\section{Housing Bond Markets in Asia}

Asian economies with relatively developed capital markets, such as Japan, have well-functioning housing bond markets. Contrarily, the People's Republic of China (PRC) is an economy whose housing bond market began developing only recently. Thus, its housing bond market is a relatively pioneering, small market compared to the size of the country's overall capital market. In some members of the Association of Southeast Asian Nations (ASEAN), the housing bond market exists but does not function properly yet. In others, housing finance is still provided only through financial intermediaries, primarily banks.

The mortgage market is divided into primary and secondary markets. In the primary mortgage market, a lender extends a loan to a borrower to purchase a house. In the secondary mortgage market, mortgage loans are held or sold (Weiss and Jones 2017). ${ }^{2}$ The housing bond market is where housing bonds are issued and traded. Housing bonds include structured securities such as MBS and mortgage-backed bonds whose underlying assets are mortgages in the secondary market and other securities issued by housing finance entities. The existence of a market for securities backed by mortgages in an economy means that the secondary mortgage market is functioning.

The East Asian economies that have such secondary mortgage markets are Hong Kong, China; Indonesia; Japan; the Republic of Korea; Malaysia; the Philippines; and Thailand. These markets are operated mainly by government agencies tasked with securitizing mortgages. Therefore, the analysis of the roles of these agencies is not much different from that of the housing bond market. In the PRC, however, RMBS are issued by multiple financial institutions rather than a government agency. This implies that the structure of the housing bond market in the PRC is different from that of the housing bond markets in other economies.

2 It is distinguished from the terminology in securities markets wherein the primary market refers to the structure in which the securities are newly issued, while the secondary market is the structure the issued securities are transacted in. 


\section{Thailand}

Thailand was first among all Asian economies, except for Japan, in establishing a housing finance agency when it created the Government Housing Bank in 1953. The agency's main focus has been providing housing finance to low- and middle-income households.

It was the establishment of the Second Mortgage Corporation (SMC) in 1997 by the Ministry of Finance that led to the formation of the housing bond market in Thailand. The agency aims to develop a secondary mortgage market under the principle of asset securitization for fundraising to ensure the adequate and consistent expansion of housing mortgage financing.

In 2012, the SMC began actively buying mortgages from the National Housing Authority and raising its MBS issuance volume to provide opportunities for lower-income people to own homes.

In 2014, the SMC conducted its first public offer of MBS in Thailand, and mortgage purchases and MBS issues increased simultaneously (Figure 5). In 2016, mortgage purchases fell sharply due to credit problems in Thailand, but MBS issuances continued to increase. This was in line with the upward trend of local currency nongovernment bonds outstanding despite the overall stagnation of Thailand's bond market since 2013 (ADB 2016). Nonetheless, in 2016 the ratio of MBS issuance to Thailand's GDP was at about $0.1 \%$ and to housing loans was at about $0.4 \%$.

Figure 5: Thailand's Housing Bond Market

(B billion)

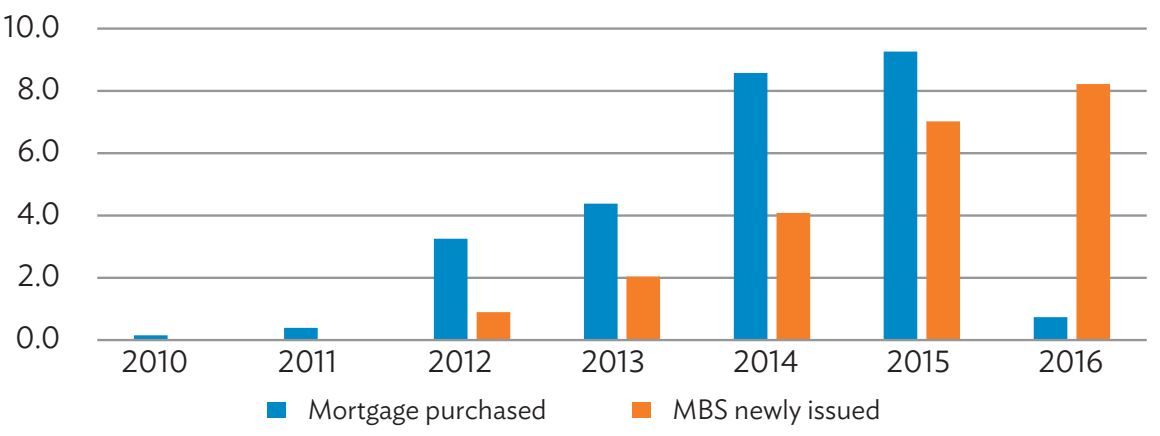

$B=$ baht, $M B S=$ mortgage-backed securities .

Source: Second Mortgage Corporation.

\section{Singapore}

Housing finance in Singapore is implemented by the Housing and Development Board (HDB), which was founded in 1969. As a government-owned entity, HDB offers housing loans at concessionary interest rates to help eligible Singaporeans purchase homes. In addition, HDB provides funds for residential and urban improvements as well as for the development and management of commerce and industry.

Compared to the relatively high development level of the capital market, the growth of the MBS market in Singapore has been poor (Figure 6). In spite of its securitization experience and policy support since 1986, Singapore has not been active in the securitization of mortgages due to a high proportion of floating-rate mortgages and high liquidity in the market (Sing and Ong 2004). As a result, the proportion of funding for housing finance through the MBS market remains small. 
Accordingly, HDB depends largely on borrowings from the government to finance its operations, but it also raises funds through the issuance of agency bonds. The volume of agency bonds issued under HDB's Medium-Term Note Program has increased steadily since the global financial crisis, as opposed to government borrowings, which have declined.

Figure 6: Housing Bonds Outstanding in Singapore

(S\$ billion)

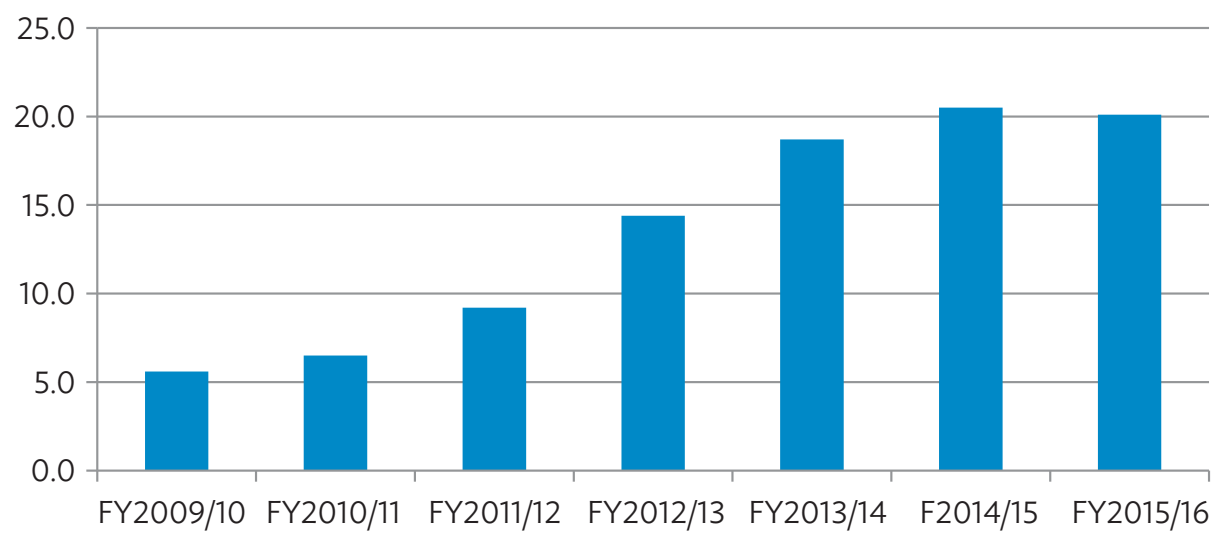

Note: FY refers to fiscal year, which is from 1 April to 31 March.

Source: Housing and Development Board.

\section{Philippines}

In the Philippines, the secondary mortgage market began in 1979 when the National Home Mortgage Finance Corporation (NHMFC) was established as an operating agency of the then Ministry for Human Settlements. Modeled after Freddie Mac in the US, the agency issued its own Bahayan Certificates and Bahayan Mortgage Participation Certificates with purchased mortgages as underlying assets (Boleat 1985).

However, the role of the NHMFC as a secondary mortgage institution has been negligible for more than 30 years ever since the NHMFC transformed into a mortgage originator in response to a financial crisis in the Philippines in the 1980s. In 2004, the Securitization Act was enacted to develop capital markets through the creation of an asset-backed securities (ABS) market, paving the way for the institutionalization of securitization.

In 2009, the NHMFC launched its securitization issue of a $P 2.06$ billion Bahay Bond, the first RBMS issued by a government agency in the Philippines. In addition, the NHMFC was allowed to purchase housing loans under the Housing Loan Receivable Purchase Program and pool them together to issue MBS. In 2012, the NHMFC issued its second Bahay Bond, the first retail MBS in the Philippines.

Compared to the NHMFC, which focuses on mortgage purchases and securitization, the Home Guaranty Corporation, a government-owned corporation established in 1950, provides cash flow guarantees for mortgages. The role of the Home Guaranty Corporation in the development of the secondary mortgage market was clarified through the Home Guaranty Corporation Act enacted in 2000.

The NHMFC stopped issuing MBS in 2017. To make MBS issuance more active in the Philippines, constraints on MBS issuance need to be addressed, including the high cost of securitization, inadequate credit information on mortgage borrowers, and the lack of institutional arrangements (Ballesteros and Dulay 2013). 
Malaysia

Cagamas Berhad, the National Mortgage Corporation of Malaysia, was created in 1986 to promote home ownership and growth of the secondary mortgage market. At the end of 2016, its shareholders were Bank Negara Malaysia (20.0\%), commercial banks (72.8\%), and investment banks (7.2\%).

Cagamas issues agency bonds and MBS - corporate bonds and sukuk (Islamic bonds) - to finance the purchase of housing loans (conventional and Islamic) from financial institutions. It is the largest issuer of debt instruments in the domestic capital market.

Two noteworthy features are seen in the issuance of Cagamas debt securities (Figure 7). First, the outstanding volume of agency bonds exceeds that of MBS. Second, the difference between the outstanding volumes of agency bonds and MBS has been gradually increasing. Following the global financial crisis, the total volume of debt instruments issued by Cagamas declined until 2012.

Figure 7: Cagamas Housing Bonds Outstanding in Malaysia

(RM billion)

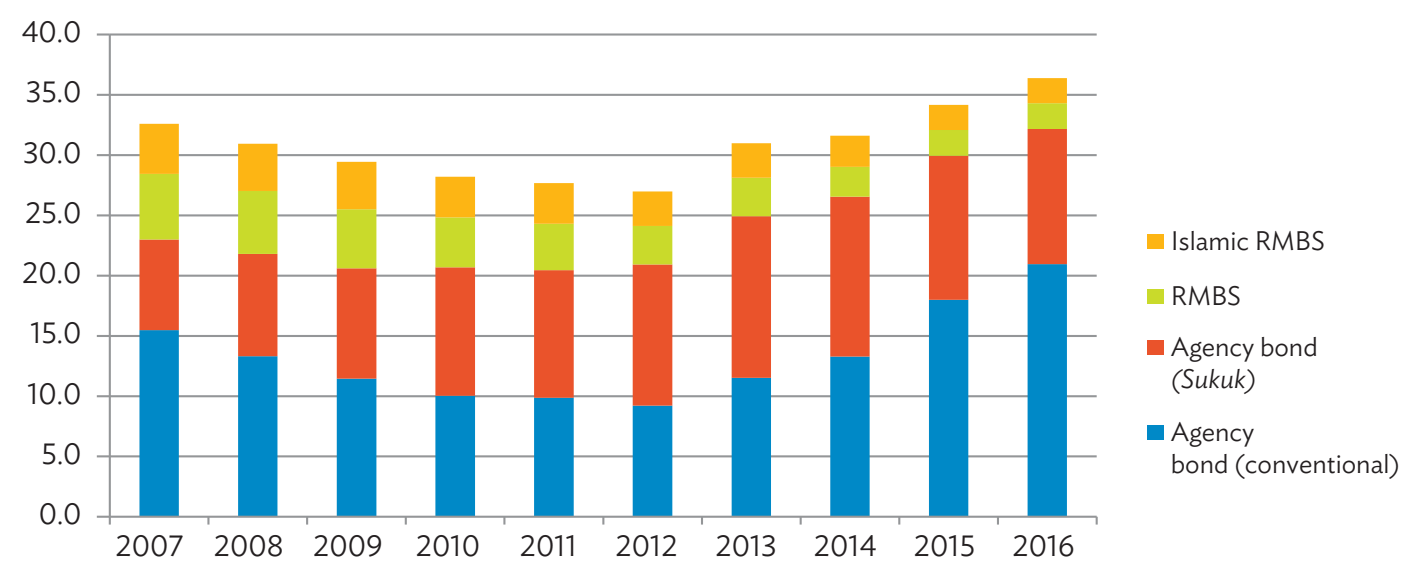

$\mathrm{RM}=$ Malaysia's ringgit, $\mathrm{RMBS}=$ residential mortgage-backed securities .

Source: Cagamas Holdings Berhard. 2016. Annual Report 2016. Kuala Lumpur.

However, with a rapid increase in the issuance of conventional agency bonds since then, the proportion of agency bonds that are outstanding Cagamas debt securities, which remained slightly higher than $70 \%$ for years, increased to $88.4 \%$ in 2016.

As a result, the portion of Islamic securities (agency bonds and MBS) in the outstanding debt securities has declined gradually from 54.0\% in 2012 to $36.5 \%$ at the end of 2016. Cagamas housing bonds outstanding totaled RM36.4 billion in 2016, accounting for $7.6 \%$ of total housing debt and $2.9 \%$ of GDP.

\section{Hong Kong, China}

Hong Kong, China's housing finance government agency is the Hong Kong Mortgage Corporation (HKMC), which was established in 1997. The HKMC purchases mortgages from loan originators, such as commercial banks, and provides mortgage insurance. Its businesses are funded through the issuance of agency bonds and MBS, as well as equity capital and credit from the Exchange Fund, which is made up of the government's fiscal reserves. 
Since 1998, the HKMC has been implementing the Debt Issuance Programme under which it issues HKD-denominated agency bonds, targeting domestic institutional investors. As mortgages, which were on a steady growth path, soared after the global financial crisis, the HKMC launched the multicurrency Medium-Term Note Programme in 2007 to issue agency bonds to foreign investors. In 2001, the Retail Bond Issuance Programme was introduced to attract small domestic investors (HKMC 2017).

The HKMC began issuing MBS in 1999 and launched the Bauhinia Mortgage-Backed Securitization Programme in 2001 (HKMC 2017). However, its MBS outstanding decreased gradually from 2006 until 2013 when it reached zero (Figure 8).

Figure 8: Hong Kong Mortgage Corporation Housing Bonds Outstanding (HK\$ billion)

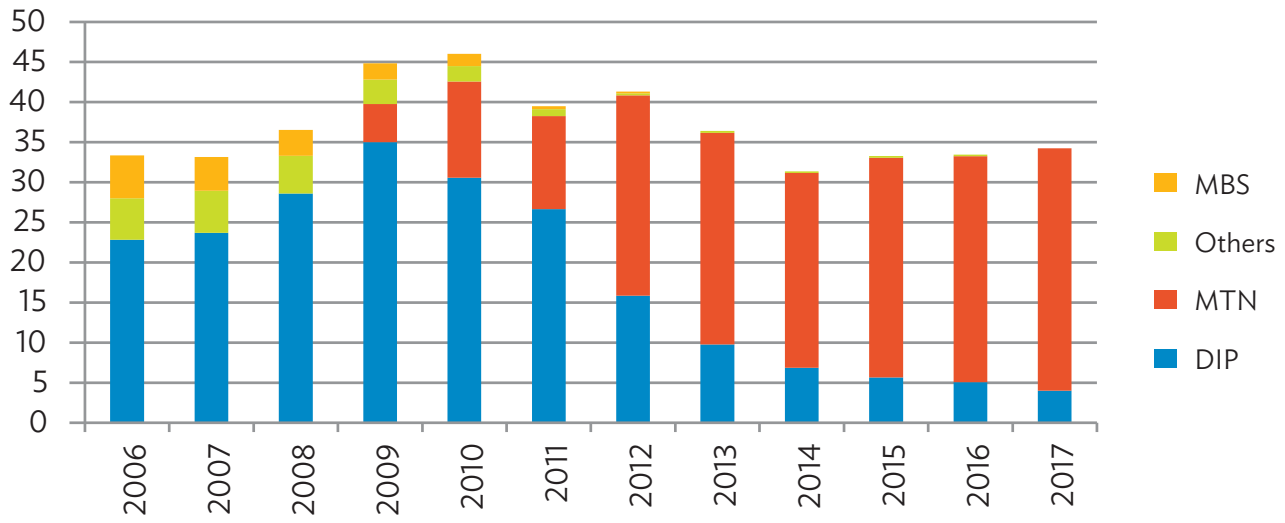

DIP = Debt Issuance Programme, MBS = mortgage-backed securities, MTN = medium-term notes .

Source: Hong Kong Mortgage Corporation. 2017. HKMC Annual Report 2017. Hong Kong, China.

The main driver of Hong Kong, China's housing bond market in recent years has been the multicurrency medium-term note, which reflects the globalization of Hong Kong, China's overall bond market. At the end of 2017, the housing bond market represented only about $2.8 \%$ of total mortgages in Hong Kong, China.

\section{Indonesia}

Since its recovery - which began in the early 2000s - from the 1997/98 Asian financial crisis, Indonesia has tried to secure sources of funding that match the duration of mortgages, which are long-term loans, amid rapidly increasing housing and mortgage demand. In the wake of the global financial crisis, Indonesia strived to introduce the securitization of assets, including loans, as a way to develop the capital market and solve liquidity problems. However, there were several institutional weaknesses (Ahmed 1998). As a result, the development of the MBS market has been slow.

The PT Sarana Multigriya Finansial (SMF) was established as a wholly owned government corporation in 2005. Its role was to resolve duration mismatch problems caused by the traditional mortgage supply and demand mechanism, which was dependent on bank-oriented, short-term deposits. SMF was allowed to issue long-term and short-term MBS and/or promissory notes to raise funds from the public to provide housing finance, and to purchase mortgages from financial institutions such as banks. SMF securitized mortgages that it purchased from PT Bank Tabungan Negara in 2008 and issued its first MBS in January 2009. 
Furthermore, SMF was allowed to offer credit enhancement service for MBS. However, the major business of $S M F$ is to provide funds for mortgage originators. A significant portion of the funding is raised through agency bond issuance. SMF agency bonds outstanding in 2016 were about Rp6.53 trillion (Figure 9).

Figure 9: Housing Bond Market in Indonesia

(Rp trillion)

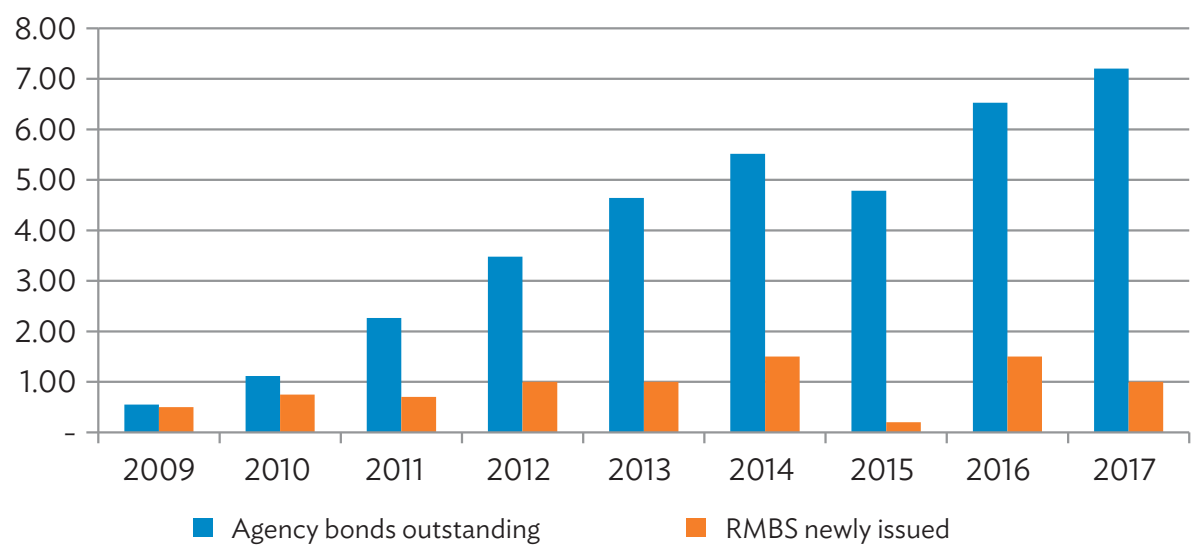

RMBS = residential mortgage-backed securities, $\mathrm{Rp}=$ rupiah.

Source: PT Sarana Multigriya Finansial (SMF). Annual Report. Jakarta (8 years: 2010-2017).

At the end of 2016, the cumulative amount of SMF lending to mortgage originators was about three times the cumulative amount of its MBS issuance. Thus, agency bond issuance, the mainstay of SMF's funding sources, was larger than MBS issuance. Nevertheless, its agency bonds outstanding accounted for less than $0.1 \%$ of GDP and $1.8 \%$ of total housing loans at the end of 2016.

\section{People's Republic of China}

In the PRC, where most housing purchases before the mid-1990s resulted from the sales of welfare housing to sitting tenants by their employers (state-owned enterprises) at low prices, there has generally been little need for a mortgage (Zhihua 2015). Around 1990, housing savings banks and the Housing Provident Fund were established. When mortgages grew rapidly as a result, demand for mortgage securitization also increased, especially among commercial banks.

The PRC's housing bond market began with the issuance of CNY3.02 billion of MBS by the China Construction Bank in 2005 (Figure 11). An additional CNY4.16 billion of MBS was issued in 2007. These securitization deals were arranged through trust companies. After the pilot issuances, the issuance of MBS was suspended due to the global financial crisis until the Government of the PRC decided to restart the securitization of credit assets in 2012 (Shaoze 2015), which laid the basis for the re-issuance of MBS.

Notably, CNY6.8 billion worth of MBS was issued in 2014 to revitalize the housing market which started to slow down in 2013. MBS issuance rose sharply in 2016 and reached CNY170.8 billion in 2017, accounting for 10.8\% of the PRC's gross ABS issuance volume. 
The striking characteristic of the secondary mortgage market in the PRC is that there is little structural difference between the process of issuing MBS and other ABS. This is because financial institutions, such as governmentowned banks and commercial banks, directly hand over their assets to special purpose entities that issue MBS and/or other ABS. Therefore, the MBS market structure in the PRC is distinguished from that of other economies in which mortgage securitization is dominated by specific government agencies.

In the PRC, the issuer of MBS who has the right to receive cash flows from underlying assets transferred from the originator is a special purpose trust. This type of securitization is used not only because it is effective in separating MBS investors from the bankruptcy of the originator by transferring assets in the form of a trust, but also because there are many restrictions on the use of a special purpose company (paper company) as an MBS issuer in the PRC under the existing Company Act. Nonetheless, MBS in the PRC are structurally distinct from European covered bonds because mortgages are actually sold to the special purpose trust and mortgages are removed from the originator's books (that is, the transfer is deemed a true sale).

Despite the recent rapid increase in MBS issuance, the housing bond market still comprises a small share of the PRC's housing finance. Considering that mortgage loans amounted to CNY21.9 trillion at the end of 2017, the share of MBS outstanding in housing finance was just $1.5 \%$.

Figure 10: Residential Mortgage-Backed Securities Outstanding in the People's Republic of China (CNY billion)

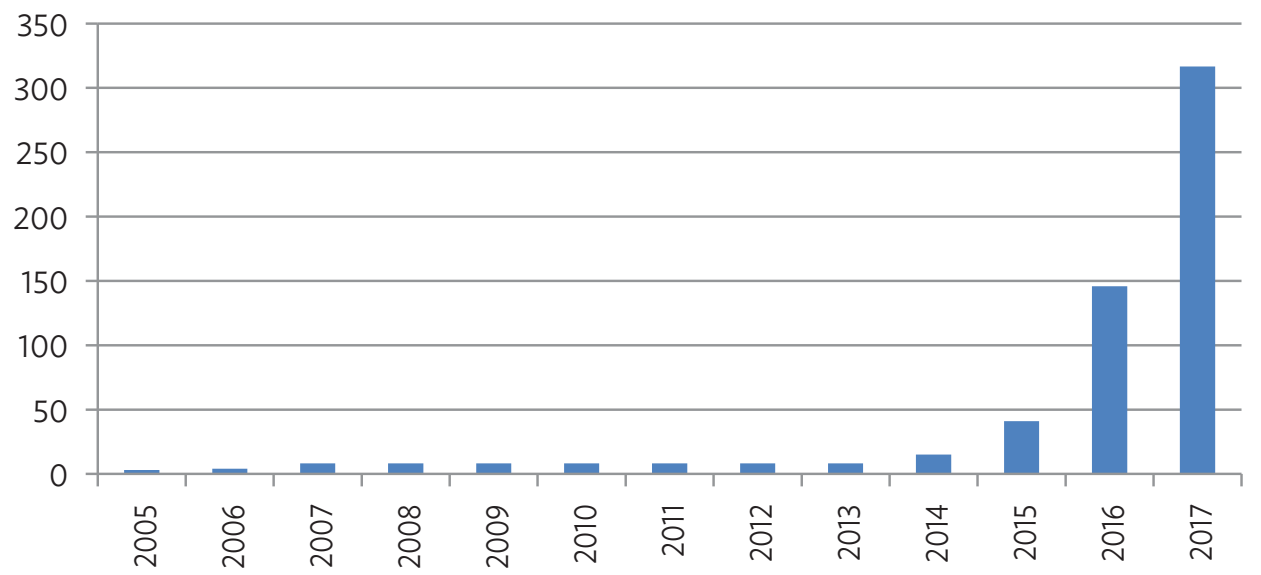

CNY = yuan, PRC = People's Republic of China .

Source: China Securitization Analytics.

However, the growth potential of the MBS market in the PRC is very strong, given the upward trend in the volume of outstanding mortgages, which have grown at a quarterly average rate of nearly 25\% since 2013 (Figure 10), and the subsequent liquidity demand from originators.

Among the housing bonds issued in each of the abovementioned economies, the market yields of structured securities, including MBS, are basically determined by the characteristics of the underlying assets. 
Agency bond yields may also vary depending on the creditworthiness of the bonds, which is determined by the degree of government support. The reason for the importance of the market yield is its role in determining the funding costs of the issuers and ultimately housing demanders.

MBS, or covered bonds, generally have higher credit ratings than their originators. In the capital market, the credit rating of housing agency bonds tends to be regarded as the same as that of government bonds, regardless of whether government support is explicit or not. Nevertheless, in reality, the agency bonds tend to be traded at a somewhat lower price and yield more than government bonds. For some Asian economies-including Hong Kong, China; India; Japan; Republic of Korea; Malaysia; Singapore; and Thailand-agency bonds and agency MBS are traded at spreads of 11-57 basis points and 25-71 basis points above government bonds, respectively (Davies et al. 2007). This may be because the credit quality of a government agency cannot be exactly the same as that of the government itself, so the value of agency bonds is considered to be somewhat lower than that of government bonds.

However, there is a view that the difference between yields on agency bonds and government bonds is attributable to the characteristics of the underlying assets, prepayment risk, and/or the smaller issuance volumes of agency bonds than government bonds and the resultant lower liquidity levels (Prokopczuk et al. 2012, Ejsing et al. 2015).

\section{Republic of Korea}

In the Republic of Korea, the creation of the housing bond market was driven mainly by the government. The government enacted the Housing Construction Promotion Act in 1972. The major source of financing was National Housing Bonds (NHBs). Type 1 NHBs were issued for the first time in 1973, with a 5-year maturity and a $6 \%$ coupon. The coupon rate was very low considering that the annual average rate of consumer price inflation for the previous 3 years was about $14 \%$.

For that reason, the issuance of the bonds could not be made based on the price mechanism, which works through demand and supply. NHBs were issued on the basis of mandatory placement, meaning that the purchase of the bonds was required for companies that obtained a license, permission, or authorization related to the construction business from the central or local government, or individuals who applied for registration of their ownership of a property or mortgage.

Type 2 NHBs had a significantly lower coupon rate than Type 1 NHBs. Type 2 NHBs were first issued in May 1983 (Figure 11), having a 10-year maturity and a zero-coupon rate. It was issued to prevent large capital gains from the difference between the actual market price and the cap price because those who wanted to purchase new apartments had to buy a larger amount of the bonds through bidding.

With the rise in apartment prices, the volume of Type $2 \mathrm{NHB}$ issuance skyrocketed owing to massive demand for the bonds from buyers of presale apartment units built under new town development plans in the Seoul metropolitan area in the late 1980s (Figure 12). The increase in new NHB issuances further accelerated the increase in the volume of NHBs outstanding, resulting in the expansion of the housing finance market.

As such, NHBs played a key role in financing public housing construction, thereby invigorating the housing market. In addition, the housing bond market contributed to the development of the early-stage bond market in the Republic of Korea, especially the government bond market. 
Figure 11: Trends in National Housing Bond Issuance and Volume in the Republic of Korea (W trillion)

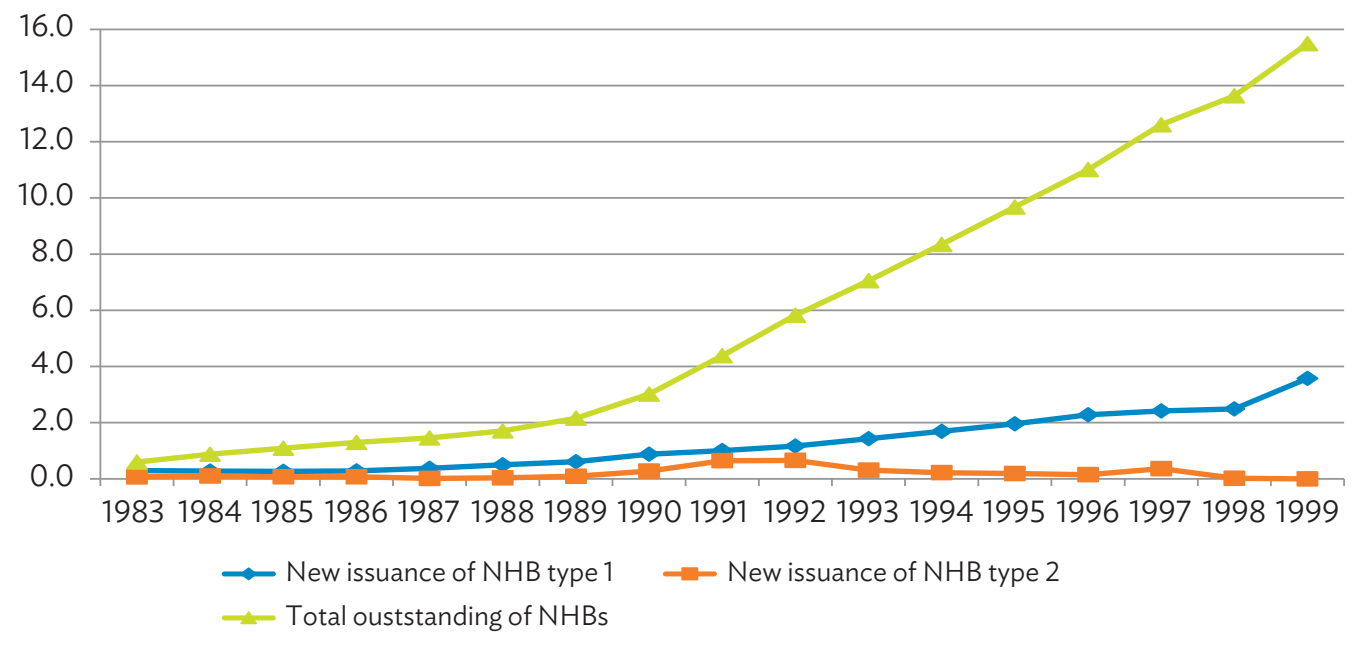

$\mathrm{W}=$ won.

New issuance of NHB type $1 \rightarrow$ New issuance of NHB type 2

Source: Government of the Republic of Korea, Ministry of Land, Infrastructure and Transport.

Figure 12: Housing Bonds Outstanding in the Republic of Korea (W trillion)

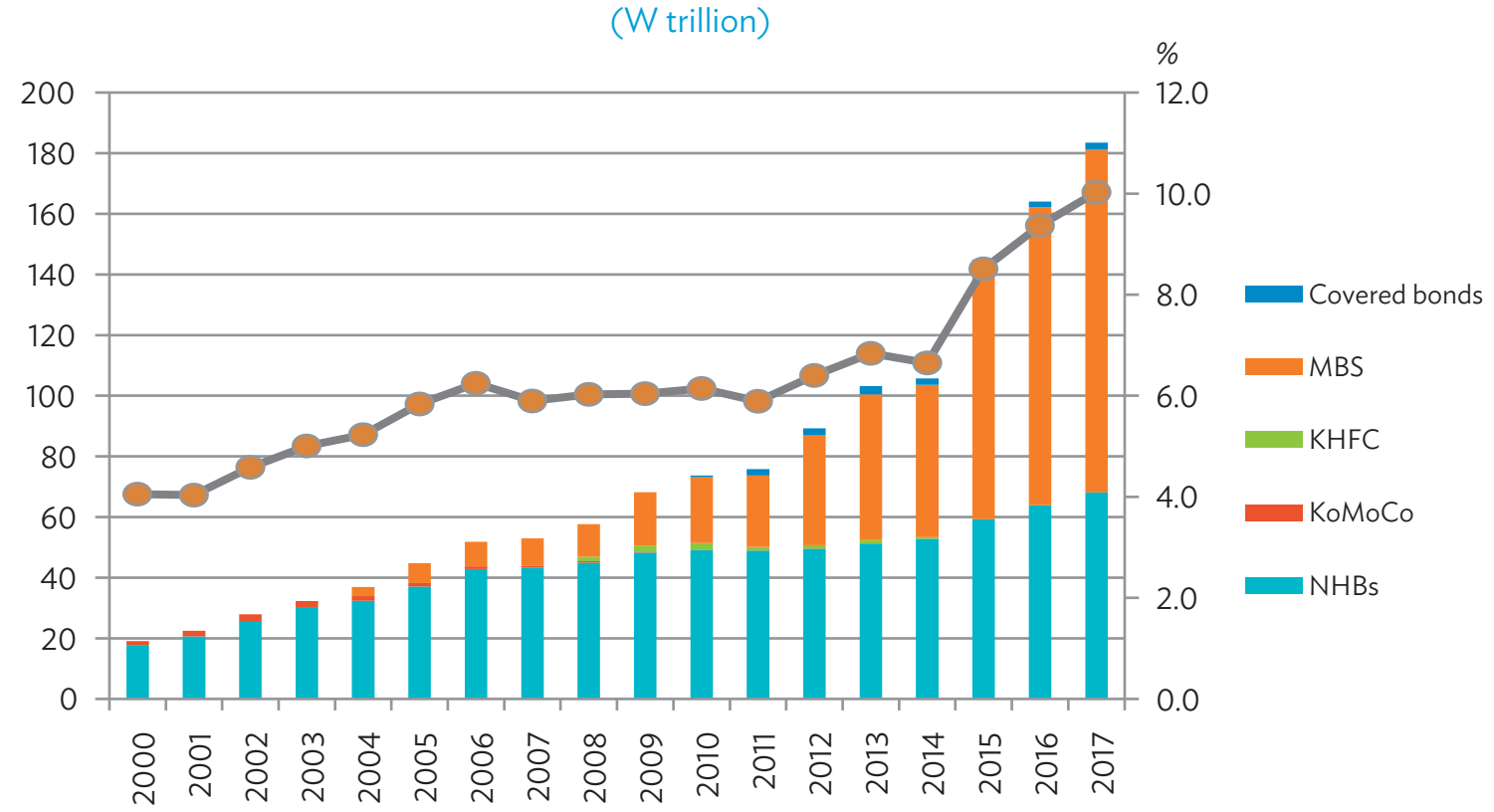

KHFC $=$ Korea Housing Finance Corporation, $\mathrm{KoMoCo}=$ Korea Mortgage Corporation, MBS = mortgage-backed securities, $\mathrm{NHBs}=$ National Housing Bonds, $\mathrm{W}=$ won .

Sources: Bank of Korea; Korea Housing Finance Corporation; Korea Financial Investment Association; Ministry of Land, Infrastructure and Transport. 
Whereas the NHB market is a housing bond market created to fund housing supply, the housing agency and MBS market, on the other hand, is a housing bond market formed to finance the housing demand side.

For the Republic of Korea, the impact of 1997/98 Asian financial crisis necessitated asset securitization to efficiently resolve nonperforming assets and restructure distressed businesses. As a result, the Asset Backed Securitization Act was enacted in September 1998. Assets securitized during this time were mainly distressed debt and NPLs. The experience of nonperforming asset securitization could be applied to the housing finance market.

The Special Purpose Companies for Mortgage-Backed Bonds Act was enacted in January 1999. In September of the same year, the Korea Mortgage Corporation (KoMoCo) was created. Its shareholders consisted of the Korean Ministry of Construction and Transportation, major domestic financial institutions, and overseas investment institutions including the International Financial Corporation.

In April 2000, KoMoCo undertook its first securitization of mortgage loans made by the National Housing Fund. A total of nine MBS deals were made by KoMoCo based on mortgages from the National Housing Fund until the transfer of the securitization business to the Korea Housing Finance Corporation (KHFC) was completed in March 2004. As a government-owned entity established in accordance with the Korea Housing Finance Corporation Act, 2003, KHFC was able to raise funds at a lower cost than KoMoCo and provide more credit support for MBS. As a consequence, MBS issuance by KHFC had increased sharply.

Such increases were attributed to the selective purchase of mortgages from financial institutions, and the active development of its own mortgage products, which could be used as underlying assets for MBS issued by KHFC. Bogeumjari Loan was the flagship mortgage product of KHFC launched in 2004. The product has been improving as the loan demand become diversified.

Meanwhile, KHFC began to issue covered bonds in 2010. Unlike NHBs for which the coupon rate is determined by the government, coupon interests of other housing bonds are determined in the market depending on the supply and demand of the bonds.

As a result, the housing bonds led by MBS have played an increasing role in the overall bond market. Although the share of $\mathrm{NHBs}$ in total bond issuance volume stayed between $3 \%$ and $5 \%$ during the review period, the share of housing bonds reached as high as $10 \%$. This implies that the housing bond market is playing a growing role in the Korean bond market. Furthermore, it has contributed to the development of the capital market through the sophistication of structuring securities.

\section{Conclusion and Policy Implications}

Housing demand in Asia is inevitably growing because Asia is experiencing faster income growth and urbanization than any other region. The shortage of housing and the steep increase in housing prices in the urban areas have destabilized the lives of urban dwellers and ultimately those of the whole population. However, there have been limits on the size and tenor of mortgage loans financed by the short-term savings of banks that have provided mortgage systems. To overcome such problems, it is necessary to activate the housing bond market as well as the role of financial intermediaries. 
The housing bond markets in developed economies mainly comprise MBS issued by government housing finance agencies and covered bonds issued by banks acting as mortgage originators. The former approach began in the US and the latter in Europe. Both markets have developed robustly.

In the US, the housing bond market is overwhelmingly large in terms of size and proportion of housing finance. This is attributable to the high demand for housing finance and because the demand is effectively linked to the supply side through a well-established bond market.

The US housing bond market has evolved through trial and error. It has moved from a bank-based housing finance system -in which bank deposits, a short-term funding source, were used to finance mortgages - toward the present form of the market in which long-term mortgages are available and lending sources are diverse due to the role of government housing finance agencies.

The US experience provides various policy implications for economies seeking to develop a well-functioning housing bond market. This is because its experience reflects a logical process that has formed the core structure of the housing bond market, including the functions to address various risks in traditional bank-based housing finance (e.g., credit, liquidity, and prepayment risks).

Fixed-rate mortgages and mortgage refinancing were introduced in the early 1930 s to manage the default rate for short-term, floating-rate mortgages. These can be used as policy options to manage financial risk in times of economic crisis. On the other hand, the introduction of mortgage insurance schemes to protect mortgage lenders against losses would help reduce the credit risk inherent in mortgage lending, thereby curbing the burden of managing risks arising from the asset transformation of mortgage lenders. This policy tool may be used to increase the stability of mortgage supply.

It was the role of secondary mortgage agencies established by the government that brought about dramatic changes in the housing finance structure. Nurturing housing finance agencies, such as Fannie Mae and Freddie Mac (MBS issuers) and Ginnie Mae (MBS credit guarantor), can be an effective policy measure to diversify funding sources and lengthen the duration of funding for housing finance. In addition, agency bonds issued to finance their business operations, together with MBS, can be used as a driving force for the advancement of the financial system as well as capital markets through the development of primary and secondary markets.

However, the US experience cannot be applied to all economies because the distorted evolution of the housing bond market-resulting from, among other causes, government intervention, a lack of transparency in the market, and the complexity of financial products - can cause totally unexpected results. The most representative example is the global financial crisis, which was triggered by expansion and derivatization of non-agency RMBS.

MBS are not the only alternative that will lead to the development of the housing bond market. European economies have developed their housing bond markets without the role of a housing finance agency. In some Asian economies, the MBS market has been a major force behind the development of the housing bond market, as is the case in the US. Other economies have achieved the goals of housing finance-including the expansion of mortgage lending, liquidity management, and credit risk diversification - through the issuance of housing agency bonds rather than the expansion of the MBS market. Contrarily, the PRC is an economy that strives to facilitate housing finance without specific government housing finance agencies by fostering the growth of the housing bond market underpinned by ABS issuance. 
Despite having a large volume of MBS issuance relative to the size of the economy, a country may not be able to accomplish the purpose of housing finance to diversify lending sources. The reason is that MBS issuances are highly likely to be repurchased by mortgage originators in the absence of a well-functioning bond market where institutional investors such as pension funds and insurance companies can play an active role.

In addition, demand-side instruments such as MBS are not the only component in the housing bond market. Instruments that enable financing for housing supply can also be an important part of the housing bond market. The positive impact of the housing bond market on housing finance and the real economy has also been proven through the Republic of Korea's experience, wherein rapid urbanization has led to the explosive housing demand and sharp increase in housing prices.

NHBs have been issued in the Republic of Korea since 1973 under the Housing Construction Promotion Act, which aims to build affordable housing for non-homeowners. NHBs have not only contributed to the funds needed to achieve the purpose of the law, but have also remained a major segment of the Republic of Korea's housing bond market for a long time.

This is because the government has adjusted the issuance method and terms and conditions based on the Republic of Korea's evolving economic and financial situations, and it has continued to issue NHBs. The trading of the bonds enabled various market participants to gain and accumulate experiences in the early stages of capital market development. In addition, funds raised via bond issuance at lower than market interest rates perform the function of redistributing wealth through an increased housing supply.

The Republic of Korea's MBS market that started with NPL securitization after the 1997/98 Asian financial crisis has greatly contributed to the higher liquidity of mortgage assets, improved liquidity and credit risk management of mortgage originators, and expansion and diversification of mortgage funding sources through capital markets. This is not much different from the experiences of advanced economies that developed their housing bond markets earlier.

MBS issuance and credit risk management are carried out by KHFC, a government agency in the Republic of Korea. The agency develops mortgage loan products, thereby playing a part in the development of the MBS market.

In addition to MBS, KHFC issues covered bonds, which in turn diversifies housing bonds and contributes to housing finance. The results of the analysis on the effects of housing bond market growth on housing construction in the Republic of Korea provide an empirical evidence of why developing economies should nurture their housing bond markets.

Conclusively, the housing bond market is not only a means to increase the amount and diversity of housing finance, but also is a pillar of the bond market that plays a role in financial deepening and economic growth. Although the policy direction for developing the housing bond market may be different depending on economy-specific conditions and constraints, the experiences of the Republic of Korea as well as those of developed economies - from which key elements driving the creation of a housing bond market can be identified-provide important policy implications for economies that want to develop their housing bond markets and housing finance. 


\section{References}

Ahmed, A.A. 1998. Comment, Introducing Asset Securitization to Indonesia: A Method in Madness. University of Pennsylvania Journal of International Economic Law. 19 (2). pp. 823-59.

Asian Development Bank. 2016. ASEAN+3 Bond Market Guide 2016 Thailand. Manila. https://www.adb.org/ publications/asean3-bond-market-guide-2016-thailand.

Ballesteros M., M. and D. Daisy. 2013. Feasibility of Mortgage-Backed Securitization for the Underserved Housing Market in the Philippines. Discussion Paper Series. No. 2013-43. Manila: Philippine Institute for Development Studies.

Berliner, B., A. Quinones, and A. Bhattacharya . 2016. Mortgage Loans to Mortgage-Backed Securities. In Fabozzi F.J., ed. The Handbook of Mortgage-Backed Securities, 7th Edition. Oxford: Oxford University Press.

Boleat, M. 1985. National Housing Finance Systems: A Comparative Study. Kent: Croom Helm.

Cagamas Berhad. https://www.cagamas.com.

Carbo-Valverde, S., R.J. Rosen, and F. Rodriguez-Fernandez. 2017. Are Covered Bonds a Substitute for Mortgage-Backed Securities? Journal of Economic Policy Reform. 20 (3). pp. 238-253.

China Securitization Analytics. https://www.cn-abs.com.

Davies, M., J. Gyntelberg, and E. Chan. 2007. Housing Finance Agencies in Asia. BIS Working Papers. No. 241. Basel: Bank for International Settlements (BIS).

Doling, J., P. Vandenberg, and J. Tolentino. 2013. Housing and Housing Finance-A Review of the Links to Economic Development and Poverty Reduction. ADB Economics Working Paper Series. No. 362. Manila: Asian Development Bank. https://www.adb.org/publications/housing-and-housing-finance-review-linkseconomic-development-and-poverty-reduction.

Ejsing, J., M. Grothe, and O. Grothe. 2015. Liquidity and Credit Premia in the Yields of Highly-Rated Sovereign Bonds. Journal of Empirical Finance. 33. pp. 160-73.

Fabozzi, F.J. 2016a. The Handbook of Mortgage Backed Securities, 7th Edition. Oxford: Oxford University Press.

Fabozzi, F.J. 2016b. Bond Markets, Analysis, and Strategies, 8th Edition. London: Pearson.

Goldsmith, R.W. 1969. Financial Structure and Development. New Heaven: Yale University Press.

HKMC Corporation. 2017. Annual Report 2017. Hong Kong, China.

HKMC Corporation. http://www.hkmc.com.hk/eng/index.html.

Housing and Development Board. https://www.hdb.gov.sg/cs/infoweb/homepage. 
Housing Finance Information Network. http://hofinet.org.

International Union for Housing Finance. http://www.housingfinance.org/housing-finance.

Japan Housing Finance Agency. https://www.jhf.go.jp/english/.

Korea Housing Finance Corporation. https://www.hf.go.kr/ehf/index.do.

Lunde, J. and C. Whitehead. 2016. Milestones in European Housing Finance. Hoboken: Wiley Backwell.

McConnell, J.J. and S. A. Buser. 2011. The Origins and Evolution of the Market for Mortgage-Backed Securities. Annual Review of Financial Economics. 3. pp. 173-192.

National Home Mortgage Finance Corporation. http://www.nhmfc.gov.ph/.

PT Sarana Multigriya Finansial (Persero). http://smf-indonesia.co.id/en/.

Scanlon, K. and C. Whitehead. 2011. The UK Mortgage Market: Responding to Volatility. Journal of Housing and the Built Environment. 26 (3). pp. 277-293.

Shaoze, L. 2015. Chinese Credit Asset Securitization: Development Status, Problems and Suggestions. International Business and Management. 11 (3). pp. 75-80.

Sing, T.F. and S. E. Ong. 2004. Residential Mortgage-Backed Securitization in Asia: The Singapore Experience. Journal of Real Estate Literature. 12 (2). pp 159-179.

Tibaijuka, A.K. 2009. Building Perspective-Housing and Economic Development. London: Routledge.

United Nations. 2014. World Urbanization Prospects. New York: United Nations Department of Economic and Social Affairs.

Weiss, N.E. and K. Jones. 2017. An Overview of the Housing Finance System in the Unites States. Washington, DC: Congressional Research Service.

World Bank. World Development Indicators. https://data.worldbank.org/indicator.

Zhihua, Z. 2015. The Development of Mortgage Finance in China: The Implications of International Experiences. China Perspective. 4. 


\section{Enhancing Infrastructure Investment through Value Capture}

Abdul Abiad, Kathleen Farrin, Chris Hale, Matthias Helble, and Grant Stillman

\section{Introduction}

Developing Asia has been experiencing rapid urbanization over the past 3 decades. Whereas only one-third of the population lived in urban areas in 1990, currently more than half of Asia reside in cities. This trend of rapid urbanization is predicted to continue. Cities are often overwhelmed by this rapid growth. As a result, urban expansion ends up being inadequately planned, resulting in sprawls and slums, inadequate utilities, traffic congestion, air pollution, and inequality in access to vital services. The predicted needs to upgrade the infrastructure in the region are very large. ADB (2017) estimates that from 2016 to 2030, developing Asia will need to invest $\$ 26$ trillion in infrastructure to maintain the region's growth momentum and respond to climate change. Excluding the People's Republic of China (PRC), the infrastructure investment gap for developing Asia-the difference between the investment needed and what is currently being spent-exceeds $5 \%$ of its gross domestic product (GDP).

One of the investments will focus on urban transit and intercity transport infrastructure, for which ADB (2017) estimates a gap of $\$ 8.4$ trillion. In particular, cities in Asia need to accelerate investment in transport infrastructure. Between 2001 and 2010, the majority of new mass rapid transit systems in the world were already built in Asia, with half of Asia's new mass rapid transit systems built in the PRC. If subway construction continues at its current trend, there would be 2,300 additional kilometers of track and 1,100 new stations in Asia between 2016 and 2030, with the PRC and India leading the way in mass rapid transit system growth (ADB 2017).

The enormous need in terms of new infrastructure is in stark contrast to the fiscal capacities of most countries and capital markets in the region. Local and other subnational tiers of government have many obligations and competing funding demands for various forms of urban infrastructure (e.g., water, waste management, parks, sewage, and public housing) and for social needs (e.g., health, police, and education). However, capital investment as well as operation and maintenance costs of new public infrastructure are typically very high.

Fiscal constraints have stimulated interest in new and innovative project funding sources as an alternative to public budget. One of these potential funding sources is the value capture, which is based on two self-evident assumptions. First, improved utility services and accessibility to infrastructure, such as transportation or water supply, creates various positive spillover effects, such as higher property prices or additional economic activity. Second, the concept of value capture also asserts that those who benefit from the positive spillovers could contribute in part to the costs of infrastructure investment.

Value capture is a particularly useful concept for cities undergoing rapid growth. These cities are characterized not only by rising real incomes and new work opportunities, but also increasing congestion levels and constraints on accessibility that can hinder future growth and livability. The conditions and drivers for discussing and potentially introducing value capture mechanisms are already at play in many rapidly growing cities across 
developing Asia. When the public sector properly secures a fair share of the windfalls from increased revenues resulting from its own infrastructure investments, the burden on traditional forms of taxpayer funding is reduced.

Recycling value capture revenues back into infrastructure investment allows cities to sustainably expand their infrastructure over decades, rather than worrying how each new addition will be funded and whether the ratepayers or potential users are sufficient and will comply. When undertaken in the context of informed and integrated urban planning, value capture also potentially promotes and supports a broader set of sustainable urban planning and development outcomes.

In this article, value capture is defined as a public funding method by which governments and their agencies

- create positive spillovers through a range of actions, including accessibility-improving infrastructure investments, particularly mass rapid transit, or regulatory decisions such as a change in land use or floor area ratios;

- institute a process to retain part of the value addition through public projects; and

- $\quad$ use the proceeds to fund ongoing or planned infrastructure investments.

Despite the promising conditions for value capture in growing and urbanizing Asia, many cities first need to build the appropriate environment for a successful value capture implementation. This can be done in several ways:

- Strengthen the needed legal, regulatory, tax-raising, and institutional frameworks.

- Gain skills and techniques, including from others' practical experiences.

- Develop sufficient institutional capacity to apply context-specific value capture techniques across complex transit projects, including comprehensive, multi-decade transit network build-out programs.

This article aims to contextualize value capture as a crucial component of urbanization in developing Asia. It presents evidence in support of the use of value capture in infrastructure investment and discusses prospects and constraints. The article starts by introducing the concept of land value capture and then broadens the analysis to value capture (or value recycling), in general.

\section{Land Value Capture: From Theory to Implementation}

The concept of land value premiums arising from utilities servicing connections and mass rapid transit is well established, reasonably intuitive, and straightforward. Economic theory suggests that transit infrastructure can have positive impacts on property values by improving accessibility (Yoshino et al. 2018). Similarly, market experience demonstrates that land fully serviced with utilities is obviously more valuable than off-grid blocks. The "bid-rent theory" for properties posits that households and firms are prepared to pay a certain amount of money for the location of the land, based on the value they place on that location's accessibility to markets, jobs, and other activities (Alonso 1964).

Proximity to transit stations is of value because transit infrastructure improves accessibility of a location to the central business district and other areas; although rents are expected to decline as distance from a transit station increases. However, a mass rapid transit may also have negative effects on rents and land values if it generates or attracts negative externalities, such as noise, congestion, and crime. These concepts are fairly well understood; but it is also important to stress that accessibility is a broad concept, of which proximity is just one part. 
Accessibility drives property values, rather than proximity. One may be relatively close to a mass rapid transit station, but if an individual is impeded by poor pedestrian, bike, or transit connection access, this will inhibit accessibility to that particular location. There are also variations to consider in terms of levels of accessibility across the different stations of a mass rapid transit network. Travel time to key destinations is not the same across stations; and those stations offering faster travel times to key destinations should see greater value, all things being equal. Even operational or service changes, such as improved frequency, safety, or reliability of service, can impact accessibility. Hence, service and operational outcomes can be influential in driving property value changes (although the academic literature has devoted less attention to this issue).

Substantive literature highlight how investment in transportation infrastructure affects property values. For example, the literature on the effect of rail transit on property values is vast and still growing. A systematic search of the literature (Abiad et al., forthcoming) yielded 61 studies, of which 43 were published over the last decade. Three-quarters of the studies analyzed mass rapid transit in advanced economies, and one-quarter examined those in developing economies. These studies analyzed a wide range of cities, property types, and rail systems, and adopted different methods - which resulted in different impact estimates. A review of this literature-using meta-regression analysis - finds significant impacts of mass rapid transit access, although these impacts vary by property type and city context.

For developing country studies that examine the impact of being in a catchment area (the definition of which varies across studies, from 100 meters to 1.6 kilometers in the study sample), the observed premium for residential properties close to a mass rapid transit station is $5 \%$. For commercial properties, the average premium is higher, at 30\%. Looking beyond the catchment area, other developing country studies examine how property values vary in terms of distance to a mass rapid transit station. Summary findings from these studies suggest that residential property prices decline by $8 \%$ on average for each 1 kilometer $(\mathrm{km})$ one moves away from a mass rapid transit station. The effect is larger for commercial properties, which see a $15 \%$ value decline on average for every additional kilometer of distance from a mass rapid transit station. Interestingly, this can be mitigated by redeveloping feeder passages such as shopping districts along river walks or converted canals radiating from the main terminals.

One should be careful in interpreting average effects, however, because another important takeaway from the literature is that the estimated effects of mass rapid transit accessibility on property values vary greatly across studies (i.e., these effects can be very context-specific). While the majority of studies find a positive effect, there are others that find negative effects of proximity on residential properties-a finding that is not implausible when considering the importance of the design dividend, as mass rapid transit stations can have negative externalities such as noise, as observed in the study. The evidence supporting an accessibility premium is more evident in studies that examine distance to mass rapid transit stations. Overall, estimates from many past studies cannot simply be taken "off-the-shelf" and used for cities elsewhere.

While the evidence for land value capture is compelling, one also needs to consider the time dimension. The question of how property values may change or grow over time, subject to zoning changes announced or anticipated, and relative to the scheduling of key phases for major transit project investments, are important questions when approaching value capture concepts.

Theory and observation suggest three broad phases of land value impact relative to major transit projects (Abiad et al., forthcoming) (Figure 1). The first is at announcement (or anticipation) of the project, at which time clever speculators or property investors would quite sensibly look to take advantage of any future changes in property value at a subject location by buying that location while prices are still low. This raises substantial questions of equity and inclusion, especially in low-trust societies. 
Figure 1: Project Phasing and Value Impact

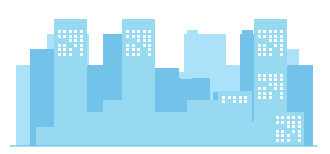

Commercial

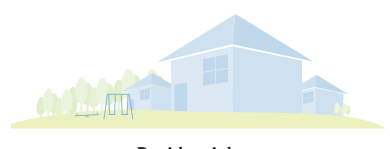

Residential

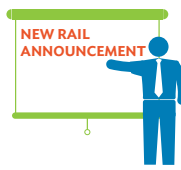

Announcement

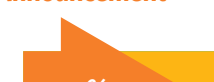

$12 \%$
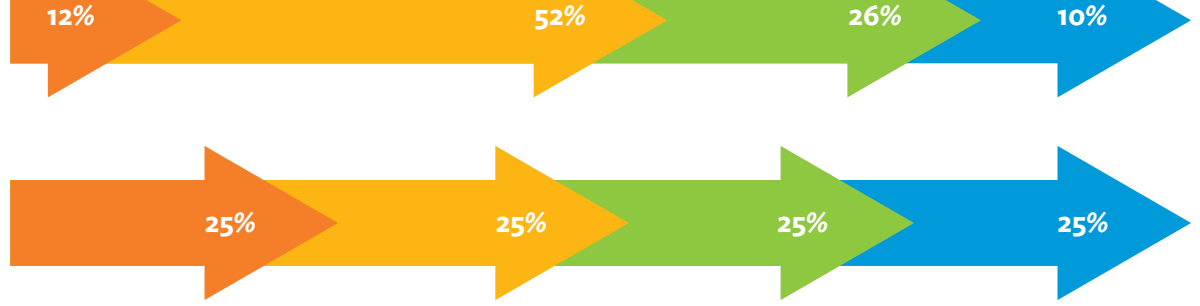

Source: A. Abiad and A.J. Adona. Forthcoming. How Do Mass Transit Investments Affect Land Values? Evidence from MRT-3. Background Paper. Manila: Asian Development Bank.

The second key phase of value creation is around the start of project construction (or at signing of project contracts). At this juncture, stated project intentions are consolidated into concrete action, representing a higher level of confidence that changes in property value will happen and are worth trading for. But even that is not certain as many planned projects fall through or get abandoned later, even in relatively developed or sophisticated cities.

The third and perhaps most obvious phase of property value impact is after opening of the new transit station, route, or service enhancement. At this phase-what is often known in real estate terms as the "ready for occupancy" stage-the actual accessibility benefits of a project manifest themselves and become obvious to even the most slow-moving property market participants. Existing landowners or tenants already in occupation simply enjoy that phase of their betterment without having done anything. One interesting aspect of this phase is that it essentially lasts into perpetuity (without some dramatic change). Hence, the nature, timing, and cycle of property market change within this apparently never-ending, post-opening phase is an intriguing set of questions.

To summarize a complex situation, most rail-accessible local property markets should somewhat stabilize at some point, after an initial burst of post-opening value growth. Some evidence on value impacts at each project phase has been documented, with the disclaimer that empirical estimates of land value uplift are context-specific. Generally, strategies employed by these studies identify "treated" groups and counterfactuals (control properties outside the area of impact), including specifications of intervention timing (announcement, construction, and operation of mass rapid transit systems). As such, the effect estimates are specific to the counterfactual and are not directly comparable across studies.

The next section presents a case about the effects of mass rapid transit on property prices in Metro Manila, Philippines. It illustrates how a new train line has affected property values differently over time. 


\section{Case Study: How MRT-3 affected land values in Metro Manila}

Line 3 of the Metro Rail Transit (MRT-3) in Metro Manila is the busiest of the three mass rapid transit lines in the metropolis. Planning for the line began in the late 1980s, but it was not until the Supreme Court upheld the validity of the MRT-3 contract in 1995 that the project moved forward in earnest. Construction began in 1996, the first section was inaugurated in 1999, and full operations commenced in 2000. To examine how residential and commercial land values are affected by the construction of MRT-3, a new study (Abiad and Adona, forthcoming) combines historical land value assessments from the Philippine Bureau of Internal Revenue with a land use map of the metropolis. This allows for the construction of a panel data set of land values for over 5,800 parcels in Metro Manila from 1990 to 2015, for a total of more than 150,000 observations.

Abiad and Adona (forthcoming) adopted a "difference-in-differences"approach-which compares changes in land values for parcels close to MRT-3 stations vis-à-vis changes for parcels farther away-and used the timing of MRT-3 contract finalization, construction, and start of operations. Their findings of the value-add are not simply based on correlations, but on the estimate of the causal impact of MRT-3 on land values. The results indicate that parcels within $1 \mathrm{~km}$ of MRT-3 stations comprise the treatment group, whose prices are expected to be most affected by MRT-3 construction. Parcels more than $2 \mathrm{~km}$ away from MRT-3 stations comprise the comparison group.

Figure 2 shows that land values for close-in treatment parcels and farther out comparison parcels moved up in parallel until 1994. However, starting in 1995-the year the MRT-3 contract was finalized-land values in the two groups began to diverge, with close-in parcels seeing larger increases in values. This divergence continued throughout the construction period and until and after the operations had commenced. Average residential and commercial land values before and after 1995 for both treatment and comparison groups show significant differences. While residential parcels farther away from MRT-3 saw a substantial increase in value from $P 2,789(\$ 107)$ to $P 7,584(\$ 172)$ per square meter $\left(\mathrm{m}^{2}\right)$, close-in residential parcels saw a substantially bigger increase, from $P 4,972(\$ 190)$ to $P 16,036(\$ 364)$ per $\mathrm{m}^{2}$, so that residential parcels in the treatment group saw values increase by $\mathrm{P} 6,268$ ( $\$ 154)$ per $\mathrm{m}^{2}$ more than in the comparison group. The difference-in-differences estimate is even larger for commercial parcels, at $\mathrm{P} 22,140$ (\$545) per $\mathrm{m}^{2}{ }^{1}$.

The study has used a more sophisticated difference-in-differences hedonic regression approach to control for other factors that affect land values, including distance to other rail lines, distance to central business districts, population density, and per capita income, among others. Study results show that the estimated impact of MRT-3 on land values has declined to P3,743 (\$92) per $\mathrm{m}^{2}$ for residential parcels and P13,968 (\$344) per $\mathrm{m}^{2}$ forcommercial parcels. Using these more conservative estimates, the impact on aggregate land values within $1 \mathrm{~km}$ of MRT-3 stations is estimated to be close to $\mathrm{P} 180$ billion ( $\$ 3.4$ billion), roughly five times the $\$ 655$ million construction cost of the MRT-3.

In other words, capturing just one-fifth of the incremental land value increase due to MRT-3 would have been enough to pay for the $\$ 655$ million total cost of MRT-3, while still leaving a very substantial windfall for private property owners. Assuming that the private property owners are prepared to accept that their land's value has increased due in part to the government's or infrastructure developer's efforts and not as a result of their good fortune or wise investment skills, this implies a substantial scope for generating "win-win" situations through land value capture. More infrastructure funding means more mass rapid transit gets built and developed more quickly. This can generate more windfalls for property owners and improve productivity and welfare for all residents.

Pre-MRT Philippine peso values are converted to US dollar values using 1990-1994 average exchange rates, while post-MRT Philippine peso values are converted to US dollar values using 1995-2015 average exchange rates. 
Figure 2: Evolution of Commercial and Residential Land Values

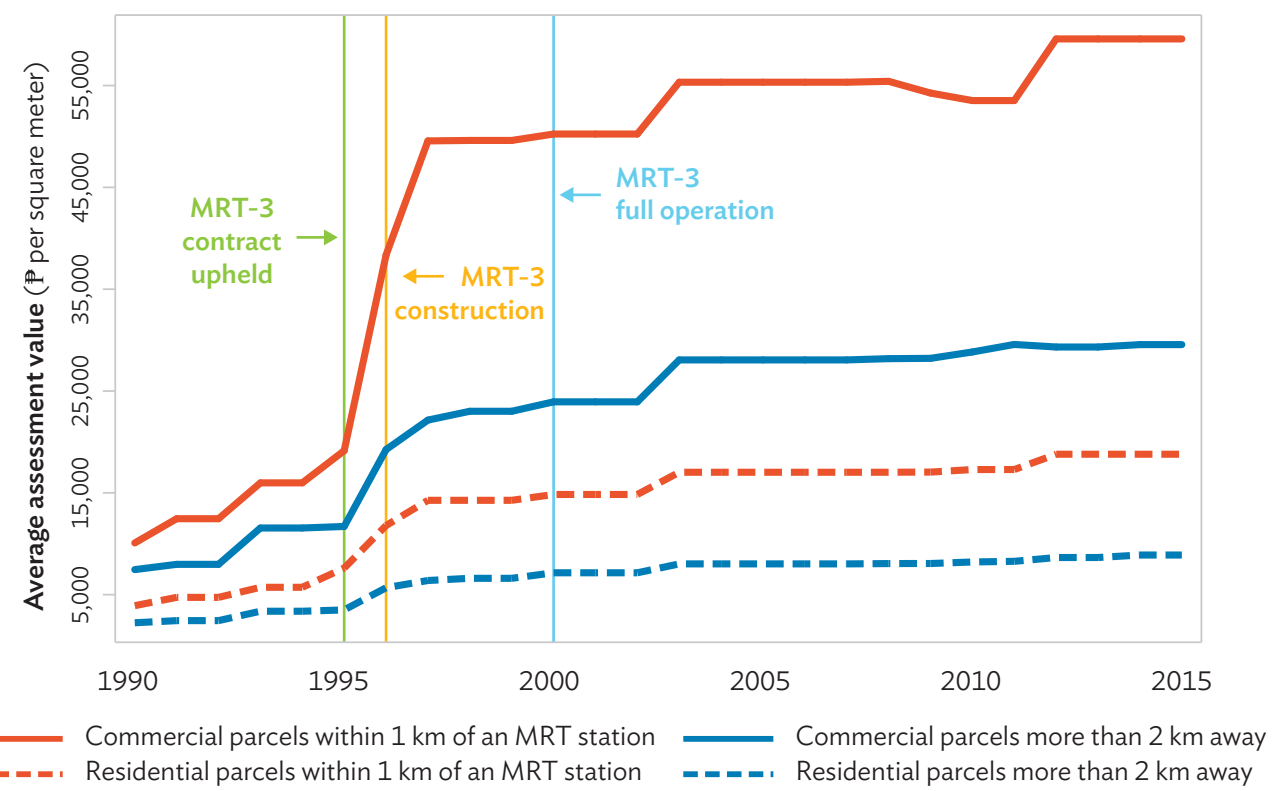

km = kilometer, $M R T=$ Metro Rail Transit.

Source: A. Abiad and A. J. Adona. Forthcoming. How Do Mass Transit Investments Affect Land Values? Evidence from MRT-3. Background Paper. Manila: Asian Development Bank.

\section{Value Capture Mechanisms}

Although value capture concepts can seem relatively complex on first encounter, this article suggests that a practical pathway to successful funding of major transit initiatives rests on five basic land value capture mechanisms (outlined and discussed in this section). The mechanisms are complementary and mutually supportive. Singapore and Hong Kong, China actually tend to use "all of the mechanisms, all of the time" to create a profound effect. The case of India is described in Box 1.

\section{Mechanism A: Value capture through the mainstream taxation system}

A great number of value capture sources, one of which is Suzuki et al. (2015), tackle tax increment financing, which is often defined confusingly, for some reason. A simplified definition of tax increment financing might be working within the existing taxation regime to identify potential tax take increases, as a consequence of the expansionary effects of major transit projects. The future increase in tax base can be utilized as a repayment stream over time, and/or borrowed-against to provide upfront funds for infrastructure delivery. Note that this does not mean that the percentage of existing taxes are being increased, or new betterment taxes or special levies are imposed on the current ratepayers for the introduced service (e.g., sewer connection).

This mechanism and the potential for its use is clearly described by Yoshino, Helble, and Abidhadjaev (2018). Increases in property-related tax take (whether at a local government level or above) are perhaps more closely associated with impacts from transit initiatives. However, as Yoshino, Helble, and Abidhadjaev (2018) posit, 


\section{Box 1: The Value Capture Finance Policy Framework in India}

Under the Value Capture Finance (VCF) Policy Framework, cities in India through state urban acts and regulations have been developing and experimenting with some instructive VCF mechanisms. The following are the current slate of tax instruments being proposed under the VCF Policy Framework.

- Land value tax based on land records, valuation, assessment, and revenue collection enables levy for rural and urban land (Mechanism A).

- Tax for land use change includes capturing gains from changes in land use from residential to industrial, commercial to industrial, and residential to commercial.

- Betterment levy. Authorities collect a "betterment levy" on a plot, assuming there are benefits from adjacent infrastructure development by the state or authority. For instance, if building roads, metros, and other transport infrastructure leads to appreciation in land prices in the vicinity of these projects, then landowners enjoy a benefit and are required to pay a betterment levy.

- Development charges. Under the Development Charges Act 1997, municipalities in India can impose development charges against lands to be developed to pay for growth-related capital costs for the municipality such as roads, water supply lines, and recreation facilities.

- Transfer of development rights (TDR) is used for trading development rights and excess floor area ratio (FAR), thereby aiming to recover monetary compensation. Some state acts restrict the use of TDR to special land use. For instance, FAR that would have been lost due to heritage conservation or land being utilized for social causes such as open spaces and affordable housing, may be traded in the form of TDR in other parts of the city. However, it must be consumed within the administrative limits of the same urban development authority.

- Premium on relaxation of FAR. TDR may be used for additional development rights beyond the permissible limits. However, the additional FAR is availed on a premium (Mechanism B).

- Vacant land tax. The land development corporation, in case of land not extensively used for agricultural purposes and are not occupied by buildings, impose a $0.5 \%$ vacant land tax on the estimated capital cost of the land.

- Town-planning schemes and land-pooling system. States such as Tamil Nadu and Maharashtra have made land value tax applicable to urban areas, under which increase in land value is tapped through increased land revenue tax. Some states such as West Bengal have formulated a system to capture tax gains from land use conversion tax. Several states resort to area-based development charges that vary from urban to rural areas.

Source: G.B. Stillman and S. Bharule. 2020. Governance Institutions: Key Elements for the Integrated Planning and Equitable Deliverability of High-Quality Transport Infrastructure. In Y. Hayashi, K. E. Seetharam, and S. Bharule, eds. 2020. Handbook on High-Speed Rail and Quality of Life. Tokyo: Asian Development Bank Institute. pp. 497-498.

other taxes such as business and income taxes may also rise due to increased economic activity. When this study refers to the existing tax regime, it overtly and clearly distinguishes from special fees and levies, enacted for one-off purposes (and covered separately under Mechanism B). Applying the above definition, Mechanism $\mathrm{A}$ is basically either a tax increment financing strategy, or simply a structured process of tracking and gathering increased property (and other catchment) taxes after opening of a stimulatory transit infrastructure facility. Either way, the estimation and reuse of increased tax take for transit infrastructure funding is a core concept and a necessity if Mechanism A is to sustain programmatic investment and growth in mass rapid transit. 


\section{Mechanism B: Special fees and levies}

Mechanism B involves special fees or charges that target a specifically defined beneficiary base, as a fee-for-service to improve transport outcomes. In contrast to Mechanism A, special fees and levies under Mechanism B are not a broad or entrenched element of an overall taxation system-and, more prosaically, as fees-for-amenity, they are simply not taxes (even though many people seem to get this issue confused). Mechanism B is defined as new and specific levies on benefits and beneficiaries in accordance with estimates of the benefit received. Practical worldwide examples of Mechanism B include the following:

- Betterment levies for specific subject areas (and not unreasonably imposed beyond) levied on beneficiaries of a major transit upgrade (particularly based on increases in property value due to enhanced connectivity).

- Connection fees where a charge is paid by major property owners for physically integrating their property to a transit station (new or existing) via a new underground or aboveground walkway connection. The 'connection fee' should exceed the narrow cost of merely constructing the access point, and address the value arising from an increase in footfall brought by better connectivity to busy transit facilities.

- Rezoning fees in return for the value increase achieved where allowable floor space is increased substantially (and/or transitioned to higher and better uses). There could be some arbitrariness introduced by this component, as noncommercial considerations, such as the historical streetscape or maximum height of skyscrapers, could result in limits to the number of commercial floors allowed in a rezoned area by the local authority.

One aspect of all of the above pathways under Mechanism B is that transit agencies or the government may be highly expected to provide clear and evidence-based information about the increase in property value and/or benefit received by subject stakeholders, relative to the special fee or levy they are requested to contribute. There is also an expectation toward clearer articulation of earmarking of betterment levies and connection fees funds into delivering transit upgrades at the location from which the fees were levied. By contrast, the Mechanism A reliance on the existing tax system implies, among other things, that there is no particular need to communicate with subject area stakeholders and property owners, nor convey any basis for the tax revenues. Indeed, it is hoped that the entirely new property owners and business owners will flock to the treated area and thereby contribute totally new taxes and revenue growth separate from the pockets of the current occupants.

\section{Mechanism C: Auction of development rights}

After reviewing the literature on value capture and discussing the property value increases provided by transit connectivity, it is natural to expect that those opportunities could be put to market in much the same way as any genuinely competitive auction offers a sound test of true market value. Thus, Mechanism $\mathrm{C}$ involves putting development opportunity and value associated with a new transit facility or line to sale, via open auction. As with the other mechanisms, the earmarking of funds raised through auction for actual transit infrastructure funding is a crucial link within a coherent value capture cycle. In practice, a development opportunity is often packaged with delivery of a station facility, or even of an entire segment of rail track infrastructure, as part of the auctioning process. Incoming bidders pay for development rights, but with a commensurate infrastructure delivery obligation.

This approach arguably simplifies the connection between value creation and realization on one hand, and infrastructure delivery on the other. An auctioning exercise looks relatively straightforward at face value and dovetails neatly with public-private partnership approaches that feature a strong emphasis on infrastructure 
delivery by private industry. As with any auction, however, the value realized by the seller (the government in this case) is closely related to the number of active bidders competitively involved in the auction. In reality, major private sector developers with strong financials and the willingness and ability to deliver rail infrastructure and property tend to be relatively few, even in the most advanced economies. Thus, proponents of the Mechanism C approach must realistically appraise the possibilities for legitimate competition and the prospects for achieving a fair value outcome for public assets at auction. In any case, if the bundling of transit infrastructure delivery with real estate development rights is considered too complex in a given location or project, government stakeholders can still proceed to carefully auction off the real estate opportunity (or land) alone, while reutilizing those sale funds for infrastructure delivery.

\section{Mechanism D: A comprehensive transit-oriented development and urban renewal agency with value capture capabilities}

The mechanisms outlined in this article are mainly delivery-focused rather than purely conceptual or theorybased. A specific agency or continuing development authority, with targeted remit and appropriate capabilities, is usually (and arguably) a reasonable response in any situation involving the delivery of complex and integrated infrastructure, or other government services for that matter. Thus, with the intent to generate land value capture, a land value capture agency could presumably perform relevant functions and deliver a more unified and equitable outcome (Stillman and Bharule 2020).

However, value capture, transit infrastructure, and associated property and planning issues are challenging and multifaceted. Many of the levers for achieving land value uplift or value capture are related to planning, zoning, property activity, value through design, and the overall strategic direction of a particular subject area. At the same time, many of these selfsame issues and levers would be part of the mainstream remit of an urban renewal authority.

It is perhaps time that parties involved in the value capture policy discussion recognize that value capture could be (and in some cases already is) achieved through a comprehensive urban renewal authority. This authority should feature rezoning powers, master planning capabilities, and the intention to generate new property valueworking with access enhancements and delivery of needed transit infrastructure. The urban renewal authority may also engage in the delivery of housing and public realm green and efficiency enhancements and can partner with private sector developers on a site-by-site basis within their subject areas. These capabilities are more or less the same as those seen in locations like Singapore (through their Urban Redevelopment Authority). Moreover, the broader suite of activities and capabilities inherent within an urban renewal authority also seem to address latent issues at large within major developing cities like Bangkok, Jakarta, Mumbai, and Manila (where there are simply plenty of large sites that would benefit from urban renewal). An urban renewal authority in any of these megacities could take on the critical role of developing (and showing strong commitment to) integrated land use and transport master plans. An urban renewal authority for these locations will not only conceivably deliver value capture and transit infrastructure, but also the much-needed precinct-based comprehensive urban renewal.

\section{Mechanism E: Direct property—rail agency as developer in the 'East Asian' style}

"Direct property" has long been a feature within the value capture discussion. East Asian rail agencies in Hong Kong, China; Japan; Singapore; and beyond arguably offer the most compelling and successful examples of direct property land value capture. Hence, Mechanism E is defined as a transit operator or agency involved in developing and trading property holdings associated with stations and precinct- or corridor-scale projects on a 
commercial basis, with the intent to use at least some of the profit from those activities for transit infrastructure and facility funding. This should be a relatively straightforward and widely understood concept by now, but two additional points are worth making.

First, the involvement of a transit stakeholder in direct property activity and dealing does not preclude any of the other four mechanisms from being applied. Indeed, enacting an East Asian "Rail + Property" model may be a key enabler, and can be very supportive of the other value capture mechanisms (particularly in major transit-oriented development projects requiring critical mass, or where station development is recognized as a catalytic exercise opening up broader property opportunity).

Second, within station environments or in very direct physical proximity to station facilities, it is usually useful to have the transit agency retain control of property holdings (e.g., for retail) so as to maintain the necessary operational control and access. Put differently, the closer one is situated to a transit platform, the better it is to have property activities and holdings in the hands of a transit agency rather than with other parties. Under Mechanism E, it is recommended that interested parties pay close attention to the sophisticated and nuanced approaches currently used successfully in Japan or by other exemplars. Their approach to synergistic property and retailing mix is now very advanced, and closely interconnected with an understanding of the demographics and daily needs of transit passengers.

\section{Bringing in the Private Sector to Build Infrastructure through Recycling Value}

As the historical record shows (Yoshino and Stillman 2017a), private financing of public infrastructure is possible and desirable, not only in Asia but also worldwide (Carrasco and Lau 2020). However, extra help is usually needed in the form of "deal sweeteners"-required reasonably_by financiers and builders, especially in the initial years before the project becomes operational with a reliable and healthy income stream. As pioneered in the North American transcontinental railway projects, these may take the form of land grants, concessional rights-of-way, and ancillary revenue opportunities through business diversification such as commercial property development, minor businesses such as exploitation of trackside lumber and minerals, or leasing of advertisement space.

Some public sector support for financing package, or partly subsidizing the costs of raising or enhancing such financing package, seems unavoidable, except for the most fortunate projects with strong prospects. This usually takes the form of tax holidays and incentives, generous credit, favorable profit sharing, government advancing the payment of interest due during construction, and transfers in kind-and implicitly including a variety of guarantees of the loan and bond indebtedness. Governments and markets need to be both realistic and sympathetic to special accommodations and even bailouts in the final years of a project when delays and cost overruns can strain the original financing plan (OECD 2016).

Future tax revenues and other recycled value can also be tapped for sharing with the private financiers and investors participating in infrastructure projects. Economic corridors along transit routes can be conveniently widened by band multiples of 500 meters to $1 \mathrm{~km}$ either into the side of the line, or into economic and tax zones that capture growing neighboring wealth, increased business activities, and future taxes rather than increasing current imposts or imposing betterment fees on present residents. The economic boundaries of such a zone may not always correspond to official city limits, geographical or political borders, or subnational municipal and state 
lines and traditional tax districts (Day 2016). Indeed, the sprawling expansion in Asia of so-called "natural" cities and agglomeration regions beyond their administrative boundaries raises many of the same questions this article has identified for the proper coordination of planning, deliverability, and governance (Abiad et al. 2019).

A thorough menu of potential types of taxes existing or to be created that could conceivably be designated for catchment to fund back-end participation is given in Table 1, segregated according to mobility in relation to land and the level of taxing authority.

Table 1: Menu of Potential Types of Taxes That Could be Designated for Catchment as Categorized by Mobility

\begin{tabular}{|c|c|c|}
\hline $\begin{array}{l}\text { Immovable (and invariably fixed } \\
\text { or related to land and/or building; } \\
\text { predictably remaining inside } \\
\text { a tax catchment area) }\end{array}$ & $\begin{array}{l}\text { Sharing characteristics of both } \\
\text { (and to a certain extent movable } \\
\text { outside a tax catchment area over } \\
\text { the medium to long term) }\end{array}$ & $\begin{array}{l}\text { Movable (highly footloose and } \\
\text { dependent on the current domicile } \\
\text { of personal taxpayers) }\end{array}$ \\
\hline $\begin{array}{l}\text { Property tax/land rates/fixed assets tax } \\
\text { (residential and commercial division) }\end{array}$ & $\begin{array}{l}\text { Business/corporate tax (as businesses can } \\
\text { move out but at slower pace than people) }\end{array}$ & $\begin{array}{l}\text { Personal income tax (collected at central, } \\
\text { province, and/or city level/s) }\end{array}$ \\
\hline Hotel room tax/surcharge & Value-added tax/(local) consumption/sales tax & Vehicle license fee tax increment \\
\hline \multirow{2}{*}{$\begin{array}{l}\text { Parcel tax/flat rate assessment on property } \\
\text { regardless of value or size }\end{array}$} & \multirow[t]{2}{*}{ Payroll tax/fee } & Vehicle registration fee \\
\hline & & Truck tonnage tax \\
\hline Betterment levies/assessment & Special tax/assessment & \multirow{2}{*}{$\begin{array}{l}\text { Other taxes on vehicles, } \\
\text { including motorcycles }\end{array}$} \\
\hline On- and off-street parking fees & Developers' fee & \\
\hline \multirow{2}{*}{$\begin{array}{l}\text { Naming rights of fixed infrastructure } \\
\text { (one-time fee) }\end{array}$} & Local commercial garage fee & Gasoline, diesel, and light oil taxes \\
\hline & Estate/wealth transfer tax & \\
\hline Sports stadium seating fees (seat licenses) & $\begin{array}{l}\text { Amusement taxes } \\
\text { (from cinemas and theaters) }\end{array}$ & \\
\hline Heating oil for premises tax & \multirow{2}{*}{$\begin{array}{l}\text { Commercial advertisement space/billboard } \\
\text { fees }\end{array}$} & \\
\hline Local/urban roads taxes & & \\
\hline Cordon/congestion pricing/peak use surcharges & Other sundry regulatory fees and user charges & \\
\hline \multicolumn{3}{|l|}{ Registration and license of land tax } \\
\hline \multicolumn{3}{|l|}{ Real estate acquisition tax } \\
\hline \multicolumn{3}{|l|}{ Urban/city planning tax } \\
\hline \multicolumn{3}{|l|}{ Street lighting tax } \\
\hline \multicolumn{3}{|l|}{$\begin{array}{l}\text { PILOT payments (i.e., direct payments by } \\
\text { landowners in lieu of real property taxes they } \\
\text { would otherwise have had to pay) }\end{array}$} \\
\hline \multicolumn{3}{|l|}{ Environment/nature reserve or national park tax } \\
\hline Tourism tax & & \\
\hline Departure tax (at air/seaports) & & \\
\hline
\end{tabular}

Source: N. Yoshino, M. Helble, and U. Abihadjaev, eds. 2018. Financing Infrastructure in Asia and the Pacific: Capturing Impacts and New Sources. Tokyo: Asian Development Bank Institute. 
Figure 3: Potential Ways to Transfer Back-End Tax Participation to Original Investors

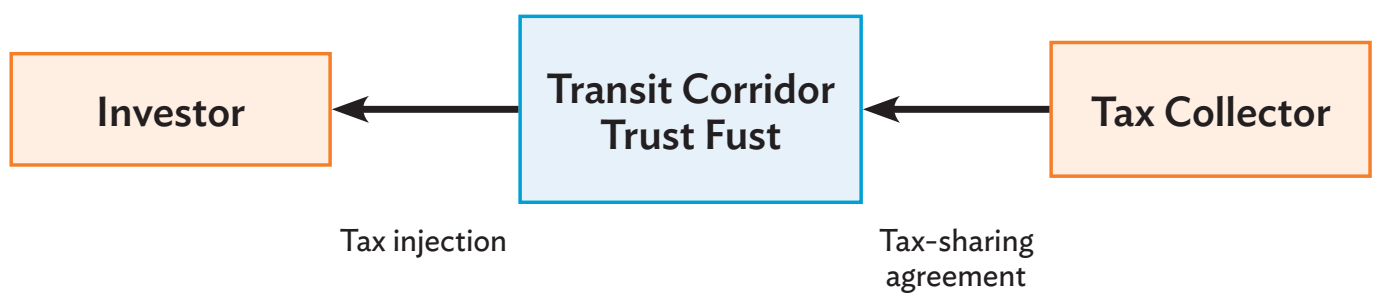

Notes:

1. Rebate check/electronic bank transfer (either to the issuer or directly to the bondholder)

2. Segregated revenue for backing any (gross domestic product-indexed) availability payments (unfettered or with collars in band)

3. Tax injected into an open-ended viability gap fund for general purposes (but there are risks of dilution, raiding for other purposes, or underfunding)

4. Deduction or tax credit for infrastructure developers on future years' tax returns (this may not be useful for overseas investors who are not taxpayers in the host country)

5. Payment by infra-advantaged beneficiary directly to issuer, constructor, or investor in lieu of real property tax or betterment levy they would have to pay to government tax collector (PILOT payment)

6. "Tax-kicker" (back-end future-tax-participating) bond

Source: Asian Development Bank.

A responsible tax-collecting authority might be able to put aside an agreed share specified in the loan or debenture of attributable new taxes in a project specific trust fund to assure back-end participants that their money will be safe and locked away when interest payments are due. There are many models and approaches to tax-sharing arrangements among central and subnational governments or with specially created districts or development agencies (Yoshino and Morgan 2017). Equitable tax-sharing arrangements across international borders may even be possible in the future.

In certain cases, tax laws may have to be amended or modernized to permit such innovative arrangements. For example, statutory or constitutional impediments to the sharing of internal revenues might be overcome by outright amendments where possible, or through the use of proxy credits passing through the general fund and fungible payments directly correlated and arising out of the calculated tax participations due.

Trust fund proceeds can then be used to close the gaps in projects' viability and profitability and help finance them; or the new revenue might simply be segregated to finance any availability payments agreed by the government in a project's concession, which could also be indexed to keep pace with growth (or inflation). Private investors should be attracted to projects that offer them this new option of enjoying back-end participation in future tax revenues from affected zones (Figure 3).

The back-end share can be simply transferred to the beneficiaries by something as basic as a bank cheque or bank wire transfer. However, a more beneficial form could be realized by compensating tax credits, deductions, or rebates on present and future tax return filings.

Structured finance projects or traditional bank loan project syndicates can easily mandate such transfers among the known and fewer parties in their bespoke documentation. This is being discreetly done in many diverse deals, business sectors, and legal jurisdictions. It is worth mentioning though that overseas financiers without domestic taxpaying obligations or local subsidiaries in a project site jurisdiction might not be able to use any tax credit or rebate mechanism offered. 
A more sophisticated global standard instrument with securitization, registration, and negotiability has even been proposed, which could draw on existing prototypes of tax-increment revenue bonds and social or development impact finance bonds with payouts contingent on achievable targets (Yoshino and Stillman 2017b). If the implemented project has been modestly successful in the long term and starts generating regional growth above the national GDP, the so-called tax-kicker bonds for infrastructure can offer higher rates of return than traditional revenue (and toll only) bonds or (availability payment) project bonds.

In theory, tax-kicker bonds should be issuable at all levels and by any entities-assuming that legal capacities to issue securities exist or are legislated for. These entities may include central and subnational governments, regional development areas, public authorities, state-owned enterprises, city municipalities, and even large and creditworthy private construction companies. Some of the risks inherent in the tax collection could be minimized if the ultimate owner or any type of issuer were the government or a public municipal entity (either owned or partially controlled by the state).

The principles of subsidiarity and efficiency require any borrower or bond issuer to be as close as possible to the grassroots of the project itself, and at the longest arm's length from the government as the market will tolerate without always relying on automatic and legally binding guarantees. Central or subnational governments are eager to keep project costs off their budgets as much as possible. This is their main reason for attracting private investment in the first place.

\section{Moving Forward with Value Capture}

Value capture is a viable option for city transformation in developing Asia. A combination of short- and longterm actions can now pave a practical pathway toward building more and better mass rapid transit by actively mobilizing key value capture and beneficiary funding mechanisms. Basic policy reform actions should be proactively considered to spur a new period of sustained growth in infrastructure investment. In the area of urban transport investment, the focus should be on integrated urban planning; high-quality transit networks; and encouraging non-car, nonmotorized, and pedestrian movement for dense yet highly accessible city areas. The pressing question for government and multilateral development stakeholders is twofold-what can be done right now and what needs to be done for the future.

It is now time for developing Asia to adopt value capture. On one hand, it must be recognized that value capture is a moderately complex subject, requiring skill, attention span, careful policy discussion and adaptation, and development of technical capabilities. It should also be recognized that this is a proven model, adopted successfully in many jurisdictions over a long period of time-to the profound betterment of infrastructure financing. This study therefore recommends enacting value capture and beneficiary funding ideas in developing Asia. One should refrain from characterizing value capture merely as an option or as something to be discussed. Mainstreaming value capture into projects and programs is now timely and pressing.

Barriers to value capture are more often informal, capacity-related, or conceptual rather than formal or structural. The authors and those who have interest in this topic have observed and learned the many reasons given for not enacting value capture. Most of these reasons are about unwillingness to change and maintaining the status quo. The difficulty of some of the changes, however, can be vastly overstated and exaggerated. Few jurisdictions have any specific legislative injunction against value capture mechanisms or approaches. In some cases, the required legislation is already in place, but remains untapped (e.g., the provision for special levies in the Local Government 
Code of the Philippines). Stakeholders should try to begin moving forward within the many opportunities that are not specifically limited by legislative or regulatory barriers.

Often the question of "who should lead this initiative" is raised. A straightforward answer to this question is that government organizations should support and provide leadership for value capture from within their core remit and primary areas of responsibility, and not far beyond. Ministries are primarily responsible for regulation, policy development, and providing advice to key decision makers. Therefore, their appropriate role in value capture includes regulation, policy development, and providing advice to decision makers. Local governments are responsible for local or area planning and localized business and property taxes, hence, their contribution to value capture should be delivered through supportive adaptation to area planning and localized business and property taxes. In terms of transport infrastructure projects, since transit agencies build and operate the transit, their primary contribution lies in effectively building and operating transit, though perhaps with some complementary and strategically useful adaptations, such as taking on a slightly more proactive commercial property-related role.

The international literature frequently highlights the issues of social equity, trust, and fairness in developing country project contexts. Although there are no easy answers, the authors recommend to major project stakeholders that careful consideration be given to issues of equality, fair dealing, inclusion of marginalized groups, and pro-poor outcomes during major project or value capture initiatives. One area of significance is the treatment of existing landholders, or of informal occupants of project lands. This study recommends that in accordance with accepted best practice, all landholders and occupants must at the very least be recompensed in line with an independent valuation of their holding, and that due material consideration also be given to any costs of relocation (whether for residential occupants or businesses) in major project contexts. Any verifiable material economic loss for a project area occupant or landholder should be fairly recognized and appropriately compensated. Low-income residents of the project area can be prioritized for any low-cost or subsidized housing produced within the overall project transit-oriented development agenda. Rather than being seen as an additional cost, fair dealing and provision of due material consideration to project stakeholders should be seen as a natural action that smooths the process of adjustment to occupancy and ownership of relevant lands (Tiwari et al., forthcoming).

The public trust needed to execute moderately complex initiatives, such as value capture funding, requires clear and unimpeachable standards of fair dealing in regard to affected occupants and landholders, as well as other stakeholders. Transparency and integrity must be supported by strong governance and enforced accountability.

Value capture is an integral part of transforming city economies in the 21st century. As the value capture progresses, it opens up huge opportunities for the private sector. A central conceptual and practical plank of value capture is the existence of positive spillover effects. For example, a mass rapid transit, funded in part through value capture, can create value and drive growth and economic interactivity through improved connectivity. Any fees, charges, or contributions made via value capture to mass rapid transit funding are only a relatively minor portion of the benefits received by beneficiaries - either directly or less directly from better transit and growing cities. In other words, property owners and the private sector have nothing to lose through the value capture, and there is everything to gain. While it is agreed that the concept requires sustained discussion, explanation, and an evidence base, stakeholders need to move forward sensibly in the full knowledge that properly conceived value capture is a "win-win" scenario and an opportunity for the private sector.

The role of value capture within major projects is set to grow, thus multilateral agencies need to adapt their lending approaches. As much as multilateral organizations (including ADB) are sponsors of capacity building and technical assistance for value capture, they are also project lenders and influential participants in project decision-making around funding arrangements for mass rapid transit. ADB and other financing institutions, 
therefore, currently need to take stock and work through issues and expectations related to the inclusion of value capture funding sources in the project funding mix. One way to do this could be to stipulate that lending requests include demonstration of a genuine effort to source funds through value capture.

\section{References}

Abiad, A. and A. J. Adona. Forthcoming. How Do Mass Transit Investments Affect Land Values? Evidence from MRT-3. Background Paper. Manila: Asian Development Bank.

Abiad, A. et al. Forthcoming. Rail Mass Transit and Land Values: A Systematic Review and Meta-regression Analysis of the Literature. Background Paper. Manila: Asian Development Bank.

Acharya, S. R. and S. Morichi. 2007. Motorization and Role of Mass Rapid Transit in East Asian Megacities. IATSS Research. 31 (2). pp. 6-16.

Asian Development Bank. 2017. Meeting Asia’s Infrastructure Needs. Manila. https://www.adb.org/publications/ asia-infrastructure-needs.

Alonso, W. 1960. A Theory of the Urban Land Market. Papers and Proceedings of the Regional Science Association. 6.

Alonso, W. 1964. Location and Land Use. Harvard University Press.

Alonso, W. 1967. A Reformulation of Classical Location Theory and its Relation to Rent Theory. Papers and Proceedings of the Regional Science Association. 19.

Carrasco, B. and E. Lau. 2020. Why Infrastructure Governance Matters. Asian Development Blog. https://blogs. adb.org/blog/why-infrastructure-governance-matters.

Day, L. 2016. A New Financing Tool for California: Enhanced Infrastructure Finance Districts.

https://www.planetizen.com/node/88347/new-financing-tool-california-enhanced-infrastructure-finance-districts.

Organisation for Economic Co-operation and Development (OECD). 2016. Getting Infrastructure Right: The Ten Key Governance Challenges and Policy Options. https://www.oecd.org/gov/ getting-infrastructure-right.pdf.

Stillman, G. B. and S. Bharule. 2020. Governance Institutions: Key Elements for the Integrated Planning and Equitable Deliverability of High-Quality Transport Infrastructure. In Hayashi, Y., K. E. Seetharam, and S. Bharule, eds. 2020. Handbook on High-Speed Rail and Quality of Life. Tokyo: ADBI Press. https://www.adb.org/publications/handbookhigh-speed-rail-quality-life.

Stillman, G.B. 2017. Introducing the Tax-Kicker Bond: Budget-Neutral Financing of Private Infrastructure by Back-End Participation in Future Tax Revenue Growth. Tokyo: ADBI. https:/www.adb.org/publications/tax-kicker-bondbudget-neutral-financing-private-infrastructure. 
Stillman, G.B. 2018. Introducing the Tax-Kicker Bond for Infrastructure: A Proposal to Securitize Back-End Participation in Future Tax Revenue Growth. In Yoshino N., Helble M., and Abidhadjaev U., eds. Financing Infrastructure in Asia and the Pacific: Capturing Impacts and New Sources. Tokyo: ADBI Press. pp. 453-474. https://www.adb.org/publications/financing-infrastructure-asia-capturing-impacts-and-new-sources.

Suzuki, H. et al. 2015. Financing Transit-Oriented Development with Land Values: Adapting Land Value Capture in Developing Countries. Washington DC: The World Bank.

Tiwari, P., Y. Yoshino, and G. B. Stillman, eds. Forthcoming. Equitable Land Use for Asian Infrastructure. Tokyo: ADBI Press.

Yoshino, N., M. Helble, and U. Abidhadjaev, eds. 2018. Financing Infrastructure in Asia and the Pacific: Capturing Impacts and New Sources. Tokyo: ADBI Press. https://www.adb.org/publications/financing-infrastructure-asiacapturing-impacts-and-new-sources.

Yoshino, N. and P. Morgan, eds. 2017. Central and Local Government Relations in Asia: Achieving Fiscal Stability. ADBI Series on Asian Economic Integration and Cooperation. Cheltenham: Edward Elgar Publishing. https://www.adb.org/publications/central-and-local-government-relations-asia.

Yoshino, N. and G. B. Stillman. 2018. Back to the Future: Intrusive Features from Past Innovations in Raising Private Finance for Infrastructure. In Yoshino N., Helble M., and Abidhadjaev U., eds. 2018. Financing Infrastructure in Asia and the Pacific: Capturing Impacts and New Sources. Tokyo: ADBI Press. https://www.adb.org/publications/ financing-infrastructure-asia-capturing-impacts-and-new-sources.

Yoshino, N. and G. B. Stillman. 2017a. Kick-start Private Infrastructure with Future Tax-sharing Bonds. www.asiapathways-adbi.org/2017/05/kick-start-private-infrastructure-with-future-tax-sharing-bonds/.

Yoshino, N. and G. B. Stillman. 2017b. Viewpoint: Could Kicker Bonds Spur Private Investment in Infrastructure? Development Finance. October. 


\section{CHAPTER 5 \\ Resilience and Rejuvenation}

\section{Increasing Urban Resilience through Nature-Based Solutions and Total Asset Management Lara Arjan, Stefan Rau, and Sonia Chand Sandhu}

ARTICLE 5B

Building Disaster Resilience in Cities in Asia and the Pacific

Thomas Kessler and Arup Chatterjee

ARTICLE 5C

Post-Pandemic Response, Recovery, and Rejuvenation Alexandra Pamela Chiang, David Elzinga, Hong Soo Lee, and Geoffrey Wilson 


\section{Increasing Urban Resilience through Nature-Based Solutions and Total Asset Management}

Lara Arjan, Stefan Rau, and Sonia Chand Sandhu

\section{Introduction to Nature-Based Solutions}

Nature-based solutions (NBS) use ecosystem services to resolve diverse economic, social, environmental, and climate challenges. NBS can provide sustainable and cost-effective options with multiple benefits. These range from restoring ecosystems to promoting health and well-being, improving institutional capacity for risk management, and mitigating and adapting to climate change. NBS complement and provide alternatives to conventional gray infrastructure, or ideally function together with these through systemic integration in planning and design. Well-planned and well-designed green spaces and networks and other forms of NBS will deliver co-benefits and improve resilience beyond a targeted function (e.g., to manage urban stormwater). NBS can improve land use; enhance biodiversity; improve air, water, and microclimate; reduce noise; and help build resilience to flooding and other natural disasters. It can also provide livelihood opportunities in urban agriculture, recreation, and culture and tourism sectors - thereby increasing land values and promoting food security.

The European Commission (n.d.) defines NBS as "inspired and supported by nature, which are cost-effective, simultaneously provide environmental, social and economic benefits and help build resilience. Such solutions bring more, and more diverse, nature and natural features and processes into cities, landscapes and seascapes, through locally adapted, resource-efficient and systemic interventions."

At the 2016 World Conservation Congress and members' assembly, members of the International Union for the Conservation of Nature (IUCN) adopted a resolution, which, for the first time, defined the use of nature that will simultaneously bring benefits to both biodiversity and human well-being. ${ }^{2}$ According to the resolution, NBS are "actions to protect, sustainably manage and restore natural or modified ecosystems that address societal challenges effectively and adaptively, simultaneously providing human well-being and biodiversity benefits" (IUCN n.d.).

The Millennium Ecosystem Assessment (n.d.) defines ecosystem services as "the benefits people derive from ecosystems." The ecosystem provides services that are distinct from each other: (i) supporting services as a foundation for ecosystems to function; (ii) provisioning services in the form of goods like food, water, fibers, fuel like wood and other raw materials, plants, animals, fungi, and microorganisms; (iii) regulating services such as air quality, climate, pollination of crops, prevention of soil erosion and water purification, and flood management; and (iv) cultural services like recreation, aesthetics, and spiritual and sense of place (Millennium Ecosystem Assessment n.d.).

Gray infrastructure involves engineered assets that provide one or multiple urban services, such as transportation or wastewater collection and treatment. International Institute for Sustainable Development. What is Grey Infrastructure. https://www.iisd.org/savi/faq/ what-is-grey-infrastructure/.

2 IUCN. 2016 Resolution. WCC-2016-Res-069: Defining Nature-Based Solutions. 
Water resource management is an area where the use of NBS has grown over the years. Green infrastructure for water uses NBS to provide options with benefits that are equivalent to, or like conventional infrastructure (gray infrastructure). NBS are usually implemented in tandem with conventional infrastructure and are used to enhance them (UN Water 2018). These solutions are known as hybrid solutions.

Considering the coronavirus disease (COVID-19) and related containment policies, NBS are more important than ever, contributing with their green open spaces; improved urban air quality and natural ventilation; and local space for respite, recreation, and physical exercise-generally enhancing resilience and contributing to public health.

Continuing rapid and massive urbanization in the Asia and Pacific region will cause further pollution, loss of green environment, and ecosystem degradation and fragmentation. If there is no strategic and integrated planning of land use, transport, and open space, unsustainable urban patterns will continue. Therefore, a comprehensive approach to integrate NBS into planning for new urban areas and for retrofitting existing urban areas is more important than ever. In the next 30 years, the last major rural to urban migration in human history is predicted to take place, with more than $80 \%$ of urbanization happening in Asia and Africa. Hence, in this closing window of opportunity, planning for sustainable development is urgently needed. It is also a great opportunity to maintain and rebuild green capital.

Although the concept of using NBS to provide ecosystem services to urban areas from within their territories dates to ancient cities and has been revived more than a hundred years ago, its acceptance as infrastructure is still new. Urban areas are traditionally and increasingly consuming ecosystem services from farther areas, rather than providing these services from within their territories. Despite its many advantages, accepting the need to invest in NBS still has its challenges compared to options for conventional gray urban infrastructure investments.

The concept of payment for ecosystem services has been established to place monetary value and is considered as an avenue to create new urban-rural partnerships.

Managing green capital and green infrastructure as part of a comprehensive urban asset management system is critical in operating and maintaining the NBS-based natural systems and green infrastructure to ensure their sustainability.

\section{Nature-Based Approaches}

The concept of NBS builds on and encompasses several approaches that are interrelated and are often used interchangeably. They include, among others, green infrastructure, sponge city, water-sensitive urban design (WSUD), and low-impact design.

\section{Green Infrastructure}

Green infrastructure uses natural processes and elements, such as combining vegetation, soils, gravel, and rocks to manage water, temperature, and air quality to create healthier, resilient, and aesthetic urban environments for the well-being of populations (Box 1). 


\section{Box 1: The New Clark City River Study}

The New Clark City (NCC) River Study in the Philippines aims to support evidence-based decision-making on the potential of the river and the green space surrounding the NCC to become integral to urban resilience and recreation.

The study evaluated the NCC's planned systems and their interlinkages by analyzing climate risks, vulnerabilities of anticipated assets, local topography, and hydrology.

The study finds that the proposed engineering solutions for the greenfield city would require massive earthworks and maintenance, and would not allow for leveraging the river as one of the most beautiful natural features of the site. Additionally, the drainage capacity was found not to be sufficient when accounting for climate change.

The study recommends the enhancement of certain riverbank conditions at multiple scales to provide urban functions and ecological services. This recommendation was taken forward by the Bases Conversion and Development Authority (BCDA), the project proponent. In the proposed 200-hectare National Government Administrative Center, which is at its pilot phase, $\mathrm{BCDA}$ will maintain the river function by establishing a river park that fulfills multiple purposes.

This nature-based approach prevents badly planned river alignments, thereby minimizing erosion and flooding risks. Furthermore, there is strong economic rationale to this approach due to significant cost savings as a result of reduced earthworks and ecological modification, and from the future savings from mitigated damages caused by flooding. For the private sector, such solutions also enhance land value capture.

Source: Asian Development Bank.

At the city scale, green infrastructure refers to a network of natural areas that provides habitat, flood protection, clean air, clean water, food, and recreation. At the local level, green infrastructure includes stormwater and drainage management systems that mimic nature by absorbing and improving its quality. For specific infrastructure systems, most importantly, it improves engineering by including natural components and bioengineering methods. At all scales, green infrastructure emphasizes NBS and the use of local resources and materials to build community self-reliance. It covers natural water management systems, slope stabilization approaches, energy conservation measures, and many natural materials and techniques. Green infrastructure applies or mimics nature to improve the performance and resilience of conventional gray infrastructure and often can replace it entirely for much cheaper and stronger results that allow for local community monitoring, maintenance, and multiple uses.

Examples of green infrastructure include green roofs and walls; hard and soft permeable surfaces; green streets; urban forestry; and green, open spaces such as parks, wetlands, and green drainage corridors. Green infrastructure also includes a wide range of green technologies for adapting and complementing buildings and infrastructure (such as roads, irrigation systems, floodgates, and canals) to become more efficient and to better cope with floods, storms, and heat (ADB 2016a).

Green infrastructure approaches that are implemented at a neighborhood or site-scale are often referred to as low-impact development (Thiagarajan 2018). Merging these various scales of green infrastructure promotes an integrated design approach. Natural interlinkages are sustained, and natural assets are enhanced through 
infrastructure, which is required in developing urban areas, wherein ecosystem services are integrated with the built environment. Thus, green infrastructure is seen as complementary to gray infrastructure and helps in reducing risks from natural disasters and extreme weather events (ADB 2016b).

\section{The Sponge City Concept}

"Sponge city" is a term used mainly in the People's Republic of China (PRC) since 2013. It is substantiated by technical guidelines and a national government program supporting a total of 30 pilot cities in two phases since 2015. Subsequently, the Government of the PRC requested all cities in the country to prepare sponge city master plans. The sponge city concept and program respond to increasing climate-change-related flooding and long dry periods. Flood events all over the country have been significantly increasing and causing loss of lives, injuries and waterborne health issues, as well as massive damage to assets, infrastructure, and harvests. Impacts of flooding have been aggravated by the fastest urban expansion in human history over the past 40 years. A highly impervious paving over green spaces significantly increases urban runoff while reducing natural infiltration. The channeling of rivers reduces the flood plains and changes the natural hydraulic systems.

The key principle of sponge cities is to sustain urban rainwater and flood risk management by reducing paved areas, making cities more pervious like a sponge, and increasing the capture and reuse of rainwater, among other measures. The overall objective of sponge cities is to improve the management of the urban water cycle especially through decentralized management of rainwater and stormwater. It also contributes to improved overall water resource management of a city by addressing flooding, water scarcity, and pollution. The sponge city concept takes into consideration increased climate variability which leads to extreme flooding, longer dry periods, and extreme heat over the year.

Stormwater is detained and slowed down to remove its potentially destructive force, as it may otherwise flood and affect people and urban areas and their assets. Rainwater is filtered and released slowly using green systems, just like a sponge does. Rainwater is either stored or reused after storms when less water is available, and for landscape irrigation, street cleaning, or other urban uses.

In northern PRC where water resources are generally scarce, the concept contributes to water security by capturing rain and stormwater for reuse. In southern PRC where water is generally abundant, the concept is primarily used to reduce flood risk from a combination of fluvial and pluvial flooding. However, due to increased variability and more extreme weather events because of a changing climate, there are more storms and urban flooding in the north and in the south, and there are more instances of longer dry periods, hence, sponge city objectives are merging, but each place has its own specific conditions and challenges.

Sponge city borrows its concepts from prior science and practices around the world, including some of the ones mentioned above (e.g., low-impact design, water-sensitive design, ecosystem-based adaptation, sustainable rainwater management). Concepts such as systems based on biomimicry and integrating natural and man-made systems are not new. Sponge city, in turn, has inspired other countries to incorporate the principle; Berlin, Germany, for example, is implementing sponge city projects. It is worth studying and replicating best practices from this application in the PRC, internationally and potentially in other developing countries.

Sponge city contributes to managing pluvial flooding or urban waterlogging caused by increased runoff from paved areas in expanding and less green cities, and fluvial flooding or river flooding aggravated by reduced space and channelization of rivers. One key to managing fluvial flooding is to use green space and wetlands and rehabilitate floodplains and riparian landscapes to retain water and increase the flow capacity of rivers. Another 
vital activity to manage pluvial urban flooding is to retain stormwater in a cascading system of green infrastructure to store and slow down the outflow into the drainage pipes and canals, and to treat water in sedimentation wetland ponds and sand filters before the water is discharged into rivers.

In dense urban settings with limited space, green infrastructure can be integrated with gray infrastructure (e.g., drainage pipes or permeable pavement on a gravel bed) and with drainage pipes that discharge into constructed underground storage tanks.

The concept of a sponge city is still deepening and moving toward a systemic catchment-wide and functional urban area approach (across local administrative boundaries following catchment as opposed to jurisdictional geography). A sponge city addresses pluvial and fluvial flooding through green and gray infrastructure simultaneously (Boxes 2 and 3). Future concepts should consider more weather extremes and any precipitation, including that of extreme storm events, as water resources are needed to manage the longer dry periods caused by climate change. That would require more extensive and systemically integrated green infrastructure planning and approaches. Future sponge city concepts also should further integrate with the overall water resource management of a city. It should stimulate urban infrastructure technology and system planning innovations (e.g., toilet innovations; separated black and gray water systems in buildings and communities; related treatment and reuse integrated with green infrastructure; catchment-based, decentralized, and clustered water supply and wastewater management system designs as opposed to the massive pipe networks across mega-urban regions).

\section{Water-Sensitive Urban Design}

Water-sensitive urban design (WSUD) is a relatively new urban development approach in developing Asian cities. Its application involves the integration of water cycle management with the built environment through urban planning and design. Specifically, it integrates water flows in urban landscaping and considers all aspects of the urban water cycle-including storage, reuse, treatment, retention, and infiltration of runoff water-as valuable urban resources. This design concept works with nature to make use of water in creating cities that are healthy and more livable. WSUD can have diverse features including wetlands, vegetated swales, bioretention basins or artificial lakes, rain gardens, green roofs, permeable pavements, infiltration wells, and cleansing biotopes. These can either complement or replace gray infrastructure depending on specific purposes and localized contexts (ADB 2019).

Engagement of local populations is pivotal to the success of WSUD. Involving beneficiaries in the planning, design, and co-management of the WSUD process can be resource-intensive and time-consuming, but very rewarding as it ensures adaptation to the local needs and conditions and community buy-in (Box 4). 


\section{Box 2: Jiangxi Pingxiang Integrated Rural-Urban Infrastructure Development Project}

Flood risk reduction is a top priority in Pingxiang, in Jianxi Province of the People's Republic of China. Flood frequency and severity have increased significantly since 1998. Floods in 1998, 2001, 2002, 2010, and 2014 affected more than 496,000 people, caused the collapse of more than 2,600 houses, and resulted in significant economic losses in agriculture. A major flood on 25 May 2014 severely impacted public safety and health and caused an estimated $\$ 115$ million in economic losses. As a headwater municipality where all rivers originate within its territory, Pingxiang is prone to fluvial flooding, a key risk aggravated in combination with pluvial flooding in urban areas. Most riverbanks in Pingxiang have inadequate flood protection, sediment accumulation from riverbank erosion, and raised riverbeds from mining, further reducing the flood discharge capacity of rivers. Urban drainage systems in Pingxiang are made of combined sewer and drainage pipes.

The Asian Development Bank (ADB) supported a project that contributes to making one of the 30 sponge city pilots more comprehensive and greener. It consolidated planning and investment for integrated river rehabilitation and flood risk management to improve climate resilience, enhance biodiversity, and contribute to urban greening as an amenity for citizens, thereby increasing livability and value of a city. The various features include green embankments, publicly accessible river greenways, floodplain protection, wetland rehabilitation, wetland parks for stormwater retention, as well as sewer and drainage separation.

The project changed the conventional gray infrastructure approach of flood control through channeling the river with walls and/or hard embankments to a green infrastructure approach. More space is provided to the rivers. Floodplains and wetlands are maintained and/or rehabilitated, and green embankments with soft water edges are applied to allow for natural and seasonal fluctuations in water levels and to reduce flooding impacts of more frequent and severe storm events, while also contributing to enhanced ecology and water quality. Climate risk and vulnerability assessment and hydraulic modeling of anticipated storm events were developed during project preparation. Specific additional adaptation measures were included in the design.
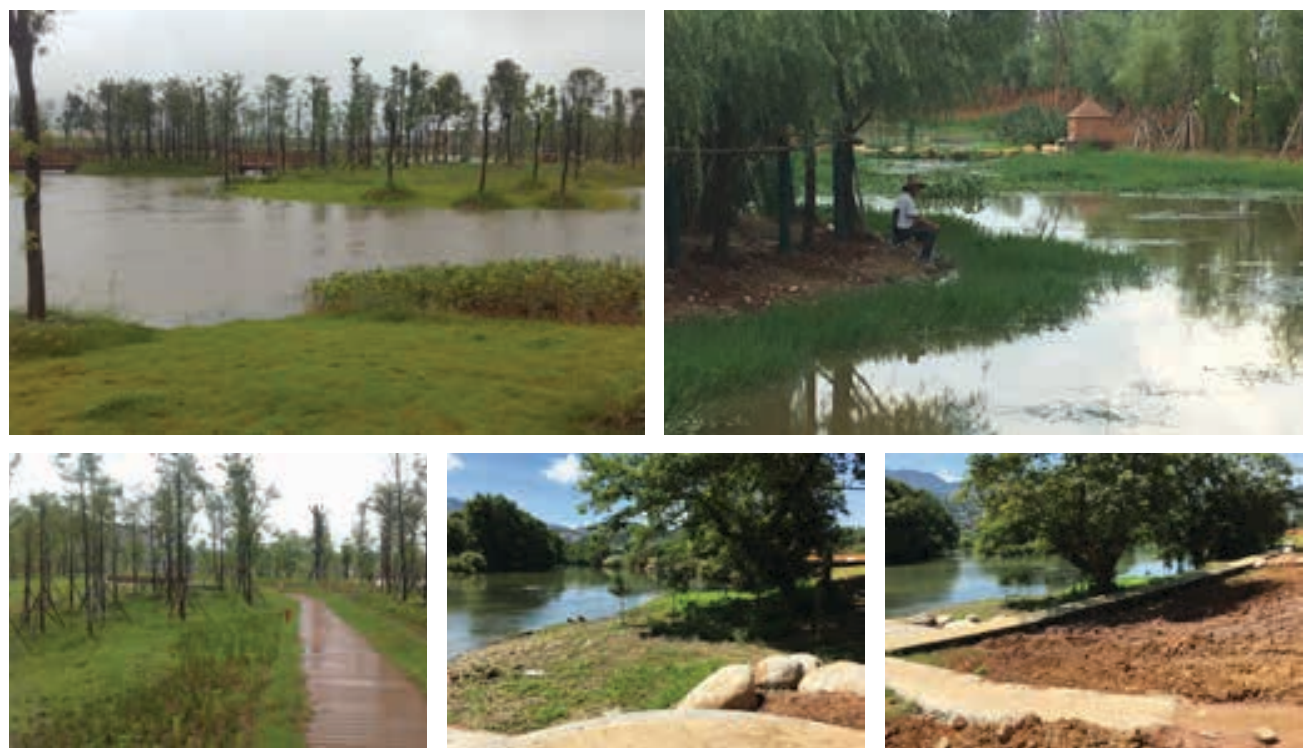

Flood risk reduction. Restored riverside wetlands and green water edges along gentle slopes along the river reduces the risk of flooding. At the same time, they provide a habitat for a diversity of plant and animal species and serve as an amenity for residents during non-flood times (photos by Stefan Rau/ADB).

Source: Asian Development Bank. 


\section{Box 3: Sponge City Concept Evolution-Yanji Low-Carbon, Climate-Resilient, and Healthy City Project}

For this project, the Asian Development Bank (ADB) used the design of sponge cities as a platform for mitigation and adaptation elements, such as public transport to promote walking and cycling and healthy lifestyles. It further piloted innovative approaches, including advanced computer modeling, demonstrating that integrating green and gray infrastructure can significantly reduce urban flooding (pluvial flooding).

Flooding is a significant problem during the rainy season in June and July. Flooding occurs for about 5 days per year on average in recent years. River flooding, flash floods, and urban flooding endanger lives, property, and livelihoods, and disturb traffic and public life. The combined sewer and drainage pipe system is outdated. Only $11.6 \%$ of the pipe network meets the required 1-in-3-year flood design standard, causing pluvial flooding during heavy summer rains. The Chaoyang River urban catchment area is currently exposed to flood risks of 1-in-20-year flood events.

ADB financed the first bus rapid transit (BRT) corridor in the northeast of the PRC and integrated it with comprehensive stormwater management and water supply system improvements. The overall concept follows the principles of transit-oriented development, focusing on higher-density, mixed-use, and pedestrian-friendly center areas including green spaces around BRT stations, thereby promoting low-carbon urban mobility. New green spaces that are designed as sponge city green infrastructure will link station areas with project-supported riverfront greenways. These spaces will create a network of sponge city infrastructure enhancing climate resilience and urban livability. These green spaces apply universal design principles to ensure accessibility and promote healthier lifestyles for residents and tourists, hence contributing to a healthy and children- and age-friendly city development.

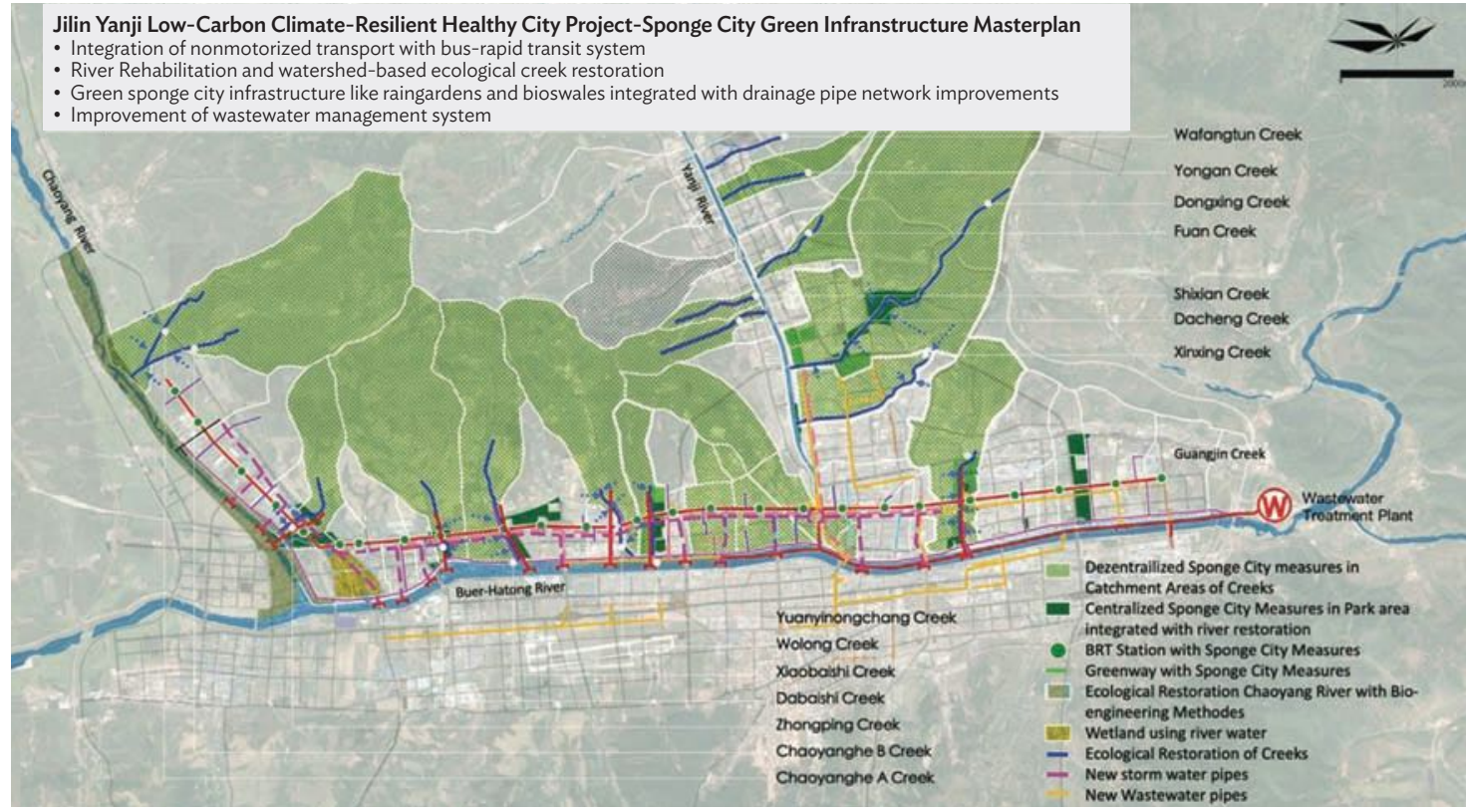

Sponge city green infrastructure master plan for Yanji City. The master plan is based on river and creek catchment areas, for the area north of the Buer Hatong River (photo by ADB). 
During project design, a catchment-based sponge city master plan for the northern part of the city was developed along with a climate risk and adaptation options assessment. A detailed digital topographic urban and hydraulic model was developed for the project. The model was piloted as an expert tool that simulates future storm scenarios and adaptation options integrating existing and newly proposed drainage pipe network improvements with at-grade sponge city green infrastructure. Improvements to drainage and flow capacity, combined with increased stormwater retention and infiltration capacity, were quantified, visualized, and evaluated to optimize flood risk reduction, investments, and green space benefits.

Investments include sponge city green infrastructure in residential areas within the catchment of creeks, integrated with improved and separated drainage pipes (at least 43 kilometers) and wastewater pipes (at least 40 kilometers), using results from a detailed hydraulic modeling. The project has significantly reduced the climate-related pluvial and fluvial flood risks (according to the project's hydraulic model up to 1-in-50-year flood events). It has also improved the water quality through the construction of end-of-pipe sedimentation tanks and reed-bed sand filters. Fluvial flooding is reduced through ecological river rehabilitation of the Chaoyang River, improving the flood protection standard from 1-in-20-year floods to 1-in-50-year flood events. Bioengineering is adopted, which includes in-stream solutions in the riverbed and green embankments as well as building pedestrian and bicycle paths with tree planting along the greenway.

Source: Asian Development Bank.

\section{Box 4: Revitalization of Informal Settlements and Their Environments Using a Water-Sensitive Approach}

Limited quality and access to sustainable services represent a significant challenge for residents of urban informal settlements, the majority of which are poor and suffering a variety of water-related stresses. Traditional, large-scale trunk infrastructure typically fails to reach these communities, leaving them particularly vulnerable to water-related health issues and increased exposure to the impacts of climate change.

The Asian Development Bank (ADB) and Monash University are implementing the Revitalization of Informal Settlements and Their Environments Using a Water-Sensitive Approach or RISE project in Makassar City in Indonesia. This project uses a community-led, nature-based approach to provide sustainable infrastructure as an alternative approach to the traditional large-scale trunk infrastructure, while directly improving community health and resilience to climate change.

This pilot project uses decentralized, green infrastructure to biologically treat water, and in doing so improves the environment quality and health of the community. It adopts a participatory approach that involves the local community in the co-design of the infrastructure. The approach comprises improved water supply through rainwater harvesting and recycling, improved sanitation, bio-filter wastewater treatment, improved drainage, and flood and tidal inundation management, along with community capacity development for long-term operations, maintenance, and system replication.

Source: Asian Development Bank. 


\section{Challenges to Developing Green Infrastructure}

Challenges to upscaling NBS so that they reach their full potential are generic across all sectors, at global, region-specific, or place-based scales. There remains a traditional disinterest and lack of awareness regarding NBS due to the overwhelming dominance of gray infrastructure solutions in the current planning and engineering regulatory frameworks - from public policy to building codes and regulations (UN Water 2018).

Gray infrastructure is the default choice of many city leaders and builders. Moreover, dominance of gray solutions exists in civil engineering, market-based economic instruments, the expertise of service providers, and consequentially in the minds of policy makers and the general public. These and other factors collectively result in NBS often being perceived to be less efficient, or riskier, compared to constructed gray systems (UN Water 2018).

Further, the financial and economic quantification of the various benefits from green infrastructure is still a challenge (Symons et al. 2015). The current costs of implementing green infrastructure vary widely and are sitespecific, and data is difficult to obtain. Developing solid cost estimates for feasibility and opportunity is essential to make the case for cost-effective green infrastructure solution (Browder et al. 2019). Kabisch et.al (2017) recognize that societal benefits are experienced differently and are not uniform across the socioeconomic spectrum.

Modernization, industrialization, and rapid urbanization, in general, have gradually eroded the reliance of societies and populations on ecosystems for their well-being. Development focuses on engineered gray solutions to provide services and ensure well-being. These services range from providing reliable safe drinking water through water storage reservoirs and treatment plants, protecting populations from floods and coastal storms by constructing dikes and seawalls, channeling water for irrigation and building dams, to using pipes and pumps to transport stormwater from cities.

In today's rapidly changing world affected by uncertainties that are exacerbated by climate change and pandemics, reliance on gray infrastructure demands a rethink. This is primarily because gray infrastructure is challenged by increasing risk of failure due to changing geological and weather systems and rising global temperatures. Nearly half of the world's population experienced water scarcity. In 2017, natural disasters affected around 96 million people. Service providers continue to rely on infrastructure principles conceived in the last century to address the 21 st century challenges. They continue to stay in the comfort of the known, ignoring and degrading natural ecosystems and/or not valuing these paradigms (Browder et al. 2019). Moreover, green infrastructure is not funded or managed as effectively as the conventional infrastructure because it is not formally recognized as infrastructure by decision makers (Sawka 2018).

\section{Strategies for Integrating Nature-Based Solutions in Urban Development}

To optimize ecosystem services, a judicious combination of urban planning strategies and principles, urban landscape and building design, and environment standards and zoning controls can provide sustainable solutions and address the urban resilience challenge faced by city managers and citizens. In this regard, ADB (2016a) recommends the following: 


\section{Creating a Fabric of Interconnected Green Corridors and Spaces}

Interconnected green corridors and spaces should be the foundation for urban development-linking trees, parks, green areas, river valleys, wetlands, and drainage corridors with vegetated pedestrian walkways, cycle paths, and transport routes. Creating this connectivity increases biodiversity and enables wildlife to flourish while building resilience to floods, drought, heat, and climate change. Cities can set targets for green cover and for urban parkland and community gardens. A network of parks has an important contribution to the quality of the environment and to the quality of life in urban areas. Such sites are valued by the community as they are beneficial to public health and well-being. These sites create learning and employment opportunities via interpretation facilities, events, rangers and green space managers, and education outreach. They also serve as an important refuge for wildlife in otherwise impoverished areas. Urban parks are an essential component in building resilience to climate change, drought, and flooding. They can be integrated with water supply, cooling, and waste treatment, and they also contribute to air purification.

\section{Greening of Core Urban Areas and Residential, Industrial, and Business Zones}

Creating tree-lined and vegetated streets and boulevards, green plazas, green roofs, and walls makes the setting attractive for shopping and leisure in town areas being intensively used. Such greening also improves the vibrancy of local economies. Street trees and green spaces create cooling, shade, cleaner air, and reduced noise-making core urban areas more livable and bringing multiple economic benefits. Industrial and business centers need to be carefully planned by applying green infrastructure and natural system solutions. The aim is to achieve sustainable and efficient transport, sustainable urban drainage, rainwater collection and wastewater cleansing, and reduced energy demands. Greening creates attractive and desirable workplaces, contributes to healthy local economies, reduces flood risk and climate change impacts, and expands the space for nature to thrive. Green spaces for recreation and healthy living encourage social interaction, neighborhood events, and food growing. Interconnected green spaces can build community cohesion and identity, making settlements more functional and livable. Green space networks also improve property values and reduce the effects of climate change. They create microclimates through natural drainage, renewable energy use, green building design, and building spacing and orientation.

\section{Greening of Cities on Rivers and Coasts}

Riverine and coastal areas provide a unique opportunity for sustainable town development with nature. River and coastal town plans need to factor in green belts as shelter against storms and for recreation and amenities, extensive wetlands linked to inland drainage corridors as part of flood and storm protection and food security, and connected habitats for wildlife. Natural systems and green infrastructure can be applied to wastewater treatment and renewable energy generation. Other economic benefits can be achieved by creating distinctive places for tourism, leisure, and learning.

\section{Creating Sustainable Urban Drainage Systems}

Attenuation ponds, swales, and reed beds need to be established throughout the urban environment, providing natural ways to reduce flood risks. They also provide temporary storage for rainwater and improve water quality. Sustainable urban drainage systems create wetland habitat for wildlife in an attractive aquatic setting with potential for recreation, education, and leisure facilities. 
An attenuation pond is designed to slow the passage of water from surface runoff to the drainage system (e.g., stormwater sewers). It does this by storing the runoff during times of heavy rainfall and slowly releasing it at a controlled rate after the peak flow has passed. A swale is a low tract of land, especially one that is moist or marshy. The term can refer to a natural landscape feature or a human-made one. Artificial swales are often designed to manage water runoff, filter pollutants, and increase rainwater infiltration.

\section{Greening and Rehabilitating Urban Catchments and Uplands}

Forested and well-maintained urban uplands and watersheds provide many benefits to towns. Some of these benefits are flood control, water supply, agricultural produce, pastureland, timber production, biomass for local combined heat and power (CHP) plants, and renewable power generation. All of these bring economic benefits and contribute to reduced climate change impacts. CHP plants can utilize waste gas as fuel for electricity and heat generation. Waste gases can be gas from animal waste, landfill gas, gas from coal mines, sewage gas, or combustible industrial waste gas. Green urban catchments allow for recreation, relaxation, and activities that contribute to a healthy lifestyle for town residents. They protect vulnerable wildlife and retain the essential natural character of the urban landscape.

\section{Total Asset Management Approach}

Asset management as a comprehensive management tool has been integral to city planning and management of service delivery. It forms an enabling mechanism to ensure urban infrastructure resilience. Urban resilience is the capacity of cities to absorb and adapt to shocks and stresses and prepare for future ones on economic, social, institutional, and environmental aspects, while maintaining the functions of a city (Figueiredo et al. 2018). The resilience of cities, therefore, depends on an ability to maintain essential assets, and ensure access to services and continuity of functions that support the needs of citizens and businesses.

Asset management is typically defined as the coordinated activity of an organization to realize value from assets (International Organization for Standardization 2014). Assets are the basis of production in the economy. These include productive assets held by an enterprise, infrastructure on which these enterprises depend to function (such as factories) and distribute their goods, or natural assets which supply the raw materials and absorb production waste. Maintaining public infrastructure performance and service delivery through efficient asset management is imperative for meeting the demands of rapidly growing urban populations, along with balancing the pressure on the natural environs that provide ecological benefits and services essential to quality of life.

City managers are challenged with balancing the increasing risks and impacts of climate change, its adverse consequences on the natural environment, and quality of life of people and service delivery. A city's assets typically cover (i) the physical and social infrastructure, and buildings that a city owns or administers; (ii) its natural environment and surroundings that belong to the community-unless privately owned-such as land, forests, rivers, lakes, and air; and (iii) its cultural and historical heritage that can be promoted to generate income and jobs. All these three categories need to be included in asset management plans for cities to accumulate benefits from systematic operation and timely maintenance. This total asset management approach builds on and enhances the conventional asset management procedures adopted in cities that most often focus on the operation and maintenance of built infrastructure. 
Total asset management enables a city to examine the need for, and the performance of assets and systems at all levels. It deploys analytical approaches toward managing an asset over its life cycle-starting with the initial demand for the asset, through its use, to its refurbishment or disposal, including managing any post-disposal liabilities. It involves balancing costs, opportunities, and risks against its desired performance to achieve the objectives of the owning organization, which in this context is the city and its taxpaying citizens. Furthermore, it involves making the right decisions and optimizing the delivery of value to minimize the entire life costs.

Deploying preventive management approaches based on risk and condition assessment, complemented by urban profiling, ensures continued asset operation and maintenance. This measure also enables compliance to planning, design, and construction standards, and to regulatory requirements for long-term asset performance and continued service delivery. Additionally, instituting mechanisms for timely corrective actions improves the adaptive and absorptive capacity of the asset, thus increasing resilience.

Effective and total asset management ensures that investments to minimize future operations and maintenance costs are made. It extends asset life and defers financing for asset replacement. Savings generated by sound total asset management can be used to improve service levels, such as extending networks and services to underserviced areas. Adopting this method as an integral aspect of planning can increase and improve a city's resilience and ensure that its services continue to deliver the desired result without interruption-as opposed to non-resilient approaches, where infrastructure may be plagued by outages, skylines are marred with smog, streets get congested, and neighborhoods and open spaces deteriorate, and where cities are prone to flooding and become unsafe.

Poor asset management or mismanagement clearly has deep consequences for citizens, such as lack of maintenance causing water supply failure, which can lead to rationing. Alternative sources of water may be tainted, and system overhauls can be time-consuming and expensive. Total asset management provides a clear objective that is in line with the vision of the city's people. It includes a comprehensive asset inventory as a baseline; current state of the assets, such as their physical condition; a valuation of the financial and replacement cost; a life cycle assessment; and the expected service outcomes determined through performance measures, targets, and timelines, including forecasting future demand. In short, an action plan can be created for maintenance, repair, replacement, disposal, and expansion of assets, including activities related to unexpected events.

For instance, a city's water body may serve multiple functions beyond just supplying water, such as a containment facility for floodwaters during storms or monsoons or a lake for recreation with green spaces. This function would be realized only if the water body's capacity and surrounding areas are maintained through timely desilting or expansion. In this context, community involvement in maintaining any asset is an important element of an action plan (ADB 2016b).

By considering natural assets within the asset management processes, local governments have been found to decrease capital, operations, and maintenance costs; increase levels of service; enhance their ability to adapt to climate change; and reduce the community's unfunded liabilities. At the same time, local governments are able to protect or enhance the multitude of other benefits that natural assets bring to communities (Asset Management $B C$ 2019). The successful implementation of an asset management plan requires mechanisms for financial sustainability; engagement with key stakeholders, including the private sector, for innovation and technical knowledge; and institutional coordination at the city level. 
Combining total asset management and NBS is a recommended approach for managing coastal cities and coastal zones (Sandhu and Huang 2019). Coastal zones present a complex range of interrelated challenges from major economic contributions (i.e., tourism) that need to be balanced with the natural ecosystems' fragility and the communities' vulnerability to natural disasters. Coastal cities inherently reside within complex ecosystems that comprise a dynamic interface of the land, marine (ocean and sea), and coastal subsystems.

Sandhu et al. (2019) quoted the definition by Augustinus of the marine subsystem as

characterized by varying water depth and sediment movement, waves, tides, and marine habitats such as coral reefs. The coastal subsystem includes the beach, foreshore, and natural coastal protection systems such as mangroves and dunes. The land subsystem is adjacent to the coast and is mainly characterized by its topography, ground and surface water resources, habitats such as wetlands, and the built environment. The coastal zone is dynamic as it undergoes continuous interactions between the waves, wind, and land, causing erosion of rocks and movement and deposition of sediments. This further causes the movement and transport of materials such as silt, sand, and organic matter.

Coastal subsystems can be described as:

(i) natural processes that include naturally occurring atmospheric and geologic interactions, such as variations induced by climate change, covering the atmosphere, lithosphere, and hydrosphere, including abiotic, biotic, and chemical processes;

(ii) user and administrative processes and functions comprising natural resource use and its management; and

(iii) infrastructure functions and processes to fulfill citizens' needs, and how these are provided, administered, and managed. This directly and/or indirectly impacts natural processes and the user functions (i and ii), resulting in environment stress and institutional conflicts (Sandhu et al. 2019).

Except for the natural processes, the user and administrative processes and the infrastructure functions require human intervention based on the social and economic demands and need. Therefore, the complexity posed to coastal city managers, both spatially and administratively, is evident. Adding to this complexity is the vulnerability to natural disasters, due to human pressures and impacts from infrastructure and services such as ports, harbors, industrial activities, fisheries, agriculture, and tourism. For effective governance of coastal cities, an understanding of this complexity is required to identify issues and address each challenge to reach a desired outcome demanded by stakeholders, primarily citizens.

Generally, coastal assets are created as physical infrastructure. For example, a sea wall that uses rubble masonry protects coastal communities from natural processes such as beach erosion. Conflicts arise among city managers regarding the ripple effects caused by the complexity of coastal systems. Although beaches are natural assets that attract tourists, by constructing a sea wall, the natural asset itself is compromised as community protection is a priority. Also, the community may be protected in that location, but wave action leads to erosion in another location, and often this erosion could be deeper and more damaging.

Another unique and fragile ecosystem with a coastal asset is the estuary, where the freshwater and seawater ecosystems merge. The common approach of river training is to build embankments that lead to the sea. Although this may protect the coastal communities during high tides or during flood-like situations due to excessive precipitation, this can destroy the natural processes and the ecosystems that they generate. These also function as a community protection, and their unique ecosystems serve as tourism sites. 
Figure 1: Hybrid Approach: Physical Infrastructure and Nature-Based Solution

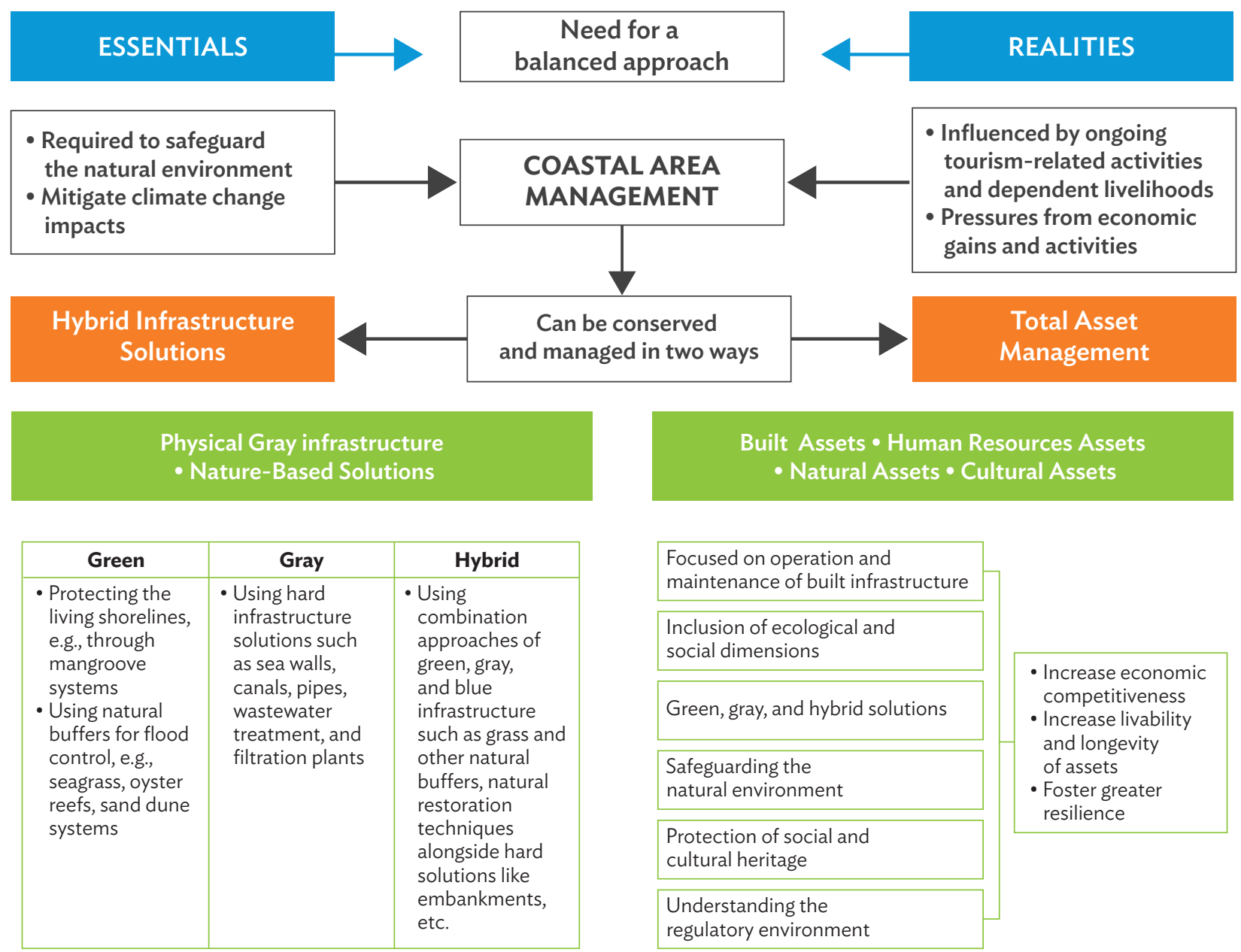

Source: S. Sandhu, V. Kelkar, and V. Sankaran. 2019. Integrated Planning Approaches: Resilient Coastal Cities for Enhancing Tourism Economy. Tokyo: Asian Development Bank Institute. https://www.adb.org/publications/resilient-coastal-cities-enhancing-tourism-economy.

Certain physical infrastructure is always a necessity, but it is very important to recognize the natural processes that function inherently in ecosystems and watersheds and integrate these in infrastructure to form a hybrid solution. This can be a win-win solution. A hybrid approach gainfully combines physical infrastructure with NBS (Figure 1). Adopting the total asset management approach can provide a pathway for integrating these aspects into city development strategies and asset management plans, adding to the resilience of the city's infrastructure and its population. Science-based hybrid solutions ensure sustainability when physical infrastructure is judiciously combined with NBS, contextualized to local situations, and adopted together with a total asset management plan for long-term operation and maintenance. 


\section{The Way Forward}

\section{Develop Evidence-Based Nature-Based Solutions}

The planning, design, implementation, and operation of interventions based on NBS should adopt an evidencebased approach to increase sustainability and contextualize the solutions to local situations. This should include valuation of co-benefits from economic gains, establishment of ecological goals, and technical functionality assessments. This would help justify the interventions and any mid-course corrections for design and implementation. Additionally, this approach would help ensure appropriate operations and maintenance costs. Methodologies for assessing the intrinsic ecological and resilience value should be applied and experiences should be documented to internalize institutional learning both from a tacit and explicit perspective.

\section{Optimize Technology for Integrated Planning Design and Implementation}

New tools have emerged from the broad discipline of data sciences. These include geographical information system (GIS), data analytics, remote sensing, artificial intelligence, and machine learning, which are increasingly and gainfully being integrated into various disciplines. For example, ADB's recently developed Spatial Data Analysis Explorer (SPADE) is a geospatial web platform, open source, and cloud-hosted. It contains layers of geospatial data used to identify and prepare projects, produce maps, develop engineering design, and analyze a project's impacts and risks. SPADE supports the preparation of assessments of land use, socioeconomic impacts, safeguards, climate risk, and vulnerability to inform country, regional, and city plans and strategies. It has the capability to provide information on the location, design, construction, and performance of infrastructure investments through project visualization and assessment of institutional overlaps and risks. The use of SPADE can increase the efficiencies of due diligence, engineering design, and monitoring, in consultation with stakeholders. In addition to existing satellite maps and climate change data sets of 21 ADB project cities, SPADE can be a repository of project GIS data sets, so that these are accessible anywhere and anytime. With all its complexities, the discipline of urban planning will greatly benefit from the use of these tools.

\section{Build a Holistic Institutional Capacity}

Institutional capacity is imperative to ensure inter- and intra-departmental coordination. Cooperation across jurisdictions and administrative boundaries is crucial for increasing urban resilience in cities, especially for applying NBS. Visible incremental improvements have the potential for deepening impacts which can be replicated by agencies and communities.

An example that has demonstrated success and can be adapted for replication is from the Greater Mekong Subregion (GMS). Three cities in the GMS participated in a study to strengthen their resilience to climate change through a targeted technical assistance program:

- Battambang (Cambodia) with its large flood and drought-prone watershed area and the Great Tonle Sap Lake;

- Kaysone Phomvihane (Lao People's Democratic Republic), facing frequent extreme flooding along the Mekong River; and

- Dong Hoi (Viet Nam), the typhoon-prone coastline city threatened by sea level rise, storm surge, and flash flooding. 
Institutional capabilities were built following a trainers' training program. Town-based climate change core groups, called the "Engines for Innovation," were established in each of the target towns. These comprised groups of 20 to 40 municipal and provincial representatives, technical experts, and nongovernment representatives. Learning by doing was used to train the core groups. They applied hands-on vulnerability assessment and adaptation planning tools to deepen their understanding of the impacts of climate change, and in particular, to formulate locally appropriate adaptation responses to those impacts and incorporate green infrastructure and NBS (ADB 2016).

\section{Use Traditional and Indigenous Knowledge to Sustain Nature-Based Solutions}

Institutional mechanisms need to be established to formalize the harnessing of traditional knowledge and the involvement of communities in the design, operation, and maintenance of NBS interventions. Communities can play a very important role in designing NBS and contribute through their local knowledge not only regarding the microclimate and ecosystem, but also of local vegetation. Creation of large-scale nurseries as required for the NBS interventions and their maintenance can be a very good source of livelihoods, which is an added benefit for the communities, in particular, for women and other disadvantaged groups.

Backcasting can be useful by looking at historic infrastructure designed to work in harmony with nature, which can provide valuable lessons. There are examples of ancient infrastructure still in place and some still in operation, such as the ancient water infrastructure in the PRC and India. The Dujiangyan flood and drainage management system is one of the stunning examples of ancient engineering. Scholars have failed to fully replicate the system's function with modern engineering software tools as fluid dynamics require simplification, and the components and fluid dynamics in place in Sichuan Province are too complex. Only local knowledge and ingenious intuition enabled such a solution regulating river flooding and siltation and providing irrigation to benefit a large area and population for more than 2,200 years. Lessons and possibilities for today of such dam-less solution would be very valuable, reflecting against current practices and policies. They also promote engineered gray infrastructure like dikes and walls to protect existing and planned urban areas and farmland from river flooding in many of ADB's developing member countries (DMCs).

Interestingly in European countries during industrialization in the 19th century, river channelization was executed for the same reasons as in today's ADB DMCs, and now they are considered a mistake. In a number of cases in Europe, rivers are built back to their natural courses, with soft and gradual water edges, to apply NBS principles. There is an opportunity to leapfrog these lessons for ADB DMCs.

\section{Conduct Interdepartmental Collaboration and Joint Planning Between Implementing Agencies}

In Singapore, the Bishan-Ang Mo Kio Park was developed to provide multiple benefits to the community. The project was delivered at a lower cost than conventional gray infrastructure. A few decades back, the Kallang River in Singapore was channeled into a concrete canal to control stormwater and flooding. The Public Utilities Board (Singapore's national water agency), based on an analysis of alternatives for repair and maintenance, considered the "naturalizing" of the river to restore its riverbed to its natural floodplain over rebuilding the existing concrete channel. For this, the Public Utilities Board initiated a new partnership with the National Parks Board that managed the land around the canal and the private sector to design and build a new "blue green infrastructure" project. The project has significantly brought community benefits and helped improve food protection and water quality. 
A cost-benefit analysis conducted in 2015 by Singapore's National University finds that the cost of rebuilding the concrete canal was approximately $\$ 94$ million (Singapore dollar [S\$]133 million in 2015), whereas the option to naturalize and interconnect the park space costs less than $\$ 50$ million ( $\$ 70$ million in 2015). Further analysis shows that the joint approach for infrastructure planning and implementation provided approximately $\$ 74$ million ( $\$ 105$ million in 2015) in benefits annually, more than paying for the investment. This "blue-green infrastructure," besides providing cost savings, successfully addressed the city's needs to enhance water supply reliability, improve water quality and flood management, and create open spaces for people and nature within the city (Beyer and Anderson 2020).

\section{Prioritize Green Space Planning Amid Continuing Rapid Urbanization}

To reap the many benefits of NBS amid continuing rapid urbanization, the principle of using brownfield for urban development first, as available, and only using new greenfield urban development if not available, should be followed, as land is increasingly becoming a scarce resource. For the remaining and really needed greenfield urban development to accommodate urban population and economic growth, territorial planning should start with green systems planning, identifying the areas in which not to build. This should be initiated with a comprehensive risk assessment of the territory and ecosystem functions mapping. Future infrastructure needs should then be integrated with opportunities for the NBS to maximize ecosystems functions and resilience of future urban areas. A prioritized, differentiated, and qualified green plan will guide urban development in the remaining areas (negative planning) and make best use of the green space for urban functions and for the benefit of citizens.

\section{Conclusion}

NBS can inform and enhance national policy and regulatory frameworks that will help mainstream these solutions into national urban plans, policies, building standards, and cascade to provincial and local level. The successful implementation of NBS rests within this premise.

To mainstream NBS, urban planners should strategically integrate green spaces and their associated ecosystem services within multiple levels of urban plans. This would also involve local stakeholders and beneficiaries in the process of planning, design, and management.

Inconsistencies in policies and regulations may be a constraint to the effective implementation of interventions, most often leading to the loss of important ecosystem functions over time. It is therefore important to open timely dialogues with decision makers at the local and/or national level and highlight such issues as risks to the sustainability of NBS interventions (IUCN 2020). 


\section{References}

Asian Development Bank (ADB). 2016a. Nature-Based Solutions for Building Resilience in Towns and Cities: Case Studies from the Greater Mekong Subregion. Manila. https://www.adb.org/publications/nature-based-solutionsbuilding-resilience-towns-cities-gms.

- - - 2016b. GrEEEn Solutions for Livable Cities. Manila. https://www.adb.org/publications/greeen-solutionslivable-cities.

- - - 2019. Nature-Based Solutions for Cities in Viet Nam: Water Sensitive Urban Design. Manila. https://www.adb. org/sites/default/files/publication/535016/nature-based-solutions-cities-viet-nam.pdf.

Asset Management BC. 2019. Integrating Natural Assets into Asset Management.

Augustinus, P. n.d. Coastal Systems. Geography. Vol. I. https://www.researchgate.net/publication/46636721_ Coastal_Systems. Quoted in Sandhu, S., V. Kelkar and V. Sankaran. 2019. Integrated Planning Approaches: Resilient Coastal Cities for Enhancing Tourism Economy. https://www.adb.org/publications/resilient-coastalcities-enhancing-tourism-economy.

Beyer, L. and J. Anderson. 2020. Collaboration on Nature-Based Solutions is Key to Resilient City Infrastructure. The City Fix. 7 July. https://thecityfix.com/blog/collaboration-nature-based-solutions-key-resilient-cityinfrastructure-lisa-beyer-james-anderson/?utm_source=linkedin\&utm_medium $=$ wri\%20ross\%20center\%20 for\%20sustainable\%20cities\&utm_campaign=socialmedia\&utm_term=2a46437e-c247-4.

Browder, G. et al. 2019. Integrating Green and Gray: Creating Next Generation Infrastructure. Washington DC: World Bank and World Resources Institute.

European Commission (EC). 2015. Towards an EC Research and Innovation Policy Agenda of Nature-Based Solutions and Re-naturing Cities. Brussels.

EC. n.d. Nature-Based Solutions. https://ec.europa.eu/research/environment/index.cfm?pg=nbs.

European Union. 2002. The Economics of Ecosystems and Biodiversity.

European Union. 2015. Nature-Based Solutions and Re-Naturing Cities: Final Report of the Horizon 2020 Expert Group. Luxembourg.

Figuerido, L., T. Honiden, and A. Schumann. 2018. Indicators for Resilient Cities. Paris: OECD.

https://dx.doi.org/10.1787/6f1f6065-en.

Inter-American Development Bank. 2020. A 12-Step Guidence Document for Project Developers: Increasing Infrastructure Resilience with Nature-based Solutions (NbS). Washington DC.

International Organization for Standardization (ISO). 2014. ISO 55000: Asset Management-Overview, Principles and Terminology. https://www.iso.org/obp/ui/\#iso:std:iso:55000:ed-1:v2:en (accessed 7 July 2020). 
International Union for Conservation of Nature (IUCN). 2020. IUCN Global Standard for Nature-based Solutions. First Edition. Gland, Switzerland. https://doi.org/10.2305/IUCN.CH.2020.08.en.

IUCN. n.d. Commission on Ecosystem Management. https://www.iucn.org/commissions/commissionecosystem-management/our-work/nature-based-solutions.

Kabisch, N. et al., eds. 2017. Nature-Based Solutions to Climate Change Adaptation: Linkages between Science Policy and Practice. Springer International Publishing.

Landscape Institute. 2014. Local Green Infrastructure: Making the Most of Our Landscape. (The Landscape Institute is the royal chartered body for landscape architects in the United Kingdom). Sandhu S. and Huang J. 2019. What Makes a City Livable? Asian Development Blog. Manila: Asian Development Bank.

Sandhu, S., V. Kelkar, and V. Sankaran. 2019. Integrated Planning Approaches. Resilient Coastal Cities for Enhancing Tourism Economy. ADB Working Paper Series No.1043. https:/www.adb.org/publications/resilientcoastal-cities-enhancing-tourism-economy.

Sawka, M. J. 2018. Bridging the Gap: Connecting to the Future of Asset Managemnet. Canadian Network of Asser Managers. Windsor.

Symons, J. J. 2015. Assessing the Economic Value of Green Infrastructure: Literature Review. Climate Change Working Paper No. 23. Melbourne: Victoria Institute of Strategic Economic Studies.

Thiagarajan, M. N. 2018. The Projected Impact of a Neighborhood-Scaled Green Infrastructure Retrofit. Sustainability. 10 (3665. 10.3390/su10103665)

UN Water. 2018. The United Nations World Water Development Report 2018: Nature-Based Solutions for Water. Paris: UNESCO. 


\section{Building Disaster Resilience in Cities in Asia and the Pacific}

Thomas Kessler and Arup Chatterjee

\section{Introduction}

Countries in Asia and the Pacific have begun to build greater resilience to climate change and disasters that afflict its burgeoning populations. However, much more needs to be done given the increasing levels of risk and uncertainty associated with climate change and urbanization. This is especially true in many of the megacities that crowd the region's coastlines, river basins, and seismically active zones and that are home to so many of its people. Disaster risk is rising in urban areas due to increasing populations and investments with insufficient regard to natural hazards and because climate change continues to exacerbate the frequency and intensity of these hazards. As such, measures need to focus on financing risk reduction and disaster response.

In finding new ways to deal with hazards, experience has shown that effective preparation and response require an integrated disaster risk management approach-a set of principles and techniques increasingly followed by governments and institutions. 'This approach shows the importance of building greater physical, eco-based, social and institutional, and financial resilience. This article aims to raise awareness of growing disaster risks and innovative measures that can reduce death, damage, and losses, and help provide immediate financing to manage residual risk when disaster strikes.

An integrated disaster risk management approach to better prepare and respond to disasters needs to tap into risk reduction techniques. Various financing sources are also required for dealing with the impact of natural hazards and other man-made disaster risks. Broadly, techniques fall under several categories-disaster risk reduction, preparedness, ex-ante financing of preparedness, and post-disaster response. "Building back better" is also an important principle in post-disaster recovery and reconstruction. Emerging new technologies, such as

\section{Acknowledgments}

The following ADB staff and consultants provided their valuable inputs for this article: Joy Amor Bailey, consultant, Urban Sector Group Secretariat, Service Advisory Service Cluster (SDSC-URB); Charlotte Benson, principal disaster risk management specialist, Climate Change and Disaster Risk Management Division (SDCD); Laila Catherina Deles, consultant, Finance Sector Group, Service Advisory Service Cluster (SDSC-FIN); Steven Goldfinch, disaster risk management specialist, SDCD; Belinda Hewitt, disaster risk management specialist, SDCD; Peter Rosenkranz, economist, Regional Cooperation and Integration Division (ERCI); and Arghya Sinha Roy, senior climate change specialist (climate change adaptation), SDCD. Eric Van Zant, editorial consultant of SDSC-FIN, edited this article.

The Climate and Resilience Hub of Willis Towers Watson gave their generous support-in particular, David Simmons, head of Disaster Risk Financing; and Jacqueline Wharton, head of Ecosystem Resilience.

A hazard that threatens life, health, environment, or property may be natural or man-made. It becomes a disaster when it impacts human society, whether through deaths and injuries or damage to property and economies. 
artificial intelligence, big data, and mobile communications, can facilitate these efforts. This article explores each of these themes, focusing on the region's expanding cities.

Notably, the risk assessment and financial optimization tools that have emerged include those developed in the insurance industry over decades of hard-won experience. These provide many, though by no means all, of the most promising measures available. Central and municipal governments will find these readily adaptable to their needs, supporting their decision-making.

Under disaster risk reduction, this article refers to experience in Da Nang (Viet Nam), Kathmandu Valley (Nepal), and Naga City (Philippines), demonstrating the effectiveness of better-designed incentive plans for reducing disaster risks in urban areas. Considering the impact of urban land use planning on disaster risk reduction and how to integrate disaster risk considerations in land use management is also key to reach fast and sustainable results.

Recovery and building back better in communities affected by disaster to become more resilient is also encouraged. This is illustrated by funding and technical assistance provided to the city of Marawi, Mindanao, Philippines, which was destroyed during a conflict in 2017, and to Palu in Indonesia, hit by a tsunami in 2018.

Eventually, disaster risk financing to manage the residual risk can include measures such as the establishment of a city disaster risk insurance pool that provides cities with rapid, cost-efficient financing for early recovery and reconstruction after disasters. An insurance pool allows participating entities to collectively buy insurance through a single platform that operates as an insurance company. Financing can also concentrate on critical public assets to be insured against disaster risks. The city of Hue in Viet Nam has done so in requesting all critical public assets be insured under the Law on Management and Use of Public Assets. Other types of financing measures include innovative schemes for insuring crucial coral reefs, which mobilize large-scale financing to increase the climate resilience of coastal cities and businesses, communities, and livelihoods.

Disaster risk resilience is particularly relevant in Asia and the Pacific, which is highly exposed and vulnerable to natural hazards. Globally, during 2000-2019, disasters killed almost 716,000 people and affected 3.3 billion. The direct physical losses totaled $\$ 676$ billion, $27 \%$ of which is in the Asia and Pacific region. ${ }^{2}$ Indeed, Asia suffers more disasters and associated deaths and economic losses than any other continent, with the risks compounded by the effects of climate change. Of the top 10 countries most affected from 1998 to 2019, according to the Global Climate Risk Index 2019, five are in Asia: Myanmar (third), Philippines (fifth), Bangladesh (seventh), Pakistan (eighth), and Viet Nam (ninth). ${ }^{3}$ Even before the coronavirus disease (COVID-19) struck, more than 100 million people in the region were estimated at risk of falling into, or back into, extreme poverty by 2030 if the region's most vulnerable countries did not implement development measures to increase their resilience to climate hazards. ${ }^{4}$ This threatens the otherwise spectacular poverty reduction of the last several decades.

This vulnerability is perhaps most apparent in the region's huge and rapidly expanding cities, which are the focus of this article. Cities like Manila, Dhaka, Karachi, Ho Chi Minh, and Bangkok crowd along the coasts. They cling to river basins, are located on flood plains, or are built in seismic zones. This concentration of urban development in areas with high exposure to natural hazards puts millions of people and infrastructure in harm's way.

2 Data extracted from EM-DAT: The OFDA/CRED International Disaster Database. Université Catholique de Louvain, Brussels. www.emdat.be (accessed March 2020).

3 Global Climate Change Index. https://germanwatch.org/en/cri (accessed December 2020).

4 As estimated in UNESCAP (2016). 
The next section discusses and quantifies the impact of disaster risks to illuminate a path toward greater resilience, as outlined in the remainder of the article. The third section details a wide range of measures for disaster reduction, preparedness, and response. Recent trends in emerging technologies and their promising impact on improving disaster risk management, including disaster risk financing solutions, are discussed in the fourth section. The article ends with conclusions and recommendations in conclusions and recommendations.

\section{Understanding and Quantifying the Impact of Disaster Risks}

Disasters and climate change can be considered an existential threat to all developing countries if population growth and urbanization is not managed in a planned and risk-informed manner. This calls for deliberate action to build resilience nationally and in urban areas, where people and economic assets increasingly concentrate.

Dealing with these threats requires clarity about what constitutes resilience. The literature presents numerous definitions, as the concept has evolved and varies with context. In recent history, the term has been extended to include the capacity to respond or recover from the uncertainties related to climate change, encompassing resilience to both shocks (extreme events) and stresses (slow-onset changes). This article focuses mainly on resilience against disasters due to natural hazards, including geophysical and weather-related hazards now and in the future, and allowing countries to acquire new capacity where needed. The outlined concept, however, is also applicable to other hazards (e.g., pandemic outbreaks, cyber risks, chemical pollution) and in fragile and conflict-affected countries.

In its support for Asia and the Pacific, the Asian Development Bank (ADB) aims to better understand and address the impacts of disasters, coordinate with others, and consult widely to help build resilience. In 2014, for example, ADB launched its Operational Plan for Integrated Disaster Risk Management in line with its 2004 Disaster and Emergency Policy. ADB has supported the development and strengthening of institutional strategies, policies, and operational practices. ADB's Strategy 2030 emphasizes the importance of climate and disaster resilience in its Operational Priority 3: "tackling climate change, building climate and disaster resilience, and enhancing environmental sustainability." Operational Priority 3 outlines four dimensions of resiliencephysical, eco-based, social and institutional, and financial.

Physical resilience. Climate change and disaster risks should be reflected in planning, design, and implementation of development and infrastructure projects. It is useful to distinguish between two types of resilience in infrastructure investments. The first seeks to increase infrastructure resilience through decisions about location, design, construction, and operation. The second type recognizes the need to increase infrastructure investment to reduce disaster risk and adapt to climate change itself. ${ }^{5}$ Major progress in this area is being made in designing and implementting projects and infrastructure under a climate risk management framework. Physical resilience also includes scaling up infrastructure investments in disaster risk reduction and climate change adaptation, such as ADB's rural roads improvement project in Cambodia's Tonle Sap Basin. To address current and future flood risk, the project includes elevated road segments, use of highly absorptive subgrade materials, tree and grass planting on embankments, development of an early warning flood system, and government capacity development (ADB 2017).

5 It is useful to distinguish between two types of resilience in infrastructure investments. The first seeks to increase infrastructure resilience through decisions about location, design, construction, and operation. The second type recognizes the need to increase infrastructure investment to reduce disaster risk and adapt to climate change itself. 
Eco-based resilience calls for greater emphasis on biodiversity and ecosystem services as part of an overall strategy to help manage disaster risks and adapt to climate change. It includes supporting approaches such as coastal protection, nature-based river basin flood risk management, erosion control, and urban water management.

Social and institutional resilience refers to the enhancement of risk governance and the human and social dimensions of climate and disaster resilience. It reflects the high impact of disaster and climate change on poor and vulnerable populations. Projects across the region prioritize investments focused on the poor and vulnerable to ensure "no one is left behind"-rural or urban. For example, innovative climate insurance protection are given to farmers to leverage investments in technology.

Financial resilience. Countries, businesses, and communities need strong and effective financial management of residual disaster risk. This, in turn, supports timely relief, early recovery, and reconstruction efforts and the incorporation of measures to build back better. In this regard, developing Asian countries, with ADB assistance, are enhancing post-disaster budget execution strategies and developing financing instruments such as disaster contingent financing and risk transfer mechanisms, including disaster insurance. The next section elaborates on these.

In building disaster and climate resilience, it is crucial that countries manage risk and uncertainties guided by data. They must build the capacity to identify the most exposed and vulnerable people and their livelihoods, business sectors and physical assets, as well as the most effective risk reduction and adaptation measures. This requires additional sources of funding, notably from the private sector, and expertise leveraging novel approaches developed in the insurance industry.

Insurance sector data, analytics, and modeling methodologies developed in recent decades can provide the Asia and Pacific region's developing countries with an additional instrument to understand and quantify their disaster risk profiles. For example, the open-source and open-access platform CLIMADA integrates multiple natural hazard and exposure data and impact functions, allowing computation of metrics to assess disaster risk and to quantify socioeconomic impact. ${ }^{6}$ Such understanding of risk can help guide the selection of measures to strengthen disaster resilience to natural hazards and efficiently combine risk reduction, preparedness, and response measures, such as emergency relief, rehabilitation, and long-term reconstruction.

Data analytics and modeling tools-designed for the public sector based on transparent and globally accepted standards - can help quantify the extent of disaster resilience measures needed and appraise their benefits. Authorities can make informed decisions about optimum disaster risk reduction and retention and eventually about residual risk-sharing and risk-transfer solutions. Better knowledge and understanding is a key prerequisite for implementing a holistic disaster risk management strategy and governance that taps the full range of disaster risk financing instruments. ${ }^{7}$

Moreover, development organizations and the Asia and Pacific region's developing countries can integrate these methodologies into their partnership strategies. In the context of wider city development visions and plans and overall urbanization patterns, the methodologies can be used to identify projects that respond to and address disasters and climate change. The methodologies can also help monitor the performance and sustainability of existing development project portfolios. The ability to quantify the socioeconomic benefits of disaster risk reduction measures will also provide authorities the evidence they need for incentivizing sovereign and

6 CLIMADA was developed by the Weather and Climate Risks Group at the Swiss Federal Institute of Technology (ETH Zurich). European Geosciences Union. Geoscientific Model Development. https://www.geosci-model-dev.net/12/3085/2019/.

7 See the third section's discussion on disaster risk financing. 
public-private partnership resilience projects. This will allow them to better mobilize private financing and attract investors. Decision makers at all levels need facts to identify and quantify the most cost-effective measures to adapt to and mitigate an ever-changing environment. They need to know what impact disasters and climate change could have and decide whether the benefits outweigh the costs.

For this purpose, open-source and open-access disaster risk modeling tools are either available today or are being developed in the private sector and academia with support from the multilateral development banks. Tools like the CLIMADA platform can support multi-hazard calculations and provide an event-based, probabilistic approach that is globally consistent for a wide range of resolutions. It can be suitable throughout a country and can provide a valuable basis for detailed city studies in which more information might be required.

The CLIMADA approach maps the hazards and exposures using the latest risk modeling and integrates the economic development and climate impact scenarios. It then assesses a comprehensive portfolio of risk reduction or transfer measures to calculate benefit based on the probability of occurrence of various frequencyseverity events (Figure 1). As such, the platform supports appraisal of risk management options and risk reduction or transfer measures. It does this by estimating the expected socioeconomic impact from disaster and climate risk today, taking also into consideration the incremental increase in risk exposure from economic growth and from further incremental increase in impact due to future climate change.

Resilience measures include, for example, building flood defenses or raising the levels of dikes, improving spatial planning, ecosystem-based approaches, formulating regulations and adjusting building codes, as well as implementing insurance solutions against some of the more extreme disaster events.

To better understand and quantify the impact of resilience measures, studies on the economics of disaster and climate resilience establish an economic framework for fully integrating the risk and reward perspectives of different stakeholders. These studies answer three main questions:

(i) What are the potential disaster and climate-related impact in the coming decades?

(ii) What can we do and how much of that damage can be avoided by using what kind of disaster and climate change resilience measures?

(iii) What investments will be needed to finance these measures, how can we prioritize them, and will their benefits outweigh the costs?

A recent study by Swiss Re (2016) on Barisal, Bangladesh illustrates how studies on the economics of disaster and climate resilience work, and demonstrates how they can be applied to other cities. Located on the great delta, that is Bangladesh's southern coast, Barisal is likely to face more frequent and severe floods and storms and sea level rise, because of climate change..$^{8}$ In 2016, the city of 400,000 people faced annual expected damage of $\$ 10$ million. As the population grows, however, by 2050 , the annual cost arising out of climate change-related events is expected to surge to $\$ 129$ million.

By doing the study, authorities were able to identify and quantify the main disaster threats through inclusive consultation of all project stakeholders and local communities, allowing prioritization of the most economically effective adaptation measures. The measures include rehabilitation and extension of drainage systems,

8 Other ADB studies can provide useful guidance. See ADB. The Economics of Climate Change in the Pacific. https://www.adb.org/sites/ default/files/publication/31136/economics-climate-change-pacific.pdf; ADB. Economics of Climate Change in East Asia. https://www.adb. org/publications/economics-climate-change-east-asia; and ADB. The Economics of Climate Change in Southeast Asia: A Regional Review. https://www.adb.org/publications/economics-climate-change-southeast-asia-regional-review. 
Figure 1: The CLIMADA Disaster Risk Modeling Tool
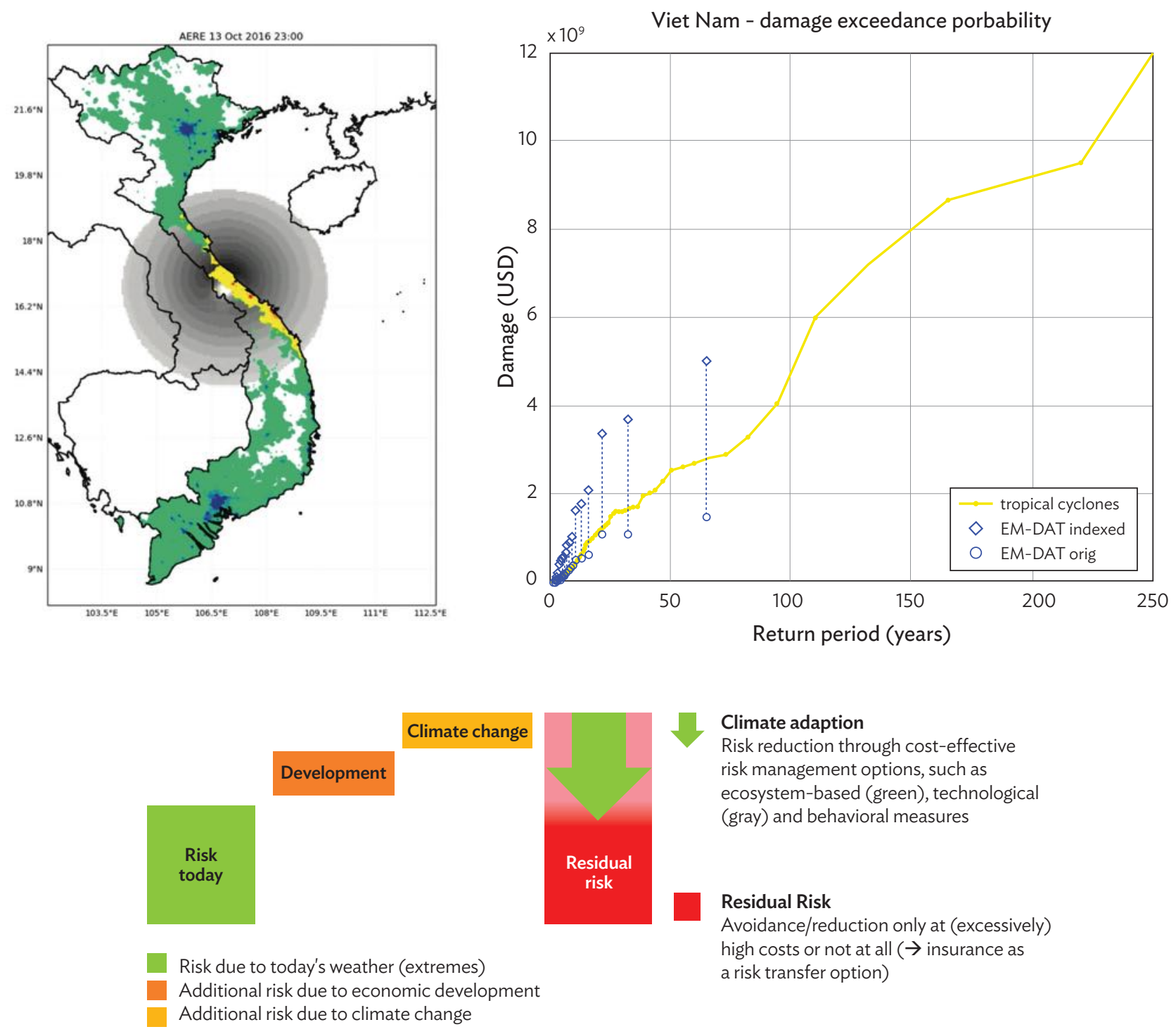

Climate adaption

Risk reduction through cost-effective risk management options, such as ecosystem-based (green), technological (gray) and behavioral measures

Residual Risk

Avoidance/reduction only at (excessively) high costs or not at all ( $\rightarrow$ insurance as a risk transfer option)

Source: Swiss Federal Institute of Technology (ETH Zurich). n.d. Weather and Climate Risks Group. Zurich.

development of flood-resilient buildings, direction of rainwater storage in ponds, solid waste management, early warning systems, embankments, and use of flood-resilient crops. These adaptation investments can effectively reduce expected annual damage costs by $60 \%$, for an average annual savings of $\$ 78$ million on that $\$ 129$ million.

The study allowed determination of the level of insurance or insurance-linked products that Barisal should purchase to adequately transfer the remaining residual risk after risk reduction measures have been implemented. It also assured the city that it has sufficient funds for disaster relief.

Barisal is only one example of a city that has conducted a comprehensive study of the economics of climate adaptation. Many more urban areas exposed to disaster events could adopt such a concept. 
The insurance industry has been active in managing and transferring disaster risks for more than 150 years, and can thus be an invaluable resource for cities as they attempt to do the same. In this context, a lot of data are being collected. For instance, Lloyd's City Risk Index analyzes 92 cities across Asia and the Pacific, comparing them with other cities across the globe. ${ }^{9}$ The index measures the gross domestic product (GDP) of 279 cities across the world that is at risk from 22 threats. These threats are in five categories: finance, economics and trade, geopolitics and security, health and humanity, and disaster due to natural hazards and climate change. Five of the world's top 10 cities with the biggest GDP risks are in Asia, including Tokyo (first), Manila (third), and Taipei,China (fourth). Typhoons are the largest threat, with the Asia and Pacific region expecting a total loss of $\$ 59.14$ billion each year.

The annual devastation caused by typhoons in the Philippines is one tragic example, as the country is the frequent first stop for typhoons generated by warm waters off its Pacific coast. Typhoon Haiyan, in 2013, for example, flattened parts of the port city of Tacloban, Leyte (central part of the country) and killed more than 6,000 people. Each year, an average of 20 typhoons hit the country, with six to nine of them making landfall (Strobl 2019).

Depending on their location, size, commonalities, and specific characteristics, cities are exposed to different types of disaster risks. To name a few examples, Greater Bangkok is exposed to flooding risk, Qingdao is prone to storm surge, and cities in many parts of Indonesia are frequently subject to severe earthquakes.

Unlike many coastal cities in Southeast Asia, metropolitan Bangkok is not particularly prone to tropical cyclones, since it is located in a sheltered position facing south onto the Gulf of Thailand. However, it is located on the low-lying floodplain of the Chao Phraya River, which runs through the heart of the country's industrial expansion, north of the city. The devastating flood in 2011 not only caused widespread casualties but also serious, far-reaching consequences beyond Thailand, given the region's importance in regional and global supply chains. Economic losses reached an estimated $\$ 48$ billion, making the flood one of the five costliest disasters triggered by a natural hazard in modern history. Flooding is thus the central climate-related threat facing the metropolitan area. The city's susceptibility to flooding has grown over the last half-century due to land subsidence, among other factors. The accumulated land subsidence of the megacity between 2002 and 2050 may reach 30 centimeters in some locations.

In the People's Republic of China (PRC), Qingdao also presents an interesting case. The city is vulnerable to flooding, among other risks, but this is specifically due to storm surge. Given the PRC's spectacular economic rise, which is heavily concentrated along the country's eastern coastline, the city's many low-lying areas and increasingly valuable assets are particularly susceptible to surging tides during storms. Another, more long-running climate threat to Qingdao is drought.

Cities in many parts of Indonesia, meanwhile, are particularly susceptible to earthquakes and the associated tsunamis - as made all too plain in the Indian Ocean Tsunami of 2004. In 2018, an earthquake and tsunami off the city of Palu in Sulawesi killed more than 4,000 people. On the other hand, the megacity of Jakarta, home to the country's government and financial districts, is hugely susceptible to flooding.

Disaster experiences in these cities are providing invaluable lessons that authorities and innovators can use to improve disaster risk management. Together with all other disciplines working in disaster risk management (including the engineering industry), the principles developed and adopted in the insurance industry can support that process. Lessons from the projects discussed in this article can help governments, multilateral development banks, and the private sector design measures to prepare for such hazards and better rebuild when disaster strikes in developing Asia and the Pacific.

$9 \quad$ Lloyd's City Risk Index. https://cityriskindex.lloyds.com/regional-reports/ (accessed December 2020). 


\section{A Broad Range of Disaster Risk Management Measures}

As cities in Asia and the Pacific enhance the well-being of their citizens and catalyze economic development, they face several challenges. These include rapid urbanization; inadequate infrastructure as cities expand; growing risks from climate change and disasters; environmental stress; and even emerging threats like cyberattacks, disease, and terrorism.

Cities have started to undertake efforts in several areas to better manage disaster risks. Multilateral development banks can further help cities improve urban environments and build capacity for climate resilience and disaster risk management. Cities are strengthening their disaster preparedness and emergency response plans and land use management. They are also improving their environments and promoting energy efficiency and "circular economy" practices. ${ }^{10}$ Increasingly, cities are adopting nature-based solutions and a systems approach to urban infrastructure resilience. These efforts can eventually provide a platform for a more holistic approach in which urban areas are considered complex "living" systems undergoing numerous dynamic exchanges at any given time.

In this context, $\mathrm{ADB}$ offers its integrated disaster risk management approach, which promotes integration of environmental sustainability, climate change, and disaster risk considerations into urban planning processes. The approach aligns well with the Sendai Framework for Disaster Risk Reduction and adopts three basic disaster risk management principles to achieve disaster resilience:

(i) Many development actions, although they may carry disaster risks, present opportunities to strengthen resilience.

(ii) When climate change is ignored, disaster risk management investments can underperform and make disasters more likely to occur.

(iii) Levels of financing risk reduction and residual risk management should reflect long-term risk profiles.

Three important disaster risk management requirements arise out of these principles: (i) disaster risk reduction should be integrated into development, (ii) measures should reflect the intersection of disaster risk management and climate change adaptation, and (iii) authorities must ensure financing arrangements are sufficient to lower the risks and to manage and transfer residual risk (ADB 2014).

The first principle-actions can carry disaster risk and provide opportunity-is central to the integrated disaster risk management approach. To reduce risks, the approach requires a wide range of policy, investment, and capacity development interventions that can work in several ways:

(i) Interventions can tackle hazards directly. This can be accomplished, for example, by reducing the probability of landslides and flooding through forest conservation on steep slopes. In the Kyrgyz Republic, for instance, a landslide risk management sector project aims to reduce landslide risk on infrastructure and human settlements and strengthen the disaster insurance system. Interventions can also deal with exposure to those hazards (e.g., by helping to integrate disaster risk considerations into land use planning).

(ii) Interventions can tackle vulnerability (e.g., by supporting livelihood diversification into more resilient occupations, rainwater harvesting, and community early warning systems). In $\mathrm{Nepal}$, a project on

10 A circular economy is designed to eliminate waste and use of new resources, particularly by reusing, sharing, repairing, refurbishing, remanufacturing, and recycling in a "circular" system. 
disaster risk reduction and livelihood restoration for earthquake-affected communities is rebuilding schools with disaster-resistant design and construction, providing microcredit, and raising community awareness about disaster preparedness.

Both structural and nonstructural measures can constitute disaster risk reduction. First, measures can cover stand-alone initiatives, such as seismic retrofitting of buildings. Second, they can incorporate disaster risk reduction components into wider projects, such as flood control elements of urban development projects. Third, disaster risk reduction measures can be integrated into other development actions, such as adjustments in road engineering design and location to strengthen resilience against extreme rainfall or landslides. The latter two can be referred to as embedded actions."

The second principle-disaster risk management investments may underperform and ultimately even exacerbate disaster risk if climate change is ignored-focuses on the intersection of investment and risk. Adaptation focuses on adjustment to actual or expected effects of climate change to minimize harm or to exploit benefits. More specifically, the intersection concentrates on planning for changes given the intensity and frequency of extreme weather events and taking action to reduce risk now and in the future. It implies that, during extreme weather events, authorities consider potential changes in the design of both stand alone and embedded disaster risk management actions (e.g., on flood defenses when the return periods of flood events change).

$A D B$ is already supporting this principle through technical assistance for disaster and climate risk assessment in the Pacific and integrating the assessment results into urban development and infrastructure planning, among other things. Across the Pacific, progress has been made on strengthening resilience by climate-proofing infrastructure and building more sustainable communities. In Kiribati, a sea water desalination plant running on solar power will provide climate-resilient water supply with reduced leakage, while in Nauru a climate-resilient port is being developed that can operate year-round. These projects benefit from rigorous climate risk assessments which inform the development of alternative approaches and designs, such as elevating roads and bridges, increasing drainage capacity, and drought-proofing water supplies.

Both the first and second principles of disaster risk management also highlight the need to consider extreme weather events, long-term climate trends, and uncertainty in the design and implementation of climate change knowledge products, programs, and actions. They also highlight the need to align disaster risk management and climate change adaptation efforts more generally.

ADB's Urban Operational Plan 2012-2020 similarly supports actions to strengthen disaster risk management as part of the organization's wider efforts to strengthen urban resilience. The plan recognizes that a considerable share of urban expansion is occurring in hazard-prone areas, such as along rivers, on the coasts, and in seismic areas, as noted earlier.

The third principle-levels of expenditure on risk reduction and residual risk management should reflect long-term risk profiles-focuses on developing and applying financing instruments to reduce risk and to manage and transfer residual risk. The principle covers the financial management of disaster risk by households and businesses as well as governments.

1 ADB is already engaged through all three routes, addressing hazards, exposure, and vulnerability. It is also exploring the development of pilots for evaluating different models for disaster risk insurance. 
ADB advocates a risk-layered approach to developing disaster risk financing strategies. ${ }^{12}$ The risk-layered approach breaks down the disaster risk according to the frequency or probability of hazard events and the associated levels of loss.

Risk reduction is frequently the most cost-effective way to deal with the first-layer, high-frequency, and low-impact hazard events. However, the returns from risk reduction can also significantly reduce the risks in low-probability, high-impact events. Risk reduction can also ensure buildings and other structures meet life safety standards.

A range of other financing instruments can then be applied to the remaining layers of risk and the most appropriate option selected based on several factors. These include the scale of funding required for each layer of loss, the required speed of disbursement, and the relative cost-effectiveness of alternative instruments for specific layers of risk. The alternative instruments include building of contingency reserves, contingent disaster financing, as well as indemnity and parametric insurance products. These, in turn, will cover property, business interruption, and (sub)sovereign budgets, and include catastrophe and disaster relief bonds and other alternative risk transfer instruments.

ADB support has thus aided risk reduction and post-disaster recovery and reconstruction. This includes emergency assistance loans with abbreviated processing requirements. ADB also supports comprehensive disaster risk financing strategies and ex-ante instruments for post-disaster response (i.e., those implemented before a disaster occurs). Good progress has been made in implementing contingent disaster financing in the Pacific and in the Philippines. The financing not only provided very rapid post-disaster liquidity, but also initiated policy actions to strengthen long-term resilience. Meanwhile, much of the risk transfer solutions focus on technical assistance to support product scoping and the development and implementation of pilot projects.

Cities can significantly reduce loss of life from disasters through effective forecasting and early warning systems, emergency response plans, and proper communication and consultation strategies, including raising awareness and training citizens. ADB, for example, has introduced a flood forecasting and early warning system under the Kolkata Environment Improvement Investment Program, the first city-level early warning system in India. ${ }^{13}$ A messaging system with sensor nodes installed in key locations throughout the city provides city officials with real-time updates on pump status, canal water levels, actual rainfall, and inundation levels.

Outside the Asia and Pacific region, Austin in Texas has implemented a sophisticated flood early warning system that monitors rainfall, water levels, and low water crossings 24 hours a day. It does this using 130 rain or creek level gauges, flashing lights or automated barricades at 15 low-water crossings, gauges of adjusted radar rainfall, cameras at low-water crossings, and predictive modeling and mapping.

Disaster response-encompassing support for post-disaster relief, early recovery, and reconstruction-remains a central aspect of ADB's integrated disaster risk management engagement, which embeds the three principles outlined above.

See the third section's discussion on disaster risk financing.

13 ADB. 2018a. Toward Resilient Kolkata: Introducing India's First Comprehensive City-Level Flood Forecasting and Early Warning System. Manila. 


\section{Disaster Risk Reduction}

Disaster risk in urban areas arises largely out of urban planning decisions about where a city will expand-often even out of unplanned development in hazardous areas or insufficient capacity among authorities to enforce their plans. Disaster risk therefore needs to be addressed within the context of wider urban development, understanding how natural hazards interact with existing and future urban growth patterns. ${ }^{14}$ Taking this proactive approach to disaster risk will help encourage investments in developments that are thus sensitive to risks. Tools such as incentives and urban land use management processes can support this approach.

However, investments to reduce disaster risk remain limited for several reasons:

- Limited resources and capacity to address disaster risk and urban planning issues, particularly when governments are competing with other economic development agendas.

- Understanding of disaster risk as a development issue is limited.

- Firsthand experience of disaster losses is sometimes lacking, especially less-frequent events such as earthquakes. This may result in discounting low-probability risks.

- Historical disaster impact data is limited, making it more difficult to assess future potential losses.

- $\quad$ Political support is weak because tangible, immediate outcomes, or positive revenue flows are absent, or policies are unpopular with voters (such as relocation of informal settlements from hazard-prone areas).

- $\quad$ Risk reduction endeavors may not reap the benefits for many years, imposing higher opportunity costs.

- Local and other authorities may lack the capacity to argue convincingly for investments, and agencies working directly on disaster risk reduction may be politically weak.

- Disaster risk is often concentrated on poorer households with limited political voice.

These obstacles, notwithstanding incentives and more accessible information, can encourage investments in disaster risk reduction to change behaviors, reward better performance, and encourage stakeholders to reduce exposure and vulnerability to natural hazards. The Seal of Good Local Governance in the Philippines, for example, awards city governments that practice good governance, including in disaster preparedness, with access to concessional loans and additional funds.

Incentives may be financial (grants, company tax credits, and company tax rebates for large businesses), or subsidies, discounts, and conditional cash transfers for households. Nonfinancial incentives could include offering to increase technical capacity, access to information, access to technology, or recognition. Incentives may be applied at different levels and across stakeholders - national government incentivizing city governments or city governments incentivizing businesses, the private sector, communities, and households.

An ADB study of experiences from Da Nang (Viet Nam), Kathmandu Valley (Nepal), and Naga City (Philippines) on incentives for disaster risk reduction reveals that urban stakeholders need a combination of financial and nonfinancial incentives (ADB 2016a). Indeed, governments wishing to encourage investment for disaster risk reduction may find nonfinancial incentives either equally valuable or more valuable than financial incentives. National and city governments in the three urban areas were familiar with financial and nonfinancial incentives to attract private investment, strengthen planning and building controls, and promote sustainable inclusive urban development. However, incentives, with disaster risk reduction as the primary purpose, were largely new to them. Such cities, nonetheless, do often have incentives to promote urban development that can indirectly contribute to reducing risk, or even directly with minor modifications. That said, caution is needed to avoid designing disincentives or perverse incentives.

14 This section is based significantly on ADB (2016a, 2016b). 
The following are some of the practices-mainly in Nepal, the Philippines, and Viet Nam-in reducing disaster risks.

Financial incentives. The Philippines' Disaster Management Assistance Fund provides concessional loans with a 0\%-1.5\% interest rate (lower than the market rate) for structural and nonstructural interventions. Loans must be repaid within the term of the local chief executive, and complying city governments are rewarded with access to subsidized loans for investment in risk reduction measures.

Urban development incentives. The Government of Nepal provides municipal and city governments access to intergovernmental grants and cash awards under its Minimum Conditions and Performance Measures system. Grants are based on performance against several indicators. Among the many minimum criteria, four clauses contribute directly or indirectly to disaster risk reduction: (i) provision of building permits leading to compliance with building codes; (ii) requirements for repair and maintenance work; (iii) requirements for bylaws, working procedures, and directives; (iv) and requirements for emergency services and disaster management.

Urban development tools. In Da Nang, investors can access planning information on the city government's web portal, including the Da Nang City Master Plan, and information about unoccupied land waiting for development. Users can search for locations, areas, uses of unoccupied land, and planning regulations by street or area, and for administrative information such as fees. While the portal does not currently provide investors with risk information, the city government could do so through an available mechanism. This information helps people identify investments that can reduce their exposure and vulnerability to local hazards.

Disincentives. In the Kathmandu Valley, developers need to obtain planning and building approval for high-rise apartments from six government agencies. The complexity of the process, unclear requirements, and timeconsuming approvals (6-36 months) all act as disincentives, that is, they lead developers to forego the formal approval process.

Urban land use management. Land use planning, development controls, greenfield development, and urban redevelopment can reduce disaster risk by regulating development activity and by giving planners greater understanding of how natural hazards in and around urban areas interact with existing and future urban growth patterns. This allows better identification of measures (policy, investments, and capacity) to promote risk-sensitive development and enhances economic and political viability of the proposed measures.

Reducing disaster risk requires long-term systemic thinking. Urban planners can encourage long-term decisions and push to institutionalize disaster risk reduction measures within wider urban development. It also requires multidisciplinary and multi-stakeholder inputs. It is important for urban planners to have good working relationships with different stakeholders - politicians, government, the scientific community, the private sector, and civil society. A good understanding of land conditions (natural, socioeconomic, and political) is also needed. Urban planners with proficiency in land use management and understanding of complex political economy provide a natural advantage. To help urban planners enhance their capacity in incorporating disaster risk considerations into land use management processes, ADB developed a set of guidance notes focusing on several processes (ADB 2016b).

Urban land use planning processes are usually guided by relevant national legislation, and the output typically results in a land use plan that provides a framework to guide growth and development of the urban area over 10-20 years. A land use plan can objectively indicate how hazards will impact development, present risk-sensitive goals, identify the development constraints hazards pose, and, where relevant, reveal policy ideas to reduce disaster risk. 
Development control instruments support the implementation of land use policies, especially policies that require binding rules. They can protect public interest issues, such as health, safety, social equity, environmental quality, and energy efficiency. Instruments commonly used in Asian urban areas include zoning, land subdivision, land acquisition, and building control, which can regulate activities in disaster risk areas.

Land use plans and development controls can be used in developing greenfield sites, which are undeveloped, or agricultural areas on the urban periphery. Plans can also ensure that locations and the proposed investments of these sites are disaster-resilient, reducing risk exposure and avoiding piecemeal or incoherent development of new areas.

Governments should require that urban redevelopment projects-usually responding to urban deterioration caused by demand for housing and infrastructure-include hazard considerations to ensure sites incorporate disaster risk reduction in the basic design and will not increase existing vulnerabilities (such as by relocating informal settlements to hazard-prone areas). In urban areas with very high disaster risk, urban redevelopment as an approach can be adopted to retrofit buildings and strengthen overall resilience.

\section{Recovery and Building Back Better}

Reconstruction after a disaster occurs is enormously challenging. Governments frequently do move swiftly to assess damage and losses, determine recovery needs, and develop recovery plans after disaster strikes. Discussion among authorities after disasters also often does mention the principles of building back better. However, this may not fully translate into actual reconstruction because of funding issues or time pressure. Immediate needs (such as water in evacuation centers) can sideline longer-term measures (such as rebuilding water supply systems). Longer-term measures, therefore, are needed to proactively prevent or mitigate the possible risks before disaster strikes.

Development partners should therefore help countries to integrate build-back-better elements into post-disaster recovery and reconstruction. These themes are evident in recovery efforts from the devastating armed conflict in 2017 in Marawi, Mindanao, Philippines, and the earthquake and tsunami that hit the city of Palu on the island of Sulawesi in Indonesia in 2018.

Following disasters, timing is a key factor. Opportunities in these instances should be seized to adopt recovery policies and prioritize investments that strengthen resilience by building back better. Current and future disaster and climate risk considerations should be incorporated in planning, design, and implementation of recovery and reconstruction. Local institutions need greater capacity to assess risk, prioritize investments to reduce risk, and manage the residual risk through greater preparedness for various types of hazards (Boxes 1 and 2).

\section{Disaster Risk Financing}

Most governments in Asia and the Pacific have disaster risk management systems. Many of them have focal point government agencies backed by an array of institutional and legislative support. Some involve private sector participation and are developing insurance/reinsurance components. Many are spread across jurisdictions-from informal community cooperation, to local government initiatives, to formal cross-agency government structures. 


\section{Box 1: Building Back Better in Marawi City, Philippines}

Human-caused disasters illustrate the opportunity and relevance of building back better. In 2017, the city of Marawi and surrounding areas in Mindanao experienced a violent conflict, a result of a combination of poverty, land issues, and weak governance. Poor access to quality of basic services (e.g., education, food, water, health, livelihoods) compounded the problems. People saw the government as neglecting their needs, giving insurgents an opening to recruit followers.

After the fighting, thousands of displaced people were housed in evacuation centers, mostly with deplorable living conditions. They had either lost their homes or had to return to former dwellings, now unsafe, and with limited access to infrastructure and services. Many also lost their livelihoods in a city where most of the income opportunities were in the informal economy.

To help encourage building back better, the Asian Development Bank (ADB) and others responded with guidance and projects promoting long-term efforts to reduce the conditions causing conflict. The $\$ 225,000$ technical assistance from the Urban Climate Change Resilience Trust Fund-a \$150 million multi-donor fund administered by ADB under the Urban Financing Partnership Facility-worked with local and international consultants to help government determine crucial investments for reconstruction and recovery. It ultimately helped bring about several projects to reconstruct and improve health and water supply services whose lack had helped spark the conflict.

A guidance note, the Resilience Framework for Post-Conflict Reconstruction and Recovery of Marawi and other Affected Areas, tackles the risks related to natural hazards, climate change, and resurgence of conflict. It helped identify programs, projects, and activities; select sites; prepare detailed architectural and engineering designs; and provide master planning. An advisory team incorporated inputs on climate change resilience into the city's 20-year Comprehensive Land Use Plan.

Urban Climate Change Resilience Trust Fund resources, meanwhile, helped inform what eventually became a $\$ 400$ million emergency assistance loan and $\$ 8$ million in grants from ADB to support the reconstruction of Marawi. The Emergency Assistance for the Reconstruction and Recovery of Marawi Project is structured to provide the Philippine government immediate and flexible financing to implement programs, projects, and activities included in the Bangon Marawi Comprehensive Rehabilitation and Recovery Program. The project included a $\$ 5$ million investment grant from the Urban Climate Change Resilience Trust Fund for interventions in priority water supply and health areas, which were both heavily damaged.

A water supply component is financing the most pressing infrastructure needs in water supply. It is expected to produce a comprehensive water supply, septage, sewerage, and drainage master plan for the city. Both are being informed by modeling and analysis of climate change projections.

A health component is constructing two health clinics and providing mobile health facilities to restore essential health services. The health units are intended as models that can be scaled up across Marawi and surrounding areas hosting displaced people. The units will include climate-resilient features, such as solar powered refrigeration and other design features that can be scaled up.

Source: Asian Development Bank. 2019. 2019 Annual Report: Urban Financing Partnership Facility. Manila. https://www.adb. org/documents/urban-financing-partnership-facility-annual-report-2019. 


\section{Box 2: Building Back Better in Sulawesi, Indonesia}

A 7.4-magnitude earthquake of September 2018 near the city of Palu in Sulawesi, Indonesia triggered a tsunami that struck adjacent coastal municipalities. The tsunami killed almost 2,000 people, injured more than 10,000 , and displaced more than 74,000. Roads, bridges, electricity, communication lines, and more than 67,000 houses were damaged across the urban areas of Palu, Sigi, and Donggala.

After the earthquake, a quick technical assistance similiar to that of Marawi helped prepare build-back-better projects. As in Marawi, a small-scale technical assistance financed by the Urban Climate Change Resilience Trust Fund supported the Asian Development Bank (ADB) in its immediate response to the Government of Indonesia's requests for support.

ADB also provided quick assistance to gain understanding of the root causes of the devastation. Assessments show that a combination of natural and human-induced factors contributed to the disaster. These include the proximity of the towns to the Palu-Koro fault, the strong tsunami surge through the narrow bay of the area, and landslides causing mud flows. Human factors include gaps in early warning systems and rapid population growth that left many people and assets in liquefaction-prone areas. Other factors are inadequate land use planning measures, below-standard infrastructure, and limited hazard awareness among the affected population.

Indonesia's BAPPENAS, the national development planning agency, assessed the needs that should be prioritized across sectors. The assessment also considered the short-, medium-, and long-term requirements. These include articulating the key principles to be adopted to ensure recovery are inclusive and efficient, and would address local needs and contribute to longer-term resilience. Based on the assessment, BAPPENAS proposed institutional arrangements for coordinating and implementing recovery, identified priority investments across key sectors, and prepared the financing plan for recovery and reconstruction.

The Central Sulawesi Recovery and Reconstruction Master Plan, finalized in early 2019, proposes spatial and socioeconomic policies to steer growth. The plan identified the development control regulations to be implemented in the area to ensure that future development is risk-sensitive. It also outlined the investments needed across sectors to strengthen resilience.

In line with this master plan, the $\$ 297.75$ million Emergency Assistance for Rehabilitation and Reconstruction was

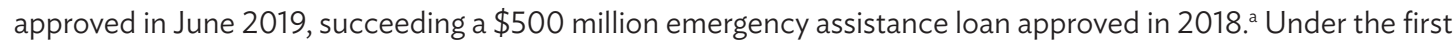
component, the government is upgrading education and water supply facilities, including water treatment and distribution, to raise disaster resilience and meet higher standards. In the province, it will rebuild the Gumbasa irrigation system to upgrade the PASIGALA raw water supply system and construct structures along the coasts to prevent further erosion and tidal flooding.

The second component supports the rehabilitation and reconstruction of airport and port infrastructure to enhance safety and boost economic development in the province. The loan will also finance repair and reconstruction of the runway and terminal at the Mutiara Sis Al Jufri Airport in Palu using disaster-resilient designs to strengthen its disaster preparedness.

${ }^{a}$ For more information on these projects, see ADB. Indonesia: Emergency Assistance for Rehabilitation and Reconstruction. https://www.adb.org/projects/52316-001/main\#project-pds; ADB. Indonesia: Emergency Assistance for Recovery and Rehabilitation from Recent Disasters. https:/www.adb.org/projects/52324-001/main\#project-pds.

Source: Asian Development Bank. 2019. 2019 Annual Report: Urban Financing Partnership Facility. Manila. https://www.adb. org/documents/urban-financing-partnership-facility-annual-report-2019. 
These disaster risk management systems, structures, and support are as diverse as the risks themselves. Some have well-defined functioning disaster risk management systems developed over many decades, such as Japan. More recent and destructive disasters, such as in the Philippines, Indonesia, and India, have jolted governments into action, using newly available technology to catch up in building risk management systems. Still others are forced to confront disasters with few available self-generated resources to run effective disaster risk management systems without large donor assistance (i.e., Fiji, Nepal, and Vanuatu).

Disaster risk management systems, nonetheless, do need to share one common feature to become most effective. Disaster risk reduction plans, government disaster risk management systems, and disaster risk financing structures must be closely aligned to the specific risks and vulnerabilities each locality faces. This is true both for ex-ante prevention and preparedness and for ex-post disaster response.

Disaster risk financing reduces country, business, community, or household exposure to disaster-related losses by offering the capacity to retain, transfer, or share risk through specifically designed financial instruments. A range of disaster risk financing instruments can be designed and offered, such as disaster contingency budgets, contingent disaster financing, emergency loans, and insurance and capital market transactions.

Despite the significant progress in enhancing disaster risk financing arrangements in recent years in most of developing Asia, this area remains at an early stage. Disaster risk financing can quickly provide the needed liquidity when disaster strikes or when predefined thresholds are breached, triggering advance financing based on parametric risk transfer products. They should be risk- or forecast-based, not designed solely on the severity and frequency of previous natural calamities.

A typical disaster risk financing system requires a layered public-private sector approach, covering risk retention, such as annual set-aside government budget reserves and calamity funds, plus contingent disaster, and risk transfer (government and private insurance and reinsurance market solutions, along with catastrophe bonds and other insurance-linked securities). Major disasters may also result in appeals for external assistance (Figure 2).

Figure 2: Disaster Risk Financing-A Layered Approach

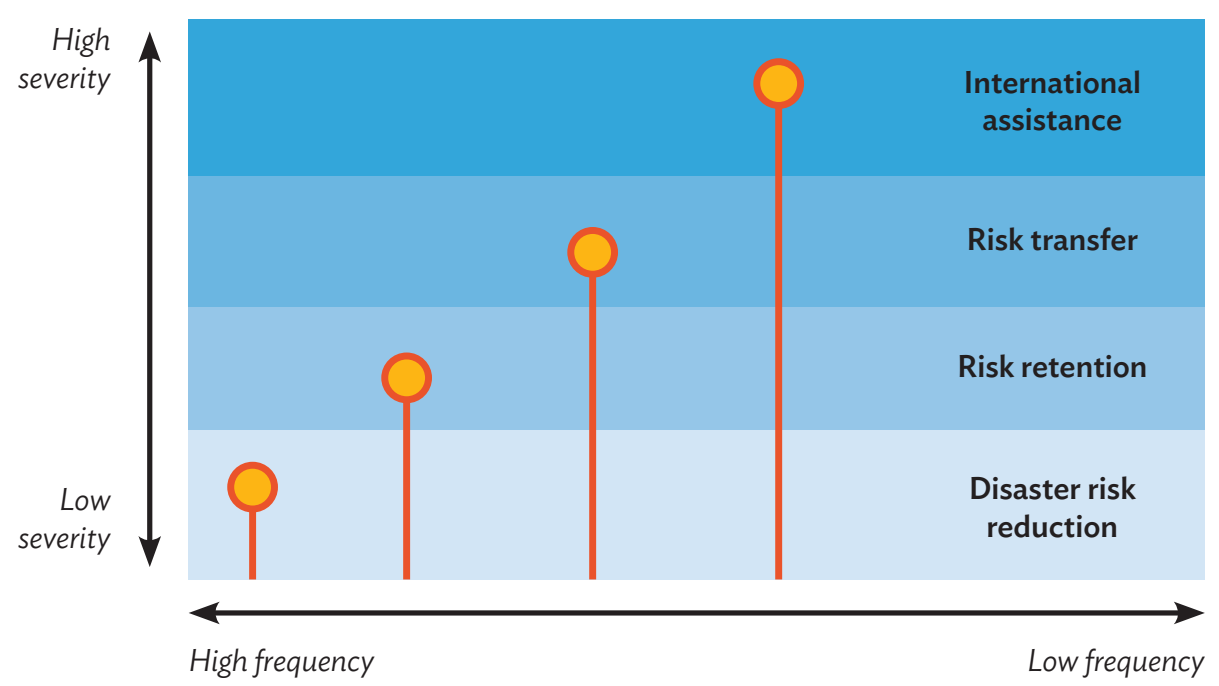

Source: Asian Development Bank. 2013. Investing in Resilience: Ensuring a Disaster Resilient Future. Manila. https://www.adb.org/ publications/investing-resilience-ensuring-disaster-resistant-future. 
The most effective disaster risk financing strategy uses a bottom-up approach to segment disaster risk. A rigorous analysis of the underlying hazard, exposure, and vulnerability measures the probable maximum losses from events over varying return periods. The strategy then matches the layers of disaster risk with the most cost-effective financial instrument based on economic and social considerations.

This approach creates a menu of ex-ante and ex-post financial instruments. Reserves and budget contingencies are the least expensive and generally cover recurrent low-risk losses. Other financing sources, such as contingent disaster financing - and possibly insurance-are best suited to medium layers of risk. Finally, less frequent but more severe high-risk disasters, causing unexpectedly high economic damage, can be financed through risk transfer instruments, such as (pooled) catastrophe risk reinsurance or catastrophe bonds, among others, and international assistance.

Creating a workable, efficient, and sufficiently funded disaster risk financing structure should be based on rigorous and robust risk assessments that help define the frequency and severity of loss. That way, it is possible to develop disaster risk financing strategies and deploy finance mechanisms more selectively and strategically.

A critical nexus is to link specific disaster risk financing instruments with disaster risk reduction. It not only adds resilience to financial protection, but simultaneously reduces risk. The more seamless the two are linked, the better disaster risk financing instruments can provide price signals to help guide other resilience-related decisions-when the marginal cost of further disaster preparedness or reduction exceeds risk transfer costs.

The parametric agriculture insurance scheme, which ADB piloted in Bangladesh in 2017, is an example of disaster risk financing. Farmers received a payout depending on various predefined weather-based indexes. Moreover, ADB is providing Contingent Disaster Financing of more than $\$ 20$ million for Pacific countries (Cook Islands, Palau, Samoa, Tonga, and Tuvalu) to ensure the rapid disbursement of financing when a disaster event occurs. By the end of 2020, 10 Pacific countries will be covered by a Contingent Disaster Financing program amounting to $\$ 99$ million. ADB also approved the Contingency Disaster Financing of $\$ 500$ million for the Philippines. ${ }^{15}$

\section{Enhancing the Enabling Environment for Disaster Risk Financing}

ADB has developed an analytical framework to identify gaps between international best practice in disaster risk financing and its application in particular countries (ADB 2020). The framework focuses on six key areas for the development of disaster insurance and capital market solutions: government policy, social protection policy, unlicensed competition, economic conditions, financial strengths of insurance/reinsurance and capital markets providers, and product appeal.

The tool generates an overview of policies and mechanisms for disaster risk financing and identifies conditions for effective use of well-established instruments as well as existing related barriers or gaps. It sets policy priorities for implementing reforms and introducing new instruments. The tool provides the basis for new or deeper engagement in disaster risk financing by governments, regulators, and development partners. It also creates a diagram of the gaps between the current enabling environment and the ideal and realistic alternatives, thus enabling identification of areas for action and development of a strategy and road map to address the gaps. The application of the framework in Fiji, Nepal (Box 3), Pakistan, and Sri Lanka provides some guidance (ADB 2019b, 2019c, 2019d).

15 ADB. Bangladesh: Pilot Project on Weather Index-Based Crop Insurance. https://www.adb.org/projects/46284-001/main; ADB. Philippines: Disaster Resilience Improvement Program. https://www.adb.org/projects/54022-001/main; ADB. Regional: Pacific Disaster Resilience Program, Phase 3. https://www.adb.org/projects/50028-003/main\#project-pds. 


\section{Box 3: Disaster Risk Financing in Nepal}

Estimates suggest that Nepal annually loses some $\$ 173$ million ( $0.88 \%$ of the country's gross domestic product in 2014) on average due to natural hazards including floods, landslides, wind and hailstorms, droughts, and earthquakes. The 100-year probable maximum loss is estimated at $\$ 1.4$ billion for earthquakes.

Strong financial arrangements for disaster response are thus urgently needed. However, the government retains nearly all public sector disaster risk and relies predominantly on financing arrangements only established in the aftermath of a disaster. The government has become accustomed to reallocating its proposed capital works program appropriation to disaster emergency assistance, recovery, and rehabilitation. Other measures have included borrowing from multilateral institutions to finance repair and reconstruction of infrastructure and housing for the economically vulnerable as well as enabling loans of retirement savings for housing rehabilitation work.

To strengthen disaster risk financing instruments, the government will develop a strategy following the risk-layered approach, compile comprehensive disaster risk data, and establish a complete register of all government-owned infrastructure and assets. The diagnostics tool identified several areas of improvement as a prerequisite for the successful implementation of disaster risk transfer instruments.

Source: Asian Development Bank. 2019. The Enabling Environment for Disaster Risk Financing in Nepal: Country Diagnostics Assessment. Manila. https://www.adb.org/publications/environment-disaster-risk-financing-nepal.

\section{Disaster Insurance Pool}

A way for cities to share and transfer disaster risks is to establish a city disaster insurance pool intended to provide rapid and cost-efficient post-disaster financing for early recovery. In the design of one such pool, for the Philippines, city governments could collectively buy insurance through a single platform that essentially operates as an insurance company acting for the benefit of participants. The pool offers parametric insurance where payouts are determined based on the physical features of a natural hazard event, such as wind speed for typhoons or ground-shaking for earthquakes, rather than actual losses suffered. Parameters are those most closely correlated to actual losses.

Reputable independent scientific agencies verify the parameters driving payouts, which make physical parameter data publicly available soon after a disaster occurs, meaning payouts can be expected within 15 business days of qualifying disaster events. This avoids the lengthy loss assessment required by traditional "indemnity" insurance.

The pooled structure reduces the cost of disaster insurance for participating cities by diversifying risk and enabling a reduction in the volatility of total losses experienced by the whole group relative to each insuring in isolation (Box 4). It absorbs the first layer of loss from pool reserves (retained profits), reducing the amount of open market insurance (local and international reinsurance) required to protect the pool. It shares the administrative costs of creation and management. A risk pool also provides an effective platform to increase disaster risk management knowledge and capacity, and to share experience and build knowledge to diversify risk, thus reducing risk charges. 


\section{Box 4: City Disaster Insurance Pool in the Philippines}

The Philippines' City Disaster Insurance Pool, developed with Asian Development Bank (ADB) support and funded through the Integrated Disaster Risk Management Fund, offers an innovative city disaster insurance pool. The pool is designed to offer earthquake and typhoon cover in the first instance, using parametric indices calculated for each city based on spectral acceleration (a measure of ground motion) for earthquake cover and on 3-second peak wind gusts (a measure of wind speed) for typhoons. These parameters are measured the center of each barangay and weighted according to the proportion of the relevant city's assets located in that barangay. Flood cover is expected to be added once existing data and modeling challenges have been addressed.

Cities purchase insurance cover based on the type of hazard they want to insure against, the frequency and scale of payouts they want, and the funding available for premium payments. The premiums paid by each city is based on the level of risk that a city brings to the pool.

Ten cities participated in the initial design of the pool. Their selection was based on a range of factors including disaster risk, demography, economic size, geographic location, data availability, and disaster risk management governance. The relative scale of government and public facilities, and thus of potential post-disaster levels of expenditure, was also considered. Once implemented, the pool would be expanded to cover additional cities.

To support optimal design, ADB engaged the 10 participating cities in (i) data collection to understand the disaster risks each faced and the potential post-disaster financing requirements and (ii) a needs assessment based on the disaster risk financing arrangements in each city. Substantial consultation and capacity development was undertaken, with individual cities visited up to 10 times and several joint capacity-building workshops also held for all the cities and other stakeholders. This resulted in strong buy-in and informed decision-making capabilities. The concept could be extended to pooling cities together at a regional level.

Source: Asian Development Bank. 2018. Philippine City Disaster Insurance Pool: Rationale and Design. Manila. https://www.adb.org/publications/philippine-city-disaster-insurance-pool.

\section{Public Asset Insurance Scheme}

Flood risk management, naturally, goes back centuries in Viet Nam. Probably drawing on that long expertise, the country has been shaping its disaster risk management approach since 2007 with the government's approved National Strategy for Natural Disaster Prevention, Response and Mitigation. This approach focuses on ex-ante disaster risk reduction and moves away from ex-post response.

In 2017, Viet Nam fostered its approach to disaster risk financing, with the country's recent revision of its Law and Decree on Management and Use of Public Assets, giving new momentum to sustainable disaster risk financing solutions. The Insurance Supervisory Authority in Viet Nam previously estimated that fewer than $1 \%$ of public assets benefited from natural catastrophe property insurance coverage. The law specifies that "highly risky property due to natural disasters (hazards), fires and other force majeure events shall be managed through insurance or other instruments as regulated by law."16

ADB is supporting Viet Nam in developing a disaster risk insurance model for public assets, with financing from the Urban Climate Change Resilience Trust Fund. This is being piloted in Hue in central Viet Nam, a city

16 According to Viet Nam's Law on Management and Use of Public Property, Article 6. 
of immense cultural and commercial significance that is exposed to flooding, tropical cyclone, and landslide risks. Hue, supported by ADB's Secondary Cities Development Program II (Green Cities), aims to better manage the cost of disaster and climate change. The program will improve institutional, regulatory, and financial environments to allow the city to use indemnity or parametric disaster insurance for public assets.

A disaster insurance feasibility assessment is ongoing to create a relevant public asset database and to ascertain appropriate structure for the insurance scheme, including its placement strategy in both the domestic and international insurance and reinsurance markets. Measures will be identified to enhance asset resilience and reduce insurance premium rates.

\section{Coral Reef Insurance Scheme}

Insurance can also be used to sustain the required funding to conserve and restore coral reefs that protect many of the world's coastal communities from flooding, storm surge, and tsunamis. Coastal cities face growing risks as rising sea levels increase the probability and intensity of storm surges and high tides during tropical cyclones and tsunamis. About $40 \%$ of the world's population lives within 100 kilometers (60 miles) off the coast (Center for International Earth Science Information Network 2013).

Tsunamis are a major risk in many parts of the the Asia and Pacific region. At least 222 people were killed and 843 injured after a tsunami hit the coastal towns of Bandar Lampung and its surrounding communities in Indonesia's Sunda Strait following the volcanic eruption of the Krakatau in December 2018.

Coral reefs can play an important role in reducing the impact of tsunamis. A healthy coral reef can break up as much as $97 \%$ of wave energy before a wave reaches the shore, dramatically reducing flooding and beach erosion. They are thus a cost-effective way to reduce coastal erosion and flooding from storms and sea level rise.

The value of services that reefs provide globally has been estimated at as much as $\$ 9.9$ trillion. In addition to tourism, healthy and well-managed coral reefs generate 5 to 10 tons of fish per square kilometer per year. In the Indo-Pacific region, about 1,800 species of coral reef fish exist and an estimated 1.2 billion people in Asia and the Pacific depend on reef fish for $25 \%$ of their protein requirements (GEF n.d.).

Damage to coral reefs by extreme weather events can be repaired by immediate post-storm clean-up and further restoration actions on the reef over time, but repairs are needed quickly. Teams of local people, called the "reef brigades," can be trained to assess damage, remove debris, carry out initial repairs, collect broken coral for reattachment, and design a repair strategy.

For this, funds are likewise needed quickly, and insurance provide a highly suitable instrument. A dedicated insurance solution for rapid liquidity to cover the reef brigades and repair costs is essential if the full protective value of the reef is to be reinstated more quickly than the natural repair process (Box 5). The reef insurance model, which uses parametric insurance designed for quick pay out after a triggering event, responds to this need and provides payment to first responder teams and for longer-term repairs. ${ }^{17}$ This can have a measurable impact on reducing the socioeconomic vulnerability of coastal cities and their local communities.

17 This income can be especially valuable as many first responders may have lost their jobs and income after a major event. 
Box 5: Protecting Coral Reefs in Fiji, Indonesia, the Philippines, and Solomon Islands

The Asian Development Bank (ADB) has launched a project focusing on four countries that are highly susceptible to disasters - Fiji, Indonesia, the Philippines, and Solomon Islands. The project aims to insure the coral reefs that may provide critical protective services against disasters causing ecological and socioeconomic damage.

The proposed project will build on the lessons from a pilot initiative in Quintana Roo, Mexico, where the world's first insurance policy for a coral reef was purchased in June 2019. The Nature Conservancy, Swiss Re, the Government of Quintana Roo, and the local hotel industry partnered to insure a stretch of the Mesoamerican Reef and adjacent beaches to protect coastal cities and businesses. Underlying the success of the model is the Coastal Zone Management Trust, an innovative financial mechanism developed to promote good governance, increase transparency, and ensure that the insurance policy is properly funded.

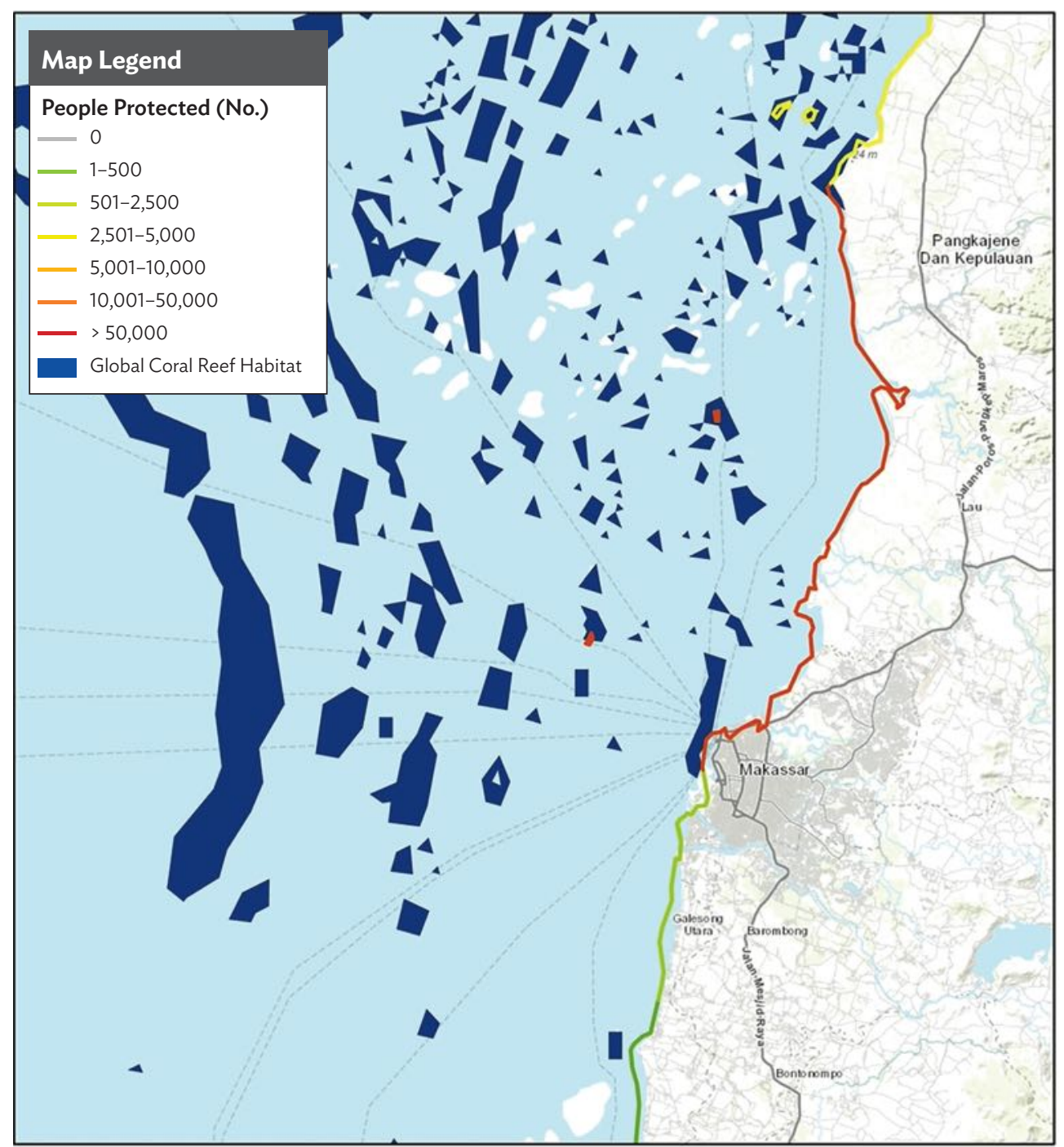

Coral reef system protecting Makassar. The 2 million people who live in Makassar (the capital of the Indonesian province of South Sulawesi) and its surrounding provinces could benefit from ADB's coral reef insurance project (photo by Mapping Ocean Wealth Explorer. http://maps.oceanwealth.org/\#). 
Box continued

Putting insurance in place includes steps in technical, legal, financial, and direct implementation aspects. The project needs to identify coastlines with cities and surrounding communities most benefiting from a coral reef insurance scheme. It also needs to establish a full project proposal able to finance the entire cycle. Hence, the project will need to collect and model socioeconomic considerations and community vulnerability, including adaptation and risk reduction considerations in the four countries. However, there are limitations that need be addressed, such as

- data limitations on resilience benefits and vulnerability;

- insufficient capacity of governments on nature-based risk transfer and in setting up sustainable financing;

- $\quad$ inadequate legal frameworks and institutional structures;

- lack of technical capacity for reef repair and restoration;

- inadequate evaluation by insurers' risk assessment and rating systems of the value of natural systems in risk reduction (thus giving little incentive for those at risk to invest in natural system maintenance and restoration, or insurers are less motivated to provide incentivization to do so); and

- limited insurance penetration in poorer coastal communities.

Source: Asian Development Bank; The Nature Conservancy. Mapping Ocean Wealth. https://oceanwealth.org/; M. W. Beck et al. 2018. The Global Flood Protection Savings Provided by Coral Reefs. http://media.coastalresilience.org/MOW/. Gobal_Flood_Protection_by_Coral_Reefs.pdf; UNEP-WCMC, WorldFish Centre, WRI, TNC. 2018. Global Distribution of Warm-Water Coral Reefs. Cambridge (UK): UN Environment World Conservation Monitoring Centre (compiled from multiple sources including the Millennium Coral Reef Mapping Project. Version 4.0. Includes contributions from IMaRSUSF and IRD [2005], IMaRS-USF [2005] and Spalding et al. [2001]). https://doi.org/10.34892/t2wk-5t34.

\section{Leveraging Technology for Disaster Risk Management}

Innovation in emerging technologies, such as artificial intelligence, big data, and mobile technologies, holds considerable promise for improving disaster risk management. Increases in the availability and quality of data from Earth observation, Internet of Things devices, and social media provide new sources of timely data on hazards, exposure and vulnerability, and losses and damages. Artificial intelligence/machine learning, cloud computing, and spatial analysis tools enhance the capacity to use that data. This could help developing countries overcome hindrances to adopting more sophisticated risk management methods.

High and very-high resolution Earth observation imagery, for example, can be combined with open data platforms - such as OpenStreetMap, a collaborative project which aims to provide a free editable map of the world - and other sources of exposure data for detailed assessment of risk even in regions with historical gaps in data coverage. ${ }^{18}$ International initiatives, such as the European Space Agency's Earth Observation for Sustainable Development program, are increasingly providing access to Earth observation data and the tools to integrate in planning decisions and post-disaster reconstruction. ADB has embedded the use of satellite-based services in its operations to

- improve resilience to floods in Kolkata,

- design embankment walls in Cambodia,

- rehabilitate mangrove forest in Pakistan,

18 OpenStreetMap. https://www.openstreetmap.org/\#map=8/46.825/8.224. 
- identify landslide risks to irrigation infrastructures in Bhutan,

- assess ocean health in the Gulf of Bengal,

- rehabilitate the city of Palu, Indonesia after the tsunami, and

- $\quad$ prioritize investments for a more sustainable use of water resources in the island of Java, Indonesia.

Connected devices allow real-time monitoring of potential hazards such as floodwater levels. Crowdsourcing enables quick access to detailed maps, gathering information to build on data from satellite imagery. For example, Twitter posts are used in Indonesia and Japan to rapidly detect heavy rain events.

These emerging technologies and innovative approaches can support improved disaster risk management mechanisms to increase resilience (Figure 3). Worldwide, technologies are improving risk awareness. They facilitate more effective planning, preparedness, investment, and response, and support development of disaster risk financing approaches and solutions, including risk transfer and sharing arrangements.

Spatial analysis and visualization tools such as geographic information systems facilitate integration of Earth observation data into risk assessment and planning decisions. Cloud computing boosts computational capacity to run complex risk or impact models and enables cooperation between geographically dispersed decision makers. Artificial intelligence and machine learning provide new approaches for processing of data to identify trends and causal factors. In Japan, new artificial intelligence-based approaches to assessing tsunami and river flood risks have been developed for implementation in the near future.

Communication tools such as mobile apps, social media, and web-based platforms can also support faster and more accessible dissemination of risk and impact information and risk reduction and preparedness advice. Following the 2015 floods in Chennai, India, for example, dedicated Twitter handles were established to source information on people willing to volunteer and those needing rescue and assistance. The Twitter handles also facilitated the development and dissemination of information on shelter and weather patterns. Meanwhile, the Government of Sri Lanka has launched a National Disaster Risk Platform to consolidate data from various sources and facilitate the sharing of geospatial data sets in a collaborative multi-agency environment.

Figure 3: Leveraging Innovation and Technology

Earth observation imagery Geo-referenced census data OpeenStreetMap Connected devices Crowdsourcing

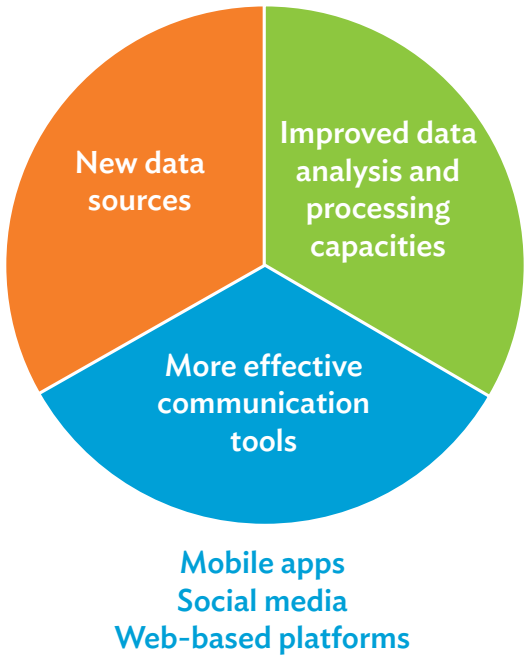

Artifical intelligence Spatial analysis tools Cloud computing

Source: Asian Development Bank and Organisation for Economic Co-operation and Development. 2019. Leveraging Technology and Innovation for Disaster Risk Management and Financing: A Note to APEC Finance Ministers on Initial Findings. Manila, Paris. 
Many of these technologies, including open-source mapping platforms, Earth observation data, crowdsourcing of information, and spatial analysis tools, have great potential for scaling up in Asia and the Pacific, as the underlying technology is well-developed and tested.

However, application of emerging technologies, such as artificial intelligence and machine learning, will require the development of technical skills, building of consumer acceptance, and regulatory adaptations to create an enabling environment. Social and cultural issues also need to be considered, such as respecting privacy and making the technology appropriate and inclusive for the poor. On the technical side, telecommunications infrastructure, mobile internet coverage, and smartphone penetration are also preconditions for many of these emerging technologies. Emerging technologies, including artificial intelligence and spatial analysis tools, and the development of parametric insurance products and blockchain solutions, require high levels of expertise. To leverage technological advances in data analysis and processing, high-quality and harmonized data sets are needed.

The effective integration of new communication tools and the distribution of new types of insurance products are also dependent on awareness, appropriateness of technology solutions with the local sociocultural context, and acceptance among target users. Furthermore, while providing an enabling environment for innovation and adoption of technology in disaster risk management, it remains important to strike the right balance between innovation and data/consumer protection. This will also be important to maintaining public trust in financial protection products and providers. Subsequently, legal and regulatory frameworks across a variety of domains are needed.

\section{Conclusion}

Cities in Asia and the Pacific face a greater share of natural hazards than any other global region. This can include social disparity after armed conflicts, a pandemic, and seismic and weather-related hazards - the latter being compounded by climate change. It shows, however, that governments can meet the challenge using well-tested measures. Multilateral banks can help support governments and individual cities in these efforts.

Cities face challenges in governance that make it difficult for them to carry out their responsibilities. They have to deal with the limitations enforced by national governments on the type or level of taxes and fees they can impose, or with restrictions from borrowing internationally in foreign exchange for infrastructure or other investments. Cities may lack staff with relevant experience in financial sectors or who can engage effectively with the private sector. Likewise, underdeveloped insurance and domestic capital markets may further limit options for funding.

The insurance sector offers numerous solutions that carry considerable promise. Yet, many barriers discourage cities from adopting such promising measures. Risk information barriers exist and may include legal and datarelated concerns that lead to high transaction costs. For instance, cities like Bangkok, Jakarta, and Qingdao already have most of their data digitized, but these are in institutional silos, and efforts in smaller cities are still nascent. Cities are also dependent on the bureaucracy, which lacks expertise on damage assessment, independent regulatory oversight, awareness of insurance benefits, and risk-sharing and transfer mechanisms.

Exploration of risk transfer solutions will identify and quantify risk and thus enable informed dialogue. The initial price tag for the risk transfer structure indicated by insurers will incentivize risk reduction measures. Municipal and 
national governments therefore need to work more closely with the private sector to take advantage of disaster financing and insurance-linked products that can make their urban areas and infrastructure more resilient.

In the area of climate change and related hazards, such as more frequent and powerful storms, flooding, and drought, this article draws from a desk study of 10 Asian cities: Bangkok, Thailand; Colombo, Sri Lanka; Barisal, Bangladesh; Can Tho and Ho Chi Minh, Viet Nam; Makati and Iloilo, Philippines; Qingdao, the People's Republic of China; and Jakarta and Semarang, Indonesia (Centennial Group International n.d.). The study identifies two types of measures (structural and nonstructural, summarized below) that could be helpful in enhancing risk governance measures. The study also emphasizes the need for an enabling environment for these measures to be effective.

Nonstructural measures are low-cost and they warrant close attention. Iloilo in the Philippines and Barisal in Bangladesh, for instance, demonstrate the value of nonstructural measures including early warning systems, cyclone shelters, and frequent drills to internalize appropriate behaviors.

Structural measures include climate- and disaster-resilient investments (e.g., better flood drainage, polders and dikes, and better solid waste management) and water retention infrastructure (e.g., afforestation, watershed management, and implementing "sponge city" concepts such as in Qingdao). ${ }^{19}$ Because these are all nonrevenuegenerating, the challenge is in "monetizing" a dividend based on the long-term cost/benefit advantage of structural measures.

Other structural measures include making power and water utilities flood-resistant and elevating expressways, which are revenue-generating. These measures have the potential for public-private partnership (PPP), which eventually transfers the responsibility for financing and management of resilience measures to the private sector. However, city officials have little experience with the project preparation standards and documentation requirements of PPPs - meaning PPPs are underused. High transaction costs due to overlapping responsibilities between national, provincial, and city governments were also the most common identified problem among cities in the sample, calling for clearer ownership and coordination among stakeholders and authorities. Development partners can help developing countries leverage funds for public and public-private project initiatives. ADB's Asia Pacific Project Preparation Facility, a $\$ 73$ million, multi-donor trust fund aims to increase infrastructure development and enhance the quality of infrastructure in Asia and the Pacific.

Others sources of funds include specific city trust funds, such as the Urban Climate Change Resilience Trust Fund, a $\$ 150$ million multi-donor trust fund (2013-2021). The fund helps fast-growing cities in Asia reduce the risks vulnerable people face from floods, storms, or droughts, through better planning and design of infrastructure. The City Development Initiative Asia Fund, another multi-donor trust fund, works with secondary cities in the region to address gaps in infrastructure development and financing. It uses a demand-driven approach to support infrastructure projects that emphasize poverty reduction, environment improvement, climate change mitigation or adaptation, and good governance.

To enhance the enabling environment for disaster resilience measures, new policies and capacity building are also needed for national and city governments. The objective is to establish integrated disaster risk management frameworks that enable implementation of comprehensive disaster risk reduction and disaster risk financing strategies. Technology and innovative solutions can then be tested using "sandbox" pilots.

19 A sponge city is designed to absorb and capture rainwater to reduce floods. It "mainstreams urban water management into the urban planning policies and designs [and] should have the appropriate planning and legal frameworks and tools in place to implement, maintain and adapt the infrastructure systems to collect, store, and treat [excess] rainwater." (Green Roof Technology n.d.) 
National measures should therefore clarify intergovernmental and interagency responsibilities for planning, financing, and execution of disaster risk management investments. They should implement national policies to regulate local government borrowing and account for local government responsibility in financing major infrastructure investments. Cities also need control over the type and level of local taxes and fees to improve accountability and increase levels of funding. In addition, measures need to develop domestic capital markets and introduce subnational governments to them. Measures are also needed to standardize approaches for cities to work with the private sector on innovative PPPs.

City governments should improve planning, budgeting, prioritization, and implementation of public and public-private projects, including structural and nonstructural measures, and work with private insurance markets and capital markets. They need to involve all stakeholders in planning and prioritization. Disaster and climate risk assessments need to be part of project feasibility studies, and governments should prioritize resiliency investments based on cost effectiveness in risk reduction and overall economic cost-benefit analyses. In addition, city governments need to adopt a full range of disaster risk financing instruments using a risk-layered approach and form private sector partnerships, especially with insurance companies through PPPs.

As countries in Asia and the Pacific work to bolster their resilience to disasters and climate change, experience shows that cities need to more heavily tap into better disaster risk management, disaster risk pooling, new technologies, and supportive policy and regulatory reforms. This article has highlighted an integrated approach to doing so. By employing such methods, cities can overcome challenges and better utilize decades of experience in insurance and in the private sector to prepare for and respond to natural and man-made hazards.

\section{References}

Asian Development Bank (ADB). 2013. Investing in Resilience: Ensuring a Disaster Resilient Future. Manila. https://www.adb.org/publications/investing-resilience-ensuring-disaster-resistant-future.

_-_. 2014. Operational Plan for Integrated Disaster Risk Management, 2014-2020. Manila. https://www.adb.org/ documents/operational-plan-integrated-disaster-risk-management-2014-2020.

_-_. 2016a. Incentives for Reducing Disaster Risk in Urban Area Experiences from Da Nang (Viet Nam), Kathmandu Valley (Nepal), and Naga City (Philippines). Manila. https://www.adb.org/publications/incentivesreducing-disaster-risk-urban-areas.

_-_. 2016b. Reducing Disaster Risk by Managing Urban Land Use: Guidance Notes for Planners. Manila. https://www.adb.org/publications/reducing-disaster-risk-urban-land-use-guidance-notes.

_-_. 2017a. Meeting Asia's Infrastructure Needs. Manila. https://www.adb.org/publications/asia-infrastructureneeds.

_-_. 2018a. Toward Resilient Kolkata: Introducing India's First Comprehensive City-Level Flood Forecasting and Early Warning System. Manila. https://www.adb.org/publications/toward-resilient-kolkata

_-_. 2018b. Philippine City Disaster Insurance Pool: Rationale and Design. Manila. https://www.adb.org/ publications/philippine-city-disaster-insurance-pool. 
-_-. 2019a. 2019 Annual Report: Urban Financing Partnership Facility. Manila. https://www.adb.org/documents/ urban-financing-partnership-facility-annual-report-2019.

-_- 2019b. The Enabling Environment for Disaster Risk Financing in Pakistan: Country Diagnostics Assessment. Manila. https://www.adb.org/publications/pakistan-environment-disaster-risk-financing.

-_- 2019c. The Enabling Environment for Disaster Risk Financing in Sri Lanka: Country Diagnostics Assessment. Manila. https://www.adb.org/publications/sri-lanka-environment-disaster-risk-financing.

_-_. 2019d. The Enabling Environment for Disaster Risk Financing in Fiji: Country Diagnostics Assessment. Manila. https://www.adb.org/publications/fiji-environment-disaster-risk-financing.

_-_. 2019e. The Enabling Environment for Disaster Risk Financing in Nepal: Country Diagnostics Assessment. Manila. https://www.adb.org/publications/environment-disaster-risk-financing-nepal.

- - . 2019. Building Resilient Infrastructure for the Future: Background Paper for the G20 Climate Sustainability Working Group. Manila. https://www.adb.org/publications/building-resilient-infrastructure-future.

- - . 2020. Assessing the Enabling Environment for Disaster Risk Financing: A Country Diagnostics Tool Kit. Manila. https://www.adb.org/publications/disaster-risk-financing-country-diagnostics-toolkit.

ADB and Organisation for Economic Co-operation and Development (OECD). 2019. Leveraging Technology and Innovation for Disaster Risk Management and Financing: A Note to APEC Finance Ministers on Initial Findings. Manila, Paris. http://mddb.apec.org/Documents/2019/FMP/FDM2/19_fdm2_012.pdf.

Beck, M. W. et al. 2018. The Global Flood Protection Savings Provided by Coral Reefs. http://media.coastalresilience. org/MOW/Gobal_Flood_Protection_by_Coral_Reefs.pdf.

Centennial Group International. n.d. Summaries of 10 Notes on Climate Change in Asian Cities. Unpublished.

Center for International Earth Science Information Network, NASA Socioeconomic Data and Applications Center. 2013. Low Elevation Coastal Zone Urban-Rural Population and Land Area Estimates, Version 2. Palisades, New York.

Global Environment Facility. GEF-7: Project Identification Form. https://www.thegef.org/project/public-privatepartnerships-ppps-coral-reef-insurance-asia-and-pacific.

Green Roof Technology. Form and Function. http://www.greenrooftechnology.com/.

Strobl, E. 2019. The Impact of Typhoons on Economic Activity in the Philippines. Manila: ADB. https://www.adb.org/ publications/impact-typhoons-philippines.

Swiss Federal Institute of Technology (ETH Zurich). n.d. Weather and Climate Risks Group. Zurich.

Swiss Re. 2016. Helping a City Prepare for Climate Change-An Economics of Climate Adaptation Study in Barisal, Bangladesh. Zurich. 
The Nature Conservancy. Mapping Ocean Wealth. https://oceanwealth.org/.

United Nations Economic and Social Commission for Asia and the Pacific (UNESCAP). 2016. The Economics of Climate Change in the Asia-Pacific Region. Bangkok. https://www.unescap.org/resources/economics-climatechange-asia-pacific-region.

UNEP-WCMC, WorldFish Centre, WRI, TNC. 2018. Global Distribution of Warm-Water Coral Reefs. Cambridge (UK): UN Environment World Conservation Monitoring Centre (compiled from multiple sources including the Millennium Coral Reef Mapping Project. Version 4.0. Includes contributions from IMaRS-USF and IRD [2005], IMaRS-USF [2005] and Spalding et al. [2001]). https://doi.org/10.34892/t2wk-5t34. 


\title{
Post-Pandemic Response, Recovery, and Rejuvenation
}

\author{
Alexandra Pamela Chiang, David Elzinga, Hong Soo Lee, and Geoffrey Wilson
}

\section{Introduction}

The coronavirus disease (COVID-19), which was declared a global pandemic by the World Health Organization on 11 March 2020, has become the most urgent crisis today. It has affected the normal lives of citizens and disrupted their work, causing severe physical, social, and economic distress. In Asia and the Pacific, the poor and vulnerable people are the most adversely affected. While various diseases and epidemics have influenced development over the centuries, the COVID-19 pandemic caused an unprecedented global impact across the world and generated lessons for response, recovery, and rejuvenation.

Governments, businesses, organizations, and individuals (collectively referred to as stakeholders in this article) in developing countries in Asia and the Pacific will need to effectively respond to the crisis in the immediate term. Stakeholders also need to plan for a green and resilient recovery in the short- and medium-term, while continuously adapting to a new normal with respect to human behaviors, social interactions, and business practices.

Lessons can be drawn from experiences around the world on how to implement more effective emergency responses and proactively plan for response, recovery, and rejuvenation. While pursuing immediate actions to recover from the initial pandemic shocks, stakeholders in Asia and the Pacific should not lose sight of short- and medium-term goals of enhancing health and safety, economic opportunity, resilience, and livability. Governments can consider a number of general approaches to planning.

Stakeholders experience varying impacts from COVID-19 and are not equal in their capacity to respond to a crisis. Therefore, while learning from others and planning their response, they should consider socioeconomic and political factors, including demographic profiles and population characteristics, economic capabilities and income levels, geographic features, urban infrastructure and pre-crisis service standards, regulatory frameworks, and available financial and personnel resources.

Stakeholders are taking a wide range of decisions affecting not only immediate prevention and protection measures but also longer-term paths to recovery. The massive changes taking place now present massive opportunities for reforms. Long-term views should be factored into the immediate response as much as possible to achieve more strategic goals and objectives that will enable a green and resilient recovery.

The COVID-19 pandemic provides a unique opportunity to upscale innovation and the use of online tools and digital solutions. Stakeholders can leverage through the use of both proven and new technologies, such as systems based on Internet of Things, network management technologies for operation of municipal infrastructure utilities, artificial intelligence for contact tracing and identifying potential cases, blockchain for more secure communications and transactions, mobile applications for citizens' awareness, and advanced online communications for work-from-home and distance learning. 
Despite the rapid deployment of digital solutions during the pandemic, vulnerable users (including low-income residents, informal sector workers and migrant workers, homeless people, single-parent households, the elderly, women and children, people with disabilities, and minorities) are often excluded from the benefits of high-level technology solutions. Many of them cannot afford technologies such as smartphones, and therefore do not have access to internet and data. It is therefore essential that stakeholders ensure future developments will bridge this digital divide. Local governments can adopt differentiated approaches for such groups, reflecting their needs and abilities in the design of future strategies and projects, to support them in complying with public health and safety measures.

Local-level organizations need to work with national or provincial governments to ensure effective implementation of measures such as quarantine directions, fiscal stimulus packages for workers and small businesses, and special social protection measures. They should also develop location-specific responses in line with national frameworks and initiatives (OECD 2020).

Most importantly, stakeholders need to carefully balance the health and well-being of citizens with the potential of resuming economic growth and livelihood opportunities as drivers for development. They should also recognize the probability of continued or recurrent restrictions. Given these multidimensional and cross-sector issues, this article focuses on specific measures for response and recovery in four sectors: urban development, transport, water, and energy.

In the urban sector, the key approaches in the immediate term are to

(i) remodel public spaces; commercial, office, and industrial buildings; and civic institutions to adapt to COVID-19;

(ii) ensure continued smooth operations of urban water and wastewater utilities; provide essential water, sanitation, and hygiene (WASH) services; and address the increasing problem in solid and medical waste management;

(iii) address the special needs of informal settlements and vulnerable people;

(iv) address changing transport needs; and

(v) effectively use information and communication technology (ICT) and digital solutions.

To rebuild greener and more resilient post-pandemic cities, efforts in the urban sector will need to

(i) enhance inclusivity through greater social protection measures for the most vulnerable groups;

(ii) improve urban services and infrastructure;

(iii) revisit urban planning to strategically incorporate lessons from COVID-19;

(iv) strengthen financial sustainability of local governments and build capacities of urban institutions and other stakeholders;

(v) focus on healthy and environmentally sustainable cities; and

(vi) build resilient cities with the ability to absorb shocks and stresses due to pandemics, disasters, and climate change.

In the transport sector, the public transport needs the most immediate responses, such as

(i) physical distancing, face masks, and frequent sanitation of vehicles and stations;

(ii) demand management through staggered ridership and reduced physical presence in workplaces; and

(iii) potentially restructuring transport operators or providing subsidies to ensure essential transport links are kept open and core transport operators remain financially viable. 
To rebuild greener and more resilient sustainable transport, the "new normal" measures should be mainstreamed into standard operating procedures. While it is unclear whether travel demand will rebound or whether people will shift to private modes of transport, public transport operators will remain vital for workers and vulnerable populations. Active modes such as walking and cycling may gain more prominence, particularly if cities plan for a greener recovery by investing in new infrastructure to facilitate their use. Public sector financial support can be linked to decarbonization and sustainable development criteria as well as job creation.

In the water sector, the immediate- to medium-term priorities are

(i) supporting the economic and financial recovery of water service providers that strikes a balance between continuing financial relief to customers in need and ensuring the resumption of critical capital and maintenance works that will enable broader access to water services;

(ii) improving water sector resilience by enabling service providers to meet the required flexibility, redundancy, and alternatives to ensure uninterrupted service delivery;

(iii) protecting vulnerable people, such as women and the poor, who have historically been marginalized from basic public services and who suffered disproportionately during the COVID-19 pandemic; and

(iv) employing new approaches and technologies that will fast-track the recovery of water sector service providers while ensuring they meet their service obligations.

Rebuilding a greener and more resilient water sector can be achieved by implementing integrated water resources management; increasing investments in water sector infrastructure and governance; and employing decentralized solutions, nature-based solutions, digital transformation, and robust planning in the face of deep uncertainty. Future health crises can be prevented and responded to more effectively by integrating water, sanitation, and hygiene (WASH) into the public health strategy, improving crisis preparedness and response management of water sector service providers, and developing and employing wastewater-based epidemiology. Sector-wide resilience means achieving and maintaining resilience for all water sector stakeholders, especially vulnerable people. Investments in digital technologies are likely to accelerate transformation in the water sector.

In the energy sector, the immediate priorities are

(i) ensuring that the energy sector continues to operate, and responding to increasing residential demand and decreasing commercial demand;

(ii) providing liquidity support to utilities and other energy suppliers to ensure that energy supply and generation remain operational;

(iii) supporting essential services and vulnerable end users during response to the pandemic; and

(iv) determining operational and maintenance protocols for essential employees to enable medium-term operation of energy suppliers and continuation of any capital investments during the active phase of COVID-19.

To rebuild a greener and more resilient energy sector, the recovery phase presents opportunities to accelerate progress in energy sector development to address air pollution, greenhouse gas (GHG) emissions, and access to energy. The recovery phase can be framed as "Recovery through Rejuvenation and Resilience" and can focus on (i) enhancing sustainable energy services including increased reliability, renewable energy and energy efficiency for businesses, public services such as health and education, and homes; (ii) improving energy sector resilience and security through better use of domestic resources, regional cooperation, and quality infrastructure; (iii) accelerating energy access for the poor and vulnerable, particularly to clean cooking; and (iv) applying advanced technology and cross-sector interventions. 


\section{Urban Development}

Cities have been experiencing unprecedented urban issues and challenges that call for new attempts to respond from a different perspective. The changed working and living patterns brought about by the inadequacy of essential urban services have jeopardized urban health, diminished social inclusiveness, contracted urban economies and job security, and weakened urban resilience. These abrupt changes require new ways of planning and operations at both public and private sectors for the cities of Asia and the Pacific. As urban planning has begun to secure public health and sanitation and to resolve environmental pollution problems, it is necessary to prepare a more comprehensive urban management structure. Not only immediate actions are needed but also short- and medium-term measures taking into account the impacts of COVID-19 and other natural and human-caused disasters (ADB 2020a).

\section{Issues and Challenges}

Most cities in developing countries experience inadequate urban services and deficits in basic urban infrastructure (i.e., transport, water supply, sanitation and wastewater management, solid waste management, energy, and telecommunications) and social infrastructure (i.e., health care, education, public and community facilities, and affordable housing). Inadequacy of urban services, which is a huge challenge even before the COVID-19 pandemic, has placed outbreak-affected areas at a greater disadvantage due to disruptions in regular operations.

Vulnerable populations also face the intensified impacts of the pandemic. Cities in developing countries with high-density environments, especially in informal settlements, are highly exposed to health risks. The impact of the COVID-19 crisis, which exacerbates existing inequalities, is highest among the urban poor, who experience the dual challenges of increased vulnerabilities to the disease and reduced opportunities due to economic restrictions. Their problems are aggravated by substandard housing and inadequate access to safe water, sanitation, and hygiene facilities. There are also reports of increased gender-based violence and elevated stress due to living within small and confined spaces during the enforced stay-at-home period (UN Women 2020). The difficulty of stocking extra food supplies and closed markets due to quarantine restrictions further deteriorate living and health conditions.

Despite the high penetration of internet and personal mobile phones in developing countries, cities often have ineffective ICT systems. They need integrated systems and equal access to ICT to effectively address crises. Incomplete and sometimes asymmetric information can trigger anxiety and panic reactions, as seen in many cities in the first few months of the pandemic. Accurate and timely information is needed to counter rumors and provide reliable public service messages. The availability of reliable data from service providers remains a challenge for governments to complement their own data sets, which are a critical requirement for effective functioning of comprehensive smart city platforms.

There are multiple economic crises at the macro and micro levels. Businesses have not been able to sufficiently withstand the economic shocks of COVID-19. The severe hardships faced by micro, small, and medium-sized enterprises (MSMEs) is evident. Workers, especially those in low-income categories, find it difficult to secure work-from-home arrangements. Similarly, cities experience economic impacts due to reduced revenues from

The addition of 1.2 billion new residents in the Asia and Pacific region's cities between 2019 and 2050 will have profound implications for the region's economy, society, and environment. UNESCAP. 2019. The Future of Asian and Pacific Cities. Bangkok. 
taxes, tariffs, and inter governmental transfers. Remittances from overseas workers have been reduced and there have been disruptions in value chains and production networks. Furthermore, social protection systems are often inadequate. The existing political, economic, and regulatory systems in developing countries often limit cities' systematic response to support workers and MSMEs and revitalize economies.

Local government planning and management systems are strained. Local governments, which are at the forefront of tackling crises, are required to immediately respond to emergency situations which can overwhelm their resources, financing, personnel, and systems and logistics. Their performance in emergency preparedness, crisis management, and operational readiness has been put to the test to meet the demands of their national governments, regulatory systems, and numerous stakeholders.

\section{Emergency Response and Immediate Actions for Urban Development}

Cities are already adapting to the crisis to sustain urban services. Sustaining and improving the provision of and access to urban infrastructure and services are essential to tackling the risks posed by any pandemic. More than ever, effective services and quality infrastructure are required in cities, especially in slums and informal settlements as well as for the poor and vulnerable communities.

Informal settlements and vulnerable people have special needs. Since a one-size-fits-all approach is not recommended for cities, similar omnibus measures for all informal settlements are not effective. Measures and policies such as resource provision, communication strategy, training, and support need to be adapted based on the characteristics of the groups of vulnerable people and informal settlement, such as physical environment, climate, population size, cultural and linguistic factors, crime rates, and relationship with the state.

Urban water and wastewater utilities need to ensure continued smooth operations. Water and wastewater utilities need to provide good quality and uninterrupted services during the pandemic and ensure a safe and healthy environment for all residents. They need to maintain operational efficiency despite reduced income, a constrained workforce, and fewer on-site visits. Innovative methods and technologies are required, especially in terms of responding to significantly different demands across various parts of the networks in contrast to normal usage.

Essential WASH services need to be ensured for everyone. WASH is central to preventing the spread of COVID-19 and other diseases. Handwashing with water and soap deactivates the virus but requires the provision of water in sufficient amount. It is also critical to have effective sanitation and proper hygiene for all the people in pandemicaffected areas. Municipalities should consider extending financial and technical support to service providers in implementing the necessary measures for WASH by providing financial support to water utilities; engaging public and private water service providers to include low-coverage areas; exempting from taxes WASH-related products imported into the country; and opening credit lines to WASH-related enterprises to help them survive.

Cities need effective ICT and digital solutions. Cities should use ICT and digital solutions to respond to the urgent needs and demands of their respective communities. They can use available technologies and solutions and quickly adapt their own systems considering the local context to enable more informed decision-making. Coordination between cities and national and local governments is also important in supporting solutions for consistent urban services during periods of restricted movement. Such an approach would also support external coherence and harmonization of processes and workflows. 
Travel needs of citizens change during crises. Transportation during the COVID-19 crisis experienced significant changes, since travel demand focuses more on essential travels, while space is constrained due to the physical distancing requirement. It is necessary to reallocate more physical space for non motorized and low-carbon modes such as walking and cycling, and for resilience-enhancing services such as health care, food, and other essential services.

Spaces in commercial, office, and industrial buildings can be repurposed. These spaces need to adjust or limit gatherings and commercial activities, except for essential activities such as in supermarkets, pharmacies, banks, insurance, and postal services. Stringent distancing measures should be applied before gradually shifting to overall confinement or vice versa. Operators will need to recalibrate building designs and systems to be more efficient, safe, and virus-free by establishing protocols for cleaning, maintenance, sanitization, and disinfection. The existing heating, ventilating, and air conditioning systems should be audited and there should be more outdoor air intake to increase the supply of fresh air (AECOM 2020).

The growing problems of solid waste and medical waste management must be addressed. Any system exercising best practices in infectious waste management can also manage the waste potentially infected with the COVID-19 virus (Healthcare without Harm 2020). For medical waste management, it is recommended that all countries consider reviewing their infectious medical waste management system and refine their protocols as appropriate. Cities will need to identify and implement the best collection, treatment, and management approaches according to the prevailing national system, considering both incineration and non-incineration methods.

\section{Greener and More Resilient: Livable Post-Pandemic Cities}

The COVID-19 pandemic is a crisis, but it is also an opportunity to redesign cities for sustainability, resilience, inclusivity, and well-being. The pandemic has exposed problems of poor physical infrastructure, unequal access to core urban services, and suboptimal densities resulting in overcrowded cities. It is time to revisit urban strategies and transform urbanization process and practices to enable a green and resilient recovery.

Cities are economic powerhouse and innovation hubs that can improve livelihoods and trigger prosperity. As cities work to mitigate the immediate crisis and plan about recovery, it is important that they prioritize investments that will build resilience and inclusivity in the short- and medium- term so that governments, households, and firms can weather future shocks and stresses, while increasing healthy urban lives (The New Climate Economy 2020). To help cities become more healthy, environmentally sustainable, and resilient, urban infrastructure and development projects have to build resilience to disasters and climate change as well as to pandemics. Similarly, to accelerate economic recovery in an inclusive manner, cities should integrate labor markets with transport and economic sectors without losing sight of MSMEs and social protection for vulnerable people. Finally, cities should plan for spatial areas that have been particularly impacted by COVID-19 such as public markets, business districts, public transport systems, and health and waste facilities. The vulnerable people who have been most adversely affected by the current crisis should be at the top of all planning considerations.

Inclusivity for vulnerable groups can be enhanced though social protection measures. Cities should identify the special needs of different vulnerable groups and provide adequate resources and devise mechanisms to implement special programs for each of these groups. They can also consider promoting economic activities, jobs, and entrepreneurship for vulnerable groups through special measures such as support for project development and financing of investments and working capital, tax relief measures, lower development charges, and streamlined administrative processes. 
Urban services and infrastructure can be improved through effective use of ICT and digital solutions. Infrastructure and services such as water supply, sanitation, power, and transport should be energy-efficient, pro-poor, gender-responsive, disabilities-inclusive, and sustainable while promoting a smart and digitalized city. ICT has a vital role in integrating hard and soft digital infrastructure into urban planning and development. The use of ICT will help improve urban services particularly in terms of early monitoring and early warning systems for disaster and disease, remote supervision by utilizing SCADA, decentralized one-stop-shop service facilities, and leveraging mobile big data.

Urban planning principles and practices can be revisited to strategically incorporate lessons from COVID-19. Cities will need to mainstream additional precautions and safety standards and consider appropriate new government arrangements across different levels of governance. Thus, coordination is required between cities and authorities at all levels including those in transport, health, land resources, building and construction, energy, environment, water, public spaces, food, civil aviation, maritime and ports, tourism, and labor.

The financial sustainability and capacities of urban stakeholders will need strengthening. Considering the impacts of the pandemic, cities require strategies to strengthen financial sustainability of local governments through maximizing revenue from taxes, tariffs, and intergovernmental transfer. Cities should also develop robust data-based collection systems; catalyze additional revenue sources such as private sector participation, public-private partnerships (PPPs), bonds, guarantees, municipal development funds; and rationalize expenditures by improving efficiencies and cutting nonessential costs (ADB, forthcoming).

Cities will need to develop locally relevant principles to become resilient, healthy, and environmentally sustainable. This will enable them to absorb shocks from disasters and pandemics. Measures may include physical distancing in urban space, public health system and standard, adjustment of public transport operations, health impact assessments, healthy and age-friendly city action, and management planning for a pandemic and for economic disruptive events (Roth et al. 2020). These principles should be mainstreamed in all aspects of urban governance-urban planning and design, infrastructure projects, cross-sector and cross-jurisdiction municipal functions, capacity-building activities, operations of urban services, and engagement with citizens and other stakeholders.

Core urban service standards can be mandated to help in planning and implementing sustainability principles. Such standards may include metrics such as health care service within certain time or distance, minimum water supply, solid waste treatment capacity, public transport availability, and public safety. The standards should consider the nationwide status of urbanization, population, economic development, finance, capacities of implementation, operation and management, applicable regulation and policy, and existing relationship and possible coordination among various tiers of governments. As these could be long-term ambitions with substantial budget requirements, it is important to undertake prioritized planning for the most optimal interventions so that the adoption of new norms can be achieved efficiently.

\section{Transport}

Transport has played a central role in the spread of COVID-19. It has also played a critical role in enabling frontline and essential workers to get to work during the pandemic and will continue to do so to support the various needs of the population throughout the different stages of recovery. Long-standing transport challenges in developing countries are further aggravated by COVID-19 and other natural and human-caused disasters (ADB 2020a). 


\section{Issues and Challenges}

Transport is a key sector in most of the economies in Asia and the Pacific. The transport sector's gross value added in the region is estimated to be $\$ 2.8$ trillion, or about $4 \%$ of the region's overall gross domestic product. About 157 million people are employed in the transport industry, of which 52\% are in road and railway transport services (including pipelines) and 17\% are in wholesale and retail trade and automobile repair (ILOSTAT 2020). Economic and social recovery depends on the transport sector. The transport sector is also a key element in responding effectively to crises and rebuilding greener and more resilient cities.

The pandemic's impact on passenger and freight transport has been profound. Mobility restrictions in response to COVID-19 have resulted in drastic changes in travel behavior. Swift lockdowns across the globe forced all nonessential workers to work from home almost overnight, and schools to shift to e-learning. With the closure of brick-and-mortar shops and restaurants during the containment period, consumers have flocked to online shopping and food delivery. Sharp reductions in economic activity also curbed regional and national freight transport activity. Urban freight and logistics, on the other hand, have prospered because of the increased online shopping and food deliveries.

Even in restrictive lockdown conditions, essential services must be maintained to ensure continuity of necessary goods and services to sustain life. Although the list of essential services varies across countries, it typically comprises sectors relating to health and social services, food supply, importers and exporters, logistics and distribution, aviation, shipping, public transit, banking and finance, and law and order. The list of essential services may also include other sectors such as water and sanitation, which are important in preventing the transmission of contagious diseases, such as COVID-19.

In developing Asia, commuters rely mainly on informal public transit modes or "paratransit" services such as jeepneys, minivans, and shared vehicles. Like businesses everywhere, these modes of transport services have been severely hit by the COVID-19 restrictions. Governments have enforced a complete ban or legislated social distancing due to the rising cases of COVID-19. Operators of informal paratransit are at a greater risk because of their small operating profits, limited financial literacy, lack of access to finance, and fragmented ownership structures (San Juan 2020).

Concerns over close physical contact have also impacted the perceived quality and attractiveness of different travel mode choices. While public transit may previously have been perceived as an efficient and affordable mode of travel, initial trends in cities that have reopened indicate that public transit is still considered as unsafe relative to the use of private vehicles, cycling, and walking, and is not bouncing back as quickly.

During the response phase, travel is still expected to be limited mainly to allowing essential workers to travel and to shipping of goods. Expected measures include protecting transport staff and passengers and frequent cleaning and sanitization, complemented by systems for contact tracing and health monitoring. Eventually, travel restrictions will be relaxed. For passenger movement, systems will gradually open up with enhanced sanitation, face mask protection, thermal scanning, and tracing measures. Urban transport systems will relax social distancing measures to ensure sufficient passenger capacity.

Further preventive and precautionary operating measures will be steadily introduced, together with advanced technology, to enable contactless processes and facilitate an agile response. As a complementary measure, capacity for walking and cycling could be scaled up to accommodate people who would normally have taken public transport. To cope with lower and uncertain travel demand on public transit, aviation, and certain strategic freight routes, it is critical to assess whether restructuring or subsidies for concessions or service agreements 
are required. The objective is to ensure essential transport links are kept open, and core transport and freight operators remain financially viable.

While there may be a rebound to old ways of working, learning, and leisure after the containment period, it is quite likely that a new norm will emerge with increased uptake of these private modes of transport compared with pre-pandemic times. If so, the new behaviors could change trip patterns across the different travel purposes. With a return to pre-pandemic transport activity levels, reductions in air pollution, carbon dioxide $\left(\mathrm{CO}_{2}\right)$ emissions, and road accidents might well be a temporary phenomenon.

As countries and cities recover from crisis, transport will continue to play an important enabling role to support the needs of the population and the economy throughout the stages of recovery. The key challenge ahead is to enable transport to serve its economic and social role while ensuring the safety of transport users and enhancing the resilience of transport systems, so they are better prepared to respond to any future pandemic. The ongoing pandemic has highlighted the need for the transport sector to handle the response as a comprehensive health and economic issue.

\section{Emergency Response and Immediate Actions for Transport}

Policy makers, regulators, and especially transport operators can take measures to enhance the health resilience of transport systems and reduce the likelihood of users becoming infected in the response phase. This is especially relevant during the phase when COVID-19 infections are declining but the risk of community transmission still exists.

During a pandemic, the physical nature of public transport and the close distance between passengers at the station and in the vehicle inevitably create conditions that promote viral transmission. In many countries, public transport operations including taxies, shared mobility services, paratransit, and tricycles have ceased, with the exception of private movement with passenger cars, bicycles, pedestrians, and some types of food delivery vehicles.

With the benefit of hindsight, it has become clear that public transport systems could be kept open, with operations limited to essential workers in the health sector and other sectors, provided the necessary preventive measures are in place, combined with widespread testing, contact tracing, and health monitoring.

The advice on safe distances in public transport ranges between 1 to 2 meters. The longer the distances, the greater the reduction of effective in-vehicle capacity, in some cases by $25 \%$ to more than $75 \%$ with safe distancing measures in place. To serve the same pre-pandemic passenger demand, the required capacity could be doubled or even quadrupled, which is not possible during the pandemic if safety measures are to be observed. Hence, practicing safe distances between passengers would be financially challenging for transport providers without some form of government subsidy. Consequently, many public transport operators, guided by regulatory policy actions, are opting for less stringent social distancing measures combined with the compulsory use of masks in public transit stations and in public transit vehicles.

Demand management measures can facilitate crowd control in public transport systems. Asian cities, especially in developing countries, may stagger ridership throughout the day and across the transit system to reduce the peak transit demand. However, considering the land use patterns, trip behaviors, and poor access to limited transit systems, enforcing such a transformation within a short period of time could be difficult. 
It may be necessary to consider restructuring transport operators or providing subsidies for concessions or service agreements to ensure essential transport links are kept open and core transport operators remain financially viable. Economies in more developed countries have enacted unprecedented financial support packages. Developing countries in Asia and the Pacific may not have the possibilities to enact similar economic support packages. However, several of them are taking measures to support transport-related industries, such as public transport and transport infrastructure. For example, Indonesia and Malaysia are providing direct stimulus to public transport operators, Viet Nam has reduced a range of vehicle fees, and Bhutan is providing stimulus for road construction.

\section{Greener and More Resilient: Sustainable Transport}

With further improvements in health conditions, rebuilding toward sustainable transport involves mainstreaming the "new normal" measures in standard operating procedures. This will result in more resilient transport systems that are better prepared to respond to any future pandemic or disaster. The introduction of advanced technologies to enable digitalizing and contactless systems during the response and recovery phases would lay the foundations for further transformative changes in the long term. At this stage, efforts should also be made to broaden digital inclusion to eventually realize the full benefits of more integrated and agile systems.

As cities and countries respond to and emerge from the pandemic, four trends are observed in the development of the transport sector in Asia and the Pacific (Figure 1). The actual scenario is likely to be a combination of the four trends and will differ between countries and possibly within countries. For example, in more developed countries, demand for public transit is gradually recovering, albeit at a slower pace than the use of private vehicles. Precautionary protective measures are in place to enhance public transit users' confidence. Economic contraction, sustained remote working, e-learning, and e-commerce are contributing to a reduced travel demand. Developing economies, such as the Philippines and Thailand, are showing similar trends, with private vehicle use recovering faster than public transit ridership. On the other hand, India is experiencing a much faster recovery of public transit ridership than driving private vehicles, most likely because of a relatively higher proportion of captive users.

Public transport plays an important role particularly in densely populated cities. It provides the most efficient way of transporting large numbers of passengers in a cost-effective, affordable, and environmentally sustainable manner. Well-planned urban public transport systems also contribute to enhancing the accessibility and vibrancy of the city and the quality of life of its residents.

Demand for urban public transit during the pandemic has been suppressed and is expected to remain below pre-COVID-19 levels if work-from-home trends and e-learning are sustained. The two key challenges will be tackling capacity challenges on public transport in the context of safe distancing requirements and regaining public confidence to return to public transport. Additional efforts will be required to reassure public transport users of safety precautions and demonstrate that public transport is clean and safe. Government policies and financial support will be essential to enable public transport operators to remain viable so that they can continue to support the movement of passengers and goods to keep the economy going while ensuring longer term sustainability.

Physically active transport, such as walking and cycling, is also a key strategy. Aside from promoting well-being and health, walking and cycling are far more environment-friendly options, contributing to enhanced air quality, lower $\mathrm{CO}_{2}$ emissions, and livability of cities. Physically active transport modes tend to offer a higher switching opportunity during change conditions such as the pandemic, as they provide a cost-effective alternative to meet 
Figure 1: Possible Post-COVID-19 Trends in the Asia and Pacific Region's Transport Sector

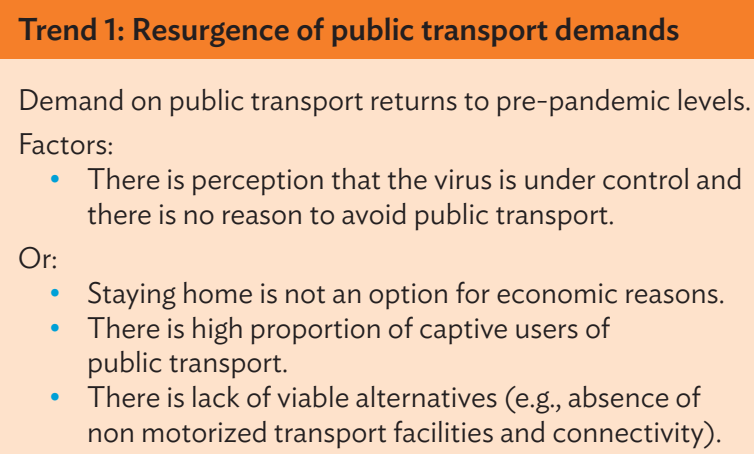

- There is lack of viable alternatives (e.g., absence of non motorized transport facilities and connectivity).

\section{Trend 2: Shift to active transport modes (walk and cycle)}

Travel mode shifts to walking, cycling, and use of use of 2-3 wheelers. There is less reliance on public transport. Use of private vehicles may hold, or be slightly suppressed through road space reallocation.

Factors:

- Safe and viable alternatives on non motorized transport modes are available.

- Road space is reallocated for non motorized transport modes.

\section{Dominance of private transport (car and motorcycle)}

There is unwillingness to return to public transport. Private transport is preferred.

Factors:

- There is lack of public confidence in public transport (due to health concerns).

- Users can afford to switch to other modes (e.g., private cars or motorcycles)

- Walking and cycling are not seen as adequate alternatives

\section{Trend 4: Decreased travel demand}

Work from home and e-commerce, and/or economic recession result in overall lower frequency of travel.

Factors:

- Economic downturn reduces demand for passenger and freight transport.

- There is reasonably high level of digital inclusion and literacy (e.g., availability of digital infrastructure and services).

- E-commerce penetration is high.

- The types of occupation allow commuters to works remotely.

Source: Asian Development Bank.

safe distancing requirements and relieve the burden on public transport. In cases where lockdown measures were less strict, increases in walking and cycling were observed. Several cities across the world have urged their citizens to walk or cycle to reduce the risk of infection. In addition to offering a viable option to ensure safe distancing, governments are also promoting cycling to avoid dramatic shifts to private vehicles after the lockdowns are lifted (Parveen and Pidd 2020).

Rebuilding greener and more resilient transport systems will require more financial support. There is an ongoing discussion on whether and how financial support can be linked to decarbonization and sustainable development criteria. ${ }^{2}$ The International Energy Agency has issued a special report on sustainable recovery, which points out that the employment multiplier, or jobs per unit of investment, for the automotive sector is low compared with investment in walking and cycling infrastructure and charging facilities. The International Labour Organization (ILO) and the United Nations Economic Commission for Europe (UNECE) estimate that increasing investment in public transit and electric vehicles could create at least 15 million new jobs globally (ILO and UNECE 2020).

In deciding the future of transport in Asia, it is important to combine the specific implications of the COVID-19 pandemic with the pre-pandemic agenda as framed by the Sustainable Development Goals (SDGs), the Paris Agreement on Climate Change and other international agreements, and ADB's Strategy 2030. This might require

2 See, for example, the International Energy Agency. 2020. World Energy Outlook Special Report: A Sustainable Recovery. https://webstore.iea.org/download/direct/3008. 
some rethinking of the solutions needed to improve transport in Asia. Transport policy is becoming increasingly complex. Development issues exist in the integration of transport across different sectors and thematic areas. There are also challenges in different modes of transport, transport management, cross-border flow of goods and people, planning and financing, and inclusivity for a wide range of users and stakeholders.

\section{Water and Sanitation}

Service providers in charge of water management (water supply, wastewater, drainage, irrigation, and water resource management) are responsible for delivering essential services to various sectors in society. Thus, they contribute to development outcomes such as poverty reduction, food security, rural development, and public and environmental health protection. Their economic, technical, commercial, human resources, and customer dimensions have been negatively affected by COVID-19. Long-standing challenges of service provision in developing countries, particularly for water and sanitation, are further aggravated by COVID-19 and other natural and human-caused disasters (ADB 2021).

\section{Issues and Challenges}

The COVID-19 pandemic has raised global alarms on public health and safety. To curtail widespread transmission, water utilities have been at the forefront of ensuring uninterrupted water supply to communities. The pandemic also underscores the importance of sanitation and wastewater management, amid fears that active severe acute respiratory syndrome coronavirus 2 (SARS-CoV-2) may persist in raw sewage or environmental waters. Disinfection steps in both drinking water and wastewater treatment plants and the associated regulatory requirements have been developed to inactivate a broad spectrum of pathogens, including corona viruses. The recent COVID-19 outbreak highlights the importance of disinfection to protect public health. With properly disinfected drinking water, the risks posed to human health by viruses become negligible.

The primary impact of the COVID-19 pandemic on water supply operators is the decrease in commercial and industrial water demand and increase in household water demand as a result of lockdown and quarantine measures. The Global Water Leaders Group survey estimates that a $27 \%$ average reduction in industrial demand is observed. The same survey reports that utilities around the world expect a reduction in revenues by $15 \%$ on average because of the pandemic (Butler and Pilotto 2020). In addition to significant decline in commercial and industrial revenues and rising operating costs, many utilities face a steep decline in financial reserves and uncertainty about the approval of new capital works programs.

In many countries, governments have intervened to prevent water supply cut-offs and freeze rates to ensure continuous service provision to households. In some places, financial relief to customers has been extended by reducing tariffs (as in Japan), providing free water service for certain groups (as in Viet Nam and Indonesia), suspending billing, and extending payment deferment options. It is not clear how water service providers will be compensated for the decreased revenues resulting from these measures.

Concerns over continuity of supply from chronically underfunded rural municipalities could accelerate consolidation plans or implementation of water service concessions under public-private partnership (PPP) arrangements in some countries. However, countries with little or no prior experience on PPPs may not be as quick to adopt PPP arrangements to fund large-scale water and sanitation projects. 
Labor challenges compound the difficulty of maintaining water service operations. Skeleton workforces and shifting schedules of operators and maintenance crew have helped maintain proper distancing protocols in critical sites such as treatment plants. Construction workers are more challenging to manage. In many cases, construction work has been suspended under quarantine and lockdown restrictions. Where maintenance or construction depends on migrant laborers, travel restrictions have capped available labor supply.

In addition to labor challenges, supply chain issues also caused delays in construction. Supply chain problems during local, national, and international transport restrictions affected the service providers' ability to obtain reliable supplies of essential chemicals such as chlorine, which in turn can compromise the safety of water supply.

Environmental protection agencies around the world expect regulated businesses to make their best efforts to meet their environmental obligations. These agencies are helping regulated businesses to adjust and adapt, recognizing that resources and capacities are severely constrained. Some agencies published time-limited COVID-19 regulatory position statements to minimize the risks to the environment and human health, wherein, for reasons beyond companies' control, compliance to normal regulatory requirements may not be possible temporarily.

Critical health information on what is known about the emerging pathogen and actions to reduce risk has been published by numerous governments, national departments of health, and international health agencies. The World Health Organization (WHO) serves as the primary source of information about COVID-19, such as advice for the public on protecting themselves and advice on traveling, country-specific advice, technical advice, and regularly updated situation reports. ${ }^{3}$

\section{Emergency Response and Immediate Actions for Water and Sanitation}

The available guidelines for protecting water and wastewater treatment plant personnel during the COVID-19 pandemic state that no additional precautions are needed over and above normal good practice. It is probable that no additional measures are required for personnel at risk of infection from raw water or wastewater beyond the previously recommended occupational hygiene for their operational conditions (Occupational Safety and Health Administration 2020).

Technical advice regarding the behavior of SARS-CoV-2 in water, air, and soil will change in line with the increasing understanding of the virus, as is true of other outbreaks and after any disaster. The advice that is most lacking in early stages of a disaster is guidance for water sector organizations on how to plan for an extended duration of the emergency and how to budget accordingly. Gaps in available guidance can only be filled once new knowledge has been generated and tested.

Water security is a determinant of a country's ability to cope with the COVID-19 pandemic and other health disasters. To better understand the pathways connecting water security and COVID-19, the International Water Centre (n.d.) developed a COVID-19 Water Security Risk Index to categorize countries' vulnerability into six temporal risk elements: (i) ability to stay alert, (ii) ability to delay the spark, (iii) ability to contain the spread,

3 WHO. Coronavirus Disease (COVID-19) Pandemic. https://www.who.int/emergencies/diseases/novel-coronavirus-2019; WHO. Coronavirus Disease (COVID-19) Advice for the Public. https://www.who.int/emergencies/diseases/novel-coronavirus-2019/advicefor-public; WHO. Country and Technical Guidance-Coronavirus Disease (COVID-19). https://www.who.int/emergencies/diseases/ novel-coronavirus-2019/technical-guidance; WHO. Coronavirus Disease (COVID-19) Weekly Epidemiological Update and Weekly Operational Update. https://www.who.int/emergencies/diseases/novel-coronavirus-2019/situation-reports/. 
(iv) ability to treat those in need, (v) ability to immunize, and (vi) ability to recover. Each temporal risk element is composed of risk factors. Of the six elements, five have water-related factors that contribute to COVID-19 risk.

Utility operations need to respond to the challenges of disasters in flexible and sometimes disruptive ways. Staff in main offices and treatment plants may be reduced to the bare minimum. Many operational activities, including some maintenance and provision of new connections, may have to be suspended. Meter readings may also be suspended by many utilities, which can bill based on estimates instead. New construction may be shut down during the lockdown phase.

\section{Greener and More Resilient: Water and Sanitation for Health}

Rejuvenation of the water sector will require a strong focus on preventing future health crises; maintaining sector-wide resilience in the face of widespread shocks like future pandemics, climate change impacts, and natural disasters; and ensuring the sustainability of quality services.

The occurrence of disease outbreaks is expected to increase with rapid climate change, urbanization, and environmental imbalance. The water sector is crucial in preventing and responding to future outbreaks. To ensure that water sector service providers are adequately prepared for this task, it is important to integrate WASH into the public health strategy, improve crisis preparedness and response management, and develop and employ wastewater-based epidemiology.

There needs to be more integrated planning between WASH service providers and public health managers, as water supply operators often plan service expansion without the lens of public health. Neighborhoods are often connected to the piped system on the basis of what is immediately practical such as proximity to main transmission lines, rather than the urgency of addressing health concerns in urban poor or peri-urban communities with high incidence of waterborne diseases. The experience of megacities during the COVID-19 pandemic clearly demonstrated that protecting the vulnerable is crucial to protecting everyone. These communities often become disease hotspots without safely managed water access and sanitation services. This is a case for stepping up WASH investments in the poorest communities. Market-based approaches are critical in institutionalizing WASH services.

Service providers must integrate the lessons learned from the COVID-19 pandemic into crisis preparedness and response. On a basic level, all water sector service providers must have a crisis response and management plan. Governments and regulators can include this in water sector service obligations and standards. It is also imperative that water sector service providers are involved in multisector COVID-19 response coordination.

Wastewater-based epidemiology (WBE) can augment disease surveillance and monitoring. Originally conceived and now widely used to evaluate the use of illicit drugs within a community, WBE has the potential to provide a snapshot of community-wide exposure to contaminants and pathogens and identify likely sources of infections.

WBE can complement current infectious disease surveillance systems and act as an early warning system for disease outbreaks. WBE's advantage is its ability to model spatial and temporal trends potentially in near real-time for some biomarkers. WBE also has the potential for detecting antibiotic resistance, an important emerging public health concern, which when left unmitigated, may result in outbreaks of diseases that are difficult to treat using conventional treatment. This risk has grown rapidly over the last 2 decades. As part of a comprehensive monitoring of environmental waters, WBE can provide scientific basis for local policy and planning to avert potential public health crises arising from antibiotic resistance. 
The water sector must achieve resilience for all service providers and at all levels. The resilience developed by many water sector service providers during the COVID-19 pandemic have to be integral to their "next normal." Investments in water sector resilience should be reframed as a necessary insurance to hedge service providers against many kinds of disruptions, including the anticipated onslaught of climate change impacts that will disproportionately affect developing countries. Future resilience investments should consider decentralization, nature-based solutions, digital technologies, and robust planning for deep uncertainty.

Decentralization can be used to enhance the resilience of water sector service providers. Over-reliance on a centralized system can breed single points of failure. Long-term resilience requires flexibility, redundancy, and alternatives. The idea is not to break up the centralized system into pockets of independent, fully decentralized systems; rather, service providers must assess the risks and opportunities where decentralization can add value to their operational efficiency and long-term sustainability.

There now exist technologies that work more efficiently and are cheaper at low-scale applications, in contrast to the large economies of scale that water sector service providers are configured for. Thus, decentralization enables equitable service provision. As the COVID-19 pandemic experience has shown, many centralized systems have excluded vulnerable communities such as the urban poor. Urban informal settlements may be better provided with WASH services using alternative, typically decentralized approaches. Decentralization allows the deployment of solutions that are not only more appropriate to the local constraints and opportunities, but also potentially more socially acceptable. Decentralization may therefore speed up the implementation of suitable sanitation systems in ADB's developing member countries (DMCs) to achieve city-wide inclusive sanitation.

Nature-based solutions (NBS) are "green" or natural solutions that may be incorporated into "gray" or engineered solutions. The concept encompasses solutions from fully intact old growth forests, to constructed wetlands and bioswales. The key is to identify which solutions are appropriate for the desired objectives, and at what scale they should be implemented.

NBS contribute to resilience primarily through flexibility and adaptability. Legacy systems of gray infrastructures are at risk of being a mismatch as climate change alters the operating parameters. Countries that experience rapid climate change are seeing climate mismatches in infrastructures only a decade old. This does not bode well for developing countries that are intensifying investments in gray infrastructures. But when properly designed, NBS have the ability to adapt to changes in the natural and man-made environment. Green infrastructure in urban areas can contribute to climate change resilience through microclimate amelioration such as combatting the heat island effect, applying sustainable drainage and storm protection, reducing urban pollution, and protecting biodiversity.

Moreover, NBS deliver multiple benefits (or co-benefits) across many sectors in society. In the water sector, one NBS project can generate value for multiple service providers. Safely managed sanitation is another area where NBS can generate social values, including public health and community resilience. In low-income urban settlements, poor soil condition and insufficient space make septic tanks impractical, and in many cases, can exacerbate fecal contamination as wastewater effluents do not infiltrate the ground to a sufficient depth. Modular constructed wetland systems can promote sanitation and enable resource recovery for horticulture and agriculture production to support local economies. As rapid urbanization and population growth sweeps across Asia and the Pacific, governments and the water sector must consider NBS and green design as components of healthy, livable, and resilient cities.

Digital technologies can also enhance resilience. To achieve sector-wide resilience, coordination is required to make the most of investments in digital transformation. Open-access data is a powerful tool to support multiple 
stakeholders, as in the case of employing satellite analytics for whole-of-catchment monitoring and management. Digital technologies will continue to evolve for more bespoke cases of use, particularly in developing country contexts. Many start-ups based in emerging economies are already developing digital solutions that are not only cheaper but also potentially more appropriate for the local context.

Digital adoption is now being accelerated by water sector regulations and public policy, data structuring solutions for legacy systems, and the demographical shift among both customers and workforces toward digital solution. There are also context-specific drivers of digitalization, such as resource scarcity which triggers the digital transformation of utilities.

With rapid climate change, the future can only be described as one of deep uncertainty as historical trends and standard probabilistic engineering methods no longer provide a straightforward projection of future conditions. This makes planning and decision-making even more difficult on top of budget constraints and conflicting interests. The water sector already feels the impacts of changing hydrological conditions such as too much or too little water. As such, the water sector must adopt frameworks and tools that promote decision-making under deep uncertainty, such as the Dynamic Adaptive Planning Pathways model. This model provides an analytical framework that identifies the vulnerabilities of current strategies to determine robust, adaptive strategies that will succeed across the broad range of plausible futures. Such modeling considers multiple plausible futures, seeks robust rather than optimal strategies, and evaluates vulnerabilities and trade-offs.

SDG 6 relates to universal access to water and sanitation, "ensuring the availability and sustainable management of water and sanitation for all." Around the world, and particularly in the developing world, many countries are off-track in meeting SDG 6 targets. It is imperative that the SDG 6 targets are achieved in the 2020s. Rejuvenating the water sector in a post-pandemic world means firmly positioning countries to achieve the SDG 6 targets.

\section{Energy}

The energy sector in developing countries is facing challenges that have been further aggravated by COVID-19. The unmet demand for reliable energy supply is an obstacle to economic development and necessitates investment in the energy sector. The unmitigated use of fossil fuels has added to deteriorating air quality and lack of progress on meeting global climate goals. Energy sector actors must increase efforts to deploy clean energy technologies that contribute to long- term sustainability while at the same time providing near-term economic stimulus. In all sectors, increased use of ICT can help optimize operation and efficiency (ADB 2020a).

\section{Issues and Challenges}

During restrictions that have occurred across Asia, energy demand across all energy sources has dropped significantly. Travel limitations and industrial sector contractions have resulted in significant global decreases in the use of fossil fuels and oil products. Power demand patterns throughout the week dropped to levels typically seen only on Sundays, the day when power demand is the lowest due to decreased economic and industrial activity. The power sector uses a broad range of inputs including fossil fuels, renewable energy, and nuclear sources. As these reductions in demand happened on a global scale, global demand for fossil fuels used in the power sector, primarily natural gas and coal, had decreased the most, depressing market prices compared to 
recent trends. Renewable power, primarily solar and wind, has increased in its share of overall power production as a result of ongoing deployment of projects that started prior to the pandemic. Also, renewable power is typically the first fuel dispatched for power production due to its low operating costs (the fuel is generally free).

Once lockdown periods had been partially relaxed in several countries, the recovery of electricity demand began to occur, but the amount of recovery varied widely across countries. In the People's Republic of China (PRC), a 13\% decrease in power demand happened in February 2020 during the lockdown. When the lockdown had been relaxed, the power demand levels largely recovered and even exceeded the 2019 levels by June 2020. Electricity demand in India has slowly been increasing since its lowest point and approaching 2019 levels by August 2020 (IEA 2020a).

Despite concerns over personnel shortages during lockdowns and limitations on operations and maintenance due to travel restrictions, the energy system operation and supply was able to continue reliably and meet the demands in response to the pandemic. Shortages of energy were not experienced by consumers, however, the lockdowns and restrictions had significant financial impacts on energy suppliers and utilities.

As in the water sector, power sector utilities have been severely affected by a combination of reduced demand and reduced payment by customers. For some utilities, reduced demand resulted in decreased revenues, but expenses were not reduced due to take-or-pay clauses in fuel or power purchase agreements. In many countries, increasing unemployment due to the pandemic limited the ability of consumers to pay their electricity bills. Some utilities were able to mitigate fuel supply problems through government support or renegotiate payment terms using the force majeure clauses in power purchase agreements. However, decreased demand, payment delays, and delinquency in the payment of utility bills by end-consumers (residential, commercial, and industrial) are beginning to have a detrimental effect along the energy supply chain. Since many utilities were already under financial stress prior to the crisis, the pandemic is further deteriorating the financial health of these organizations.

As countries enter into the recovery stage, economic recovery and related energy use is highly uncertain. Economic recovery could be fast or slow, and will likely vary dramatically across countries and sectors, depending on their specific circumstances. Annual demand in 2020 for all fuels and power are projected to decrease compared to 2019 levels except renewable power (IEA 2020b).

\section{Emergency Response and Immediate Actions for Energy}

There is significant uncertainty as to how long the health issues caused by the pandemic will remain or how countries will choose to manage these. Consequently, economic projections also become highly uncertain. The once-in-a-century nature of the pandemic is causing massive economic impacts, but lack of clarity on the magnitude of these impacts and what the "new normal" will look like for society means that specific planning in the energy sector is fraught with uncertainty.

There is a need for "no regrets" development planning in the energy sector that tackles the near-term needs of societies and continue to address long-term priorities. Despite the tremendous development progress over the last 40 years in Asia and the Pacific, there remains more than 230 million people without access to electricity and nearly 1.7 billion people without access to clean cooking (IEA 2020c). There is continued support and large agreement on the development needs in Asia for energy access, and how energy investments need to support climate change mitigation and become increasingly resilient. These priorities remain consistent from the pre-COVID-19 context. The energy sector is also viewed as a potential sector that can directly support economic recovery through the projects themselves. 
Table 1: Energy Sector Priorities for Immediate Response

\begin{tabular}{|c|c|c|}
\hline \multirow[b]{2}{*}{ Overall Objective } & \multicolumn{2}{|c|}{ Stakeholder Action } \\
\hline & DMC Government & Utilities \\
\hline $\begin{array}{l}\text { Keep the end-use } \\
\text { sectors supplied with } \\
\text { energy, responding to } \\
\text { changes in the overall } \\
\text { demand and in the } \\
\text { utilities' and end users' } \\
\text { ability to pay }\end{array}$ & $\begin{array}{l}\text { - Prepare for short-term financial support to } \\
\text { maintain liquidity of essential actors } \\
\text { - Provide energy subsidy to poor and } \\
\text { vulnerable groups } \\
\text { - Encourage/stipulate flexibility in the timing } \\
\text { of deployment of existing projects } \\
\text { - Prepare for vaccine rollout and energy } \\
\text { needs to maintain cold-chain. }\end{array}$ & $\begin{array}{l}\text { - Maintain technical operation of energy } \\
\text { systems to ensure society is supplied } \\
\text { with energy } \\
\text { - } \text { Develop operation protocols to address } \\
\text { COVID-19 safety for all employees } \\
\text { - Identify key changes in revenue and } \\
\text { manage finances under changing } \\
\text { revenue scenario } \\
\text { - } \text { Adjust and manage infrastructure and } \\
\text { maintenance, identifying and prioritizing } \\
\text { essential maintenance aspects for reliability }\end{array}$ \\
\hline
\end{tabular}

COVID-19 = coronavirus disease, $\mathrm{DMC}=$ developing member country.

Source: Asian Development Bank.

The overall strategic priorities for the energy sector can be identified by separating the initial response to COVID-19 from support for the recovery phase, which by necessity will overlap with the initial response phase. The wide range of stakeholders in the energy sector will have specific roles to be carried out (Table 1).

In many countries, governments have intervened by maintaining electricity services to the population during the lockdown, while also reducing the negative financial impact on the energy sector (IFC 2020). This has helped stakeholders keep the energy system operating reliably and as normal as possible as this will support continued health response to the pandemic. A reliable power supply can also help minimize the economic impacts of the pandemic by enabling continuous operations of industries and commercial enterprises.

The pandemic has also affected capital investments. For instance, since the epidemic started, many solar power developers in Asia and other parts of the world have experienced protracted delays in importing solar photovoltaic (PV) modules and other supplies. According to the International Renewable Energy Agency, 50 leading solar PV panel manufacturers maintain factories in 23 countries, with the PRC accounting for about two-thirds of global production in 2018. The implementation of solar projects was also affected because international experts and managers were unable to report for work due to travel restrictions.

\section{Greener and More Resilient: Clean Energy}

The financial impacts on energy supply chain caused by the pandemic together with significant inflows of stimulus to help address the economic impacts of COVID-19 may be an opportunity for countries to address structural energy sector problems (e.g., inefficient generation, sub-cost recovery tariff structures, ineffective regulators, and fossil fuel investments with future stranded asset risk).

The recovery phase presents an opportunity to accelerate progress in energy sector development, especially in areas that have traditionally not progressed enough such as addressing air pollution, GHG emissions, and access to energy. Governments' responses to COVID-19 indicate a clear willingness to provide funding to counter 
immediate public health impacts. Additional financial stimulus to support economic recovery from the pandemic may increase interest among DMCs to accelerate low-carbon developments in the energy sector. Conventional pollution control and increased emphasis on technology innovation with climate change benefits could be areas of investment opportunities for DMCs.

The recovery phase can focus on four pillars-(i) provide better energy services, including renewable energy and energy efficiency, to businesses, public services such as health and education, and homes; (ii) improve energy sector resilience and security; (iii) accelerate energy access to the poor and vulnerable groups, particularly for clean cooking; and (iv) employ advanced technology and cross-sector interventions.

While the timing for recovery of overall energy demand is not certain, many countries have demonstrated that electricity has been the fastest to recover (IEA 2020d). In developing countries in Asia, the power sector is typically in need of rejuvenation, modernization, and expansion to serve the growing needs of society as they develop. Countries do not need to follow the energy-intensive development pathways of the past that have fossil fossil fuel-based power generation. The current low levels of energy use per capita indicates that even sustainable and efficient development pathways will result in significant increases in household and overall national energy demand. From this perspective, power sector development with a strong focus on renewables and demand-side energy efficiency will be very important to limit overall investment and environmental impacts. The power sector plays an important role in addressing COVID-19, such as enabling high-quality medical care, developing the cold-chain for vaccine delivery, supporting education, and building ventilation in cities and in all aspects of modern lives.

Stakeholders in the energy sector must work together to ensure the sector can support recovery from the pandemic. The actions highlighted in Table 2 offer a broad range of aspects in the energy sector that must be addressed. These are meant to be quite comprehensive in an overarching manner, but it is expected that new and additional opportunities for energy sector development exist in specific country contexts. Though Table 2 highlights the most prominent energy sector stakeholders, it should be noted that end users, financiers, and the private sector also have important roles.

Table 2: Energy Sector Priorities for Recovery

Recovery through Rejuvenation and Resilience

Provide better energy service to businesses, public services (e.g., health, education), and homes that addresses air quality issues and is low-carbon, affordable, and reliable

\section{Stakeholder Action}

DMC government

- Create low-carbon road map for energy sector development, aligned with the Paris Agreement

Energy utilities

- Engage in energy sector planning process

- Analyze changes in demand patterns due to COVID-19 and identify critical paths in systems development

Regulator

- Design and strengthen regulatory frameworks to support technical and financial sustainability of utilities 
Table continued

Recovery through Rejuvenation and Resilience

Improve energy sector resilience and security to a broad range of crises including climate, markets, and pandemics

\section{Stakeholder Action}

DMC government

- Identify energy sector resilience and security vulnerabilities to a broad range of crises

- Consider the opportunities for regional energy trade and integration over national security of supply

Energy utilities

- Include resilience aspects in all parts of planning, operations, and maintenance

- Work with end users to determine their energy needs in the context of specific crises

Regulator

- Encourage and enable energy resilience and security investments by allowing cost recovery

Accelerate energy access for the poor and vulnerable groups

DMC government

- Develop or update targets for energy access for electricity and heating and cooling, including clean cooking

- Provide capital cost support and tariff subsidies where cost recovery is not initially viable

Utilities

- Develop business models through piloting and deploying more distributed power supply, microgrids, and minigrids

Regulator

- Develop and encourage pro-poor and pro-vulnerable tariff structures and regulation

Optimize advanced technology and implement cross-sector interventions, including specific technologies to address the impacts and prevent the spread of COVID-19
DMC government

- Determine country-specific opportunities for advanced technology and business models and provide funding and incentives

- Identify cross-sector approaches to leverage solutions to address

Utilities multiple problems

- Evaluate opportunities for deploying alternative technologies to address systemic issues and high upfront costs through business model and

Regulator programmatic approaches

- Enable exception-based regulation for piloting of new technologies to reduce barriers to tapping these technologies

COVID-19 = coronavirus disease, $\mathrm{DMC}=$ developing member country.

Source: Asian Development Bank.

\section{Rejuvenation: The Way Forward}

As activities shift from initial response mode to economic recovery mode, developing countries in Asia face both tremendous challenges and unprecedented opportunities.

Aligning urban sector investments to address COVID-19 impacts. To address the impacts of COVID-19, investment programs in all sectors should help cities become more healthy, inclusive, and resilient. Investments should also support local economic development and create jobs. Livable cities projects will include components to support, among others, (i) integrated urban planning process and coordination across departments and 
local administrative boundaries to strategically incorporate lessons from COVID-19 for safe and healthy cities; (ii) greater social protection measures for the most vulnerable groups, including affordable housing with integrated urban services in cities; and (iii) improvement of urban environments including more focus on uninterrupted utility operations, WASH, wastewater and fecal sludge management, and solid waste and medical waste management. The livable cities projects will also strengthen financial sustainability, support financial inclusion, use technologies and digital solutions to improve urban services, and build capacities of urban institutions and other stakeholders including the communities.

Way forward for post-pandemic cities. Most cities in developing countries are currently focusing their resources on the immediate management and response to COVID-19. While this is critical, cities paying attention to how immediate actions align with the short- and medium-term measures will gain an advantage toward greener and more resilient cities. It will also be useful to understand how short- and medium-term actions synergize with other ongoing or planned investments and broader agendas (e.g., national development strategies, public investment plans, ADB's Strategy 2030, SDGs and Agenda 2030, and Nationally Determined Contributions in line with the Paris Climate Agreement). Not to discount the human toll and tragedy of the COVID-19 pandemic, this crisis can be turned into an opportunity and momentum to reduce inequalities of access and make cities more safe, healthy, environmentally sustainable, resilient, and inclusive in a post-COVID-19 world. ADB also will help cities understand their challenges and opportunities; prepare their own visions, plans, and road maps; take appropriate actions to address pandemics; and implement projects to become more livable.

Aligning transport sector investments to address COVID-19 impacts. Regardless of the COVID-19 pandemic, it is clear that developing Asia and the Pacific will significantly require additional transport infrastructure and services. Efforts to promote sustainable transport projects to counter the negative trend of a possible shift to private modes need to step up by further promoting public transit, providing quality alternatives in physically active transport modes such as walking and cycling, promoting e-vehicles, and developing green infrastructure delivery approaches. Transport system resilience could be enhanced by harnessing advanced technology and promoting digital inclusion. Preparedness for multiple, simultaneous hazards and disasters could be mainstreamed in project design to promote enhanced pandemic and disaster resilience.

Way forward for the post-pandemic transport sector. The COVID-19 pandemic highlights the need for a more robust transport system that is green and resilient to future disasters. Human-centered approaches using big data analytics, artificial intelligence, digitalization, and automation offer fresh innovative solutions to transport sector development. More robust logistics and supply chains will be critical in enhancing countries' resilience to future shocks. These enhanced efforts could help realize the SDGs and the Paris Agreement. Further research is needed to understand what needs to be put in place to enhance the preparedness and agility of the transport system to tackle another pandemic or natural disaster. Alternative measures ought to be developed to mitigate operational and financial impacts on public transit and aviation. Emerging evidence on changing consumer behavior and travel patterns, and better understanding on the plausible future scenarios and strategies, would be instrumental in planning and developing future transport projects.

Aligning water sector investments to address COVID-19 impacts. Investments in the water sector should enhance resilience, sustainability, and inclusivity of water and sanitation services. First, universal access to water and sanitation for all should be a priority, as these services are foundational to public health and social stability. Investments from both public and private sectors must be predicated by an aggressive overarching ambition and policy to expand water sector services to all, including the vulnerable, marginalized, and disadvantaged groups. Second, existing and planned water sector infrastructures and services must be designed (or redesigned) for resilience under deep uncertainty. The full extent of climate change impacts, including the possibility of more frequent and/or devastating pandemics and natural disasters, has yet to manifest in many countries. The aging 
legacy systems of many water service providers were not designed for these outlier events. Future investments must be geared toward rectifying redundancy and the lack of flexibility. Governments should consider alternatives in water service provision, and investments in decentralized and nature-based solutions as well as in resource recovery. Finally, investments must support the digital and technological transformation of water sector service providers. In addition to improving operational efficiency and enhancing resilience, innovative technologies have the potential for unlocking new value in the water sector (e.g., circular economy).

Way forward for the post-pandemic water sector. Many countries in Asia and the Pacific are not on track to achieve most of the SDG 6 targets. The region's economy will continue to reel in the aftermath of the COVID-19 pandemic. Financial recovery of the hardest-hit water sector service providers needs immediate support, particularly in resuming critical capital and maintenance works that have been delayed because of the pandemic. The water sector must also take advantage of the importance placed on WASH during the pandemic, and hence should integrate water planning with public health strategy, which could pave the way for more investments being earmarked for the sector.

Aligning energy sector investments to address COVID-19 impacts. The impacts of the pandemic have helped identify the levels of pollution created by the energy sector (and transport). Such knowledge can be used as motivation to utilize modern clean energy technologies and greatly reduce pollution. While the energy sector has largely operated reliably during the pandemic, there is a clear need for financial strengthening of energy utilities to sustain their operations and help them prepare for future crises. This can be accomplished more readily today as renewable energy and energy efficiency technologies have become more economically viable and have advanced in capability together with continued development and utilization of information and communication technologies. The eventual delivery of a vaccine will require energy for its cold-chain. Such energy function can be developed and later deployed for general development purposes, such as in agriculture and fisheries. These efforts should be redoubled to provide access to the poor and vulnerable and those living in rural locations.

Way forward for the post-pandemic energy sector. The energy sector in Asia and the Pacific must continue to deliver on its pre-pandemic goals to provide sustainable energy access to all. Ongoing development needs and alignment with the Paris Agreement and the SDGs provide an opportunity to support economic recovery by ensuring a reliable supply of sustainable energy and at the same time act as an economic stimulus through investments and creation of jobs. For example, creation of new jobs or reinstatement of jobs that were suspended will be a key part of economic recovery from the pandemic. In 2019, there were approximately 40 million people employed in the global energy industry. It is estimated that nearly 8 million jobs have been lost or are at risk of being lost due to COVID-19 impacts. Investments in the energy sector can support the overall economic development of DMCs. During the recovery phase, energy projects can also provide job and livelihood opportunities directly, hence stimulating the economies of developing countries. ${ }^{4}$ Such investments will provide the infrastructure needed by countries to recover from the pandemic and help accelerate their journey toward economic development.

4 The International Energy Agency has developed a sustainable recovery scenario that focuses on the deployment of infrastructure in the power sector; energy-efficient buildings and industries; manufacturing of vehicles, fuels production, and other transport measures; and renewables in end uses, recycling, and innovation. Under this scenario, more than 9 million jobs might be created per year over 3 years from 2021 to 2023. IEA. 2020. Sustainable Recovery. Paris. https://www.iea.org/reports/sustainable-recovery. 


\section{References}

AECOM. 2020. The Future of Workplace Re-Occupancy. https://publications.aecom.com/coronavirus-resilience/ report/the_future_of_workplace_re-occupancy.

Asian Development Bank (ADB). 2020a. COVID-19 and Livable Cities in Asia and the Pacific: Guidance Note. Manila. https://www.adb.org/documents/covid-19-livable-cities-asia-pacific-guidance-note.

- - . Forthcoming. COVID-19 and the Water Sector in Asia and the Pacific. Manila.

- - . Forthcoming. Creating Livable Asian Cities: 4A: Advancing the Financial Sustainability of Asian Cities. Manila.

Butler, G. and R. G. Pilotto. 2020. The Impact of COVID-19 on the Water and Sanitation Sector.

Health Care Without Harm. 2020. Health Care Waste Management: Coronavirus Update. 24 March.

https://noharm-global.org/sites/default/files/documents-files/6339/HCWH\%20Covid-19\%20Waste\%20

Facts_0.pdf.

International Energy Agency (IEA). 2020a. COVID-19 Impact on Electricity. https://www.iea.org/reports/covid19-impact-on-electricity.

- - . 2020b. Global Energy Review. Paris. https://www.iea.org/reports/global-energy-review-2020.

- - . 2020c. SDG7: Data and Projections. Paris. https://www.iea.org/reports/sdg7-data-and-projections.

-_- 2020d. Sustainable Recovery. Paris. https://www.iea .org/reports/sustainable-recovery.

International Finance Corporation (IFC). 2020. The Impact of COVID-19 on the Power Sector. Washington DC. https://www.ifc.org/wps/wcm/connect/industry_ext_content/ifc_external_corporate_site/infrastructure/ resources/the+impact+of+covid-19+on+the+power+sector.

ILOSTAT. 2020. https://ilostat.ilo.org/data (accessed 20 June 2020).

International Labour Organization (ILO) and United Nations Economic Commission for Europe (UNECE). 2020. Jobs in Green and Healthy Transport: Making the Green Shift. https:/www.ilo.org/wcmsp5/groups/public/--dgreports/---dcomm/---publ/documents/publication/wcms_745151.pdf.

International WaterCentre. COVID-19 Water Security Risk Index. http://www.watercentre.org/covid-19-watersecurity-risk-index/.

Occupational Safety and Health Administration, United States Department of Labor. 2020. COVID-19 Control and Prevention. https://www.osha.gov/SLTC/covid-19/controlprevention.html\#solidwaste.

Organisation for Economic Co-operation and Development (OECD). 2020. Tackling Coronavirus (COVID-19) Contributing to a Global Effort: Cities Policy Responses. Paris. http://www.oecd.org/coronavirus/policy-responses/ cities-policy-responses-fd1053ff/. 
Parveen, N. and H. Pidd. 2020. Encourage Cycling and Walking after Lockdown, UK Mayors Told. The Guardian. 1 May. https://www.theguardian.com/uk-news/2020/may/01/encourage-cycling-and-walking-after-lockdownuk-mayors-told.

Roth, S., S. Rau, N. Habib, F. Silva, and J. Shandro. 2020. Healthy and Age-Friendly Cities in the People's Republic of China: Proposal for Health Impact Assessment and Healthy and Age-Friendly City Action and Management Planning. https://www.adb.org/publications/healthy-age-friendly-cities-prc.

San Juan, A. 2020. Traditional Jeepney Operators Unsure When LTFRB Will Allow Them to Resume Operation. Manila Bulletin. 25 June. https://news.mb.com.ph/2020/06/25/traditional-jeepney-operators-unsure-whenItfrb-will-allow-them-to-resume-operations/.

The New Climate Economy. 2020. NCE Key Message Pack-Special Edition on COVID-19. May.

United Nations Economic and Social Commission for Asia and the Pacific. 2019. The Future of Asian and Pacific Cities. Bangkok.

UN Women. 2020. The First 100 Days of the COVID-19 Outbreak in Asia and the Pacific: A Gender Lens. New York. 


\section{Creating Livable Asian Cities}

This book explores how Asia's fast-growing cities can fulfil their potential as engines of economic prosperity and provide a livable environment for all citizens. But for this to happen, major challenges that reduce urban communities' quality of life and economic opportunities must be addressed. These include poor planning, a lack of affordable housing, inequalities, pollution, climate vulnerabilities, and urban infrastructure deficits. The book's 19 articles unwrap these challenges and present solutions focused on smart and inclusive planning, sustainable transport and energy, innovative financing, and resilience and rejuvenation.

\section{About the Asian Development Bank}

ADB is committed to achieving a prosperous, inclusive, resilient, and sustainable Asia and the Pacific, while sustaining its efforts to eradicate extreme poverty. Established in 1966, it is owned by 68 members -49 from the region. Its main instruments for helping its developing member countries are policy dialogue, loans, equity investments, guarantees, grants, and technical assistance. 